San Jose State University

SJSU ScholarWorks

Master's Theses

Master's Theses and Graduate Research

2007

\title{
Effect of design factors on microvia reliability of flipchip substrates
}

Dennis Chi Pong Leung

San Jose State University

Follow this and additional works at: https://scholarworks.sjsu.edu/etd_theses

\section{Recommended Citation}

Leung, Dennis Chi Pong, "Effect of design factors on microvia reliability of flipchip substrates" (2007).

Master's Theses. 3475.

DOI: https://doi.org/10.31979/etd.r69g-edtn

https://scholarworks.sjsu.edu/etd_theses/3475

This Thesis is brought to you for free and open access by the Master's Theses and Graduate Research at SJSU ScholarWorks. It has been accepted for inclusion in Master's Theses by an authorized administrator of SJSU

ScholarWorks. For more information, please contact scholarworks@sjsu.edu. 


\title{
EFFECT OF DESIGN FACTORS ON MICROVIA RELIABILITY OF FLIPCHIP SUBSTRATES
}

\author{
A Thesis \\ Presented to \\ The Faculty of the Department of Chemical and Materials Engineering \\ San Jose State University
}

In Partial Fulfillment

of the Requirements for the Degree

Master of Science

by

Dennis Chi Pong Leung

December 2007 
UMI Number: 1452058

\section{INFORMATION TO USERS}

The quality of this reproduction is dependent upon the quality of the copy submitted. Broken or indistinct print, colored or poor quality illustrations and photographs, print bleed-through, substandard margins, and improper alignment can adversely affect reproduction.

In the unlikely event that the author did not send a complete manuscript and there are missing pages, these will be noted. Also, if unauthorized copyright material had to be removed, a note will indicate the deletion.

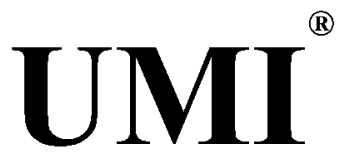

UMI Microform 1452058

Copyright 2008 by ProQuest LLC.

All rights reserved. This microform edition is protected against unauthorized copying under Title 17, United States Code.

ProQuest LLC

789 E. Eisenhower Parkway

PO Box 1346

Ann Arbor, MI 48106-1346 
(C) 2007

Dennis Chi Pong Leung

ALL RIGHTS RESERVED 
San Jose State University

The Undersigned Faculty Committee Approves the

EFFECT OF DESIGN FACTORS ON MICROVIA RELIABILITY OF

FLIPCHIP SUBSTRATES

of

Dennis Chi Pong Leung

APPROVED FOR

THE DEPARTMENT OF CHEMICAL AND MATERIALS ENGINEERING

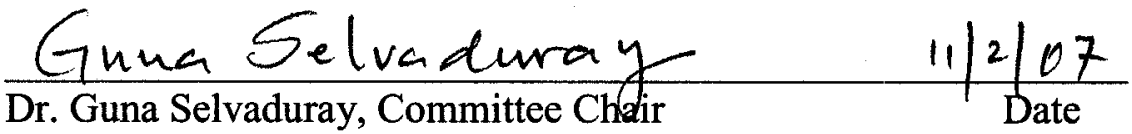
Department of Chemical and Materials Engineering

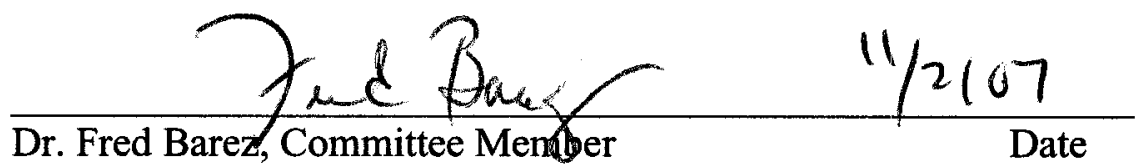

Department of Mechanical and Aerospace Engineering

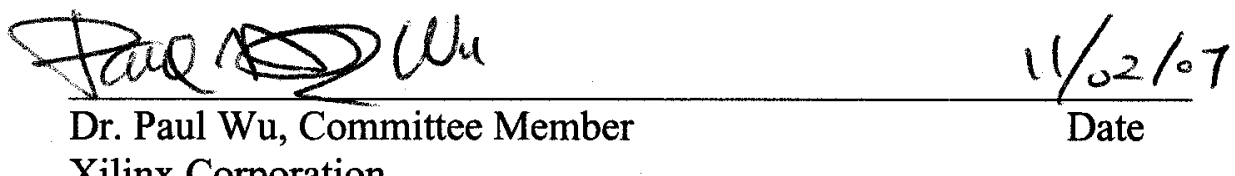

Xilinx Corporation

APPROVED FOR THE UNIVERSITY

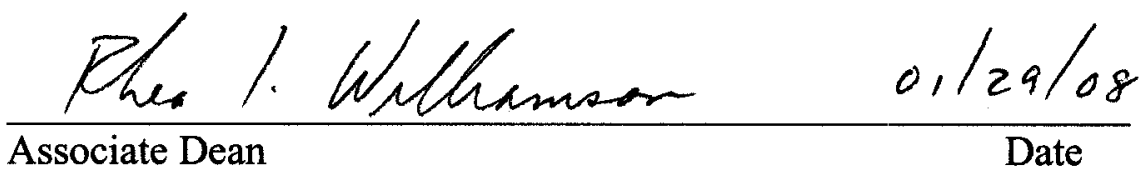




\title{
ABSTRACT \\ EFFECT OF DESIGN FACTORS ON MICROVIA RELIABILITY OF FLIPCHIP SUBSTRATES
}

\author{
By Dennis C.P. Leung
}

The objective of this investigation was to determine the relationship between reliability and design factors of the microvias in flipchip polymeric substrates. A 10layer substrate was used to investigate these contrasting design factors: "Stack-on-core" vs. "Non-stack-on-core," “High" vs. "Low" aspect ratio, "Stacked" vs. "Staggered," and "Fillet" vs. "Non-fillet." Temperature cycling was used to generate stresses on the microvias. Electrical resistance was measured and analyzed, using design of experiment (DOE), to determine the effects of these design factors on microvia reliability. The significant single factors for a robust microvia were "Non-stack-on-core" and "Staggered." "Non-fillet" was significant when interacting with "Non-stack-on-core" and "Staggered." Cross-sectioning was employed to understand the failure pattern. Cracks occurred on "Stack-on-core" and "Stacked" designs only. All the cracks were located at the interface between the capture pad and the bottom of the microvia where stress is the highest due to the CTE mismatch of different materials. 


\section{ACKNOWLEDGEMENTS}

Many people have contributed to this thesis in offering suggestions and advice, reviewing the text, data and figures, and working on the samples and experiments. Without their generous support, this thesis would not be materialized.

The author would like to express his heartfelt appreciation and thanks to his thesis advisor, Dr. Guna Selvaduray, Professor, Department of Chemical and Materials Engineering, San Jose State University. It is due to his guidance, encouragement, and consultation in overseeing this project from its beginning to its completion that the author could finally complete the project. The author has known Dr. Selvaduray personally for many years. Over all these years, Dr. Selvaduray has never stopped to motivate the author to learn and to do his best.

The author would like to thank Dr. Fred Barez, Professor, Department of Mechanical and Aerospace Engineering, San Jose State University, for his valuable advice and for being the author's thesis committee member. The author is indebted to his manager and mentor, Dr. Paul Wu, Principal Engineer, Xilinx Corporation, for his technical guidance and encouragement in this project, and also being the author's thesis committee member. Thanks are due to Dr. Leilei Zhang, Staff Packaging Process Engineer, Xilinx Corporation, for her technical advice in manufacturing processes and support in acquiring samples, and to Peter Ubaldo, Senior Packaging Technician, Xilinx Corporation for his support with the experiment from setup to getting invaluable data. Of course, the author is grateful for Xilinx Corporation, which sponsored this project. 
The author wishes to thank his mother, Hang-mui Choi, for her unfailing love.

She did not have a chance to accept formal education herself due to poverty, but was still able, as a single mother, to support all of her three sons in receiving high school education during the 1970 s in Hong Kong. It is her belief in education that encourages the author in the pursuit of continual and higher education. Last, and certainly not least, to my wife, Grace, for her dedication and persistent support over the years, the author expresses his earnest appreciations. 


\section{TABLE OF CONTENTS}

Page

LIST OF FIGURES

LIST OF TABLES $\quad$ XV

CHAPTER 1. INTRODUCTION 1

1.1 The Main Drivers for the Development of FCBGA 1

1.2 Changes in Microelectronic Packaging for the Development of FCBGA 3 .

1.3 Challenges Facing FCBGA Development 5

$\begin{array}{lll}1.4 & \text { The Focus of this Research } & 7\end{array}$

CHAPTER 2. LITERATURE REVIEW 9

2.1 Road Map and Future Developments of Micro-via Technology 9

2.2 Reliability Assessments of Vias $\quad 12$

2.2.1 Micro-vias in a Flip Chip Package $\quad 12$

2.2.2 Photo-defined Micro-vias in a Printed Circuit Board 13

2.2.3 Mechanically Drilled Vias in a Land Grid Array Package 15

2.3 Thermo-mechanical Formations of Micro-via Cracks 20

2.3.1 Mechanically Drilled Vias in a LGA Package 20

2.3.2 Thermo-mechanical Fatigue Analysis of High Density Interconnect 23 Vias

2.4 Design Factors $\quad 29$

2.4.1 Non-stack-on-core vs. Stack-on-core 30

2.4.2 Aspect Ratio 32 
2.4.4 Fillet vs. Non-fillet

2.5 Summary of Literature Review

CHAPTER 3. RESEARCH OBJECTIVE

4.1 Test Vehicle Design $\quad 40$

$\begin{array}{lll}4.2 & \text { Substrate Manufacturing } & 43\end{array}$

4.3 Packaging and Assembly $\quad 43$

4.4 Temperature Cycling Tests and Resistance Measurements 44

$\begin{array}{lll}\text { 4.5 Data Analysis } & 46\end{array}$

$\begin{array}{lll}4.6 & \text { Failure Analysis } & 47\end{array}$

CHAPTER 5. RESULTS 50

5.1 Electrical Resistance at the $0^{\text {th }}$ Cycle $\quad 50$

5.2 Resistance Changes from Temperature Cycling Tests 54

5.2.1 Results Based on Temperature Cycling Tests 56

5.2.2 Results Based on Daisy Chains $\quad 59$

$\begin{array}{lll}5.3 & \text { DOE Results } & 61\end{array}$

$\begin{array}{lll}5.4 & \text { Failure Analysis } & 67\end{array}$

5.4.1 Packages with High Net Resistance Change (Phase I) 69

5.4.2 Packages with Low Net Resistance Change (Phase II) 86

5.4.3 Summary of Failure Analysis $\quad 92$ 
$\begin{array}{lll}6.1 & \text { DOE Analyses } & 93\end{array}$

6.1.1 DOE Analysis at the TCB $1200^{\text {th }}$ Cycle 95

6.1.1.1 Single Factor Effects 95

6.1.1.2 Two-factor Interaction Effects 96

6.1.2 DOE Analysis at the TCB $2012^{\text {th }}$ Cycle 100

6.1.2.1 Single Factor Effects 101

6.1.2.2 Two-factor Interaction Effects 102

$\begin{array}{ll}\text { 6.1.3 DOE Analysis at the TCC } 300^{\text {th }} \text { Cycle } & 104\end{array}$

$\begin{array}{lll}\text { 6.1.3.1 Single Factor Effects } & 105\end{array}$

6.1.3.2 Two-factor Interaction Effects 106

$\begin{array}{ll}\text { 6.1.4 DOE Analysis at the TCC } 500^{\text {th }} \text { Cycle } & 109\end{array}$

6.1.4.1 Single Factor Effects 109

6.1.4.2 Two-factor Interaction Effects 110

6.1.5 Summary of the DOE Analyses 113

$\begin{array}{lll}6.2 & \text { Failure Analysis } & 115\end{array}$

6.2.1 Observations from Cross-sectioned Daisy Chains 115

6.2.2 Failure Analysis, Correlations, and Explanations 117

$\begin{array}{ll}\text { CHAPTER 7. CONCLUSION } & 123\end{array}$

$\begin{array}{ll}\text { CHAPTER 8. FUTURE WORK } & 126\end{array}$

$\begin{array}{ll}\text { REFERENCES } & 127\end{array}$

$\begin{array}{lll}\text { APPENDIX A } & \text { Measured Electrical Resistances at the } 0^{\text {th }} \text { Cycle }\end{array}$ 
APPENDIX B ANOVA of Electrical Resistance at the $0^{\text {th }}$ Cycle

APPENDIX C-1 Measured Electrical Resistances at the Measured

APPENDIX C-2 Derived Resistance Changes at the Measured

APPENDIX D Average Resistance Changes for Each Measured

APPENDIX E Average Resistance Changes for Each Daisy Chain

190

APPENDIX F-1 Calculated Effects at the Measured Temperature Cycles

APPENDIX F-2 Detailed Effect and Sum of Square (SS) at the

APPENDIX G

Cracked Via Cross-section Micrographs 


\section{LIST OF FIGURES}

Page

Figure 1. Cross section of a typical Flip Chip Ball Grid Array (FCBGA). 1

Figure 2. Top view, side view, and bottom view of a $35 \mathrm{~mm}$ x $35 \mathrm{~mm}$ FCBGA. 2

Figure 3. A quarter of the die pad layout and a quarter of the package pin 3 layout in a Xilinx Vertex 4 device.

Figure 4. Cross section of a 10-layer FCBGA polymeric substrate. 6

Figure 5. A micro-via crack in a 10-layer FCBGA polymeric substrate. 7

Figure 6. A failed $50 \mu \mathrm{m}$ micro-via in the ITRI-2.4 sample [11]. 14

Figure 7. A $25 \mu \mathrm{m}$ micro-via survived 2000 thermal shock cycles in 15 the ITRI HDI Fine Line 1A sample [11].

Figure 8. Cross-sections of the mechanically drilled vias [12]. 16

Figure 9. Crack initiation from inside of knee [12]. 19

Figure 10. A completely failed mechanically drilled via [12]. 19

Figure 11. Stress-strain hysteresis loops for worst case element in 22 substrate via [13].

Figure 12. Total equivalent strain in via of Leg 1 at $-55^{\circ} \mathrm{C}[13] . \quad 23$

Figure 13. Total equivalent strain in via of Leg 1 at $125^{\circ} \mathrm{C}$ [13]. 24

Figure 14. Predicted fatigue life of vias for Leg 1 to Leg 9 [13]. 25

Figure 15. The schematic of the high density interconnect [4]. 26

Figure 16. The hysteresis loop for the temperature cycle with a temperature 26 rise of $215^{\circ} \mathrm{C}$ [4].

Figure 17. Stress (Vonmises) contour plot over via at $150^{\circ} \mathrm{C}[4] . \quad 27$

Figure 18. Results of the finite element analysis for via in the 2nd layer [4]. 28 
Figure 19. Illustration of stack-on-core via and non-stack-on-core via.

Figure 20. Via aspect ratios.

Figure 20. Stack via design vs. staggered via design.

Figure 22. An illustration of a fillet between a trace and a via capture pad. 35

Figure 23. Investigation flow chart. 39

Figure 24. Detailed design of the test vehicle. 42

Figure 25. Ransco dual-zone temperature cycle chamber. 46

Figure 26. Checksum open-short tester. 46

Figure 27. JEOL JSM-6360LV low vacuum scanning electron microscope. $\quad 49$

Figure 28. Statistical analysis of resistance changes in the measured cycles. 57

Figure 29. Statistical analysis of resistance changes of all daisy chains. 60

Figure 30. An illustration of a crack and a minor crack. 69

Figure 31(a). Cross-section locations for Daisy Chain 04 and Daisy Chain $14 . \quad 70$

Figure 31(b). Cross-section locations for Daisy Chain 06 and Daisy Chain $08 . \quad 71$

Figure 31(c). Cross-section locations for Daisy Chain $02 . \quad 71$

Figure 32(a). The cross-section micrograph of the upper layers of 73 Daisy 06/PKG 36.

Figure 32(b). The cross-section micrograph of the lower layers of Daisy 06/PKG 36.

Figure 32(c). The cross-section micrograph of the upper layers of Daisy 06/PKG 43.

Figure 32(d). The cross-section micrograph of the lower layers of Daisy 06/PKG 43.

Figure 33(a). The cross-section micrograph of the upper layers of Daisy 04/PKG 06\&10. 
Figure 33(b). The cross-section micrograph of the lower layers of Daisy 04/PKG 06\&10.

Figure 33(c). The cross-section micrograph of the upper layers of Daisy 04/PKG 19\&47.

Figure 33(d). The cross-section micrograph of the lower layers of Daisy 04/PKG 19\&47.

Figure 34(a). The cross-section micrograph of the upper layers of Daisy 14/PKG 23\&26.

Figure 34(b). The cross-section micrograph of the lower layers of 79 Daisy 14/PKG 23\&26.

Figure 34(c). The cross-section micrograph of the upper layers of Daisy 14/PKG 42\&44.

Figure 34(d). The cross-section micrograph of the lower layers of 80 Daisy 14/PKG $42 \& 44$.

Figure 35(a). The cross-section micrograph of the upper layers of Daisy 08/PKG 04\&35.

Figure 35(b). The cross-section micrograph of the lower layers of Daisy 08/PKG 04\&35.

Figure 35(c). The cross-section micrograph of the upper layers of Daisy 08/PKG 32\&48.

Figure 35(d). The cross-section micrograph of the lower layers of Daisy 08/PKG 32\&48.

Figure 36(a). The cross-section micrograph of the upper layers of Daisy 02/PKG 02.

Figure 36(b). The cross-section micrograph of the lower layers of Daisy 02/PKG 02.

Figure 36(c). The cross-section micrograph of the upper layers of Daisy 02/PKG 39.

Figure 36(d). The cross-section micrograph of the lower layers of Daisy 02/PKG 39. 
Figure 37(a). The cross-section micrograph of the upper layers of Daisy 06/PKG 41.

Figure 37(b). The cross-section micrograph of the lower layers of Daisy 06/PKG 41.

Figure 37(c). The cross-section micrograph of the upper layers of Daisy 06/PKG 33.

Figure 37(d). The cross-section micrograph of the lower layers of Daisy 06/PKG 33.

Figure 38(a). The cross-section micrograph of the upper layers of Daisy 02/PKG 22.

Figure 38(b). The cross-section micrograph of the lower layers of Daisy 02/PKG 22.

Figure 38(c). The cross-section micrograph of the upper layers of Daisy 02/PKG 46.

Figure 38(d). The cross-section micrograph of the lower layers of Daisy 02/PKG 46.

Figure 39. Single factor plots at the TCB $1200^{\text {th }}$ cycle.

Figure 40. Two-factor interaction plots at the TCB $1200^{\text {th }}$ cycle.

Figure 41. Single factor plots at the TCB $2012^{\text {th }}$ cycle.

Figure 42. Two-factor interaction plots at the TCB $2012^{\text {th }}$ cycle.

Figure 43. Single factor plots at the TCC $300^{\text {th }}$ cycle.

Figure 44. Two-factor interaction plots at the TCC $300^{\text {th }}$ cycle.

Figure 45. Single factor plots at the TCC $500^{\text {th }}$ cycle.

Figure 45. Two-factor interaction plots at the TCC $500^{\text {th }}$ cycle.

Figure 47. Materials surrounding stack-on-core via and non-stack-on-core via. 


\section{LIST OF TABLES}

Page

Table 1. Main features of the previous research on via cracks.

Table 2. General design rules of each generation of micro-via technology [2]. 10

Table 3. Experimental matrix of mechanically drilled vias [12]. 16

Table 4. Cracks found in five worst case units from each leg after 1,300 temperature cycles [12].

Table 5. Summary of HDI test results [4].

Table 6. Experimental design matrix of the daisy chains.

Table 7. DOE for each resistance measurement process.

Table 8(a). Design features of daisy chains \#01 - 06 and their statistical resistance data at the $0^{\text {th }}$ cycle.

Table 8(b). Design features of daisy chains \#07 - 12 and their statistical resistance data at the $0^{\text {th }}$ cycle.

Table 8(c). Design features of daisy chains \#13 - 16 and their statistical resistance data at the $0^{\text {th }}$ cycle.

Table 9(a). Average resistance changes of daisy chains \#01 - 08 at all the measured cycles.

Table 9(b). Average resistance changes of daisy chains \#09-16 at all the measured cycles.

Table 10. Statistical analysis of resistance changes in the measured cycles.

Table 11(a). Statistical analysis of resistance changes of daisy chains \#01 - $06 . \quad 59$

Table 11(b). Statistical analysis of resistance changes of daisy chains \#07 - 12. 59

Table 11(c). Statistical analysis of resistance changes of daisy chains \#13 - 16. 59

Table 12(a). The rankings of the effects for the measured cycles TCB238 - TCB1016. 
Table 12(b). The rankings of the effects for the measured cycles

TCB1200 - TCB2012.

Table 12(c). The rankings of the effects for the measured cycles TCC100 - TCC500.

Table 13(a). ANOVA: DOE for the TCB $1200^{\text {th }}$ cycle. 64

Table 13(b). ANOVA: DOE for the TCB 2012 ${ }^{\text {th }}$ cycle. 65

Table 13(c). ANOVA: DOE for the TCC $300^{\text {th }}$ cycle. 66

Table 13(d). ANOVA: DOE for the TCC 500 ${ }^{\text {th }}$ cycle. 67

Table 14. The daisy chains and the packages selected for cross-section 69 in Phase I.

Table 15. The cross-section report of Daisy Chain 06 in Phase I. 72

Table 16. The cross-section report of Daisy Chain $04 . \quad 75$

Table 17. The cross-section report of Daisy Chain $14 . \quad 78$

Table 18. The cross-section report of Daisy Chain $08 . \quad 81$

Table 19. The cross-section report of Daisy Chain 02 in Phase I. 84

Table 20. The daisy chains and the packages selected for cross-section $\quad 87$ in Phase II.

Table 21. The cross-section report of Daisy Chain 06 in Phase II. 87

Table 22. The cross-section report of Daisy Chain 02 in Phase II. 90

Table 23. The top three contributing factors and interaction and their 93 rankings.

Table 24. Single factor effects at the TCB $1200^{\text {th }}$ cycle. 96

Table 25. Two-factor interaction effects at the TCB $1200^{\text {th }}$ cycle. 97

Table 26. Single factor effects at the TCB $2012^{\text {th }}$ cycle. 101

Table 27. Two-factor interaction effects at the TCB 2012 $2^{\text {th }}$ cycle. 102 
Table 28. Single factor effects at the TCC $300^{\text {th }}$ cycle.

Table 29. Two-factor interaction effects at the TCC $300^{\text {th }}$ cycle.

Table $30 . \quad$ Single factor effects at the TCC $500^{\text {th }}$ cycle.

Table 31. Two-factor interaction effects at the TCC $500^{\text {th }}$ cycle.

Table 32. Summary of number of failed vias and their locations. 


\section{CHAPTER ONE}

\section{INTRODUCTION}

Ever since the first Integrated Circuit (IC) was packaged in the 1960s, the microelectronics packaging industry has never stopped creating new IC packages to meet numerous demands from the ever evolving electronic products. For the past seven years the Flip Chip Ball Grid Array (FCBGA), an advanced microelectronic package, has been developed to package high density and high frequency chips such as microprocessors, high end memories, Application-Specific ICs (ASICs), and Field Programmable Gate Arrays (FPGAs). A cross section of a FCBGA showing the major components is shown in Figure 1. The top view, the side view, and the bottom view of a $35 \times 35 \mathrm{~mm}$ FCBGA are shown in Figure 2. In Figure 2, the heat spreader was intentionally removed so that the silicon chip is visible in the top view.

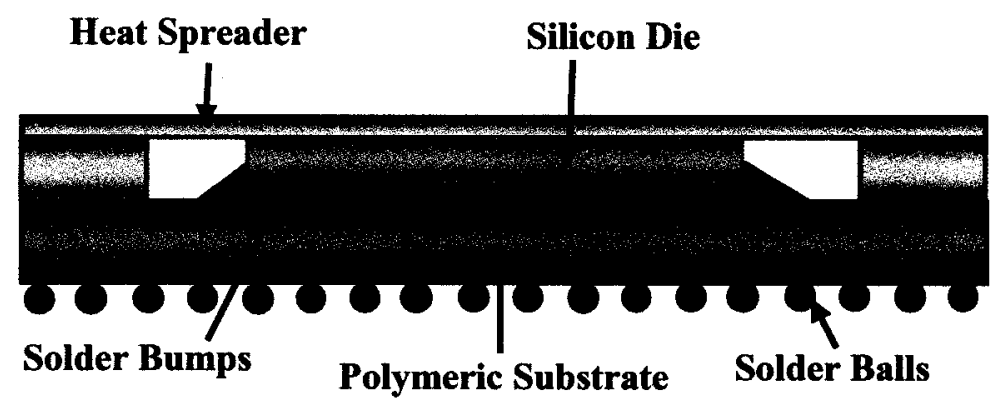

Figure 1. Cross section of a typical Flip Chip Ball Grid Array (FCBGA).

\subsection{The Main Drivers for the Development of FCBGA}

Density and frequency are two of the major drivers for IC packaging development. The year 2005 marked the $40^{\text {th }}$ anniversary of Moore's prediction, commonly known as 
Moore's Law, which states that "the number of transistors on a chip roughly doubles every two years [1]." As the feature size has shrunk to $65 \mathrm{~nm}$ and the physical gate length has dropped to $35 \mathrm{~nm}$, the microelectronics packaging industry has attempted to follow the trend and develop packages that handle and offer more and more Input/Output (I/O) counts within an acceptable size. For instance, the latest Intel Itanium-2 processor, which is packaged in a $42.5 \mathrm{~mm} \times 42.5 \mathrm{~mm}$ FCBGA, contains 592 million transistors [1]. Another example can be found in a Xilinx Vertex 4 FPGA device that has more than 8,000 die pads ${ }^{*}$. The same $42.5 \mathrm{~mm}$ x $42.5 \mathrm{~mm}$ FCBGA is used to route all the die pads of the device to 1760 package pins ${ }^{\dagger}$. A quarter of the die pad layout and a quarter of the package pin layout of this device are shown side-by-side in Figure 3.

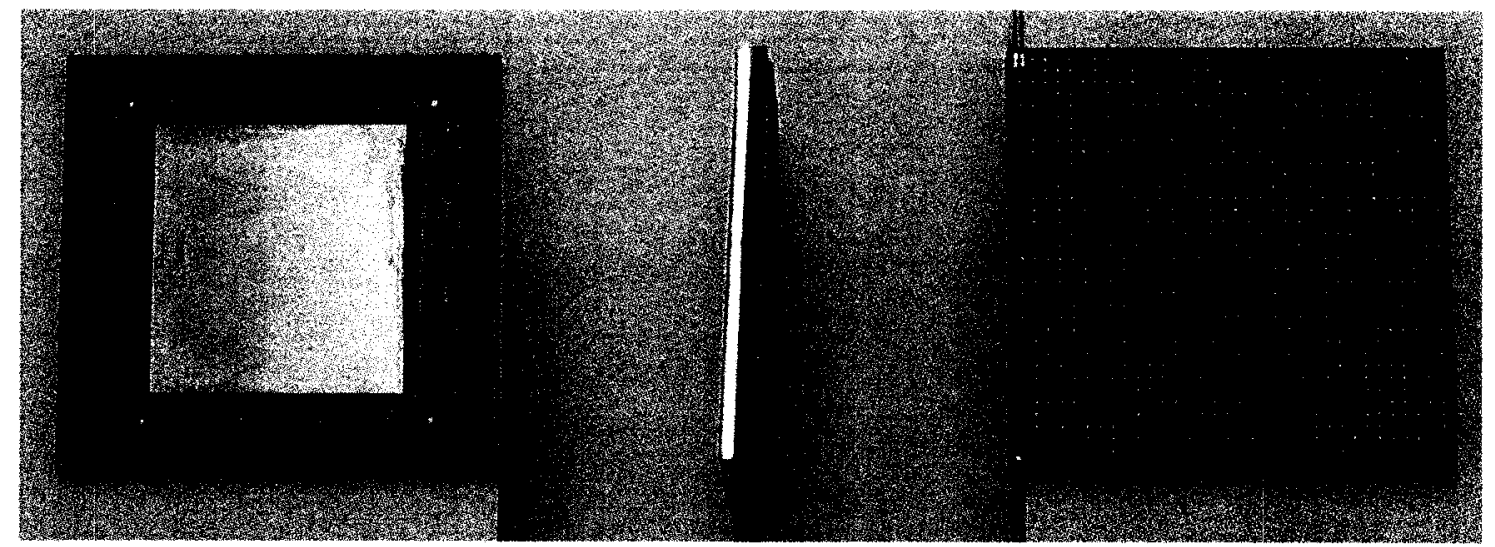

Figure 2. Top view, side view, and bottom view of a $35 \mathrm{~mm}$ x $35 \mathrm{~mm}$ FCBGA.

The development of worldwide information technology requires the electronic products to manipulate a very large number of data in a relatively short time. As the

\footnotetext{
"A die pad is an elevated pad on the surface of a chip. A die pad is interconnected to a ground, a power, or an $\mathrm{I} / \mathrm{O}$ of the chip.

${ }^{\dagger}$ A package pin is a ball, pin or lead coming out from a package. A package pin is routed to a die pad (or die pads) of the chip inside the package and, therefore, is interconnected to a ground, a power, or an I/O of the chip.
} 
optical networking technology has evolved from megabits per second to gigabits per second, the microelectronics packaging industry also had to follow the trend and develop packages that offer faster and faster clock speeds. Today the latest Intel Pentium-4 processor, which uses similar Flip Chip Pin Grid Array (FCPGA) packaging technology, can provide clock speeds of up to $3.73 \mathrm{GHz}$. The Xilinx Vertex-4 FPGA family is another example. The Vertex-4 FPGAs, which are packaged in FCBGAs, provide channels of Multi-Gigabit serial Transceiver (MGT) capable of running up to 10 Gigabits per second.

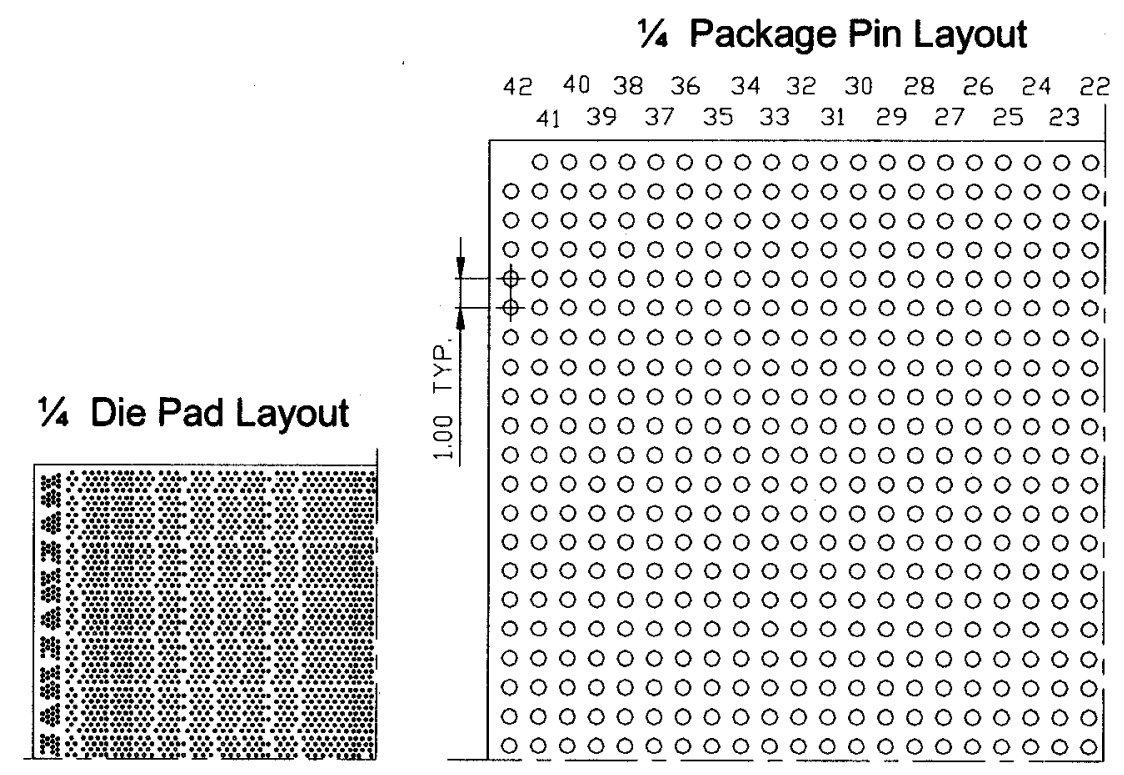

Figure 3. A quarter of the die pad layout and a quarter of the package pin layout in a Xilinx Vertex 4 device.

\subsection{Changes in Microelectronic Packaging for the Development of FCBGA}

Traditional leaded packages, which have leads on their sides, can no longer meet the density requirements. The largest leaded package, having an envelope size of about $35 \mathrm{~mm} \times 35 \mathrm{~mm}$ and a lead pitch of $0.5 \mathrm{~mm}$, only provides 240 package pins. In contrast, 
a ball grid array (BGA) package of similar size provides 1156 package pins. The main advantage of the BGA package is that arrays of solder balls are laid out over the entire bottom area for package pins. Today the largest BGA package has a body size of $50 \mathrm{~mm}$ x $50 \mathrm{~mm}$. With a ball pitch ${ }^{*}$ of $1 \mathrm{~mm}$, up to 2400 package pins can be provided.

Wire bonding, an interconnect technology that uses gold wire to join a chip I/O to a package lead, has been facing limitations in terms of density and speed. Density-wise, since wire bond pads can only be placed on the four sides of a chip, even with the most advanced technology that reduces the effective bond pad pitch to $30 \mu \mathrm{m}$, a maximum of only 2,600 die pads can be placed on a $20 \mathrm{~mm}$ x $20 \mathrm{~mm}$ silicon. Flip chip technology, or Controlled Collapse Chip Connection (C4) technology, conversely, makes use of the entire area of the chip to place arrays of solder bumps for die pads. The same $20 \mathrm{~mm} \mathrm{x}$ $20 \mathrm{~mm}$ die can provide more than 8,000 die pads with a $200 \mu \mathrm{m}$ solder bump pitch. Speed-wise, most I/Os of a wire-bond package have unavoidably long interconnect paths. First, the gold wire itself can be very long and is also very inductive. Second, a long redistribution path is needed inside the die to bring an $\mathrm{I} / \mathrm{O}$ to the periphery of a chip. Thus wire bond interconnection can hardly meet the frequency and performance requirements of an advanced IC chip. On the contrary, almost all I/Os of a flip chip package have the most direct interconnect path. Therefore, flip chip technology is extensively chosen for packaging high speed and high performance chips.

\footnotetext{
* Ball pitch is the nominal distance between the center lines of two adjacent rows of balls. Nowadays, the commonly used ball pitches are $0.8 \mathrm{~mm}, 1 \mathrm{~mm}$, and $1.27 \mathrm{~mm}$ for FCBGAs in the industry.
} 


\subsection{Challenges Facing FCBGA Development}

FCBGA utilizes a polymeric substrate as the IC carrier and interconnection of die pads and package pins. Although ceramic substrates are more robust, polymeric substrates are chosen for commercial and industrial usage mainly because of their low cost. However, the cost of a FCBGA polymeric substrate ranges from $35 \%$ to $70 \%$ of the total assembly cost. (For example, the cost of an 8-layer $35 \mathrm{~mm}$ x $35 \mathrm{~mm}$ FCBGA polymeric substrate is $\$ 12$ each, the cost of the assembly is $\$ 8$ each, and so the total assembly cost is $\$ 20$ each.) But the cost of a leadframe is less than $20 \%$ of the total assembly cost of a leaded package. (The total assembly cost of a 240 pin PBGA, which has about $35 \mathrm{~mm} \times 35 \mathrm{~mm}$ envelope size, is only about $\$ 3$ each.) In some cases, the cost of the polymeric substrate is even higher than the cost of the silicon. Consequently, many companies have started to put a lot of effort into improving the yield and lowering the cost of FCBGA polymeric substrates.

Unlike leadframes that normally offer a "one size fits all" solution, FCBGA polymeric substrates are custom designed for each IC-package combination according to the die pad layout, package pin layout, netlist ${ }^{*}$, and signal integrity requirements. The structure of a polymeric substrate is similar to that of a printed wiring board (PWB). But, every feature in it is in miniature size. For example, the minimum trace width and gap used are $20 \mu \mathrm{m}$ and $25 \mu \mathrm{m}$, respectively, and the minimum blind laser via diameter is 50 $\mu \mathrm{m}[2]$.

\footnotetext{
"A netlist is a list of all the electrical "nets" inside a package. Each net is an interconnection of a die pad (or die pads) and a package pin (or package pins).
} 
A common FCBGA polymeric substrate requires six to twelve copper layers for $\mathrm{I} / \mathrm{O}$ routing and power and ground planes. Laser vias and core vias are used to interconnect I/Os, powers, and grounds in the copper layers according to the netlist and the signal integrity requirements of a microelectronic package. Up to 50,000 vias may exist in a $50 \mathrm{~mm} \times 50 \mathrm{~mm}$ 12-layers FCBGA polymeric substrate. A failure in one via will cause a complete failure of the device. A cross section displaying the layers and the vias of a FCBGA polymeric substrate is shown in Figure 4.

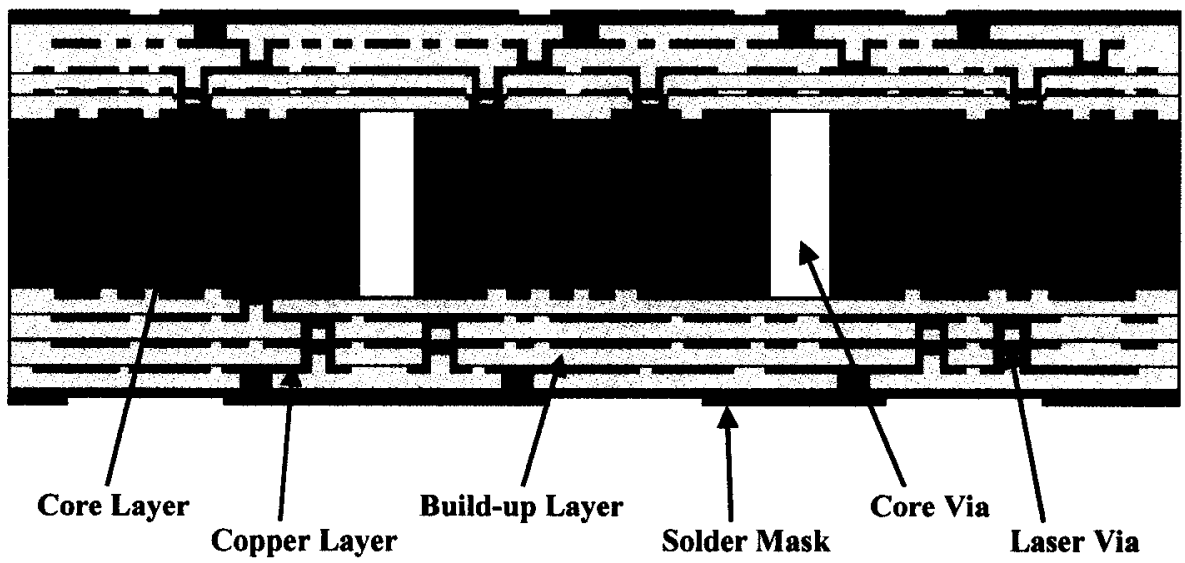

Figure 4. Cross section of a 10-layer FCBGA polymeric substrate.

High yield loss, as much as $50 \%$, is common in the manufacture of FCBGA polymeric substrates. The causes of yield loss include over/under etching of metal patterns, warping, delamination of layers, presence of plating impurities, and laser blind via failure, among others. Out of all failures, via failure due to micro-cracks is particularly difficult to be noticed and tested for [3]. Sometimes the minuscule microcracks remain unnoticed and the substrate is passed on to the IC assembly and packaging 
operations. A photograph showing the crack in a micro-via of a 10-layer FCBGA polymeric substrate is shown in Figure 5.

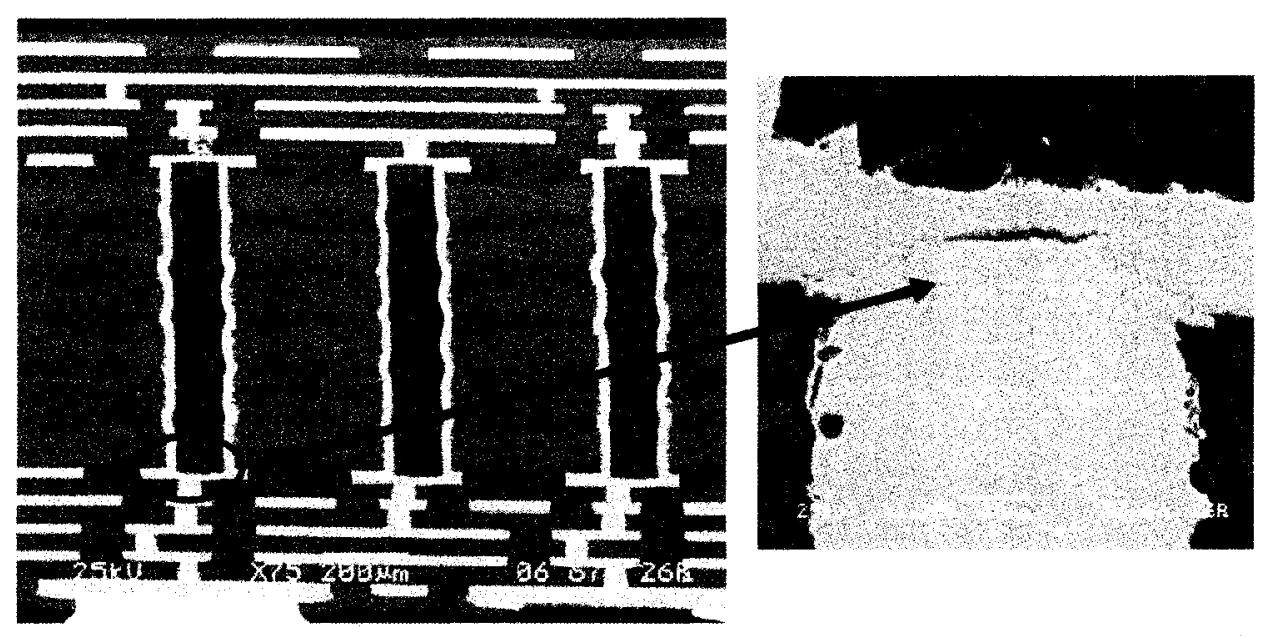

Figure 5. A micro-via crack in a 10-layer FCBGA polymeric substrate.

After packaging, due to coefficient of thermal expansion (CTE) mismatch of the silicon and the substrate and of the copper and the polymeric materials, the substrate is unavoidably subjected to thermal stresses [4-6]. Micro-cracks due to manufacturing defects may become wider or propagate in length. In addition, new micro-cracks may also be created. Intermittent failure due to laser via micro-cracks is one of the major failures when the chip is tested or even when it is in service [7]. The economic impact on the users and the chip manufacturers is incredibly large. Therefore there is a need to investigate causes of via failure.

\subsection{The Focus of this Research}

The first phase of this investigation focused on the study of the causes of via micro-cracks of the microelectronic packages in current usage, including the effect of via 
structures, via diameters, substrate materials, manufacturing processes, thermal stress and fatigue, and fracture mechanisms. The second phase focused on identifying the major design factors contributing to via cracks in an assembled FCBGA. Existing commonly used via structures, patterns, sizes, and features were analyzed to locate the potential factors. The types of experiment, measurement data and techniques, and design of experiment (DOE) were then developed to achieve the goal. A test vehicle containing the combinations of all the potential factors was designed. A sufficient number of test vehicles, for statistical significance, were fabricated and fully assembled for the experiment. The next phase of the research focused on setting up the experiment series, carrying them out, and analyzing the results and data. All the test vehicles were subjected to thermal stress cycles, and electrical resistances were measured and analyzed. After that, cross-sectioning and failure analyses were performed on selected test vehicles to obtain further information on failure modes. All of the experimental data and the results were analyzed and evaluated to understand the effect of design factors on laser via reliability of a FCBGA.

In Chapter 2, the background of laser via reliability and a general outline of the current design factors which are the possible causes of reliability concerns are presented. In Chapter 3, the objective and the parameters of the investigation are described. In Chapter 4 , the experimental approach is explained. Chapter 5 and Chapter 6 contain the results and discussions of the results, respectively. The conclusions of this investigation are presented in Chapter 7, and recommendations for future work in Chapter 8. 


\section{CHAPTER TWO}

\section{LITERATURE REVIEW}

Before the Ball Grid Array (BGA) and Pin Grid Array (PGA) packages emerged as the mainstream microelectronic packages in the 1990's, vias were not commonly known to the first level packaging industry as being part of the packaging interconnect structures. In the last 17 years, numerous articles, journals, and papers have discussed practically every aspect of vias. Many of these also identified via crack or via delamination as a potential issue in the development of reliable packages. Nevertheless, due to the competitive nature of the packaging industry, publications with detailed studies on via cracks are relatively few. The purpose of this chapter is to review and discuss the valuable works that have been done by other researchers. Table 1 is a summary of these works and the main features of the studies.

\subsection{Road Map and Future Developments of Micro-via Technology}

Every two years, the Semiconductor Industry Association (SIA), which consists of a group of semiconductor companies, assembles and updates a technology roadmap known as the International Technology Roadmap for Semiconductors (ITRS) to assure the growth of the semiconductor industry up to 10-15 years ahead. As reported by Sundaram et al. in 2004 [8], the 2002 ITRS roadmap required much finer vias than the current micro-vias of $50 \mu \mathrm{m}$ diameter to match the $100 \mu \mathrm{m}$ array die pad pitch and data rates of 10 Gigabits per second in 2010. By then, the micro-via diameter would be decreased to 10-30 $\mu \mathrm{m}$, and the line and space, conductor thickness, and dielectric 
thickness would also be decreased. A comparison of the general design rules for four consecutive generations of micro-via technologies is shown in Table 2. Currently the industry has reached the second generation.

Table 1. Main features of the previous research on via cracks.

\begin{tabular}{|c|c|c|}
\hline & Studies & Main Features of the studies \\
\hline \multirow[t]{2}{*}{1} & \multirow{2}{*}{$\begin{array}{l}\text { Road map and future } \\
\text { developments of } \\
\text { micro-via technology }\end{array}$} & The need of decreasing micro-via diameter \\
\hline & & $\begin{array}{l}\text { Reliability assessment of } 25 \mu \mathrm{m} \text { micro-vias in a C-SiC } \\
\text { composite board }\end{array}$ \\
\hline \multirow[t]{3}{*}{2} & \multirow{3}{*}{$\begin{array}{l}\text { Reliability } \\
\text { assessments }\end{array}$} & Micro-vias in a flip chip package \\
\hline & & $\begin{array}{l}\text { Photo-defined micro-vias of different sizes in PCB } \\
\text { based test vehicles }\end{array}$ \\
\hline & & $\begin{array}{l}\text { Mechanical drilled vias of different sizes, features, and } \\
\text { pre-conditioning processes in a land grid array package }\end{array}$ \\
\hline \multirow[t]{2}{*}{3} & \multirow[t]{2}{*}{$\begin{array}{l}\text { Thermo-mechanical } \\
\text { formations of micro- } \\
\text { via cracks }\end{array}$} & $\begin{array}{l}\text { Use of FEA for thermal-stress analyses and fatigue-life } \\
\text { prediction on mechanical drilled vias and high density } \\
\text { interconnect vias }\end{array}$ \\
\hline & & Comparing the FEA results with the experimental data \\
\hline \multirow[t]{4}{*}{4} & \multirow{4}{*}{$\begin{array}{l}\text { Analyses of design } \\
\text { factors }\end{array}$} & Micro via location with respect to a core via \\
\hline & & Aspect ratio \\
\hline & & Micro via location among each other \\
\hline & & Fillet \\
\hline
\end{tabular}

Table 2. General design rules of each generation of micro-via technology [2].

\begin{tabular}{|l|c|c|c|c|}
\hline & $\begin{array}{l}\text { First Generation } \\
\text { Build-up }\end{array}$ & $\begin{array}{l}\text { Co- } \\
\text { Lamination } \\
\text { Technology }\end{array}$ & $\begin{array}{l}\text { Second } \\
\text { Generation } \\
\text { Build-up }\end{array}$ & $\begin{array}{l}\text { Future SOP } \\
\text { Interposer } \\
\text { Substrate }\end{array}$ \\
\hline $\begin{array}{l}\text { Line /Spacing } \\
(\mu \mathrm{m})\end{array}$ & $75 / 75-100 / 100$ & $50 / 50-75 / 75$ & $10 / 10-30 / 30$ & $3 / 3-10 / 10$ \\
\hline $\begin{array}{l}\text { Via/Land/Pitch } \\
(\mu \mathrm{m})\end{array}$ & $\begin{array}{l}150-200 / 300- \\
400 / 400-500\end{array}$ & $\begin{array}{l}70-100 / 170- \\
300 / 210-300\end{array}$ & $\begin{array}{c}30-50 / 60- \\
80 / 100-150\end{array}$ & $\begin{array}{l}10-30 / 20- \\
50 / 30-100\end{array}$ \\
\hline Layer Counts & $2+\mathrm{n}+2$ & $6-20$ & $3+\mathrm{n}+3$ & $3-5$ \\
\hline $\begin{array}{l}\text { Conductor } \\
\text { Thickness }(\mu \mathrm{m})\end{array}$ & $70-100$ & $50-100$ & $3-10$ & $3-10$ \\
\hline $\begin{array}{l}\text { Dielectric } \\
\text { Thickness }(\mu \mathrm{m})\end{array}$ & $70-100$ & $50-100$ & $10-15$ & $10-15$ \\
\hline
\end{tabular}


Sundaram's research pointed out that the current substrates and dielectric materials would not meet future requirements, and thus, development of the next generation micro-via and global wiring technologies would be needed. Several sets of substrate and dielectric materials were then identified as potential candidates. However, methods on how small and reliable micro-vias would be developed were not included.

The research was continued by Kumbhat et al., including Sundaram, in 2005 [9]. A new substrate set of carbon-silicon carbide (C-SiC) based composite board material was identified as a promising candidate substrate material for the next-generation microsystems. One of the main reasons that $\mathrm{C}-\mathrm{SiC}$ was selected as the basic board material was due to its minimal via-pad misalignment, which is a significant advantage for the multilayer built-up structure required to achieve very high wiring density. However, the authors also indicated that the use of $\mathrm{C}-\mathrm{SiC}$ could potentially cause delamination and cracking in the interlayer dielectric due to its high CTE mismatch with the dielectric material and copper. On the whole, the authors indicated that the achievement of high density package wiring depended greatly on the reliability of micro-via interconnects.

The reliability of a $25 \mu \mathrm{m}$ micro-via, based on finite element modeling and coupon testing, was then presented. Some test vehicles were designed, built and subjected to air-to-air thermal shock tests from $-55^{\circ} \mathrm{C}$ to $125^{\circ} \mathrm{C}$. The result was that the $25 \mu \mathrm{m}$ micro-via structure survived 1,200 cycles without any failures. Measurement data and detailed procedures of how the conclusions were drawn were not included in the paper. Nevertheless, the roadmap and the future development needs of micro-via 
technology presented in these two papers confirm the need and the importance for continued research on micro-vias.

\subsection{Reliability Assessments of Vias}

Accelerated thermal stress tests such as thermal cycling and thermal shock are commonly used for the reliability assessments of micro-electronic packages. Similar tests are also used for the reliability assessments of polymeric substrates. Because via failure is a major problem in the development of microelectronic packages, some investigations have been done specifically on the vias.

\subsubsection{Micro-vias in a Flip Chip Package}

The reliability assessment of flip chip on built-up laminate based multi-chip package with emphasis on micro-via interconnection reliability was investigated by Chai et al. in 2002 [10]. The reliability of micro-vias was assessed in three different test vehicles: (i) a 2 built-up layers daisy chain test coupon with 740 micro-vias, (ii) a comb pattern with line and space of $50 \mu \mathrm{m}$ each, and (iii) a bare substrate. The test coupon and the bare substrate were tested in thermal shock from $-55^{\circ} \mathrm{C}$ to $125^{\circ} \mathrm{C}$ up to 2,000 cycles, and the comb pattern was tested in $5 \mathrm{~V}$ bias in a hot air stress test at $131^{\circ} \mathrm{C}$ and $85 \% \mathrm{RH}$. After the thermal shock and biased hot air stress tests, the resistance values of the daisy chain patterns were measured. Not a single failure was found in these samples because the resistance change of the daisy chain pattern was within $\pm 3 \%$ of the original value. The samples were also checked by visual inspection followed by C-Scan Acoustic Microscopy (CSAM) inspection. No delamination or visual abnormalities were found on 
the test coupons. The conclusion was that the substrate technology that was used to build the micro-via and fine metal line interconnection demonstrated good reliability.

Although a cross-section of the test coupon was included in the paper, the important information of the test vehicles such as the size and the structure of the microvias, and the dielectric thickness were not mentioned. Moreover, the conditions of the thermal shock experiment such as cycle time and pre-conditioning level were not provided. The sample size of the experiment was unknown. The resistance measurement data and the statistical analysis were not given. The process and criteria used for visual inspection of abnormalities on the micro-vias was also not clear. These data and information are essential to support the results and the conclusion drawn. They would also be beneficial for further investigation.

\subsubsection{Photo-defined Micro-vias in a Printed Circuit Board}

Micro-via reliability issues for photo dielectric epoxy materials and processes were evaluated by Liu et al. in 2002 [11]. Two test vehicles designed by the Interconnect Technology Research Institute (ITRI) were used for the study. The ITRI-2.4 test sample had a $50 \mu \mathrm{m}$ thick dielectric film with micro-vias of $50,75,100$, and $125 \mu \mathrm{m}$. The ITRI HDI Fine Line 1A test sample had a $25 \mu \mathrm{m}$ thick dielectric film with micro-vias of 25,50 , 75 , and $100 \mu \mathrm{m}$. The numbers of vias and daisy chains and all the main features of the test vehicles were given in detail. The samples were tested in liquid-to-liquid thermal shock cycling from $-55^{\circ} \mathrm{C}$ to $125^{\circ} \mathrm{C}$ using an EPSEC Thermal Shock Chamber TSB-5 up to 2,000 cycles. The cycle time was 10 minutes and the liquid-to-liquid transfer time was 
10 seconds maximum. Resistance measurements were taken at every 100 cycles, and a $10 \%$ increase in resistance was considered a failure.

The first failure was found at 1,000 cycles for the $50 \mu \mathrm{m}$ micro-vias in the ITRI2.4 test vehicle, and the $25 \%$ failure rate was reached at 2,000 cycles. All the micro-vias of 75,100 , and $125 \mu \mathrm{m}$ in the ITRI-2.4 test vehicle passed 2,000 cycles. The crosssection of a failed $50 \mu \mathrm{m}$ micro-via after 2,000 cycles is shown in Figure 6 . As can be seen in Figure 6, a crack occurred at the foot of the via. All the $25,50,75$, and $100 \mu \mathrm{m}$ micro-vias in the ITRI HDI Fine Line $1 \mathrm{~A}$ test vehicle passed 2,000 cycles. The crosssection of a $25 \mu \mathrm{m}$ micro-via that survived 2,000 cycles is shown in Figure 7.

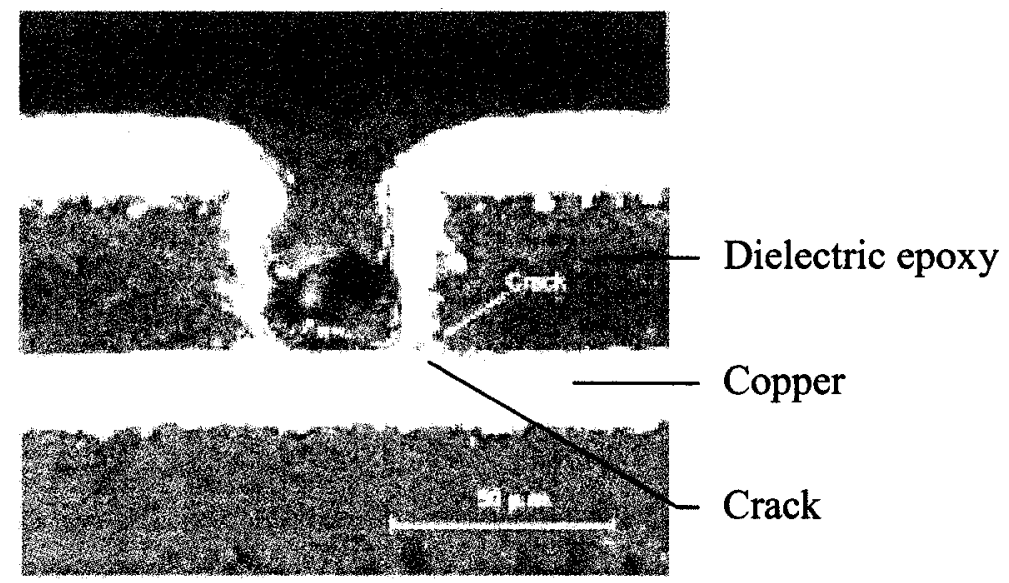

Figure 6. A failed $50 \mu \mathrm{m}$ micro-via in the ITRI-2.4 sample [11].

It was summarized that the cracks were a result of CTE mismatch between the copper and the dielectric epoxy layer. A high aspect ratio (dielectric thickness to via diameter) was the cause since it resulted in the copper plating at the foot of the vias being thin. This small micro-via metallization was not strong enough to withstand the stresses caused by the CTE mismatch. 


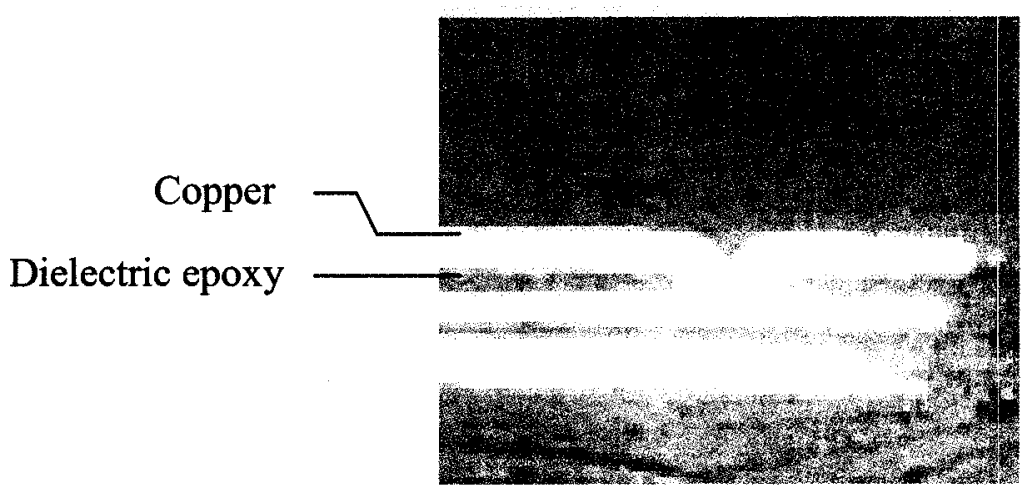

Figure 7. A $25 \mu \mathrm{m}$ micro-via survived 2000 thermal shock cycles in the ITRI HDI Fine Line 1A sample [11].

The authors stated that process-related defects such as inefficient control of dielectric roughening and copper plating processes, insufficient copper thickness on via walls, incomplete polymer curing, etc, might be the main causes of failures. However, details of the process related defects were not discussed.

Throughout the paper, the sample size used for the experiment was not given. If the sample size of each test vehicle were one, then the total number of vias tested would be merely a few hundreds for each via diameter. Since one flip chip package may contain as many as 70,000 laser micro-vias, the sample size of the experiments from this paper would be considered small. Moreover, resistance measurement data and statistical analysis are not provided in the paper. These data and information would be beneficial for further investigation.

\subsubsection{Mechanically Drilled Vias in a Land Grid Array Package}

The substrate via reliability of the mechanically drilled vias in a Land Grid Array (LGA) package was examined by Darveaux et al. in 2003 [12]. Nine different laminate 
constructions were used as test vehicles in this experiment. All the nine test vehicles had the same outline of $10 \mathrm{~mm} \times 10 \mathrm{~mm} 34$ LGA package with two daisy chains that consisted of drill vias of $250 \mu \mathrm{m}$ and $300 \mu \mathrm{m}$, respectively. The variables of the nine test vehicles are summarized in Table 3. The cross sections of the vias are shown in Figure 8.

Table 3. Experimental matrix for mechanically drilled vias [12].

\begin{tabular}{|l|c|c|c|c|c|c|c|c|c|}
\hline Leg & $1 \mathrm{a}$ & $2 \mathrm{a} / \mathrm{b}$ & $3 \mathrm{a}$ & $4 \mathrm{a} / \mathrm{b}$ & $5 \mathrm{a} / \mathrm{b}$ & $6 \mathrm{a}$ & $7 \mathrm{a}$ & $8 \mathrm{a}$ & $9 \mathrm{a}$ \\
\hline Total Thickness $(\mu \mathrm{m})$ & 470 & 490 & 451 & 471 & 290 & 490 & 290 & 490 & 378 \\
\hline Dielectric Thickness $(\mu \mathrm{m})$ & 387 & 392 & 355 & 362 & 213 & 408 & 209 & 411 & 212 \\
\hline Trace Thickness $(\mu \mathrm{m})$ & 28 & 40 & 28 & 35 & 26 & 26 & 24 & 33 & 67 \\
\hline Via Cap Thickness $(\mu \mathrm{m})$ & 18 & 18 & 17 & 19 & N/A & N/A & N/A & 20 & 18 \\
\hline Via Wall Thickness $(\mu \mathrm{m})$ & 60 & 51 & 65 & 60 & 28 & 28 & 22 & 62 & 63 \\
\hline \# of Metal Layers & 2 & 2 & 4 & 4 & 2 & 2 & 2 & 2 & 2 \\
\hline $\begin{array}{l}\text { Inner Layer Thickness } \\
(\mu \mathrm{m})\end{array}$ & N/A & N/A & 18 & 18 & N/A & N/A & N/A & N/A & N/A \\
\hline
\end{tabular}
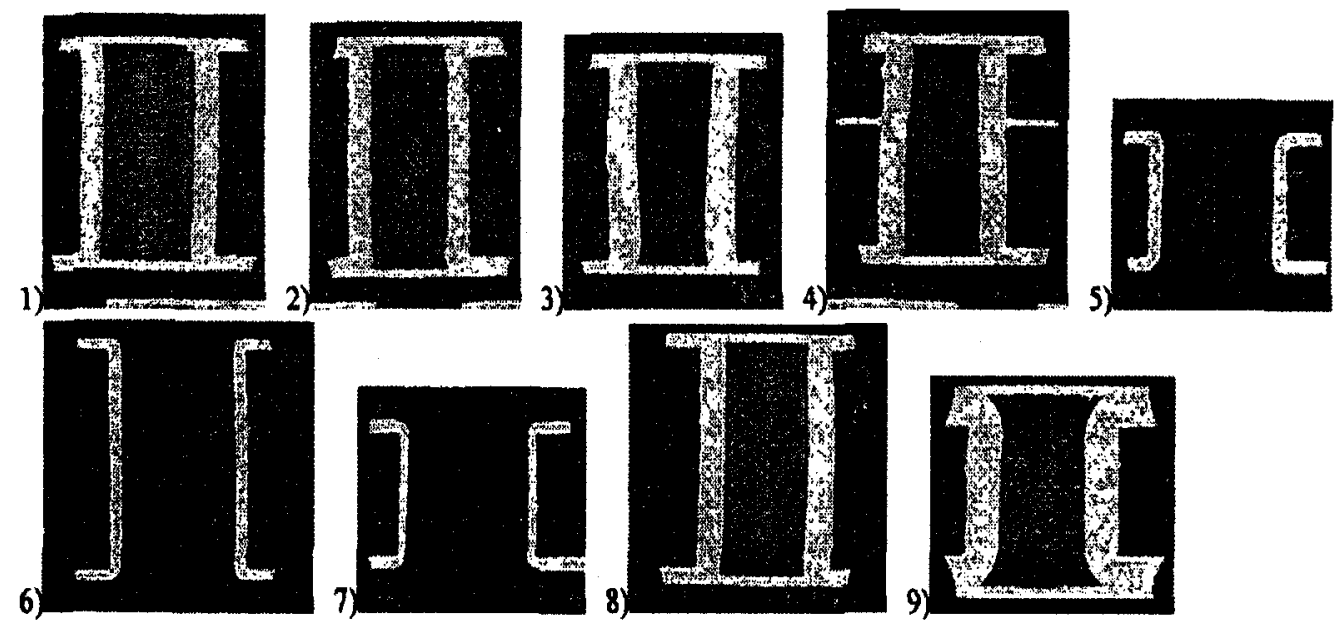

Figure 8. Cross-sections of mechanically drilled vias [12].

The number of samples used was twenty-two for each test vehicle. All the samples were subjected to temperature cycling from $-55^{\circ} \mathrm{C}$ to $125^{\circ} \mathrm{C}$ with a cycle time of 
30 minutes. Resistance measurements were taken every 200 cycles on the two daisy chains of all the samples. The initial resistances of all the daisy chains were between 600 $\mathrm{m} \Omega$ to $900 \mathrm{~m} \Omega$. A $200 \mathrm{~m} \Omega$ increase in resistance was considered a failure.

The first failure was found at 600 cycles. Fourteen samples out of forty-four of Leg 1a had failures due to cracks. At 800 cycles, twenty cumulative samples of Leg 1a had failure, and one out of the forty-four samples in Leg $5 \mathrm{~b}$ had failure. At 1,200 cycles, thirty-seven cumulative samples of Leg la had failure, three cumulative samples of Leg $5 \mathrm{~b}$ had failure and one sample of Leg $8 \mathrm{a}$ had failure. All other samples survived the temperature cycling test. It was identified that the construction for Leg la used a less robust manufacturing process during the fabrication of the substrates at the supplier's premises. However, via cracking of Leg $5 \mathrm{~b}$ could not be verified in cross-sectional photos. The experiment was continued up to 1,300 cycles, but no resistance measurements were recorded. In each leg, cross-section analyses were made on five units which had the greatest increase in resistance. The results of the cross-section are shown in Table 4. As can be seen from Table 4, all of the vias examined in Leg 1a were cracked. But cracks were also found in Legs $2 \mathrm{a}, 3 \mathrm{a}, 8 \mathrm{a}, 2 \mathrm{~b}$, and $4 \mathrm{~b}$. All of the vias of these legs had caps on them. The only capped via without cracks was Leg 9 which had the thickest via wall and the thickest copper layer among the nine constructions. None of the non-capped vias was found to have cracks. Also, the $300 \mu \mathrm{m}$ drills had more cracks than the $250 \mu \mathrm{m}$ drills did, and the legs that were pre-conditioned at $260^{\circ} \mathrm{C}$ had more cracks than the legs that were pre-conditioned at $240^{\circ} \mathrm{C}$ did. 
Table 4. Cracks found in five worst case units from each leg after 1,300 temperature cycles [12].

\begin{tabular}{|l|c|c|c|}
\hline \multirow{2}{*}{ Leg } & Pre-conditioning & $250 \mu \mathrm{m}$ via & $300 \mu \mathrm{m}$ via \\
\cline { 3 - 4 } & \# of cracks / \# inspected & \# of cracks / \# inspected \\
\hline 1a & L3-240 $\mathrm{C}$ & $5 / 5$ & $5 / 5$ \\
\hline 2a & L3-240 $\mathrm{C}$ & $0 / 5$ & $5 / 5$ \\
\hline $3 \mathrm{a}$ & $\mathrm{L} 3-240^{\circ} \mathrm{C}$ & $2 / 5$ & $2 / 5$ \\
\hline $4 \mathrm{a}$ & $\mathrm{L} 3-240^{\circ} \mathrm{C}$ & $0 / 5$ & $0 / 5$ \\
\hline $5 \mathrm{a}$ & $\mathrm{L} 3-240^{\circ} \mathrm{C}$ & $0 / 5$ & $0 / 5$ \\
\hline $6 \mathrm{a}$ & $\mathrm{L} 3-240^{\circ} \mathrm{C}$ & $0 / 5$ & $0 / 5$ \\
\hline $7 \mathrm{a}$ & $\mathrm{L} 3-240^{\circ} \mathrm{C}$ & $0 / 5$ & $0 / 5$ \\
\hline $8 \mathrm{a}$ & $\mathrm{L} 3-240^{\circ} \mathrm{C}$ & $0 / 5$ & $5 / 5$ \\
\hline $9 \mathrm{a}$ & $\mathrm{L} 3-240^{\circ} \mathrm{C}$ & $0 / 5$ & $0 / 5$ \\
\hline $2 \mathrm{~b}$ & $\mathrm{~L} 3-260^{\circ} \mathrm{C}$ & $3 / 5$ & $5 / 5$ \\
\hline $4 \mathrm{~b}$ & $\mathrm{~L} 3-260^{\circ} \mathrm{C}$ & $0 / 5$ & $5 / 5$ \\
\hline $5 \mathrm{~b}$ & $\mathrm{~L} 3-260^{\circ} \mathrm{C}$ & $0 / 5$ & $0 / 5$ \\
\hline
\end{tabular}

The cross-section of a cracked via from Leg $2 b$, after 1,300 cycles, is shown in Figure 9. As can be seen in Figure 9, the crack most probably initiated from the inside of the knee at the intersection between the via wall and the via cap where a stress concentration point is clearly seen. The cross-section of a failed via from Leg la after 1,000 cycles is shown in Figure 10. It is thought that the crack started at the same stress concentration point at the intersection between the via wall and the via cap, and then propagated along the interface, and finally split open the interface.

From the experimental results, the following observations were made:

- Only one of the nine constructions failed before 1,000 temperature cycles. This construction was identified having a substrate manufacturing process error.

- All the cracks were found between the via cap and the via wall. Thus, the samples without via caps were better than those with caps. The authors indicated that a 
thin via wall might be a factor in avoiding cracks. Compared to other capped parts, the non-via-capped parts had a much thinner wall thickness. However, this finding contradicts with the conclusion of "insufficient copper thickness on via walls" as one of the process related defects for via crack proposed by Liu et al [11], as described in Section 2.2.2.

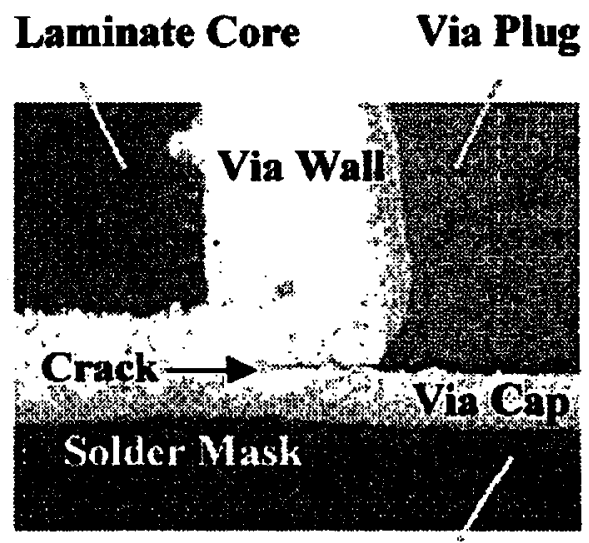

Bottom Surface of Module

Figure 9. Crack initiation from inside of knee [12].

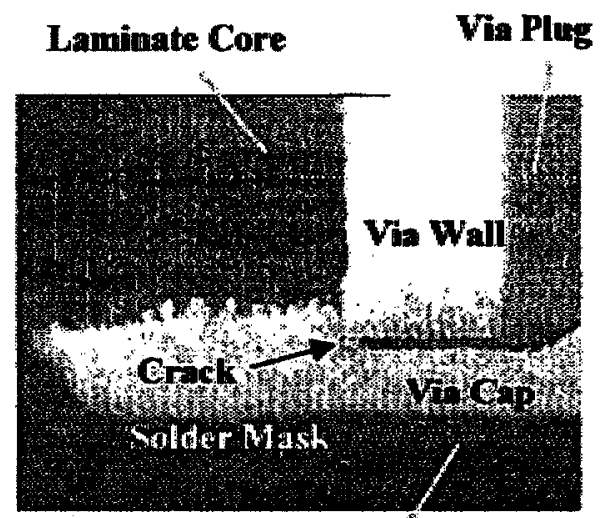

Bottom Surface of Module

Figure 10. A completely failed mechanically drilled via [12]. 
- Legs with $260^{\circ} \mathrm{C}$ pre-conditioning reflow temperature showed more cracking than legs with $240^{\circ} \mathrm{C}$ pre-conditioning reflow temperature do. No explanation was given in the report.

- Legs with $300 \mu \mathrm{m}$ drilled vias showed more cracking than legs with $250 \mu \mathrm{m}$ drilled vias do. Again, no explanation was given in the report.

\subsection{Thermo-mechanical Formations of Micro-via Cracks}

Finite Element Analysis (FEA) is commonly used for the analysis of thermomechanically induced cracks on micro-vias. Stress concentration points of a via at the highest and the lowest temperatures of a temperature cycling test can be pin-pointed. Fatigue lives of a via under different situations can also be predicted.

\subsubsection{Mechanically Drilled Vias in a LGA Package}

Darveaux et al. [13] went on to study the mechanically drilled vias reviewed in Section 2.2.3 to understand the experimental results. The fatigue lives of the vias were predicted using the results obtained in FEA and were compared with the experimental data.

Finite element models were created for all the different via constructions shown in Figure 8 in Section 2.2.3. The materials were setup as follows in the FEA model:

- The laminate core materials were modeled with orthotropic properties.

- All other materials were modeled with isotropic properties.

- Copper was modeled in its elastic-plastic region.

- All other materials were modeled in the liner elastic region. 
- Temperature dependent material properties were not used in the FEA because the data were not available for all the materials.

The structure was assumed to be stress free at $35^{\circ} \mathrm{C}$. The stress and strain distribution was calculated using the following three load steps:

1. Ramped up to $125^{\circ} \mathrm{C}$

2. Ramped down to $-55^{\circ} \mathrm{C}$

3. Ramped back up to $125^{\circ} \mathrm{C}$

Both kinematic hardening and isotropic hardening ${ }^{*}$ rules were applied for simulating fatigue loading. The stress-strain hysteresis loops of a via are shown in Figure 11. Kinematic hardening was chosen to obtain the total strain range. After that, the fatigue life, $\mathrm{N}$, of a via was estimated based on Equation 1 . The $1^{\text {st }}$ term of the Equation is the strain in the plastic region and the $2^{\text {nd }}$ term is the strain in the elastic region.

$$
\varepsilon_{\mathrm{T}}=\mathrm{N}^{-0.6} \varepsilon_{\mathrm{u}}+(0.9 / \mathrm{E}) \sigma_{\mathrm{u}}\left[\exp \left(\varepsilon_{\mathrm{u}}\right) / 0.36\right]^{0.1785 \log _{10}(100000 / \mathrm{N})} \quad \text { Equation } 1
$$

Where $\quad \mathrm{N}=$ Fatigue life

$\varepsilon_{\mathrm{T}}=$ Total strain range

$\varepsilon_{\mathrm{u}}=$ Ultimate ductility

$\mathrm{E}=$ Elastic modulus

$\sigma_{\mathrm{u}}=$ Ultimate tensile strength

The total equivalent strain distributions of the vias were obtained for the different legs during the temperature cycling. The total equivalent strains in Leg 1 at $-55^{\circ} \mathrm{C}$ and at $125^{\circ} \mathrm{C}$ are shown in Figure 12 and Figure 13, respectively. As can be seen in Figure 12

\footnotetext{
*Assuming the elastic domain and the shape remain unchanged in general multi-axial stress state, isotropic hardening only expands uniformly in sizes, and kinematic hardening translates in the stress space.
} 
and Figure 13, the highest strain in both situations happens in the lower outer knee of the via.

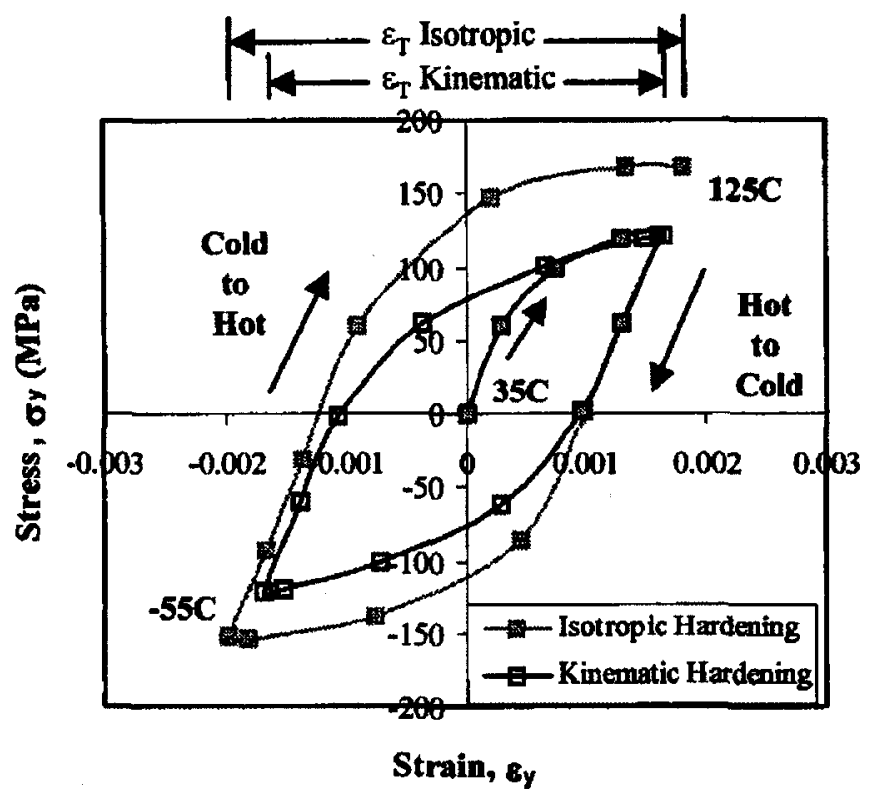

Figure 11. Stress-strain hysteresis loops for worst case element in substrate via [13].

The predicted fatigue lives for the vias in all the legs are shown in Figure 14. In each via the fatigue life was calculated in the sections of the bottom inner, bottom outer, top inner, and top outer corners because one of these four sections contains the worst case element. The non-capped vias in Legs 5-7 exhibit about a 2 times longer fatigue life than the vias in the other legs. This finding correlates with the experimental results. However, as can be seen in Figure 14, at 1,200 cycles all of the vias except those in Leg 7 would fail in one corner or the other. Since there are twelve legs in the experiment, the total failure rate would be about $92 \%$. But in the experiment a total of only $5 \%$ of the daisy chains failed at 1,200 cycles in the resistance tests, and about $30 \%$ of the vias were found 
to have cracks at 1,300 cycles in the cross-section analyses. So, the predicted fatigue lives are significantly conservative.

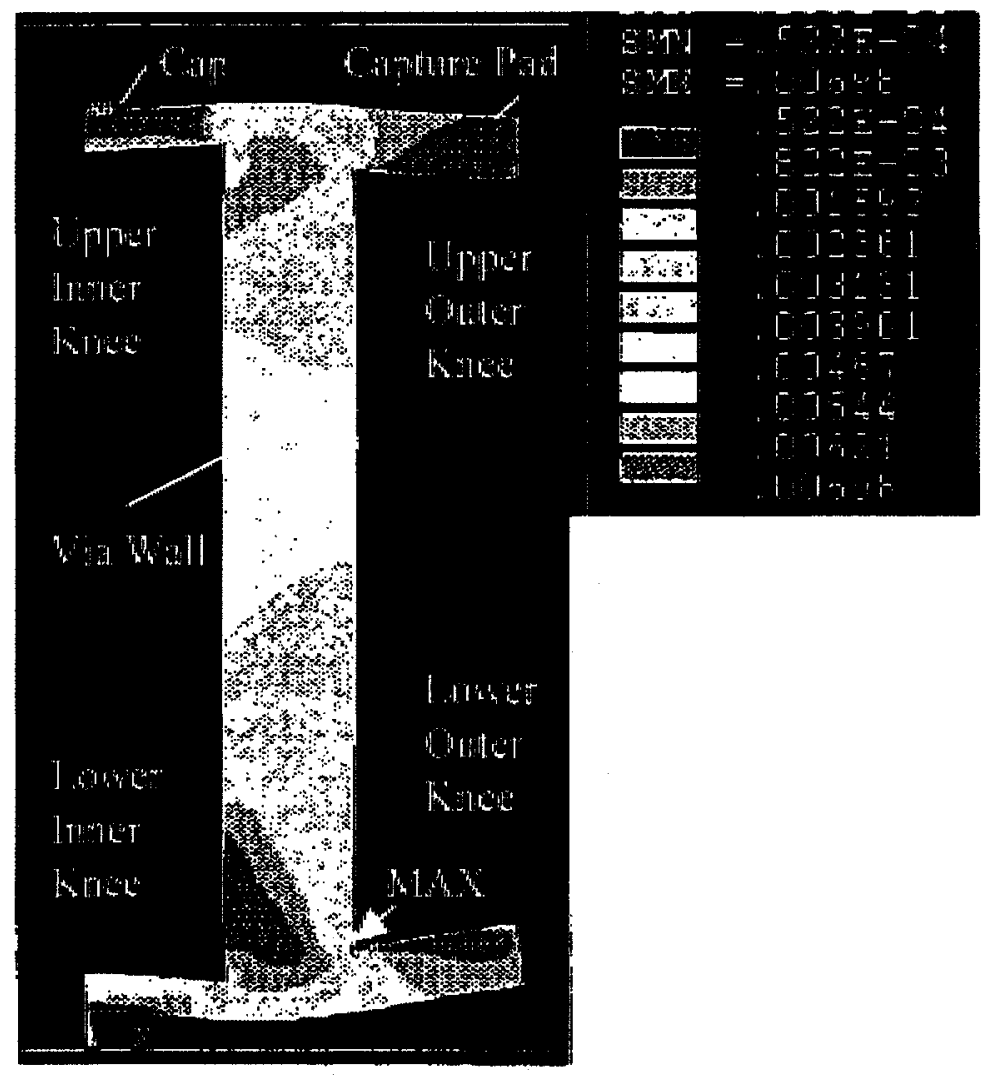

Figure 12. Total equivalent strain in via of $\operatorname{Leg} 1$ at $-55^{\circ} \mathrm{C}[13]$.

\subsubsection{Thermo-mechanical Fatigue Analysis of High Density Interconnect Vias}

A detailed thermo-mechanical fatigue analysis of high density interconnected (HDI) vias was undertaken by Prabhu et al. in 1995 [4]. FEA analysis was done on the HDI via structure to determine the effect of temperature cycling. The results were then used to determine the fatigue life of the via structure based on the extreme levels of 
thermal stress. Finally the fatigue life results were compared with the results obtained from the test samples.

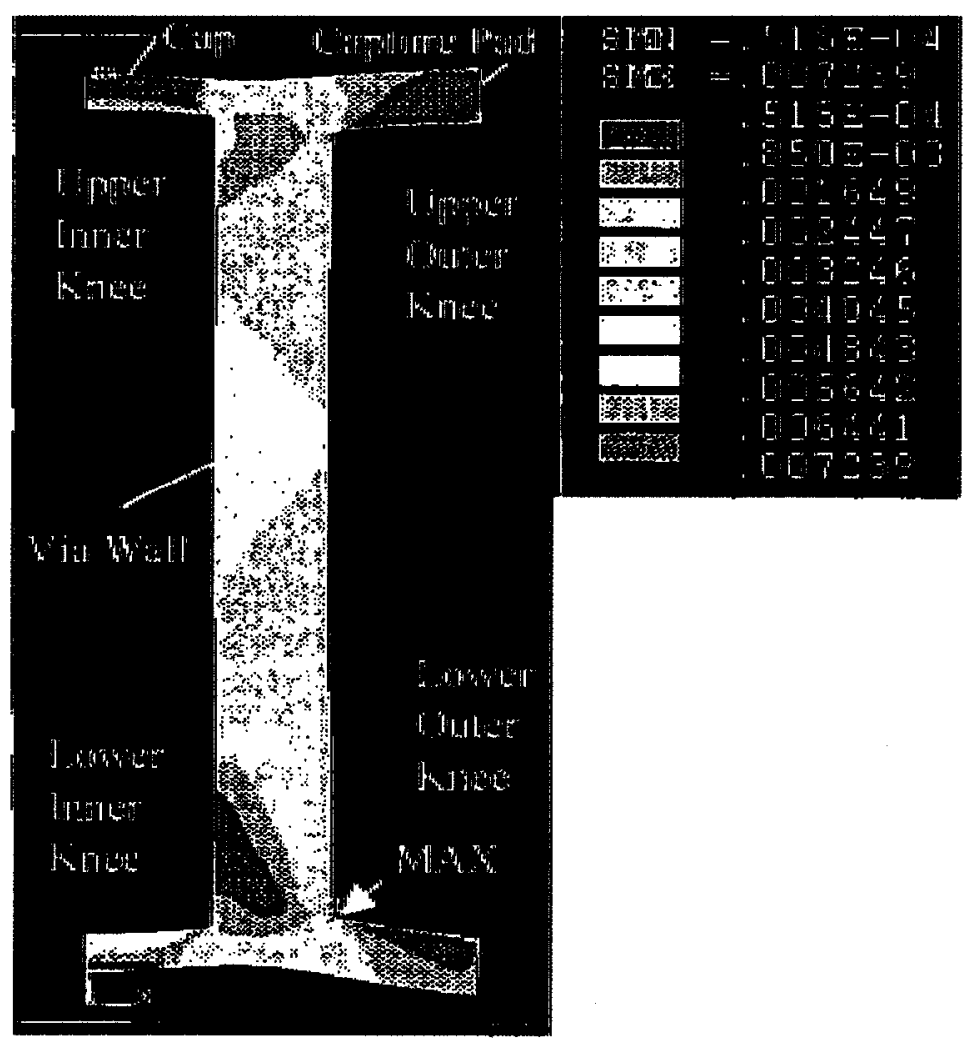

Figure 13. Total equivalent strain in via of Leg 1 at $125^{\circ} \mathrm{C}$ [13].

The schematic of the HDI employed in this study is shown in Figure 15. Finite element models were created for the via constructions. The materials in the FEA models were setup as follows:

- All polymeric materials were modeled with orthotropic properties.

- All metals were modeled with isotropic properties.

- All materials were modeled in the elastic-plastic region.

- Temperature dependent material properties were used. 


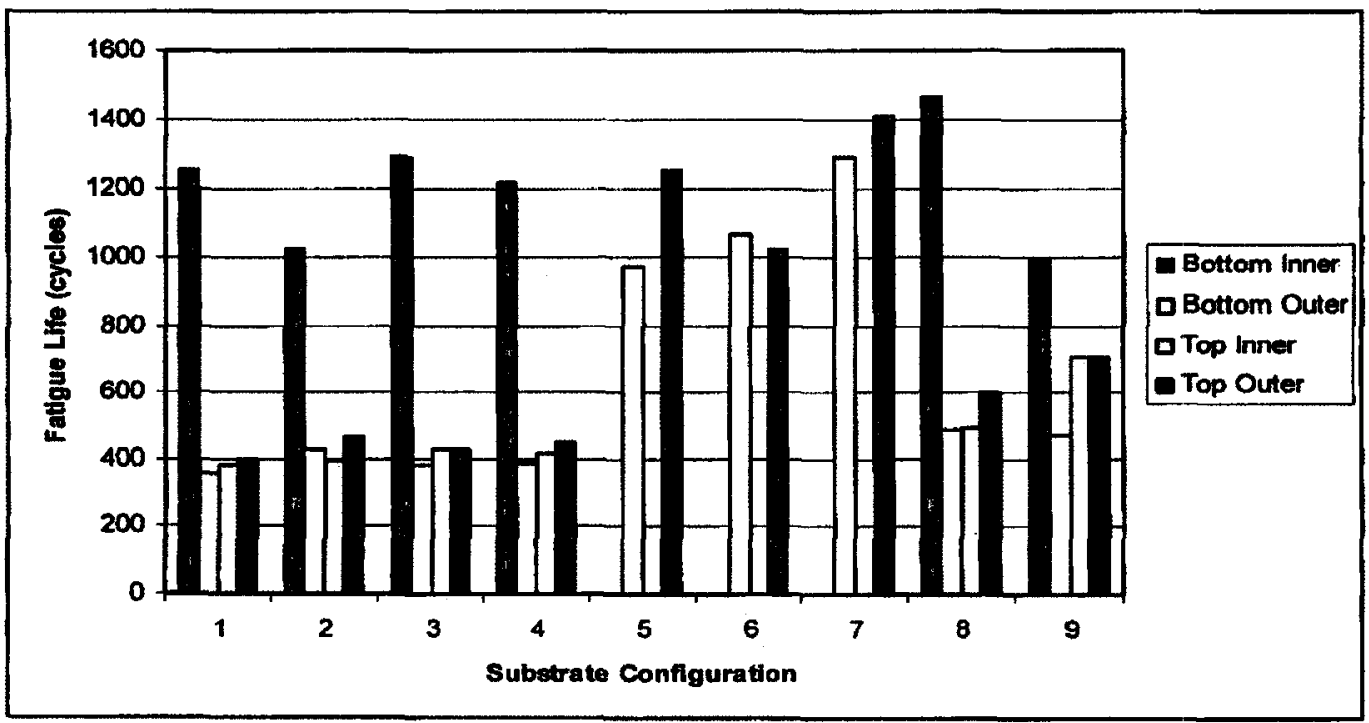

Figure 14. Predicted fatigue life of vias for Leg 1 to $\operatorname{Leg} 9$ [13].

Thermo-mechanical analyses were run for three different temperature cycles:

1. Between $-65^{\circ} \mathrm{C}$ and $150^{\circ} \mathrm{C}\left(\Delta \mathrm{T}\right.$ of $\left.215^{\circ} \mathrm{C}\right)$

2. Between $-40^{\circ} \mathrm{C}$ and $125^{\circ} \mathrm{C}\left(\Delta \mathrm{T}\right.$ of $\left.165^{\circ} \mathrm{C}\right)$

3. Between $3^{\circ} \mathrm{C}$ and $43^{\circ} \mathrm{C}\left(\Delta \mathrm{T}\right.$ of $\left.40^{\circ} \mathrm{C}\right)$

Three load steps were used for each temperature cycle. The cycle was repeated until the stress was stabilized. A stress-strain hysteresis loop for the temperature cycling of $\Delta \mathrm{T} 215^{\circ} \mathrm{C}$ is shown in Figure 16. The total strain range, $\varepsilon_{\mathrm{T}}$, of 0.006 was obtained from Figure 16 for the calculation of the fatigue life. A stress contour plot of the via at $150^{\circ} \mathrm{C}$ is shown in Figure 17. 


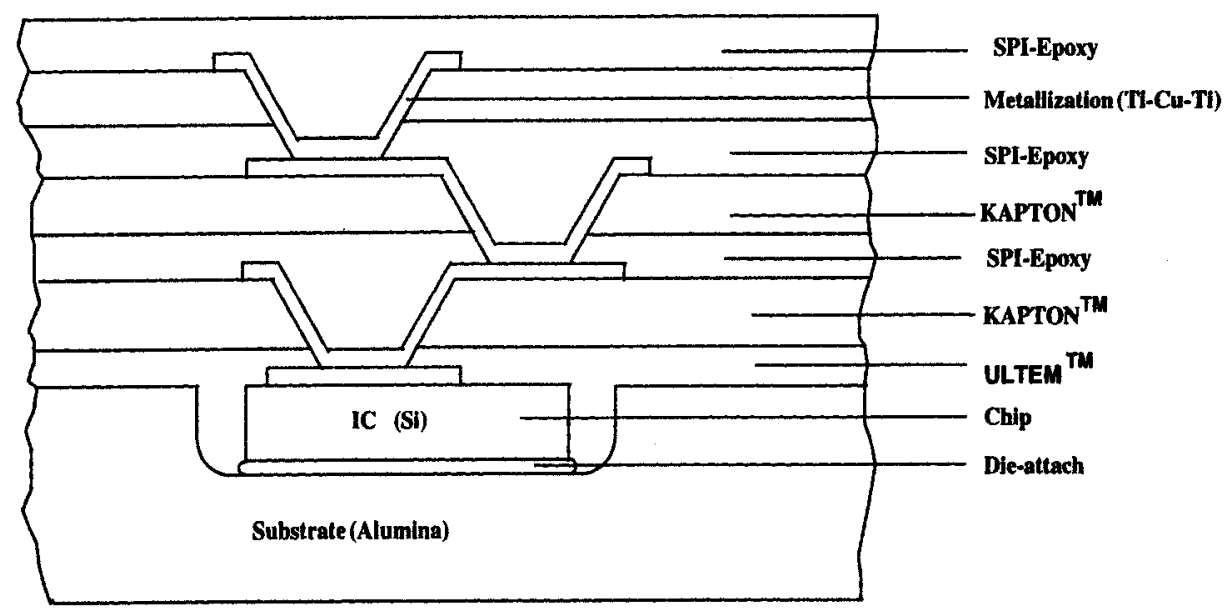

Figure 15. The schematic of the high density interconnect [4].

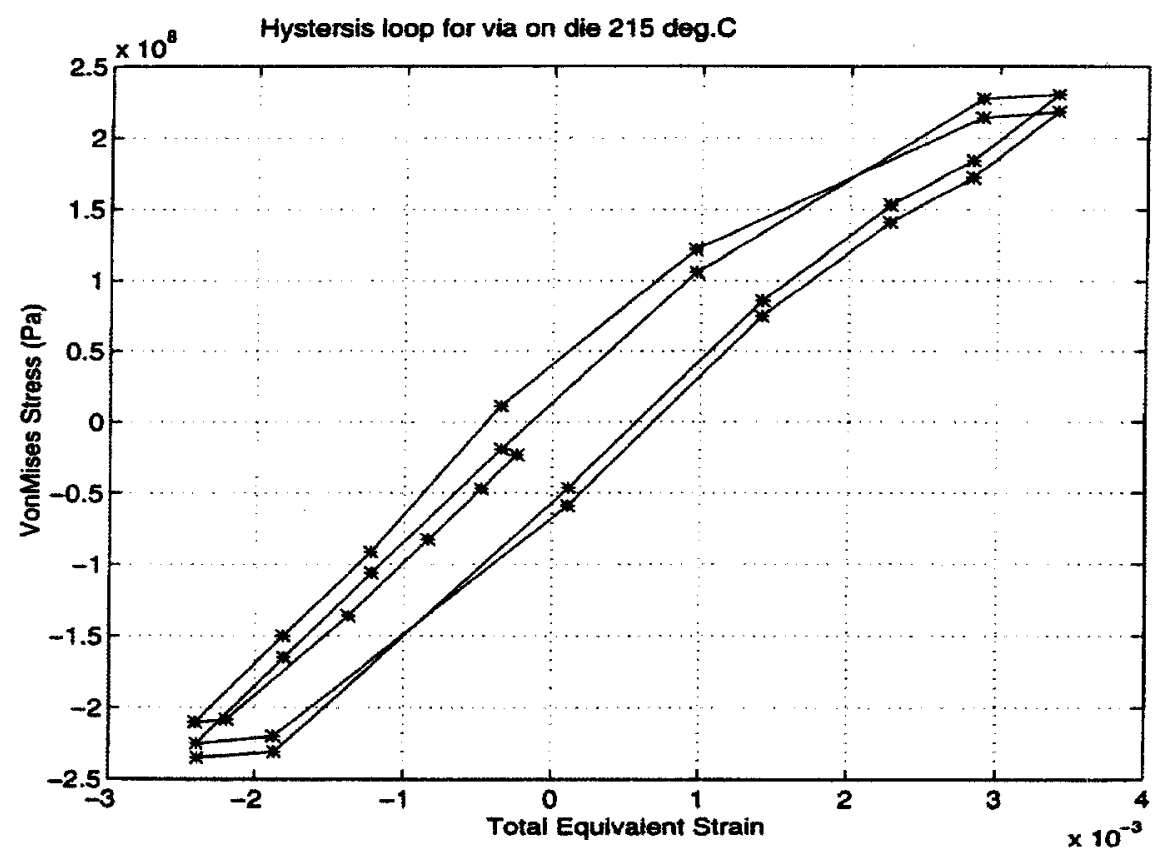

Figure 16. The hysteresis loop for the temperature cycle with a temperature rise of $215^{\circ} \mathrm{C}[4]$. 


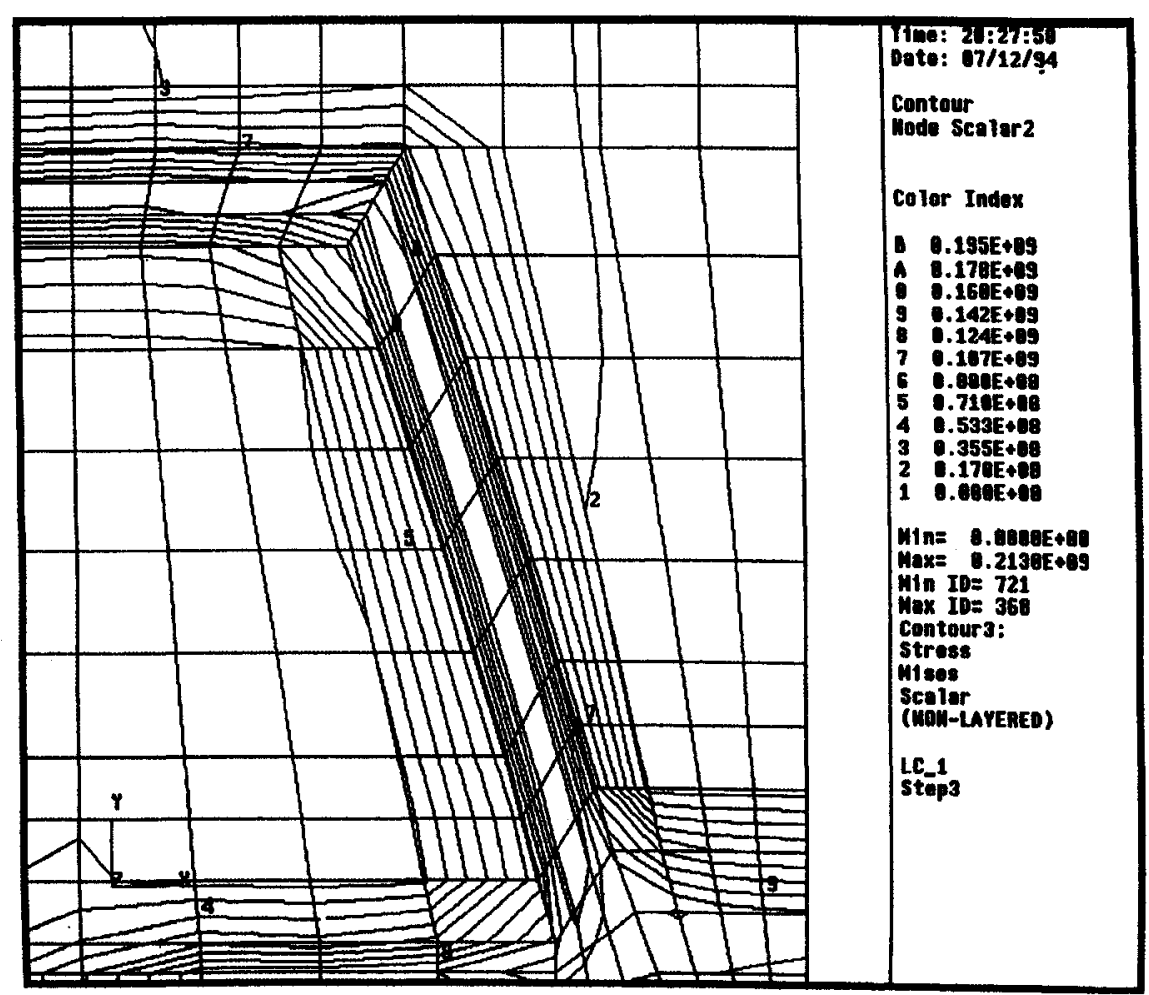

Figure 17. Stress (Vonmises) contour plot over via at $150^{\circ} \mathrm{C}[4]$.

The fatigue life, $\mathrm{N}$, of a via was estimated based on Equation 2.

$$
\varepsilon_{\mathrm{T}}=\mathrm{N}^{-0.6} \mathrm{D}_{\mathrm{f}}^{0.75}+(0.9 / \mathrm{E}) \mathrm{S}_{\mathrm{u}}\left[\exp \left(\mathrm{D}_{\mathrm{f}}\right) / 0.36\right]^{0.1785 \log _{10}(100000 / \mathrm{N})} \quad \text { Equation } 2
$$

Where

$$
\begin{aligned}
& N=\text { Fatigue life } \\
& \varepsilon_{T}=\text { Total equivalent strain range } \\
& D_{\mathrm{f}}=\text { Fatigue ductility coefficient } \\
& E=\text { Elastic modulus } \\
& S_{\mathrm{u}}=\text { Tensile strength }
\end{aligned}
$$

Compared to Equation 1 discussed in Section 2.3.1, Equation 2 uses the fatigue ductility coefficient and tensile strength instead of the ultimate ductility and ultimate tensile strength. Since it is difficult to obtain the exact value of the fatigue ductility 
coefficient ${ }^{*}\left(D_{f}\right)$ of the plated copper, two extreme values were used. $D_{f}=10 \%$ indicates a brittle material whereas $\mathrm{D}_{\mathrm{f}}=30 \%$ indicates a relatively ductile material.

The number of cycles to failure for the via in Layer 2 is shown in Figure 18. This plot was used to predict the fatigue life of the via. For example, the via could fail at about 10 cycles in a temperature cycle test with a $\Delta \mathrm{T}$ of $215^{\circ} \mathrm{C}$, with copper having a $10 \%$ fatigue ductility coefficient.

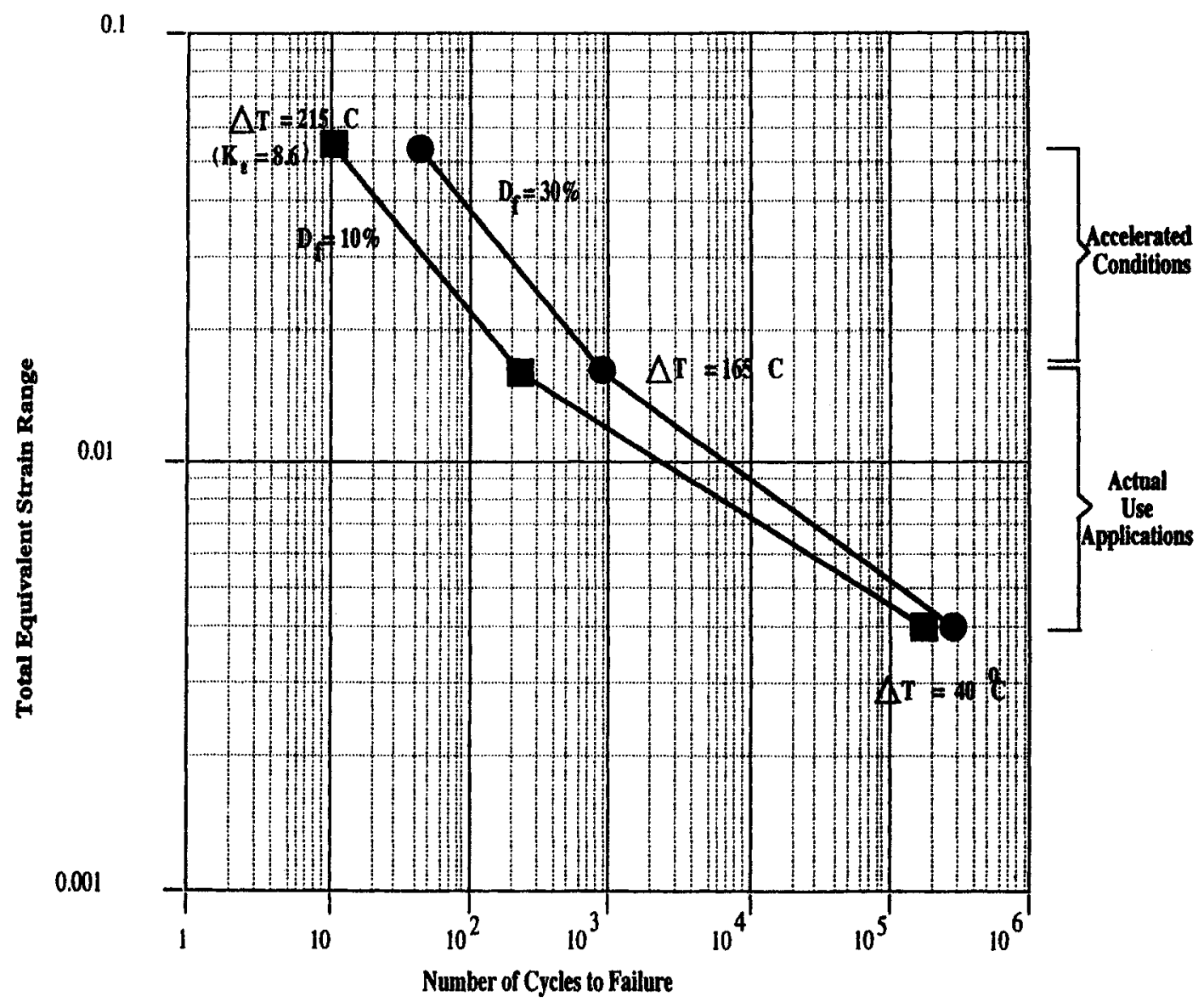

Figure 18. Results of the finite element analysis for via in the 2nd layer [4].

\footnotetext{
* Fatigue ductility coefficient is the amount of strain that causes a material to fracture at the first reversal of cyclic loading.
} 
Test samples from Texas Instruments (TI) and General Electric (GE) were built and subjected to five different accelerated thermal stress tests including the three temperature cycling conditions used for the FEA. The experiments were still in progress when the paper was published. The literature was searched to find the results published upon completion of the experiment. Unfortunately, these could not be found. The preliminary experimental results are shown in Table 5. In the temperature cycle test of $\Delta \mathrm{T}=215^{\circ} \mathrm{C}\left(-65^{\circ} \mathrm{C}\right.$ to $\left.150^{\circ} \mathrm{C}\right)$, an average of $56 \%$ increase in resistance was found on the two TI samples after 250 cycles, and three out of the four GE parts showed intermittent opens after $110-200$ cycles. But in a lower $\Delta \mathrm{T}$ temperature cycle test of $\Delta \mathrm{T}=180^{\circ} \mathrm{C}(-$ $55^{\circ} \mathrm{C}$ to $125^{\circ} \mathrm{C}$ ), an average of $34 \%$ increase in resistance was found on the three TI samples after 250 cycles, and none of the four GE parts failed after 150 cycles. This clearly shows that the higher the $\Delta \mathrm{T}$, the greater the increase in via resistance and the higher the failure rate.

The authors pointed out that the early failure analysis results from the experiments supported the predictions obtained in the FEA models. However, the paper indicated that the amount of data from the experiment was inadequate to fully develop predictive capability. The authors concluded that the predictions by the model could represent the lower bound of the life of the vias, and that the model might be conservative in predicting the number of cycles to failure.

\subsection{Design Factors}

Several factors need to be taken into account in the design and development of FCBGAs. These include the geometrical relationship between a laser via and a core via, 
the ratio of dielectric thickness to laser via diameter, the geometrical relationship between two laser vias, and the existence of a fillet between a via pad and a trace. According to Xilinx and a substrate manufacturer, some combinations of these design factors could potentially result in via crack formation $[14,15]$.

Table 5. Summary of HDI test results [4].

\begin{tabular}{|c|c|c|c|}
\hline Test & Conditions & Source & Test Results \\
\hline \multirow{2}{*}{$\begin{array}{l}\text { Thermal Shock } \\
\text { (Mil-std-883 } \\
\text { M1011) }\end{array}$} & \multirow{2}{*}{$\begin{array}{l}-65^{\circ} \mathrm{C} \text { to } \\
150^{\circ} \mathrm{C}\end{array}$} & TI & $\begin{array}{l}5 \text { parts tested to } 300-500 \text { cycles. No observed } \\
\text { opens at room temperature. Via resistance } \\
\text { increase averages } 58 \% \text { after } 250 \text { cycles. }\end{array}$ \\
\hline & & GE & $\begin{array}{l}5 \text { parts tested to } 70-200 \text { cycles. Intermittent } \\
\text { opens on at least one part. }\end{array}$ \\
\hline \multirow{2}{*}{$\begin{array}{l}\text { Temperature } \\
\text { Cycle (Mil-std- } \\
883 \text { M1010) }\end{array}$} & \multirow{2}{*}{$\begin{array}{l}-65^{\circ} \mathrm{C} \text { to } \\
150^{\circ} \mathrm{C}\end{array}$} & TI & $\begin{array}{l}2 \text { parts tested to } 450 \text { cycles. No observed } \\
\text { opens at room temperature. Via resistance } \\
\text { increase averages } 56 \% \text { after } 250 \text { cycles. }\end{array}$ \\
\hline & & GE & $\begin{array}{l}4 \text { parts tested to } 110-200 \text { cycles. Intermittent } \\
\text { opens on } 3 \text { parts. }\end{array}$ \\
\hline $\begin{array}{l}\text { Thermal Shock } \\
\text { (Mil-std-883 } \\
\text { M1011) }\end{array}$ & $\begin{array}{l}-55^{\circ} \mathrm{C} \text { to } \\
125^{\circ} \mathrm{C}\end{array}$ & GE & 4 parts tested to 200 cycles. No failures. \\
\hline \multirow[t]{2}{*}{$\begin{array}{l}\text { Temperature } \\
\text { Cycle (Mil-std- } \\
883 \text { M1010) }\end{array}$} & \multirow[t]{2}{*}{$\begin{array}{l}-55^{\circ} \mathrm{C} \text { to } \\
125^{\circ} \mathrm{C}\end{array}$} & TI & $\begin{array}{l}9 \text { parts tested to } 150-300 \text { cycles. No opens } \\
\text { observed at room temperature. Via resistance } \\
\text { increase averages } 34 \% \text { after } 250 \text { cycles. }\end{array}$ \\
\hline & & GE & 4 parts tested to 150 cycles. No failures. \\
\hline $\begin{array}{l}\text { Power } \\
\text { Temperature } \\
\text { Cycle }\end{array}$ & $\begin{array}{l}-40^{\circ} \mathrm{C} \text { to } \\
125^{\circ} \mathrm{C}\end{array}$ & GE & $\begin{array}{l}6 \text { parts tested to } 1000-1500 \text { cycles. One } \\
\text { failure at } 1000 \text { cycles. }\end{array}$ \\
\hline
\end{tabular}

\subsubsection{Non-stack-on-core vs. Stack-on-core}

A stack-on-core via, which resembles a through-hole drill, has its center-line in line with the center-line of a plated through hole (PTH) which is also known as a "core via". On the other hand, a non-stack-on-core via has its center-line offset from the center-line of a core via. A stack-on-core via is shown in Figure 19(a), while a non- 
stack-on-core via is shown in Figure 19(b). The amount of the offset equals to, or is larger than, the sum of the via capture pad radii of the laser via and the core via. For example, a $60 \mu \mathrm{m}$ laser via may have a capture pad diameter ranging from $100 \mu \mathrm{m}$ to 135 $\mu \mathrm{m}$, and a $200 \mu \mathrm{m}$ core via may require a capture pad diameter ranging from $300 \mu \mathrm{m}$ to $350 \mu \mathrm{m}$, depending on the process capability of the substrate manufacturers. So, the offset can range from $200 \mu \mathrm{m}$ to $243 \mu \mathrm{m}$.
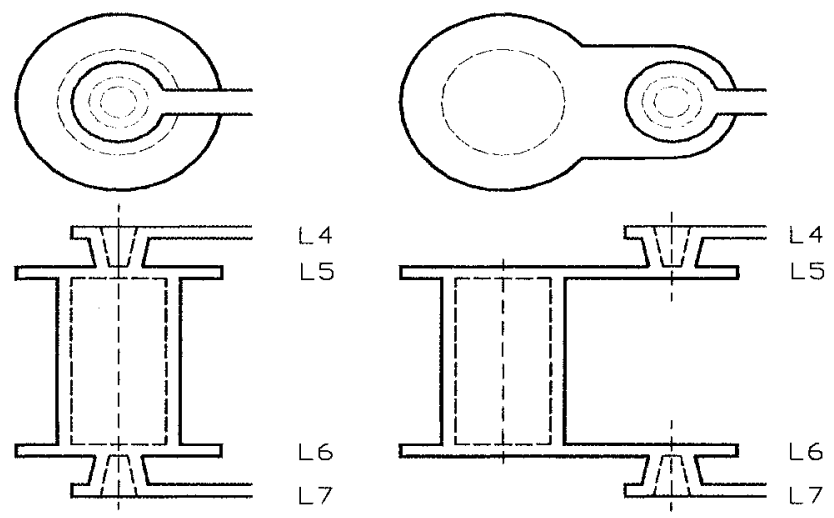

(a) stack on care via

(b) Non-stack on core vio

Figure 19. Illustration of stack-on-core via and non-stack-on-core via

The total percentage of metal content and the metal distribution are different in each of the copper layers of a FCBGA substrate because the circuit design in each layer is different. Some layers may have more traces and less metal content while some may have more solid planes and more metal content. Because of the unevenness of metal content in each layer, warpage is induced to a substrate during lamination processes. However, substrate warpage should be kept at a minimum because it is one of the major causes of yield loss in the assembly process. As a result, almost all of the FCPBG polymeric substrates employ a thick core layer to provide the mechanical strength 
required to keep the warpage within an acceptable level. As shown in Figure 4 and Figure 5, a core layer is much thicker than the other built-up layers. The core thickness, depending on the size of the package, ranges from $400 \mu \mathrm{m}$ to $800 \mu \mathrm{m}$. The larger the package, the thicker the core thickness.

As shown in Figure 19(a), the stack-on-core via requires only one core via capture pad on the core copper layers (L5 and L6) while the non-stack-on-core via needs an extra laser via capture pad. The main advantage of a stack-on-core via is that it requires less space on a substrate, and thus allows more space for routing more I/Os as well as increasing the power/ground plane density. But, in substrate manufacturing, a stack-oncore via structure requires a few more manufacturing steps than a non-stack-on-core substrate does. These extra processes may leave some residues on the copper surface, and these residues in turn weaken the adhesion between the core layer and its adjacent built-up layer [14].

\subsubsection{Aspect Ratio}

The aspect ratio is the ratio of dielectric thickness to via diameter. An aspect ratio of 0.7 is shown in Figure 20(a) while a ratio of 0.5 is shown in Figure 20(b). For a fixed dielectric thickness, a higher aspect ratio suggests a smaller via and a via capture pad which in turn saves space in a substrate and increases I/O routing and power/ground plane density. However, according to Liu et al. [11] in Section 2.2.2, a high aspect ratio results in thin copper plating at the foot of the via, which in turn causes small micro-via metallization. If the metallization of the via is not strong enough to withstand the stresses 
caused by CTE mismatch, the via will crack. This finding suggests that the chance of via failure is greater when the aspect ratio is higher.
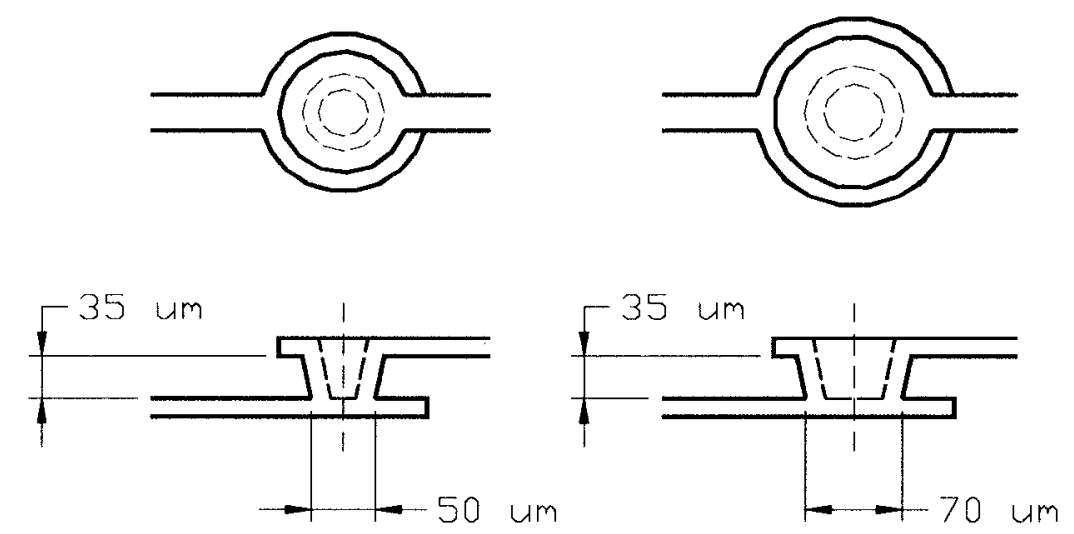

(a) Aspect ratio $=0.7$

(b) Aspect ratio $=0.5$

Figure 20. Via aspect ratios.

\subsubsection{Staggered Via vs. Stacked Via}

In a stacked via design, which resembles a through-hole drill design, two or more vias are stacked on one another along the same axis. In a staggered via design the two vias of the neighboring layers interconnect to each other along two different axes. A stacked via design is shown in Figure 21(a), while a staggered via design is shown in Figure 21(b). In the staggered via design, the distance between the axes is equal to or larger than the via capture pad diameter. For a $60 \mu \mathrm{m}$ via diameter, the via capture pad diameter ranges from $100 \mu \mathrm{m}$ to $135 \mu \mathrm{m}$, depending on the process capability of the substrate manufacturers. 
As shown in Figure 21, the middle layer has only one via capture pad in the stacked via design, while it has two capture pads in the staggered via design. The main advantage of the stacked via design is that it saves space in the substrate, and thus increases $\mathrm{I} / \mathrm{O}$ routing and power/ground plane density. However, some manufacturers do not accept vias that are stacked in three layers or more because the chance of micro-crack occurrence can be increased [14]. Generally, a staggered via design is believed to be more robust in terms of resisting thermal stresses.
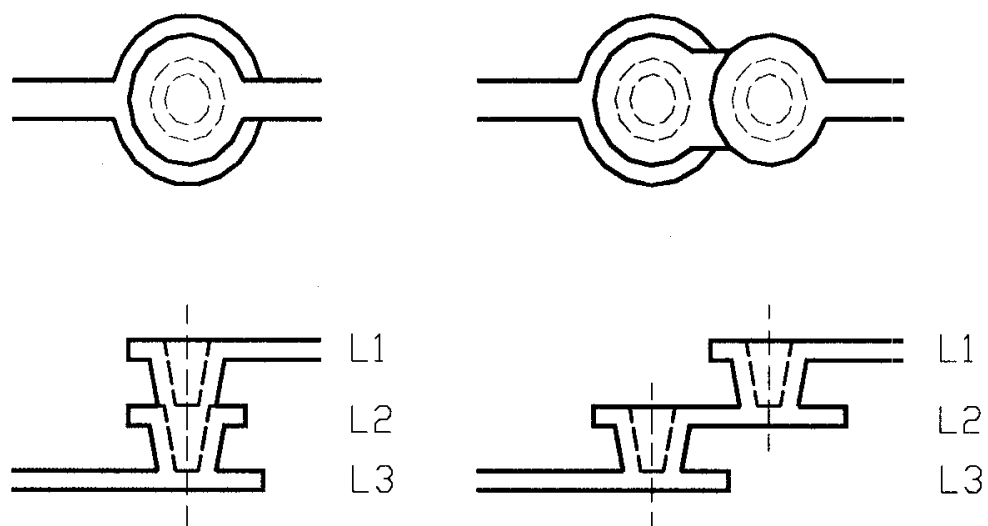

(a) Stacked via design

(b) Staggered via

Figure 21. Stacked via design vs. staggered via design.

\subsubsection{Fillet vs. Non-fillet}

In the wire bond package designs, a fillet, also known as a "teardrop", is commonly used to strengthen every intersection of the trace-via capture pad and the trace-BGA ball pad because it removes the stress concentration points. A design without fillets is shown in Figure 22(a), and a fillet of R $50 \mu \mathrm{m}$ added between the $30 \mu \mathrm{m}$ traces and the via capture pads is shown in Figure 22(b). The main reason for adding fillets is 
to minimize the chance of trace cracks at the intersection. However, fillets are seldom used in flip chip substrate designs due to technical problems associated with computer aided design and manufacturing, the details of which are beyond the scope of this thesis. However, the emerging issue of laser via micro-cracks has made some substrate manufacturers consider using fillets on flip chip substrate designs [14].
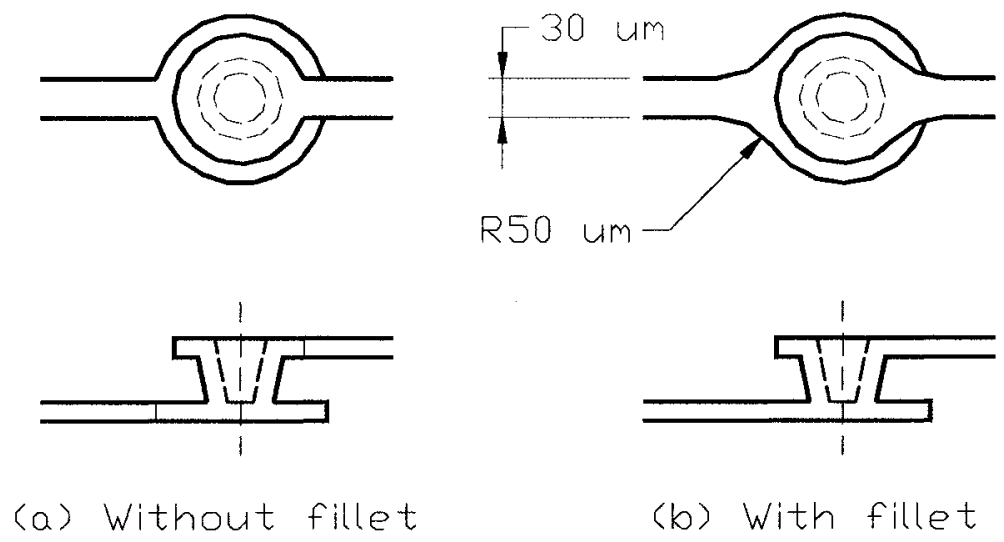

Figure 22. An illustration of a fillet between a trace and a via capture pad.

\subsection{Summary of Literature Review}

The literature search confirmed that research on, and study of, laser via microcracking is important in the development of future micro-electronic packages. There are several factors that affect via reliability. For design related factors, a via of high aspect ratio such as $1: 1$ has thinner plating at the foot of the via when compared to other vias of relatively low aspect ratio such as $0.67: 1$ and lower. The thinner the plating, the higher the chance of cracking. A via structure with fewer stress concentration points, such as the uncapped vias, exhibited longer thermal fatigue life when compared to a via structure 
with more stress concentration points, such as the capped vias. From the experiences shared by a manufacturer and the packaging process engineering department of Xilinx, the non-stack-on-core via and the staggered via are more robust in terms of resisting thermal stresses when compared to the stack-on-core via and the stacked via [15]. Because the laser stacked via design and the stack-on-core via design are relatively new in the substrate manufacturing industry, research papers were not found.

Two of the papers reviewed cover the use of FEA on the mechanically drilled vias and the HDI via structure to analyze stresses and predict fatigue lives of the vias. The intent of reviewing the papers was to understand the causes of via failure mechanism which may alleviate the study of the laser micro-via cracks because these via structures have many similarities to the laser via structure used in the FCBGA substrates. However, due to the fact that many variables are involved in the analysis, both of these FEA results tend to be very conservative when compared with experimental data. 


\section{CHAPTER THREE}

\section{RESEARCH OBJECTIVE}

From the literature review, it was found that laser via micro-cracks can originate from many different sources such as substrate manufacturing process parameters, laser technologies, and via design. The overall objective of this investigation was to determine if there is a relationship between via design and laser via micro-crack formation.

To minimize the "noises" that might come from the substrate manufacturing processes, only one test vehicle design that contained all the different via design parameters was used for the experiment. Furthermore, to minimize the "noises" that might come from the laser technologies, all the vias of the test samples were made by only one laser technology in one machine. In this experiment, $\mathrm{CO}_{2}$ laser, which is still the most commonly used laser via technology in manufacturing FCBGA substrates, was selected.

In this research, four design parameters were studied: (i) stack-on-core via design vs. non-stack-on-core via design, (ii) aspect ratio, (iii) stacked via design vs. staggered via design, and (iv) fillet between via capture pad and trace vs. non-fillet. To reduce the chances of laser via crack, lowering aspect ratio and restricting the use of stack-on-core and stacked via structures have been proposed by some substrate manufacturers, without valid theoretical or experimental bases. However, more space is needed in the substrate when larger vias, non-stack-on-core, and staggered via designs are used, and thus I/O routing and power/ground plane density will be decreased. Although adding a fillet does not decrease the $\mathrm{I} / \mathrm{O}$ routing density significantly, it requires more time in the design 
process, which is already quite lengthy. This investigation was aimed at determining the extent to which these parameters, individually and in combination, are actually related to the causes of laser via micro-crack. A Design of Experiment (DOE) approach was used in the investigation to check the effects of the main factors and the interactions among them on micro-via reliability of FCBGA substrates. 
CHAPTER FOUR

\section{EXPERIMENTAL APPROACH}

The investigation was divided into the following seven steps: (i) design of the test vehicle, (ii) ordering and fabricating of the test vehicle, (iii) packaging and assembling the test vehicle, (iv) temperature cycling testing with periodic measurement of resistance of each daisy chain, (v) analyzing the measured data, and (vi) cross-sectioning and analyzing the failed vias. The investigation process is shown schematically, in the form of a flow chart, in Figure 23.

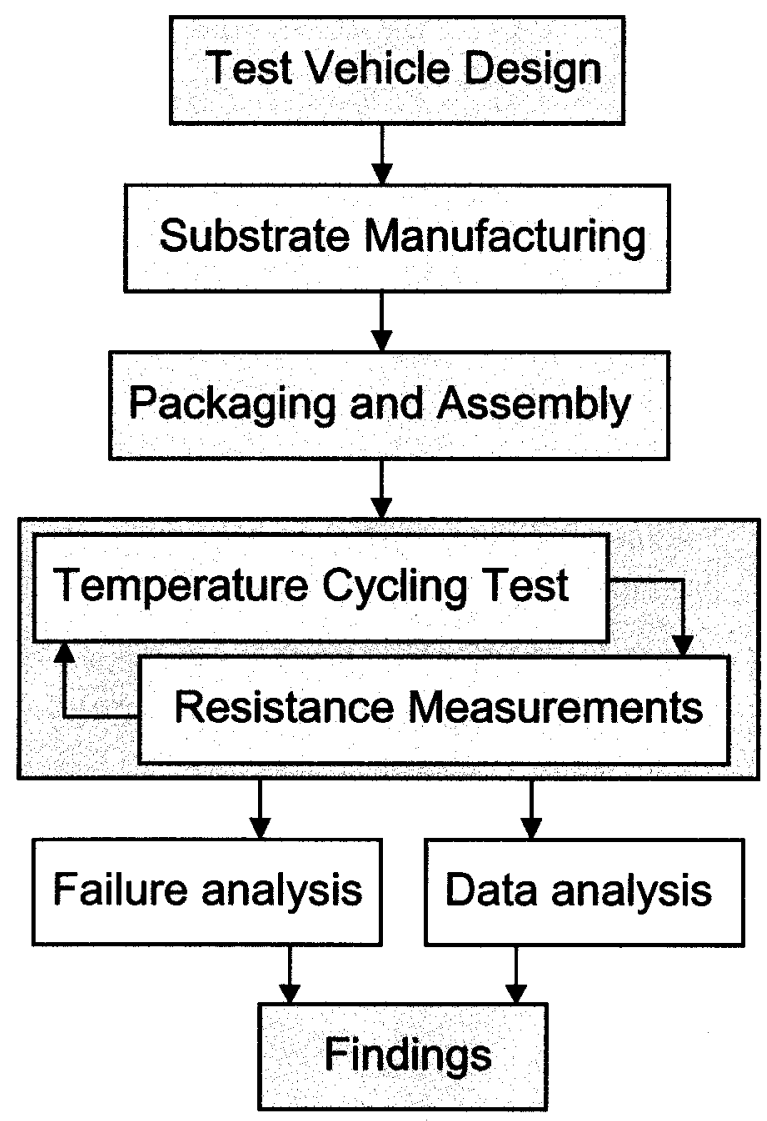

Figure 23. Investigation flow chart. 


\subsection{Test Vehicle Design}

The Xilinx Virtex 4vlx200 die of about $24 \mathrm{~mm} \times 21 \mathrm{~mm}$ and a $40 \mathrm{~mm}$ x $40 \mathrm{~mm}$ $4+2+4^{*}$ built-up FCBGA substrate with 1513 balls was selected by Xilinx as the test vehicle. Sixteen daisy chains were designed in the test vehicle, with each daisy chain occupying one sixteenth of the total substrate area. Each of these sixteen daisy chains contained a total of 768 laser vias and 96 plated through holes. Details of the design are presented in Figure 24(a) through Figure 24(f). The electrical resistance of the daisy chains, depending on the trace length, via diameter, and via structure, was in the range of $5.2 \mathrm{ohm}$ to $11.0 \mathrm{ohm}$.

The experimental matrix of the daisy chains is shown in Table 6. A.ll the laser vias in Daisy Chain 01 have the design factors of stack-on-core, low aspect ratio (or large via/pad size), stacked via (except Layer 3 and Layer 8), and fillet. All the laser vias in Daisy Chain 16 have the design factors of non-stack-on-core, high aspect ratio (or small $\mathrm{via/pad} \mathrm{size),} \mathrm{staggered} \mathrm{via,} \mathrm{and} \mathrm{non-fillet.}$

At present most of the substrate vendors do not recommend and support three laser vias being stacked on each other along the same axis, because of the concern of via crack or reliability, not because of their capabilities. For a 10-layer design, staggered vias are still required on Layer 3 and on Layer 8 so that only two stacked vias can be inline on three metal layers. But in this test vehicle, Daisy Chain 02 and Daisy Chain 06 were designed in such a way that all of the laser vias and the plated through hole (PTH)

\footnotetext{
* A 4+2+4 substrate is a ten copper-layer substrate having two copper layers built on the two sides of a core structure, four copper build-up layers above the core, and another four copper build-up layers below it.
} 
were stacked together along the same axis in order to test the extreme condition of having eight laser vias and a PTH stacked along the same axis.

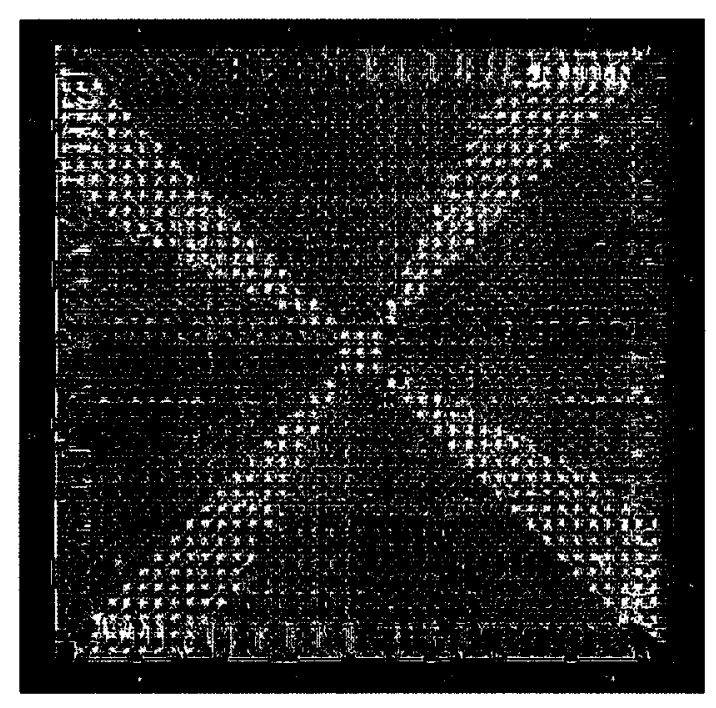

Figure 24(a). The overall view of the test vehicle.

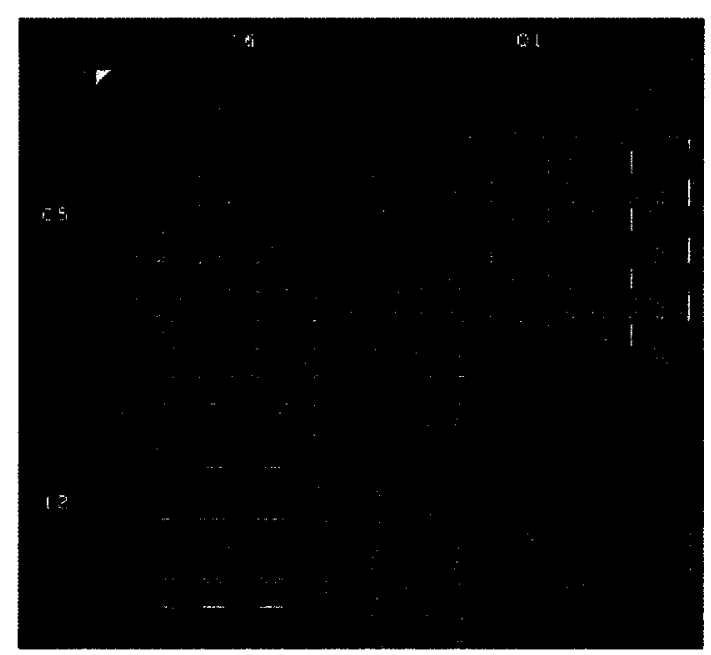

Figure 24(b). The upper left quarter design showing the top layer of Daisy Chains 01, 16, 05, and 12.

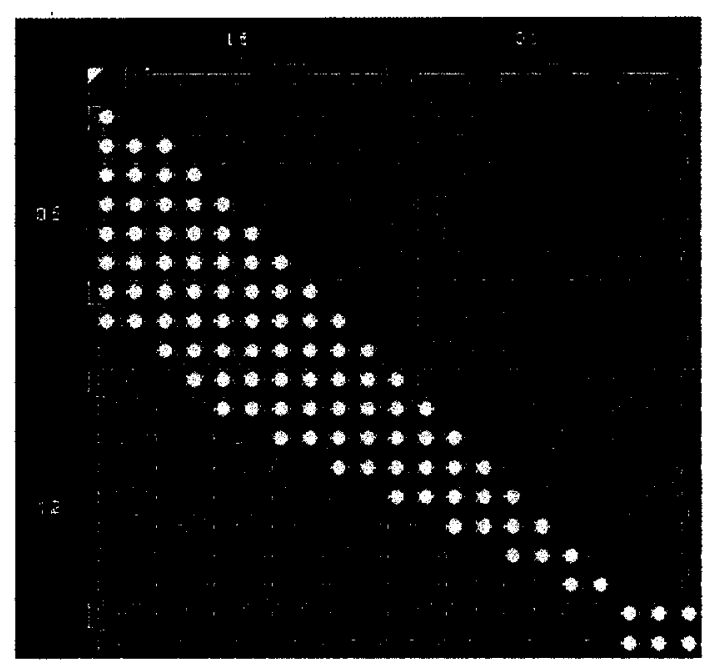

Figure 24(c). The upper left quarter design showing the bottom layer of Daisy Chains 01, 16, 05, and 12 .

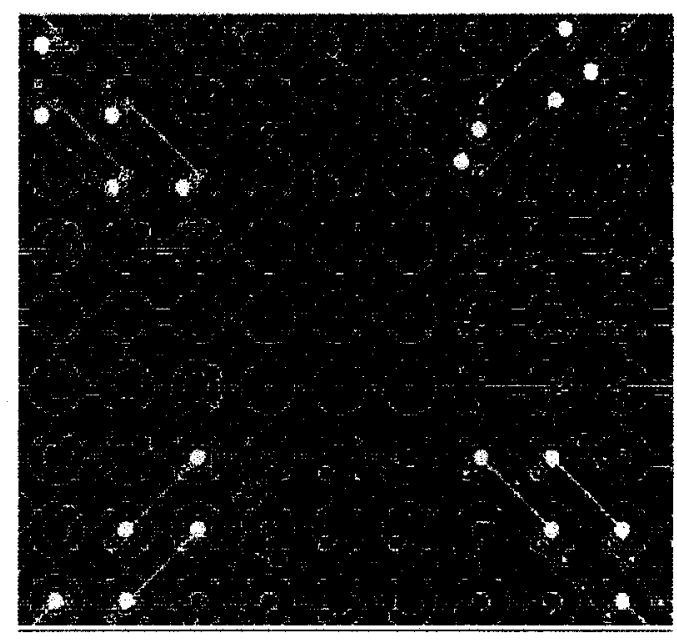

Figure 24(d). A zoom-in view at the package center with the ball pads and die pins omitted showing part of all 16 daisy chains. 


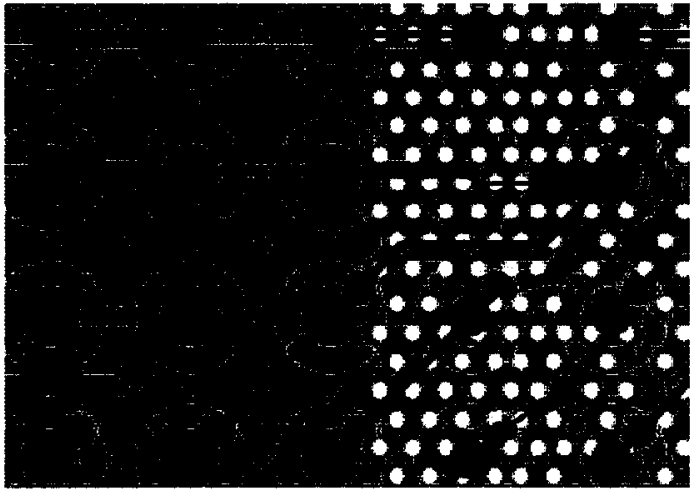

Figure 24(e). A zoom-in view of Daisy Chain 06 (red) and Daisy Chain 11 (blue) with the ball pads omitted showing stack-on-core (Daisy 06) and non-stackon-core (Daisy 11).

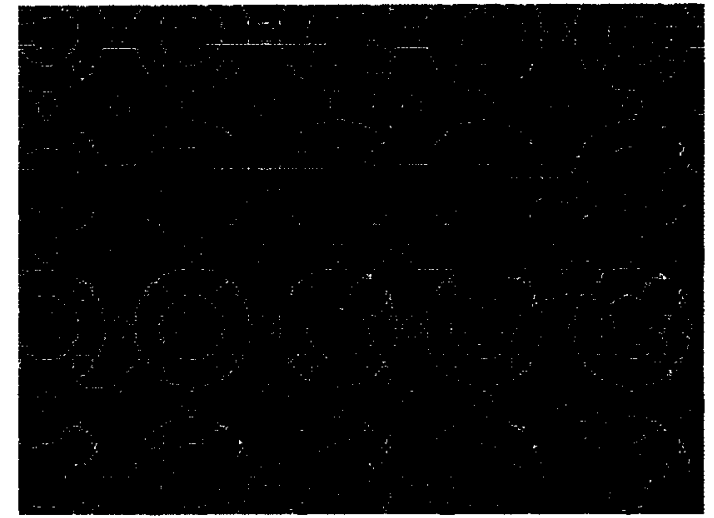

Figure 24(f). A zoom-in view of Daisy Chain 06 (red) and Daisy Chain 11 (blue) with the ball pads, die pins, and core vias omitted showing Daisy 06 of high aspect ratio, stacked via, and non-fillet, and Daisy 11 of low aspect ratio, staggered via, and fillet.

Figure 24. Detailed design of the test vehicle.

Table 6. Experimental design matrix of the daisy chains.

\begin{tabular}{|l|c|c|c|c|}
\hline & Stack on core & Via/Pad Size & Stacked vs Staggered & Fillet \\
\hline Daisy Chain 01 & Yes & $80 / 140$ & Stacked & Yes \\
\hline Daisy Chain 02 & Yes & $80 / 140$ & Stacked & No \\
\hline Daisy Chain 03 & Yes & $80 / 140$ & Staggered & Yes \\
\hline Daisy Chain 04 & Yes & $80 / 140$ & Staggered & No \\
\hline Daisy Chain 05 & Yes & $50 / 110$ & Stacked & Yes \\
\hline Daisy Chain 06 & Yes & $50 / 110$ & Stacked & No \\
\hline Daisy Chain 07 & Yes & $50 / 110$ & Staggered & Yes \\
\hline Daisy Chain 08 & Yes & $50 / 110$ & Staggered & No \\
\hline Daisy Chain 09 & No & $80 / 140$ & Stacked & Yes \\
\hline Daisy Chain 10 & No & $80 / 140$ & Stacked & No \\
\hline Daisy Chain 11 & No & $80 / 140$ & Staggered & Yes \\
\hline Daisy Chain 12 & No & $80 / 140$ & Staggered & No \\
\hline Daisy Chain 13 & No & $50 / 110$ & Stacked & Yes \\
\hline Daisy Chain 14 & No & $50 / 110$ & Stacked & No \\
\hline Daisy Chain 15 & No & $50 / 110$ & Staggered & Yes \\
\hline Daisy Chain 16 & No & $50 / 110$ & Staggered & No \\
\hline
\end{tabular}


There are two advantages of having all sixteen combinations of the four factors in a test vehicle. First, the tooling cost can be kept to a minimum because only one substrate is needed. Second, the noises, or unwanted effects, from substrate manufacturing processes, assembly and temperature cycling test can be assumed to be identical for all the daisy chains and their vias in the same package.

The total time spent in the design from conceptual design to final approval was about 8 weeks. Cadence Advanced Packaging Designer v14.2 was used to design the test vehicle and Autodesk AutoCAD R15 was used for documentation.

\subsection{Substrate Manufacturing}

After the design was completed and verified, the substrates were fabricated by a substrate manufacturer in Taiwan. The price was about $\$ 25.00$ each with a minimum order quantity of 300 and a non-recurrent engineering cost of $\$ 3,500$. The total manufacturing cost was $\$ 11,000$. The lead time for manufacturing and testing of the substrates was 10 weeks. After the testing was done, the substrates were delivered to the appointed package assembly plant which was also located in Taiwan.

\subsection{Packaging and Assembly}

The substrates were assembled with the Virtex 4vlx200 ink dies, heat spreaders, and solder balls in the package assembly plant. The assembly cost per piece was $\$ 10.00$ with a minimum assembly cost of $\$ 600$. Sixty pieces of the test vehicle were assembled. The total assembly time taken was about four weeks. The test vehicles were fully 
assembled and delivered to Xilinx for the temperature cycling tests and resistance measurements.

\subsection{Temperature Cycling Tests and Resistance Measurements}

Similar to the experiments described in Sections 2.2.1 to 2.2.3, this experiment was also designed to measure the resistance increase so that cracks would be detected. If there are cracks in the vias, the resistance of the daisy chains will increase. The greater the number of cracked vias, the higher the resistance increase. In addition, the longer and larger the crack, the higher the resistance increase. Temperature cycling was used to induce mechanical stresses on the test samples until at least a $10 \%{ }^{*}$ increase in resistance was detected in one or more daisy chains.

Fifty assembled parts, out of the total of sixty, were randomly selected for the experiment. First, the electrical resistance value of each daisy chain in each of these fifty parts was measured and recorded. Then the parts were submitted to the Temperature Cycling B (TCB) test. The temperature range was from $-55^{\circ} \mathrm{C}$ to $125^{\circ} \mathrm{C}$, according to Condition B of the Joint Electron Device Engineering Council (JEDEC) standard JESD22-A104C [17]. Each cycle time of the test took about thirty minutes. At 100-300 cycle intervals, the parts were removed from the temperature cycling chamber and left in an open area to cool down. After the parts were completely cooled down for about an hour, resistance values of the daisy chains were measured and recorded. Then the parts

\footnotetext{
"In the field of microelectronics packaging, there has not been any industrial specification that defines via failure by the extent of resistance increase. In commercial usage, if the electrical resistance of a via does not increase by $10 \%$ or more after TCB 1000 cycles, the via is still not counted as a failure by many companies [16].
} 
were put back into the temperature cycling chamber for another round of cycles before the next resistance measurements were taken.

In the TCB temperature cycling test, the parts were removed for measurement at the $238^{\text {th }}, 457^{\text {th }}, 643^{\text {rd }}, 875^{\text {th }}, 1016^{\text {th }}, 1200^{\text {th }}, 1492^{\text {nd }}, 1724^{\text {th }}$, and $2012^{\text {th }}$ cycles. After the TCB 2,012 ${ }^{\text {th }}$ temperature cycle, maximum increase in resistance was still far from the $10 \%$ target. Therefore, the Temperature Cycling C (TCC) test was used in order to accelerate the failures. The range of temperatures of TCC is from $-65^{\circ} \mathrm{C}$ to $150^{\circ} \mathrm{C}$, according to Condition $\mathrm{C}$ of the Joint Electron Device Engineering Council (JEDEC) standard JESD22-A104C [15]. The required cycle time of the TCC test was also thirty minutes. A subcontracting test house located in Fremont, CA was selected for the TCC test. The cost of each TCC cycle was $\$ 2.50$. Every 100 cycles, the parts were removed from the temperature cycling chamber and sent back to Xilinx for resistance measurements. In the TCC temperature cycling test, the parts were pulled out for measurement at the $100^{\text {th }}, 200^{\text {th }}, 300^{\text {th }}, 400^{\text {th }}$, and $500^{\text {th }}$ cycles. At the TCC $400^{\text {th }}$ cycle, the maximum increase in resistance in two daisy chains had passed the $10 \%$ target. The similar measurement data were obtained in the same daisy chains at the TCC $500^{\text {th }}$ cycle. Hence, the experiment was stopped at the TCC $500^{\text {th }}$ cycle.

A Ransco dual-zone temperature cycle chamber was used to perform the TCB temperature cycling tests. A photograph of the temperature cycle chamber is shown in Figure 25. A Checksum open-short tester equipped with a programmable resistance measurement fixture, as shown in Figure 26, was used for carrying out the resistance 
measurements. The total time spent for both TCB and TCC temperature cycling tests and resistance measurement was 20 weeks.

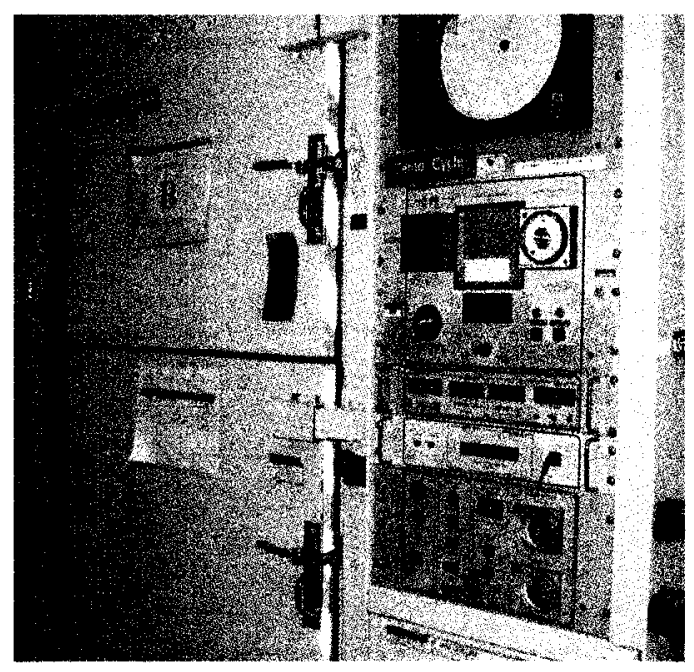

Figure 25. Ransco dual-zone temperature cycle chamber.

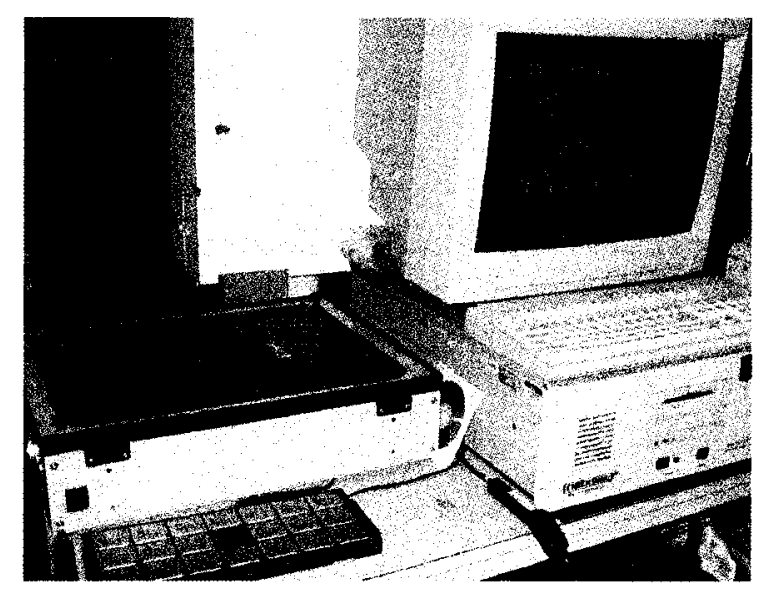

Figure 26. Checksum open-short tester.

\subsection{Data Analysis}

The net resistance change of all the daisy chains in these fifty packages was computed and recorded at the TCB $238^{\text {th }}, 457^{\text {th }}, 643^{\text {rd }}, 875^{\text {th }}, 1016^{\text {th }}, 1200^{\text {th }}, 1492^{\text {nd }}$, 
$1724^{\text {th }}, 2012^{\text {th }}$ cycles and at the TCC $100^{\text {th }}, 200^{\text {th }}, 300^{\text {th }}, 400^{\text {th }}$, and $500^{\text {th }}$ cycles. The data were statistically analyzed to verify that the data were reliable, to locate the daisy chains that had the highest net resistance increases and decreases, and to locate the daisy chains that had the abnormal trends of net resistance changes.

A 2-level 4-factor full factorial $\left(2^{4}\right)$ DOE, as shown in Table 7, was used to estimate the effects of the resistance change from all the factors and interactions in every measured cycle. Further analysis was done to find the top contributing factors and interactions. Analysis of variance (ANOVA) was performed on the estimated effects at the TCB $1200^{\text {th }}, \mathrm{TCB}_{2012^{\text {th }}}, \mathrm{TCC} 300^{\text {th }}$, and TCC500 ${ }^{\text {th }}$ cycles to determine the significant contributing factors and the interactions. These significant contributing factors and the interactions were cross examined and analyzed to filter out the ones that were actually irrelevant. Microsoft EXCEL was used for the data analysis.

\subsection{Failure Analysis}

If a complete open in electrical resistance is measured in a daisy chain, then that daisy chain is considered a failure and a full crack of at least one via is expected. However, throughout the experiment, a complete open was not found. Since it was not possible to cross-section all the vias of all the daisy chains in all the packages due to time and cost constraints, only some daisy chains were selected. The daisy chains selected for cross-sectioning either showed extreme net resistance change, displayed an abnormal trend of net resistance change, or had the extreme stacked via structure. Also, each of the chosen daisy chains was cross-sectioned in two areas: 1) at the outer package periphery; 
and 2) under the die. The results enabled the investigators to have a better idea of which of these two areas had a greater chance of containing failed vias.

Table 7. DOE for each resistance measurement process.

\begin{tabular}{|c|c|c|c|c|c|c|c|c|c|c|c|c|c|c|c|}
\hline & 1 & 2 & 3 & 4 & 12 & 13 & 14 & 23 & 24 & 34 & 123 & 124 & 134 & 234 & 1234 \\
\hline DAISY06 & - & - & - & - & + & + & + & + & + & + & - & - & - & - & + \\
\hline DAISY14 & + & - & - & - & - & - & - & + & + & + & + & + & + & - & - \\
\hline DAISY02 & - & + & - & - & - & + & + & - & - & + & + & + & - & + & - \\
\hline DAISY10 & + & + & - & - & + & - & - & - & - & + & - & - & + & + & + \\
\hline DAISY08 & - & - & + & - & + & - & + & - & + & - & + & - & + & + & - \\
\hline DAISY16 & + & - & + & - & - & + & - & - & + & - & - & + & - & + & + \\
\hline DAISY04 & - & + & + & - & - & - & + & + & - & - & - & + & + & - & + \\
\hline DAISY12 & + & + & + & - & + & + & - & + & - & - & + & - & - & - & - \\
\hline DAISY05 & - & - & - & + & + & + & - & + & - & - & - & + & + & + & - \\
\hline DAISY13 & + & - & - & + & - & - & + & + & - & - & + & - & - & + & + \\
\hline DAISY01 & - & + & - & + & - & + & - & - & + & - & + & - & + & - & + \\
\hline DAISY09 & + & + & - & + & + & - & + & - & + & - & - & + & - & - & - \\
\hline DAISY07 & - & - & + & + & + & - & - & - & - & + & + & + & - & - & + \\
\hline DAISY15 & + & - & + & + & - & + & + & - & - & + & - & - & + & - & - \\
\hline DAISY03 & - & + & + & + & - & - & - & + & + & + & - & - & - & + & - \\
\hline DAISY11 & + & + & + & + & + & + & + & + & + & + & + & + & + & + & + \\
\hline
\end{tabular}

\begin{tabular}{|c|c|c|c|}
\hline Single factor Effect & Description & + & - \\
\hline 1 & Stack on core & no & yes \\
\hline 2 & Aspect Ratio & low & high \\
\hline 3 & Stacked v Staggered & staggered & stacked \\
\hline 4 & Fillet & yes & no \\
\hline
\end{tabular}

After cross-sectioning, a Scanning Electron Microscope (SEM) was used to find the failed vias, to identify the location of the crack in each failed via, and to understand the failure mechanism. A JEOL JSM-6360LV low vacuum scanning electron microscope, as shown in Figure 27, was used for failure analysis. The total time spent in crosssectioning and failure analysis was about 6 weeks. 


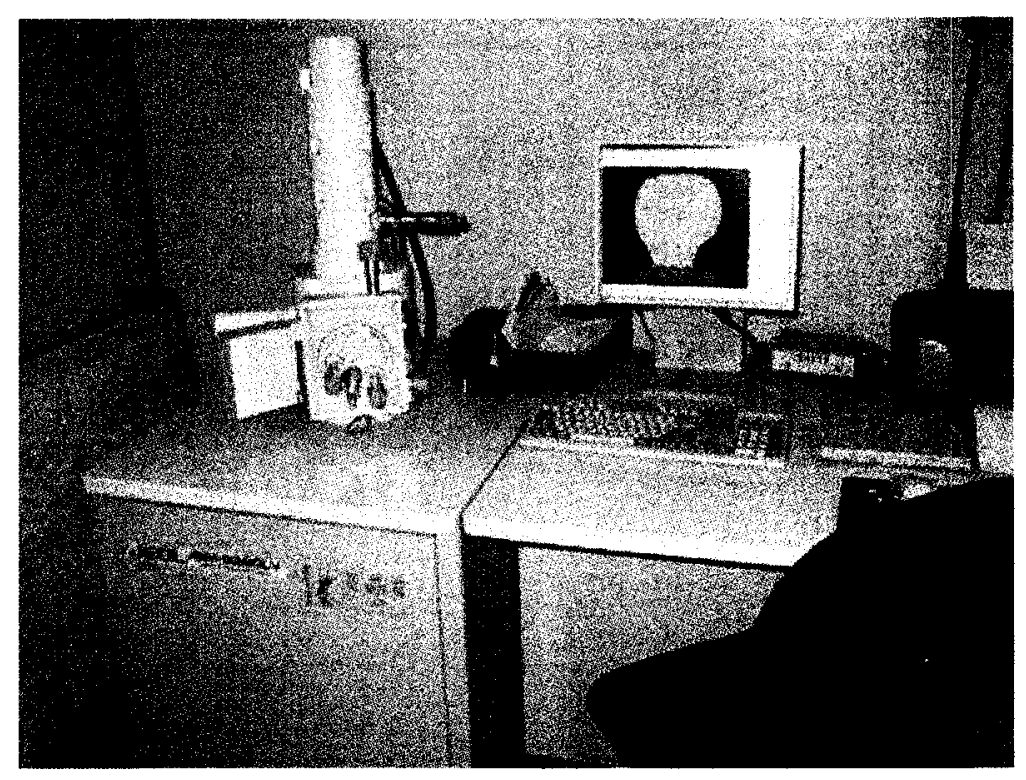

Figure 27. JEOL JSM-6360LV low vacuum scanning electron microscope. 


\section{CHAPTER FIVE}

\section{RESULTS}

The results of the resistance measurements and the resistance changes, the DOE analyses, and the failure analyses are presented in this chapter.

\subsection{Electrical Resistance at the $0^{\text {th }}$ Cycle}

Before the temperature cycling tests were begun, the electrical resistances of all sixteen daisy chains in the fifty packages were measured. These data are referred as the $0^{\text {th }}$ cycle resistances. During the data analysis, it was found that Package 33 and Package 34 had the same resistance values in all the daisy chains, and Package 34 consistently had the highest resistance decrease in all the measured cycles. It was concluded that the $0^{\text {th }}$ resistances of all the sixteen daisy chains in Package 34 were mistaken. Thus, all the data from Package 34 was removed from the experiment.

The design features and the statistical analyses (average, standard deviation, maximum, minimum, and range) of the electrical resistances of all the daisy chains at $0^{\text {th }}$ cycle are shown in Table 8(a) through Table 8(c). The detailed measurement data are included in Appendix A. Among all the sixteen daisy chains, Daisy 06 had the minimum average resistance of $5.20 \mathrm{ohm}$, a fairly small difference between the maximum and the minimum resistance data, and a fairly small standard deviation. Daisy 16 had the maximum average resistance of $11.06 \mathrm{ohm}$, the largest difference between the maximum and the minimum resistance data, and the largest standard deviation. All of these data are within the expected range for this test vehicle. 
Table 8(a). Design features of daisy chains \#01 - 06 and their statistical resistance data at the $0^{\text {th }}$ cycle.

\begin{tabular}{|l|c|c|c|c|c|c|}
\hline & DAISY01 & DAISY02 & DAISY03 & DAISY04 & DAISY05 & DAISY06 \\
\hline $\begin{array}{l}\text { Conductor } \\
\text { length }\end{array}$ & $204 \mathrm{~mm}$ & $148 \mathrm{~mm}$ & $295 \mathrm{~mm}$ & $243 \mathrm{~mm}$ & $234 \mathrm{~mm}$ & $114 \mathrm{~mm}$ \\
\hline $\begin{array}{l}\text { Stack on } \\
\text { core }\end{array}$ & yes & yes & yes & yes & yes & yes \\
\hline $\begin{array}{l}\text { Via/Pad } \\
\text { size }\end{array}$ & large & large & large & large & small & small \\
\hline $\begin{array}{l}\text { Stacked/ } \\
\text { Staggered }\end{array}$ & stacked & stacked & staggered & staggered & stacked & stacked \\
\hline Fillet & yes & no & yes & no & yes & no \\
\hline Mean & 6.27 & 6.05 & 7.61 & 6.4 & 7.76 & 5.2 \\
\hline SD & 0.3 & 0.35 & 0.29 & 0.4 & 0.45 & 0.32 \\
\hline Max & 7.01 & 7.15 & 8.36 & 7.6 & 9.29 & 6.2 \\
\hline Min & 5.7 & 5.41 & 6.98 & 5.59 & 6.9 & 4.61 \\
\hline Range & $20.90 \%$ & $28.75 \%$ & $18.11 \%$ & $31.52 \%$ & $30.74 \%$ & $30.45 \%$ \\
\hline
\end{tabular}

The electrical resistance of a daisy chain depends on the design as well as how it is manufactured. The accuracy of the electrical resistance measurements depends on the measurement equipment. From the perspective of design, the total trace length in a daisy chain is the predominant contributory factor to resistance: the longer the trace, the higher the resistance. Since the "total trace length" includes the additional length in the staggered via and the non-stack-on-core via designs, then whether the design is Nonstack-on-core or Stack-on-core, and Staggered Via or Stacked Via has no effect on electrical resistance. The other contributing factors are the via diameter and the fillet. The smaller the via diameter, the higher the resistance. Also, resistance is higher if a fillet is not incorporated between the traces and via pads. As can be seen in Table 8(a) through Table $8(\mathrm{c})$, Daisy chain 06 had the lowest average resistance of $5.20 \mathrm{ohm}$, mainly 
because it had the shortest total length of $114 \mathrm{~mm}$. Daisy chain 16 had the highest average resistance of $11.2 \mathrm{ohm}$ because it had a fairly long total trace length of $372 \mathrm{~mm}$, and its via diameter was small and there was no fillet incorporated between the traces and the via pads.

Table 8(b). Design features of daisy chains \#07-12 and their statistical resistance data at the $0^{\text {th }}$ cycle.

\begin{tabular}{|l|c|c|c|c|c|c|}
\hline & DAISY07 & DAISY08 & DAISY09 & DAISY10 & DAISY11 & DAISY12 \\
\hline $\begin{array}{l}\text { Conductor } \\
\text { length }\end{array}$ & $285 \mathrm{~mm}$ & $255 \mathrm{~mm}$ & $398 \mathrm{~mm}$ & $271 \mathrm{~mm}$ & $478 \mathrm{~mm}$ & $316 \mathrm{~mm}$ \\
\hline $\begin{array}{l}\text { Stack on } \\
\text { core }\end{array}$ & yes & yes & no & no & no & no \\
\hline $\begin{array}{l}\text { Via/Pad } \\
\text { size }\end{array}$ & small & small & large & large & large & large \\
\hline $\begin{array}{l}\text { Stacked / } \\
\text { Staggered }\end{array}$ & staggered & staggered & stacked & stacked & staggered & staggered \\
\hline Fillet & yes & no & yes & no & yes & no \\
\hline Mean & 9.35 & 7.98 & 7.76 & 8.28 & 8.92 & 8.44 \\
\hline SD & 0.4 & 0.54 & 0.46 & 0.38 & 0.45 & 0.38 \\
\hline Max & 10.61 & 9.62 & 8.86 & 9.22 & 10.53 & 9.53 \\
\hline Min & 8.55 & 7.04 & 6.92 & 7.48 & 8.15 & 7.78 \\
\hline Range & $22.03 \%$ & $32.33 \%$ & $25.06 \%$ & $20.93 \%$ & $26.62 \%$ & $20.68 \%$ \\
\hline
\end{tabular}

From the manufacturing end, resistance is mainly determined by the etching process. Over etching results in a thinner trace width and thus the resistance is higher. On the other hand, under etching leaves a wider trace which in turn decreases the resistance. Other factors such as the manufacturing variance in the diameter of the laser vias and the core drills, and the variances in the electro-plating thicknesses of the vias and drills also affect the variation of the electrical resistance. 
Table 8(c). Design features of daisy chains \#13 - 16 and their statistical resistance data at the $0^{\text {th }}$ cycle.

\begin{tabular}{|l|c|c|c|c|}
\hline & DAISY13 & DAISY14 & DAISY15 & DAISY16 \\
\hline $\begin{array}{l}\text { Conductor } \\
\text { length }\end{array}$ & $364 \mathrm{~mm}$ & $266 \mathrm{~mm}$ & $427 \mathrm{~mm}$ & $372 \mathrm{~mm}$ \\
\hline $\begin{array}{l}\text { Stack on } \\
\text { core }\end{array}$ & no & no & no & no \\
\hline $\begin{array}{l}\text { Via/Pad } \\
\text { size }\end{array}$ & small & small & small & small \\
\hline $\begin{array}{l}\text { Stacked/ } \\
\text { Staggered }\end{array}$ & stacked & stacked & staggered & staggered \\
\hline Fillet & yes & no & Yes & no \\
\hline Mean & 8.77 & 8.2 & 10.26 & 11.06 \\
\hline SD & 0.42 & 0.39 & 0.51 & 0.57 \\
\hline Max & 9.75 & 9.13 & 11.71 & 12.9 \\
\hline Min & 7.87 & 7.47 & 9.11 & 9.86 \\
\hline Range & $21.49 \%$ & $20.27 \%$ & $25.32 \%$ & $27.53 \%$ \\
\hline
\end{tabular}

In this investigation, a Checksum open-short tester equipped with a

programmable resistance measurement fixture was used for electrical resistance measurements. Although the data are more reliable than if the data were obtained from manual measurements with an ohm-meter, measurement errors may still come from the calibration of the equipment, the cleanliness of the contact pins and the parts, and human error.

The maximum, minimum, and standard deviation in Table 8(a) through Table 8 (c) reveal how much variation of the electrical resistance values comes from manufacturing and measurements. In the $0^{\text {th }}$ cycle data, Daisy Chain 16 had the highest standard deviation of $0.56 \mathrm{ohm}$, and the daisy chains $\# 04,05,06$, and 08 had a range of $30 \%$ or more. These variances are not uncommon in FCBGA substrate manufacturing, 
A one-way ANOVA was used to compare the variability between the means to the inherent variability. The hypothesis was that the mean of the electrical resistance is the same for all the daisy chains. The results of this analysis showed that the hypothesis was rejected because the mean is not same for all sixteen daisy chains at the $95 \%$ confidence level. Detailed calculations of ANOVA are shown in Appendix B.

\subsection{Resistance Changes from Temperature Cycling Tests}

Throughout the TCB and TCC temperature cycling tests, the actual electrical resistances of all the daisy chains in all the fifty packages were measured at the TCB $238^{\text {th }}, 457^{\text {th }}, 643^{\text {td }}, 875^{\text {th }}, 1016^{\text {th }}, 1200^{\text {th }}, 1492^{\text {nd }}, 1724^{\text {th }}, 2012^{\text {th }}$ cycles and at the TCC $100^{\text {th }}, 200^{\text {th }}, 300^{\text {th }}, 400^{\text {th }}$, and $500^{\text {th }}$ cycles. The measured data are contained in Appendix $\mathrm{C}-1$. These data were used to derive the net resistance change and the resistance change as a percentage by using Equation 3 and Equation 4, respectively.

Net resistance change $=$ Measured resistance - Resistance in the $0^{\text {th }}$ cycle Equation 3 $\%$ Resistance change $=\frac{\text { Net resistance change }}{\text { Resistance from }} \times 100 \%$

Resistance from the $0^{\text {th }}$ cycle Equation 4

The average resistance change for each daisy chain and each measured cycle are shown in Table 9(a) and Table 9(b). The detailed data of resistance change and the statistical values, including average, standard deviation, maximum, and minimum are shown in Appendix C-2. As can be seen in Table 9(a) and Table 9(b), the average resistance shift did not go beyond $9 \%$ before the TCC $400^{\text {th }}$ cycle in any of the daisy 
chains. At and after the TCC $400^{\text {th }}$ cycle, the average resistance shift of Daisy chain 04 and Daisy chain 06 went up to more than $16 \%$ while Daisy chain 14 fell to $-5 \%$.

Table 9(a). Average resistance changes of daisy chains \#01-08 at all the measured cycles.

\begin{tabular}{|l|l|l|l|l|l|l|l|l|}
\hline & $\begin{array}{l}\text { Daisy } \\
01\end{array}$ & $\begin{array}{l}\text { Daisy } \\
02\end{array}$ & $\begin{array}{l}\text { Daisy } \\
03\end{array}$ & $\begin{array}{l}\text { Daisy } \\
04\end{array}$ & $\begin{array}{l}\text { Daisy } \\
05\end{array}$ & $\begin{array}{l}\text { Daisy } \\
06\end{array}$ & $\begin{array}{l}\text { Daisy } \\
07\end{array}$ & $\begin{array}{l}\text { Daisy } \\
08\end{array}$ \\
\hline TCB 238 & $-0.55 \%$ & $1.71 \%$ & $0.57 \%$ & $0.01 \%$ & $-0.39 \%$ & $2.20 \%$ & $0.56 \%$ & $2.21 \%$ \\
\hline TCB 457 & $0.25 \%$ & $2.95 \%$ & $0.81 \%$ & $1.40 \%$ & $0.00 \%$ & $2.25 \%$ & $1.62 \%$ & $0.07 \%$ \\
\hline TCB 643 & $1.06 \%$ & $1.61 \%$ & $-0.51 \%$ & $-0.61 \%$ & $0.27 \%$ & $1.16 \%$ & $0.45 \%$ & $-1.73 \%$ \\
\hline TCB 875 & $1.17 \%$ & $2.45 \%$ & $0.10 \%$ & $-0.39 \%$ & $0.38 \%$ & $4.70 \%$ & $0.81 \%$ & $-0.39 \%$ \\
\hline TCB 1016 & $5.81 \%$ & $3.17 \%$ & $0.50 \%$ & $-0.19 \%$ & $-0.45 \%$ & $3.02 \%$ & $1.30 \%$ & $-0.08 \%$ \\
\hline TCB 1200 & $2.14 \%$ & $3.13 \%$ & $0.00 \%$ & $-0.31 \%$ & $-0.50 \%$ & $4.74 \%$ & $1.58 \%$ & $0.47 \%$ \\
\hline TCB 1492 & $0.33 \%$ & $2.19 \%$ & $-0.16 \%$ & $-0.39 \%$ & $-0.74 \%$ & $5.09 \%$ & $1.57 \%$ & $0.42 \%$ \\
\hline TCB 1724 & $3.69 \%$ & $2.87 \%$ & $0.67 \%$ & $0.54 \%$ & $0.79 \%$ & $5.36 \%$ & $2.41 \%$ & $-0.61 \%$ \\
\hline TCB 2012 & $3.07 \%$ & $2.94 \%$ & $0.28 \%$ & $-0.20 \%$ & $0.13 \%$ & $5.47 \%$ & $1.50 \%$ & $0.08 \%$ \\
\hline TCC 100 & $1.07 \%$ & $2.40 \%$ & $0.24 \%$ & $-0.01 \%$ & $-0.02 \%$ & $5.63 \%$ & $1.14 \%$ & $-0.81 \%$ \\
\hline TCC 200 & $1.77 \%$ & $2.58 \%$ & $0.26 \%$ & $0.07 \%$ & $-0.92 \%$ & $8.06 \%$ & $1.29 \%$ & $-0.31 \%$ \\
\hline TCC 300 & $6.68 \%$ & $3.75 \%$ & $1.60 \%$ & $1.25 \%$ & $0.62 \%$ & $8.65 \%$ & $3.59 \%$ & $1.95 \%$ \\
\hline TCC 400 & $3.44 \%$ & $4.77 \%$ & $0.72 \%$ & $16.81 \%$ & $-0.15 \%$ & $19.56 \%$ & $1.83 \%$ & $8.33 \%$ \\
\hline TCC 500 & $2.38 \%$ & $4.77 \%$ & $-0.22 \%$ & $17.03 \%$ & $-0.17 \%$ & $19.12 \%$ & $1.87 \%$ & $8.55 \%$ \\
\hline
\end{tabular}

The purpose of temperature cycling tests is to induce mechanical stresses on the vias. It is expected that the higher the $\Delta T$ and the greater the number of cycles, the higher the increase in via resistance. Also, the higher the resistance increase, the longer and larger the via crack.

As shown in Equation 4, the resistance change is normalized by its original resistance value and is used throughout the data analysis in this experiment. The resistance changes have been statistically analyzed and presented based on two testing methods: 1) by the temperature cycling tests, and 2) by the daisy chains. 
Table 9(b). Average resistance changes of daisy chains \#09-16 at all the measured cycles.

\begin{tabular}{|l|l|l|l|l|l|l|l|l|}
\hline & $\begin{array}{l}\text { Daisy } \\
09\end{array}$ & $\begin{array}{l}\text { Dasiy } \\
10\end{array}$ & $\begin{array}{l}\text { Daisy } \\
11\end{array}$ & $\begin{array}{l}\text { Daisy } \\
12\end{array}$ & $\begin{array}{l}\text { Daisy } \\
13\end{array}$ & $\begin{array}{l}\text { Daisy } \\
14\end{array}$ & $\begin{array}{l}\text { Daisy } \\
15\end{array}$ & $\begin{array}{l}\text { Daisy } \\
16\end{array}$ \\
\hline TCB 238 & $0.63 \%$ & $2.11 \%$ & $1.53 \%$ & $-1.30 \%$ & $-0.23 \%$ & $-0.44 \%$ & $0.82 \%$ & $-0.33 \%$ \\
\hline TCB 457 & $1.88 \%$ & $4.30 \%$ & $1.75 \%$ & $-1.40 \%$ & $-0.20 \%$ & $0.04 \%$ & $1.68 \%$ & $0.84 \%$ \\
\hline TCB 643 & $0.55 \%$ & $0.31 \%$ & $-0.12 \%$ & $-2.19 \%$ & $-0.84 \%$ & $-1.01 \%$ & $0.01 \%$ & $-0.31 \%$ \\
\hline TCB 875 & $0.71 \%$ & $0.41 \%$ & $1.03 \%$ & $-1.68 \%$ & $-0.15 \%$ & $0.03 \%$ & $0.34 \%$ & $0.57 \%$ \\
\hline TCB 1016 & $1.18 \%$ & $1.35 \%$ & $1.84 \%$ & $-1.87 \%$ & $-0.33 \%$ & $0.68 \%$ & $2.39 \%$ & $0.63 \%$ \\
\hline TCB 1200 & $1.43 \%$ & $0.43 \%$ & $0.70 \%$ & $-1.24 \%$ & $-0.10 \%$ & $-0.11 \%$ & $0.41 \%$ & $0.28 \%$ \\
\hline TCB 1492 & $0.65 \%$ & $0.52 \%$ & $0.51 \%$ & $-1.71 \%$ & $-0.33 \%$ & $-0.12 \%$ & $0.08 \%$ & $-0.13 \%$ \\
\hline TCB 1724 & $1.26 \%$ & $0.14 \%$ & $0.82 \%$ & $-1.33 \%$ & $0.08 \%$ & $0.74 \%$ & $0.33 \%$ & $0.14 \%$ \\
\hline TCB 2012 & $1.07 \%$ & $1.43 \%$ & $1.17 \%$ & $-1.85 \%$ & $-0.64 \%$ & $0.03 \%$ & $0.36 \%$ & $-0.20 \%$ \\
\hline TCC 100 & $0.50 \%$ & $0.11 \%$ & $1.01 \%$ & $-2.01 \%$ & $-0.72 \%$ & $0.49 \%$ & $0.07 \%$ & $-0.24 \%$ \\
\hline TCC 200 & $0.45 \%$ & $-0.04 \%$ & $0.26 \%$ & $-1.63 \%$ & $-1.22 \%$ & $-0.27 \%$ & $1.35 \%$ & $-0.52 \%$ \\
\hline TCC 300 & $2.71 \%$ & $2.02 \%$ & $1.23 \%$ & $-1.69 \%$ & $0.28 \%$ & $2.88 \%$ & $2.07 \%$ & $0.75 \%$ \\
\hline TCC 400 & $-0.61 \%$ & $1.03 \%$ & $2.86 \%$ & $-0.33 \%$ & $0.32 \%$ & $-5.45 \%$ & $2.55 \%$ & $1.27 \%$ \\
\hline TCC 500 & $-1.43 \%$ & $0.58 \%$ & $2.40 \%$ & $0.00 \%$ & $-0.01 \%$ & $-5.17 \%$ & $2.91 \%$ & $1.17 \%$ \\
\hline
\end{tabular}

\subsubsection{Results Based on Temperature Cycling Tests}

The mean, standard deviation, maximum increase, maximum decrease, and the range of the average resistance changes in the fourteen measured cycles are tabulated in Table 10 and plotted in Figure 28. A graph showing all the average resistance changes for each temperature cycling test is included in Appendix D.

Throughout the TCB tests the maximum increase in resistance gradually rose from $2.21 \%$ to $5.47 \%$ with the exceptions at TCB 643 and TCB 1016 where it dipped to $1.61 \%$ and ascended to $5.81 \%$, respectively. However, the average change in resistance fluctuated within a narrow margin, between $-0.12 \%$ and $1.18 \%$. There is no strong evidence indicating that the via resistance increased with an increase in the number of cycles. 
Table 10. Statistical analysis of resistance changes in the measured cycles.

\begin{tabular}{|l|c|c|c|c|c|}
\hline & Mean & SD & Max. Increase & Max. Decrease & Range \\
\hline TCB 238 & $0.57 \%$ & $1.11 \%$ & $2.21 \%$ & $-1.30 \%$ & $3.51 \%$ \\
\hline TCB 457 & $1.14 \%$ & $1.39 \%$ & $4.30 \%$ & $-1.40 \%$ & $5.71 \%$ \\
\hline TCB 643 & $-0.12 \%$ & $1.03 \%$ & $1.61 \%$ & $-2.19 \%$ & $3.80 \%$ \\
\hline TCB 875 & $0.63 \%$ & $1.40 \%$ & $4.70 \%$ & $-1.68 \%$ & $6.38 \%$ \\
\hline TCB 1016 & $1.18 \%$ & $1.82 \%$ & $5.81 \%$ & $-1.87 \%$ & $7.68 \%$ \\
\hline TCB 1200 & $0.82 \%$ & $1.50 \%$ & $4.74 \%$ & $-1.24 \%$ & $5.99 \%$ \\
\hline TCB 1492 & $0.49 \%$ & $1.52 \%$ & $5.09 \%$ & $-1.71 \%$ & $6.80 \%$ \\
\hline TCB 1724 & $1.12 \%$ & $1.69 \%$ & $5.36 \%$ & $-1.33 \%$ & $6.69 \%$ \\
\hline TCB 2012 & $0.92 \%$ & $1.74 \%$ & $5.47 \%$ & $-1.85 \%$ & $7.32 \%$ \\
\hline TCC 100 & $0.55 \%$ & $1.67 \%$ & $5.63 \%$ & $-2.01 \%$ & $7.64 \%$ \\
\hline TCC 200 & $0.70 \%$ & $2.25 \%$ & $8.06 \%$ & $-1.63 \%$ & $9.69 \%$ \\
\hline TCC 300 & $2.40 \%$ & $2.48 \%$ & $8.65 \%$ & $-1.69 \%$ & $10.35 \%$ \\
\hline TCC 400 & $3.56 \%$ & $6.42 \%$ & $19.56 \%$ & $-5.45 \%$ & $25.02 \%$ \\
\hline TCC 500 & $3.36 \%$ & $6.45 \%$ & $19.12 \%$ & $-5.17 \%$ & $24.29 \%$ \\
\hline
\end{tabular}

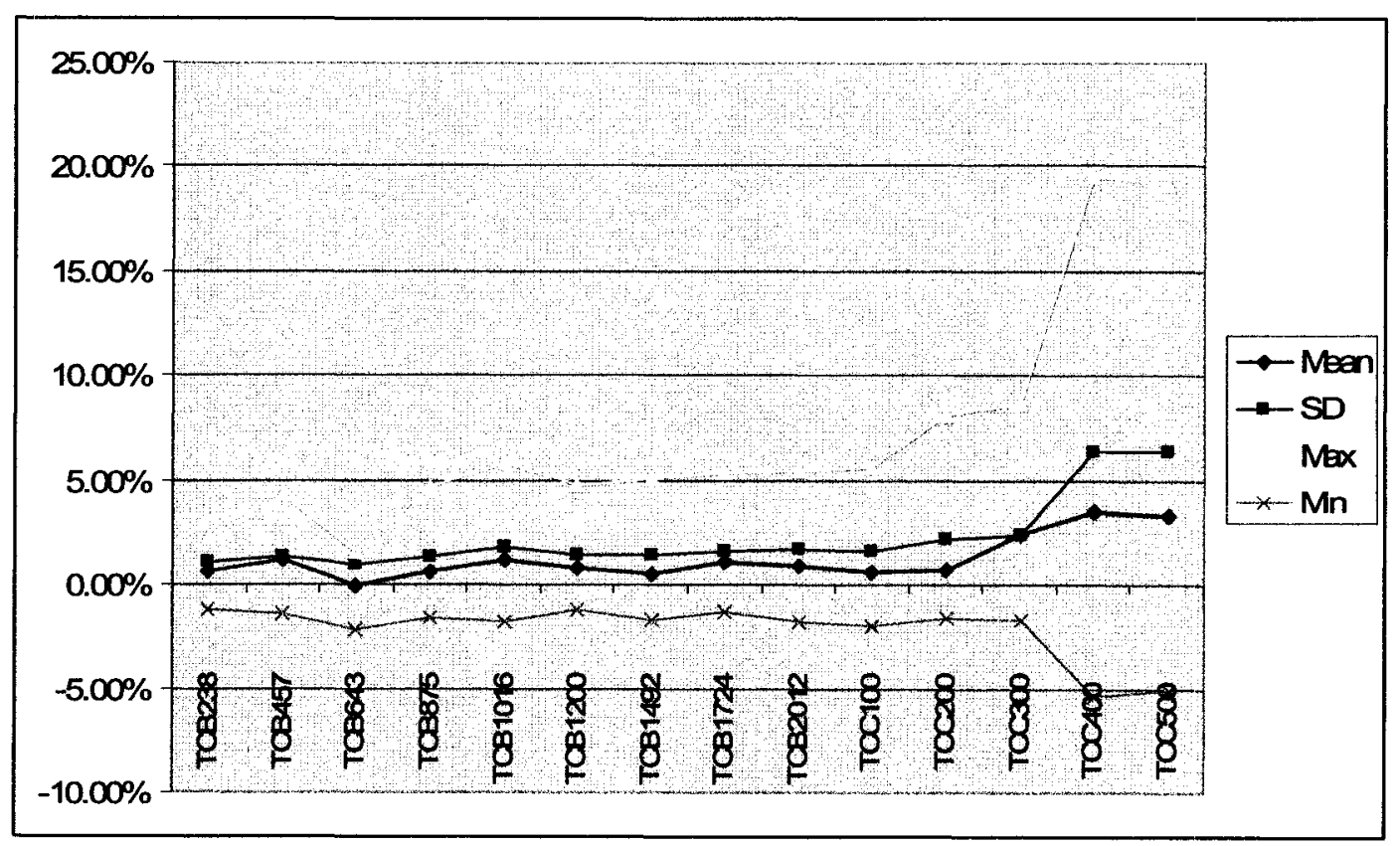

Figure 28. Statistical analysis of resistance changes in the measured cycles. 
In the TCC tests, the average change in resistance increased from $0.55 \%$ at the TCC $100^{\text {th }}$ cycle to $3.56 \%$ at the TCC $400^{\text {th }}$ cycle, but slipped slightly back to $3.36 \%$ at the TCC $500^{\text {th }}$ cycle. Since the TCC had a higher $\Delta \mathrm{T}$ compared to the TCB tests, it is thought that the increase in via resistance is higher when $\Delta \mathrm{T}$ is higher. Also, it is indicated that the resistance increased with an increase in the number of cycles, but only up to the TCC $400^{\text {th }}$ cycle.

Throughout the TCB tests and up to the TCC $300^{\text {th }}$ cycle, the maximum resistance change did not go beyond the $10 \%$ target, and the maximum resistance decrease barely went below $-2.2 \%$. But at the TCC $400^{\text {th }}$ cycle and the TCC $500^{\text {th }}$ cycle, some daisy chains exhibited a sudden rise in resistance to $16.8 \%$ or higher while some showed a sudden drop in resistance down to $-5 \%$. These phenomena in the last two temperature cycling tests were unexpected. It is suggested that, on the one hand, some cracks might have occurred rapidly, driving the resistance upward, while on the other hand, some interlayer contacts might have improved because of the higher TCC temperature, and thus drove the resistance downward.

As can be seen in Appendix D, the average resistance changes of all the daisy chains do not show a regular pattern at and before the TCB $643^{\text {rd }}$ cycle. Between the TCB $875^{\text {th }}$ cycle and the TCC $300^{\text {th }}$ cycle, the resistance changes of all the daisy chains showed a regular pattern, except Daisy Chain 01 . At and after the TCC $400^{\text {th }}$ cycle, the resistance changes of several daisy chains exhibited irregular jumps or dips. These findings were used to establish the scope of further investigations using DOE and ANOVA. 


\subsubsection{Results Based on Daisy Chains}

The mean, standard deviation, maximum increase, maximum decrease, and the range of the average resistance changes of the sixteen daisy chains are tabulated in Table 11(a) through Table 11(c) and plotted in Figure 29. A graph showing all the average resistance changes for each daisy chain is included in Appendix E.

Table 11(a). Statistical analysis of resistance changes of daisy chains \#01 - 06.

\begin{tabular}{|l|c|c|c|c|c|c|}
\hline & DAISY01 & DAISY02 & DAISY03 & DAISY04 & DAISY05 & DAISY06 \\
\hline Mean & $2.31 \%$ & $2.95 \%$ & $0.35 \%$ & $2.50 \%$ & $-0.08 \%$ & $6.79 \%$ \\
\hline SD & $2.08 \%$ & $0.96 \%$ & $0.53 \%$ & $6.14 \%$ & $0.50 \%$ & $5.71 \%$ \\
\hline $\begin{array}{l}\text { Max } \\
\text { Increase }\end{array}$ & $6.68 \%$ & $4.77 \%$ & $1.60 \%$ & $17.03 \%$ & $0.79 \%$ & $19.56 \%$ \\
\hline $\begin{array}{l}\text { Max } \\
\text { Decrease }\end{array}$ & $-0.55 \%$ & $1.61 \%$ & $-0.51 \%$ & $-0.61 \%$ & $-0.92 \%$ & $1.16 \%$ \\
\hline Range & $7.23 \%$ & $3.16 \%$ & $2.11 \%$ & $17.65 \%$ & $1.71 \%$ & $18.41 \%$ \\
\hline
\end{tabular}

Table 11(b). Statistical analysis of resistance changes of daisy chains \#07 - 12 .

\begin{tabular}{|l|c|c|c|c|c|c|}
\hline & DAISY07 & DAISY08 & DAISY09 & DAISY10 & DAISY11 & DAISY12 \\
\hline Mean & $1.54 \%$ & $1.30 \%$ & $0.78 \%$ & $1.05 \%$ & $1.21 \%$ & $-1.45 \%$ \\
\hline SD & $0.79 \%$ & $3.19 \%$ & $1.00 \%$ & $1.17 \%$ & $0.81 \%$ & $0.61 \%$ \\
\hline $\begin{array}{l}\text { Max } \\
\text { Increase }\end{array}$ & $3.59 \%$ & $8.55 \%$ & $2.71 \%$ & $4.30 \%$ & $2.86 \%$ & $0.00 \%$ \\
\hline $\begin{array}{l}\text { Max } \\
\text { Decrease }\end{array}$ & $0.45 \%$ & $-1.73 \%$ & $-1.43 \%$ & $-0.04 \%$ & $-0.12 \%$ & $-2.19 \%$ \\
\hline Range & $3.15 \%$ & $10.28 \%$ & $4.14 \%$ & $4.35 \%$ & $2.98 \%$ & $2.19 \%$ \\
\hline
\end{tabular}

Table 11(c). Statistical analysis of resistance changes of daisy chains \#13 - 16 .

\begin{tabular}{|l|c|c|c|c|}
\hline & DAISY13 & DAISY14 & DAISY15 & DAISY16 \\
\hline Mean & $-0.29 \%$ & $-0.55 \%$ & $1.10 \%$ & $0.28 \%$ \\
\hline SD & $0.43 \%$ & $2.20 \%$ & $1.04 \%$ & $0.59 \%$ \\
\hline Max Increase & $0.32 \%$ & $2.88 \%$ & $2.91 \%$ & $1.27 \%$ \\
\hline Max Decrease & $-1.22 \%$ & $-5.45 \%$ & $0.01 \%$ & $-0.52 \%$ \\
\hline Range & $1.54 \%$ & $8.34 \%$ & $2.90 \%$ & $1.79 \%$ \\
\hline
\end{tabular}




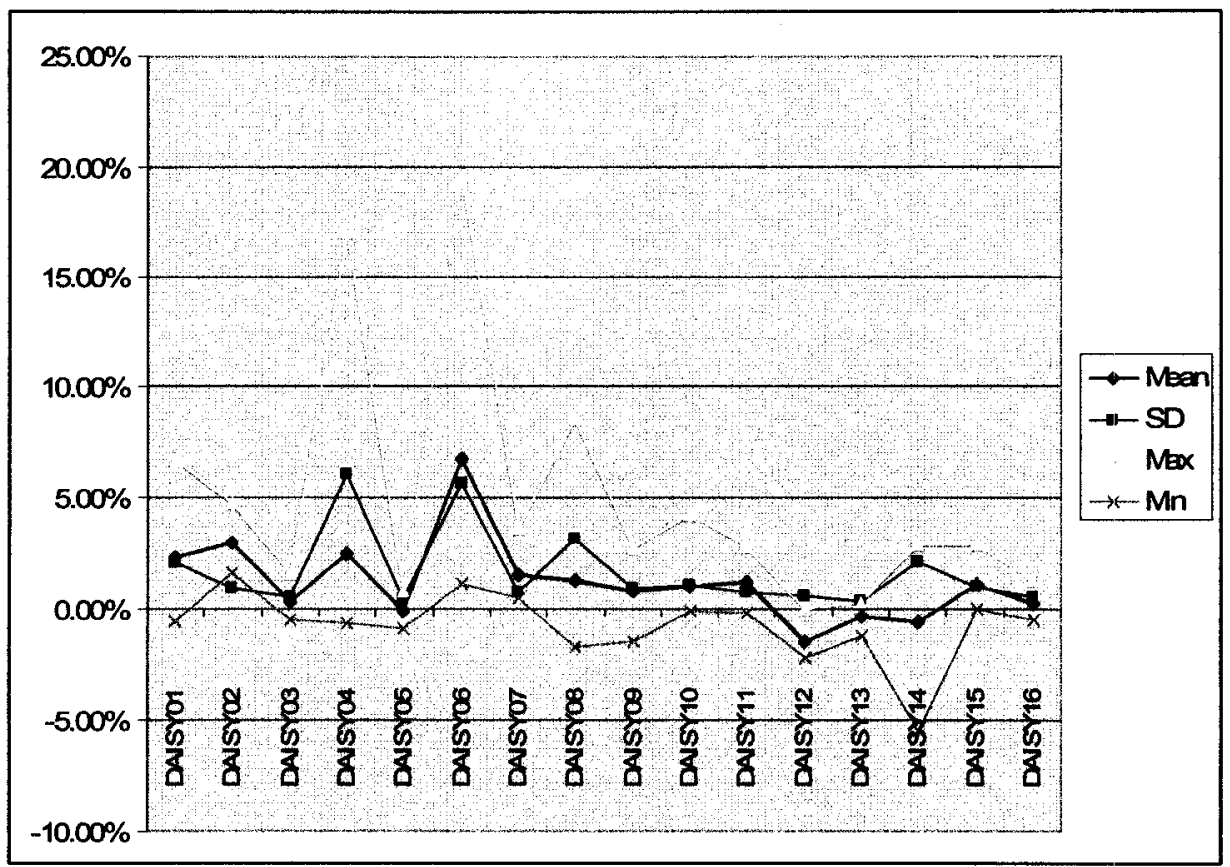

Figure 29. Statistical analysis of resistance changes of all daisy chains.

As can be seen from Table 11(a) through 11(c), Daisy Chain 06 had the highest mean resistance change of $6.79 \%$ while Daisy Chain 02 had the $2^{\text {nd }}$ highest mean resistance change of $2.95 \%$. Daisy Chain 02 and Daisy Chain 06 were the two daisy chains designed to test the extreme condition of having all vias stacked on each other. Daisy Chain 02 had a smaller aspect ratio, or a larger via diameter, whereas Daisy Chain 06 had a smaller via diameter. It is clearly seen that the risk of via crack is high when all vias are stacked on each other. Among these two daisy chains, the via set that has the smaller via diameter had the highest risk.

As can be seen from Figure 29, the standard deviations for Daisy Chains 09 to 16, excluding Daisy Chain 14, are more stable than those for Daisy Chains 01 to 08 . Daisy 
Chains 09 to 16 consist of Non-stack-on-core vias while Daisy Chains 01 to 08 consist of Stack-on-core vias. Therefore, it is suggested that Non-stack-on-core vias are more stable and robust than Stack-on-core vias.

From Appendix $\mathrm{E}$ it is seen that the average resistance changes of eleven daisy chains (Daisy Chains 02, 03, 05, 07, 09, 10,11, 12, 13, 15, and 16) stayed within a range of $5 \%$ throughout the fourteen temperature cycling tests. However, the TCC $400^{\text {th }}$ and TCC $500^{\text {th }}$ cycles produced irregular data that were not fully explicable in some daisy chains. Daisy chain 04 stayed below $0 \%$ before the TCC $200^{\text {th }}$ cycle and jumped from $1.25 \%$ at the TCC $300^{\text {th }}$ cycle up to $16.81 \%$ or more at the TCC $400^{\text {th }}$ and $500^{\text {th }}$ cycles. Daisy chain 06 had a gradual increase of resistance from $4.74 \%$ at the TCB $1200^{\text {th }}$ cycle to $8.65 \%$ at the TCC $300^{\text {th }}$ cycle, and jumped to more than $19.12 \%$ at the TCC $400^{\text {th }}$ and $500^{\text {th }}$ cycles. Daisy Chain 08 stayed below $1.95 \%$ before the TCC $300^{\text {th }}$ cycle and jumped to $8.33 \%$ or more at the TCC $400^{\text {th }}$ and $500^{\text {th }}$ cycles. These three daisy chains had the same irregular pattern. On the other hand, Daisy Chain 14 dropped from $2.88 \%$ at the TCC $300^{\text {th }}$ cycle to $-5.17 \%$ or more at the TCC $400^{\text {th }}$ and TCC $500^{\text {th }}$ cycles. These findings were used to establish the scope of the cross-sectioning and failure analyses.

\subsection{DOE Results}

In the 2-level 4-factor full factorial $\left(2^{4}\right) \mathrm{DOE}$, the average resistance changes were used to calculate the effects of the factors and the interactions in all the measured cycles. The ranking of the effects are listed in Table 12(a) through Table 12(c). The detailed effect calculations of all the measured cycles are shown in Appendix F-1. 
Table 12(a). The rankings of the effects for the measured cycles TCB238 - TCB1016.

\begin{tabular}{|c|c|c|c|c|c|c|c|c|c|c|}
\hline Rank & \multicolumn{2}{|c|}{ TCB 238} & \multicolumn{2}{l|}{ TCB 457 } & \multicolumn{2}{l|}{ TCB 643} & \multicolumn{2}{l|}{ TCB 875 } & \multicolumn{2}{c|}{ TCB 1016 } \\
\hline 1 & 34 & $1.13 \%$ & 34 & $1.57 \%$ & 3 & $1.02 \%$ & 34 & $1.21 \%$ & 23 & $1.57 \%$ \\
\hline 2 & 14 & $1.08 \%$ & 23 & $1.12 \%$ & 23 & $0.73 \%$ & 3 & $1.16 \%$ & 13 & $1.27 \%$ \\
\hline 3 & 12 & $0.75 \%$ & 123 & $1.01 \%$ & 34 & $0.71 \%$ & 13 & $0.98 \%$ & 3 & $1.24 \%$ \\
\hline 4 & 234 & $0.65 \%$ & 1234 & $0.77 \%$ & 1 & $0.66 \%$ & 1 & $0.95 \%$ & 34 & $1.19 \%$ \\
\hline 5 & 23 & $0.65 \%$ & 2 & $0.71 \%$ & 13 & $0.61 \%$ & 14 & $0.81 \%$ & 24 & $1.02 \%$ \\
\hline 6 & 1 & $0.44 \%$ & 14 & $0.67 \%$ & 1234 & $0.51 \%$ & 1234 & $0.77 \%$ & 1234 & $0.99 \%$ \\
\hline 7 & 4 & $0.41 \%$ & 3 & $0.59 \%$ & 4 & $0.45 \%$ & 24 & $0.72 \%$ & 1 & $0.90 \%$ \\
\hline 8 & 124 & $0.32 \%$ & 234 & $0.35 \%$ & 123 & $0.45 \%$ & 134 & $0.62 \%$ & 12 & $0.80 \%$ \\
\hline 9 & 24 & $0.31 \%$ & 124 & $0.34 \%$ & 124 & $0.44 \%$ & 123 & $0.44 \%$ & 234 & $0.71 \%$ \\
\hline 10 & 123 & $0.27 \%$ & 12 & $0.34 \%$ & 2 & $0.26 \%$ & 2 & $0.31 \%$ & 4 & $0.69 \%$ \\
\hline 11 & 13 & $0.22 \%$ & 4 & $0.33 \%$ & 14 & $0.24 \%$ & 23 & $0.26 \%$ & 2 & $0.58 \%$ \\
\hline 12 & 134 & $0.19 \%$ & 24 & $0.31 \%$ & 134 & $0.22 \%$ & 12 & $0.23 \%$ & 134 & $0.47 \%$ \\
\hline 13 & 1234 & $0.19 \%$ & 13 & $0.20 \%$ & 234 & $0.09 \%$ & 234 & $0.16 \%$ & 14 & $0.38 \%$ \\
\hline 14 & 3 & $0.12 \%$ & 134 & $0.09 \%$ & 12 & $0.09 \%$ & 4 & $0.16 \%$ & 124 & $0.33 \%$ \\
\hline 15 & 2 & $0.04 \%$ & 1 & $0.06 \%$ & 24 & $0.01 \%$ & 124 & $0.13 \%$ & 123 & $0.26 \%$ \\
\hline
\end{tabular}

Table 12(b). The rankings of the effects for the measured cycles TCB1200 - TCB2012.

\begin{tabular}{|c|c|c|c|c|c|c|c|c|}
\hline Rank & \multicolumn{2}{|c|}{ TCB 1200} & \multicolumn{2}{|c|}{ TCB 1492} & \multicolumn{2}{|c|}{ TCB 1724} & \multicolumn{2}{|c|}{ TCB 2012} \\
\hline 1 & 1 & $1.18 \%$ & 34 & $1.45 \%$ & 1 & $1.69 \%$ & 3 & $1.54 \%$ \\
\hline 2 & 3 & $1.16 \%$ & 1 & $1.10 \%$ & 3 & $1.50 \%$ & 1 & $1.49 \%$ \\
\hline 3 & 34 & $1.09 \%$ & 14 & $1.08 \%$ & 34 & $1.10 \%$ & 34 & $1.47 \%$ \\
\hline 4 & 14 & $0.99 \%$ & 3 & $0.92 \%$ & 1234 & $1.06 \%$ & 1234 & $1.07 \%$ \\
\hline 5 & 23 & $0.83 \%$ & 134 & $0.82 \%$ & 234 & $1.01 \%$ & 13 & $0.94 \%$ \\
\hline 6 & 134 & $0.82 \%$ & 1234 & $0.82 \%$ & 13 & $0.93 \%$ & 24 & $0.92 \%$ \\
\hline 7 & 13 & $0.78 \%$ & 24 & $0.68 \%$ & 24 & $0.78 \%$ & 14 & $0.73 \%$ \\
\hline 8 & 24 & $0.78 \%$ & 12 & $0.60 \%$ & 134 & $0.63 \%$ & 23 & $0.73 \%$ \\
\hline 9 & 1234 & $0.73 \%$ & 4 & $0.50 \%$ & 14 & $0.43 \%$ & 234 & $0.53 \%$ \\
\hline 10 & 234 & $0.53 \%$ & 2 & $0.49 \%$ & 23 & $0.32 \%$ & 12 & $0.42 \%$ \\
\hline 11 & 12 & $0.27 \%$ & 13 & $0.43 \%$ & 4 & $0.28 \%$ & 134 & $0.31 \%$ \\
\hline 12 & 4 & $0.22 \%$ & 23 & $0.43 \%$ & 124 & $0.15 \%$ & 123 & $0.26 \%$ \\
\hline 13 & 124 & $0.08 \%$ & 234 & $0.40 \%$ & 2 & $0.07 \%$ & 124 & $0.22 \%$ \\
\hline 14 & 2 & $0.06 \%$ & 123 & $0.26 \%$ & 123 & $0.07 \%$ & 2 & $0.15 \%$ \\
\hline 15 & 123 & $0.01 \%$ & 124 & $0.08 \%$ & 12 & $0.03 \%$ & 4 & $0.10 \%$ \\
\hline
\end{tabular}


Table 12(c). The rankings of the effects for the measured cycles TCC100-TCC500.

\begin{tabular}{|c|c|c|c|c|c|c|c|c|c|c|}
\hline Rank & \multicolumn{2}{|c|}{ TCC 100} & \multicolumn{2}{l|}{ TCC 200} & \multicolumn{2}{l|}{ TCC 300} & \multicolumn{2}{l|}{ TCC 400} & \multicolumn{2}{l|}{ TCC 500} \\
\hline 1 & 34 & $1.67 \%$ & 34 & $1.97 \%$ & 1 & $2.23 \%$ & 1 & $6.71 \%$ & 14 & $6.61 \%$ \\
\hline 2 & 1 & $1.30 \%$ & 1 & $1.80 \%$ & 3 & $2.10 \%$ & 14 & $6.53 \%$ & 1 & $6.61 \%$ \\
\hline 3 & 3 & $1.26 \%$ & 14 & $1.41 \%$ & 24 & $1.82 \%$ & 1234 & $4.66 \%$ & 4 & $4.79 \%$ \\
\hline 4 & 14 & $0.91 \%$ & 234 & $1.38 \%$ & 234 & $1.74 \%$ & 4 & $4.38 \%$ & 1234 & $4.41 \%$ \\
\hline 5 & 1234 & $0.89 \%$ & 13 & $1.34 \%$ & 34 & $1.66 \%$ & 123 & $3.18 \%$ & 123 & $3.02 \%$ \\
\hline 6 & 13 & $0.87 \%$ & 3 & $1.21 \%$ & 1234 & $1.32 \%$ & 234 & $2.33 \%$ & 234 & $2.45 \%$ \\
\hline 7 & 24 & $0.86 \%$ & 24 & $1.03 \%$ & 23 & $1.09 \%$ & 124 & $1.79 \%$ & 3 & $1.70 \%$ \\
\hline 8 & 134 & $0.63 \%$ & 1234 & $1.02 \%$ & 13 & $0.72 \%$ & 23 & $1.46 \%$ & 124 & $1.61 \%$ \\
\hline 9 & 234 & $0.61 \%$ & 134 & $0.92 \%$ & 14 & $0.68 \%$ & 3 & $1.39 \%$ & 23 & $1.52 \%$ \\
\hline 10 & 123 & $0.46 \%$ & 123 & $0.78 \%$ & 124 & $0.60 \%$ & 13 & $1.37 \%$ & 13 & $1.42 \%$ \\
\hline 11 & 4 & $0.28 \%$ & 124 & $0.66 \%$ & 2 & $0.41 \%$ & 12 & $1.01 \%$ & 12 & $1.01 \%$ \\
\hline 12 & 12 & $0.28 \%$ & 4 & $0.59 \%$ & 123 & $0.13 \%$ & 24 & $0.41 \%$ & 134 & $0.41 \%$ \\
\hline 13 & 2 & $0.28 \%$ & 2 & $0.47 \%$ & 134 & $0.12 \%$ & 134 & $0.23 \%$ & 2 & $0.35 \%$ \\
\hline 14 & 124 & $0.21 \%$ & 12 & $0.39 \%$ & 4 & $0.10 \%$ & 34 & $0.15 \%$ & 34 & $0.16 \%$ \\
\hline 15 & 23 & $0.05 \%$ & 23 & $0.24 \%$ & 12 & $0.02 \%$ & 2 & $0.05 \%$ & 24 & $0.02 \%$ \\
\hline
\end{tabular}

The TCB $1200^{\text {th }}, \mathrm{TCB} 2012^{\text {th }}, \mathrm{TCC} 300^{\text {th }}$, and $\mathrm{TCC} 500^{\text {th }}$ cycles were chosen for the detailed $2^{4}$ DOE analyses. In each of these analyses, all the raw data of resistance changes were used to derive contrast, effect and sum of square (SS). The detailed DOE calculations are shown in Appendix F-2. In order to find the major contributing factors and the interactions of resistance changes, analysis of variance (ANOVA) was used to evaluate the significance of the effects. The ANOVA results are shown in Table 13(a) through Table 13(d). Among the 15 main factors and interactions, Factor 1 (Stack-oncore), Factor 3 (Stacked Via) and Interaction 34 (Stacked Via and Fillet) were found to be the three most significant factors contributing to resistance changes. Detailed DOE analyses are presented in Section 6.1 . 
Table 13(a). ANOVA: DOE for the TCB $1200^{\text {th }}$ cycle.

\begin{tabular}{|c|c|c|c|c|c|c|c|c|}
\hline Factor & Effect & SS & $\begin{array}{c}\text { contr- } \\
\text { bution }\end{array}$ & DOF & MS & F0 & P-value & Conclusion \\
\hline 1 & -0.0118 & 0.0275 & 5.83 & 1 & 0.0275 & 69.12 & $4.2 \mathrm{E}-16$ & Significant \\
\hline 2 & -0.0006 & 0.0001 & 0.02 & 1 & 0.0001 & 0.18 & 0.67001 & \\
\hline 3 & -0.0116 & 0.0263 & 5.59 & 1 & 0.0263 & 66.27 & $1.6 \mathrm{E}-15$ & Significant \\
\hline 4 & -0.0022 & 0.0009 & 0.19 & 1 & 0.0009 & 2.31 & 0.12908 & \\
\hline 12 & 0.0027 & 0.0014 & 0.31 & 1 & 0.0014 & 3.62 & 0.05762 & \\
\hline 13 & 0.0078 & 0.0120 & 2.56 & 1 & 0.0120 & 30.31 & $5 \mathrm{E}-08$ & Significant \\
\hline 14 & 0.0099 & 0.0191 & 4.06 & 1 & 0.0191 & 48.09 & $8.7 \mathrm{E}-12$ & Significant \\
\hline 23 & -0.0083 & 0.0136 & 2.89 & 1 & 0.0136 & 34.27 & $7.1 \mathrm{E}-09$ & Significant \\
\hline 24 & 0.0078 & 0.0119 & 2.53 & 1 & 0.0119 & 29.99 & $5.9 \mathrm{E}-08$ & Significant \\
\hline 34 & 0.0109 & 0.0234 & 4.96 & 1 & 0.0234 & 58.81 & $5.3 \mathrm{E}-14$ & Significant \\
\hline 123 & 0.0001 & 0.0000 & 0.00 & 1 & 0.0000 & 0.01 & 0.94189 & \\
\hline 124 & -0.0008 & 0.0001 & 0.03 & 1 & 0.0001 & 0.31 & 0.5777 & \\
\hline 134 & -0.0082 & 0.0133 & 2.82 & 1 & 0.0133 & 33.46 & $1.1 \mathrm{E}-08$ & Significant \\
\hline & -0.0053 & 0.0055 & 1.17 & 1 & 0.0055 & 13.81 & 0.00022 & Fairly \\
\hline 234 & & & & & & & & significant \\
\hline 1234 & 0.0073 & 0.0105 & 2.24 & 1 & 0.0105 & 26.50 & $3.3 \mathrm{E}-07$ & Significant \\
\hline Model & & 0.1658 & 35.19 & 15 & 0.0111 & 27.80 & $1.9 \mathrm{E}-62$ & Significant \\
\hline Error & & 0.3052 & 64.81 & 768 & 0.0004 & & & \\
\hline Total & & 0.4710 & & 783 & & & & \\
\hline
\end{tabular}


Table 13(b). ANOVA: DOE for the TCB $2012^{\text {th }}$ cycle.

\begin{tabular}{|c|c|c|c|c|c|c|c|c|}
\hline Factor & Effect & SS & $\begin{array}{c}\% \\
\text { contri- } \\
\text { bution }\end{array}$ & DOF & MS & F0 & P-value & Conclusion \\
\hline 1 & -0.0149 & 0.0434 & 7.26 & 1 & 0.0434 & 88.94 & $4.7 \mathrm{E}-20$ & Significant \\
\hline 2 & 0.0015 & 0.0004 & 0.07 & 1 & 0.0004 & 0.90 & 0.34284 & \\
\hline 3 & -0.0154 & 0.0467 & 7.81 & 1 & 0.0467 & 95.79 & $2.1 \mathrm{E}-21$ & Significant \\
\hline 4 & -0.0010 & 0.0002 & 0.03 & 1 & 0.0002 & 0.37 & 0.54387 & \\
\hline 12 & 0.0042 & 0.0034 & 0.58 & 1 & 0.0034 & 7.06 & 0.00804 & $\begin{array}{c}\text { Fairly } \\
\text { significant }\end{array}$ \\
\hline 13 & 0.0094 & 0.0174 & 2.91 & 1 & 0.0174 & 35.67 & $3.6 \mathrm{E}-09$ & Significant \\
\hline 14 & 0.0073 & 0.0106 & 1.77 & 1 & 0.0106 & 21.69 & $3.8 \mathrm{E}-06$ & Significant \\
\hline 23 & -0.0073 & 0.0105 & 1.76 & 1 & 0.0105 & 21.62 & $3.9 \mathrm{E}-06$ & Significant \\
\hline 24 & 0.0092 & 0.0164 & 2.75 & 1 & 0.0164 & 33.66 & $9.6 \mathrm{E}-09$ & Significant \\
\hline 34 & 0.0147 & 0.0422 & 7.06 & 1 & 0.0422 & 86.55 & $1.4 \mathrm{E}-19$ & Significant \\
\hline 123 & -0.0026 & 0.0013 & 0.21 & 1 & 0.0013 & 2.62 & 0.10622 & \\
\hline 124 & -0.0022 & 0.0009 & 0.16 & 1 & 0.0009 & 1.94 & 0.16405 & \\
\hline 134 & -0.0031 & 0.0019 & 0.32 & 1 & 0.0019 & 3.87 & 0.04946 & $\begin{array}{c}\text { Fairly } \\
\text { significant }\end{array}$ \\
\hline 234 & -0.0053 & 0.0055 & 0.92 & 1 & 0.0055 & 11.31 & 0.00081 & $\begin{array}{c}\text { Fairly } \\
\text { significant }\end{array}$ \\
\hline 1234 & 0.0107 & 0.0223 & 3.73 & 1 & 0.0223 & 45.78 & $2.6 \mathrm{E}-11$ & Significant \\
\hline Model & & 0.2232 & 37.35 & 15 & 0.0149 & 30.52 & $6.5 \mathrm{E}-68$ & Significant \\
\hline Error & & 0.3745 & 62.65 & 768 & 0.0005 & & & \\
\hline Total & & 0.5978 & & 783 & & & & \\
\hline
\end{tabular}


Table 13(c). ANOVA: DOE for the TCC $300^{\text {th }}$ cycle.

\begin{tabular}{|c|c|c|c|c|c|c|c|c|}
\hline Factor & Effect & SS & $\begin{array}{c}\% \\
\text { contri- } \\
\text { bution }\end{array}$ & DOF & MS & F0 & P-value & Conclusion \\
\hline 1 & -0.0223 & 0.0975 & 11.17 & 1 & 0.0975 & 177.12 & $1.6 \mathrm{E}-36$ & Significant \\
\hline 2 & -0.0041 & 0.0033 & 0.37 & 1 & 0.0033 & 5.94 & 0.01506 & $\begin{array}{c}\text { Fairly } \\
\text { significant }\end{array}$ \\
\hline 3 & -0.0210 & 0.0867 & 9.94 & 1 & 0.0867 & 157.64 & $5.1 \mathrm{E}-33$ & Significant \\
\hline 4 & -0.0010 & 0.0002 & 0.02 & 1 & 0.0002 & 0.35 & 0.55512 & \\
\hline 12 & -0.0002 & $1 \mathrm{E}-05$ & 0.00 & 1 & $1 \mathrm{E}-05$ & 0.02 & 0.89247 & \\
\hline 13 & 0.0072 & 0.0102 & 1.17 & 1 & 0.0102 & 18.56 & $1.9 \mathrm{E}-05$ & Significant \\
\hline 14 & 0.0068 & 0.0091 & 1.04 & 1 & 0.0091 & 16.52 & $5.3 \mathrm{E}-05$ & Significant \\
\hline 23 & -0.0109 & 0.0232 & 2.66 & 1 & 0.0232 & 42.17 & $1.5 \mathrm{E}-10$ & Significant \\
\hline 24 & 0.0182 & 0.0650 & 7.45 & 1 & 0.0650 & 118.17 & $1.1 \mathrm{E}-25$ & Significant \\
\hline 34 & 0.0166 & 0.0538 & 6.16 & 1 & 0.0538 & 97.70 & $9.1 \mathrm{E}-22$ & Significant \\
\hline 123 & -0.0013 & 0.0003 & 0.04 & 1 & 0.0003 & 0.56 & 0.45446 & \\
\hline & -0.0060 & 0.0070 & 0.80 & 1 & 0.0070 & 12.68 & 0.00039 & Fairly \\
\hline 124 & & & & & & & & \\
\hline 134 & -0.0012 & 0.0003 & 0.03 & 1 & 0.0003 & 0.47 & 0.49104 & \\
\hline 234 & -0.0174 & 0.0595 & 6.82 & 1 & 0.0595 & 108.15 & $8.7 \mathrm{E}-24$ & Significant \\
\hline 1234 & 0.0132 & 0.0343 & 3.93 & 1 & 0.0343 & 62.27 & $1 \mathrm{E}-14$ & Significant \\
\hline Model & & 0.4503 & 51.59 & 15 & 0.0300 & 54.55 & $5 \mathrm{E}-110$ & Significant \\
\hline Error & & 0.4226 & 48.41 & 768 & 0.0006 & & & \\
\hline Total & & 0.8729 & & 783 & & & & \\
\hline
\end{tabular}


Table 13(d). ANOVA: DOE for the TCC $500^{\text {th }}$ cycle.

\begin{tabular}{|c|c|c|c|c|c|c|c|c|}
\hline Factor & Effect & SS & $\begin{array}{c}\% \\
\text { contri- } \\
\text { bution }\end{array}$ & DOF & MS & F0 & P-value & Conclusion \\
\hline 1 & -0.0661 & 0.8564 & 24.15 & 1 & 0.8564 & 1355.89 & $8 \mathrm{E}-172$ & Significant \\
\hline 2 & -0.0035 & 0.0023 & 0.07 & 1 & 0.0023 & 3.70 & 0.05493 & \\
\hline 3 & 0.0170 & 0.0569 & 1.60 & 1 & 0.0569 & 90.03 & $2.9 \mathrm{E}-20$ & Significant \\
\hline 4 & -0.0479 & 0.4499 & 12.69 & 1 & 0.4499 & 712.35 & $2 \mathrm{E}-111$ & Significant \\
\hline 12 & 0.0101 & 0.0199 & 0.56 & 1 & 0.0199 & 31.43 & $2.9 \mathrm{E}-08$ & Significant \\
\hline 13 & 0.0142 & 0.0396 & 1.12 & 1 & 0.0396 & 62.73 & $8.3 \mathrm{E}-15$ & Significant \\
\hline 14 & 0.0661 & 0.8567 & 24.16 & 1 & 0.8567 & 1356.45 & $7 \mathrm{E}-172$ & Significant \\
\hline 23 & 0.0152 & 0.0455 & 1.28 & 1 & 0.0455 & 72.08 & $1.1 \mathrm{E}-16$ & Significant \\
\hline 24 & -0.0002 & $1.1 \mathrm{E}-$ & 0.00 & 1 & $1.1 \mathrm{E}-$ & 0.02 & 0.89358 & \\
\hline 34 & -0.0016 & 0.0005 & 0.01 & 1 & 0.0005 & 0.80 & 0.37182 & \\
\hline 123 & -0.0302 & 0.1793 & 5.06 & 1 & 0.1793 & 283.93 & $1.9 \mathrm{E}-54$ & Significant \\
\hline 124 & -0.0161 & 0.0506 & 1.43 & 1 & 0.0506 & 80.17 & $2.6 \mathrm{E}-18$ & Significant \\
\hline & 0.0041 & 0.0033 & 0.09 & 1 & 0.0033 & 5.18 & 0.02315 & Fairly \\
\hline 134 & & & & & & & & \\
\hline 234 & -0.0245 & 0.1181 & 3.33 & 1 & 0.1181 & 186.93 & $3 \mathrm{E}-38$ & Significant \\
\hline 1234 & 0.0441 & 0.3818 & 10.77 & 1 & 0.3818 & 604.44 & $7 \mathrm{E}-99$ & Significant \\
\hline Model & & 3.0608 & 86.32 & 15 & 0.2041 & 323.07 & 0 & Significant \\
\hline Error & & 0.4851 & 13.68 & 768 & 0.0006 & & & \\
\hline Total & & 3.5458 & & 783 & & & & \\
\hline
\end{tabular}

\subsection{Failure Analysis}

After the TCC 500 cycles, cross-sectioning was used to verify whether the net resistance change was related to the via crack, and also to investigate the failure mechanism of the cracks. The daisy chains that were selected for cross-sectioning showed extreme net resistance change, displayed an abnormal trend of net resistance change, or had the extreme stacked via structure. For the daisy chains that contained Non-stack-on-core or Staggered vias, two packages which had the closet readings were 
selected for cross-sectioning. For the daisy chains that had all the vias aligned in one axis, one package was used for cross-sectioning.

In order to understand whether the geographical locations played any roles in crack formation, each of these daisy chains was cross-sectioned in two areas: at the outer periphery and under the die.

The micrographs of all the cracked vias are shown in Appendix G. Some fractures are very obvious and some are not that noticeable. In this study, a fracture that was continuous between both corners of the via was classified as a crack and was considered a failure*. An illustration of a crack is shown in Figure 30(a), and an actual example of a crack is shown in Figure 32(a) which is a micrograph of Via 2-3. A fracture that occurred only at one corner of the via and was less than half of the diameter of the via was considered a minor crack and was not counted as a failure. An illustration of a minor crack is shown in Figure 30(b), and Figure 32(d) is a micrograph of an actual minor crack in Via 6-7. If a fracture that was longer than half of the diameter of the via, it was still considered a crack, and thus a failure. An example of such a crack is shown in Figure 32(b) which is a micrograph of Via 8-9.

\footnotetext{
* In the field of microelectronics packaging, an industrial specification that defines via failure by the extent of via crack has not been developed. In commercial usage, if a via is not fully cracked after TCB 1000 cycles, the via is still not considered to be a failure by many companies [16].
} 


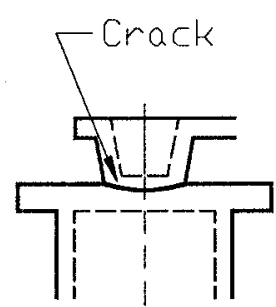

(a) Crack

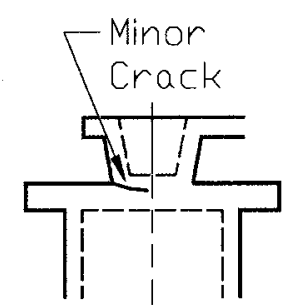

(b) Minor Crack

Figure 30. An illustration of a crack and a minor crack

\subsubsection{Packages with High Net Resistance Change (Phase I)}

Packages that had high net resistance changes in a daisy chain were first selected for cross-sectioning. The daisy chains and the packages that were selected are shown in Table 14. Their cross-section locations are shown in Figures 31(a) through 31(c).

Table 14. The daisy chains and the packages selected for cross-section in Phase I.

\begin{tabular}{|l|c|c|l|l|}
\hline Daisy chains & \multicolumn{4}{|l|}{ Packages } \\
\hline Daisy06 & PKG36 & PKG43 & & \\
\hline Daisy04 & PKG06 & PKG10 & PKG19 & PKG47 \\
\hline Daisy14 & PKG23 & PKG26 & PKG42 & PKG44 \\
\hline Daisy08 & PKG04 & PKG32 & PKG35 & PKG48 \\
\hline Daisy02 & PKG02 & PKG39 & & \\
\hline
\end{tabular}

Daisy Chain 06 and Daisy Chain 04 were selected because they had the highest resistance increase. The cross-section report and the micrographs of one of the via sets (each via set can be represented by its ball \#) of Daisy Chain 06 are shown in Table 15 and Figures 32(a) through 32(d), respectively. All of the ten cross-sectioned via sets had 
failed. The failures were on V2-3, V4-5, V6-7, and V8-9 for the via sets at the outer periphery, and on the upper layers V1-2, V2-3, V3-4, and V4-5 for the via sets under the die. The cross-section report and the micrographs of one of the via sets of Daisy Chain 04 are shown in Table 16 and Figures 33(a) through 33(d), respectively. All of the five cross-sectioned via sets at the outer periphery had failed on the stack-on-core vias on V45 and V6-7. None of the four cross-sectioned via sets under the die failed.

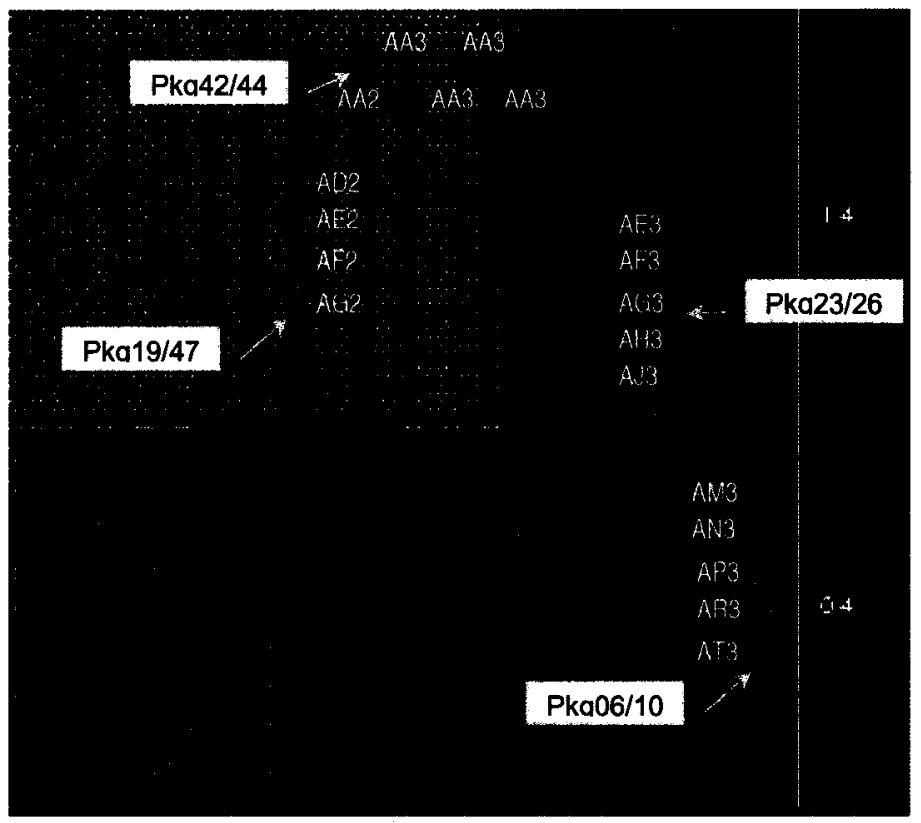

Figure 31(a). Cross-section locations for Daisy Chain 04 and Daisy Chain 14. 


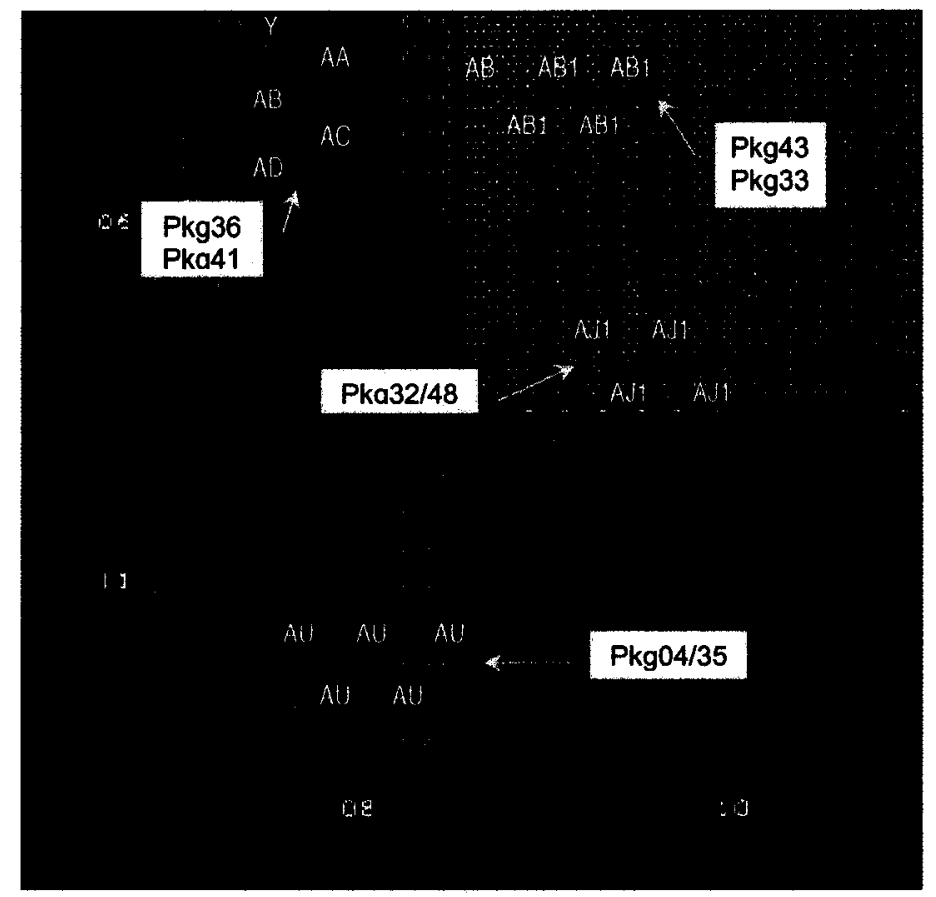

Figure 31(b). Cross-section locations for Daisy Chain 06 and Daisy Chain 08.

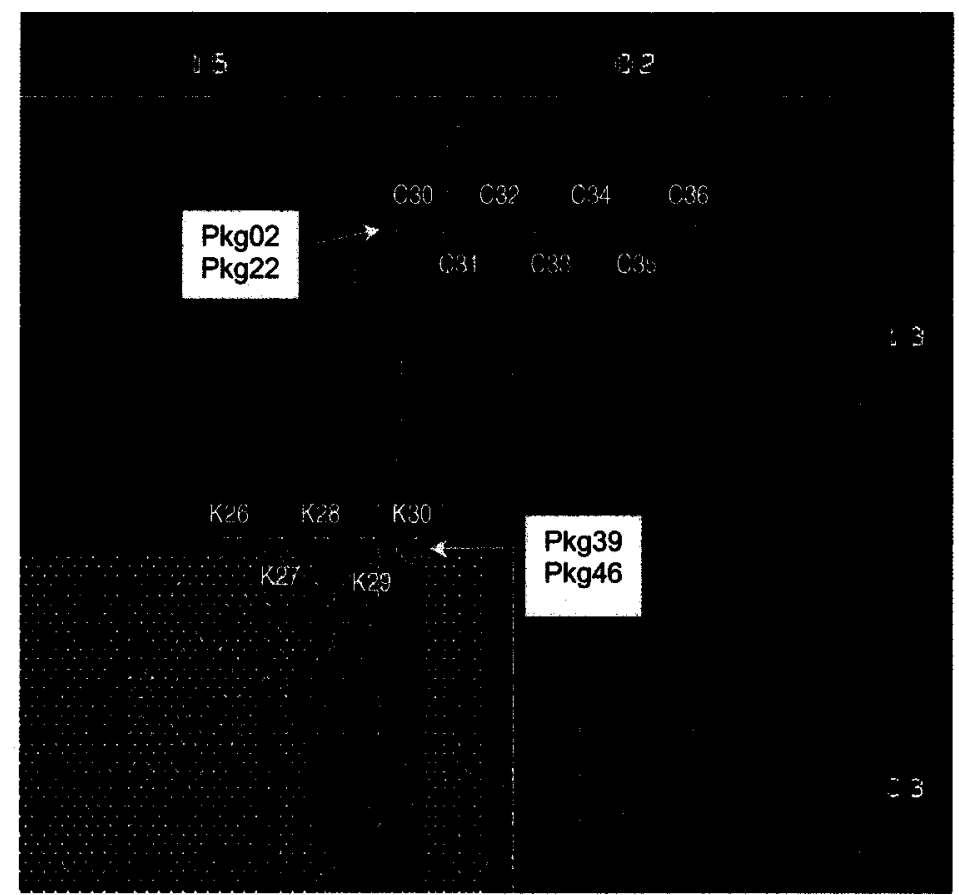

Figure 31(c). Cross-section locations for Daisy Chain 02. 
Table 15. The cross-section report of Daisy Chain 06 in Phase I.

\begin{tabular}{|c|c|c|c|c|c|c|c|c|}
\hline Pkg 36 & At the & iter peri & ery & & & & & \\
\hline Ball No & V1-2 & V2-3 & V3-4 & V4-5 & V6-7 & V7-8 & V8-9 & V9-10 \\
\hline $\mathrm{Y} 4$ & No & $\begin{array}{l}\text { Crack } \\
\text { on L3 }\end{array}$ & No & $\begin{array}{l}\text { Crack } \\
\text { on L5 }\end{array}$ & $\begin{array}{l}\text { Crack } \\
\text { on L6 }\end{array}$ & No & $\begin{array}{c}\text { Unclear } \\
\text { micro- } \\
\text { graph }\end{array}$ & $\begin{array}{c}\text { Minor } \\
\text { crack on } \\
\text { L9 }\end{array}$ \\
\hline AA4 & No & $\begin{array}{l}\text { Crack } \\
\text { on L3 }\end{array}$ & No & $\begin{array}{l}\text { Crack } \\
\text { on L5 }\end{array}$ & $\begin{array}{l}\text { Crack } \\
\text { on L6 }\end{array}$ & No & $\begin{array}{l}\text { Crack } \\
\text { on L8 }\end{array}$ & $\begin{array}{c}\text { Minor } \\
\text { crack on } \\
\text { L9 }\end{array}$ \\
\hline AB4 & No & $\begin{array}{l}\text { Crack } \\
\text { on L3 }\end{array}$ & No & $\begin{array}{l}\text { Crack } \\
\text { on L5 }\end{array}$ & $\begin{array}{l}\text { Crack } \\
\text { on L6 }\end{array}$ & $\begin{array}{c}\text { Minor } \\
\text { crack } \\
\text { on L7 }\end{array}$ & $\begin{array}{l}\text { Crack } \\
\text { on L8 }\end{array}$ & No \\
\hline $\mathrm{AC} 4$ & No & $\begin{array}{l}\text { Crack } \\
\text { on L3 }\end{array}$ & No & $\begin{array}{l}\text { Crack } \\
\text { on L5 }\end{array}$ & $\begin{array}{l}\text { Crack } \\
\text { on L6 }\end{array}$ & No & $\begin{array}{l}\text { Crack } \\
\text { on L8 }\end{array}$ & No \\
\hline AD4 & No & $\begin{array}{l}\text { Crack } \\
\text { on L3 }\end{array}$ & No & $\begin{array}{l}\text { Crack } \\
\text { on L5 }\end{array}$ & $\begin{array}{l}\text { Crack } \\
\text { on L6 }\end{array}$ & No & $\begin{array}{l}\text { Crack } \\
\text { on L8 }\end{array}$ & No \\
\hline Pkg 43 & Under & e die & & & & & & \\
\hline Ball No & $\mathrm{V} 1-2$ & V2-3 & V3-4 & V4-5 & V6-7 & V7-8 & V8-9 & V9-10 \\
\hline AB9 & $\begin{array}{l}\text { Crack } \\
\text { on L2 }\end{array}$ & $\begin{array}{l}\text { Crack } \\
\text { on L3 }\end{array}$ & $\begin{array}{l}\text { Crack } \\
\text { on L4 }\end{array}$ & $\begin{array}{l}\text { Crack } \\
\text { on L5 }\end{array}$ & No & No & $\begin{array}{l}\text { No in- } \\
\text { line via }\end{array}$ & $\begin{array}{l}\text { No in- } \\
\text { line via }\end{array}$ \\
\hline $\mathrm{AB} 10$ & $\begin{array}{c}\text { Minor } \\
\text { crack } \\
\text { on L2 } \\
\end{array}$ & $\begin{array}{l}\text { Crack } \\
\text { on L3 }\end{array}$ & $\begin{array}{l}\text { Crack } \\
\text { on L4 }\end{array}$ & $\begin{array}{l}\text { Crack } \\
\text { on L5 }\end{array}$ & $\begin{array}{c}\text { Minor } \\
\text { crack } \\
\text { on L6 }\end{array}$ & $\begin{array}{c}\text { Minor } \\
\text { crack } \\
\text { on L7 }\end{array}$ & No & No \\
\hline AB11 & $\begin{array}{l}\text { Crack } \\
\text { on L2 }\end{array}$ & $\begin{array}{l}\text { Minor } \\
\text { crack } \\
\text { on L3 } \\
\end{array}$ & $\begin{array}{l}\text { Crack } \\
\text { on L4 }\end{array}$ & $\begin{array}{l}\text { Crack } \\
\text { on L5 }\end{array}$ & $\begin{array}{l}\text { Minor } \\
\text { crack } \\
\text { on L6 } \\
\end{array}$ & No & No & No \\
\hline AB12 & $\begin{array}{l}\text { Crack } \\
\text { on L2 }\end{array}$ & $\begin{array}{l}\text { Minor } \\
\text { crack } \\
\text { on L3 }\end{array}$ & $\begin{array}{l}\text { Crack } \\
\text { on L4 }\end{array}$ & $\begin{array}{l}\text { Crack } \\
\text { on L5 }\end{array}$ & No & No & No & No \\
\hline $\mathrm{AB} 13$ & $\begin{array}{l}\text { Crack } \\
\text { on L2 }\end{array}$ & $\begin{array}{l}\text { Crack } \\
\text { on L3 }\end{array}$ & $\begin{array}{l}\text { Crack } \\
\text { on L4 }\end{array}$ & $\begin{array}{l}\text { Crack } \\
\text { on L5 }\end{array}$ & $\begin{array}{c}\text { Minor } \\
\text { crack } \\
\text { on L6 } \\
\end{array}$ & No & No & No \\
\hline
\end{tabular}


Daisy Chain 06, Pkg 36, Ball no. AC4, Via 1-5

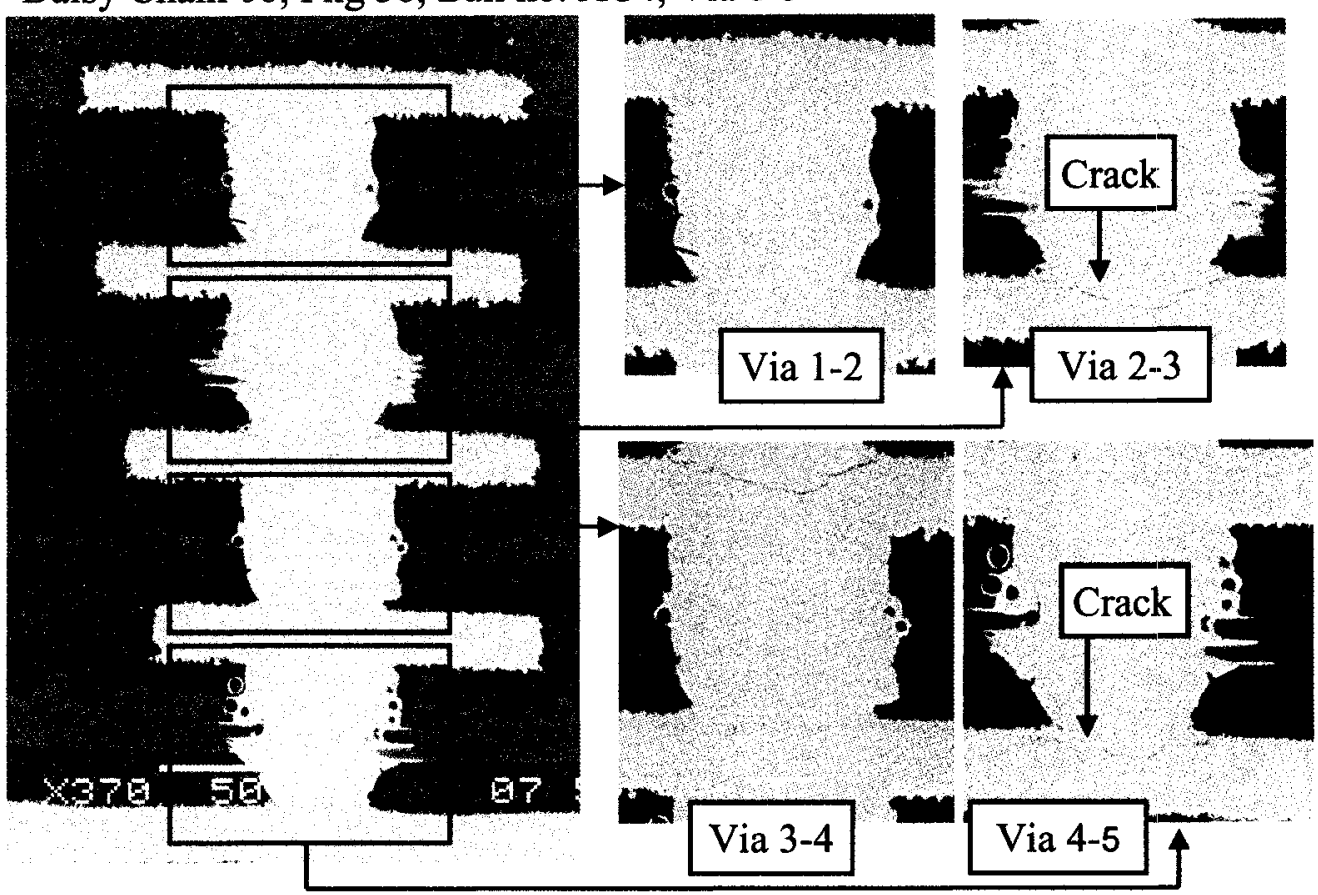

Figure 32(a). The cross-section micrograph of the upper layers of Daisy 06/PKG 36.

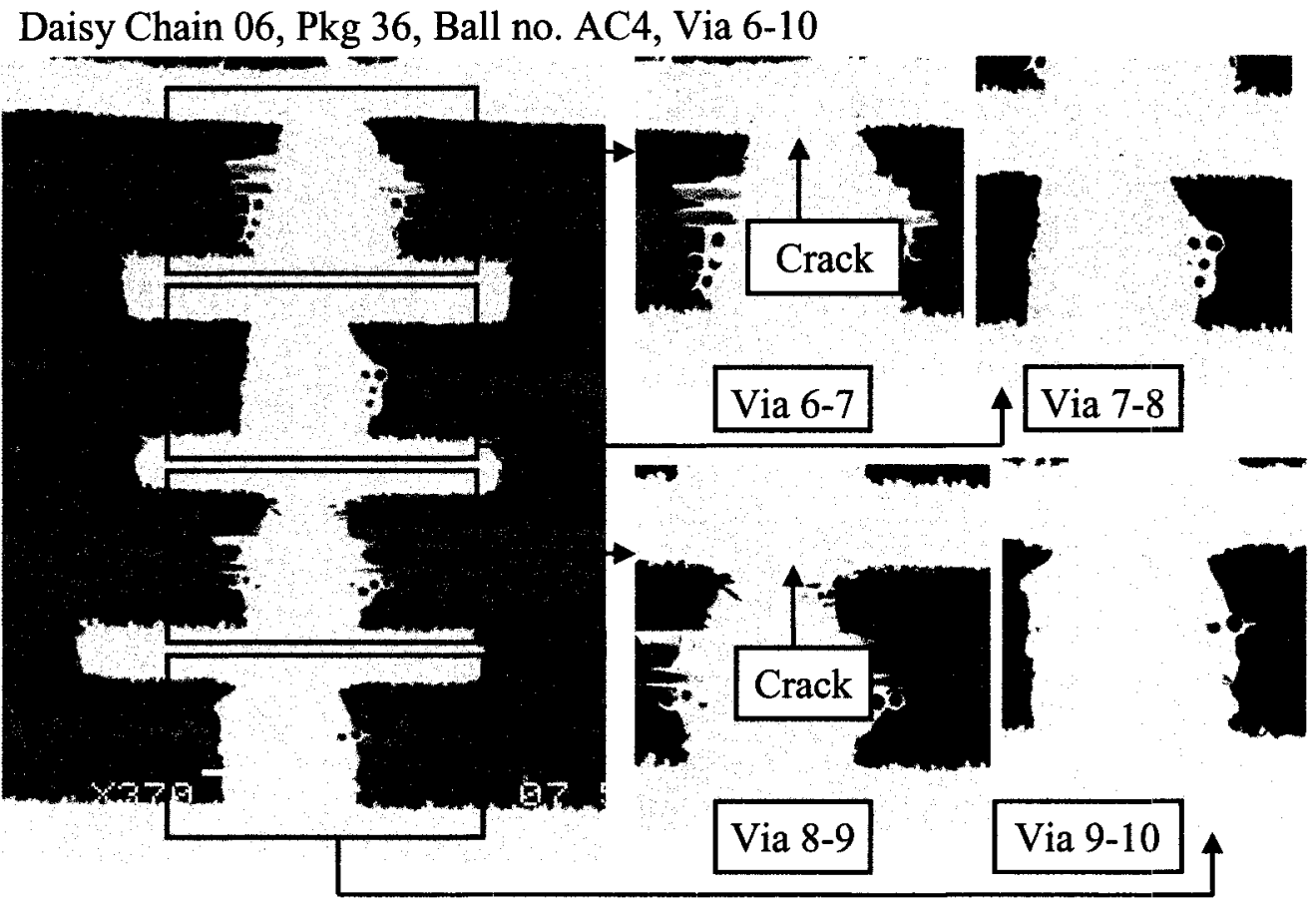

Figure 32(b). The cross-section micrograph of the lower layers of Daisy 06/PKG 36. 
Daisy Chain 06, Pkg 43, Ball no. AB13, Via 1-5

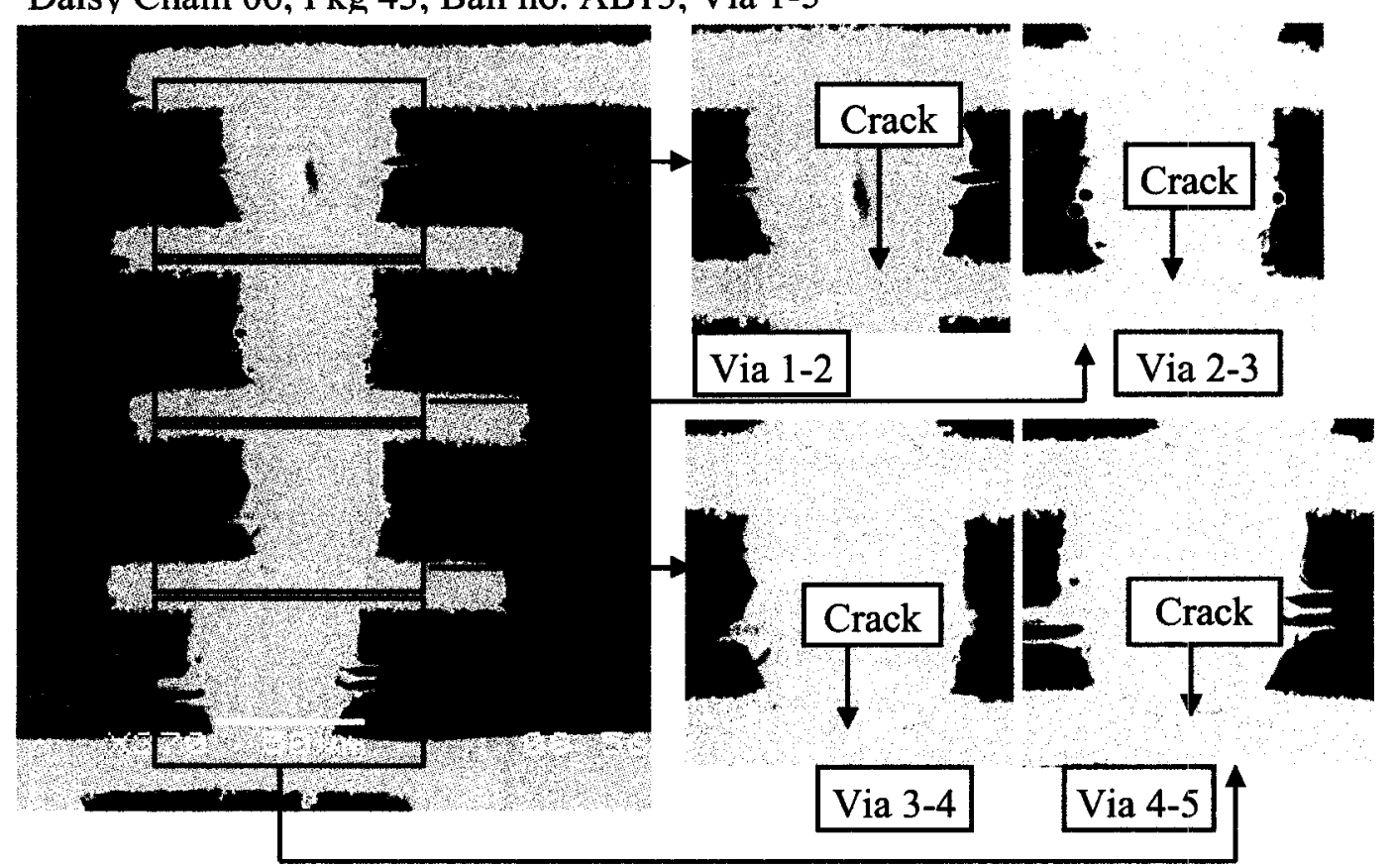

Figure 32(c). The cross-section micrograph of the upper layers of Daisy 06/PKG 43.

Daisy Chain 06, Pkg 43, Ball no. AB13, Via 6-10

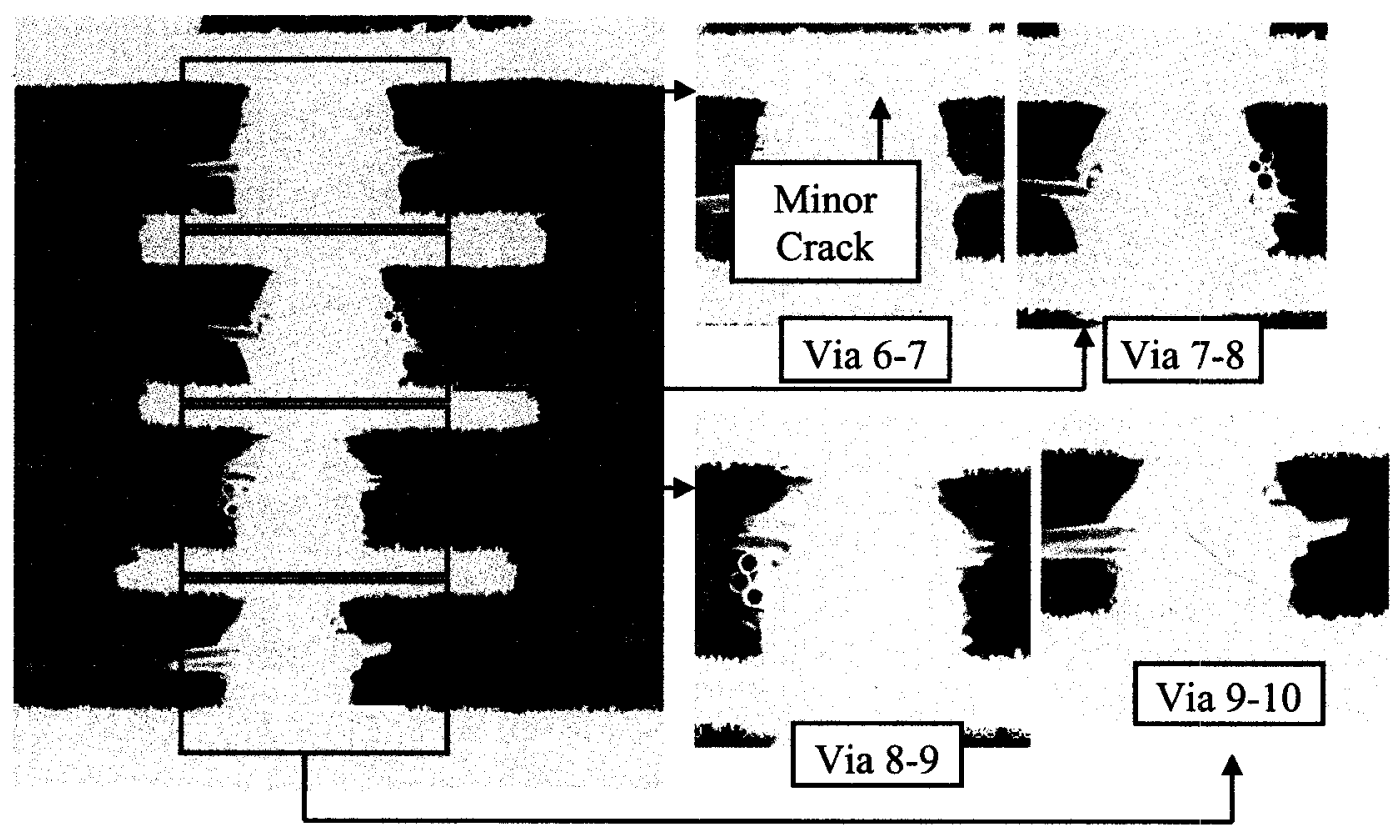

Figure 32(d). The cross-section micrograph of the lower layers of Daisy 06/PKG 43. 
Table 16. The cross-section report of Daisy Chain 04 .

\begin{tabular}{|c|c|c|c|c|c|c|c|c|}
\hline \multicolumn{2}{|c|}{ Pkg 06 and Pkg 10} & \multicolumn{7}{|c|}{ At the outer periphery } \\
\hline Ball No & V1-2 & V2-3 & V3-4 & V4-5 & V6-7 & V7-8 & V8-9 & V9-10 \\
\hline AT39 & $\begin{array}{l}\text { No in- } \\
\text { line via }\end{array}$ & No & No & $\begin{array}{l}\text { Crack } \\
\text { on L5 }\end{array}$ & $\begin{array}{l}\text { Crack } \\
\text { on L6 }\end{array}$ & No & No & No \\
\hline AR39 & $\begin{array}{l}\text { No in- } \\
\text { line via }\end{array}$ & No & No & $\begin{array}{l}\text { Crack } \\
\text { on L5 }\end{array}$ & $\begin{array}{l}\text { Crack } \\
\text { on L6 }\end{array}$ & No & No & No \\
\hline AP39 & $\begin{array}{l}\text { No in- } \\
\text { line via }\end{array}$ & No & No & $\begin{array}{l}\text { Crack } \\
\text { on L5 }\end{array}$ & $\begin{array}{l}\text { Crack } \\
\text { on L6 }\end{array}$ & No & No & No \\
\hline AN39 & $\begin{array}{l}\text { No in- } \\
\text { line via }\end{array}$ & No & No & $\begin{array}{l}\text { Crack } \\
\text { on L5 }\end{array}$ & $\begin{array}{l}\text { Crack } \\
\text { on L6 }\end{array}$ & No & No & No \\
\hline AM39 & $\begin{array}{l}\text { No in- } \\
\text { line via }\end{array}$ & No & No & $\begin{array}{l}\text { Crack } \\
\text { on L5 } \\
\end{array}$ & $\begin{array}{l}\text { Crack } \\
\text { on L6 }\end{array}$ & No & No & No \\
\hline \multicolumn{9}{|c|}{ Pkg 19 and Pkg 47 Under the die } \\
\hline Ball No & V1-2 & V2-3 & V3-4 & V4-5 & V6-7 & V7-8 & V8-9 & V9-10 \\
\hline AG27 & $\begin{array}{l}\text { No in- } \\
\text { line via }\end{array}$ & No & No & No & No & No & No & No \\
\hline AF27 & $\begin{array}{l}\text { No in- } \\
\text { line via }\end{array}$ & No & No & No & No & No & No & No \\
\hline $\mathrm{AE} 27$ & $\begin{array}{l}\text { No in- } \\
\text { line via }\end{array}$ & No & No & No & No & No & No & No \\
\hline $\mathrm{AD} 27$ & $\begin{array}{l}\text { No in- } \\
\text { line via }\end{array}$ & No & No & No & No & No & No & No \\
\hline
\end{tabular}

Daisy Chain 04, Pkg 06/10, Ball no. AT39, Via 2-5
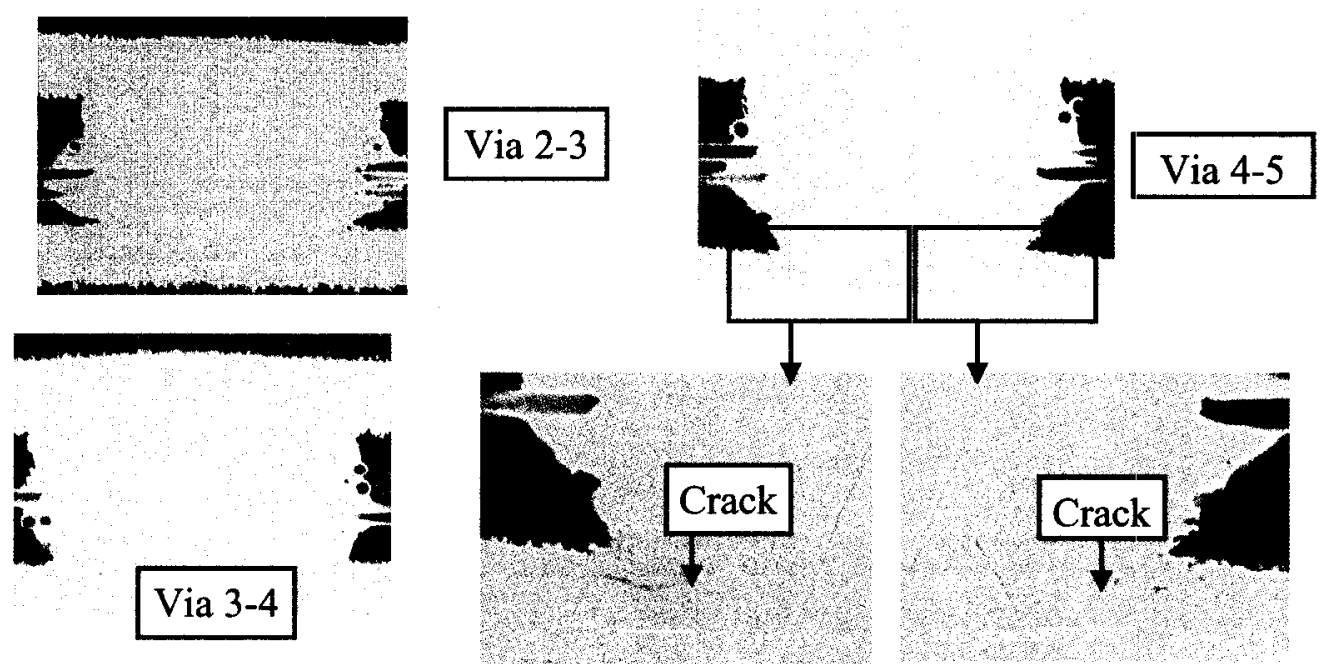

Figure 33(a). The cross-section micrograph of the upper layers of Daisy 04/PKG 06\&10. 
Daisy Chain 04, Pkg 06/10, Ball no. AT39, Via 6-10

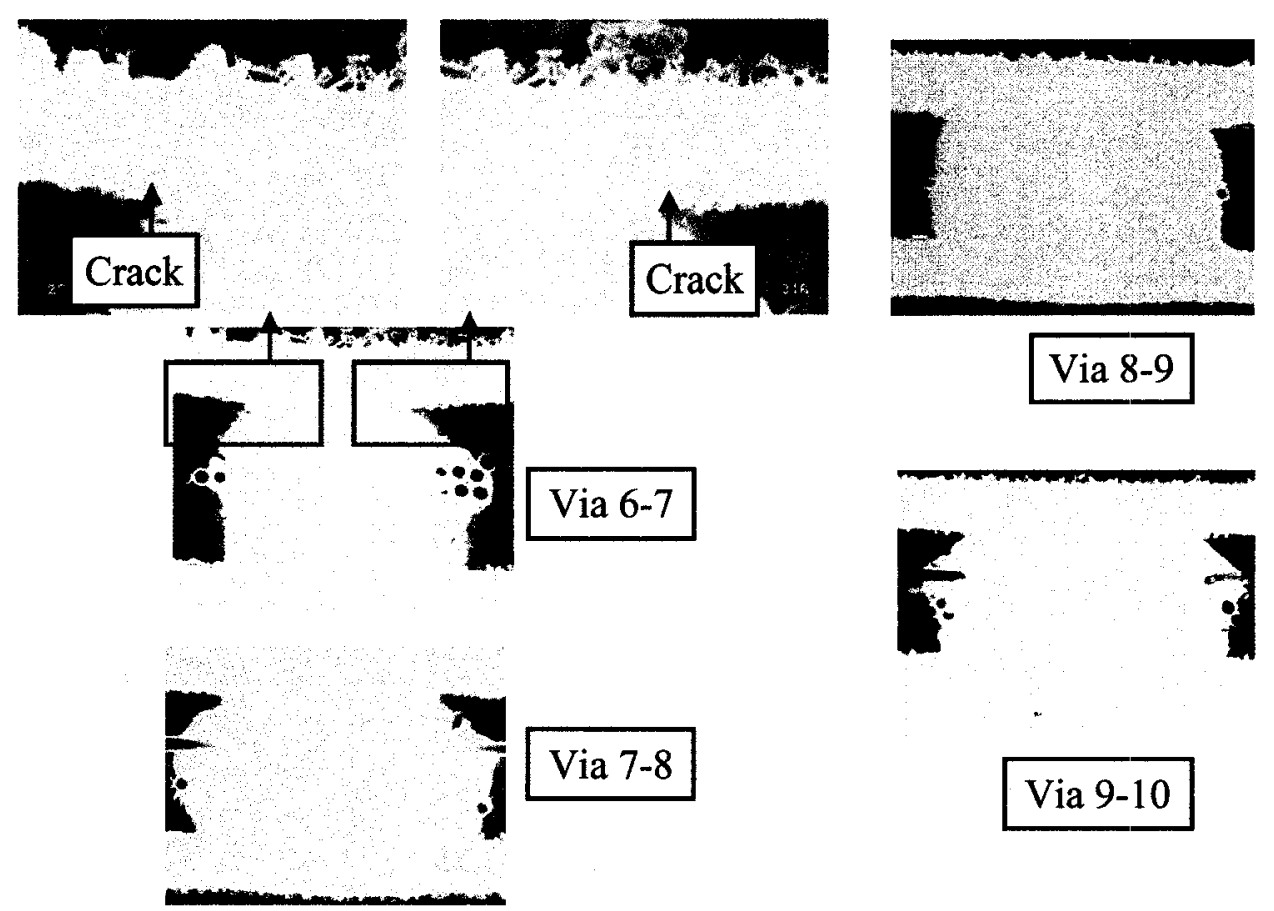

Figure 33(b). The cross-section micrograph of the lower layers of Daisy 04/PKG 06\&10.

Daisy Chain 04, Pkg 19/47, Ball no. AF27, Via 2-5

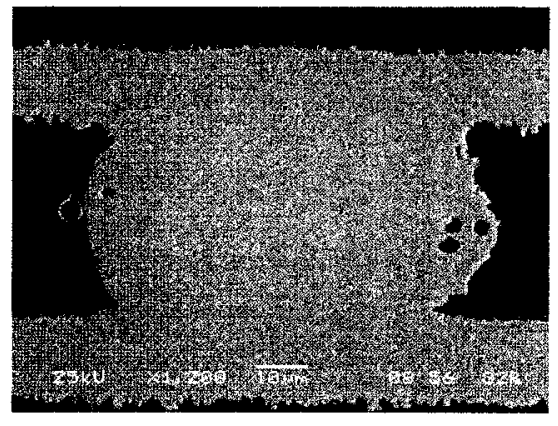

Via 3-4

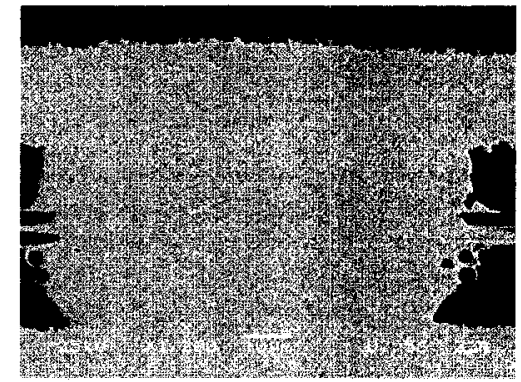

Via 2-3

Via 4-5

Figure 33(c). The cross-section micrograph of the upper layers of Daisy 04/PKG $19 \& 47$. 
Daisy Chain 04, Pkg 19/47, Ball no. AF27, Via 6-10
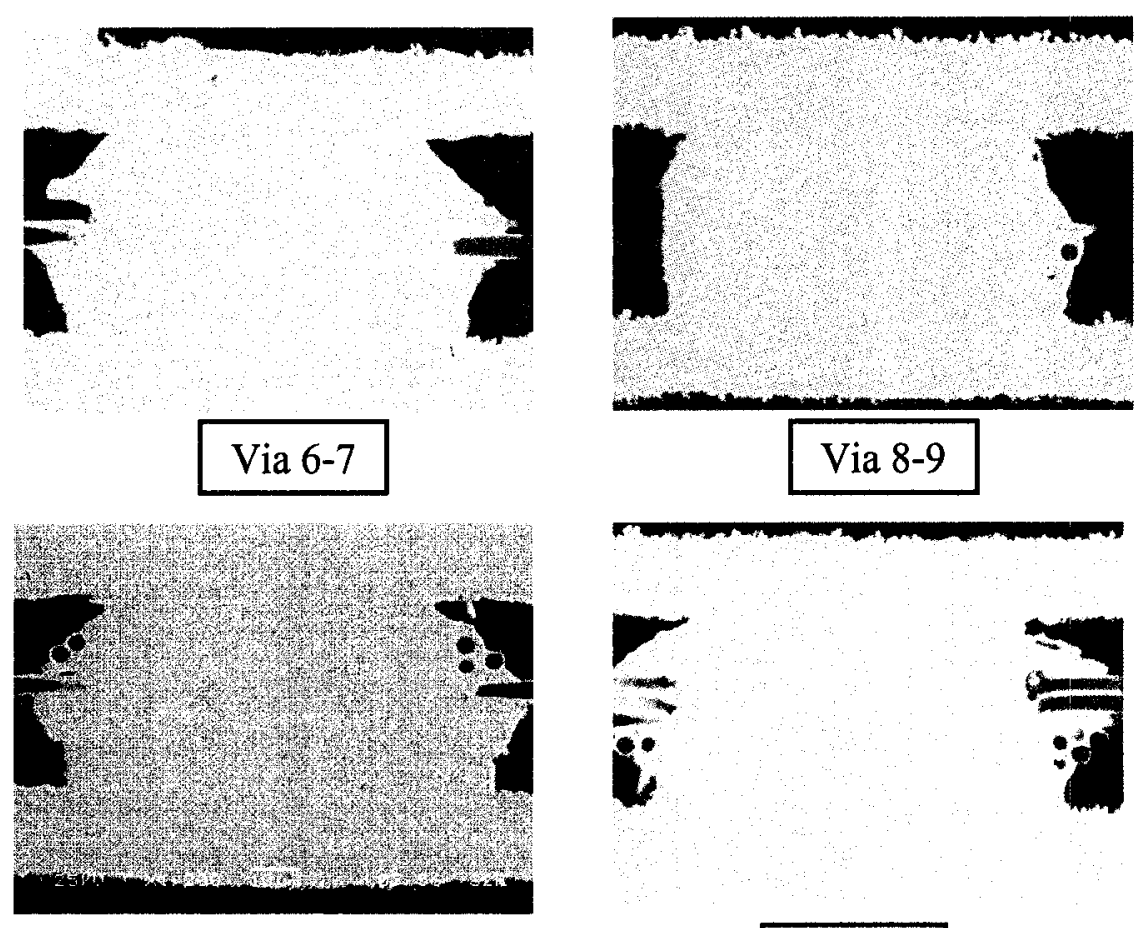

Via 7-8

Via $9-10$

Figure 33(d). The cross-section micrograph of the lower layers of Daisy 04/PKG $19 \& 47$.

Daisy Chain 14 was selected because it had the highest net resistance decrease.

The cross-section report and the micrographs of one of the via sets are shown in Table 17 and Figures 34(a) to 34(d), respectively. None of the ten cross-sectioned via sets had failed. 
Table 17. The cross-section report of Daisy Chain 14.

\begin{tabular}{|l|c|c|c|c|c|c|c|c|}
\hline Pkg 23 and Pkg 26 & At the outer periphery \\
\hline Ball No & V1-2 & V2-3 & V3-4 & V4-5 & V6-7 & V7-8 & V8-9 & V9-10 \\
\hline AJ37 & No & No & No & No & No & No & No & No \\
\hline AH37 & No & No & No & No & No & No & No & No \\
\hline AG37 & No & No & No & No & No & No & No & No \\
\hline AF37 & No & No & No & No & No & No & No & No \\
\hline AE37 & No & No & No & No & No & No & No & No \\
\hline Pkg 42 and Pkg 44 & Under the die & \multicolumn{7}{|c|}{} \\
\hline Ball No & V1-2 & V2-3 & V3-4 & V4-5 & V6-7 & V7-8 & V8-9 & V9-10 \\
\hline AA33 & No & No & No & No & No & No & No & No \\
\hline AA32 & No & No & No & No & No & No & No & No \\
\hline AA31 & No & No & No & No & No & No & No & No \\
\hline AA30 & No & No & No & No & No & No & No & No \\
\hline AA29 & No & No & No & No & No & No & No & No \\
\hline
\end{tabular}

Daisy Chain 14, Pkg 26, Ball no. AJ37, Via 1-3/4-5

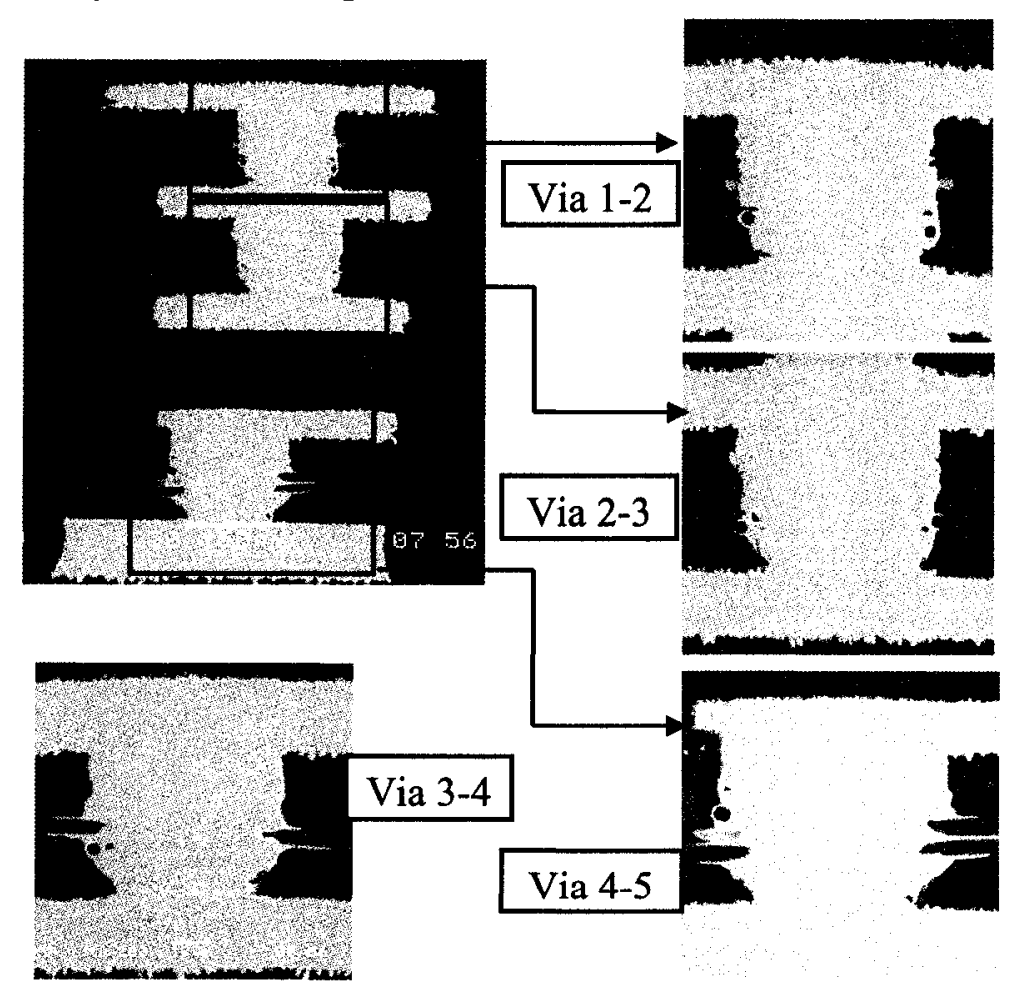

Daisy Chain 14, Pkg 23, Ball no. AJ37, Via 3-4

Figure 34(a). The cross-section micrograph of the upper layers of Daisy 14/PKG $23 \& 26$. 
Daisy Chain 14, Pkg 26, Ball no. AJ37, Via 6-7/8-10

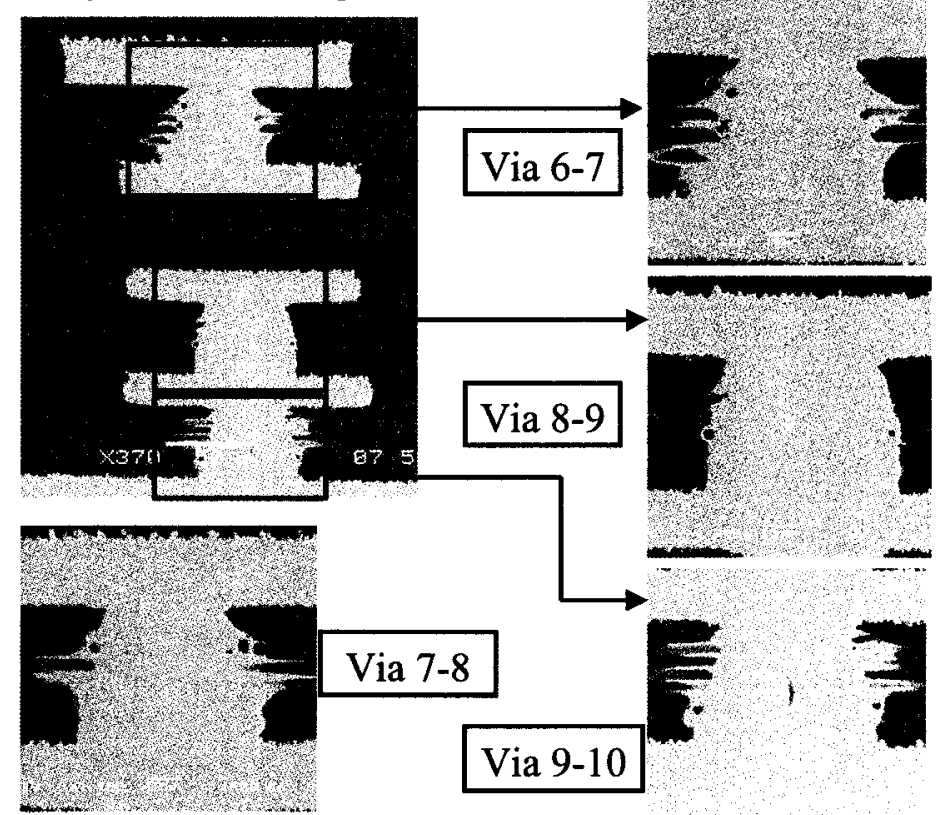

Daisy Chain 14, Pkg 23, Ball no. AJ37, Via 7-8

Figure 34(b). The cross-section micrograph of the lower layers of Daisy 14/PKG $23 \& 26$.

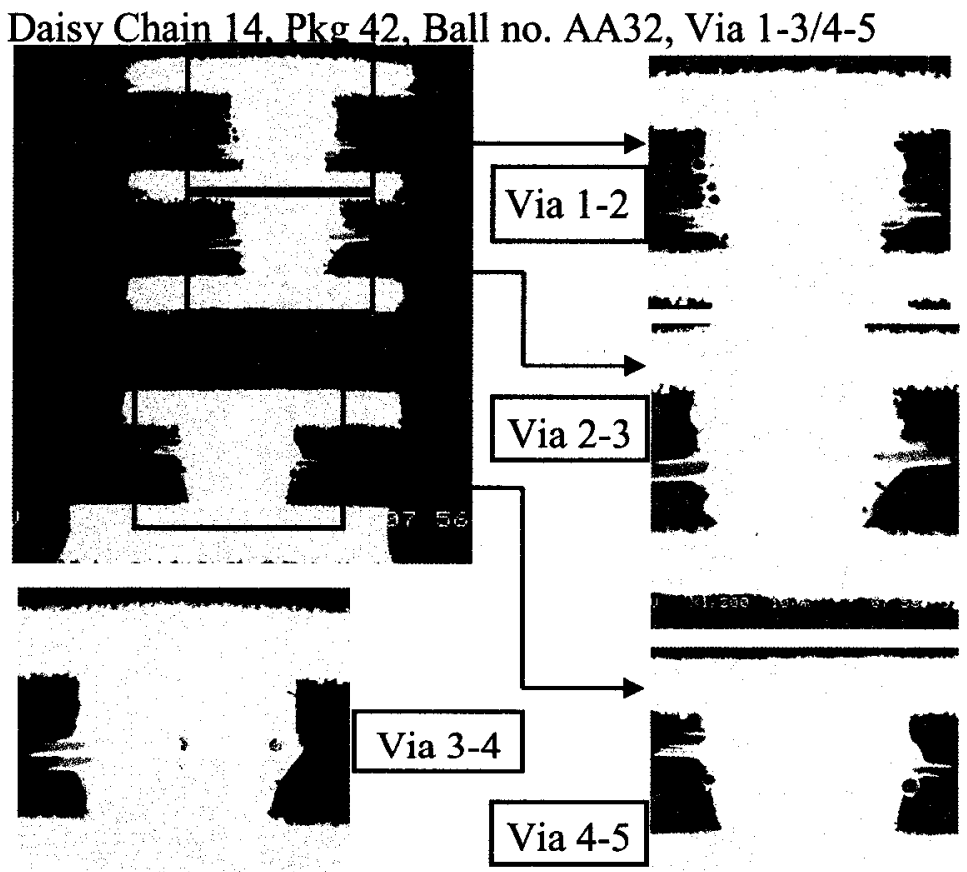

Daisy Chain 14, Pkg 44, Ball no. AA32, Via 3-4

Figure 34(c). The cross-section micrograph of the upper layers of Daisy 14/PKG 42\&44. 
Daisy Chain 14, Pkg 42, Ball no. AA32, Via 6-7/8-10

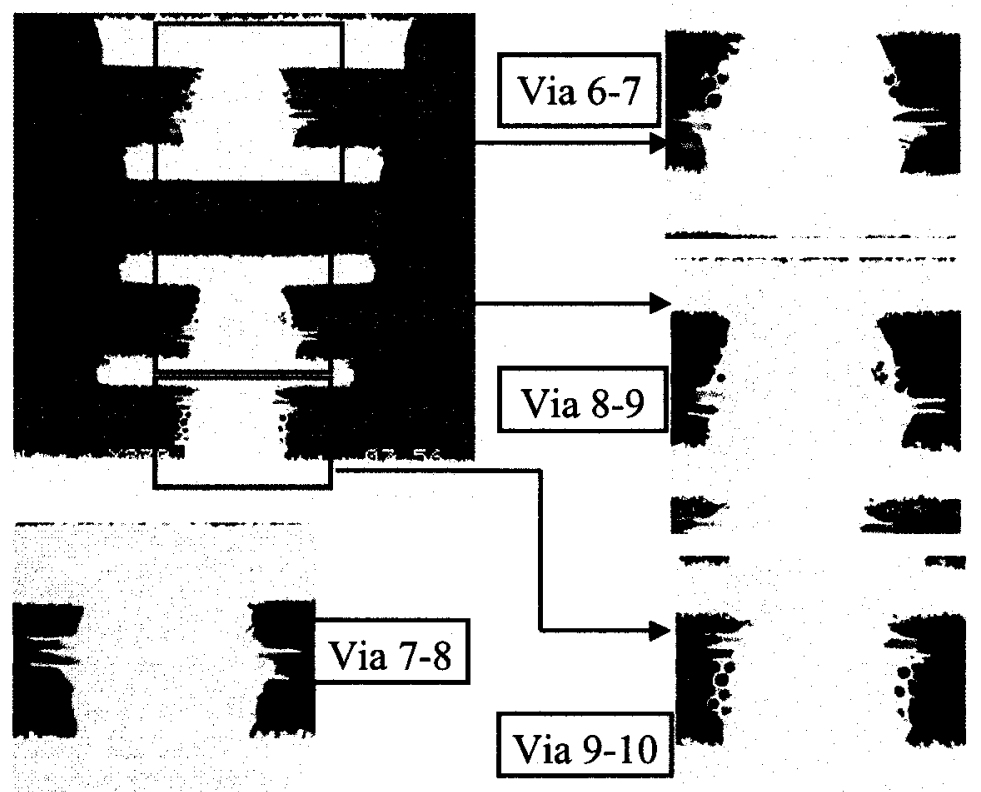

Daisy Chain 14, Pkg 44, Ball no. AA32, Via 7-8

Figure 34(d). The cross-section micrograph of the lower layers of Daisy $14 / \mathrm{PKG} 42 \& 44$.

Daisy Chain 08 was selected because it showed a big jump in net resistance increase after TCC 300 cycles. This cross-section report and the micrographs of one of the via sets are shown in Table 18 and Figures 35(a) to 35(d), respectively. None of the nine cross-sectioned via sets failed. Only two minor cracks, which were not considered failures, were seen on the stack-on core vias on V4-5. 
Table 18. The cross-section report of Daisy Chain 08.

\begin{tabular}{|l|c|c|c|c|c|c|c|c|}
\hline \multicolumn{2}{|l|}{ Pkg 04 and Pkg 35 } & At the outer periphery \\
\hline Ball No & V1-2 & V2-3 & V3-4 & V4-5 & V6-7 & V7-8 & V8-9 & V9-10 \\
\hline AU4 & No & No & No & No & No & No & No & No \\
\hline AU5 & No & No & No & No & No & No & No & No \\
\hline AU6 & No & No & No & No & No & No & No & No \\
\hline AU7 & No & No & No & No & No & No & No & No \\
\hline AU8 & No & No & No & No & No & No & No & No \\
\hline Pkg 32 and Pkg 48 & Under the die & & & & & \\
\hline Ball No & V1-2 & V2-3 & V3-4 & V4-5 & V6-7 & V7-8 & V8-9 & V9-10 \\
\hline AJ12 & $\begin{array}{c}\text { No in- } \\
\text { line via }\end{array}$ & No & No & $\begin{array}{c}\text { Minor crack } \\
\text { on L5 }\end{array}$ & No & No & No & No \\
\hline AJ13 & $\begin{array}{c}\text { No in- } \\
\text { line via }\end{array}$ & No & No & No & No & No & No & No \\
\hline AJ14 & $\begin{array}{c}\text { No in- } \\
\text { line via }\end{array}$ & No & No & No & No & No & No & No \\
\hline AJ15 & $\begin{array}{c}\text { No in- } \\
\text { line via }\end{array}$ & No & No & $\begin{array}{c}\text { Minor crack } \\
\text { on L5 }\end{array}$ & No & No & No & No \\
\hline
\end{tabular}

Daisy Chain 08, Pkg 04/35, Ball no. AU5, Via 1-5
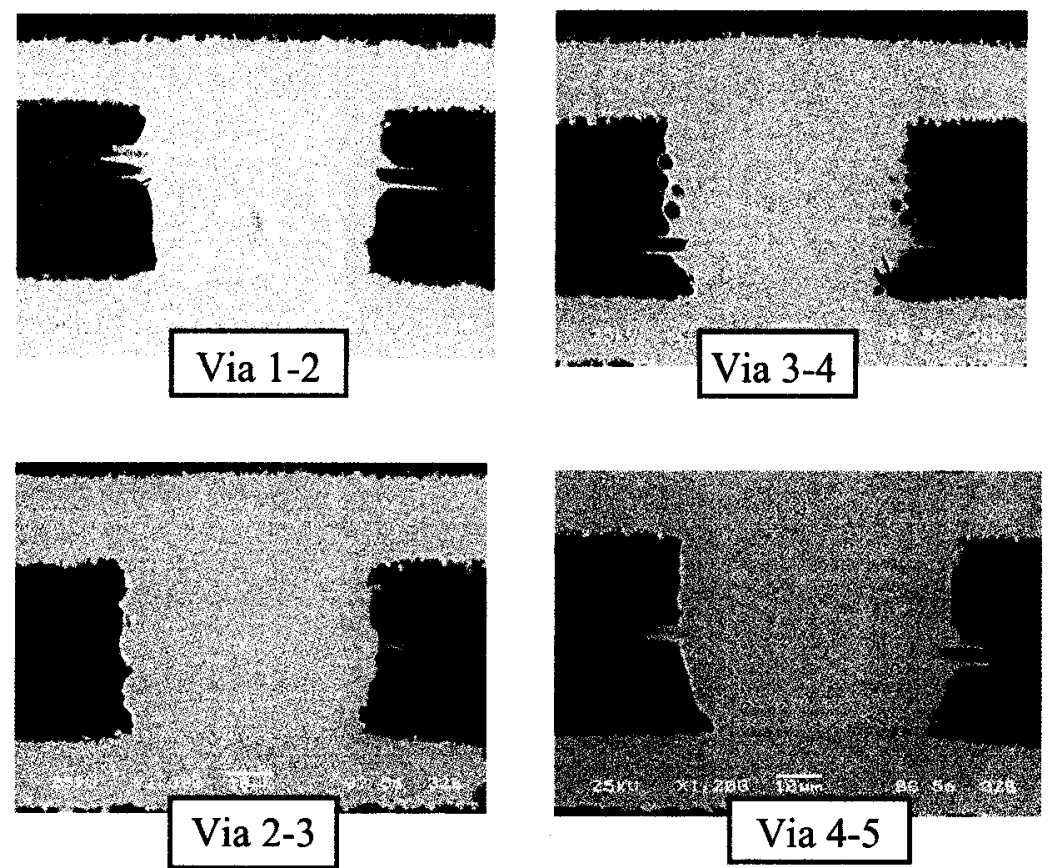

Figure 35(a). The cross-section micrograph of the upper layers of Daisy 08/PKG 04\&35. 
Daisy Chain 08, Pkg 04/35, Ball no. AU5, Via 6-10
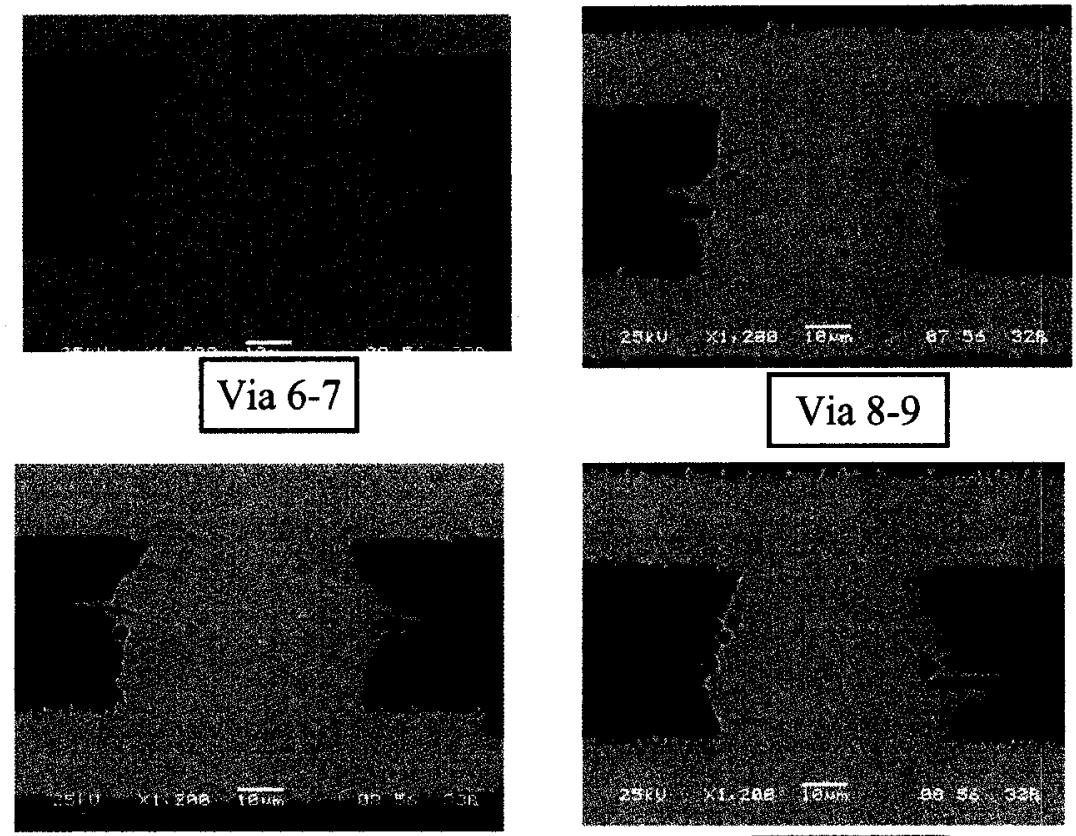

Via 7-8

Via $9-10$

Figure 35(b). The cross-section micrograph of the lower layers of Daisy 08/PKG 04\&35.

Daisy Chain 08, Pkg 32/48, Ball no. AJ14, Via 2-5

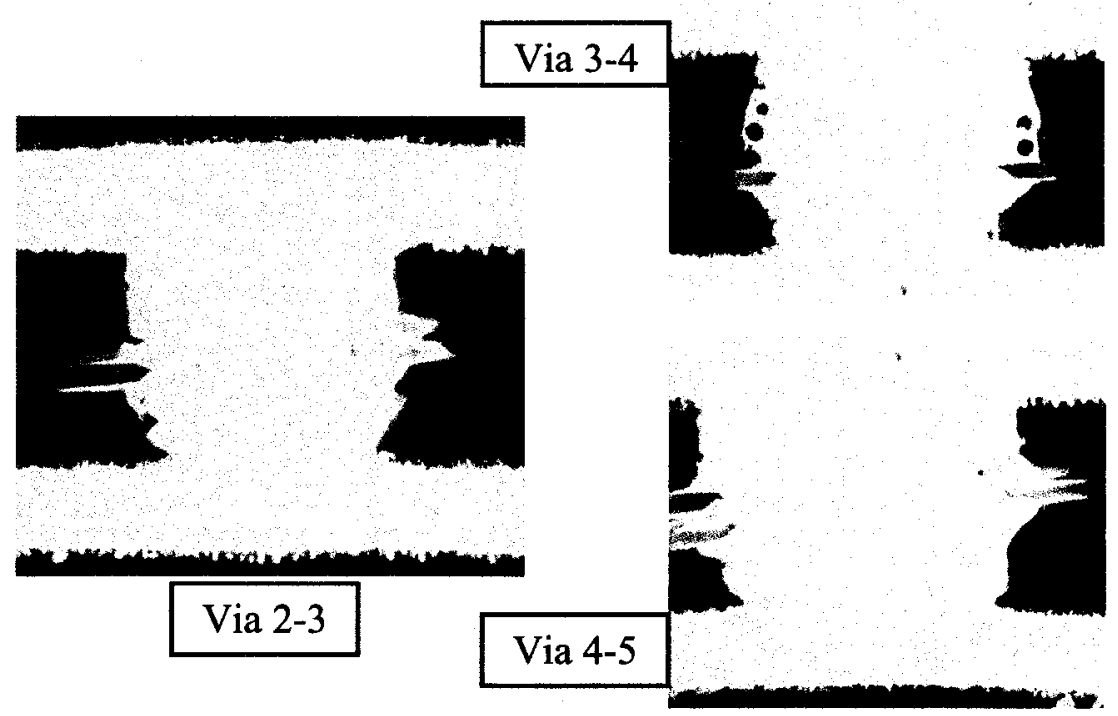

Figure 35(c). The cross-section micrograph of the upper layers of Daisy 08/PKG 32\&48. 
Daisy Chain 08, Pkg 32/48, Ball no. AJ14, Via 6-10
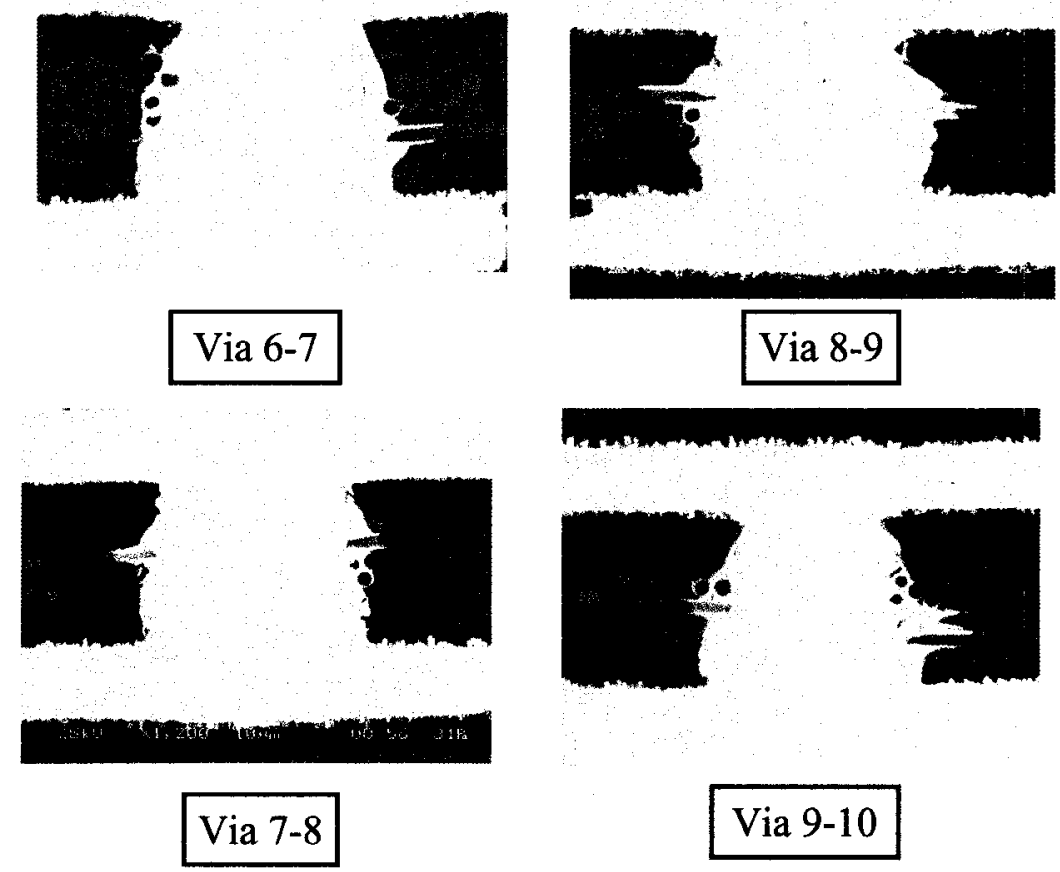

Via 9-10

Figure 35(d). The cross-section micrograph of the lower layers of Daisy 08/PKG 32\&48.

Daisy Chain 02 was selected because it was one of the two "extreme" stacked via structures. The cross-section report and the micrographs of one of the via sets of Daisy Chain 02 are shown in Table 19 and Figures 36(a) to 36(d), respectively. All of the seven cross-sectioned via sets at the outer periphery failed on the stack vias on V7-8. None of the five cross-sectioned via sets under the die failed. 
Table 19. The cross-section report of Daisy Chain 02 in Phase I.

\begin{tabular}{|c|c|c|c|c|c|c|c|c|}
\hline Pkg 02 & At the & $\overline{\text { uter } p}$ & riphery & & & & & \\
\hline Ball No & V1-2 & V2-3 & V3-4 & V4-5 & V6-7 & V7-8 & V8-9 & V9-10 \\
\hline C36 & No & No & No & $\begin{array}{l}\text { Minor crack } \\
\text { on L5 }\end{array}$ & No & Crack on L7 & No & No \\
\hline C35 & No & No & No & No & No & Crack on L7 & No & No \\
\hline C34 & No & No & No & No & No & Crack on L7 & No & No \\
\hline $\mathrm{C} 33$ & No & No & No & No & No & Crack on L7 & No & No \\
\hline $\mathrm{C} 32$ & No & No & No & No & No & Crack on L7 & No & No \\
\hline C31 & No & No & No & No & No & Crack on L7 & No & No \\
\hline $\mathrm{C} 30$ & No & No & No & No & No & Crack on L7 & No & No \\
\hline Pkg 39 & Under & he die & & & & & & \\
\hline Ball No & V1-2 & V2-3 & V3-4 & V4-5 & V6-7 & V7-8 & V8-9 & V9-10 \\
\hline K30 & No & No & No & No & No & No & No & No \\
\hline K29 & No & No & No & No & No & No & No & No \\
\hline K28 & No & No & No & No & No & No & No & No \\
\hline K27 & No & No & No & No & No & No & No & No \\
\hline K26 & No & No & No & No & No & No & No & No \\
\hline
\end{tabular}

Daisy Chain 02, Pkg 02, Ball no. C36, Via 1-5

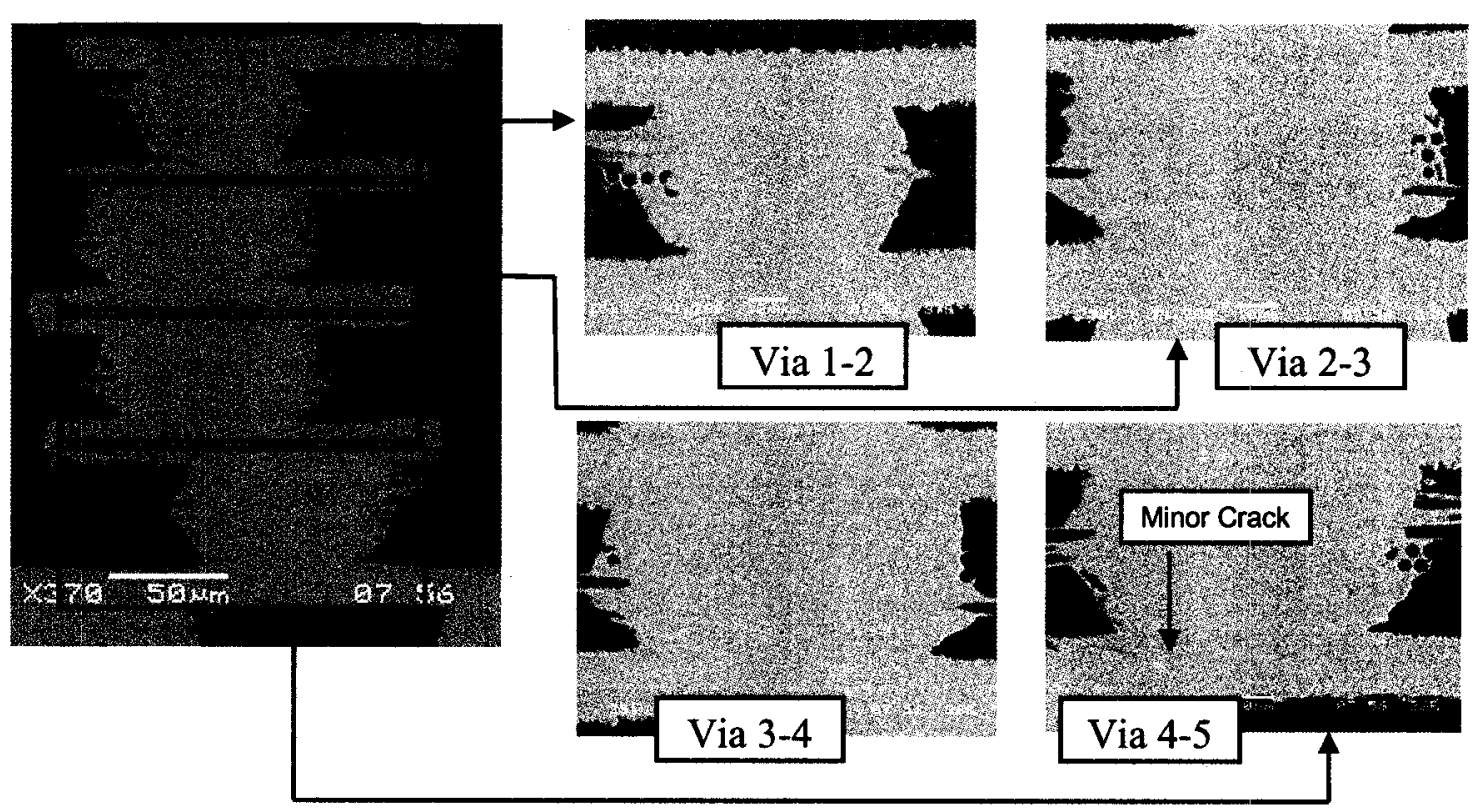

Figure 36(a). The cross-section micrograph of the upper layers of Daisy 02/PKG 02. 
Daisy Chain 02, Pkg 02, Ball no. C36, Via 6-10

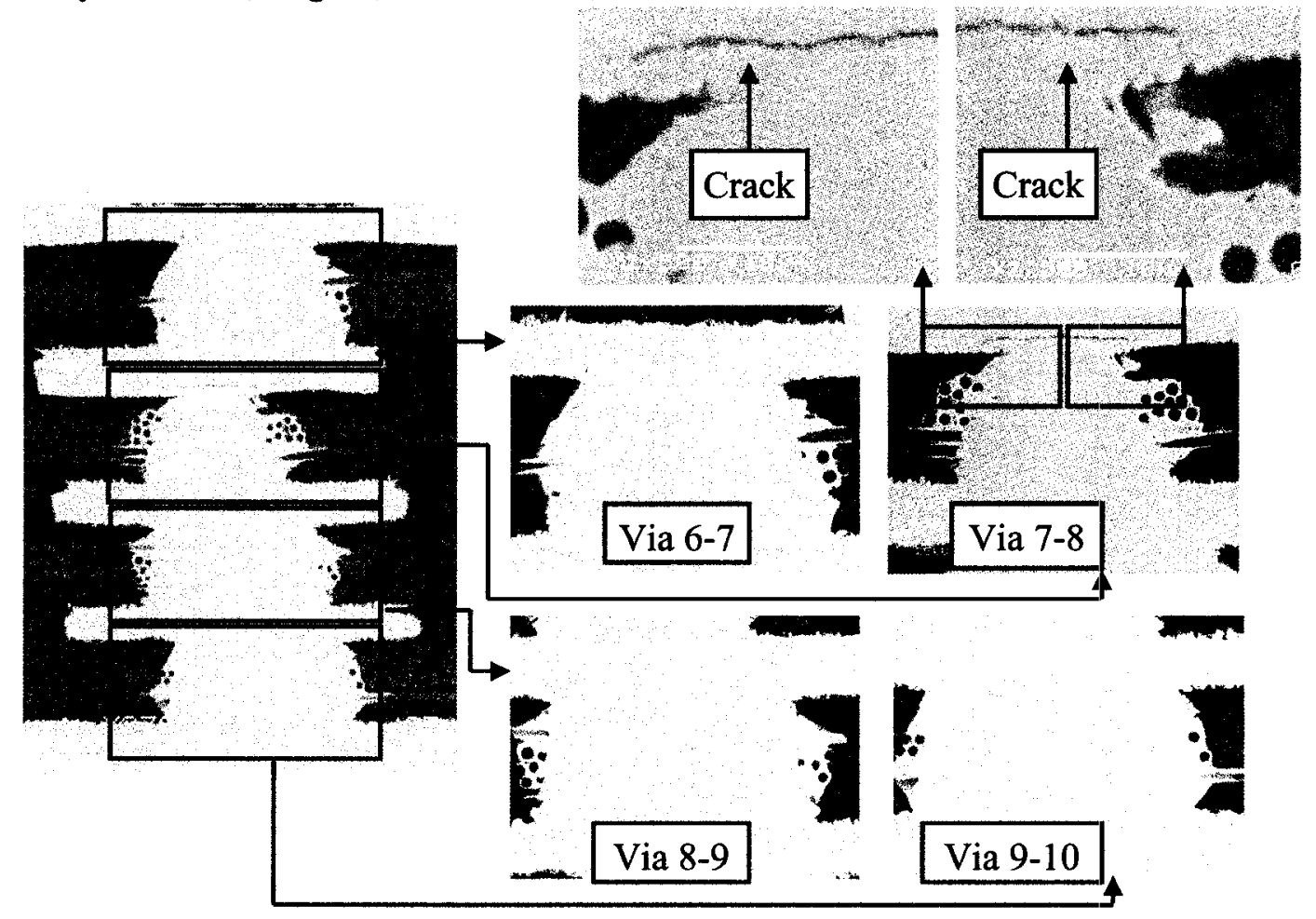

Figure 36(b). The cross-section micrograph of the lower layers of Daisy 02/PKG 02.

Daisy Chain 02, Pkg 39, Ball no. K30, Via 1-5

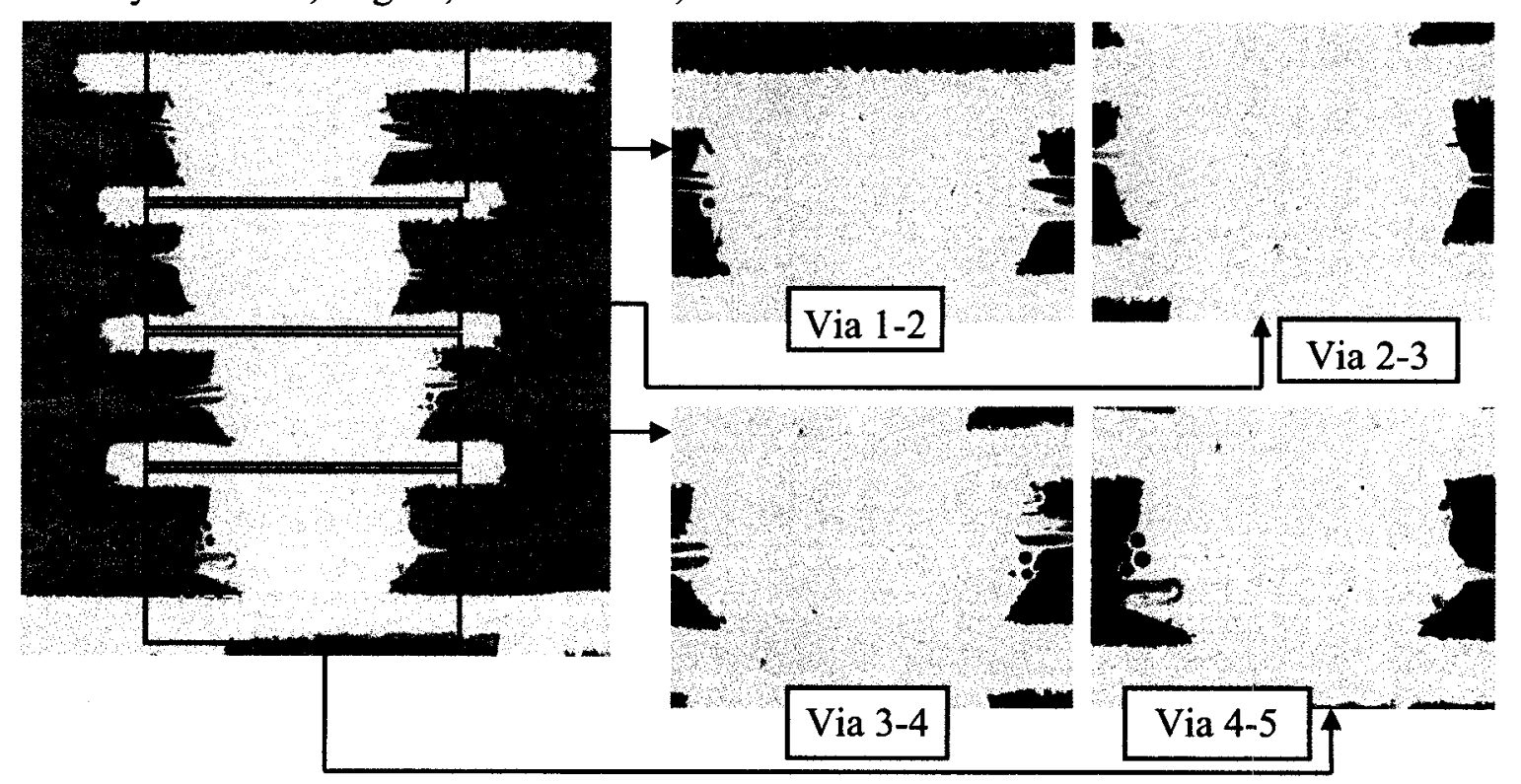

Figure 36(c). The cross-section micrograph of the upper layers of Daisy 02/PKG 39. 
Daisy Chain 02, Pkg 39, Ball no. K30, Via 6-10

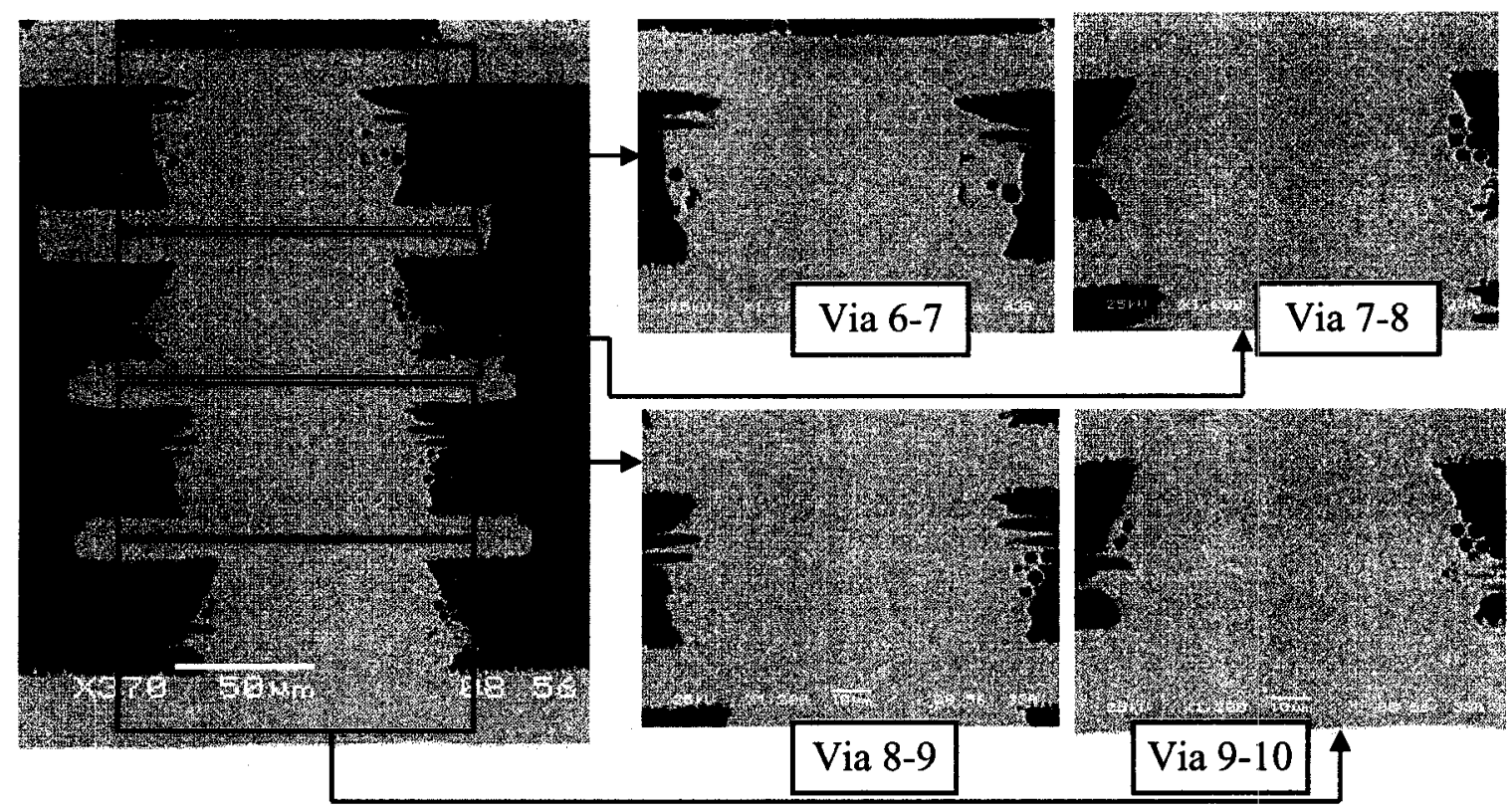

Figure 36(d). The cross-section micrograph of the lower layers of Daisy 02/PKG 39.

\subsubsection{Packages with Low Net Resistance Change (Phase II)}

The purpose of Phase II was to investigate whether the failed via locations found in Phase I, which used the packages with higher net resistance change, were also found in the packages with lower net resistance changes. The packages that had very low net resistance change in Daisy Chain 06 and Daisy Chain 02 were selected for further study, as shown in Table 20. Their cross-section locations are shown in Figures 31(b) and 31(c). The cross-section report and the micrographs of one of the via sets of Daisy Chain 06 are shown in Table 21 and Figures 37(a) through 37(d), respectively. None of the twelve cross-sectioned via sets had failed. The cross-section report and the micrographs of one 
of the via sets of Daisy Chain 02 are shown in Table 22 and Figures 38(a) through 38(d), respectively. None of the ten cross-sectioned via sets failed.

Table 20. The daisy chains and the packages selected for cross-section in Phase II.

\begin{tabular}{|l|c|c|}
\hline Daisy chains & \multicolumn{2}{|c|}{ Packages } \\
\hline Daisy06 & PKG33 & PKG41 \\
\hline Daisy02 & PKG22 & PKG46 \\
\hline
\end{tabular}

Table 21. The cross-section report of Daisy Chain 06 in Phase II.

\begin{tabular}{|c|c|c|c|c|c|c|c|c|}
\hline Pkg 41 & At the ou & er periphe & & & & & & \\
\hline Ball No & V1-2 & V2-3 & V3-4 & V4-5 & V6-7 & V7-8 & V8-9 & V9-10 \\
\hline Y4 & No & No & No & No & No & No & $\begin{array}{l}\text { No in- } \\
\text { line via }\end{array}$ & $\begin{array}{l}\text { No in- } \\
\text { line via }\end{array}$ \\
\hline AA4 & No & No & No & No & No & No & $\begin{array}{l}\text { No in- } \\
\text { line via }\end{array}$ & $\begin{array}{l}\text { No in- } \\
\text { line via }\end{array}$ \\
\hline AB4 & No & No & No & No & No & No & $\begin{array}{l}\text { No in- } \\
\text { line via }\end{array}$ & $\begin{array}{l}\text { No in- } \\
\text { line via }\end{array}$ \\
\hline AC4 & No & No & No & No & No & No & $\begin{array}{l}\text { No in- } \\
\text { line via }\end{array}$ & $\begin{array}{l}\text { No in- } \\
\text { line via }\end{array}$ \\
\hline AD4 & No & No & No & No & No & No & $\begin{array}{l}\text { No in- } \\
\text { line via }\end{array}$ & $\begin{array}{l}\text { No in- } \\
\text { line via }\end{array}$ \\
\hline AE4 & No & No & No & No & No & No & $\begin{array}{l}\text { No in- } \\
\text { line via }\end{array}$ & $\begin{array}{l}\text { No in- } \\
\text { line via }\end{array}$ \\
\hline Pkg 33 & Under th & die & & & & & & \\
\hline Ball No & $\mathrm{V} 1-2$ & V2-3 & V3-4 & V4-5 & V6-7 & V7-8 & V8-9 & V9-10 \\
\hline AB10 & $\begin{array}{l}\text { No in- } \\
\text { line via }\end{array}$ & $\begin{array}{l}\text { No in- } \\
\text { line via }\end{array}$ & No & No & No & No & No & No \\
\hline $\mathrm{AB} 11$ & $\begin{array}{l}\text { No in- } \\
\text { line via }\end{array}$ & No & No & No & No & No & No & No \\
\hline $\mathrm{AB} 12$ & $\begin{array}{l}\text { No in- } \\
\text { line via }\end{array}$ & No & No & No & No & No & No & No \\
\hline $\mathrm{AB} 13$ & $\begin{array}{l}\text { No in- } \\
\text { line via }\end{array}$ & No & No & No & No & No & No & No \\
\hline AB14 & No & No & No & No & No & No & No & No \\
\hline AB15 & No & No & No & No & No & No & No & $\mathrm{No}$ \\
\hline
\end{tabular}


Daisy Chain 06, Pkg 41, Ball no. AC4, Via 1-5

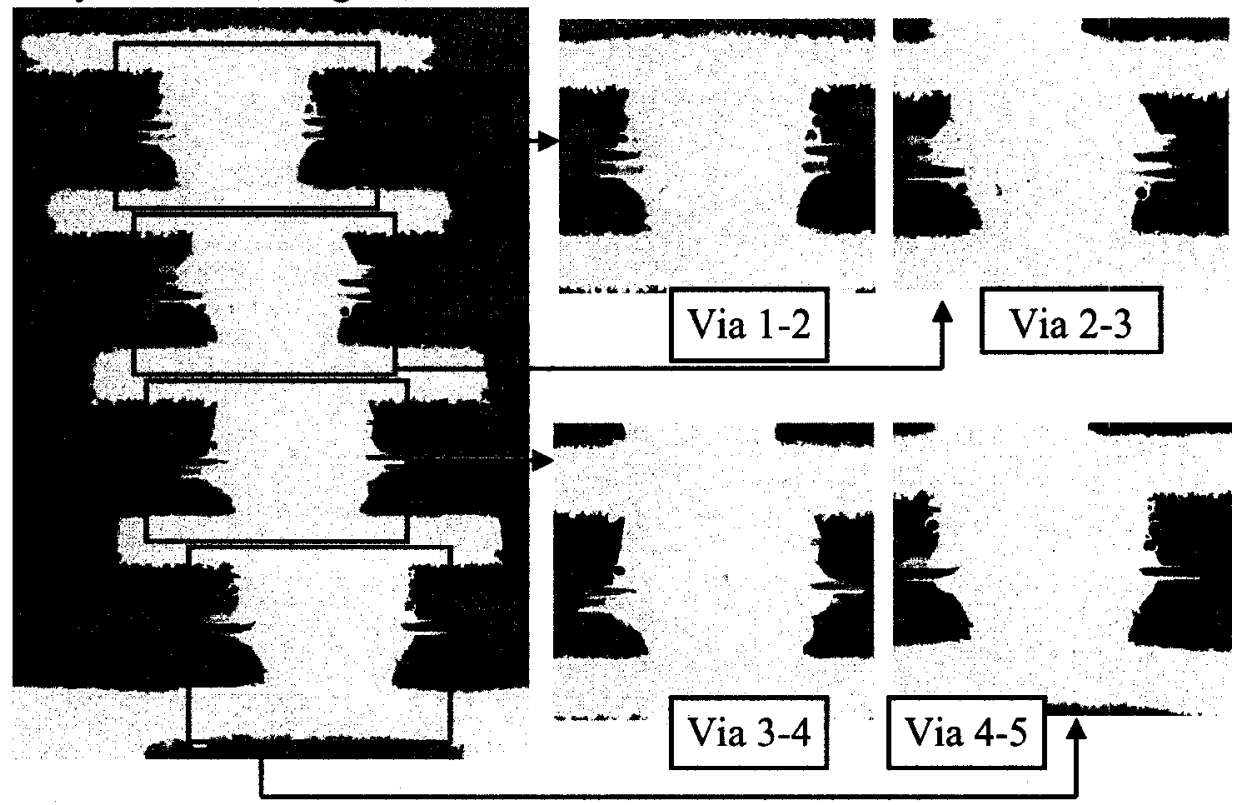

Figure 37(a). The cross-section micrograph of the upper layers of Daisy 06/PKG 41.

Daisy Chain 06, Pkg 41, Ball no. AC4, Via 6-10

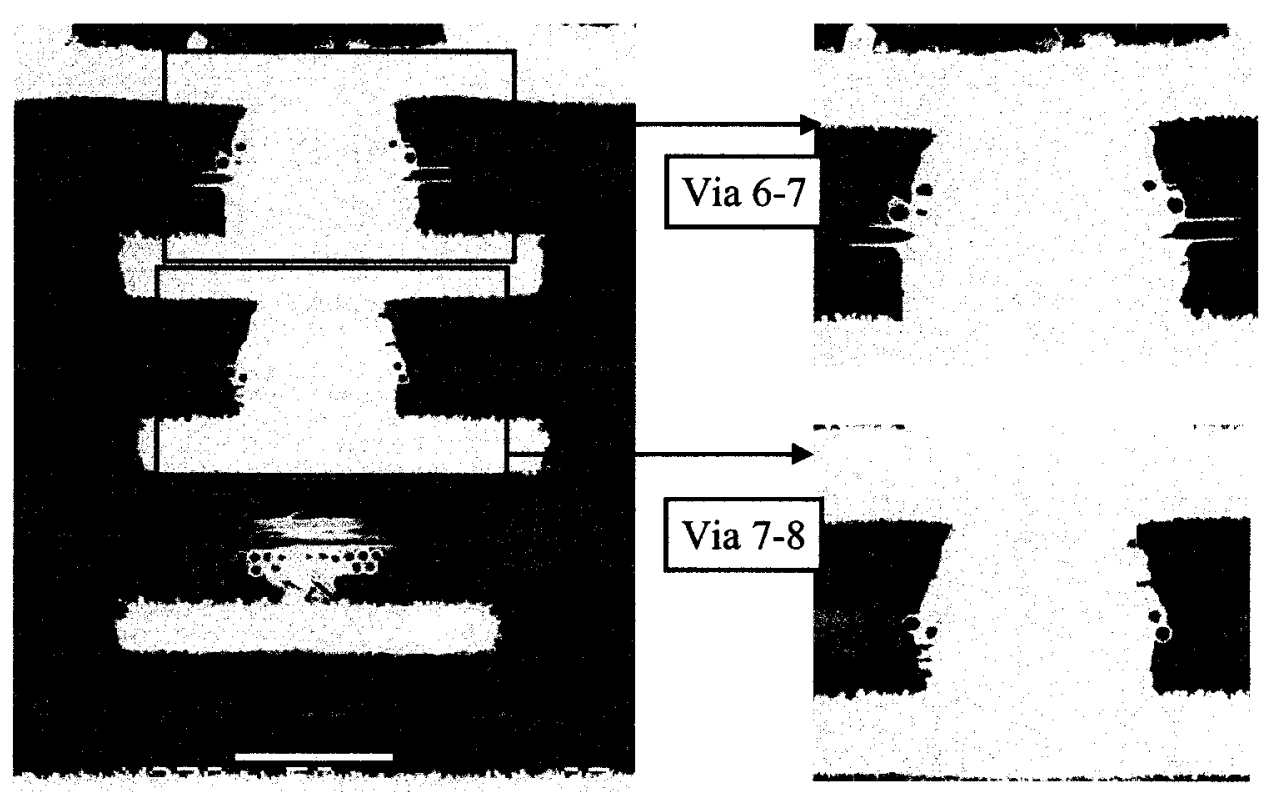

Figure 37(b). The cross-section micrograph of the lower layers of Daisy 06/PKG 41. 
Daisy Chain 06, Pkg 33, Ball no. AB15, Via 1-5

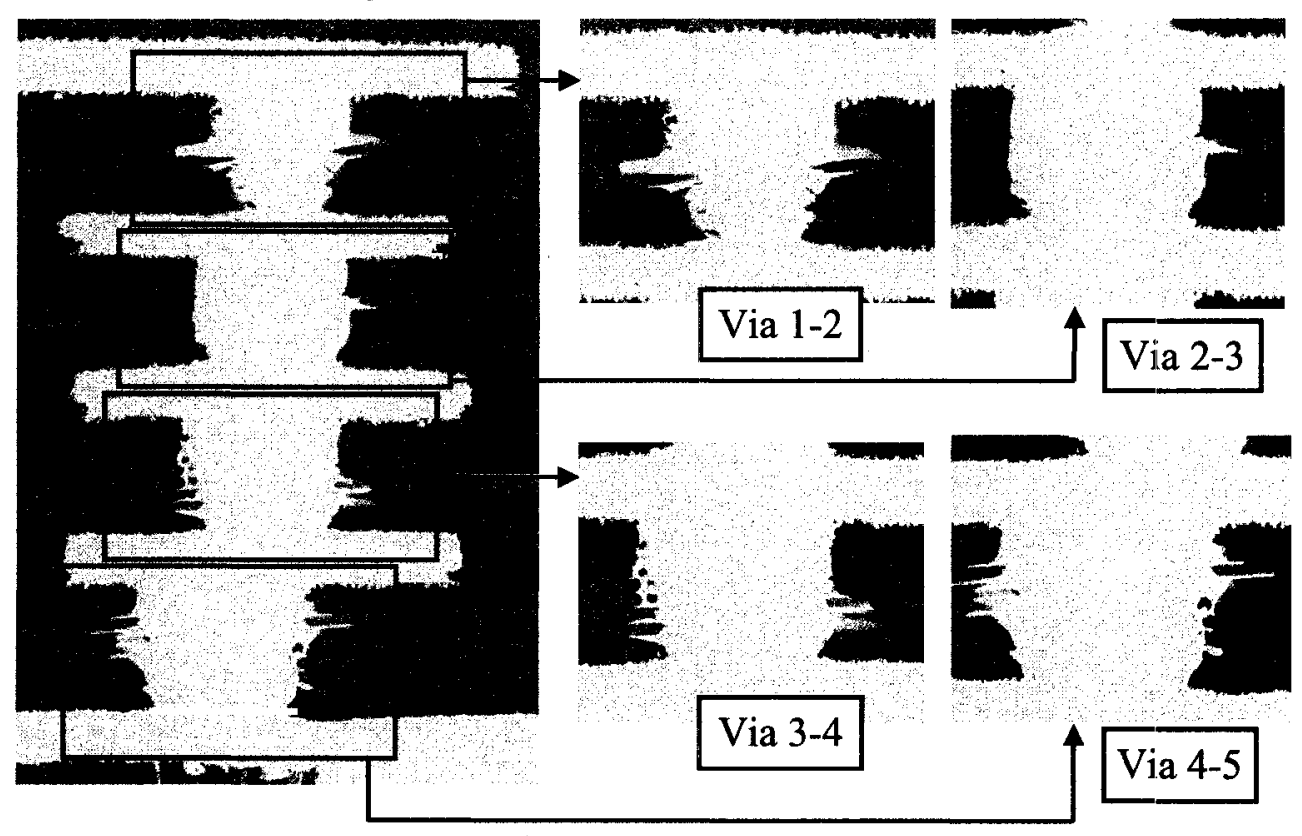

Figure 37(c). The cross-section micrograph of the upper layers of Daisy 06/PKG 33.

Daisy Chain 06, Pkg 33, Ball no. AB15, Via 6-10

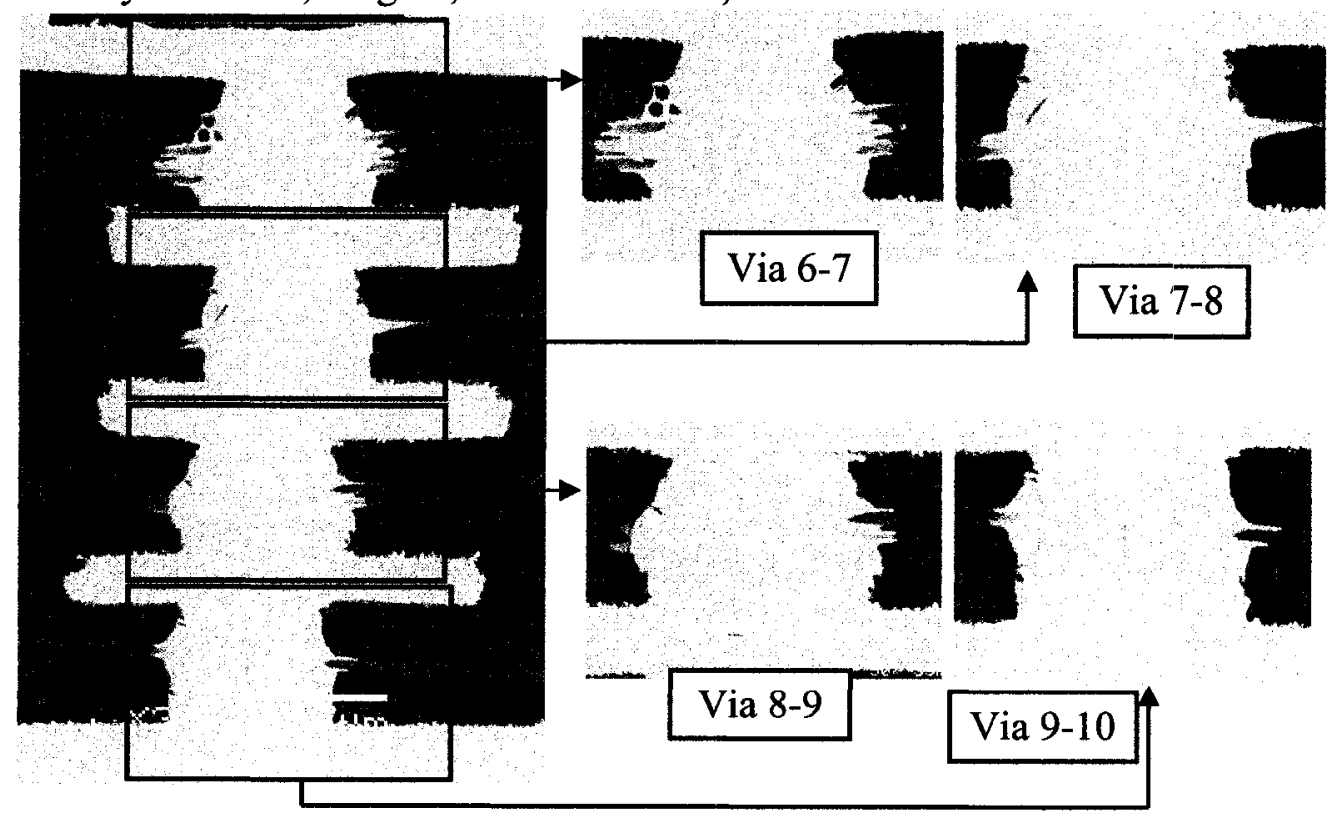

Figure 37(d). The cross-section micrograph of the lower layers of Daisy 06/PKG 33. 
Table 22. The cross-section report of Daisy Chain 02 in Phase II.

\begin{tabular}{|l|c|c|c|c|c|c|c|c|}
\hline Pkg 22 & At the outer periphery \\
\hline Ball No & V1-2 & V2-3 & V3-4 & V4-5 & V6-7 & V7-8 & V8-9 & V9-10 \\
\hline C36 & No & No & No & No & No & No & No & No \\
\hline C35 & No & No & No & No & No & No & No & No \\
\hline C34 & No & No & No & No & No & No & No & No \\
\hline C33 & No & No & No & No & No & No & No & No \\
\hline C32 & No & No & No & No & No & No & No & No \\
\hline Pkg 46 Under the die \\
\hline Ball No & V1-2 & V2-3 & V3-4 & V4-5 & V6-7 & V7-8 & V8-9 & V9-10 \\
\hline K30 & No & No & No & No & No & No & No & No \\
\hline K29 & No & No & No & No & No & No & No & No \\
\hline K28 & No & No & No & No & No & No & No & No \\
\hline K27 & No & No & No & No & No & No & No & No \\
\hline K26 & No & No & No & No & No & No & No & No \\
\hline
\end{tabular}

Daisy Chain 02, Pkg 22, Ball no. C32, Via 1-5

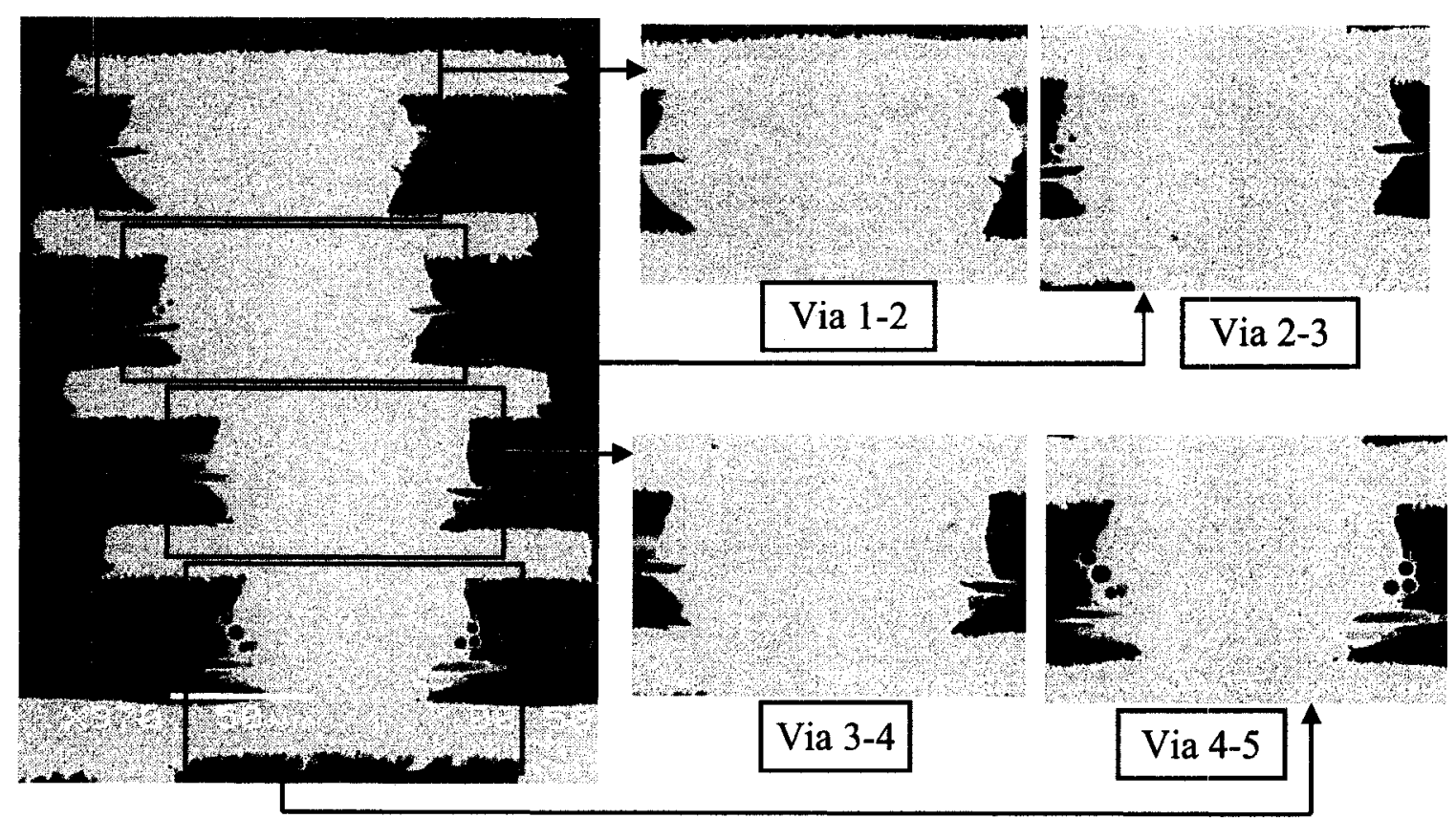

Figure 38(a). The cross-section micrograph of the upper layers of Daisy 02/PKG 22. 


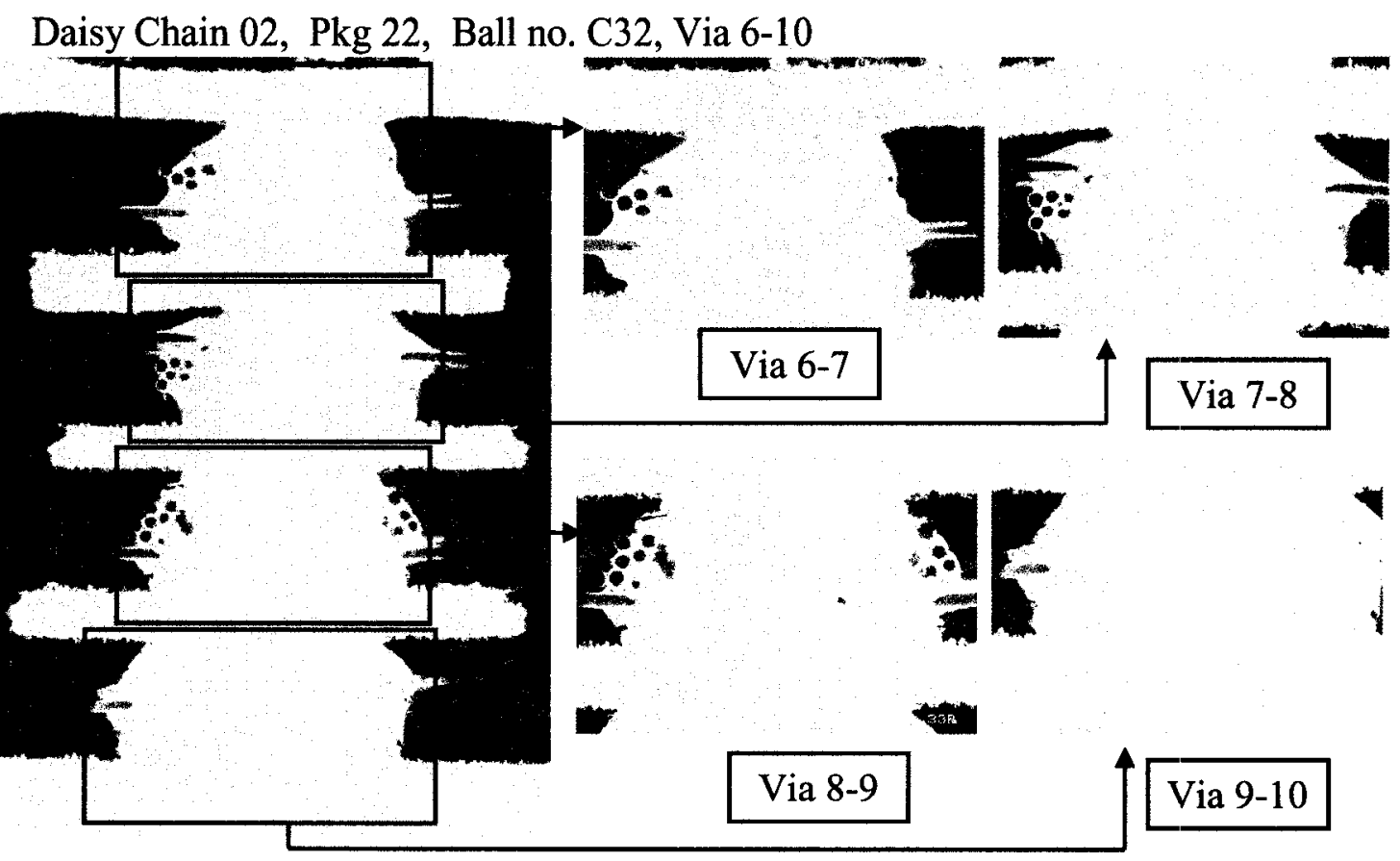

Figure 38(b). The cross-section micrograph of the lower layers of Daisy 02/PKG 22.

Daisy Chain 02, Pkg 46, Ball no. K26, Via 1-5

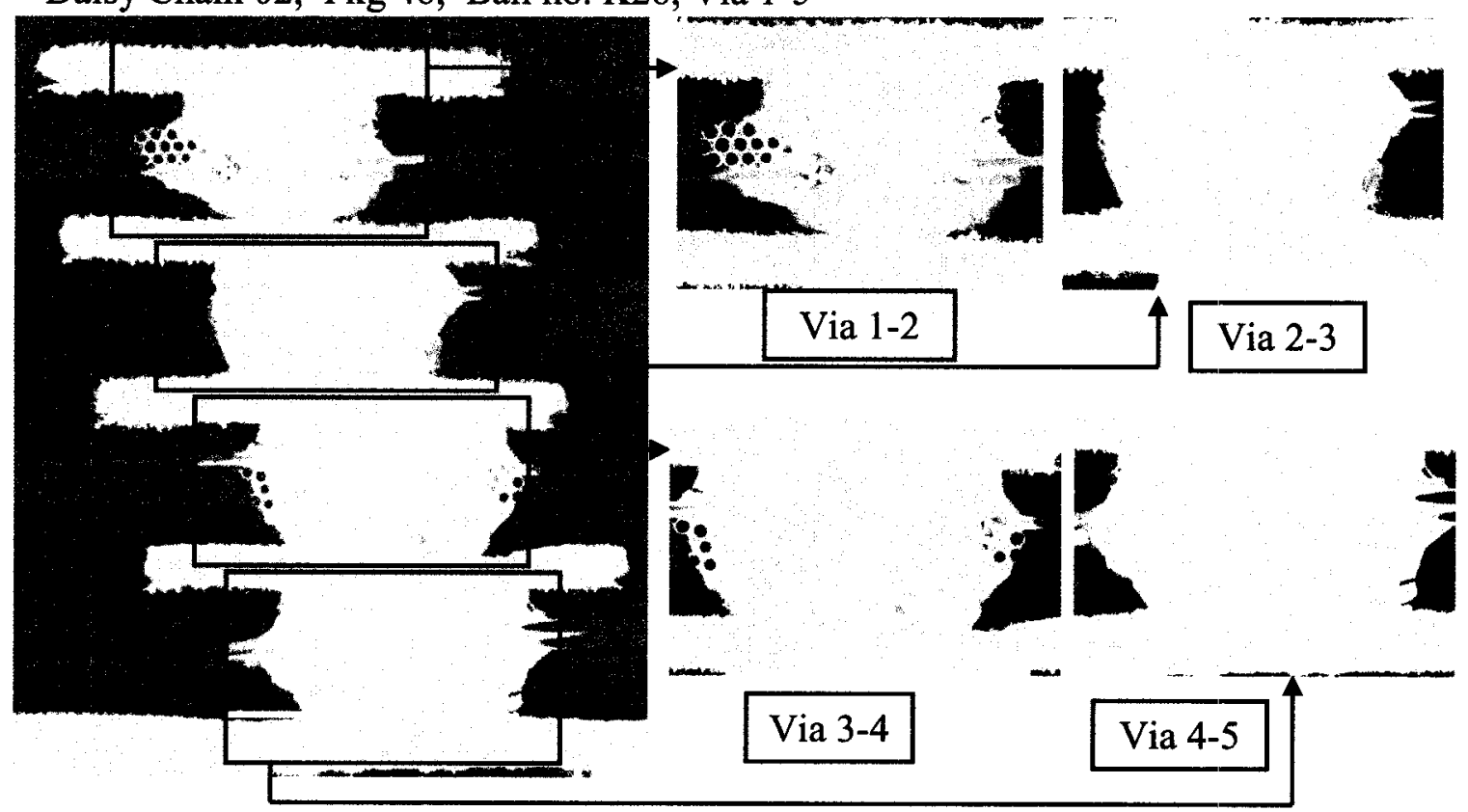

Figure 38(c). The cross-section micrograph of the upper layers of Daisy 02/PKG 46. 


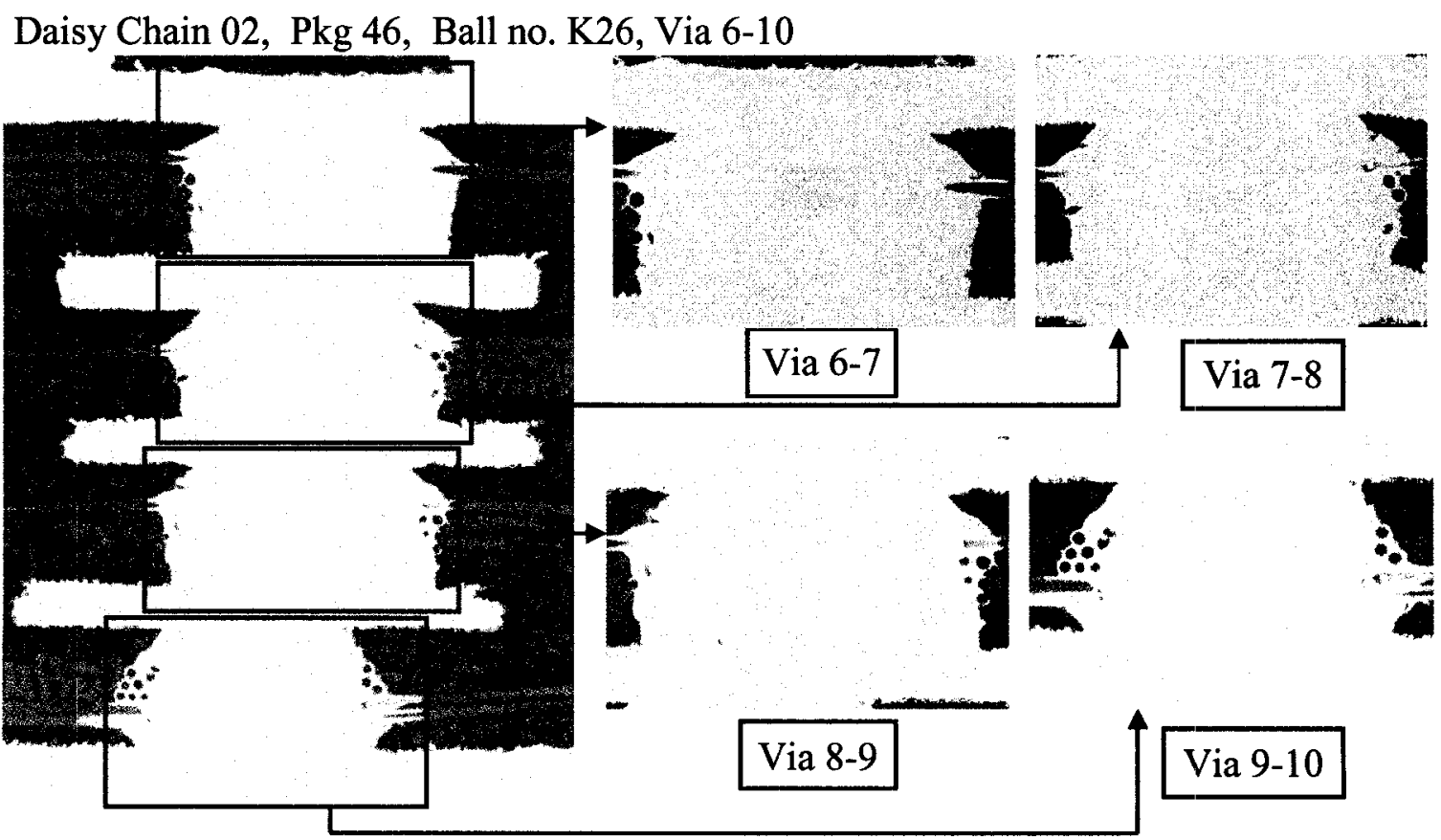

Figure 38(d). The cross-section micrograph of the lower layers of Daisy 02/PKG 46.

\subsubsection{Summary of Failure Analysis}

As can be seen from the micrographs of the vias that had cracks or minor cracks, every crack was located at the interface between the "bottom" of the laser via and the "top" surface of the copper layer below the laser via. All of the cracks were found in the laser vias that were stacked on the core via or on each other, and were located at various layers and geographical locations. 


\section{CHAPTER SIX \\ DISCUSSIONS OF RESULTS}

The overall DOE analysis and the detailed DOE analyses at some selected temperature cycles, the failure analysis, and the correlations from these analyses are discussed in this chapter.

\subsection{DOE Analyses}

From a general overview of Table 12(a) through Table 12(c), it does not look like the effects are consistent from one measured cycle to the other. However, if the first three measured cycles (the TCB $238^{\text {th }}, 457^{\text {th }}$, and $643^{\text {rd }}$ cycles) and the last two measured cycles (the TCC $400^{\text {th }}$ and $500^{\text {th }}$ cycles) are removed, Factor 1, Factor 2, and Interaction 34 are the top three contributing effects among the 15 main factors and interactions.

Their rankings in each measured cycle, from the TCB $875^{\text {th }}$ cycle to the TCC $300^{\text {th }}$ cycle, are listed in Table 23. Detailed DOE analyses at the TCB $1200^{\text {th }}$, TCB $2012^{\text {th }}$, and TCC $300^{\text {th }}$ measured cycles are presented in Sections 6.1.1 through 6.1.3.

Table 23. The top three contributing factors and interaction and their rankings.

\begin{tabular}{|l|c|c|c|c|c|c|c|c|c|}
\hline & TCB & TCB & TCB & TCB & TCB & TCB & TCC & TCC & TCC \\
& 875 & 1016 & 1200 & 1492 & 1724 & 2012 & 100 & 200 & 300 \\
\hline Factor 1 & 4 & 7 & 1 & 2 & 1 & 2 & 2 & 2 & 1 \\
\hline Factor 3 & 2 & 3 & 2 & 4 & 2 & 1 & 3 & 6 & 2 \\
\hline Interaction 34 & 1 & 4 & 3 & 1 & 3 & 3 & 1 & 1 & 5 \\
\hline
\end{tabular}

The removal of the first three and the last two measured cycles is rational for the DOE analyses in this investigation. From the experiences of temperature cycling tests, 
most of the failures do not appear before the TCB 500 cycles. So, it is thought that in the first two measured cycles the laser vias were not sufficiently strained to produce measurable and permanent cracks. The resistance change data may come partly from experimental error and partly from very minor inter-layer separation. As for the third measured cycle, it is thought that the experimental error might be too high. As can be seen in Figure 28, all of the statistical data of the TCB $643^{\text {rd }}$ cycle were generally lower than those in the other measured cycles. Even the average net resistance of all the daisy chains is $0.12 \%$ lower than that of the $0^{\text {th }}$ cycle. Therefore, the first three measured cycles were excluded in the DOE analyses. On the other hand, some daisy chains did not follow the pattern of resistance change at and after the TCC $400^{\text {th }}$ cycles. For example, daisy Chain \# 04, 06, and 08 had a sudden rise in resistance while Daisy Chains 09 and 14 have sudden drops in resistance at both the TCC $400^{\text {th }}$ and TCC $500^{\text {th }}$ cycles. These findings and the possible explanations were discussed in Section 6.1.1. Therefore, it is reasonable to exclude the last two measured cycles in the DOE analyses.

As can be seen from Table 13(a) through Table 13(d), many three- and fourfactor interactions are significant in this experiment. However, in any $2^{4} \mathrm{DOE}$ it is safe to assume that all of the effects from the three- and four-interactions are negligible because the higher-order interactions would predominantly measure differences from experimental error. On the other hand, significant two-factor interactions must be examined carefully because they may be real contributors or they may magnify the effects from the major factors. 
Detailed $2^{4}$ DOE analyses for the TCB $1200^{\text {th }}, \mathrm{TCB}_{2012^{\text {th }}}, \mathrm{TCC} 300^{\text {th }}$, and TCC500 ${ }^{\text {th }}$ cycles are presented Sections $6.1 .1,6.1 .2,6.1 .3$, and 6.1.4, respectively. The overall summary for the DOE is presented in Section 6.1.5.

\subsubsection{DOE Analysis at the TCB $1200^{\text {th }}$ Cycle}

The TCB $1200^{\text {th }}$ cycle was selected for further analysis because the minimum number of cycles that Xilinx uses for TCB cycling test on FCBGAs is 1,200 . The minimum number of TCB cycles commonly acceptable in the industry is 1,000 .

\subsubsection{Single Factor Effects}

As can be seen from the ANOVA results in Table 13(a), the main effects of Factor 1 (Stack-on-core vs. Non-stack-on-core) and Factor 3 (Staggered Via vs. Stacked Via) are significant. But which aspect of Factor 1 causes more change in the resistance and which causes less? The same question also applies to Factor 3 . The effects of these two single factors were further calculated. The data are shown in Table 24 and plotted in Figure 39. It can be seen that the rate of resistance change is lower when the laser vias are not stacked on the core via $(1+)$. On the other hand, the rate of resistance change is higher when the laser vias are stacked on the core via (1-). In the same way, it is when the laser vias are not stacked on each other $(3+)$ that a lower resistance change is exhibited. But, if the vias are stacked on each other (3-), a higher resistance change can be seen. Also, it can be seen in Table 24 that the effects of these two factors are within $0.01 \%$ for higher resistance change and within $0.02 \%$ for lower resistance change; therefore it is not possible to determine which factor is more dominant. 
Table 24. Single factor effects at the TCB $1200^{\text {th }}$ cycle.

\begin{tabular}{|c|c|c|}
\hline Factor 1 & Stack-on-core (1-) & Non-stack-on-core (1+) \\
\hline & $1.41 \%$ & $0.22 \%$ \\
\hline Factor 3 & Stacked Via (3-) & Staggered Via (3+) \\
\hline & $1.40 \%$ & $0.24 \%$ \\
\hline
\end{tabular}

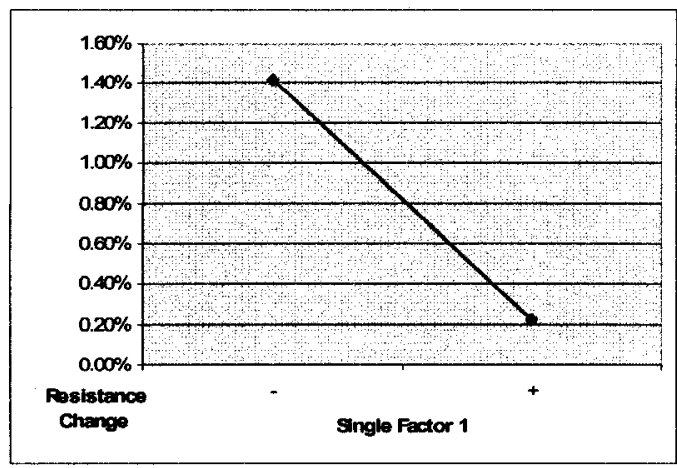

(a) Factor 1

\begin{tabular}{|l|l|}
\hline Stack-on-core (1-) & Non-stack-on-core $(1+)$ \\
\hline
\end{tabular}

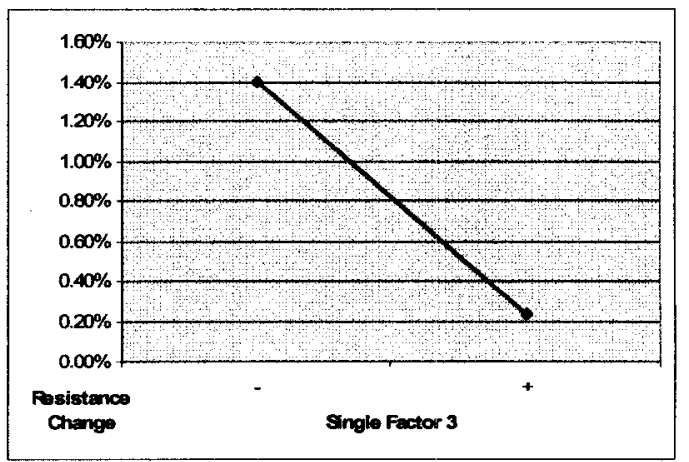

(b) Factor 3

\begin{tabular}{|l|l|}
\hline Stacked Via (3-) & Staggered Via (3+) \\
\hline
\end{tabular}

Figure 39. Single factor plots at the TCB $1200^{\text {th }}$ cycle.

\subsubsection{Two-factor Interaction Effects}

As can be seen from the ANOVA results in Table 13(a), Interactions 13, 14, 23, 24 , and 34 are the significant two-factor interactions. Among these five significant twofactor interactions, Interactions 34 and 14 have higher contributions. These interactions were further calculated and examined. The data are shown in Table 25 and plotted in Figure 40.

As can be seen from Figure 40(a), when the laser vias are not stacked on each other $(3+)$ and not stacked on the core via $(1+)$, the rate of resistance change is slightly 
lower. But, when the laser vias are stacked on each other (3-), the rate of resistance change is sharply higher if the laser vias are also stacked on the core via (1-). Interaction 13 substantiates and magnifies the results of the single factor effects discussed in Section 6.1.1.1.

Table 25. Two-factor interaction effects at the TCB $1200^{\text {th }}$ cycle.

\begin{tabular}{|c|c|c|}
\hline Interaction 13 & Stack-on-core (1-) & Non-stack-on-core (1+) \\
\hline Stacked Via (3-) & $2.38 \%$ & $0.41 \%$ \\
\hline Staggered Via (3+) & $0.44 \%$ & $0.04 \%$ \\
\hline Interaction 14 & Stack-on-core (1-) & Non-stack-on-core (1+) \\
\hline Non-fillet (4-) & $2.01 \%$ & $-0.16 \%$ \\
\hline Fillet (4+) & $0.81 \%$ & $0.61 \%$ \\
\hline Interaction 23 & Stacked Via (3-) & Staggered Via (3+) \\
\hline High Aspect Ratio (2-) & $1.01 \%$ & $0.68 \%$ \\
\hline Low Aspect Ratio (2+) & $1.78 \%$ & $-0.21 \%$ \\
\hline Interaction 24 & High Aspect Ratio (2-) & Low Aspect Ratio (2+) \\
\hline Non-fillet (4-) & $1.34 \%$ & $0.50 \%$ \\
\hline Fillet (4+) & $0.35 \%$ & $1.07 \%$ \\
\hline Interaction 34 & Stacked Via (3-) & Staggered Via (3+) \\
\hline Non-fillet (4-) & $2.05 \%$ & $-0.20 \%$ \\
\hline Fillet (4+) & $0.74 \%$ & $0.67 \%$ \\
\hline
\end{tabular}

From Figure 40(b) Interaction 14 can be analyzed as: (i) the presence of a fillet $(4+)$ has very little effect on the rate of resistance change regardless of whether the laser vias are stacked on the core via (1-) or not (1+), (ii) it is the absence of the fillet (4-) that causes the rate of resistance change to be lowered when the laser vias are not stacked on the core via (1+), and (iii) it is the absence of the fillet (4-) that results in the higher rate of resistance change when the laser vias are stacked on the core via (1-). 


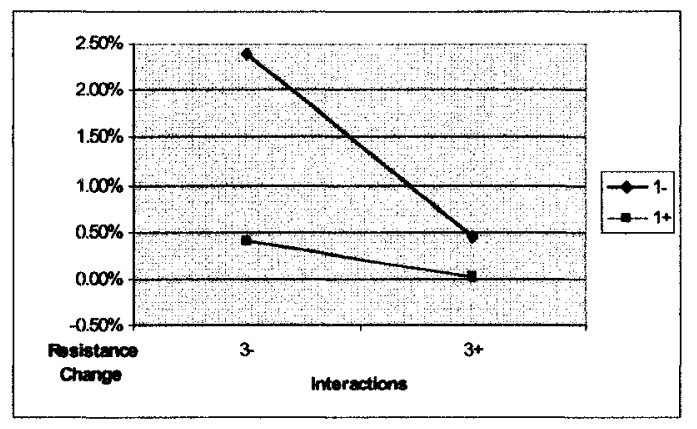

(a) Interaction 13

\begin{tabular}{|l|l|}
\hline Stack-on-core (1-) & Stacked Via (3-) \\
\hline Non-stack-on-core (1+) & Staggered Via (3+) \\
\hline
\end{tabular}

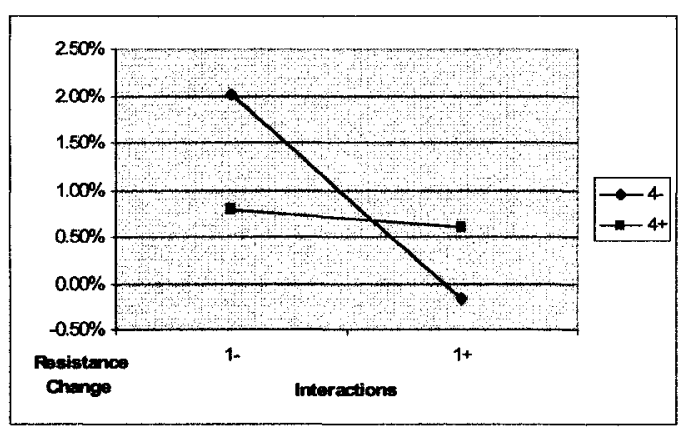

(b) Interaction 14

\begin{tabular}{|l|l|}
\hline Stack-on-core (1-) & Non-fillet (4-) \\
\hline Non-stack-on-core (1+) & Fillet (4+) \\
\hline
\end{tabular}

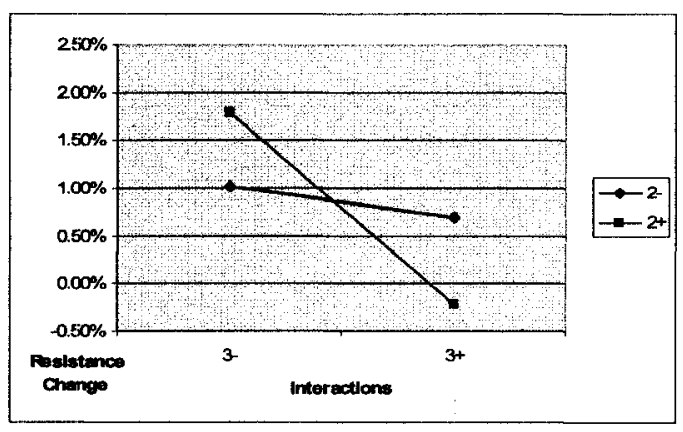

(c) Interaction 23

\begin{tabular}{|l|l|}
\hline High Aspect Ratio (2-) & Stacked Via (3-) \\
\hline
\end{tabular}

\begin{tabular}{|l|l|}
\hline Low Aspect Ratio (2+) & Staggered Via (3+) \\
\hline
\end{tabular}

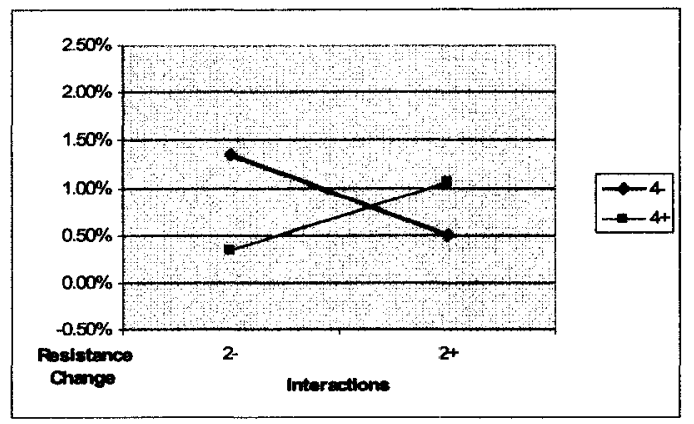

(d) Interaction 24

\begin{tabular}{|l|l|}
\hline High Aspect Ratio (2-) & Non-fillet (4-) \\
\hline
\end{tabular}

\begin{tabular}{|l|l|}
\hline Low Aspect Ratio (2+) & Fillet (4+) \\
\hline
\end{tabular}

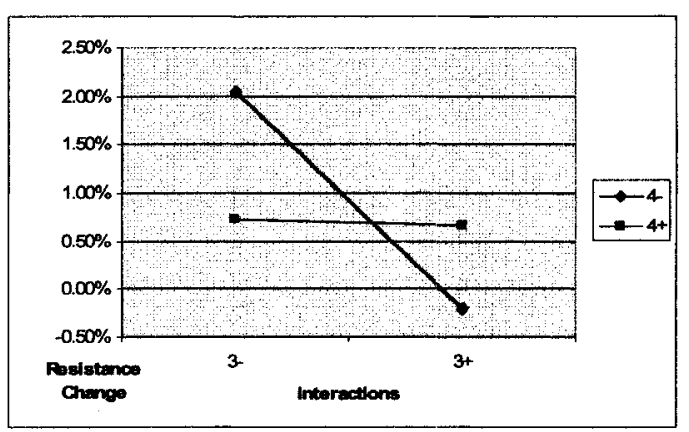

(e) Interaction 34

\begin{tabular}{|l|l|}
\hline Stacked Via (3-) & Non-fillet (4-) \\
\hline
\end{tabular}

\begin{tabular}{|l|l}
\hline Staggered Via (3+) & Fillet (4+) \\
\hline
\end{tabular}

Figure 40. Two-factor interaction plots at the TCB $1200^{\text {th }}$ cycle. 
But, in the design, when a laser via is stacked on the core via, there is no trace required and thus there is no fillet needed. In other words, the combination of Stack-oncore (1-) and Fillet (4+) does not exist in the actual design, and thus the lower point on the left side in Figure 40(b) which represents the combination of Stack-on-core (1-) and Fillet (4+) can be ignored. In the same way, the combination of Stack-on-core (1-) and the absence of a fillet (4-) can be seen as Stack-on-core only. Therefore, the only conclusion that can be drawn is that the absence of a fillet (4-) causes the rate of resistance change to be lowered when the laser vias are not stacked on the core via (1+).

As can be seen from Figure 40(c), a high aspect ratio (2-), or smaller via, has very little effect on the rate of resistance change regardless of whether the laser vias are stacked on each other (3-) or not (3+). However, it is a low aspect ratio (2+), or larger via, that causes the rate of resistance change to be lowered when the laser vias are not stacked on each other (3+). On the contrary, it is the low aspect ratio (2+) that results in the higher rate of resistance change when the laser vias are stacked on each other (3-).

From the analysis of Interaction 24 in Table 25 and Figure 40(d), when the aspect ratio is high (2-), the presence of a fillet (4+) results in the lower rate of resistance change being lowered. But, when the aspect ratio is low (2+), it is the absence of the fillet (4-) that results in the lower rate of resistance change.

Similar to the analysis of Interaction 14, Interaction 34 in Figure 40(e) can be analyzed as: (i) the presence of a fillet (4+) has very little effect on the rate of resistance change regardless of whether the laser vias are stacked on each other (3-) or not (3+), (ii) it is the absence of the fillet (4-) that causes the rate of resistance change to be lowered 
when the laser vias are not stacked on each other (3+), and (iii) it is the absence of the fillet (4-) that results in the higher rate of resistance change when the laser vias are stacked on each other (3-).

In fact, the combinations of Factor 3 (Stacked Via vs. Staggered Via) and Factor 4 (Fillet vs. Non-fillet) are quite complicated in the design. Daisy Chains 02 and 06 do not have fillets because all of the vias are stacked on each other along the same axis in a via set. Also, for Daisy Chains $01,05,09,10,13$, and 14 that are labeled as having the element of Stacked Via, the laser vias are not stacked on each other on Layers 3 and 8 whereas the laser vias are stacked on each other on the remaining four built-up layers which are Layers 1, 2, 9, and 10. The reason for this was explained in Section 4.1. For the sake of simplicity, these daisy chains are still considered as having Stacked Vias because the number of Stacked Vias is greater than the number of Staggered Vias. Therefore, the lower point on the left side in Figure 40(e) which represents the combination of Stacked Via (3-) and Fillet (4+) is ignored. In the same way, the combination of Stacked Via (3-) and the absence of a fillet (4-) is seen as Stacked Via only. Therefore, the only conclusion that can be drawn is that the absence of a fillet (4-) causes the rate of resistance change to be lowered when the laser vias are not stacked on each other $(3+)$.

\subsubsection{DOE Analysis at the TCB 2012 ${ }^{\text {th }}$ Cycle}

The TCB $2012^{\text {th }}$ cycle was selected for further analysis because it was the last cycle of the TCB temperature cycling test in this experiment. 


\subsubsection{Single Factor Effects}

As can be seen from Table 13(b), the main effects of Factor 1 and Factor 3 are significant. The effects of these two single factors were further analyzed. The data are shown in Table 26 and plotted in Figure 41. Similar to the findings at the TCB $1200^{\text {th }}$ cycle, the rate of resistance change is lower when the laser vias are not stacked on the core via $(1+)$. Likewise, when the laser vias are not stacked on each other $(3+)$, the rate of resistance change is also lower. Since the effects of these two factors are very close, it is not possible to determine if either one of them is more dominant.

Table 26. Single factor effects at the TCB $2012^{\text {th }}$ cycle.

\begin{tabular}{|c|c|c|}
\hline Factor 1 & Stack-on-core (1-) & Non-stack-on-core (1+) \\
\hline & $1.66 \%$ & $0.17 \%$ \\
\hline Factor 3 & Stacked Via (3-) & Staggered Via (3+) \\
\hline & $1.69 \%$ & $0.14 \%$ \\
\hline
\end{tabular}

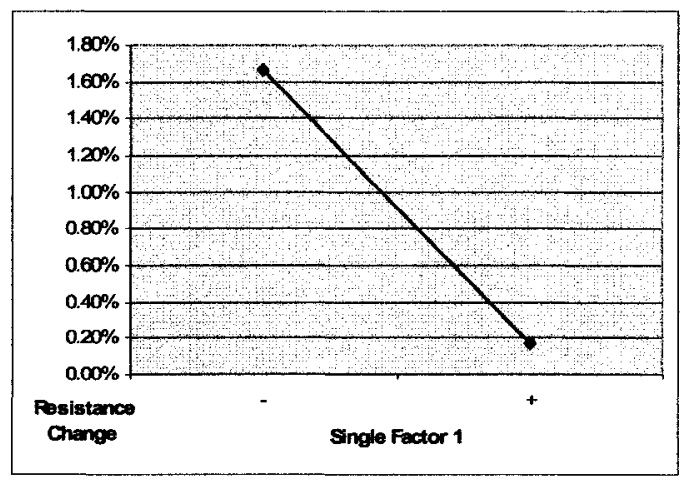

(a) Factor 1

\begin{tabular}{|l|l|}
\hline Stack-on-core (1-) & Non-stack-on-core (1+) \\
\hline
\end{tabular}

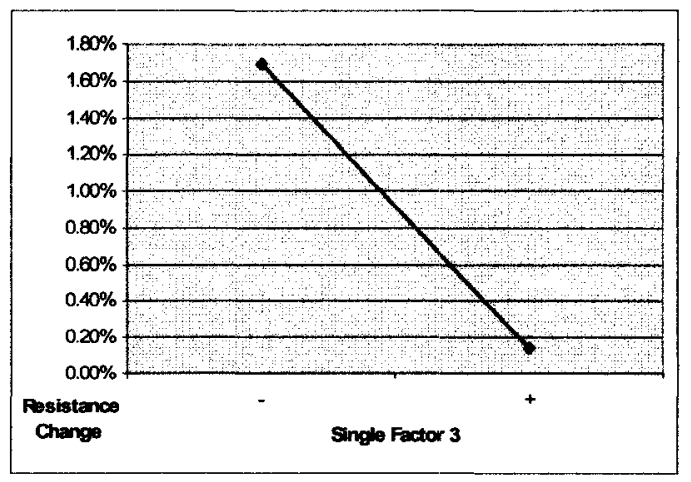

(b) Factor 3

\begin{tabular}{|l|l|}
\hline Stacked Via (3-) & Staggered Via (3+) \\
\hline
\end{tabular}

Figure 41. Single factor plots at the TCB $2012^{\text {th }}$ cycle. 


\subsubsection{Two-factor Interaction Effects}

As can be seen from Table 13(b), Interactions 13, 14, 23, 24, and 34 are significant with Interaction 34 being the largest contributor among all of the two-factor interactions. All of these interactions are also significant at the TCB $1200^{\text {th }}$ cycle. These two-factor interactions were further examined. The data are shown in Table 27 and plotted in Figure 42.

Table 27. Two-factor interaction effects at the TCB $2012^{\text {th }}$ cycle.

\begin{tabular}{|c|c|c|}
\hline Interaction 13 & Stack-on-core (1-) & Non-stack-on-core (1+) \\
\hline Stacked Via (3-) & $2.90 \%$ & $0.47 \%$ \\
\hline Staggered Via (3+) & $0.42 \%$ & $-0.13 \%$ \\
\hline Interaction 14 & Stack-on-core (1-) & Non-stack-on-core (1+) \\
\hline Non-fillet (4-) & $2.07 \%$ & $-0.15 \%$ \\
\hline Fillet (4+) & $1.24 \%$ & $0.49 \%$ \\
\hline Interaction 23 & Stacked Via (3-) & Staggered Via (3+) \\
\hline High Aspect Ratio (2-) & $1.25 \%$ & $0.44 \%$ \\
\hline Low Aspect Ratio (2+) & $2.13 \%$ & $-0.15 \%$ \\
\hline Interaction 24 & High Aspect Ratio (2-) & Low Aspect Ratio (2+) \\
\hline Non-fillet (4-) & $1.35 \%$ & $0.58 \%$ \\
\hline Fillet (4+) & $0.33 \%$ & $1.40 \%$ \\
\hline Interaction 34 & Stacked Via (3-) & Staggered Via (3+) \\
\hline Non-fillet (4-) & $2.47 \%$ & $-0.54 \%$ \\
\hline Fillet (4+) & $0.91 \%$ & $0.83 \%$ \\
\hline
\end{tabular}

Similar to the findings at the TCB $1200^{\text {th }}$ cycle, Interaction 13 is in agreement with the analysis from the single factor effects. It suggests that the rate of resistance change is being lowered further when the laser vias are not stacked on the core via $(1+)$ and on each other $(3+)$.

Interaction 14 is also similar to that at the TCB $1200^{\text {th }}$ cycle. The only conclusion that can be drawn from Figure 42(b) is that the absence of a fillet (4-) results in the lower rate of resistance change when the laser vias are not stacked on the core via $(1+)$. 


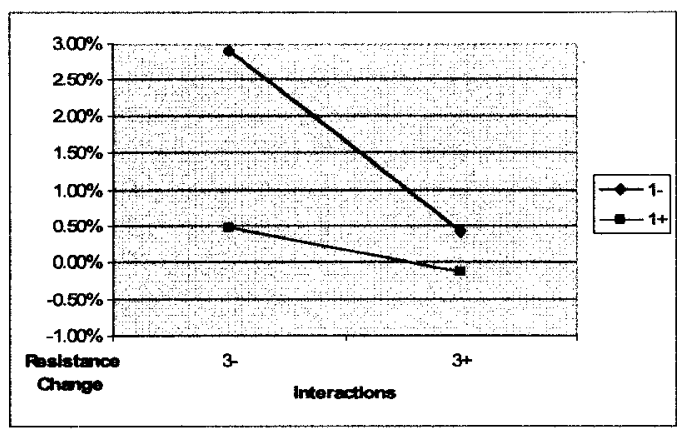

(a) Interaction 13

\begin{tabular}{|l|l|}
\hline Stack-on-core (1-) & Stacked Via (3-) \\
\hline
\end{tabular}

\begin{tabular}{|l|l|}
\hline Non-stack-on-core (1+) & Staggered Via (3+) \\
\hline
\end{tabular}

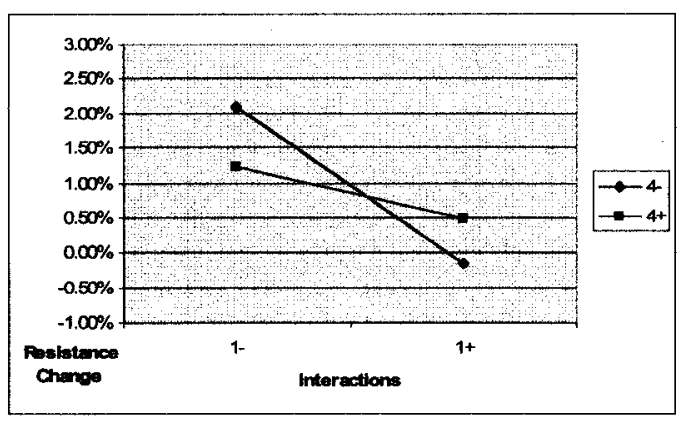

(b) Interaction 14

\begin{tabular}{|l|l|}
\hline Stack-on-core (1-) & Non-fillet (4-) \\
\hline Non-stack-on-core (1+) & Fillet (4+) \\
\hline
\end{tabular}

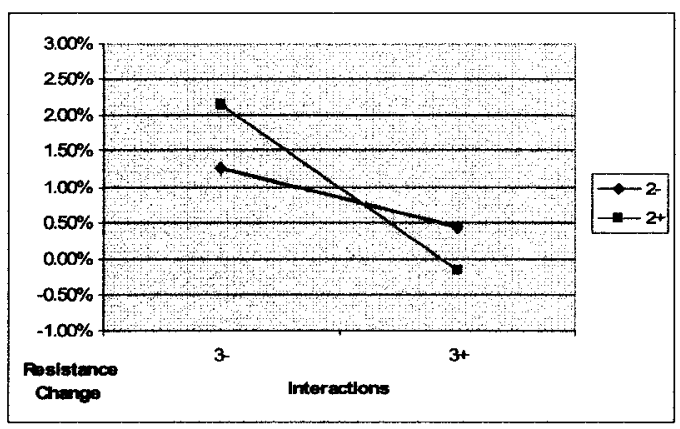

(c) Interaction 23

\begin{tabular}{|l|l|}
\hline High Aspect Ratio (2-) & Stacked Via (3-) \\
\hline
\end{tabular}

\begin{tabular}{|l|l|}
\hline Low Aspect Ratio (2+) & Staggered Via (3+) \\
\hline
\end{tabular}

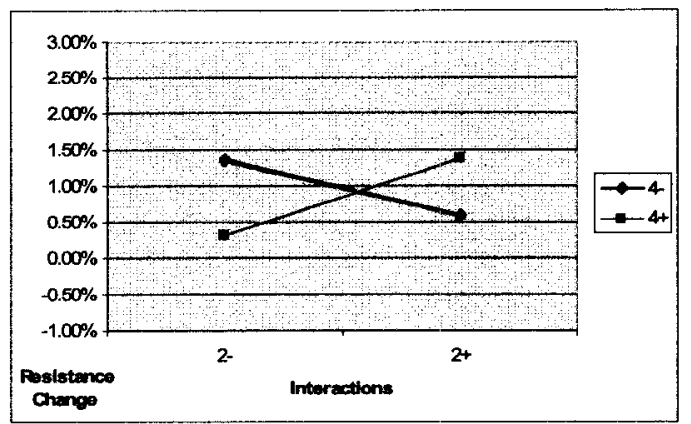

(d) Interaction 24

\begin{tabular}{|l|l|}
\hline High Aspect Ratio (2-) & Non-fillet (4-) \\
\hline Low Aspec Rato (2+) &
\end{tabular}

\begin{tabular}{|l|l}
\hline Low Aspect Ratio (2+) & Fillet (4+) \\
\hline
\end{tabular}

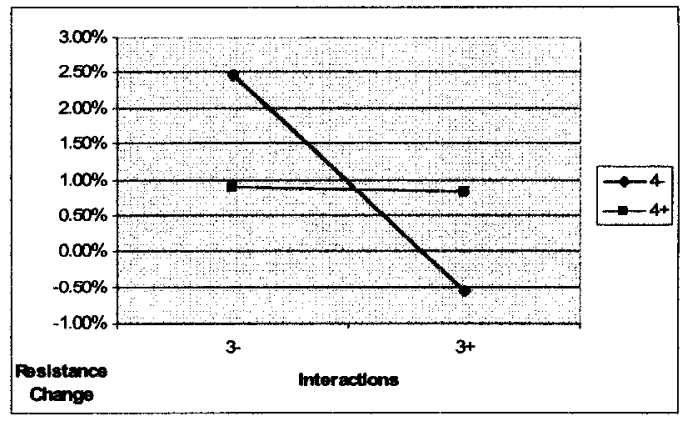

(e) Interaction 34

\begin{tabular}{|l|l|}
\hline Stacked Via (3-) & Non-fillet (4-) \\
\hline Staggered Via (3+) & Fillet (4+) \\
\hline
\end{tabular}

Figure 42. Two-factor interaction plots at the TCB $2012^{\text {th }}$ cycle. 
Interaction 23 is also similar to that at the TCB $1200^{\text {th }}$ cycle. As can be seen from Figure 42(c), High Aspect Ratio (2-) has very little effect on the rate of resistance change whether the laser vias are stacked on each other (3-) or not (3+). However, it is the low aspect ratio $(2+)$ that results in the lower rate of resistance change when the laser vias are not stacked on each other $(3+)$. On the contrary, it is the low aspect ratio $(2+)$ that results in the higher rate of resistance change when the laser vias are stacked on each other (3-).

Interaction 24 also has the pattern similar to the one at the TCB $1200^{\text {th }}$ cycle. As can be seen in Figure 42(d), when the aspect ratio is high (2-), the presence of a fillet (4+) results in the lower rate of resistance change. But, when the aspect ratio is low (2+), it is the absence of the fillet (4-) that results in the lower rate of resistance change.

Once more, Interaction 34 is the same in both the TCB $1200^{\text {th }}$ and TCB $2012^{\text {th }}$ cycles. The only conclusion that can be drawn in Figure 42(e) is that the absence of a fillet (4-) results in the lower rate of resistance change when the laser vias are not stacked on each other $(3+)$.

\subsubsection{DOE Analysis at the TCC $300^{\text {th }}$ Cycle}

The TCC $300^{\text {th }}$ cycle was used for further analysis because some daisy chains started to show inexplicable resistance change after this cycling test. Therefore, the TCC $300^{\text {th }}$ temperature cycling test appeared to be the last temperature cycling test from which the data were reasonable. 


\subsubsection{Single Factor Effects}

As can be seen from the ANOVA results in Table 13(c), the main effects of Factor 1 and Factor 3 are significant, and the main effect of Factor 2 (Low aspect ratio vs. High aspect ratio) is fairly significant. The effects of these three single factors were further calculated. The data are shown in Table 28 and plotted in Figure 43. As was the case with the single factor effects at the TCB $1200^{\text {th }}$ and the TCB $20120^{\text {th }}$ cycles, the rate of resistance change was lower when the laser vias were not stacked on the core via (1+). Likewise, when the laser vias were not stacked on each other $(3+)$, the rate of resistance change was also lower. The effects of these two factors are very close and it is not possible to determine if one is more dominant than the other.

As shown in Figure 43(b), the rate of resistance change is lower when the aspect ratio is low (2+) and is higher when the aspect ratio is high (2-). But since the difference between the higher and the lower resistance changes is only $0.31 \%$, it is suggested that the effect of Factor 2 is not distinctive. Also, as shown in Table 13(c), the contribution of Factor 2 is $0.37 \%$ which is about 30 times less than that of Factor 1 and 26 times less than that of Factor 3. Therefore, it is reasonable to exclude the effect of Factor 2, the aspect ratio, from the single factor effects in this cycle.

Table 28. Single factor effects at the TCC $300^{\text {th }}$ cycle.

\begin{tabular}{|c|c|c|}
\hline Factor 1 & Stack-on-core (1-) & Non-stack-on-core (1+) \\
\hline & $3.51 \%$ & $1.28 \%$ \\
\hline Factor 2 & High Aspect Ratio (2-) & Low Aspect Ratio (2+) \\
\hline & $2.60 \%$ & $2.19 \%$ \\
\hline Factor 3 & Stacked Via (3-) & Staggered Via (3+) \\
\hline & $3.45 \%$ & $1.35 \%$ \\
\hline
\end{tabular}




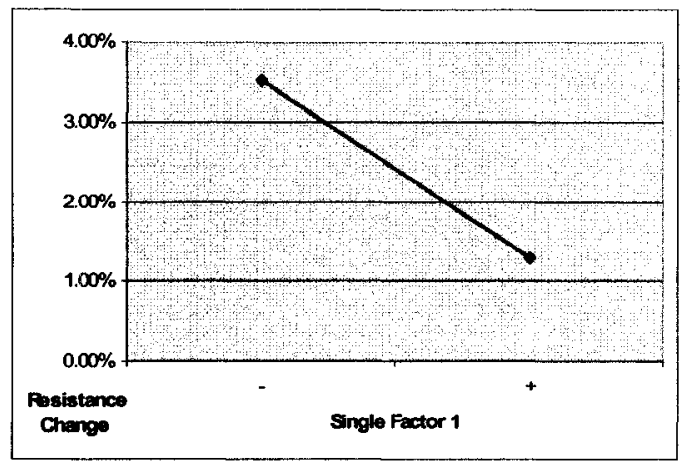

(a) Factor 1

\begin{tabular}{|l|l|}
\hline Stack-on-core (1-) & Non-stack-on-core (1+) \\
\hline
\end{tabular}

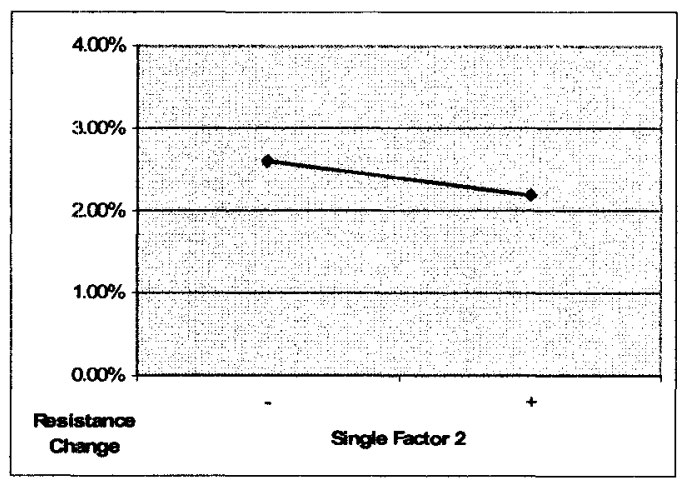

(b) Factor 2

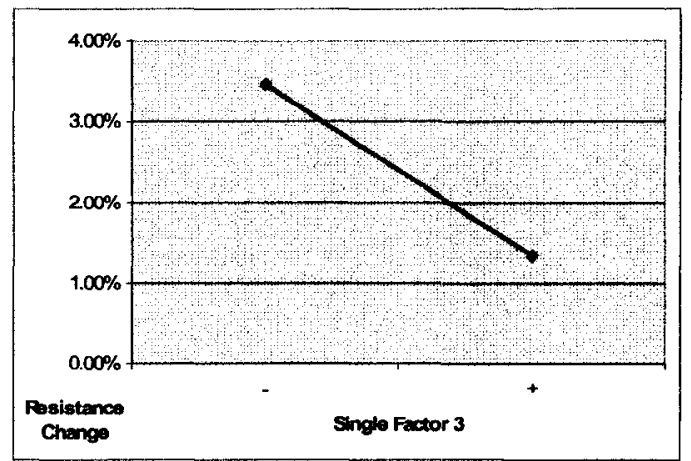

(c) Factor 3

\begin{tabular}{|l|l|}
\hline Stacked Via (3-) & Staggered Via (3+) \\
\hline
\end{tabular}

Figure 43. Single factor plots at the TCC $300^{\text {th }}$ cycle.

\subsubsection{Two-factor Interaction Effects}

As can be seen from Table 13(c), Interactions 13, 14, 23, 24, and 34 are significant. These interactions are also significant at both the TCB $1200^{\text {th }}$ and the TCB $2012^{\text {th }}$ cycles. Among these five significant two-factor interactions, Interactions 34 and 24 have higher contributions. Interaction 34 is the two-factor interaction of Factor 3 (Stacked Via) and Factor 4 (Fillet), whereas Interaction 24 is the two-factor interaction of 
Factor 2 (Aspect ratio) and Factor 4 (Fillet.) All the significant two-factor interactions were further calculated and examined. The data are shown in Table 29 and plotted in Figure 44 .

Table 29. Two-factor interaction effects at the TCC $300^{\text {th }}$ cycle.

\begin{tabular}{|c|l|l|}
\hline Interaction 13 & Stack-on-core (1-) & Non-stack-on-core (1+) \\
\hline Stacked Via (3-) & $4.93 \%$ & $1.97 \%$ \\
\hline Staggered Via (3+) & $2.10 \%$ & $0.59 \%$ \\
\hline Interaction 14 & Stack-on-core (1-) & Non-stack-on-core (1+) \\
\hline Non-fillet (4-) & $3.90 \%$ & $0.99 \%$ \\
\hline Fillet (4+) & $3.12 \%$ & $1.57 \%$ \\
\hline Interaction 23 & Stacked Via (3-) & Staggered Via (3+) \\
\hline High Aspect Ratio (2-) & $3.11 \%$ & $2.09 \%$ \\
\hline Low Aspect Ratio (2+) & $3.79 \%$ & $0.60 \%$ \\
\hline Interaction 24 & High Aspect Ratio (2-) & Low Aspect Ratio (2+) \\
\hline Non-fillet (4-) & $3.56 \%$ & $1.33 \%$ \\
\hline Fillet (4+) & $1.64 \%$ & $3.05 \%$ \\
\hline Interaction 34 & Stacked Via (3-) & Staggered Via (3+) \\
\hline Non-fillet (4-) & $4.33 \%$ & $0.57 \%$ \\
\hline Fillet (4+) & $2.57 \%$ & $2.12 \%$ \\
\hline
\end{tabular}

Since the patterns of the two-factor interactions in all of these three measured cycles are similar, the same observations as those noted in Sections 6.1.1.2 and 6.1.2.2 can be drawn. Furthermore, when Figure 44 is compared with Figures 40 and 42 , the resistance changes for each two-factor interaction at the TCC $300^{\text {th }}$ cycle are generally higher than the corresponding data at the TCB $1200^{\text {th }}$ cycle and TCB $2012^{\text {th }}$ cycles. Therefore, it is suggested that the TCC $300^{\text {th }}$ cycle caused more stresses on the daisy chains and thus created more effects on the design factors examined than the previous cycles did. 


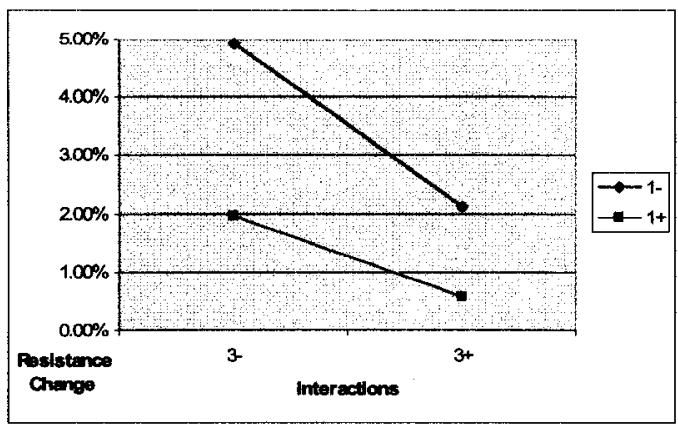

(a) Interaction 13

\begin{tabular}{|l|l|}
\hline Stack-on-core (1-) & Stacked Via (3-) \\
\hline Non-stack-on-core (1+) & Staggered Via (3+) \\
\hline
\end{tabular}

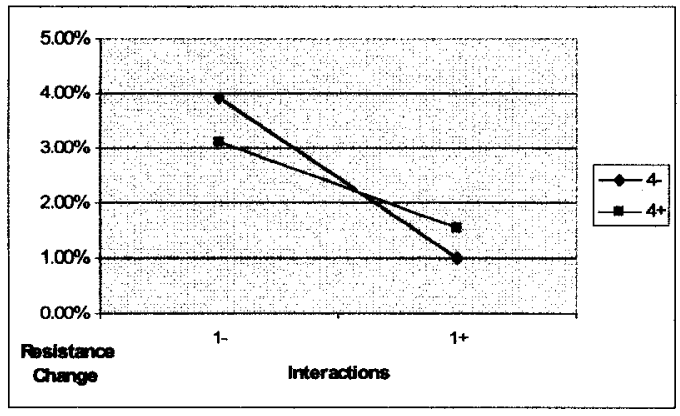

(b) Interaction 14

\begin{tabular}{|l|l|}
\hline Stack-on-core (1-) & Non-fillet (4-) \\
\hline Non-stack-on-core (1+) & Fillet (4+) \\
\hline
\end{tabular}

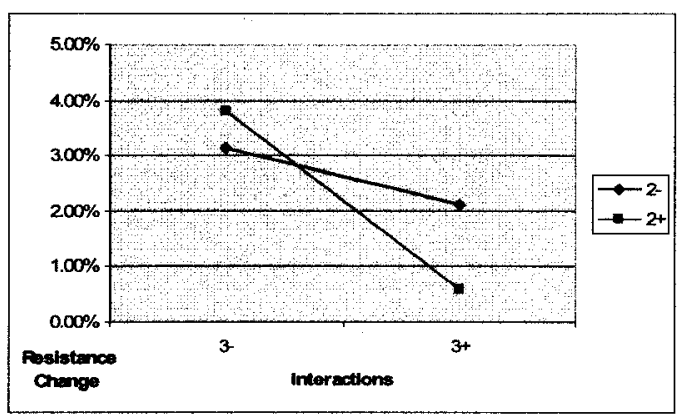

(c) Interaction 23

\begin{tabular}{|l|l|}
\hline High Aspect Ratio (2-) & Stacked Via (3-) \\
\hline
\end{tabular}

\begin{tabular}{|l|l|}
\hline Low Aspect Ratio (2+) & Staggered Via (3+) \\
\hline
\end{tabular}

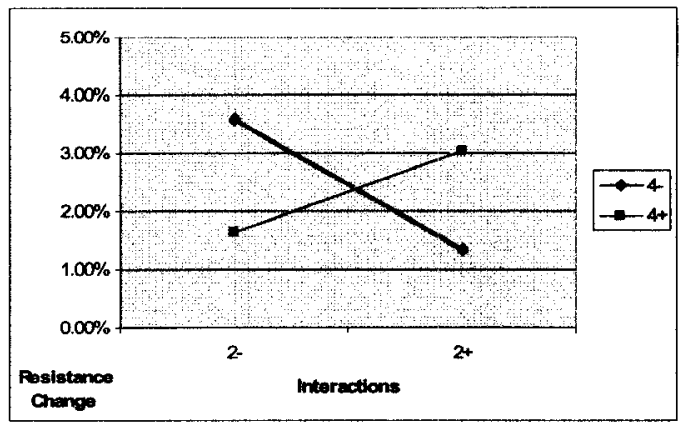

(d) Interaction 24

\begin{tabular}{|l|l|}
\hline High Aspect Ratio (2-) & Non-fillet (4-) \\
\hline Low Aspect Ratio (2+) & Fillet (4+) \\
\hline
\end{tabular}

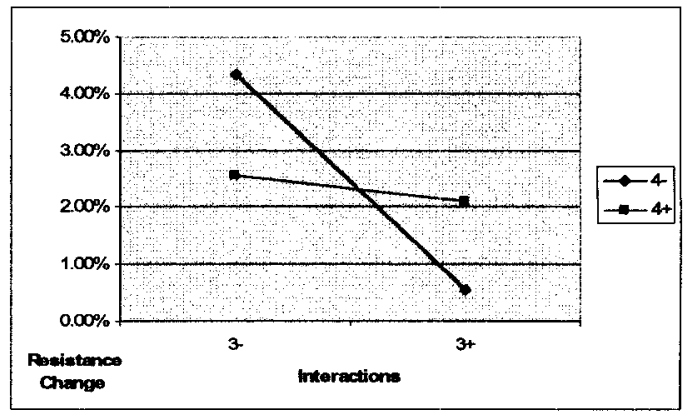

(e) Interaction 34

\begin{tabular}{|l|l|}
\hline Stacked Via (3-) & Non-fillet (4-) \\
\hline
\end{tabular}

\begin{tabular}{l|l} 
Staggered Via (3+) & Fillet (4+) \\
\hline
\end{tabular}

Figure 44. Two-factor interaction plots at the TCC $300^{\text {th }}$ cycle. 


\subsubsection{DOE Analysis at the TCC $500^{\text {th }}$ Cycle}

The TCC $500^{\text {th }}$ cycle was the last cycle of the TCC temperature cycling test in this investigation. Although some daisy chains did not follow the pattern of resistance change at and after the TCC $400^{\text {th }}$ cycle, the TCC $500^{\text {th }}$ cycle was examined so that the data and results could be compared with the data from the other cycles that were analyzed.

\subsubsection{Single Factor Effects}

As can be seen from the ANOVA results in Table 13(d), the main effects of Factor 1 (Stack on core vs. Non-stack on core), Factor 3 (Staggered via vs. Stacked via), and Factor 4 (Fillet vs. Non-fillet) are significant. The effects of these three single factors were further calculated, and the data are shown in Table 30 and plotted in Figure 45. As was the case with the single factor effects at the TCB $1200^{\text {th }}$, TCB $2012^{\text {th }}$, and TCC $300^{\text {th }}$ cycles, Non-stack-on core $(1+)$ has low resistance changes. However, the presence of a fillet $(4+)$ has also resulted in a lower resistance change. Factor 4 is not a major single factor in the other cycles that were analyzed. In contrast to the findings from the TCB $1200^{\text {th }}$, TCB $2012^{\text {th }}$, and TCC $300^{\text {th }}$ cycles, the rate of resistance change is lower when the laser vias are stacked on each other (3-) and is higher when the laser vias are not stacked on each other $(3+)$.

Table 30. Single factor effects at the TCC $500^{\text {th }}$ cycle.

\begin{tabular}{|c|c|c|}
\hline Factor 1 & Stack-on-core (1-) & Non-stack-on-core (1+) \\
\hline & $6.67 \%$ & $0.06 \%$ \\
\hline Factor 3 & Stacked Via (3-) & Staggered Via (3+) \\
\hline & $2.51 \%$ & $4.21 \%$ \\
\hline Factor 4 & Non-Fillet (4-) & Fillet (4+) \\
\hline & $5.76 \%$ & $0.97 \%$ \\
\hline
\end{tabular}




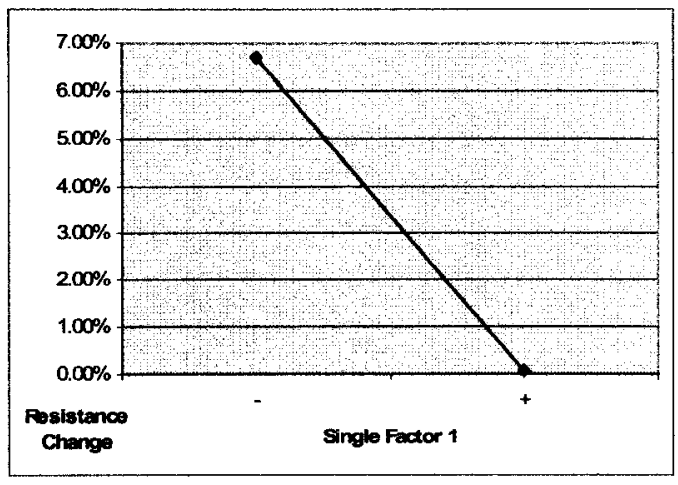

(a) Factor 1

\begin{tabular}{|l|l|}
\hline Stack-on-core (1-) & Non-stack-on-core (1+) \\
\hline
\end{tabular}

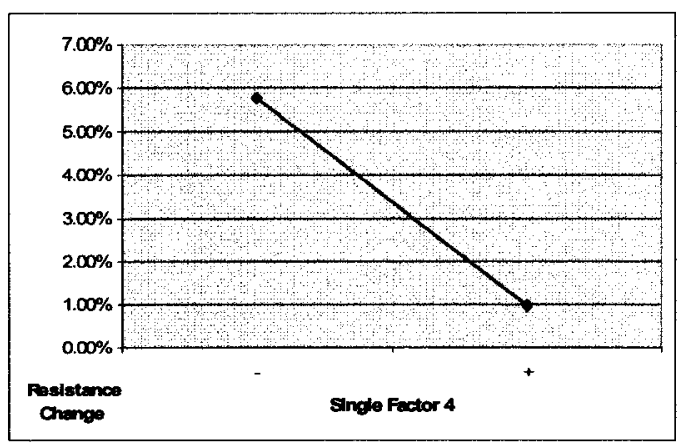

(c) Factor 4

\begin{tabular}{|l|l|} 
Non-fillet (4-) & Fillet (4+) \\
\hline
\end{tabular}

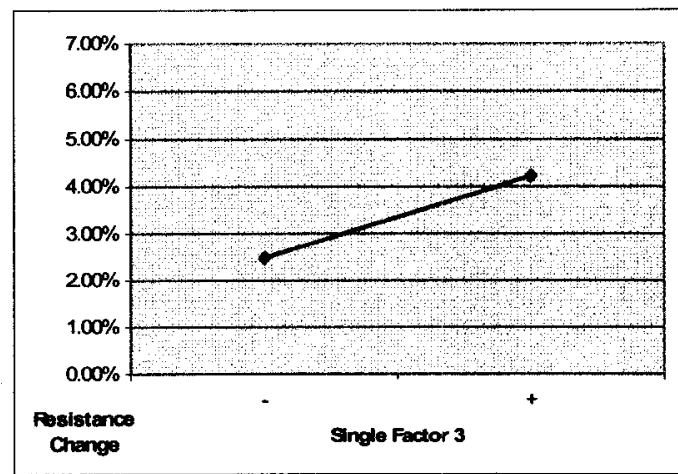

(b) Factor 3

\begin{tabular}{|l|l|}
\hline Stacked Via (3-) & Staggered Via (3+) \\
\hline
\end{tabular}

Figure 45. Single factor plots at the TCC $500^{\text {th }}$ cycle.

\subsubsection{Two-factor Interaction Effects}

As can be seen from Table 13(d), Interactions 12, 13, 14, and 23 are significant, with Interaction 14 being the largest contributor among all of the two-factor interactions. All of the interactions except Interaction 12 are also significant at the TCB $1200^{\text {th }}$, TCB $2012^{\text {th }}$, and TCC $300^{\text {th }}$ cycles. But some of the significant interactions at these cycles, such as Interactions 24 and 34 , become not significant at the TCC $500^{\text {th }}$ cycle. The two- 
factor interactions were further calculated and examined. The data are shown in Table 31 and plotted in Figure 46.

Table 31. Two-factor interaction effects at the TCC $500^{\text {th }}$ cycle.

\begin{tabular}{|c|c|c|}
\hline Interaction 12 & Stack-on-core (1-) & Non-stack-on-core (1+) \\
\hline High Aspect Ratio (2-) & $7.34 \%$ & $-0.27 \%$ \\
\hline Low Aspect Ratio (2+) & $5.99 \%$ & $0.39 \%$ \\
\hline Interaction 13 & Stack-on-core (1-) & Non-stack-on-core (1+) \\
\hline Stacked Via (3-) & $6.53 \%$ & $-1.51 \%$ \\
\hline Staggered Via (3+) & $6.81 \%$ & $1.62 \%$ \\
\hline Interaction 14 & Stack-on-core (1-) & Non-stack-on-core (1+) \\
\hline Non-fillet (4-) & $12.37 \%$ & $-0.85 \%$ \\
\hline Fillet (4+) & $0.97 \%$ & $0.97 \%$ \\
\hline Interaction 23 & Stacked Via (3-) & Staggered Via (3+) \\
\hline High Aspect Ratio (2-) & $3.45 \%$ & $3.62 \%$ \\
\hline Low Aspect Ratio (2+) & $1.58 \%$ & $4.80 \%$ \\
\hline
\end{tabular}

As can be seen from Figure 46(a), when the laser vias are stacked on the core vias (1-), a low aspect ratio (2+) results in the rate of resistance change being lowered.

However, when the laser vias are not stacked on the core vias $(1+)$, it is the high aspect ratio (2-) that results in the rate of resistance change being lowered but by only a very small fraction. Therefore, it can be concluded that the dominating element of Interaction 12 in lowering the rate of resistance change is when the laser vias are not stacked on the core via $(1+)$.

As can be seen from Figure 46(b), whether the laser vias are stacked on each other (3-) or not (3+), the rate of resistance change remains unchanged when the laser vias are stacked on the core via (1-). But, when the laser vias are not stacked on the core via $(1+)$, the resistance change is lowered if the laser vias are stacked on each other (3-). This 
phenomenon was unexpected, and the probable explanations were discussed in Section

5.2.1. However, when the laser vias are not stacked on the core via $(1+)$, the rate of resistance change is still low if the laser vias are not stacked on each other (3+).

Therefore, the only conclusion that can be made is that the dominating element of Interaction 13 in lowering the rate of resistance change is when the laser vias are not stacked on the core via $(1+)$.

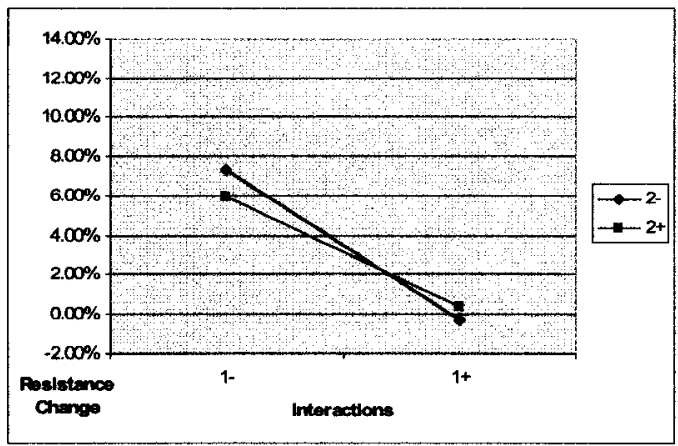

(a) Interaction 12

Stack-on-core (1-) $\quad$ High Aspect Ratio (2-) \begin{tabular}{|l|l|}
\hline Non-stack-on-core (1+) & Low Aspect Ratio (2+) \\
\hline
\end{tabular}

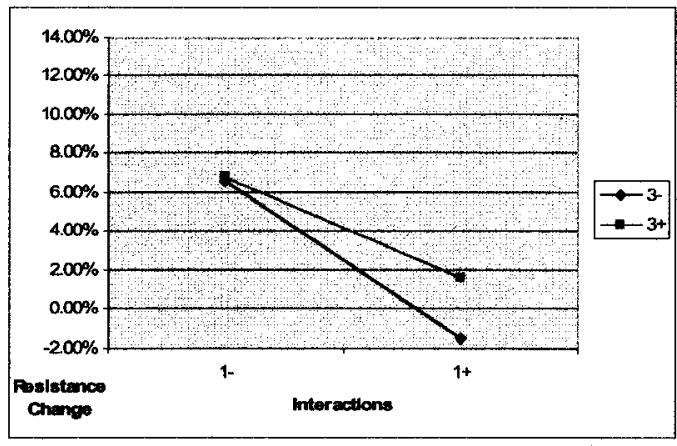

(b) Interaction 13

\begin{tabular}{|l|l|}
\hline Stack-on-core (1-) & Stacked Via (3-) \\
\hline Non-stack-on-core & Stiggered Via (3+) \\
\hline
\end{tabular}

\begin{tabular}{|l|l|}
\hline Non-stack-on-core (1+) & Staggered Via (3+) \\
\hline
\end{tabular}

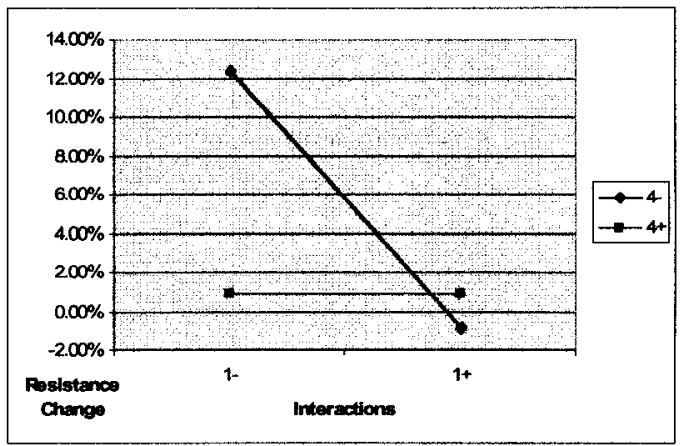

(c) Interaction 14

\begin{tabular}{|l|l|}
\hline Stack-on-core (1-) & Non-fillet (4-) \\
\hline Non-stack-on-core(1+) & Fillet (4+) \\
\hline
\end{tabular}

\begin{tabular}{|l|l|} 
Non-stack-on-core (1+) & Fillet (4+) \\
\hline
\end{tabular}

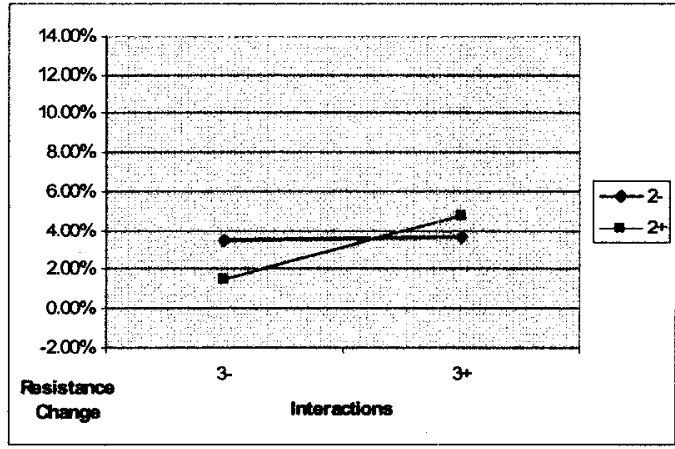

(d) Interaction 23

High Aspect Ratio (2-) Stacked Via (3-)
\begin{tabular}{|l|l|}
\hline Low Aspect Ratio (2+) & Staggered Via (3+) \\
\hline
\end{tabular}

Figure 46. Two-factor interaction plots at the TCC $500^{\text {th }}$ cycle. 
Interaction 14 in Figure $46(\mathrm{c})$ is similar to those at the TCB $1200^{\text {th }}$, TCB $2012^{\text {th }}$, and TCC $300^{\text {th }}$ cycles and it can be deduced that the absence of a fillet (4-) drives the rate of resistance change to being lower when the laser vias are not stacked on the core via (1+). However, this finding does not agree with the analysis from the main factor effects in which the presence of a fillet $(4+)$ was a major factor for lower resistance changes. Therefore, the only conclusion that can be made is that Interaction 14 is effective in lowering the rate of resistance change when the laser vias are not stacked on the core via $(1+)$.

From Figure 46(d) Interaction 23 can be interpreted as: (i) a high aspect ratio (2-) has very little effect on the rate of resistance change when the laser vias are stacked on each other (3-) or not (3+) because the difference between the higher and the lower resistance changes is only $0.17 \%$, (ii) it is the low aspect ratio $(2+)$ that results in the higher rate of resistance change when the laser vias are not stacked on each other $(3+)$, and (iii) it is the low aspect ratio $(2+)$ that drives the rate of resistance change to being lower when the laser vias are stacked on each other (3-).

\subsubsection{Summary of the DOE Analyses}

Since the analyses of TCB $1200^{\text {th }}$, TCB $2012^{\text {th }}$, and TCC $300^{\text {th }}$ cycles match each other very well, it can be stated that the conclusion drawn from these analyses are applicable to the entire investigation. From the analyses of the single factor effects, it is clearly seen that if a laser via is not stacked on the core via (1+) and not on each other $(3+)$ in a via set, it will undergo less resistance change and will be more robust. The analysis of the two-factor interactions further suggests that the absence of a fillet (4-) will 
make the laser via more reliable if it is not stacked on the core via $(1+)$ and is offset to each other $(3+)$. When a laser via is not stacked on each other $(3+)$, it is the low aspect ratio $(2+)$ that makes the laser via more robust. In addition, when a low aspect ratio $(2+)$ is used, it is the absence of a fillet (4-) that makes a laser via even more reliable. Therefore, it can be concluded that a robust laser via set should contain the following design elements:

- Laser vias not stacked on the core via

- Laser vias not stacked on one another

- The ratio of dielectric thickness to via diameter be low

- A fillet between a via pad and a trace is not needed

From the analyses of the single factor effects at the TCC $500^{\text {th }}$ cycle, it can be concluded that if a laser via is not stacked on the core via (1+) but on each other (3-) in a via set, it will undergo less resistance change. The study from the two-factor interactions suggests that a low aspect ratio (2+) will further lower the resistance change when the laser vias are stacked on each other (3-). The analysis of the TCC 500th cycle does not match with those from the TCB $1200^{\text {th }}$, TCB $2012^{\text {th }}$, and TCC $300^{\text {th }}$ cycles. In particular, the inferences of Factor 3 (whether a laser via is stacked on each other or not) in these two sets of analyses are contradictory to each other. The results of failure analysis reported in Section 6.2 shows that cracks can be found on the vias that are stacked on each other but not on the vias that are offset to each other. Also, as mentioned in Section 5.2.1, five of the daisy chains had sudden resistance rises or drops on and after the TCC 
$400^{\text {th }}$ cycles. Therefore, the results of the DOE analysis obtained at the TCC $500^{\text {th }}$ cycle are not reliable.

\subsection{Failure Analysis}

The number of the daisy chains examined, and the number of failed daisy chains and the failure locations are summarized in Table 32. As indicated in Section 5.4, a minor crack is not regarded as a failure whereas a full crack is considered a failure.

Table 32. Summary of number of failed vias and their locations.

\begin{tabular}{|l|c|c|l|l|l|l|}
\hline & \multicolumn{3}{|l|}{ At the outer periphery } & \multicolumn{2}{l|}{ Under the die } \\
\hline $\begin{array}{l}\text { Daisy } \\
\text { Chain \# }\end{array}$ & $\begin{array}{l}\text { Package } \\
\#\end{array}$ & $\begin{array}{l}\text { Failure } \\
\text { Rate }\end{array}$ & Location & $\begin{array}{l}\text { Package } \\
\#\end{array}$ & $\begin{array}{l}\text { Failure } \\
\text { Rate }\end{array}$ & Location \\
\hline \multirow{2}{*}{ Daisy06 } & 36 & $5 / 5$ & $\begin{array}{l}\text { On V2-3, V4-5, } \\
\text { V6-7, and V8-9 }\end{array}$ & 43 & $5 / 5$ & $\begin{array}{l}\text { On V1-2, V2-3, } \\
\text { V3-4, and V4-5 }\end{array}$ \\
\cline { 2 - 8 } & 41 & $0 / 6$ & & 33 & $0 / 6$ & \\
\hline \multirow{2}{*}{ Daisy04 } & $06 / 10$ & $5 / 5$ & $\begin{array}{c}\text { On V4-5 and } \\
\text { V6-7 }\end{array}$ & $19 / 47$ & $0 / 4$ & \\
\hline Daisy08 & $04 / 35$ & $0 / 5$ & & $32 / 48$ & $0 / 5$ & \\
\hline Daisy02 & 02 & $7 / 7$ & On V7-8 & 39 & $0 / 5$ & \\
\cline { 2 - 8 } & 22 & $0 / 5$ & & 46 & $0 / 5$ & \\
\hline Daisy14 & $23 / 26$ & $0 / 5$ & & $42 / 44$ & $0 / 5$ & \\
\hline
\end{tabular}

\subsubsection{Observations from Cross-sectioned Daisy Chains}

Daisy Chain 06 had the highest resistance increase from the TCB $1200^{\text {th }}$ cycle up to the TCC $500^{\text {th }}$ cycle. Daisy Chain 06 is one of the two daisy chains that had all of the laser vias and the core via stacked on each other along the same axis in each via set.

Because all the vias were stacked on one another, a fillet was not applicable in Daisy Chain 06. The laser via diameter is small because Daisy Chain 06 was designed with a high aspect ratio. In the failure analysis, Packages \#36 and \#43 of Daisy chain 06 , which 
showed the highest resistance increase among all 49 packages, failed completely in the locations identified as "At the outer periphery" and "Under the die". The failed vias were both stacked on the core via and on each other and were located at various layers.

However, Packages \#41 and \#33, which showed lower resistance increase among all 49 packages, did not fail in any locations at all.

Daisy Chain 04 maintained a very low resistance change before the TCC $300^{\text {th }}$ cycle. The resistance sharply increased at the TCC $400^{\text {th }}$ cycle and caused Daisy Chain 04 to have the $2^{\text {nd }}$ highest resistance increase at the end of the temperature cycling test. All the laser vias of Daisy Chain 04 were stacked on the core via but not on each other. A fillet was not incorporated in the intersection of a trace and a via pad. The laser via diameter was large because Daisy Chain 06 was designed with a low aspect ratio. In the failure analysis, Package combo \# 06/10 failed completely in the location identified as "At the outer periphery" on V4-5 and V6-7. Both of these two laser vias were stacked directly on the core via. However, Package combo \# 19/47 did not fail in the location identified as "Under the die." These four packages showed higher resistance increase among all 49 packages.

Daisy Chain 08 had the $3^{\text {rd }}$ highest resistance increase at the TCC $500^{\text {th }}$ cycle. All the laser vias of Daisy Chain 08 were stacked on the core via but not on each other. A fillet was not incorporated between the trace and the via pad, and the laser via diameter was small. The cross-sections of Package combos \# 04/35 and \# 32/48 showed that this daisy chain did not fail at all. These four packages showed higher resistance increase among all 49 packages. 
Daisy Chain 02 was the other daisy chain that had all of the laser vias and the core via stacked on each other along the same axis in each via set. The only difference between Daisy Chain 02 and Daisy Chain 06 was that Daisy Chain 02 had a larger laser via diameter. Package \# 22 of Daisy Chain 02 failed completely in the location identified as "At the outer periphery" on V7-8, which was a stacked laser via. However, Package \# 39 did not fail in the location identified as "Under the die". These two packages had the highest resistance increases among all 49 packages. On the other hand, Packages \# 22 and \#46, which had the lowest resistance increases among all 49 packages, did not fail at any of the locations.

The average resistance change of Daisy Chain 14 was $+2.9 \%$ at the TCC $300^{\text {th }}$ cycle but it dropped down to $-5.2 \%$ or lower at the TCC $400^{\text {th }}$ and TCC $500^{\text {th }}$ cycles. In fact, Daisy Chain 14 had the highest resistance decrease at the end of the temperature cycling test. All the laser vias of Daisy Chain 14 were not stacked on the core via but on each other. A fillet was not incorporated, and the laser via diameter was small. The cross-sections of Package combos \# 23/26 and \# 42/44, which had the highest resistance decreases among all 49 packages, did not fail at any of the locations.

\subsubsection{Failure Analyses, Correlations, and Explanations}

Although cross-sections were taken on selected daisy chains and on only a few of the via sets, it is still clear from the discussion in Section 6.2.1 that the greater the increase in via resistance, the higher the failure rate. This correlates with the published literature that via failure can be predicted by the increase of resistance. 
None of the failed vias were from those that were not stacked on the core via or on each other. Conversely, although not all the laser vias that were stacked on the core via and on each other failed, all of the failed vias were from those that were either stacked on the core or stacked on each other. These findings correlate to the DOE analysis that Non-stack-on-core and Staggered Via resulted in lower resistance change, or a lower probability of via crack. The aspect ratio of the failed vias was either high or low. This finding also correlates to the DOE analysis that the effect of Factor 2 (High Aspect Ratio vs. Low Aspect Ratio) is not significant. Since fillets cannot be incorporated in the vias that are stacked on the core via or on each other, Factor 4 (Fillet vs. Non-fillet) cannot be examined by the failure analysis.

As can be seen from the micrographs of the failed vias in Section 5.4, all of the cracks were found at the interface between the capture pad and the bottom of the laser via. For example, a V2-3 crack always happens on L3 as the laser drill starts from L2 and ends on L3, and a V6-7 crack always happens on L6 as the laser drill starts from L7 and ends on L6. In the laser via structure, a stress concentration point is located at the intersection between the bottom via wall and the capture pad which is part of the copper layer. During the temperature cycling tests, the highest stress occurs at the intersection due to the coefficient of thermal expansion (CTE) mismatch between the different materials of the substrate. As can be seen from the micrographs of the failed vias, all the cracks have the same failure pattern. The crack initiates at the intersection and then propagates through the path of least strength which is along the interface between the copper layer and the bottom of the via. This finding correlates with the outcome 
examined by Darveaux et al. [12] on the mechanically drilled vias in a Land Grid Array (LGA) package. For a minor crack, the crack does not propagate all the way through and stops somewhere in the middle of the via. For a full crack, the crack starts at the sharp corner of one side and ends at the sharp corner of the other side and splits open the interface.

Although each via had its own stress concentration points, if two or more vias of the two adjacent layers are staggered in a manner that they are offset to each other, there will be more leverage for the structure to absorb the CTE mismatch between the layers. So, the staggered via structure is more robust than the stacked via structure. The DOE results prove that Staggered Via had a lower resistance increase than Stacked Via did. In the failure analysis, via cracks were not found on the staggered via structure.

The same explanation can be applied to Factor 1 (Stack-on-core vs. Non-stack-oncore). When the laser vias and the core via are aligned in the same axis, there is less leverage for the structure to absorb the CTE mismatch between the two layers. Thus, Stack-on-core is weaker than Non-stack-on-core in terms of structure, and is easier to fail when subjected to stresses and strains from the CTE mismatch between the two layers. Moreover, as shown in Figure 47(a), Stack-on-core is surrounded by two types of materials, and they are the composite material of the dielectric layers, and the filling epoxy of the core via. As shown in Figure 47(b), Non-stack-on-core, due to its offset from the core via, only deals with one material that is the composite material of the dielectric layers, so it is subjected to less stresses and strains from the CTE mismatch. As a result, the non-stack-on-core via structure is stronger than the stack-on-core via 
structure. The DOE results prove that Non-stack-on-core had lower resistance increase than Stack-on-core did. In the failure analysis, via cracks were not found on the nonstack-on-core structure.

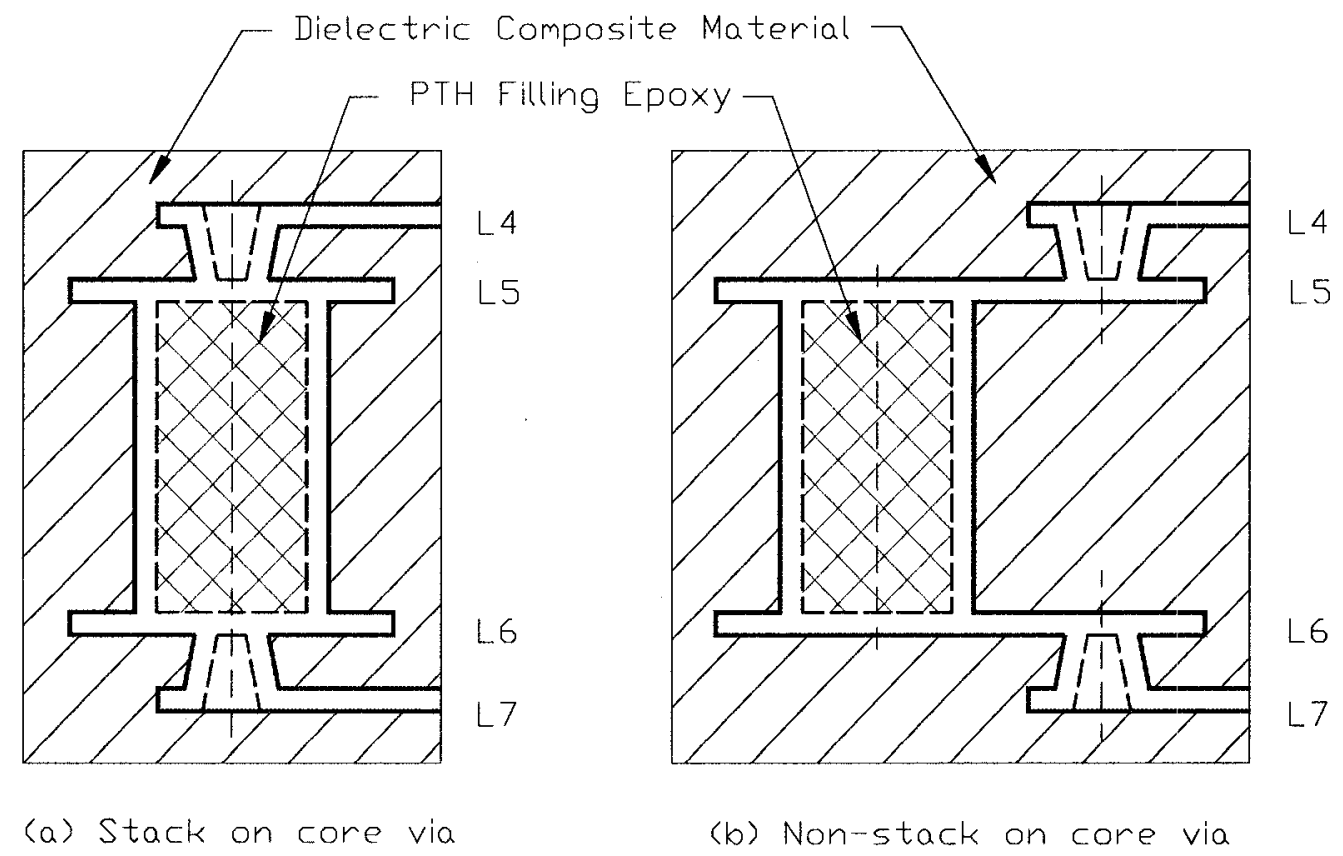

Figure 47. Materials surrounding stack-on-core via and non-stack-on-core via.

As shown in Figure 31(a) through Figure 31(c), four to seven via sets were revealed in one cross-section. When a crack was seen at a particular via location in a cross-section, cracks were also found in all of the other via sets at the same via location of that cross-section. Furthermore, the crack pattern and the extent of the crack in the failed vias were very similar. One example is in Table 16. The cross-sectioning cut in the "Outer Periphery" of Daisy Chain 04 revealed all the via sets of Ball \#AM39, AN39, AP39, AR39, and AT39 of Package 06. All the vias at the via locations of V4-5 and V67 of all these balls had serious cracks. As shown in the cross-section micrographs in 
Appendix G, all the cracks at the via location V4-5 looked alike and so did the cracks at the via location V6-7. Another example is in Table 19. Seven via sets in Ball \#C30-C36 of Package 02 of Daisy Chain 02 were revealed by one cross-sectioning cut. All of the vias at the location of V7-8 of all these balls had serious cracks. As shown in the crosssection micrographs in Appendix G, all of these cracks looked alike.

This phenomenon led to a question of whether the cracks found in these failed daisy chains in certain via locations were consistent regardless of the packages selected or not. In Phase II of the failure analysis, cross-sections were done on some other packages of Daisy Chain 02 and Daisy Chain 06 at the same cross-section locations done in Phase I. The difference between Phase I and Phase II was that in Phase I the packages selected were from those that had the highest resistance increase while in Phase II the packages selected were from those that had the lowest resistance increase. The result was that no crack was found in Daisy Chain 02 and Daisy Chain 06 of the packages selected in Phase II. So it can be concluded that for the same daisy chain, via failure happened in the packages that showed higher resistance change but not in the packages that showed lower resistance change. Also, if a package was found having failed vias, the failures happened at the same locations in a certain area of the package.

These findings suggest that the manufacturing processes have a major effect on via crack formation. In some manufacturing processes such as laser via drilling, electroless plating, and electrolytic plating, some residues may not be completely cleaned away and may remain on the substrate. If certain layers and certain areas of the substrate have more residues, those areas are more vulnerable to failure. Since the detail of the 
manufacturing processes is beyond the scope of this thesis, these findings are not further explored.

The coefficient of thermal expansion (CTE) of the composite FCPBGA substrate is in the range of $16-20 \mathrm{ppm}$ in the planer direction while the silicon die is about $2.6 \mathrm{ppm}$ [18]. Due to the CTE mismatch of the die and the substrate, the vias above the core layer of the substrate are subjected to more stresses and strains than the vias under the core layer during the temperature cycles. Thus, a higher number of failed vias can be expected above the core layer than below the core layer. As can be seen in Table 32, a total of 35 vias above the core layer and a total of 22 vias below the core were cracked. Although not many cross-sectioned samples were done, the investigation still demonstrates that the failed vias are located more above the core layer than below the core layer.

Due to the CTE mismatch of the die and the substrate, the via sets in the region of "At the outer Periphery" of the package are subjected to more stresses and strains than the via sets in the region of "Under the die" during the temperature cycles. However, in this experiment, a failure rate of $44.7 \%$ (17 out of 38 via sets are failed) happens in "At the outer periphery" and $14.3 \%$ (5 out of 35 via sets are failed) in "Under the die" according to Table 32. These failures are due to a combination of contributing factors, including those from the manufacturing processes, which cannot be discerned individually. Therefore, based on the limited number of cross-sectioned samples, it is not possible to separately identify the contributors to failure. 


\section{CHAPTER SEVEN}

\section{CONCLUSION}

The effects of the four design parameters, which were interweaved in the sixteen daisy chains of the test vehicle, on micro-via reliability were evaluated by a $2^{4} \mathrm{DOE}$ approach and failure analysis. Several conclusions can be drawn from the experimental results of this investigation.

After 2012 cycles of TCB test, the average resistance increase of all the sixteen daisy chains was still within $1 \%$, and the maximum resistance increase was not beyond $5.5 \%$. According to the common industry acceptance level that the increase in resistance cannot be more than $10 \%$ at and after the TCB $1000^{\text {th }}$ cycle, all sixteen daisy chains passed the current requirement on via reliability. In other words, each combination of the $2^{4}$ design parameters, including the extreme situation where all the laser vias and core via were stacked on each other in this 10-layer test vehicle, passed the industry requirement. However, the objective of this experiment was to evaluate the effects of these four design factors on laser via reliability. The experiment was therefore continued with TCC tests to accelerate the stress level until a minimum resistance increase of $10 \%$ occurred in at least one daisy chain. Two daisy chains had their resistance increase beyond $10 \%$ at the TCC $400^{\text {th }}$ cycle. From the statistical analysis of the resistance changes in the temperature cycling tests, it can be concluded that the higher the temperature difference in a test $(\Delta \mathrm{T}$ $=180^{\circ} \mathrm{C}$ in the $\mathrm{TCB}$ test, and $\Delta \mathrm{T}=215^{\circ} \mathrm{C}$ in the $\mathrm{TCC}$ test), the higher the increase in via resistance. 
From the $2^{4}$ DOE analyses, it was found that a robust laser via set is formed by: (i) laser vias not being stacked on the core via, (ii) laser vias not being stacked on one another, (iii) the ratio of dielectric thickness to via diameter being low, and (iv) the absence of a fillet between a via pad and a trace. The most dominating design factors are (i) laser vias not stacked on the core via, and (ii) laser vias not stacked on one another. Of all the vias examined in the failure analysis, no cracks were found in the vias that were not stacked on the core via and were offset to each other. Therefore, Non-stack-on-core and Staggered Vias are recommended for a FCBGA that requires long-term reliability. However, these factors require more "real-estate" and thus decrease the I/O routing density and power/ground plane integrity, which are necessary for high density and high performance chips. This conflict has to be resolved so that a reliable substrate can be provided for the next generation microelectronic devices of $45 \mathrm{~nm}$ gate size and everincreasing clock speeds.

In the failure analysis, a higher number of failed vias were found in Daisy Chain 06 than in the other fifteen daisy chains. Daisy Chain 06 was constructed with laser vias of high aspect ratio, and had all the laser vias and the core vias stacked on each other along the same axis. This daisy chain displayed the highest resistance change from the TCB $1200^{\text {th }}$ cycle up to the end of the TCC cycling tests.

From the failure analysis, it was concluded that the higher the increase in via resistance the higher the failure rate of micro vias. For each of the failed vias, the increase in resistance for that package and daisy chain was more than $10 \%$. All the cracks in the failed laser vias had the same failure pattern. The crack initiated at the 
stress concentration point, which is the interface between the capture pad and the bottom of the laser via, due to the CTE mismatch of the different materials in the substrate, and then propagated through the interface and finally split it open.

When comparing the data of a daisy chain from different packages, it was found that there was a discernible pattern of via failures; the failures tended to be restricted to certain vias, which were located in certain layers and areas. This indicates that the manufacturing processes can potentially have a major effect on via crack formation. 


\section{CHAPTER EIGHT}

\section{FUTURE WORK}

The analyses of via cracks at different geographical locations such as "at the outer periphery", "under the die", "above the core layer," and "under the core layer" could not be unequivocally identified due to the lack of sufficient data to distinguish the failures solely based on location. Therefore, it is recommended that another test vehicle and another set of temperature cycling experiments be designed so that electrical resistance measurements aimed at identifying location-specific data can be collected and analyzed.

It was identified in this study that manufacturing processes have a major effect on via crack formation. A detailed study of how the manufacturing processes affects via crack formation is needed in order to improve the long term micro-via reliability of FCBGA polymeric substrates.

As the feature sizes of the FCBGA substrates become smaller, laser vias will continue to shrink and micro-cracking can be expected to continue to be a barrier. In the 2002 ITRS roadmap presented by Sundaram et al. [8], the size of the vias may have to be shrunk to $10-30 \mu \mathrm{m}$ in order to satisfy future FCBGA developments. The minimum size of the via that this experiment employed was $50 \mu \mathrm{m}$, which is the smallest via diameter that substrate manufacturers currently use for mass production. Although it is concluded that the aspect ratio was not a significant single-factor for via crack in this research, study of via cracks as related to via diameter is still needed before the next smaller via diameter can be employed for production. 


\section{REFERENCES}

1. Intel Cooperation (2005). Moore's Law [Online]. Available at http://www.intel.com/technology/silicon/mooreslaw/index.htm (accessed 25 September 2005). WWW Article.

2. Y. Tsukada, K. Yamanaka, Y. Kodama and K. Kobayashi, "Features of new laser micro-via organic substrate for semiconductor package," Electrochimica Acta, 48, 20-22, pp. 2997-3003 (September, 2003).

3. B. L. Park, S. R. Hah, C. G. Park, D. K. Jeong, H. S. Son, H. S. Oh, J. H. Chung, J. L. Nam, K. M. Park and J. D. Byun, "Mechanism of stress-induced voids in multi-lever Cu interconnects," in Proceedings of IEEE 2002 International Interconnect Technology Conference, June 2002, pp. 130-132.

4. A. S. Prabhu, D. B. Barker, M.G. Pecht, Evans, J. W. Evans, W. Grieg, E. S. Beranrd and E. Smith, "Thermal-mechanical fatigue analysis of high density interconnect vias," American Society of Mechanical Engineers EEP, 10, 1, pp. 187-216 (1995).

5. M. Rastani, "Failure mechanism of metallization layer of a multichip module substrate," American Society of Mechanical Engineers Material Sections, 80, pp. 469475 (1997).

6. H. P. Yeoh, M. J. Lii, B. Sankman and H. Azimi, "Flipchip pin grid array (FC-PFG) packaging technology," in Proceedings of $3^{\text {rd }}$ Electronic Packaging Technology Conference, December 2000, pp. 33-40.

7. H. Reiter and O. Leitner, "Bad vias are the cause for electrical test yield losses after plastic chip assembly," in Proceedings of SPIE - The International Society for Optical Engineering, 3510, pp. 194-202 (1998).

8. V. Sundaram, R. R. Tummala, F. Liu, P. A. Kohl, J. Li, S. A. Bidstrup-Allen and Y. Fukuoka, "Next-generation microvia and global wiring technologies for SOP," IEEE Transactions on Advanced Packaging, 27, 2, pp. 315-325 (May 2004).

9. N. Kumbhat, P. M. Raj, R. V. Pucha, S. Atmur, R. Doraiswamy, V. Sundaram, S. Bhattacharya, S. K. Sitaraman and R. R. Tummala, "Recent advances in composite substrate materials for high-density and high reliability packaging applications," in Proceedings of IEEE 2005 Electronic Components and Technology Conference, 2005, pp. 1364-1372. 
10. T.C. Chai, C. Lee, Y.Y. Ma, E. H. Wong, X. W. Zhang, D. Pinjala, S. S. Murthy and P. S. Teo, "Reliability assessment of flipchip on build up laminate based multi-chip package," in Proceedings of IEEE 2002 Electronic Components and Technology Conference, 2002, pp. 747-752.

11. F. Liu, J. Lu, V. Sundaram, D. Sutter, G. White, D. F. Baldwin and R. R. Tummala, "Reliability assessment of microvias in HDI printed circuit boards," in Proceedings of IEEE 2001 Electronic Components and Technology Conference, 2001, pp. 1159-1163.

12. R. Darveaux, J. Yang, A. Syed, B. Buella and P. Villareal, "Board Level Reliability Evaluation of RF Module Vias," in Proceedings of IEEE 2003 Electronic Manufacturing Technology Symposium, July 2003, pp. 305-311.

13. R. Darveaux, J. Yang, R. Sheridan, B. Buella and P. Villareal, " $R F P A$ module substrate via reliability, " in Proceedings of IEEE 2003 Electronic Components and Technology Conference, 2003, pp. 1181-1189.

14. P. Lu (Sales and Marketing Director of Kinsus Corp.), private communication (August 2005).

15. L. Zhang (Staff Process Development Engineer of Xilinx Corp.) and P. Lu (Sales and Marketing Director of Kinsus Corp.), private communication (October 2005).

16. L. Zhang (Staff Process Development Engineer of Xilinx Corp.), private communication (June 2007).

17. Electronic Industries Alliance, JEDEC Standard: JESD22-A104C, "Temperature Cycling”, May 2005.

18. D. P. Seraphim, D. E. Barr, W. T. Chen, G. P. Schmitt and R. R. Tummala, "Printed-circuit Board Packaging," in Microelectronics Packaging Handbook, edited by R. R. Tummala, E. J. Rymaszewski and A.G. Klopfenstein (Van Nostrand Reinhold, New York, 1989), pp. 885-917. 


\section{APPENDIX A}

\section{Measured Electrical Resistances at the $0^{\text {th }}$ Cycle}

Table A-1: Daisy01 - Daisy08.

\begin{tabular}{|c|c|c|c|c|c|c|c|c|}
\hline & DAISY01 & DAISY02 & DAISY03 & DAISY04 & DAISY05 & DAISY06 & DAISY07 & DAISY08 \\
\hline Starting Ball \# & A14 & A32 & P39 & AM39 & H1 & AF1 & AW26 & AW8 \\
\hline Ending Ball \# & A18 & A38 & V39 & AV39 & B1 & AB 1 & AW22 & AW2 \\
\hline Conductor. Length $\mathrm{mm}$ & 204 & 148 & 295 & 243 & 234 & 114 & 285 & 255 \\
\hline Stack on core & yes & yes & yes & yes & yes & yes & yes & yes \\
\hline Via/Pad size & large & large & large & large & small & smail & small & smiall \\
\hline Stacked vs Staggered & stacked & stacked & staggered & staggered & stacked & stacked & staggered & staggered \\
\hline Fillet & yes & no & yes & no & yes & no & yes & no. \\
\hline PKG01 & 6.1024 & 5.8436 & 7.3194 & 6.1291 & 7.6552 & 5.1744 & 9.0060 & 7.6234 \\
\hline PKG02 & 6.1749 & 5.8979 & 7.5852 & 6.3768 & 7.7700 & 5.1200 & 9.5619 & 8.1189 \\
\hline PKG03 & 6.7187 & 6.5867 & 7.8934 & 6.9085 & 8.3319 & 5.5067 & 9.7250 & 8.3183 \\
\hline PKG04 & 6.0238 & 5.7952 & 7.3496 & 6.2439 & 7.4618 & 4.9509 & 9.4954 & 7.6718 \\
\hline PKG05 & 6.1386 & 6.0973 & 7.6336 & 6.2318 & 7.7760 & 5.2590 & 9.4471 & 8.1008 \\
\hline PKG06 & 5.7036 & 5.4388 & 6.9810 & 5.5853 & 7.1779 & 4.6125 & 8.7281 & 7.0374 \\
\hline PKG07 & 6.1326 & 6.0007 & 7.2046 & 5.9901 & 7.6431 & 5.0838 & 8.8852 & 7.4784 \\
\hline PKG08 & 6.6703 & 6.3753 & 8.1411 & 7.0414 & 8.4044 & 5.4161 & 10.3170 & 9.1219 \\
\hline PKG09 & 6.0057 & 5.8677 & 7.3617 & 6.3224 & 7.6733 & 5.2590 & 9.2900 & 7.8651 \\
\hline PKG10 & 6.5978 & 6.4538 & 7.7967 & 6.6487 & 8.3621 & 5.4040 & 9.6223 & 8.3726 \\
\hline PKG11 & 6.2715 & 6.0973 & 7.4644 & 6.2982 & 7.9271 & 5.0113 & 9.1087 & .5086 \\
\hline PKG12 & 6.6643 & 6.3934 & 7.8209 & 6.7272 & 8.4769 & 5.6819 & 9.7492 & 8.5177 \\
\hline PKG13 & 5.9755 & 5.7106 & 7.3315 & 5.9176 & 7.4618 & 4.8784 & 9.1027 & 7.8289 \\
\hline PKG14 & 7.0147 & 6.8707 & 8.1230 & 7.2589 & 8.8092 & 5.7424 & 10.1420 & 8.9768 \\
\hline PKG15 & 6.0661 & 5.7227 & 7.3556 & 6.0022 & 7.7156 & 4.9509 & 9.0181 & .6718 \\
\hline PKG16 & 7.0147 & 7.1486 & 8.3586 & 7.6033 & 9.2865 & 6.1955 & 10.6130 & $9.6 \overline{173}$ \\
\hline PKG17 & 6.5072 & 6.2967 & 7.7121 & 6.4251 & 8.1748 & 5.5732 & 9.5861 & 8.6143 \\
\hline PKG18 & 6.2413 & 5.8919 & 7.5671 & 6.2197 & 7.7700 & 5.1442 & 9.3686 & 8.2397 \\
\hline PKG19 & 6.0117 & 5.7409 & 7.3858 & 6.0082 & 7.4739 & 4.8965 & 9.0604 & 7.6718 \\
\hline PKG20 & 6.1749 & 5.8919 & 7.4342 & 6.2439 & 7.4316 & 5.2167 & 9.3383 & 7.9799 \\
\hline PKG21 & 6.2413 & 6.0127 & 7.5731 & 6.2136 & 7.8062 & 5.0777 & 9.1813 & 8.0464 \\
\hline PKG22 & 6.3622 & 6.1517 & 7.6759 & 6.5218 & 7.5706 & 5.0536 & 9.3444 & 7.8047 \\
\hline PKG23 & 5.7157 & 5.4690 & 7.4100 & 6.1653 & 7.0268 & 4.7092 & 8.8791 & 7.2488 \\
\hline PKG24 & 5.9090 & 5.7167 & 7.0596 & 5.7484 & 7.3652 & 4.8904 & 8.7281 & 7.3213 \\
\hline PKG25 & 6.2957 & 6.1698 & 7.8027 & 6.7756 & 7.6854 & 5.2046 & 9.6284 & 8.6264 \\
\hline PKG26 & 6.2413 & 6.2061 & 7.7786 & 6.4735 & 7.7277 & 5.1502 & 9.6646 & 7.9316 \\
\hline PKG27 & 6.2897 & 5.9221 & 7.6336 & 6.2861 & 7.5887 & 4.8723 & 9.3565 & 7.6476 \\
\hline PKG28 & 5.9997 & 5.9100 & 7.5308 & 6.2620 & 7.3470 & 4.9388 & 9.1571 & 7.9678 \\
\hline PKG29 & 6.3199 & 6.2303 & 7.9236 & 6.7151 & 7.7760 & 5.2167 & 9.6404 & 8.2881 \\
\hline PKG30 & 6.1084 & 6.0550 & 7.4583 & 6.0747 & 7.4377 & 5.0536 & 9.2054 & 7.3334 \\
\hline PKG31 & 5.8003 & 5.4085 & 7.1019 & 5.8028 & 6.8999 & 4.8723 & 8.5529 & 7.2247 \\
\hline PKG32 & 6.1205 & 6.0007 & 7.3435 & 6.3345 & 7.3289 & 4.8300 & 8.9335 & 7.2247 \\
\hline PKG33 & 6.5072 & 6.1698 & 7.7000 & 6.5218 & 7.7639 & 5.4584 & 9.4411 & 8.2881 \\
\hline PKG34 & & 6.1698 & 7.7000 & 6.5218 & 7.7639 & 5.4584 & 9.4411 & 8.2881 \\
\hline PKG35 & 6.3320 & 6.0309 & 7.5550 & 6.0566 & 7.7156 & 5.3255 & 9.2175 & 7.6416 \\
\hline PKG36 & 6.5072 & 6.5384 & 8.0988 & 7.1683 & 8.0660 & 5.5430 & 9.6827 & 8.1008 \\
\hline PKG37 & 6.3682 & 6.1034 & 7.6698 & 6.2499 & 7.8727 & 5.2288 & 9.4350 & 8.3062 \\
\hline PKG38 & 6.6582 & 6.3088 & 7.8088 & 6.7272 & 8.1265 & 5.5974 & 9.4048 & 7.8772 \\
\hline PKG39 & 6.2232 & 5.9886 & 7.5792 & 6.5762 & 7.7398 & 5.5248 & 9.4471 & 8.2941 \\
\hline PKG40 & 6.1688 & 5.9705 & 7.7967 & 6.2680 & 7.5404 & 5.3073 & 9.2417 & 7.7201 \\
\hline PKG41 & 6.5616 & 6.4357 & 7.8934 & 6.7272 & 8.2352 & 5.9055 & 9.5982 & 8.7050 \\
\hline PKG42 & 6.3320 & 5.8859 & 7.7121 & 6.4795 & 7.7942 & 5.2227 & 9.4169 & 8.1853 \\
\hline PKG43 & 6.1447 & 5.9705 & 7.5308 & 6.2741 & 7.7096 & 5.0052 & 9.2477 & 8.2035 \\
\hline PKG44 & 6.1688 & 5.7227 & 7.3133 & 6.3768 & 7.4981 & 838 & 8.8852 & .5207 \\
\hline PKG45 & \begin{tabular}{l|l|}
6.3622 \\
\end{tabular} & 6.1517 & 7.6698 & 6.7393 & 7.7639 & 5.0415 & \begin{tabular}{|c|}
9.3625 \\
\end{tabular} & 7.8349 \\
\hline PKG46 & 6.6703 & 6.5505 & 7.9719 & 6.9810 & 8.1265 & 5.4765 & 9.6102 & 8.2216 \\
\hline PKG47 & \begin{tabular}{|l|}
5.9997 \\
\end{tabular} & 5.9402 & 7.5006 & 6.1895 & 7.4618 & 5.2590 & 9.1631 & 7.9255 \\
\hline PKG48 & 5.9513 & 5.4992 & 7.6517 & 6.2378 & 7.0268 & 4.7636 & 9.1631 & 7.5811 \\
\hline PKG49 & 6.1628 & 5.7952 & 7.2831 & 6.0928 & 7.3652 & 4.8965 & \begin{tabular}{|c|}
8.6435 \\
\end{tabular} & 7.0615 \\
\hline PKG50 & 6.6522 & 6.1396 & 7.8632 & 6.4916 & 8.2413 & 5.1623 & \begin{tabular}{|c|}
9.8096 \\
\end{tabular} & 8.6022 \\
\hline Mean & 6.2778 & 6.0549 & 7.6082 & 6.4047 & 7.7631 & 5.2041 & 9.3530 & 7.9872 \\
\hline$S D$ & 0.2952 & 0.3439 & 0.2861 & 0.3924 & 0.4448 & 0.3152 & 0.3985 & 0.5334 \\
\hline Max & 7.0147 & 7.1486 & 8.3586 & 7.6033 & 9.2865 & 6.1955 & 10.6130 & 9.6173 \\
\hline Min & 5.7036 & 5.4085 & 6.9810 & 5.5853 & 6.8999 & 4.6125 & 8.5529 & 7.0374 \\
\hline Diff & 1.3111 & 1.7401 & 1.3776 & 2.0180 & 2.3866 & 1.5830 & 2.0601 & 2.5799 \\
\hline
\end{tabular}


Table A-2: Daisy09 - Daisyl6.

\begin{tabular}{|c|c|c|c|c|c|c|c|c|}
\hline & DAISY09 & DAISY10 & DAISY 11 & DAISY12 & DAISY13 & DAISY14 & DAISY15 & DAISY16 \\
\hline Starting Ball \# & AW38 & AW19 & AV1 & $w_{1}$ & B39 & AA39 & A21 & A2 \\
\hline Ending Ball \# & AW29 & AW11 & AJ1 & L1 & $\angle 39$ & AJ39 & A29 & A11 \\
\hline Conductor. Length $\mathrm{mm}$ & 398 & 271 & 478 & 316 & 364 & 266 & 427 & 372 \\
\hline Stack on core & no & no & no & no & no & no & no & no \\
\hline Via/Pad size & large & large & large & large & small & small & small & small \\
\hline Stacked vs Staggered & stacked & stacked & staggered & staggered & stacked & stacked & staggered & staggered \\
\hline Fillet & yes & no & yes & no & yes & no & Yes & no \\
\hline PKG01 & 7.5086 & 8.1108 & 8.8666 & 8.2564 & 8.9446 & 8.0876 & 9.9995 & 10.8230 \\
\hline PKG02 & 7.5268 & 8.0444 & 9.4467 & 8.5404 & 8.3948 & 7.8701 & 10.0600 & 11.0290 \\
\hline PKG03 & 8.6385 & 8.7634 & 9.1627 & 8.7216 & 9.3857 & 9.0181 & 10.4530 & 11.4460 \\
\hline PKG04 & 7.7987 & 8.1531 & 8.6672 & 8.1537 & 8.7513 & 8.2145 & 10.2230 & 10.9200 \\
\hline PKG05 & 7.4301 & 7.9538 & 8.9814 & 8.4437 & 8.6002 & 7.9185 & 10.2410 & 11.2820 \\
\hline PKG06 & 6.9165 & 7.4946 & 8.1778 & 7.7791 & 7.9537 & 7.6103 & 9.4376 & 10.1530 \\
\hline PKG07 & 7.5389 & 7.9356 & 8.6975 & 8.0993 & 8.4613 & 8.2085 & 9.7578 & 10.7690 \\
\hline PKG08 & 8.4452 & 8.9326 & 10.0210 & 9.3560 & 9.4763 & 8.7281 & 11.3530 & 12.3340 \\
\hline PKG09 & 7.5086 & 7.9900 & 8.8364 & 8.4014 & 8.3646 & 7.9668 & 9.7820 & 10.8110 \\
\hline PKG10 & 8.1189 & 8.4915 & 9.2352 & 8.8062 & 9.1501 & 8.5106 & 10.5490 & 11.6150 \\
\hline PKG11 & 8.0343 & 8.7271 & 8.5706 & 8.0630 & 9.0594 & 8.6435 & 9.9451 & 10.5390 \\
\hline PKG12 & 8.4633 & 8.9749 & 9.5071 & 8.9029 & 9.3736 & 8.6797 & 10.5430 & 11.5600 \\
\hline PKG13 & 7.1703 & 8.0383 & 8.6612 & 8.2926 & 8.4854 & 7.8701 & 9.7880 & 10.7930 \\
\hline PKG14 & 8.4452 & 8.9144 & 9.7004 & 9.1748 & 9.5911 & 8.6133 & 11.3470 & 12.4060 \\
\hline PKG15 & 7.4361 & 8.0565 & 8.6431 & 8.5041 & 8.5942 & 7.9305 & 10.1750 & 10.8900 \\
\hline PKG16 & 8.8621 & 9.2165 & 10.5280 & 9.5252 & 9.7543 & 9.1329 & 11.7090 & 12.9020 \\
\hline PKG17 & 7.9255 & 8.8117 & 9.0600 & 8.4558 & 8.9446 & 8.3233 & 10.2050 & 11.1430 \\
\hline PKG18 & 7.6234 & 8.2136 & 9.1083 & 8.7035 & 8.5519 & 8.1480 & 10.0180 & 11.0040 \\
\hline PKG19 & 7.5207 & 8.0927 & 8.6672 & 8.2383 & 8.6727 & 7.8822 & 9.9028 & 10.7270 \\
\hline PKG20 & 7.7382 & 8.2921 & 8.8848 & 8.3954 & 8.6788 & 8.0695 & 10.0240 & 10.9740 \\
\hline PKG21 & 7.5207 & 8.1834 & 8.6129 & 3531 & 3546 & 7.9970 & 9.8968 & 10.8170 \\
\hline PKG22 & 7.7262 & 8.2196 & 8.8062 & 8.5524 & 8.8359 & 8.1964 & 10.2290 & 10.8410 \\
\hline PKG23 & 6.9769 & 7.4825 & 8.5162 & 8.3108 & 8.1350 & 7.6828 & 9.8605 & 10.5450 \\
\hline PKG24 & 7.2670 & 7.8994 & 8.1960 & 8.0993 & 8.3465 & 7.8762 & 9.4195 & 10.2070 \\
\hline PKG25 & 7.9074 & 8.2679 & 8.9814 & 8.5404 & 8.9748 & 8.3595 & 10.3860 & 11.1620 \\
\hline PKG26 & 8.2156 & 8.2438 & 8.8123 & 8.4679 & 9.0836 & 8.5649 & 0.4710 & 11.1800 \\
\hline PKG27 & 7.4845 & 7.9356 & 8.5766 & 8.2987 & 8.7936 & 8.1360 & 10.2650 & 11.0290 \\
\hline PKG28 & 7.2549 & 7.7181 & 8.6370 & 8.1114 & 8.2377 & 7.4713 & 9.9874 & 10.8470 \\
\hline PKG29 & 7.9558 & 8.4432 & 9.0298 & 8.8968 & 8.9205 & 8.2870 & 10.9000 & 11.2760 \\
\hline PKG30 & 7.8530 & 8.2438 & 8.5222 & 8.2383 & 8.6425 & 7.9970 & 9.9934 & 10.6120 \\
\hline PKG31 & 6.9467 & 7.7483 & 8.1537 & 7.7912 & 7.8691 & 7.5499 & 9.1113 & 9.8565 \\
\hline PKG32 & 7.5328 & 8.2256 & 8.4860 & 7.9120 & 8.4371 & 7.8762 & 9.4738 & 10.1530 \\
\hline PKG33 & 7.8772 & 8.1954 & 9.1506 & 8.5706 & 8.6486 & 7.8157 & 10.2170 & 11.2040 \\
\hline PKG34 & 7.8772 & 8.1954 & 9.1506 & 8.5706 & 8.6486 & 7.8157 & 10.2170 & 11.2040 \\
\hline PKG35 & 7.8530 & 8.3344 & 8.7820 & 8.5947 & 8.7815 & 8.0393 & 9.9511 & 10.7020 \\
\hline PKG36 & 8.3243 & 8.5096 & 9.1929 & 8.5222 & 9.3796 & 8.5891 & 10.6400 & 11.2760 \\
\hline PKG37 & 7.6416 & 8.2559 & 9.0298 & 8.3591 & 8.6848 & 8.0453 & 10.4280 & 11.4640 \\
\hline PKG38 & 8.8198 & 9.0957 & 8.8666 & 8.3893 & 9.3736 & 8.8973 & 10.4830 & 11.0410 \\
\hline PKG39 & 7.6597 & 8.4129 & 9.0358 & 8.7820 & 8.6969 & 8.1360 & 10.0780 & 11.0650 \\
\hline PKG40 & 7.6295 & 8.0988 & 8.8123 & 8.6370 & 8.6727 & 8.0997 & 10.2710 & 10.9920 \\
\hline PKG41 & 7.9980 & 8.3586 & 9.4165 & 8.8908 & 8.9567 & 8.5710 & 10.7060 & 11.5910 \\
\hline PKG42 & 7.9860 & 8.2800 & 9.1989 & 8.4195 & 8.6969 & 8.3172 & 10.6040 & 11.4640 \\
\hline PKG43 & 7.6234 & 8.2559 & 8.9512 & 8.3108 & 8.6244 & 8.2447 & 10.2410 & 11.1490 \\
\hline PKG44 & 7.5389 & 8.1773 & 8.7398 & 7.9241 & 8.5036 & 8.2326 & 9.8726 & 10.6720 \\
\hline PKG45 & 8.0464 & 8.4311 & 8.7700 & 8.2624 & 8.9930 & 8.5589 & 10.6040 & 11.0530 \\
\hline PKG46 & 8.1189 & 8.4311 & 9.3802 & 8.8968 & 9.4461 & 8.6918 & 10.8940 & 11.7290 \\
\hline PKG47 & 7.2368 & 7.9356 & 8.8848 & 8.1537 & 8.2619 & 7.6284 & 10.4410 & 10.7510 \\
\hline PKG48 & 7.2488 & 8.0927 & 8.5947 & 8.1416 & 8.3888 & 7.8278 & 10.4650 & 10.8470 \\
\hline PKG49 & 7.3516 & 8.2861 & 8.2685 & 7.8153 & 8.4733 & 7.8762 & 10.0900 & 10.5570 \\
\hline PKG50 & 8.2095 & 8.8903 & 9.2715 & 8.7458 & 9.1621 & 8.6012 & 11.1290 & 11.9350 \\
\hline Mean & 7.7666 & 8.2811 & 8.9250 & 8.4474 & 8.7703 & 8.1882 & 10.2568 & 11.0668 \\
\hline SD & 0.4579 & 0.3791 & 0.4447 & 0.3724 & 0.4166 & 0.3876 & 0.5004 & 0.5608 \\
\hline Max & 8.8621 & 9.2165 & 10.5280 & 9.5252 & 9.7543 & 9.1329 & 11.7090 & 12.9020 \\
\hline Min & 6.9165 & 7.4825 & 8.1537 & 7.7791 & 7.8691 & 7.4713 & 9.1113 & 9.8565 \\
\hline Diff & 1.9456 & 1.7340 & 2.3743 & 1.7461 & 1.8852 & 1.6616 & 2.5977 & 3.0455 \\
\hline
\end{tabular}


Figure A-1: Average electrical resistance at the $0^{\text {th }}$ cycle.

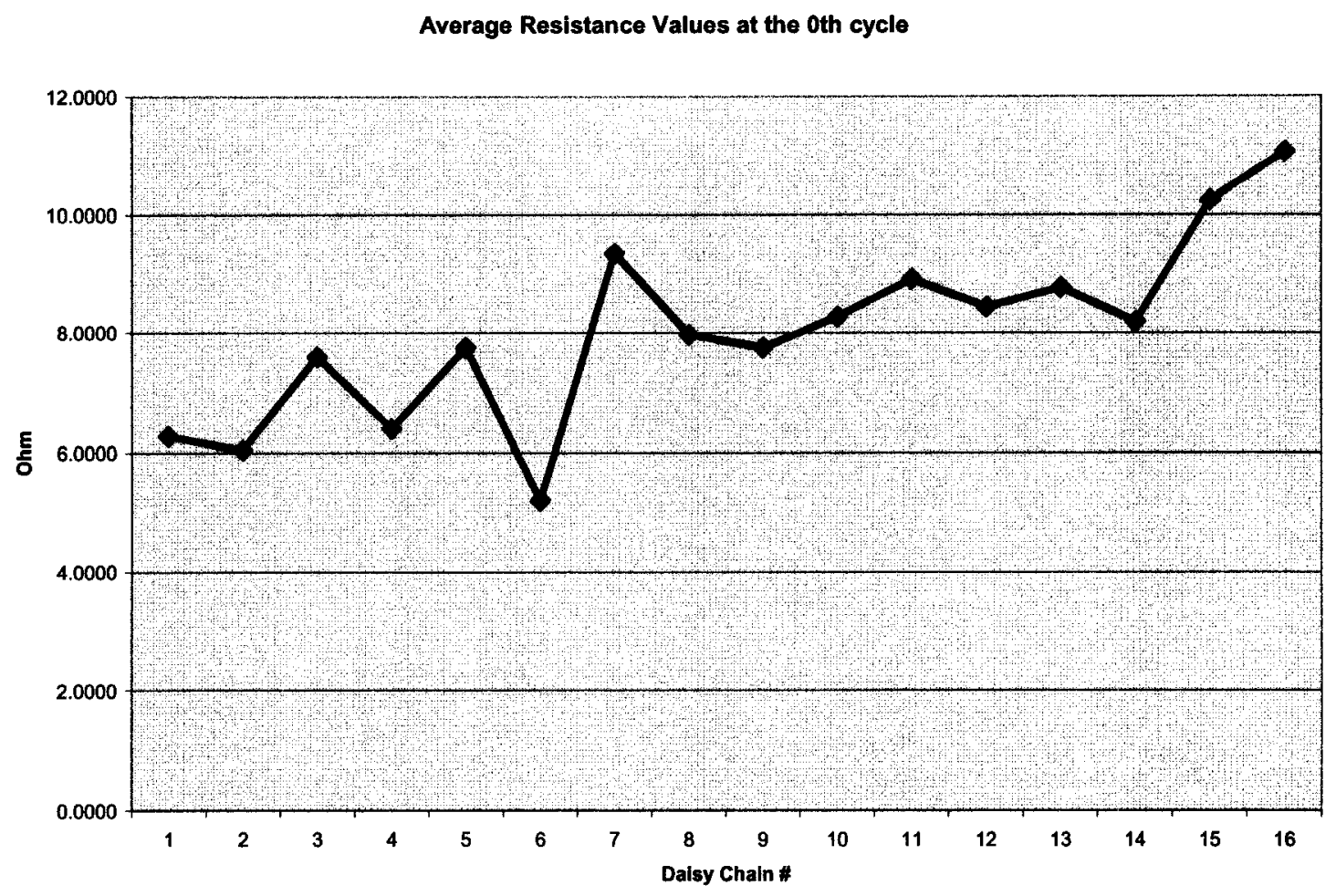




\section{APPENDIX B}

ANOVA of Electrical Resistance at the $0^{\text {th }}$ Cycle

Anova: Single

Factor

SUMMARY

\begin{tabular}{lrrrr}
\hline \multicolumn{1}{c}{ Groups } & \multicolumn{1}{c}{ Count } & \multicolumn{1}{c}{ Sum } & Average & Variance \\
\hline DAISY01 & 49 & 307.3844 & 6.273151 & 0.087858 \\
DAISY02 & 49 & 296.5759 & 6.052569 & 0.120441 \\
DAISY03 & 49 & 372.7093 & 7.606312 & 0.083363 \\
DAISY04 & 49 & 313.7133 & 6.402312 & 0.15691 \\
DAISY05 & 49 & 380.3907 & 7.763076 & 0.201996 \\
DAISY06 & 49 & 254.7486 & 5.198951 & 0.100047 \\
DAISY07 & 49 & 458.2067 & 9.351157 & 0.161976 \\
DAISY08 & 49 & 391.0703 & 7.981027 & 0.288474 \\
DAISY09 & 49 & 380.4548 & 7.764384 & 0.213776 \\
DAISY10 & 49 & 405.8602 & 8.282861 & 0.146558 \\
DAISY11 & 49 & 437.0996 & 8.9204 & 0.200802 \\
DAISY12 & 49 & 413.8014 & 8.444927 & 0.141219 \\
DAISY13 & 49 & 429.864 & 8.772735 & 0.176885 \\
DAISY14 & 49 & 401.5925 & 8.195765 & 0.15044 \\
DAISY15 & 49 & 502.6212 & 10.25758 & 0.255598 \\
DAISY16 & 49 & 542.1375 & 11.06403 & 0.320691 \\
\hline
\end{tabular}

ANOVA

\begin{tabular}{lcrrrrr}
\hline Source of Variation & \multicolumn{1}{c}{$S S$} & \multicolumn{1}{c}{ df } & \multicolumn{1}{c}{$M S$} & $F$ & $P$-value & $F$ crit \\
\hline Between Groups & 1739.707 & 15 & 115.9805 & 661.0846 & 0 & 1.679419 \\
Within Groups & 134.7377 & 768 & 0.17544 & & & \\
& & & & & & \\
Total & 1874.445 & 783 & & & & \\
\hline
\end{tabular}




\section{APPENDIX C-1}

Measured Electrical Resistances at the Measured Temperature Cycles

Table C-1-1: TCB238 ${ }^{\text {th }}$ cycle; Daisy01 - Daisy08.

\begin{tabular}{|c|c|c|c|c|c|c|c|c|}
\hline & DAISY01 & DAISY02 & DAISYO3 & DAISY04 & DAISY05 & DAISY06 & DAISY07 & DAISY08 \\
\hline PKG01 & 6.1069 & 6.1724 & 7.4886 & 6.0566 & 8.0117 & 5.4282 & 9.1692 & 8.0222 \\
\hline PKG02 & 6.2519 & 6.0576 & 8.1653 & 6.7816 & 8.0117 & 5.7182 & 10.0510 & 8.7291 \\
\hline PKG03 & 6.6809 & 6.8853 & 8.0746 & 6.9931 & 8.6823 & 5.7544 & 10.1240 & 9.1037 \\
\hline PKG04 & 6.1371 & 6.1301 & 7.5429 & 6.6728 & 7.6552 & 5.8149 & 9.5921 & 7.7624 \\
\hline PKG05 & 6.2519 & 6.3234 & 7.8148 & 6.6305 & 7.9633 & 5.9236 & 9.6767 & 8.1128 \\
\hline PKG06 & 5.8592 & 5.6709 & 7.0837 & 5.6699 & 7.1839 & 5.4705 & 9.0785 & 7.4482 \\
\hline PKG07 & 6.1190 & 6.1663 & 7.3375 & 6.0626 & 7.6612 & 5.6517 & 9.1752 & 7.7926 \\
\hline$\overline{\text { PKG08 }}$ & 6.5963 & 6.5651 & 8.1955 & 7.1683 & 8.3198 & 5.4946 & 10.4140 & 9.4602 \\
\hline PKG09 & 6.0102 & 5.9609 & 7.5671 & 6.4432 & 7.5766 & 5.7967 & 9.6948 & 7.9678 \\
\hline PKG10 & 6.7534 & 6.7161 & 7.8329 & 6.7876 & 8.3500 & 5.9599 & 9.8338 & 8.7110 \\
\hline PKG11 & 6.3002 & 6.1180 & 7.5369 & 6.9810 & 7.8787 & 5.4584 & 9.3323 & 7.7987 \\
\hline PKG12 & 6.5419 & 6.5470 & 7.7967 & 7.2408 & 8.4225 & 5.8330 & 9.8882 & 8.5056 \\
\hline PKG13 & 5.9498 & 5.6709 & 7.4463 & 6.0143 & 7.3652 & 5.1079 & 9.3263 & 7.9618 \\
\hline PKG14 & 6.8742 & 7.1451 & 8.1834 & 7.3254 & 8.6944 & 5.6940 & 10.2270 & 9.3877 \\
\hline PKG15 & 6.0767 & 5.9669 & 7.3677 & 6.0082 & 7.5102 & 5.1079 & 9.3021 & 8.1491 \\
\hline PKG16 & 7.1824 & 7.2962 & 8.4372 & 7.6456 & 9.2140 & 6.3043 & 10.7700 & 10.0100 \\
\hline PKG17 & 6.3365 & 6.3415 & 7.7604 & 6.5339 & 8.0177 & 5.5248 & 9.5861 & 8.3424 \\
\hline PKG18 & 6.2459 & 6.1482 & 7.5611 & 6.4614 & 7.8123 & 5.2046 & 9.3988 & 8.3424 \\
\hline PKG19 & 6.0223 & 5.8703 & 7.4100 & 6.2257 & 7.4800 & 4.9811 & 9.1087 & 7.8772 \\
\hline PKG20 & 6.1250 & 6.0032 & 7.5308 & 6.5399 & 7.4921 & 5.0415 & 9.4229 & 8.2458 \\
\hline PKG21 & 6.2398 & 6.1784 & 7.5248 & 6.2982 & 7.7035 & 5.2167 & 9.2235 & 7.6839 \\
\hline PKG22 & 6.2036 & 6.0394 & 7.8390 & 6.4976 & 7.5706 & 5.0777 & 9.4169 & 8.2578 \\
\hline PKG23 & 5.8229 & 5.6225 & 7.5188 & 5.9901 & 6.9845 & 4.7333 & 8.9637 & 7.8409 \\
\hline PKG24 & 5.9861 & 5.7978 & 7.1683 & 5.5369 & 7.3168 & 4.9509 & 8.6375 & 7.4663 \\
\hline PKG25 & 6.3184 & 6.2509 & 8.2015 & 6.7151 & 7.6491 & 5.3134 & 9.5740 & 8.4029 \\
\hline PKG26 & 6.3425 & 6.3536 & 7.6879 & 6.4493 & 7.6431 & 5.1563 & 9.4954 & 8.1128 \\
\hline PKG27 & 6.2096 & 5.9669 & 7.6275 & 6.3405 & 7.5162 & 4.9750 & 9.1208 & 7.7564 \\
\hline PKG28 & 5.9136 & 5.9790 & 7.4644 & 6.2076 & 7.3229 & 5.0657 & 9.0906 & 7.8953 \\
\hline PKG29 & 6.3969 & 6.1784 & 7.8269 & 6.7212 & 7.7639 & 5.3255 & 9.5800 & 8.3485 \\
\hline PKG30 & 6.0102 & 5.8582 & 7.4825 & 6.0988 & 7.4135 & 5.3678 & 9.0785 & 7.5086 \\
\hline PKG31 & 5.6235 & 5.4715 & 7.0052 & 5.5551 & 6.9543 & 4.7092 & 8.5287 & 7.2549 \\
\hline PKG32 & 6.0223 & 6.0032 & 7.2106 & 5.8572 & 7.4256 & 4.8421 & 8.8973 & 7.1824 \\
\hline PKG33 & 6.3667 & 6.1784 & 7.6698 & 6.3224 & 7.7760 & 5.2530 & 9.4108 & 8.5902 \\
\hline PKG34 & 5.9619 & 5.8098 & 7.6215 & 6.1109 & 7.1779 & 4.7817 & 9.0967 & 7.6718 \\
\hline PKG35 & 6.2761 & 6.0576 & 7.4704 & 5.9720 & 7.6552 & 5.1321 & 9.1510 & 7.8832 \\
\hline PKG36 & 6.4271 & 6.6739 & 8.1834 & 6.8843 & 7.9815 & 5.5007 & 9.6707 & 8.4693 \\
\hline PKG37 & 6.3063 & 6.1240 & 7.7121 & 6.2136 & 7.7821 & 5.2771 & 9.2054 & 8.3545 \\
\hline PKG38 & 6.4694 & 99 & 7.8148 & 6.4312 & 8.0721 & 5.2650 & 9.3021 & 8.1249 \\
\hline PKG39 & 6.1975 & 5.9851 & 7.5067 & 6.2076 & 7.6733 & 5.1321 & 9.3806 & 8.4089 \\
\hline PKG40 & 6.1311 & 5.9851 & 7.7363 & 6.2318 & 7.4135 & 4.9267 & 9.1873 & 7.6657 \\
\hline PKG41 & 6.4150 & 6.4745 & 7.9598 & 6.6910 & 8.0358 & 5.6336 & 9.5559 & 8.7050 \\
\hline PKG42 & 6.1915 & .0032 & 7.7242 & 6.2861 & 7.6431 & 5.2167 & 9.3504 & 8.4149 \\
\hline PKG43 & 6.1311 & 0032 & 7.4463 & 6.1170 & 7.5646 & 5.1382 & 9.2054 & 8.1128 \\
\hline PKG44 & 6.0465 & 5.8582 & 7.2590 & 5.9478 & 7.4014 & 4.9811 & 8.9214 & 7.7080 \\
\hline PKG45 & 6.2821 & 6.2328 & 7.7242 & 6.6003 & 7.6129 & 5.1200 & 9.3988 & 8.0645 \\
\hline PKG46 & 6.5359 & 6.4866 & 7.9719 & 6.7695 & 7.9754 & 5.4040 & 9.5559 & 8.2216 \\
\hline PKG47 & 136 & & 7.3254 & 6.1109 & 7.3168 & 5.1986 & 331 & 7.9437 \\
\hline PKG48 & 5.8290 & 5.6890 & 7.5308 & 6.0686 & 6.9362 & 4.6910 & 9.1087 & 7.6476 \\
\hline PKG49 & 6.0344 & 5.9065 & 7.1804 & 5.8934 & 7.3229 & 4.9629 & 8.6979 & 7.2549 \\
\hline PKG50 & 6.5842 & 6.2086 & 7.9236 & 6.4674 & 8.1446 & 5.2348 & 9.7311 & 8.6022 \\
\hline Mean & 6.2322 & 6.1489 & 7.6490 & 6.3967 & 7.7210 & 5.2971 & 9.3974 & 8.1457 \\
\hline SD & 0.2881 & 0.3641 & 0.3170 & 0.4485 & 0.4523 & 0.3569 & 0.4299 & 0.5647 \\
\hline Max & 7.1824 & 7.2962 & 8.4372 & 7.6456 & 9.2140 & 6.3043 & 10.7700 & 10.0100 \\
\hline Min & 5.6235 & 5.4715 & 7.0052 & 5.5369 & 6.9362 & 4.6910 & 8.5287 & 7.1824 \\
\hline Diff & 1.5589 & 1.8247 & 1.4320 & 2.1087 & 2.2778 & 1.6133 & 2.2413 & 2.8276 \\
\hline
\end{tabular}


Table C-1-2: TCB 238 ${ }^{\text {th }}$ cycle; Daisy09 - Daisyl6.

\begin{tabular}{|c|c|c|c|c|c|c|c|c|}
\hline & AISY09 & DAISY10 & DAISY11 & DAISY12 & DAISY13 & DAISY14 & DAISY15 & DAISY16 \\
\hline PKG01 & 7.8107 & 8.2498 & 8.9754 & 8.2806 & 8.5217 & 8.0514 & 10.3200 & 10.8840 \\
\hline PKG02 & 7.8168 & 8.6123 & 9.7790 & 8.4256 & 8.4371 & 8.1843 & 10.5980 & 11.5780 \\
\hline PKG03 & 9.0010 & 9.1803 & 9.7125 & 8.4497 & 9.4944 & 8.7160 & 0.5980 & 1.6450 \\
\hline PKG04 & 7.9618 & 8.7573 & 9.2050 & 8.1476 & 8.7634 & 8.4199 & 10.1570 & 0.8230 \\
\hline PKG05 & 7.5630 & 8.5519 & 9.2171 & 8.5464 & 8.6063 & 7.8157 & 10.8330 & 11.4150 \\
\hline PKG06 & 6.9769 & 8.0202 & 8.3410 & 7.7549 & 8.0383 & 7.4834 & 9.4497 & 10.2010 \\
\hline PKG07 & 7.5811 & 8.3465 & 8.7639 & 8.0328 & 8.6304 & 7.8520 & 10.5130 & 10.8290 \\
\hline PKG08 & 8.6445 & 9.3193 & 10.0870 & 9.1687 & 9.5126 & 8.6979 & 11.4980 & 12.6120 \\
\hline PKG09 & 7.5509 & 8.0927 & 8.9875 & 8.4860 & 8.3102 & 7.7070 & 10.0780 & 10.8780 \\
\hline PKG10 & 8.1551 & 8.7694 & 258 & 8.8546 & 9.1863 & 8.5589 & 10.9060 & 11.5480 \\
\hline PKG11 & 47 & 8.6546 & 491 & 8.1960 & 9.1138 & 8.7341 & 10.3740 & 10.6660 \\
\hline PKG12 & 8.4331 & 65 & 796 & 8.7820 & 9.3132 & 8.7160 & 0.5800 & 11.5660 \\
\hline PKG13 & 7.2186 & 325 & 339 & 8.1174 & 8.3525 & 7.8157 & 10.1140 & 10.7870 \\
\hline PKG14 & 8.4452 & 634 & 581 & 9.0660 & 9.6153 & 8.7583 & 11.2260 & 12.5090 \\
\hline PKG15 & 7.4543 & 7.9356 & 485 & 8.3349 & 8.4190 & 7.7976 & 9.9995 & 11.0230 \\
\hline PKG16 & 8.9769 & 9.3193 & 10.9030 & 9.4346 & 9.8328 & 8.9758 & 12.1260 & 13.0100 \\
\hline PKG17 & 551 & 8.7996 & 9.3017 & 8.4316 & 8.9869 & 8.4985 & 10.5490 & 11.1370 \\
\hline PKG18 & 7.6537 & 8.4009 & 379 & 8.4497 & 8.6788 & 8.2326 & 10.3800 & 11.1010 \\
\hline PKG19 & 207 & 202 & 325 & 8.1356 & 8.4431 & 7.7734 & 9.9934 & 10.8050 \\
\hline PKG20 & & & & 364 & 8.5821 & 16 & 0780 & 10.9320 \\
\hline PKG21 & & 32 & & 74 & 5821 & 01 & 1140 & 20 \\
\hline PKG22 & & 94 & & 91 & 8419 & 43 & 470 & 110 \\
\hline PKG23 & 78 & 79 & & 12 & 8.0806 & 47 & 300 & 370 \\
\hline PKG24 & 7.6778 & 992 & 58 & 7.8153 & 8.2860 & 7.8943 & 5645 & 10.1040 \\
\hline PKG25 & 370 & 129 & 667 & 8.5645 & 8.8359 & 8.3958 & .5190 & 11.0470 \\
\hline PKG26 & 83 & 50 & 787 & 8.3833 & 8.9990 & 8.4199 & 10.5610 & 11.0100 \\
\hline PKG27 & & & 31 & 8.3349 & 8.6365 & 8.0876 & 10.2530 & 10.8900 \\
\hline PKG28 & 22 & 7.8994 & 491 & 8.1356 & 8.1773 & 7.7855 & 9874 & 10.7750 \\
\hline PKG29 & 76 & 300 & 98 & 8.5283 & 8.8902 & 8.4320 & .5610 & 11.3490 \\
\hline PKG30 & & 44 & 93 & 37 & 8.7211 & 8.2024 & 2230 & 10.6000 \\
\hline PKG31 & & 42 & 16 & 7.6099 & 7.7181 & 07 & 1717 & 9.7961 \\
\hline PKG32 & 74 & & 20 & 7.8214 & 8.4733 & 05 & 5826 & 10.1340 \\
\hline PKG33 & 7.7262 & & 94 & 8.4981 & 8.6123 & 64 & 2470 & 1.1560 \\
\hline PKG34 & & & & 12 & 190 & 191 & 1930 & 0.7750 \\
\hline PKG35 & & & & 8.0449 & 8.7090 & 8.4018 & 0360 & 10.6120 \\
\hline PKG36 & 20 & 540 & 171 & 8.4377 & 9.2286 & 8.5287 & 6880 & 11.1370 \\
\hline PKG37 & 784 & 250 & 264 & 8.2866 & 8.9688 & 7.9789 & 2650 & 11.1740 \\
\hline PKG38 & 727 & 386 & 271 & 8.2866 & 9.5005 & 8.7523 & 3620 & 10.9020 \\
\hline PKG39 & 7.7020 & 580 & 902 & 8.2745 & 8.9023 & 8.1058 & 10.2470 & 10.9740 \\
\hline PKG40 & 7.7503 & 165 & 381 & 8.2081 & 8.8177 & 8.0091 & 10.3440 & 10.8650 \\
\hline PKG41 & 18 & & 38 & 8.6914 & 8.9748 & 8.2447 & 9420 & 11.3850 \\
\hline PKG42 & & & & 16 & 04 & 55 & 960 & 310 \\
\hline PKG43 & & & & & 8.5036 & 80 & 1570 & 780 \\
\hline PKG44 & & & & 9966 & 8.5217 & 7.8520 & 3061 & 10.5820 \\
\hline PKG45 & 8.1068 & 036 & 062 & 8.2685 & 8.9205 & 8.4381 & 10.4100 & 10.8410 \\
\hline PKG46 & 572 & 80 & & 8.6672 & 15 & 8.6072 & 10.7120 & 11.5660 \\
\hline PKG47 & 32 & 571 & 666 & 8.2685 & 8.2619 & 7.7251 & 8061 & 10.6780 \\
\hline PKG48 & & & & 72 & & 7.7 & 10.4650 & 10.8290 \\
\hline PKG49 & 66 & 11 & & 7.7066 & 8.4311 & 7.7614 & 9.7155 & 10.4790 \\
\hline PKG50 & 156 & 59 & 319 & 8.6250 & 9.1440 & 8.6918 & 10.6820 & 11.5600 \\
\hline Mean & 7.8023 & 8.4426 & 477 & 8.3284 & 8.7461 & 8.1496 & 10.3352 & 11.0226 \\
\hline SD & 0.4637 & 0. & 608 & 0.3515 & 0.4419 & 0.3906 & 0.5003 & 0.5873 \\
\hline $\mathrm{Ma}$ & & & 10. & 9.4346 & 9.8328 & 8.9758 & 12.1260 & 13.0100 \\
\hline Min & & & & 6099 & 7.7181 & 7.3807 & .1717 & 9.7961 \\
\hline Diff & 2.1026 & 1.5951 & 2.5620 & 1.8247 & 2.1147 & 1.5951 & 2.9543 & 3.2139 \\
\hline
\end{tabular}


Table C-1-3: TCB $457^{\text {th }}$ cycle; Daisy01 - Daisy08.

\begin{tabular}{|c|c|c|c|c|c|c|c|c|}
\hline & AISY01 & DAISY02 & DAISY03 & DAISY04 & DAISY05 & \begin{tabular}{|l|} 
DAISY06 \\
\end{tabular} & DAISY07 & AISY08 \\
\hline PKG01 & 6.2036 & 6.0213 & 7.4946 & 6.1109 & 7.7458 & 5.3557 & 9.2538 & 7.7503 \\
\hline PKG02 & 6.3365 & 6.4140 & 7.8994 & 7.3677 & 7.9633 & 5.4161 & .7915 & 8.5237 \\
\hline PKG03 & 6.7292 & 7.0726 & 8.1411 & 7.3677 & 8.4467 & 5.7847 & 9.9667 & 8.7231 \\
\hline PKG04 & 6.1069 & 6.1603 & 7.5369 & 6.7635 & 7.5766 & 5.2348 & 9.4652 & 7.9437 \\
\hline PKG05 & 6.3486 & 6.4866 & 7.7423 & 6.8360 & 7.8848 & 5.4584 & 9.5438 & 8.6989 \\
\hline PKG06 & 3410 & 5.7434 & 7.2046 & 6.0988 & 7.2262 & 5.1382 & .9879 & 7.5086 \\
\hline PKG07 & 311 & 6.4443 & 7.4100 & 6.4312 & 7.7337 & 3678 & 510 & 7.6476 \\
\hline PKG08 & 6.6144 & 6.5349 & 8.3103 & 7.3133 & 8.3379 & 5.7967 & 10.4620 & 9.1521 \\
\hline PKG09 & 6.1009 & 6.2751 & 7.5611 & 6.5943 & 7.6431 & 5.8934 & 5256 & 1793 \\
\hline PKG10 & 7413 & 6.6195 & 7.9236 & 6.8481 & 8.4406 & 5.6699 & 3640 & 8.2941 \\
\hline PKG11 & 6.3486 & 6.2449 & 7.5550 & 6.4432 & 7.8244 & 5.2288 & 3202 & 7.4180 \\
\hline PKG12 & 6.6628 & 6.7766 & 7.8813 & 6.9145 & 8.4890 & 5.9236 & 063 & 8.7050 \\
\hline PKG13 & 6.0102 & 5.9790 & 7.3315 & 6.2016 & 7.3289 & 5.1925 & 9.2598 & 7.7624 \\
\hline PKG14 & 7.0072 & 7.2358 & 8.3405 & 7.4402 & 8.7730 & 5.9297 & 10.2390 & 8.9406 \\
\hline PKG15 & 6.1734 & 5.8823 & 7.5127 & 6.1895 & 7.7639 & 5.0959 & 900 & 7.6416 \\
\hline PKG16 & & 7.3445 & 8.4855 & & 201 & 043 & 10.8370 & 9.8590 \\
\hline PKG17 & & 6.5409 & 7.6 & & & 5.6457 & 371 & 4885 \\
\hline PKG18 & & 9 & 7.8 & & & & & 326 \\
\hline KG19 & 283 & 5.9186 & 7.5852 & & & & & 926 \\
\hline PKG20 & 50 & 5.9730 & 7.5490 & & & 382 & 773 & 672 \\
\hline PKG21 & & 42 & 7.5 & & & 590 & & 597 \\
\hline PKG22 & & 515 & 7.7121 & 762 & & 00 & 15 & 591 \\
\hline PKG23 & 202 & 5286 & 7.4644 & 6.2439 & 845 & 4.8481 & 571 & 697 \\
\hline PKG24 & 954 & 8582 & 7.1019 & 5.6880 & 7.3470 & 5.0173 & 979 & 7.0797 \\
\hline PKG25 & 821 & 2509 & 7.9477 & 7.0535 & 7.7398 & 650 & 552 & 8.1128 \\
\hline PKG26 & 942 & 6.3899 & 7.7604 & 6.7272 & 7.6431 & 5.2288 & 223 & 7.8349 \\
\hline PKG27 & 244 & 34 & 7.6577 & 768 & 62 & 750 & & 7.9678 \\
\hline PKG28 & 81 & 6.0032 & 7.5188 & 361 & 866 & 925 & 054 & 7.7201 \\
\hline PKG29 & & & 17 & & & & & 666 \\
\hline PKG30 & & 39 & 7.4946 & & & & & 784 \\
\hline PKG31 & & 473 & & & & 44 & & 265 \\
\hline KG32 & 46 & 51 & 7.3435 & 30 & 12 & 69 & & 213 \\
\hline PKG33 & 788 & 6.3476 & 7.7000 & 6.5278 & 156 & 859 & 56 & 8.3183 \\
\hline PKG34 & 342 & 5.8642 & 7.5671 & 395 & 33 & 300 & 340 & 7.4059 \\
\hline PKG35 & 184 & 6.0999 & 7.3919 & 03 & 519 & 227 & 325 & 7.7322 \\
\hline PKG36 & 419 & 6.7464 & 8.1532 & 370 & 7.9754 & 248 & 915 & 8.2941 \\
\hline PKG37 & 150 & 6.2026 & 7.6275 & 6.2499 & 123 & 5.3496 & 169 & 7.9497 \\
\hline PKG38 & 023 & 6.3899 & 7.6879 & 6.4976 & 023 & 5.2771 & 652 & 7.6416 \\
\hline PKG39 & 821 & 6.0455 & 7.6336 & 6.3768 & 7.7277 & 5.1744 & 075 & 7.9980 \\
\hline PKG40 & 52 & 0636 & 7.6940 & 828 & 102 & 4.9629 & 988 & 7.7382 \\
\hline PKG41 & & & 2 & & & 313 & & 814 \\
\hline PKG42 & & & & & & & & 524 \\
\hline PKG43 & 34 & 92 & 7.6 & 22 & 87 & 884 & 38 & 376 \\
\hline PKG44 & 44 & 51 & 33 & 172 & 18 & 61 & 58 & 301 \\
\hline PKG45 & 727 & 6.2992 & 7.7484 & 943 & 512 & 288 & 740 & 7.6959 \\
\hline PKG46 & 6.5661 & 6.6316 & 8.0807 & 6.8420 & 8.0600 & 5.4826 & .6404 & 8.2216 \\
\hline PKG47 & 706 & 0032 & 7.4281 & 6.2439 & 7.3652 & 5.3315 & 9.2235 & 7.8168 \\
\hline PKG48 & 075 & 5.7253 & 7.6034 & 36 & 6.9724 & 4.8300 & 296 & 7.4663 \\
\hline PKG49 & 767 & 549 & 7.1985 & 5.8270 & 7.4256 & 4.9690 & 825 & 6.9649 \\
\hline PKG50 & 023 & 2630 & 7.8571 & 6.5762 & 8.3138 & 5.2409 & 9.8640 & 8.3424 \\
\hline Mean & 328 & 6.2236 & 7.6662 & 6.5038 & 7.7490 & 5.3023 & 9.4977 & 7.9721 \\
\hline SD & 22 & 0.3825 & 0.3077 & 0.4738 & 0.4548 & 0.3126 & 114 & 0.5478 \\
\hline Mas & 30 & 445 & 4855 & 7.9417 & 9.2201 & 6.3043 & 10.8370 & 9.8590 \\
\hline Min & & 473 & & .5430 & & 4.8300 & 8.6979 & 6.9649 \\
\hline Diff & 1.5528 & 1.8972 & 1.5226 & 2.3987 & 2.3081 & 1.4743 & 2.1391 & 2.8941 \\
\hline
\end{tabular}


Table C-1-4: TCB $457^{\text {th }}$ cycle; Daisy09 - Daisy16.

\begin{tabular}{|c|c|c|c|c|c|c|c|c|}
\hline & DAISY09 & DAISY10 & DAISY11 & DAISY12 & DAISY13 & DAISY14 & DAISY15 & DAISY16 \\
\hline PKG01 & 7.6416 & 8.2740 & 8.9814 & 8.3833 & 8.6727 & 8.0453 & 10.5980 & 10.9680 \\
\hline PKG02 & 7.8107 & 8.8782 & 9.4225 & 8.5102 & 8.7029 & 8.0635 & 10.5730 & 11.2820 \\
\hline PKG03 & 8.8318 & 9.2951 & 9.4648 & 8.5343 & 9.6032 & 8.9093 & 10.8700 & 11.6330 \\
\hline PKG04 & 8.1068 & 8.9809 & 8.8485 & 8.3229 & 8.9567 & 8.3233 & 10.2830 & 10.8410 \\
\hline PKG05 & 7.7685 & 8.8117 & 9.1687 & 8.5827 & 8.6848 & 8.0030 & 10.5310 & 11.5300 \\
\hline PKG06 & 7.2186 & 8.1954 & 8.3531 & 7.7549 & 867 & 7.5922 & 9.4980 & 10.2730 \\
\hline PKG07 & 7.7262 & 8.0806 & 8.6431 & 8.1416 & 8.7150 & 7.9245 & 9.8605 & 10.7690 \\
\hline PKG08 & 8.8077 & 9.0594 & 10.0450 & 9.2292 & 9.5005 & 8.8731 & 11.4070 & 12.4180 \\
\hline PKG09 & 7.6355 & 8.1531 & 8.9693 & 8.3591 & 8.3888 & 7.7976 & 10.0420 & 10.8410 \\
\hline PKG10 & 8.4633 & 8.9326 & 9.3621 & 8.7579 & 9.2890 & 8.4502 & 10.7430 & 11.7050 \\
\hline PKG11 & 8.3062 & 8.7090 & 8.8123 & 8.1658 & 9.0896 & 8.5649 & 10.3320 & 10.7200 \\
\hline PKG12 & 8.5418 & 9.1924 & 9.9421 & 8.8485 & 9.2951 & 8.7281 & 10.6880 & 11.7600 \\
\hline PKG13 & 7.4845 & 8.4673 & 9.0600 & 8.4195 & 8.2860 & 7.8218 & 10.2110 & 10.8720 \\
\hline PKG14 & 8.4693 & 9.2045 & 10.0630 & 9.1023 & 9.5730 & 8.7281 & 11.4250 & 12.7080 \\
\hline PKG15 & 7.4120 & 8.4009 & 8.6491 & 8.2322 & 8.5398 & & 10.2470 & 11.0100 \\
\hline PKG16 & 8.8439 & 9.5307 & 10.5890 & 9.5917 & & & 610 & \\
\hline PKG17 & 8.2035 & 8.8057 & 9.5615 & 8.4497 & 8.9507 & & 010 & 070 \\
\hline PKG18 & 7.7201 & 36 & 9.3319 & 8.4497 & 8.6727 & 06 & 890 & 520 \\
\hline PKG19 & 7.4905 & 8.3163 & 8.8364 & 8.3410 & 8.4915 & 349 & 200 & 530 \\
\hline PKG20 & 7.8289 & 9.0957 & 9.0721 & 8.2503 & 8.5519 & 8.2266 & 10.2350 & 680 \\
\hline PKG21 & 7.6416 & 8.5338 & 8.6854 & 8.0812 & 8.5036 & 7.9789 & 10.0780 & 10.8960 \\
\hline PKG22 & 7.8712 & 8.6123 & 8.7941 & 8.2503 & 8.6788 & 8.4260 & 10.9360 & 10.9560 \\
\hline PKG23 & 7.2609 & 8.0383 & 8.5222 & 7.9422 & 8.1531 & 7.7372 & 10.0600 & 10.5690 \\
\hline PKG24 & 7.3516 & 8.3525 & 8.3712 & 7.7972 & 8.2740 & 7.9 & 395 & 10.2250 \\
\hline PKG25 & 8.0524 & 8.4975 & 9.0600 & 8.3108 & 8.9809 & & 10.7250 & 11.2460 \\
\hline PKG26 & & 80 & & & & & & \\
\hline PKG27 & 32 & 8.4975 & 8.7277 & 39 & 11 & & 880 & 330 \\
\hline PKG28 & 34 & 34 & 8.7156 & 7.9845 & 10 & 91 & 320 & 720 \\
\hline PKG29 & 8.0464 & 8.8540 & 9.1989 & 8.5464 & 8.9325 & 97 & 180 & 270 \\
\hline PKG30 & 7.7685 & 8.4855 & 8.6552 & 7.9603 & 8.6727 & 64 & 10.2710 & 10.7870 \\
\hline PKG31 & 7.0555 & 7.8269 & 8.2081 & 7.5193 & 7.7664 & 7.4351 & 9.5040 & 10.1340 \\
\hline PKG32 & 7.9376 & 8.3042 & 8.4920 & 7.8032 & 8.4613 & 091 & 9.7095 & 10.4430 \\
\hline PKG33 & 8.0283 & 8.4734 & 9.2715 & 8.5041 & 8.5217 & 37 & 10.4710 & 11.4940 \\
\hline PKG34 & 7.6234 & 8.0867 & 8.8243 & 8.0933 & 8.3646 & 7.8459 & 0.4220 & 10.9080 \\
\hline PKG35 & 7.7805 & 8.9567 & 9.0962 & 8.1295 & 8.6848 & & 10.0780 & 10.7330 \\
\hline PKG36 & 572 & 84 & 9.3862 & 77 & 9.2 & & 10 & 210 \\
\hline PKG37 & 82 & 8.6 & & & & & & \\
\hline PKG38 & 8.5418 & 09 & 06 & 8.2 & 15 & 14 & 60 & 280 \\
\hline PKG39 & 7.8833 & 38 & 04 & 8.3 & 8.6 & & 40 & 430 \\
\hline PKG40 & 7.7322 & 8.5761 & 9.2533 & 8.1778 & 8.6606 & 364 & 10.4160 & 800 \\
\hline PKG41 & 8.0706 & 8.7453 & 9.6763 & 8.6310 & 8.9627 & 8.2931 & 10.7250 & 11.8560 \\
\hline PKG42 & 7.9376 & 8.2861 & 9.5313 & 8.3772 & 8.6304 & 8.1541 & 10.3920 & 11.2940 \\
\hline PKG43 & 7.6476 & 8.4915 & 9.4527 & 8.2564 & 8.4854 & 7.9910 & 10.4280 & 11.0950 \\
\hline PKG44 & 7.6174 & 8.3767 & 8.7277 & 8.0147 & 8.5277 & 7.9064 & 9.9693 & 10.6300 \\
\hline PKG45 & 8.1128 & 8.8419 & 8.7820 & 8.1658 & 8.9084 & 8.4260 & 10.4830 & 10.8840 \\
\hline PKG46 & 8.1068 & & & 8.6008 & & & & 11.6150 \\
\hline PKG47 & 7.6234 & 8.4673 & & & & & & 020 \\
\hline PKG48 & 7.6597 & & & & & & 10.5550 & 10.7630 \\
\hline PKG49 & 7.8228 & 8.2317 & 8.3229 & 7.7247 & 8.4 & 7.8218 & 9.9028 & 10.3520 \\
\hline PKG50 & 8.3304 & 9.1138 & 9.2956 & 8.5887 & 9.1198 & 8.4622 & 10.7250 & 11.6450 \\
\hline Mean & 7.9004 & 8.6239 & 9.0722 & 8.3203 & 8.7472 & 8.1895 & 10.4250 & 11.1515 \\
\hline SD & 0.4209 & 0.3783 & 0.4818 & 0.3718 & 0.4391 & 0.3659 & 0.4463 & 0.5781 \\
\hline Max & 8.8439 & 9.5307 & 10.5890 & 9.5917 & 9.8993 & 8.9214 & 11.6610 & 13.0350 \\
\hline Min & 7.0555 & 7.8269 & 8.2081 & 7.5193 & 7.7664 & 7.4351 & 9.4980 & 10.1340 \\
\hline Diff & 1.7884 & 1.7038 & 2.3809 & 2.0724 & 2.1329 & 1.4863 & 2.1630 & 2.9010 \\
\hline
\end{tabular}


Table C-1-5: TCB $643^{\text {rd }}$ cycle; Daisy01 - Daisy08.

\begin{tabular}{|c|c|c|c|c|c|c|c|c|}
\hline & AISY01 & DAISY02 & DAISY03 & DAISY04 & DAISY05 & DAISY06 & DAISY07 & DAISY08 \\
\hline PKG01 & 6.0223 & 5.9126 & 7.3919 & 6.2076 & 7.6612 & 5.2046 & 9.0846 & 7.5751 \\
\hline PKG02 & 2579 & 6.2147 & 7.5973 & 6.6608 & 7.7035 & .2530 & 6404 & 8.1551 \\
\hline PKG03 & 6.8380 & 6.8612 & 7.8571 & 7.0233 & 8.2654 & .6638 & .9003 & 8.3485 \\
\hline PKG04 & 6.0404 & 6.0697 & 7.4463 & 6.3828 & 7.3410 & 5.0294 & 9.2598 & 7.5268 \\
\hline PKG05 & 1734 & 6.2449 & 7.6275 & 6.4493 & 7.7096 & 5.3798 & 9.4169 & 7.9437 \\
\hline PKG06 & 5.7504 & 5.5863 & 6.9931 & 5.7061 & 7.0933 & 4.8361 & 8.7341 & 7.0494 \\
\hline PKG07 & 3002 & 6.2267 & 7.2771 & 6.0747 & 7.8062 & 5.2590 & 8.9637 & 7.4180 \\
\hline PKG08 & 6.8138 & 6.4866 & 8.1653 & 7.0595 & 8.2413 & 5.5128 & 10.2990 & 9.0312 \\
\hline PKG09 & 1129 & 6.0515 & 7.4402 & 6.3043 & 7.7337 & 5309 & 9.3202 & 7.8832 \\
\hline PKG10 & 7051 & 6.5168 & 7.7967 & 6.6305 & 8.4406 & .6034 & 9.6102 & 8.1974 \\
\hline PKG11 & 6.4392 & 6.2509 & 7.5188 & 6.2861 & 7.8244 & 5.1079 & 9.0604 & 7.3938 \\
\hline PKG12 & 6930 & 6.5832 & 7.7665 & 6.7756 & 8.4104 & 5.6155 & 465 & 8.4452 \\
\hline PKG13 & 1311 & 5.8098 & 7.2831 & 5.9418 & 7.3893 & 5.0717 & 9.1510 & 7.6536 \\
\hline PKG14 & 6.9709 & 7.0001 & 8.2317 & 7.2952 & 8.9240 & 5.8390 & 10.0940 & 8.9406 \\
\hline PKG15 & 6.1734 & 5.8642 & 7.3798 & 5.9478 & 7.7337 & 5.0113 & 9.0967 & 7.4966 \\
\hline PKG16 & 7.2488 & 7.2056 & 8.4492 & 7.5852 & 9.2019 & 6.3405 & 10.6740 & 9.5508 \\
\hline PKG17 & 6.5721 & 6.3778 & 7.6275 & 6.5339 & 8.3621 & 5.5248 & 9.6284 & 8.1733 \\
\hline PKG18 & 6.2700 & 6.0153 & 7.5369 & 6.3405 & 7.8908 & 5.2832 & 9.3625 & 8.0524 \\
\hline PKG19 & 9861 & 5.9911 & 7.3919 & 6.0263 & 7.6250 & 5.0657 & 9.1510 & 7.5570 \\
\hline PKG20 & 57 & 34 & 402 & 466 & 310 & 5.2530 & 446 & 7.8953 \\
\hline PKG21 & 21 & 15 & 221 & 14 & 87 & 25 & 58 & 7.4663 \\
\hline PKG22 & 63 & 730 & 517 & 432 & 035 & 779 & 69 & 7.7201 \\
\hline PKG23 & 1592 & 5.5138 & 7.3375 & 6.0384 & 7.1477 & 4.8361 & 85 & 7.3455 \\
\hline PKG24 & 0102 & 5.7253 & 6.9750 & 5.6397 & 7.3954 & 4.9690 & 918 & 7.0434 \\
\hline PKG25 & 3727 & 6.2811 & 7.8450 & 6.7756 & 035 & 5.2832 & 767 & 8.0524 \\
\hline PKG26 & 1030 & 6.2630 & 7.7242 & 6.5157 & 7.5827 & 5.2046 & 9.5800 & 7.8591 \\
\hline PKG27 & 02 & 9911 & 5973 & 251 & 5404 & 4.9327 & 9.2054 & 7.6536 \\
\hline PKG28 & 27 & 32 & 342 & 439 & 383 & 448 & & 7.6476 \\
\hline PKG29 & 34 & 90 & 32 & 37 & 23 & 046 & 13 & 128 \\
\hline PKG30 & 25 & 32 & & 11 & 39 & 234 & & 515 \\
\hline PKG31 & 90 & 4775 & 92 & 71 & 83 & 65 & & 588 \\
\hline PKG32 & 34 & 5.9669 & 304 & 115 & 91 & 31 & & 186 \\
\hline PKG33 & 346 & 6.4624 & 75 & 68 & 519 & 188 & 54 & 760 \\
\hline PKG34 & 223 & 5.7736 & 7.4523 & 351 & 7.2081 & 4.8663 & 873 & 7.3757 \\
\hline PKG35 & 4271 & 6.0697 & 7.3979 & 659 & 7.6673 & 5.3919 & 598 & 7.6416 \\
\hline PKG36 & 869 & 6.7403 & 203 & 629 & 8.0902 & 5.4584 & 9.7552 & 8.1612 \\
\hline PKG37 & 30 & & 429 & 834 & 7.7942 & 5.3255 & 323 & 7.8530 \\
\hline PKG38 & 842 & 6.2751 & 879 & 6.4009 & 319 & 5.2107 & 9.4290 & 7.6536 \\
\hline PKG39 & 480 & 5.9428 & 369 & 6.3405 & 760 & 5.2832 & 9.4411 & 8.1189 \\
\hline PKG40 & 552 & 5.9488 & 136 & 93 & 29 & 200 & 144 & 7.6174 \\
\hline PKG41 & 82 & 5228 & 13 & & 81 & 340 & 13 & 331 \\
\hline PKG42 & 157 & 9730 & 996 & 647 & 679 & 305 & 015 & 947 \\
\hline PKG43 & 6.3486 & 5.9126 & 7.5308 & 6.2076 & 7.5464 & 5.1744 & 9.3504 & 7.7926 \\
\hline PKG44 & 371 & 5.8219 & 7.2106 & 8209 & 7.4921 & 5.1382 & 819 & 7.3757 \\
\hline PKG45 & 3848 & 6.1905 & 7.6456 & 6.4795 & 7.9029 & 5.1321 & 9.5256 & 7.7080 \\
\hline PKG46 & 199 & 6.5349 & 7.9780 & 6.8058 & 8.1990 & 5.4282 & 9.7129 & 8.2095 \\
\hline PKG47 & 311 & 5.9669 & 7.3194 & 6.0445 & 7.4256 & 5.1684 & 9.2538 & 7.7624 \\
\hline PKG48 & & 978 & 671 & 88 & 510 & 179 & 115 & 7.4543 \\
\hline PKG49 & 34 & 5.9730 & 7.1381 & 5.7605 & 7.5646 & 4.9629 & 8.9698 & 6.9467 \\
\hline PKG50 & 205 & 6.2992 & 7.8450 & 6.4493 & 8.3077 & 5.3073 & 9.8157 & 8.4149 \\
\hline Mean & 330 & 6.1418 & 7.5658 & 6.3579 & 7.7724 & 5.2489 & 9.3877 & 7.8321 \\
\hline SD & & 334 & 0.3047 & 164 & 0.4563 & 0.3024 & 0.3851 & 0.5227 \\
\hline Max & 488 & 2056 & 4492 & 7.5852 & 9.2019 & 6.3405 & 10.6740 & 9.5508 \\
\hline Min & 04 & 5.4775 & 50 & 5.5671 & 483 & 79 & 918 & 6.9467 \\
\hline Diff & 1.4984 & 1.7281 & 1.4742 & 2.0181 & 2.2536 & 1.5226 & 1.9822 & 2.6041 \\
\hline
\end{tabular}


Table C-1-6: TCB $643^{\text {rd }}$ cycle; Daisy09 - Daisy16.

\begin{tabular}{|c|c|c|c|c|c|c|c|c|}
\hline & DAISY09 & DAISY10 & DAISY11 & DAISY12 & DAISY13 & DAISY14 & DAISY15 & DAISY16 \\
\hline PKG01 & 7.5086 & 8.1229 & 8.8485 & 8.5404 & 8.4733 & 7.9487 & 10.4220 & 11.1130 \\
\hline PKG02 & 7.6053 & 8.2136 & 9.0962 & 8.5162 & 8.3223 & 7.8822 & 10.5610 & 11.1130 \\
\hline PKG03 & 8.9164 & 8.8057 & 9.2231 & 8.6008 & 9.3917 & 8.8248 & 10.5310 & 11.4520 \\
\hline PKG04 & 8.1914 & 8.2438 & 8.6370 & 8.0328 & 8.7573 & 8.1480 & 10.2650 & 10.7020 \\
\hline PKG05 & 7.8530 & 8.0867 & 9.0600 & 8.3712 & 8.6244 & 7.8157 & 10.3020 & 11.3670 \\
\hline PKG06 & 7.2851 & 7.7362 & 8.2020 & 7.8757 & 7.9416 & 7.3868 & 9.3953 & 10.2130 \\
\hline PKG07 & 7.9195 & 8.0686 & 8.6431 & 8.0026 & 8.5579 & 7.9124 & 9.8484 & 10.6780 \\
\hline PKG08 & 9.1339 & 9.1803 & 10.0690 & 9.0962 & 9.6032 & 8.7402 & 11.3410 & 12.3760 \\
\hline PKG09 & 7.6899 & 7.9900 & 8.9150 & 8.0570 & 8.3223 & 7.7312 & 9.7820 & 10.7450 \\
\hline PKG10 & 8.1249 & 8.4673 & 9.3379 & 8.6491 & 9.1863 & 8.3595 & 6100 & 11.4700 \\
\hline PKG11 & 8.1249 & 8.5277 & 8.5947 & 8.1597 & 9.0775 & 8.5589 & 2110 & 10.4730 \\
\hline PKG12 & 8.4512 & 8.8721 & 9.5554 & 8.6672 & 9.2407 & 8.6193 & 10.8700 & 11.5420 \\
\hline PKG13 & 7.1884 & 7.9900 & 8.1839 & 8.0691 & 8.2679 & 7.7855 & 9.9693 & 10.6900 \\
\hline PKG14 & 8.4029 & 8.7211 & 9.0298 & 9.2171 & 9.5730 & 8.6314 & 11.3110 & 12.4550 \\
\hline PKG15 & 7.4361 & 7.9417 & 8.6914 & 8.1416 & 8.5036 & 7.8943 & 10.1690 & 10.8720 \\
\hline PKG16 & 8.8862 & & 10.5 & 406 & & 8.8489 & 580 & 12.9020 \\
\hline PKG17 & 8.0 & & & & & & 230 & 1800 \\
\hline PKG18 & 7.6778 & 8.2256 & 9.4 & 47 & 186 & 191 & 570 & 11.0650 \\
\hline PKG19 & \begin{tabular}{|l|}
7.5147 \\
\end{tabular} & 686 & 9.0 & 114 & & 01 & 968 & 870 \\
\hline PKG20 & 7.6537 & 8.2498 & 9.3923 & 174 & & 360 & 380 & 840 \\
\hline PKG21 & 7.4845 & & 8.6370 & & & & 393 & 140 \\
\hline PKG22 & 7.7624 & 8.1652 & 8.7579 & 537 & 788 & 085 & 010 & 3720 \\
\hline PKG23 & 7.0736 & 7.6758 & 8.4316 & 7.9543 & 323 & 7.6768 & 3726 & 5330 \\
\hline PKG24 & 7.2549 & 7.8933 & 8.2806 & 7.7005 & 8.2860 & 7.7674 & 557 & 2070 \\
\hline PKG25 & 7.8530 & 8.4432 & 9.0419 & 8.3168 & 8.9325 & 8.3172 & 10.3920 & 2880 \\
\hline PKG26 & 7.9920 & 104 & 62 & 503 & 355 & 931 & 5980 & 190 \\
\hline PKG27 & 43 & & & & & & & \\
\hline PKG28 & 7.0495 & 50 & & & & & 240 & 870 \\
\hline PKG29 & 7.8107 & & & & & & 990 & 430 \\
\hline PKG30 & 7.7443 & 317 & 464 & 543 & 348 & 360 & 380 & 690 \\
\hline PKG31 & 6.9588 & 7.5973 & 8.1778 & 7.4951 & 7.7846 & 928 & 959 & 3988 \\
\hline PKG32 & 7.7805 & 7.9719 & 8.3349 & 7.7066 & 327 & 245 & 309 & 1830 \\
\hline PKG33 & 7.8893 & 8.2679 & 9.1929 & 8.4014 & 915 & 943 & .4160 & 3130 \\
\hline PKG34 & 7.6295 & 8.0625 & & 328 & 585 & 916 & 1320 & 9080 \\
\hline KG35 & 7.7020 & 8.4190 & 8.7398 & & 788 & 514 & 9.9270 & 6540 \\
\hline PKG36 & 8.5902 & 8.6305 & 8.0510 & & 2588 & 616 & .5370 & 2880 \\
\hline PKG37 & 7.5 & & & & 346 & 89 & 200 & 2400 \\
\hline PKG38 & 8.5 & & & & & & & \\
\hline PKG39 & 7.8228 & & 98 & 03 & & 45 & 290 & 170 \\
\hline PKG40 & 7.6114 & 311 & 7.7 & 22 & 61 & 39 & 370 & 440 \\
\hline PKG41 & 7.9799 & 432 & 9.5856 & 16 & 446 & 870 & 7180 & 3330 \\
\hline PKG42 & 7.6597 & 8.3404 & 9.1385 & 8.3531 & 519 & 393 & 1810 & 11.1430 \\
\hline PKG43 & 7.5872 & 8.4190 & 8.9814 & 8.3047 & 8.3706 & 7.9124 & 10.2770 & 11.0350 \\
\hline PKG44 & 7.5389 & 8.3827 & 8.6975 & 8.0026 & 8.3706 & 7.8701 & 9.6853 & 10.5820 \\
\hline PKG45 & 8.0826 & 8.8419 & 8.8062 & 839 & 8.8600 & 8.3354 & 10.2710 & 10.8410 \\
\hline PKG46 & & & & & & & & 840 \\
\hline KG47 & 7.2609 & & & & & & & 960 \\
\hline PKCA & & & & & & & & \\
\hline 349 & 7.4422 & & & & & & 007 & 400 \\
\hline PKG50 & 8.0343 & 8.8298 & 9.2715 & 8.5827 & & 8.4079 & 10.6040 & 11.6390 \\
\hline Mean & 7.8022 & 8.3003 & & & & & 10.2523 & 11.0272 \\
\hline SD & 0.4804 & 0.3459 & 0.5156 & 0.3696 & 0.4465 & 694 & 0.4779 & 5607 \\
\hline Max & 9.1339 & 9.1803 & 10.5580 & 9.4406 & 9.7543 & 8.8610 & 11.7580 & 12.9020 \\
\hline Min & 6.9588 & 7.5973 & 7.7005 & 7.4951 & 7.7846 & 7.3868 & 9.1959 & 9.8988 \\
\hline Diff & 2.1751 & 1.5830 & 2.8575 & 1.9455 & 1.9697 & 1.4742 & 2.5621 & 3.0032 \\
\hline
\end{tabular}


Table C-1-7: TCB $875^{\text {th }}$ cycle; Daisy01 - Daisy08.

\begin{tabular}{|c|c|c|c|c|c|c|c|c|}
\hline & AISY01 & DAISYO2 & DAISY03 & DAISY04 & DAISY05 & DAISY06 & DAISY07 & DAISY08 \\
\hline PKG01 & 6.1069 & 6.0999 & 7.4644 & 6.0566 & 7.9392 & 5.3073 & 9.1933 & 7.7503 \\
\hline PKG02 & 6.2942 & 6.1724 & 7.7000 & 6.5580 & 7.9392 & 5.6578 & 9.7492 & 8.4935 \\
\hline PKG03 & 4.2218 & 6.8853 & 7.9417 & 6.9629 & 8.4165 & 5.8511 & 10.0090 & .6325 \\
\hline PKG04 & 6.0465 & 6.2570 & 7.4704 & 6.3284 & 7.7700 & 5.4282 & 9.4471 & 7.9135 \\
\hline PKG05 & 6.2459 & 6.1784 & 7.6275 & 6.3889 & 7.9271 & 5.5611 & 9.5679 & 8.1672 \\
\hline PKG06 & 5.8713 & 5.7555 & 7.0837 & 5.6638 & 7.2866 & 5.1079 & 8.8550 & 7.1582 \\
\hline PKG07 & 6.1311 & 6.1724 & 7.5127 & 6.0505 & 7.7579 & 5.5490 & 9.0544 & 7.6174 \\
\hline PKG08 & 6.6265 & 6.5470 & 8.2015 & 7.2952 & 8.4104 & 5.6940 & 10.4320 & 9.1944 \\
\hline PKG09 & 6.0888 & 6.0455 & 7.5188 & 6.3768 & 7.7579 & 5.4403 & .4350 & 8.1189 \\
\hline PKG10 & 6.5963 & 6.6316 & 7.8692 & 6.5580 & 8.3681 & 5.5430 & 9.7432 & 8.4029 \\
\hline PKG11 & 6.4452 & 6.1542 & 7.5006 & 6.4251 & 7.9331 & 5.1684 & 9.2779 & 7.5630 \\
\hline PKG12 & 6.6265 & 6.5591 & 7.8269 & 6.7997 & 8.5373 & 6.0445 & 9.8761 & 8.5116 \\
\hline PKG13 & 6.1371 & 5.7736 & 7.3617 & 5.9901 & 7.5525 & 5.4221 & 9.1631 & 7.7322 \\
\hline PKG14 & 6.9769 & 7.0364 & 8.2076 & 7.3495 & 8.7427 & 5.8934 & 10.2200 & 9.1702 \\
\hline PKG15 & 6.1311 & 5.9609 & 7.4523 & 6.0203 & 7.4618 & 5.0777 & 9.1571 & 7.8228 \\
\hline PKG16 & 7.1643 & 7.3143 & 8.4915 & 7.7242 & 9.4255 & 6.3949 & 10.7460 & 9.8650 \\
\hline PKG17 & 694 & 6.3718 & 7.6638 & 6.5520 & 8.1385 & 5.8451 & 9.6586 & 8.3183 \\
\hline PKG18 & 82 & 36 & 154 & 68 & 7.7156 & 5.4100 & 9.4048 & 3.1612 \\
\hline PKG19 & 104 & 84 & 38 & 888 & 7.4679 & .0717 & 785 & .5449 \\
\hline PKG20 & & & 44 & & 7.5041 & .2952 & 350 & .0524 \\
\hline PKG21 & & & 7.5 & & 7.7821 & .3073 & 719 & .5147 \\
\hline PKG22 & & & 7.7 & 95 & 7.6189 & 5671 & 27 & 8899 \\
\hline PKG23 & & & 7.4 & 80 & 6.9906 & 1744 & & 7.2790 \\
\hline PKG24 & 6.0283 & 5.8340 & 335 & 99 & 7.4618 & 5.3617 & 160 & 7.0615 \\
\hline PKG25 & 6.3184 & 6.2811 & 7.8873 & 7.1139 & 7.6552 & 5.5007 & 223 & 8.0343 \\
\hline PKG26 & 6.3969 & 6.4322 & 7.7846 & 097 & 7.6794 & 5.2952 & 525 & 7.8712 \\
\hline PKG27 & 6.4030 & 6.0817 & 7.6759 & 499 & 7.5766 & 5.1502 & 235 & 7.6174 \\
\hline PKG28 & 6.0223 & 5.9911 & 7.5006 & 680 & 7.3712 & 5.1442 & 390 & 7.7564 \\
\hline PKG29 & 1452 & 6.3053 & 7.8632 & 970 & 7.7035 & 5.5309 & 284 & 8.1008 \\
\hline PKG30 & & 80 & 344 & 53 & 7.4437 & 5.3073 & 3785 & 7.3818 \\
\hline PKG31 & 169 & 5.4836 & 7.0233 & 094 & 6.8939 & 4.9569 & 254 & 6.9951 \\
\hline PKG32 & 6.2398 & 5.9911 & 7.2 & 174 & 7.4135 & 5.0113 & 60 & 7.2790 \\
\hline PKG33 & 6.4694 & 6.2207 & 13 & 70 & 7.8304 & 5.5007 & 773 & 8.2458 \\
\hline PKG34 & 794 & 5.9730 & 7.4704 & 016 & 7.1960 & 5.0113 & 2779 & 7.5086 \\
\hline PKG35 & 117 & 6.1422 & 7.4342 & 230 & 7.8667 & 5.6759 & 296 & 7.8409 \\
\hline PKG36 & 567 & 732 & 142 & 9904 & 8.0298 & 5.5551 & $\overline{096}$ & 8.0947 \\
\hline PKG37 & 6.5238 & 6.1059 & 275 & 2801 & 7.9210 & 5.3436 & 9.2840 & 7.9014 \\
\hline PKG38 & 6.7292 & 6.3657 & 7.7121 & 6.4735 & 8.1929 & 5.3255 & 9.3746 & 7.7141 \\
\hline PKG39 & 332 & & 7.5550 & 647 & 7.7337 & 5.5913 & 9.4290 & 7.9799 \\
\hline PKG40 & 6.3063 & 5.9790 & 7.5973 & 164 & 7.4981 & 5.0717 & 9.5256 & 7.7564 \\
\hline PKG41 & 6.5963 & 6.7101 & 7.8 & 91 & 8.2654 & 5.6699 & 9.6707 & 8.4995 \\
\hline PKG42 & 119 & 76 & 7. & 05 & 7.8002 & 5.4765 & 652 & 8.1310 \\
\hline PKG43 & & & 7.5 & & 7.5766 & 5.4705 & 83 & 7.9799 \\
\hline PKG44 & & & 7.2710 & & 7.4800 & 5.4282 & 156 & 7.3576 \\
\hline PKG45 & 6.4996 & 174 & 7.7786 & 218 & 7.7035 & 5.4342 & 9.5740 & 7.7443 \\
\hline PKG46 & 6.7171 & 6.5470 & 7.9719 & 6.6970 & 8.1265 & 5.6638 & 9.7492 & 8.3847 \\
\hline PKG47 & 6.2217 & 6.0213 & 7.3798 & 6.0928 & 7.4135 & 5.4765 & 9.3021 & 7.9135 \\
\hline PKG48 & 5.8471 & 5.7132 & 7.5006 & 653 & 6.9785 & 4.9025 & 9.1933 & 7.4663 \\
\hline PKG49 & 6.2761 & 5.9186 & 7.1200 & 5.7786 & 7.4377 & 5.2530 & 8.7825 & 7.3032 \\
\hline PKG50 & 6.6930 & 6.3053 & 7.9236 & 6.6366 & 8.3440 & 5.5369 & 9.8942 & 8.3847 \\
\hline Mean & 6.2908 & 6.1952 & 7.6107 & 6.3739 & 7.7807 & 5.4291 & 9.4240 & 7.9396 \\
\hline SD & 0.4105 & 0.3520 & 0.2944 & 0.4303 & 0.4644 & 0.2884 & 0.4108 & 0.5522 \\
\hline Max & 43 & 43 & 915 & 7242 & 9.4255 & 6.3949 & 10.7460 & 9.8650 \\
\hline Min & 4.2218 & 5.4836 & 7.0233 & 5.6094 & 6.8939 & 4.9025 & 8.6254 & 6.9951 \\
\hline Diff & 2.9425 & 1.8307 & 1.4682 & 2.1148 & 2.5316 & 1.4924 & 2.1206 & 2.8699 \\
\hline
\end{tabular}


Table C-1-8: TCB $875^{\text {th }}$ cycle; Daisy09 - Daisy16.

\begin{tabular}{|c|c|c|c|c|c|c|c|c|}
\hline & DAISY09 & DAISY10 & DAISY11 & DAISY12 & DAISY13 & DAISY14 & DAISY15 & DAISY16 \\
\hline PKG01 & 7.6476 & 8.2861 & 9.1567 & 8.4256 & 8.7090 & 7.9849 & 10.1440 & 10.9920 \\
\hline PKG02 & 7.7382 & 8.3465 & 9.3379 & 8.4437 & 8.5036 & 8.0574 & 10.1510 & 11.1980 \\
\hline PKG03 & 8.7352 & 8.9869 & 9.4165 & 8.4739 & 9.5186 & 8.9698 & 10.5980 & 11.5780 \\
\hline PKG04 & 7.8953 & 8.4432 & 8.8787 & 8.0751 & 9.0353 & 8.4079 & 10.0840 & 10.9320 \\
\hline PKG05 & 7.7141 & 8.1411 & 9.3319 & 8.4316 & 8.6848 & 8.0755 & 10.3020 & 11.3910 \\
\hline PKG06 & 7.0555 & 7.7544 & 8.3410 & 7.8757 & 8.1229 & 7.7553 & 9.4376 & 10.2610 \\
\hline PKG07 & 7.6295 & 8.0867 & 8.7458 & 8.0812 & 8.7815 & 8.2810 & 9.8605 & 10.7450 \\
\hline PKG08 & 8.6023 & 8.9386 & 10.1290 & 9.1989 & 9.5549 & 8.8489 & 11.4070 & 12.4550 \\
\hline PKG09 & 7.5993 & 7.9538 & 8.9089 & 8.1960 & 8.4129 & 7.8701 & 9.9330 & 10.8350 \\
\hline PKG10 & 8.1672 & 8.6123 & 9.2533 & 8.6793 & 9.2467 & 8.5408 & 10.6520 & 11.6390 \\
\hline PKG11 & 8.1612 & 8.6365 & 8.6491 & 8.0208 & 9.1259 & 8.7160 & 10.3560 & 10.6900 \\
\hline PKG12 & 8.5479 & 9.0534 & 9.6038 & 8.6733 & 9.2890 & 8.6495 & 10.6340 & 11.7660 \\
\hline PKG13 & 7.2911 & 8.0565 & 8.8123 & 8.0570 & 8.3163 & 7.7191 & 9.9693 & 10.8410 \\
\hline PKG14 & 8.3968 & 8.8601 & 9.8273 & 9.0177 & 9.5670 & 8.6495 & 11.6670 & 12.6900 \\
\hline PKG15 & 7.4301 & 8.0444 & 8.6914 & 8.2081 & 8.5579 & 7.9547 & 10.1200 & 10.9860 \\
\hline PKG16 & 8.8198 & 9.1259 & 10.6130 & 9.5192 & 9.7965 & 9.0362 & 11.6430 & 13.0100 \\
\hline PKG17 & 8.3787 & 8.6425 & 9.2775 & 8.3772 & 8.9688 & 8.4441 & 10.3560 & 11.3910 \\
\hline PKG18 & 7.7322 & 8.2921 & 9.1627 & 8.3833 & 8.6546 & 8.2145 & 10.1930 & 11.1190 \\
\hline PKG19 & 7.5389 & 7.9900 & 8.6431 & 8.2201 & 8.4431 & 7.8278 & 9.9874 & 10.9080 \\
\hline PKG20 & 7.7020 & & & 8.2322 & 8.5579 & 8.1480 & 10.1870 & 11.0830 \\
\hline PKG21 & 7.5811 & & & & 8.5761 & 7.9728 & 9.9693 & 10.8840 \\
\hline PKG22 & 7.8168 & 23 & 8.8485 & 383 & 8.7936 & 8.3233 & 10.6940 & 11.1070 \\
\hline PKG23 & 7.0676 & 758 & 8.5102 & 8.0570 & 8.2196 & 7.6466 & 9.9089 & 10.7140 \\
\hline PKG24 & 7.2851 & 7.9175 & 8.4497 & 7.9362 & 8.3163 & 7.8278 & 9.3953 & 10.3100 \\
\hline PKG25 & 7.9799 & 8.2679 & 9.1325 & 8.3651 & 8.9325 & 8.4199 & 10.4160 & 11.3070 \\
\hline PKG26 & 7.9678 & 8.2740 & 8.8123 & 8.2987 & 9.1319 & 8.4743 & 10.5310 & 11.1920 \\
\hline PKG27 & 7.4543 & 8.0323 & 8.6914 & 8.1778 & 8.6909 & 8.1360 & 10.2710 & 11.0770 \\
\hline PKG28 & 7.1340 & 7.9356 & 8.6914 & 7.9905 & 8.3042 & 7.6224 & 9.9572 & 10.8470 \\
\hline PKG29 & 7.8651 & 8.7453 & 9.1083 & 8.4799 & 9.0413 & 8.4260 & 10.5980 & 11.4880 \\
\hline PKG30 & 7.7262 & 8.1652 & 8.5766 & 8.0570 & 8.6727 & 8.0876 & 10.0060 & 10.6840 \\
\hline PKG31 & 6.9528 & 7.5912 & 8.1960 & 7.5978 & 7.7483 & 7.4713 & 9.2684 & 10.0500 \\
\hline PKG32 & 7.5328 & 7.9840 & 8.5464 & 7.9362 & 8.4673 & 7.9728 & 9.5826 & 10.2010 \\
\hline PKG33 & 7.5630 & 8.0686 & 9.1929 & 8.4799 & 8.5398 & 8.0876 & 10.3320 & 11.3490 \\
\hline PKG34 & 7.3576 & 7.8571 & 8.7458 & 8.0630 & 8.3042 & 7.8459 & 10.2230 & 10.9560 \\
\hline PKG35 & 7.7262 & 63 & 8.8787 & 8. & 8.6848 & 8.0937 & 9.9693 & 10.7690 \\
\hline PKG36 & 8.4572 & 8.6123 & 9.3077 & 8.3410 & 9.2709 & 8.6616 & 10.6460 & 11.3430 \\
\hline PKG37 & 7.6295 & 8.3223 & 9.1144 & 8.3168 & 8.6365 & 8.0937 & 10.4590 & 11.3970 \\
\hline PKG38 & 8.4935 & 8.9688 & 8.9512 & 8.2503 & 9.3978 & 8.7945 & 10.4040 & 11.0650 \\
\hline PKG39 & 7.8410 & 8.5096 & 9.0298 & 8.2020 & 8.6425 & 8.1480 & 10.2710 & 11.1620 \\
\hline PKG40 & 7.6114 & 8.1713 & 8.8787 & 8.1960 & 8.6304 & 8.0755 & 10.2290 & 11.0410 \\
\hline PKG41 & 7.9920 & 8.3586 & 9.5373 & 8.6672 & 8.8902 & 8.2931 & 10.7730 & 11.7110 \\
\hline PKG42 & 7.6718 & 8.1954 & 9.2412 & 8.4739 & 8.5942 & 8.1058 & 10.2410 & 11.2460 \\
\hline PKG43 & 7.6174 & 8.3042 & 9.0660 & 8.3833 & 8.5036 & 7.9547 & 10.1320 & 11.0590 \\
\hline PKG44 & 7.5751 & 8.1290 & 8.7035 & 7.9966 & 8.4371 & 7.9728 & 10.1810 & 10.6660 \\
\hline PKG45 & 8.0403 & 8.6305 & 8.7337 & 8.1053 & 8.8661 & 8.4441 & 10.7610 & 10.9860 \\
\hline PKG46 & 8.2639 & 8.4855 & 9.3983 & 8.6491 & 9.3857 & 8.6435 & 10.6940 & 11.5480 \\
\hline PKG47 & 7.7624 & 7.8571 & 8.9633 & 8.0691 & 8.2015 & 7.6526 & 9.8545 & 10.6240 \\
\hline PKG48 & 7.6053 & 7.8933 & 8.6612 & 8.2866 & 8.2679 & 7.7855 & 10.3080 & 10.7750 \\
\hline PKG49 & 7.5207 & 7.9719 & 8.4860 & 7.7549 & 8.3767 & 7.8097 & 10.0360 & 10.4060 \\
\hline PKG50 & 8.5056 & 8.6667 & 9.4285 & 8.5947 & 9.1380 & 8.4804 & 10.6340 & 11.6630 \\
\hline Mean & 7.8076 & 8.3054 & 9.0062 & 8.2958 & 8.7502 & 8.1895 & 10.2885 & 11.1227 \\
\hline SD & 0.4461 & 0.3732 & 0.4491 & 0.3412 & 0.4339 & 0.3746 & 0.4764 & 0.5679 \\
\hline Max & 8.8198 & 9.1259 & 10.6130 & 9.5192 & 9.7965 & 9.0362 & 11.6670 & 13.0100 \\
\hline Min & 6.9528 & 7.5912 & 8.1960 & 7.5978 & 7.7483 & 7.4713 & 9.2684 & 10.0500 \\
\hline Diff & 1.8670 & 1.5347 & 2.4170 & 1.9214 & 2.0482 & 1.5649 & 2.3986 & 2.9600 \\
\hline
\end{tabular}


Table C-1-9: TCB $1016^{\text {th }}$ cycle; Daisy01 - Daisy08.

\begin{tabular}{|c|c|c|c|c|c|c|c|c|}
\hline & AISY01 & \begin{tabular}{|l} 
DAISY02 \\
\end{tabular} & DAISY03 & DAISY04 & DAISY05 & DAISY06 & DAISY07 & DAISY08 \\
\hline PKG01 & 7.6718 & 6.0274 & 7.4644 & 6.1895 & 7.7216 & 5.4282 & 9.3383 & 7.9980 \\
\hline PKG02 & 7.7805 & 6.2207 & 7.7363 & 6.6849 & 7.7398 & 5.3255 & 9.8036 & 8.6445 \\
\hline PKG03 & 7.6476 & 6.8732 & 8.0263 & 6.9991 & 8.2956 & 5.6880 & 10.2690 & 8.4874 \\
\hline PKG04 & 6.7111 & 6.0757 & 7.5913 & 6.3587 & 7.4377 & 5.1200 & 9.6102 & 7.7684 \\
\hline PKG05 & 6.8199 & 6.2267 & 7.7967 & 6.4553 & 7.6310 & 5.3980 & 9.5740 & 8.3062 \\
\hline PKG06 & 6.4815 & 5.5863 & 7.1865 & 5.6638 & 7.0812 & 4.8663 & 8.8248 & 7.1522 \\
\hline PKG07 & 6.7111 & 6.2630 & 7.3375 & 6.1472 & 7.6310 & 5.2952 & 9.0060 & 7.5388 \\
\hline PKG08 & 7.2670 & 6.4866 & 8.2438 & 7.0716 & 8.2896 & 5.5974 & 10.3410 & 9.1581 \\
\hline PKG09 & 6.5963 & 6.1240 & 7.5188 & 6.2922 & 7.5706 & 5.3557 & 9.4773 & 8.0403 \\
\hline PKG10 & 7.0132 & 6.4926 & 7.8511 & 6.6668 & 8.2715 & 5.4946 & 11.1270 & 8.3243 \\
\hline PKG11 & 6.8078 & 6.1422 & 7.6215 & 6.2922 & 7.7639 & 5.1079 & 9.3081 & 7.5388 \\
\hline PKG12 & 6.9347 & 6.5530 & 7.8813 & 6.6849 & 8.4769 & 5.7424 & 9.8821 & 8.4935 \\
\hline PKG13 & 6.3486 & 5.8461 & 7.4100 & 5.9901 & 7.3410 & 5.1442 & 9.1631 & 7.6657 \\
\hline PKG14 & 7.3938 & 7.1210 & 8.2378 & 7.2468 & 8.8334 & 5.8149 & 10.2690 & 8.9225 \\
\hline PKG15 & 6.5661 & 5.9246 & 7.4402 & 6.0384 & 7.6431 & 5.1321 & 9.1994 & 7.5630 \\
\hline PKG16 & 7.7443 & 7.4231 & 8.4794 & 7.6698 & 9.2503 & 6.4009 & 10.7400 & 6717 \\
\hline PKG17 & 6.6869 & 6.4382 & 7.7484 & 6.5822 & 8.0056 & 5.7242 & 9.5559 & 8.3424 \\
\hline KG18 & 6.8682 & 6.1180 & 7.6456 & 6.4070 & 7.6854 & 5.2952 & 9.3927 & 0947 \\
\hline KG19 & 6.6144 & 5.8582 & 7.5127 & 5.9357 & 33 & 5.0475 & 346 & 114 \\
\hline PKG20 & 6.7171 & 6.0334 & 7.4704 & 6.2318 & 85 & 5.2590 & 9.4531 & 1431 \\
\hline PKG21 & 6.6688 & 6.2449 & 7.5792 & 6.3345 & 7.6854 & 5.4040 & 9.2658 & 7.6476 \\
\hline PKG22 & 6.4936 & 6.1059 & 7.7182 & 6.4614 & 7.6552 & 5.2590 & 9.5438 & 8.3062 \\
\hline PKG23 & 6.0767 & 5.6407 & 7.4100 & 6.0807 & 6.9483 & 4.8300 & 9.0785 & 7.8530 \\
\hline PKG24 & 6.4392 & 5.9367 & 7.0233 & 5.6699 & 7.2866 & 5.0354 & 8.6979 & 7.1522 \\
\hline PKG25 & 6.4211 & 6.3174 & & 6.7635 & 7.7096 & & 552 & 128 \\
\hline PKG26 & 6.4634 & 6.3778 & 7.7846 & 6.5943 & 7.5948 & 23 & 388 & 7.9376 \\
\hline KG27 & 6.4271 & 6.1845 & 7.6638 & 6.3 & 404 & 42 & 202 & 7.7201 \\
\hline KG28 & 6.0 & 6.0092 & 69 & 6.3284 & 7.2322 & 354 & 263 & 7.6899 \\
\hline KG29 & 6.6 & 6.3295 & 7.9477 & 6.7816 & 35 & 5.2952 & 404 & 733 \\
\hline PKG30 & 6.3425 & 6.1603 & 7.5006 & 6.1351 & 7.3954 & 5.3798 & 9.3263 & 7.4482 \\
\hline PKG31 & 6.0404 & 5.6950 & 7.0294 & 5.6397 & 6.9060 & 4.7575 & 8.6435 & 6.9528 \\
\hline PKG32 & 6.3546 & 6.1965 & 7.2952 & 5.8692 & 7.4377 & 5.2530 & 8.9577 & 7.2488 \\
\hline PKG33 & 6.6265 & 6.3174 & 7.6638 & 6.4735 & 7.8244 & 5.5067 & 9.5377 & 8.2518 \\
\hline KG34 & 6.3727 & 5.8703 & 7.5852 & 6.1714 & 7.1597 & 5.0596 & 9.2054 & 7.3757 \\
\hline KG35 & 6.7353 & 6.1482 & 7.5550 & 5.9720 & 7.8606 & 5.3919 & 9.2840 & 7.6657 \\
\hline KG36 & 6.6748 & 6.7403 & 8.0988 & 6.9870 & 8.0419 & 5.4765 & 9.7975 & 8.2156 \\
\hline PKG37 & 6.6144 & 6.2207 & 7.6275 & 6.2318 & 7.8667 & 5.3859 & 9.3444 & 8.0041 \\
\hline KG38 & 6.8259 & 6.4503 & & 6.5 & & 5.3 & 9.4773 & 7.7805 \\
\hline KG39 & 34 & 80 & 7. & 6.2861 & 7.8 & 50 & 9.4108 & 8.1491 \\
\hline KG40 & & 82 & & 66 & 7. & 67 & 86 & 107 \\
\hline KG41 & 96 & 6.7766 & 7.8 & 6.7333 & 8.1204 & 5.6517 & 10.0090 & 8.5720 \\
\hline PKG42 & 6.6326 & 6.2026 & 7.6456 & 6.4009 & 7.8002 & 5.4765 & 9.6586 & 8.1551 \\
\hline PKG43 & 6.3667 & 6.1180 & 7.5308 & 6.2620 & 7.7398 & 5.3798 & 9.3142 & 7.9255 \\
\hline PKG44 & 6.3365 & 6.0274 & 7.2106 & 5.9176 & 7.4558 & 5.3315 & 9.2356 & 7.5026 \\
\hline PKG45 & 6.4452 & 6.4201 & 7.6638 & 6.5520 & 7.6914 & 5.3617 & 9.5861 & 7.8168 \\
\hline PKG46 & 3165 & 6.5832 & 7.9659 & 6.8178 & 8.1748 & 6.0505 & 9.7069 & 8.2156 \\
\hline PKG47 & 332 & 6.1180 & 7.3617 & 6.2 & & 5.8451 & 9.2900 & 7.8289 \\
\hline KG48 & & & 7.7242 & & & 4.8723 & 9.2719 & 7.5328 \\
\hline PKG49 & 6.3244 & 6.0394 & 7.2771 & 5.9659 & 7.3652 & \begin{tabular}{|l|}
5.1563 \\
\end{tabular} & 8.6737 & 7.0555 \\
\hline PKG50 & 6.7715 & 6.4926 & 7.9296 & 6.6185 & 8.2413 & 5.3557 & 9.9305 & 8.3726 \\
\hline Mean & 6802 & 6.2352 & 7.6429 & 6.3850 & 7.7166 & 5.3462 & 9.4953 & 7.9588 \\
\hline SD & 0.4093 & 0.3459 & 0.2943 & 0.4059 & 0.4524 & 0.3046 & 0.4798 & 0.5273 \\
\hline Max & 7.7805 & 7.4231 & 8.4794 & 7.6698 & 9.2503 & 6.4009 & 11.1270 & 9.6717 \\
\hline Min & 6.0404 & 5.5863 & 7.0233 & 5.6397 & 6.9060 & 4.7575 & 8.6435 & 6.9528 \\
\hline Diff & 1.7401 & 1.8368 & 1.4561 & 2.0301 & 2.3443 & 1.6434 & 2.4835 & 2.7189 \\
\hline
\end{tabular}


Table C-1-10: TCB $1016^{\text {th }}$ cycle; Daisy09 - Daisy16.

\begin{tabular}{|c|c|c|c|c|c|c|c|c|}
\hline & DAISY09 & DAISY10 & DAISY11 & DAISY12 & DAISY13 & DAISY14 & DAISY15 & DAISY16 \\
\hline PKG01 & 7.8107 & 8.2740 & 9.1748 & 8.2262 & 8.7392 & 8.2689 & 10.4350 & 10.9200 \\
\hline PKG02 & 7.7685 & 8.4432 & 9.5192 & 8.4316 & 8.4733 & 8.1178 & 10.5550 & 11.1010 \\
\hline PKG03 & 8.7170 & 8.9567 & 9.4648 & 8.4195 & 9.5005 & 9.0725 & 11.1600 & 11.4880 \\
\hline PKG04 & 7.8470 & 8.2317 & 9.0600 & 8.0328 & 8.6909 & 8.3112 & 10.6880 & 10.6720 \\
\hline PKG05 & 7.6053 & 8.0686 & 9.3379 & 8.4074 & 8.5761 & 8.0272 & 10.5190 & 11.3490 \\
\hline PKG06 & 7.0313 & 7.7242 & 8.3349 & 7.7549 & 7.9839 & 7.5741 & 9.6672 & 10.0500 \\
\hline PKG07 & 7.5811 & 8.0746 & 8.8666 & 8.0812 & 8.5459 & 8.1480 & 10.2170 & 10.7330 \\
\hline PKG08 & 8.5841 & 9.2407 & 10.3710 & 9.1627 & 9.4582 & 9.0121 & 11.4310 & 12.3760 \\
\hline PKG09 & 7.5086 & 7.9960 & 9.4588 & 8.1899 & 8.2860 & 7.8037 & 10.3560 & 10.7990 \\
\hline PKG10 & 8.2518 & 8.6063 & 9.6038 & 8.5645 & 9.0594 & 8.7039 & 10.7180 & 11.5720 \\
\hline PKG11 & 8.2881 & 8.7090 & 8.8304 & 7.9845 & 9.1138 & 8.7100 & 10.5010 & 5750 \\
\hline PKG12 & 8.4149 & 8.8057 & 9.8817 & 9.0419 & 9.2346 & 9093 & 10.6640 & 7480 \\
\hline PKG13 & 7.3999 & 8.1411 & 9.0539 & 8.1778 & 8.2498 & 7.7916 & 10.2530 & 8050 \\
\hline PKG14 & 8.4512 & 8.7392 & 9.7427 & 8.9814 & 9.5488 & 8.6979 & 11.6730 & 6060 \\
\hline PKG15 & 7.6718 & 8.1592 & 8.7337 & 8.3047 & 8.4794 & 7.9728 & 10.5130 & 11.1370 \\
\hline PKG16 & 8.7835 & 9.2045 & 10.5100 & 9.4829 & 9.9174 & 8.9093 & 12.0840 & 13.0100 \\
\hline PKG17 & 8.0645 & 8.6909 & 9.1506 & 8.3651 & 9.0594 & 8.4320 & 10.6760 & 11.2580 \\
\hline PKG18 & 7.9799 & 8.2740 & 9.1567 & 8.4981 & 8.5821 & 8.3293 & 10.4160 & 11.0890 \\
\hline PKG19 & 8.1068 & 8.0988 & 8.6733 & 8.0933 & 8.4673 & 7.9185 & 10.0900 & 10.8110 \\
\hline PKG20 & 7.6657 & 8.4311 & 9.0962 & 8.1658 & 8.5700 & 8.1964 & 590 & 620 \\
\hline PKG21 & 7.5691 & 8.2861 & 31 & 8.0691 & 8.6002 & 695 & 540 & 410 \\
\hline PKG22 & 8.1431 & 8.3767 & 331 & 993 & 782 & 012 & 610 & 920 \\
\hline PKG23 & 7.1220 & 7.7967 & 8.6733 & 7.9845 & 1048 & 070 & 320 & 180 \\
\hline PKG24 & 7.2428 & 8.0323 & 8.3712 & 7.7126 & 8.2317 & 7.8580 & 9.7457 & 1830 \\
\hline PKG25 & 7.9920 & 8.3102 & 9.0721 & 8.3470 & 232 & 8.4804 & 10.4650 & 4390 \\
\hline PKG26 & 7.9558 & 8.6667 & 9.0298 & 8.3229 & 9.0353 & 8.4260 & 11.0210 & 11.0290 \\
\hline PKG27 & 7.5509 & 8.0202 & 8.7881 & 8.2081 & 8.7634 & 8.2024 & 10.4650 & 11.0350 \\
\hline PKG28 & 7.5026 & 8.1834 & 8.7579 & 8.1235 & 8.2498 & 7.7312 & 10.0600 & 10.7930 \\
\hline PKG29 & 8.0887 & 8.6244 & 9.3500 & 8.4860 & 8.8963 & 8.5347 & 10.9960 & 11.3490 \\
\hline PKG30 & 7.7322 & 8.2921 & 8.6793 & 8.1235 & 8.6546 & 964 & 10.2900 & 10.5750 \\
\hline PKG31 & 6.9528 & 7.5550 & 8.2443 & 7.4891 & 7.8027 & 136 & 584 & 2290 \\
\hline PKG32 & 7.7322 & 8.1954 & .3772 & 7.7972 & 5519 & 7.9789 & 8826 & 3390 \\
\hline PKG33 & 7.8107 & 8.6969 & 1989 & 8.4739 & 090 & 970 & 680 & 780 \\
\hline PKG34 & 7.5268 & 7.9054 & 7277 & 3108 & 8.4552 & 7.8580 & 10.2290 & 590 \\
\hline PKG35 & 7.7624 & 8.4069 & 8.7639 & 933 & 996 & 453 & 0300 & 9560 \\
\hline PKG36 & 8.4391 & 8.6305 & 9.3500 & 954 & 9.3132 & 8.7825 & 8570 & 11.5600 \\
\hline PKG37 & 7.7987 & 8.1229 & 9.1506 & 8.3229 & 8.7815 & 8.4743 & 10.4950 & 11.5600 \\
\hline PKG38 & 8.6385 & 8.9024 & 9.0781 & 8.2624 & 9.3555 & 8.9093 & 10.6460 & 11.2400 \\
\hline PKG39 & 7.9739 & 8.4975 & 9.0781 & 8.2806 & 8.6365 & 8.1903 & 10.2470 & 11.2100 \\
\hline PKG40 & 7.6718 & 8.2498 & 8.9210 & 8.2141 & 8.5519 & 8.1843 & 10.4950 & 11.1740 \\
\hline PKG41 & 8.0403 & 8.5580 & 9.6279 & 8.7277 & 8.9265 & 8.2024 & 11.0870 & 11.6750 \\
\hline PKG42 & 7.7262 & 8.3344 & 9.2896 & 8.4437 & 8.5700 & 8.1360 & 10.6460 & 11.3670 \\
\hline PKG43 & 7.6295 & 8.5580 & 8.9754 & 618 & 8.4733 & 7.9547 & 10.2770 & 560 \\
\hline PKG44 & 7.5389 & 8.7271 & 8.7277 & 570 & 8.5579 & 8.2568 & 10.0660 & 3170 \\
\hline PKG45 & 8.1068 & 8.5700 & 8.9512 & 8.1416 & 8.9023 & 8.3354 & 10.8570 & 10.9740 \\
\hline PKG46 & 8.1370 & 8.5519 & 9.5010 & 8.6008 & 9.4038 & 8.5468 & 10.8390 & 11.6390 \\
\hline PKG47 & 7.5268 & 7.9658 & 8.9150 & 8.0449 & 8.2196 & 7.7070 & 10.2410 & 10.8780 \\
\hline PKG48 & 7.2730 & 7.9356 & 8.7216 & 8.0570 & 8.2860 & 7.8399 & 10.3200 & 11.0890 \\
\hline PKG49 & 7.4784 & 8.2619 & 8.4195 & 7.7126 & 8.5640 & 7.8943 & 10.0420 & 10.5270 \\
\hline PKG50 & 8.0645 & 9.0353 & 9.2231 & 8.5887 & 9.0896 & 8.5710 & 10.9660 & 11.7420 \\
\hline Mean & 7.8452 & 8.3824 & 9.0770 & 8.2864 & 8.7385 & 8.2418 & 10.4943 & 11.1317 \\
\hline SD & 0.4241 & 0.3685 & 0.4639 & 0.3648 & 0.4341 & 0.3913 & 0.4867 & 0.5727 \\
\hline Max & 8.7835 & 9.2407 & 10.5100 & 9.4829 & 9.9174 & 9.0725 & 12.0840 & 13.0100 \\
\hline Min & 6.9528 & 7.5550 & 8.2443 & 7.4891 & 7.8027 & 7.5136 & 9.5584 & 9.9290 \\
\hline Diff & 1.8307 & 1.6857 & 2.2657 & 1.9938 & 2.1147 & 1.5589 & 2.5256 & 3.0810 \\
\hline
\end{tabular}


Table C-1-11: TCB $1200^{\text {th }}$ cycle; Daisy01 - Daisy08.

\begin{tabular}{|c|c|c|c|c|c|c|c|c|}
\hline & DAISY01 & DAISY02 & DAISY03 & DAISY04 & DAISY05 & DAISY06 & DAISY07 & DAISY08 \\
\hline PKG01 & 6.3546 & 6.0515 & 7.4704 & 6.1411 & 7.7398 & 5.2046 & 9.2719 & 7.8772 \\
\hline PKG02 & 6.4150 & 6.4020 & 7.5973 & 6.5943 & 7.7035 & 5.4282 & 9.7734 & 8.7956 \\
\hline PKG03 & 6.8017 & 6.8249 & 7.8994 & 7.0354 & 8.3440 & 5.7665 & 9.9123 & 8.6445 \\
\hline PKG04 & 6.6628 & 6.3597 & 7.4886 & 6.2620 & 7.4135 & 5.3798 & 9.3686 & 7.9980 \\
\hline PKG05 & 6.7111 & 6.5530 & 7.6215 & 6.4009 & 7.6914 & 5.4221 & 9.5498 & 8.2699 \\
\hline PKG06 & 6.0102 & 5.6769 & 7.1079 & 5.5490 & 6.9724 & 4.9448 & 9.0000 & 7.2972 \\
\hline PKG07 & 6.1794 & 6.3174 & 7.2952 & 6.1170 & 7.6008 & 5.3194 & 9.0846 & 7.6355 \\
\hline PKG08 & 6.7836 & 6.6859 & 8.2015 & 7.1079 & 8.2775 & 5.6215 & 10.6010 & 9.2729 \\
\hline PKG09 & 6.1613 & 6.1482 & 7.4100 & 6.2197 & 7.5162 & 5.4765 & 9.6646 & 8.0645 \\
\hline PKG10 & 6.9044 & 6.5832 & 7.7967 & 6.6547 & 8.2413 & 5.5248 & 9.9909 & 8.3304 \\
\hline PKG11 & 6.5842 & 6.1482 & 7.5429 & 6.3405 & 7.7821 & 5.5792 & 9.3202 & 7.5630 \\
\hline PKG12 & 6.8984 & 6.6799 & 7.7967 & 6.8178 & 8.4527 & 5.8934 & 9.8519 & 8.8439 \\
\hline PKG13 & 6.2640 & 5.8159 & 7.2952 & 5.9599 & 7.3833 & 5.3315 & 9.1933 & 7.8530 \\
\hline PKG14 & 7.2368 & 7.1089 & 8.1834 & 7.2347 & 8.7125 & 5.9538 & 10.3170 & 9.0010 \\
\hline PKG15 & 6.4875 & 5.9851 & 7.3617 & 5.9901 & 7.5041 & 5.1261 & 9.0906 & 7.7382 \\
\hline PKG16 & 7.4301 & 7.3083 & 8.5157 & 7.6819 & 9.1294 & 6.3707 & 10.7940 & 9.7019 \\
\hline PKG17 & 6.7776 & 6.4382 & 7.6275 & 6.6366 & 8.0902 & 5.6517 & 9.5861 & 8.3545 \\
\hline PKG18 & 6.4271 & 6.0817 & 7.6275 & 6.4372 & 6.2776 & 5.6457 & 9.3927 & 8.2397 \\
\hline PKG19 & 6.1311 & 5.9307 & 7.4402 & 6.0747 & 7.4135 & 5.3255 & 9.1148 & 7.7201 \\
\hline PKG20 & 6.2579 & 6.1119 & 7.4644 & 6.2439 & 7.4921 & 5.4100 & 9.3686 & 8.0343 \\
\hline PKG21 & 6.3002 & 6.2026 & 7.5550 & 6.1955 & 7.7881 & 5.5611 & 2598 & 7.6718 \\
\hline PKG22 & 6.2217 & 757 & 7.6698 & 6.3526 & 7.3954 & 5.5188 & 163 & 8.0222 \\
\hline PKG23 & 5.8229 & 5.6165 & 7.4281 & 6.1291 & 6.9906 & 4.8723 & 517 & 7.7201 \\
\hline PKG24 & 6.0223 & 5.9367 & 7.1019 & 5.6336 & 7.3773 & 678 & 677 & 7.2428 \\
\hline PKG25 & 6.4150 & 6.3476 & 7.9477 & 6.7393 & 7.5404 & 5.5248 & 9.6948 & 8.1189 \\
\hline PKG26 & 6.4332 & 6.3476 & 7.7544 & 6.5883 & 7.6794 & 5.3919 & 9.5619 & 8.0464 \\
\hline PKG27 & 6.4332 & 6.1059 & 7.6759 & 6.2922 & 7.5162 & 5.1865 & 9.7009 & 7.6355 \\
\hline PKG28 & 6.0888 & 6.0213 & 7.5248 & 6.2922 & 7.3229 & 5.2046 & 9.3988 & 7.6114 \\
\hline PKG29 & 6.4996 & 6.3959 & 7.9175 & 6.8722 & 7.7760 & 5.4040 & 9.9123 & 8.1551 \\
\hline PKG30 & 6.2882 & 6.0999 & 7.5369 & 6.2680 & 7.5766 & 5.0717 & 9.5498 & 7.5811 \\
\hline PKG31 & 5.7444 & 5.5923 & 7.0233 & 5.6215 & 6.9845 & 4.9267 & 8.7462 & 6.9769 \\
\hline PKG32 & 6.2157 & 6.0515 & 7.3133 & 5.9418 & 7.5646 & 5.2469 & 9.0060 & 7.2367 \\
\hline PKG33 & 6.4634 & 536 & 7.7242 & 6.4432 & 7.8485 & 5.4584 & 9.6102 & 8.3062 \\
\hline PKG34 & 6.0465 & 5.9609 & 7.6396 & 6.1230 & 7.1597 & 4.8723 & 9.2477 & 7.4301 \\
\hline PKG35 & 6.3425 & 6.2992 & 7.4765 & 5.9478 & 7.7277 & 5.3859 & 9.3202 & 7.7987 \\
\hline PKG36 & 6.6084 & 6.7222 & 8.0686 & 6.9447 & 8.0177 & 5.5067 & 9.7613 & 8.1793 \\
\hline PKG37 & 6.3184 & 6.1542 & 7.5792 & 6.2801 & 7.8244 & 5.3859 & 9.3686 & 8.0101 \\
\hline PKG38 & 6.7292 & 6.4261 & 7.7000 & 6.6003 & 8.0902 & 5.5490 & 9.5075 & 7.8349 \\
\hline PKG39 & 6.3123 & 6.1119 & 7.5731 & 6.2922 & 7.7096 & 5.3738 & 9.5256 & 8.0101 \\
\hline PKG40 & 6.1794 & 6.1361 & 7.6396 & 6.4009 & 7.5041 & 5.0898 & 9.3927 & 7.7987 \\
\hline PKG41 & 6.5600 & 6.5651 & 7.8209 & 6.7333 & 8.1446 & 5.7484 & 9.7734 & 8.6325 \\
\hline PKG42 & 6.3667 & 6.0817 & 7.6819 & 6.6124 & 7.8848 & 5.6880 & 9.4531 & 8.1793 \\
\hline PKG43 & 6.3727 & 5.9428 & 7.5006 & 6.1170 & 7.5585 & 5.5974 & 9.4713 & 7.9980 \\
\hline PKG44 & 6.1734 & 5.9911 & 7.2529 & 5.8692 & 7.4498 & 5.4282 & 9.1148 & 7.4663 \\
\hline PKG45 & 6.3365 & 6.3295 & 7.6819 & 6.5399 & 7.6794 & 6.0082 & 9.6646 & 7.8651 \\
\hline PKG46 & 6.6628 & 6.5772 & 8.0021 & 6.8058 & 8.1023 & 5.7665 & 9.7794 & 8.2156 \\
\hline PKG47 & 6.1915 & 5.9609 & 7.3254 & 6.1955 & 7.4981 & 5.3073 & 9.3806 & 7.9739 \\
\hline PKG48 & 5.9498 & 5.7132 & 7.4946 & 6.2076 & 7.0147 & 5.1925 & 9.2658 & 7.6718 \\
\hline PKG49 & 6.2579 & 6.0092 & 7.1804 & 5.8088 & 7.4679 & 5.3678 & 8.7764 & 7.1219 \\
\hline PKG50 & 6.6507 & 6.4201 & 7.8148 & 6.5278 & 8.1990 & 5.7182 & 9.9667 & 8.4029 \\
\hline Mean & 6.4097 & 6.2352 & 7.6070 & 6.3775 & 7.6826 & 5.4419 & 9.4938 & 8.0030 \\
\hline SD & 0.3264 & 0.3505 & 0.2925 & 0.4214 & 0.4767 & 0.2925 & 0.4202 & 0.5330 \\
\hline Max & 7.4301 & 7.3083 & 8.5157 & 7.6819 & 9.1294 & 6.3707 & 10.7940 & 9.7019 \\
\hline Min & 5.7444 & 5.5923 & 7.0233 & 5.5490 & 6.2776 & 4.8723 & 8.6677 & 6.9769 \\
\hline Diff & 1.6857 & 1.7160 & 1.4924 & 2.1329 & 2.8518 & 1.4984 & 2.1263 & 2.7250 \\
\hline
\end{tabular}


Table C-1-12: TCB $1200^{\text {th }}$ cycle; Daisy09 - Daisy16.

\begin{tabular}{|c|c|c|c|c|c|c|c|c|}
\hline & DAISY09 & DAISY10 & DAISY11 & DAISY12 & DAISY13 & DAISY14 & DAISY15 & DAISY16 \\
\hline PKG01 & 7.7020 & 8.3042 & 8.7760 & 8.2503 & 8.6002 & 7.9910 & 10.5130 & 10.9800 \\
\hline PKG02 & 7.7443 & 8.1531 & 9.1446 & 8.4316 & 8.4129 & 7.9547 & 10.3320 & 11.1370 \\
\hline PKG03 & 8.7352 & 8.8601 & 9.3500 & 8.6310 & 9.4038 & 8.7764 & 10.4890 & 11.7290 \\
\hline PKG04 & 7.7987 & 8.3042 & 8.8243 & 8.0449 & 8.7936 & 8.2689 & 10.2530 & 10.7750 \\
\hline PKG05 & 7.6416 & 8.0988 & 9.1204 & 8.5283 & 8.6123 & 8.0635 & 10.3920 & 11.2580 \\
\hline PKG06 & 7.0857 & 7.6456 & 8.2624 & 7.6884 & 8.0564 & 7.5197 & 9.7699 & 10.1830 \\
\hline PKG07 & 7.5993 & 8.0988 & 8.7398 & 8.1537 & 8.6909 & 8.0514 & 9.9814 & 10.7750 \\
\hline PKG08 & 8.5781 & 8.9446 & 10.0810 & 9.2231 & 9.5005 & 8.7704 & 11.3290 & 12.3940 \\
\hline PKG09 & 7.5630 & 7.9840 & 8.8666 & 8.2262 & 8.3827 & 7.8037 & 9.9089 & 11.0770 \\
\hline PKG10 & 8.1370 & 8.5700 & 9.3137 & 8.6250 & 9.1803 & 8.4924 & 10.5980 & 11.6090 \\
\hline PKG11 & 8.1128 & 8.5459 & 8.6431 & 8.0389 & 9.0594 & 8.5710 & 10.0540 & 10.8900 \\
\hline PKG12 & 8.4693 & 8.8298 & 9.6461 & 8.7458 & 9.2769 & 8.7281 & 10.6340 & 11.7050 \\
\hline PKG13 & 7.4059 & 8.1350 & 8.7458 & 8.2806 & 8.2679 & 7.8399 & 9.9814 & 10.7510 \\
\hline PKG14 & 8.4633 & 8.7573 & 9.7790 & 9.1748 & 9.6334 & 8.7160 & 11.2320 & 12.7080 \\
\hline PKG15 & 7.3395 & 7.9960 & 8.6733 & 8.2262 & 8.5942 & 7.9245 & 10.0180 & 10.8780 \\
\hline PKG16 & 8.9164 & 9.2830 & 10.5830 & 9.4890 & 9.8026 & 9.0906 & 11.6490 & 12.8350 \\
\hline PKG17 & 8.1370 & 8.4734 & 9.1929 & 8.3954 & 8.9386 & 8.4260 & 10.6220 & 11.2220 \\
\hline PKG18 & 7.8168 & 8.2317 & 9.1929 & 8.3772 & 8.6546 & 8.1843 & 10.1140 & 11.0040 \\
\hline PKG19 & 7.5811 & 8.4975 & 8.8183 & 8.2987 & 8.4311 & 7.8580 & 9.9149 & 10.8410 \\
\hline PKG20 & 7.9437 & 8.2498 & 9.0539 & 8.3047 & 6365 & 8.1118 & 1260 & 10.9680 \\
\hline PKG21 & 7.6234 & 8.1834 & 8.7579 & 8.1356 & 5761 & 7.9728 & 900 & 10.9020 \\
\hline PKG22 & 7.9316 & 8.3707 & 8.8425 & 8.4014 & 8.7392 & 8.4260 & 830 & 10.8530 \\
\hline PKG23 & 7.7685 & 7.6033 & 8.5645 & 8.0751 & 8.1350 & 7.7130 & 10.1930 & 10.5940 \\
\hline PKG24 & 7.3636 & 7.8813 & 8.3712 & 7.8274 & 8.3163 & 7.9366 & 9.4436 & 10.2430 \\
\hline PKG25 & 8.2881 & 8.3102 & 9.1204 & 8.6008 & 8.9265 & 8.4381 & 10.5130 & 11.2700 \\
\hline PKG26 & 8.1612 & 8.3525 & 8.9089 & 8.2806 & 8.9869 & 8.5589 & 10.4950 & 11.1070 \\
\hline PKG27 & 7.5811 & 8.0806 & 8.6250 & 8.2201 & 8.7513 & 8.1964 & 10.2470 & 11.0230 \\
\hline PKG28 & 7.2247 & 8.1108 & 8.6250 & 7.9180 & 8.3102 & 7.7372 & 9.9934 & 10.8050 \\
\hline PKG29 & 7.9437 & 8.2075 & 9.0962 & 8.5041 & 8.9446 & 8.4502 & 10.6340 & 11.2940 \\
\hline PKG30 & 8.0766 & 8.3827 & 8.5102 & 8.0026 & 8.6848 & 8.1360 & 10.1510 & 10.5690 \\
\hline PKG31 & 588 & 7.6094 & 8.2383 & 7.5978 & 7.7966 & 7.4593 & 9.4859 & 9.8988 \\
\hline PKG32 & 7.5207 & 8.0565 & 8.3349 & 7.8214 & 8.4854 & 7.9728 & 9.6853 & 10.3400 \\
\hline PKG33 & 7.6174 & 8.2136 & 9.2956 & 8.4799 & 365 & 7.9910 & 10.2770 & 11.3250 \\
\hline PKG34 & 7.3455 & 7.9356 & 8.5706 & 8.0872 & 8.4311 & 7.9124 & 10.1630 & 10.9560 \\
\hline PKG35 & 7.7201 & 8.3888 & 8.6733 & 8.0933 & 8.7694 & 8.0695 & 9.9149 & 10.7930 \\
\hline PKG36 & 8.7170 & 8.5519 & 9.2231 & 8.5222 & 9.4038 & 8.2447 & 10.6040 & 11.3490 \\
\hline PKG37 & 7.6959 & 8.0927 & 9.0116 & 8.5887 & 8.7513 & 8.1541 & 10.2590 & 11.3130 \\
\hline PKG38 & 8.4633 & 9.3072 & 8.8243 & 8.3229 & 9.4280 & 8.5045 & 10.3440 & 10.9260 \\
\hline PKG39 & 7.8712 & 8.4552 & 8.9331 & 8.3289 & 8.6365 & 8.1118 & 10.1630 & 11.0350 \\
\hline PKG40 & 7.6959 & 8.2136 & 8.7700 & 8.2322 & 8.6969 & 8.0333 & 10.2110 & 10.9320 \\
\hline PKG41 & 8.2095 & 8.4734 & 9.6702 & 8.8062 & 111 & 8.3051 & 10.6520 & 11.5780 \\
\hline PKG42 & 7.9980 & 8.2740 & 9.5192 & 8.4377 & 8.7754 & 8.2266 & 10.6700 & 11.5970 \\
\hline PKG43 & 7.9558 & 8.2196 & 9.1567 & 8.3531 & 8.5459 & 8.0453 & 10.6220 & 11.0040 \\
\hline PKG44 & 7.9980 & 8.2498 & 8.6552 & 8.0328 & 8.5398 & 7.9607 & 9.8424 & 10.8170 \\
\hline PKG45 & 8.1793 & 8.5459 & 8.8727 & 8.2383 & 8.9688 & 8.3897 & 10.3380 & 10.9380 \\
\hline PKG46 & 8.3243 & 8.5459 & 9.4104 & 8.7881 & 9.4038 & 8.7643 & 10.7250 & 11.5970 \\
\hline PKG47 & 7.4361 & 7.9900 & 9.0539 & 8.1718 & 8.2921 & 7.8097 & 10.0720 & 10.9140 \\
\hline PKG48 & 7.3999 & 7.9658 & 8.6370 & 8.1778 & 8.2981 & 7.8037 & 10.1140 & 10.7690 \\
\hline PKG49 & 7.4905 & 8.0927 & 8.3168 & 7.7972 & 8.4613 & 7.8580 & 9.7095 & 10.3760 \\
\hline PKG50 & 8.4995 & 8.7936 & 9.3440 & 8.7095 & 9.2165 & 8.6193 & 10.5550 & 11.7110 \\
\hline Mean & 7.8766 & 8.3084 & 8.9748 & 8.3337 & 8.7570 & 8.1789 & 10.2912 & 11.0910 \\
\hline$\widehat{S D}$ & 0.4453 & 0.3618 & 0.4645 & 0.3704 & 0.4259 & 0.3542 & 0.4251 & 0.5619 \\
\hline Max & 8.9164 & 9.3072 & 10.5830 & 9.4890 & 9.8026 & 9.0906 & 11.6490 & 12.8350 \\
\hline Min & 6.9588 & 7.6033 & 8.2383 & 7.5978 & 7.7966 & 7.4593 & 9.4436 & 9.8988 \\
\hline Diff & 1.9576 & 1.7039 & 2.3447 & 1.8912 & 2.0060 & 1.6313 & 2.2054 & 2.9362 \\
\hline
\end{tabular}


Table C-1-13: TCB $1492^{\text {nd }}$ cycle; Daisy01 - Daisy08.

\begin{tabular}{|c|c|c|c|c|c|c|c|c|}
\hline & AISY01 & DAISY02 & DAISY03 & $\overline{\text { DAIS }}$ & DAISY05 & DAISY06 & DAISY07 & 0,100 \\
\hline PKG01 & 6.2277 & 5.9609 & 7.5006 & 6.1472 & 7.7035 & 5.2288 & 9.5559 & 7.9980 \\
\hline PKG02 & 2398 & 1784 & 7.7000 & 6064 & 7.7035 & 4040 & 552 & 5902 \\
\hline $\mathrm{KGO3}$ & 930 & 3974 & 9659 & 541 & 8.1990 & 363 & 1000 & 8198 \\
\hline KGO4 & 283 & 0999 & 7.4946 & 6.2076 & 7.3470 & 2046 & 9.3927 & 7.9980 \\
\hline KG05 & 492 & 2388 & 7.6336 & 6.3043 & 7.6371 & 5.3315 & .4652 & B.4995 \\
\hline KG06 & 833 & 5.7132 & 7.0535 & 5.6336 & 6.9906 & 4.9750 & 9396 & 7.6959 \\
\hline KG07 & 063 & 1603 & 550 & 6.1472 & 7.6189 & 496 & 2296 & .0947 \\
\hline KG08 & 232 & 4866 & 411 & 7.0474 & 8.2715 & 6578 & 10.5100 & 9.1400 \\
\hline KG09 & 277 & .0697 & 7.4463 & 6.1714 & 7.6733 & 517 & 223 & 9947 \\
\hline KG10 & 292 & 5228 & 7.8027 & 6.5 & 8.1627 & 155 & 7371 & 364 \\
\hline KG11 & 002 & 6.1784 & & & 7639 & 1321 & 752 & 966 \\
\hline KG12 & 667 & 51 & 7.8269 & & 984 & 9901 & 157 & 433 \\
\hline KG13 & 888 & 5.7615 & 556 & 6.0445 & 954 & 5.1200 & 9.2477 & 7.8651 \\
\hline PKG14 & 769 & 7.1089 & & 7.3254 & 8.7125 & 5.8451 & 10.2390 & 9.8650 \\
\hline KG15 & 646 & 5.8642 & 7.4100 & 6.0445 & 7.4679 & 5.5369 & 9.1873 & 7.5691 \\
\hline KG16 & & 7.3506 & 311 & & & 6.4734 & 10.8250 & 9.6536 \\
\hline KG17 & 52 & 38 & & & & 5.7121 & 948 & \\
\hline KG18 & 277 & 34 & & & & 7121 & 256 & 733 \\
\hline G19 & & & & & & & & 78 \\
\hline 620 & & & & & & & & 343 \\
\hline KG21 & 77 & 4 & & & & & & 32 \\
\hline KG22 & & & & & & 65 & & 712 \\
\hline KG23 & & 3 & & & 49 & 5.0777 & & 7.4784 \\
\hline KG24 & 138 & 01 & & & & 5.1442 & & 7.1340 \\
\hline KG25 & 700 & 3295 & & & & 4.7998 & & 8.1612 \\
\hline G26 & & & & & & & & 99 \\
\hline G27 & & & & & 64 & 65 & 235 & 7.6778 \\
\hline KG28 & & & & & & & 19 & 080 \\
\hline KG29 & & & & & & & & 114 \\
\hline KG30 & & & & & & & & \\
\hline PKG31 & & & & & & & & 346 \\
\hline KG32 & & & & & & & & 509 \\
\hline KG33 & & & & & & 17 & 34 & 8.2760 \\
\hline KG34 & & & & & & & & 7.4663 \\
\hline PKG35 & & & & & & & & 866 \\
\hline PKG36 & & & & & & 20 & 669 & 518 \\
\hline PKG37 & & & & & & 82 & & 7.8953 \\
\hline PKG38 & & & & & & & & 080 \\
\hline <G39 & & & & & & & & 980 \\
\hline KG40 & & & & & & & & 778 \\
\hline KG41 & & & & & & & & \\
\hline KG42 & & & & & & & & \\
\hline KG43 & & & & & & 05 & & 30 \\
\hline PKG44 & & & & & & & & 7.4361 \\
\hline PKG45 & 21 & & & & 337 & 5.4403 & 438 & 7.7322 \\
\hline PKG46 & & & 698 & & 77 & 5.8269 & 311 & 8.1914 \\
\hline G47 & & & & & & 678 & 202 & 7.8107 \\
\hline PKG48 & & & & & & & & 7.4482 \\
\hline PKG49 & & & & & & & 489 & 7.0917 \\
\hline PKG50 & 61 & 20 & 50 & & & 88 & 750 & 8.3364 \\
\hline Mean & & 4 & & & & 93 & & 8.0009 \\
\hline 0 & & 16 & & & & 51 & & 0.5856 \\
\hline & & & & & & & & 650 \\
\hline Min & & & & & & & 7100 & 6.9346 \\
\hline Diff & 1.8368 & 1.8368 & 1.4380 & 2.0664 & 2.2174 & 1.6736 & 2.1150 & 2.930 \\
\hline
\end{tabular}


Table C-1-14: TCB $1492^{\text {nd }}$ cycle; Daisy09 - Daisy16.

\begin{tabular}{|c|c|c|c|c|c|c|c|c|}
\hline & 09 & 10 & 11 & DAISY12 & AISY13 & DAISY14 & DAISY15 & DAISY16 \\
\hline PKG01 & 7.6295 & 8.4734 & 8.8968 & 8.2322 & 8.6727 & 8.0876 & 10.1140 & 10.7870 \\
\hline PKG02 & 391 & 223 & 9.2292 & 1195 & 3881 & 7.8580 & 2470 & .0040 \\
\hline PKG03 & 566 & 232 & 929 & 102 & 878 & 7462 & 5860 & .343 \\
\hline PKG04 & 19 & 223 & 8.6672 & 0872 & 3727 & 8.2810 & 2290 & 0.6600 \\
\hline PKG05 & 745 & 8.6607 & 9.0479 & 8.4860 & 8.6123 & 7.8641 & .2590 & 1.2460 \\
\hline PKG06 & 0797 & 7.7544 & 8.1899 & 7.8395 & 8.1712 & 7.6345 & 9.7155 & 0.0620 \\
\hline PKG07 & 5509 & 8.4069 & 8.6370 & 8.1356 & 8.7815 & 8.0393 & .0780 & 0.7930 \\
\hline PKG08 & 902 & .0957 & 10.0750 & 9.4104 & 9.4763 & 9.1933 & .3890 & 2.3400 \\
\hline KG09 & 053 & 1592 & 8.8243 & 597 & 8.2860 & 8.0453 & 3303 & 0.8900 \\
\hline PKG10 & 914 & 6788 & 9.2956 & 364 & 9.0896 & 8.6193 & 10.6100 & 11.5420 \\
\hline PKG11 & & 40 & 8.5766 & 330 & 9.0050 & 8.6012 & .4220 & 0.6660 \\
\hline PKG12 & & & 98 & & 9.2709 & 3.6677 & 6220 & 1.6510 \\
\hline PKG13 & & & & & & 7.9124 & 0240 & 0.6720 \\
\hline PKG14 & 452 & 7150 & 9.8092 & & 488 & 8.5710 & 6850 & 2.5150 \\
\hline PKG15 & 328 & 8.0806 & 8.6975 & & 8.4794 & 7.8943 & 9995 & 0.8720 \\
\hline PKG16 & 044 & 9.1682 & 10.5220 & 9.4346 & .8570 & 8.8671 & 9990 & 2.9920 \\
\hline PKG17 & 276 & 8.6305 & & & & 8.4441 & 3380 & 1.4090 \\
\hline PKG18 & & 8.7332 & & 8.3229 & & 8.2387 & 1140 & 1.2580 \\
\hline PKG19 & & 44 & & & & 8.0635 & 0480 & 11.0290 \\
\hline G20 & 201 & 31 & 8.9 & & & 8.0997 & 0420 & 170 \\
\hline PKG21 & 509 & 350 & 8.6612 & & 8.5579 & 8.1601 & 9209 & 10.8290 \\
\hline PKG22 & & 00 & & & & 8.2206 & 1930 & 880 \\
\hline PKG23 & & & & & & 7.5861 & 3001 & \\
\hline PKG24 & & & & & & 7.7855 & 013 & \\
\hline$\langle G 25$ & & & & & & 8.5468 & 590 & 520 \\
\hline PKG26 & & & & & & 8.3112 & 1710 & 1.0590 \\
\hline PKG27 & 666 & 67 & & & & 8.0937 & 350 & 0.9380 \\
\hline PKG28 & 005 & 7242 & & & & 7.6586 & 480 & 10.8230 \\
\hline PKG29 & & & & & & 8.3595 & 5730 & .3730 \\
\hline KG30 & $\overline{03}$ & & & & & 8.1722 & 9451 & \\
\hline KG31 & & 98 & & & & 7.3626 & 1717 & .9954 \\
\hline <G3 & & & & & & 7.9185 & 209 & 000 \\
\hline KG33 & & & & & & 8.0272 & 470 & \\
\hline PKG34 & & & & & & 7.7855 & 510 & \\
\hline PKG35 & & & & & & 8.0755 & 420 & \\
\hline PKG36 & & & & & & 8.6677 & 190 & \\
\hline PKG37 & & & & & & 997 & 40 & \\
\hline PKG38 & & & & & & 3.7462 & 590 & 560 \\
\hline PKG39 & & & & & & 8.1964 & 320 & 0.9920 \\
\hline PKG40 & & & & & & 8.0635 & 630 & 10.8410 \\
\hline PKG41 & & & & & & 8.2085 & 7850 & 11.5840 \\
\hline PKG42 & & & & & & 8.1722 & 3260 & 980 \\
\hline PKG43 & & & & & & 7.9849 & 650 & 490 \\
\hline G44 & & & & & & 7.9305 & 061 & 930 \\
\hline KG45 & & & & & & 8.3776 & 860 & 10.8900 \\
\hline PKG46 & & & & & & 8.6979 & 490 & 20 \\
\hline PKG47 & & & & & & 7.7009 & 484 & \\
\hline PKG48 & & & & & & & & \\
\hline PKG49 & & & & & & & & \\
\hline PKG50 & & & & & & 106 & 550 & \\
\hline Mean & 24 & & & & 106 & 8.1763 & 2606 & 11.0448 \\
\hline SD & & & & 651 & & 3739 & 904 & 5581 \\
\hline Max & & & & & & 33 & 11.9990 & 12.9920 \\
\hline Min & & & & 7.5555 & & 7.3626 & 1717 & 9.9954 \\
\hline Diff & 1.9335 & 1.5347 & 2.3442 & 1.8791 & 1.9939 & 1.8307 & 2.8273 & 2.9966 \\
\hline
\end{tabular}


Table C-1-15: TCB $1724^{\text {th }}$ cycle; Daisy01 - Daisy08.

\begin{tabular}{|c|c|c|c|c|c|c|c|c|}
\hline & DAISY01 & DAISY02 & DAISY03 & DAISY04 & DAISY05 & DAISY06 & DAISY07 & DAISY08 \\
\hline PKG01 & 6.2519 & 6.0817 & 7.5369 & 6.1955 & 7.8727 & 5.3859 & 9.2477 & 7.7564 \\
\hline PKG02 & 6.2761 & 6.0697 & 7.7665 & 6.6305 & 7.7579 & 5.7182 & 9.7673 & 8.2397 \\
\hline PKG03 & 6.8682 & 6.9216 & 8.0565 & 6.9447 & 8.2836 & 5.8390 & 9.8519 & 8.5418 \\
\hline PKG04 & 6.1734 & 6.1059 & 7.5792 & 6.6668 & 7.4014 & 5.3557 & 9.4048 & 7.7987 \\
\hline PKG05 & 6.3002 & 6.2630 & 7.6940 & .5157 & 7.7519 & 5.4946 & 9.6223 & 8.2699 \\
\hline PKG06 & 5.8108 & 5.7857 & 7.1079 & 5.6880 & 7.2383 & 5.0475 & 8.8006 & 7.1945 \\
\hline PKG07 & 6.2338 & 6.2751 & 7.3858 & 6.4614 & 7.8123 & 5.5913 & 9.1027 & 7.5811 \\
\hline PKG08 & 7.0011 & 6.5409 & 8.2015 & 7.2468 & 8.3742 & 5.8088 & 10.5230 & 9.2608 \\
\hline PKG09 & 6.2761 & 6.1542 & 7.5188 & 6.3768 & 7.6129 & 5.4221 & 9.5800 & 8.1310 \\
\hline PKG10 & 7.1220 & 6.5470 & 7.8752 & 6.7635 & 8.3440 & 5.7726 & 10.0150 & 3.3424 \\
\hline PKG11 & 6.8017 & 6.2267 & 7.5550 & 6.3768 & 7.8244 & 5.3073 & 9.2356 & 7.4663 \\
\hline PKG12 & 6.9709 & 6.5953 & 7.8088 & 6.7272 & 8.6521 & 5.8813 & 9.9607 & 8.4633 \\
\hline PKG13 & 6.3909 & 5.7676 & 7.4100 & 5.9357 & 7.3773 & 5.3073 & 9.6586 & 7.7322 \\
\hline PKG14 & 7.3334 & 7.1874 & 8.2317 & 7.2589 & 8.8757 & 5.9176 & 10.6620 & 8.9708 \\
\hline KG15 & 6.3365 & 8582 & 7.4765 & 6.0505 & 7.7277 & 5.2348 & 9.4894 & 7.6899 \\
\hline PKG16 & 7.7987 & 7.4049 & 8.5701 & 7.6637 & 9.4557 & .5339 & 10.7940 & .6475 \\
\hline PKG17 & 6.5359 & 6.3778 & 7.6698 & 6.5339 & 8.1265 & 5.7484 & 9.7069 & 3.1551 \\
\hline PKG18 & 6.5057 & 6.0636 & 7.6034 & 6.3284 & 7.8667 & 5.8330 & 9.6102 & 8.0947 \\
\hline PKG19 & 6.3002 & 5.9488 & 7.3919 & 6.1472 & 7.4014 & 5.2409 & 9.3806 & 7.5932 \\
\hline PKG20 & 6.2640 & 5.9669 & 7.4523 & 6.2439 & 7.7398 & 5.3678 & 9.3988 & 7.9799 \\
\hline PKG21 & 6.5661 & 6.1965 & 7.5731 & 6.1653 & 7.8304 & 5.4221 & 9.5256 & 7.5751 \\
\hline PKG22 & 6.5721 & 6.1361 & 7.6336 & 6.4372 & 7.6068 & 5.3255 & 9.6525 & 7.7805 \\
\hline PKG23 & 5.8471 & 5.5863 & 7.4100 & 5.9659 & & .9629 & 8.9939 & 7.2549 \\
\hline PKG24 & 6.3184 & 5.7978 & 7.0354 & 5.6094 & & 200 & 8.9214 & 7.1038 \\
\hline PKG25 & 3386 & 3113 & 38 & 20 & & 515 & 10.1180 & 3.1128 \\
\hline PKG26 & 6.6869 & 6.4443 & 7.8571 & 6.6487 & 54 & .3678 & 525 & 8.1733 \\
\hline PKG27 & 6.5298 & 6.0636 & 7.7302 & 6.3284 & 7.6371 & 5.1200 & 9.4108 & 7.6778 \\
\hline PKG28 & 6.2398 & 6.1784 & 7.6154 & 6.3224 & 7.3591 & 5.2832 & 9.5861 & 7.5026 \\
\hline PKG29 & 6.6386 & 6.4986 & 8.0867 & 6.8118 & 7.9029 & 5.3859 & 9.7734 & 8.3968 \\
\hline PKG30 & 6.4513 & 6.2086 & 7.5671 & 6.2318 & 7.4679 & 5.1200 & .1571 & 7.3274 \\
\hline PKG31 & 4241 & 5.7132 & 7.0052 & 5.7424 & 7.2806 & 382 & .7039 & 6.9890 \\
\hline PKG32 & 6.1734 & 6.0878 & 7.3254 & 5.9478 & 7.4014 & 5.1563 & 906 & 7.1522 \\
\hline PKG33 & 6.3788 & 6.3657 & 7.7665 & 6.4976 & & 5.4826 & 9.7794 & 8.1914 \\
\hline PKG34 & 6.3244 & 6.1240 & 7.7363 & 6.2922 & & 5.0717 & 9.4229 & 7.3757 \\
\hline PKG35 & 3446 & 03 & 7.5671 & 32 & 92 & 5.4523 & 652 & 7.6597 \\
\hline PKG36 & 863 & 007 & 32 & 7.1320 & 48 & .5248 & 486 & 8.1128 \\
\hline PKG37 & 5963 & 2207 & 994 & 6.3526 & 63 & 913 & 740 & 7.9135 \\
\hline PKG38 & 6.8742 & 5409 & 7.7484 & 6.6366 & 54 & 5.4282 & 377 & 7.7141 \\
\hline PKG39 & 6.3244 & 6.0636 & 7.6456 & 6.4130 & 7.8002 & .5007 & 311 & 8.0947 \\
\hline PKG40 & 6.1854 & 6.0455 & 7.7000 & 6.4735 & 5827 & .2288 & 4290 & 7.8530 \\
\hline PKG41 & 6.8621 & 6.7161 & 7.8813 & 6.8239 & 8.1506 & 5.9780 & 8277 & 8.6989 \\
\hline PKG42 & 6.4815 & 6.1603 & 7.6819 & 6.3949 & 304 & 5.4282 & 163 & 8.1733 \\
\hline PKG43 & 6.3969 & 6.0394 & 7.5611 & 6.3526 & 7.7156 & 5.7001 & 3927 & 7.9437 \\
\hline PKG44 & 2761 & & 38 & & & 5.3678 & 290 & 7.4845 \\
\hline PKG45 & 117 & .2449 & 7.7484 & & & 5.6215 & 9.5921 & 7.8832 \\
\hline PKG46 & 3446 & 07 & 8.0867 & 8.8360 & & 5.7967 & 363 & 8.2518 \\
\hline PKG47 & 069 & 65 & 160 & 99 & 21 & 5.3798 & 565 & 7.7443 \\
\hline PKG48 & 256 & 132 & & & & 717 & 988 & 7.5026 \\
\hline PKG49 & 4996 & 3367 & 7.1562 & 5.7484 & & 5.1684 & 489 & 7.0434 \\
\hline PKG50 & 6.9769 & 6.3718 & 7.9115 & 6305 & 8.3440 & 5.7363 & 9.9848 & 8.3726 \\
\hline Mean & 6.4907 & 6.2241 & 592 & 6.4331 & & 5.4498 & 9.5728 & 7.9194 \\
\hline$\overline{S D}$ & 0.3977 & 0.3622 & 0.3085 & 0.4173 & 0.4529 & 0.3171 & 0.4232 & 0.5441 \\
\hline Max & 7.7987 & 49 & 01 & 7.6637 & 557 & 6.5339 & 10.7940 & 9.6475 \\
\hline Min & 5.4241 & 5.5863 & 052 & $\overline{94}$ & 66 & 4.7515 & 8.7039 & 6.9890 \\
\hline Diff & 2.3746 & 1.8186 & 1.5649 & 2.0543 & 2.4591 & 1.7824 & 2.0901 & 2.6585 \\
\hline
\end{tabular}


Table C-1-16: TCB $1724^{\text {th }}$ cycle; Daisy09 - Daisy16.

\begin{tabular}{|c|c|c|c|c|c|c|c|c|}
\hline & DAISY09 & DAISY10 & DAISY11 & DAISY12 & DAISY13 & DAISY14 & DAISY15 & DAISY16 \\
\hline PKG01 & 7.7503 & 8.2679 & 8.9150 & 8.2564 & 8.5881 & 8.1420 & 10.0060 & 10.8960 \\
\hline PKG02 & 7.7685 & 8.1713 & 9.3198 & 8.5766 & 8.4854 & 8.0997 & 10.2410 & 11.1800 \\
\hline PKG03 & 8016 & 8.8661 & 9.3258 & 8.4497 & 9.5428 & 8.8731 & 10.5070 & 11.7540 \\
\hline PKG04 & 7.9316 & 1042 & 8.7156 & 597 & 3359 & 3051 & 10.2110 & 10.6240 \\
\hline PKG05 & 7.6053 & 8.0625 & 9.0841 & 8.4497 & 5217 & 7.8580 & 10.3200 & 11.2580 \\
\hline PKG06 & 7.0313 & 7.5852 & 8.3047 & 7.7791 & 1531 & 7.6043 & 9.7397 & 10.0740 \\
\hline PKG07 & 7.6053 & 8.0565 & 8.6975 & 8.1899 & 8.6727 & 8.0876 & 10.2170 & 10.7140 \\
\hline PKG08 & 8.7110 & 8.9628 & 10.0810 & 9.2352 & 9.4763 & 8.9154 & 11.4800 & 12.3760 \\
\hline PKG09 & 7.4966 & 8.0202 & 8.8848 & 8.2262 & 8.3042 & 7.3686 & 9.9451 & 10.8590 \\
\hline PKG10 & 8.1733 & 8.6063 & 9.3137 & 8.6431 & 9.1380 & 831 & 10.8390 & 11.5000 \\
\hline PKG11 & 8.2639 & 8.5640 & 8.5947 & 8.0691 & 9.0111 & 8.5649 & 10.1750 & 10.5390 \\
\hline PKG12 & 8.8560 & 8.8601 & 9.5977 & 8.6733 & 9.2346 & 8.7583 & 10.7430 & 11.6990 \\
\hline PKG13 & 7.4241 & 8.0444 & 8.8183 & 8.0630 & 8.3163 & 7.7916 & 10.0420 & 10.7930 \\
\hline PKG14 & 8.7896 & 8.8540 & 9.7427 & 9.0237 & 9.6697 & 8.6375 & 11.5520 & 12.4790 \\
\hline PKG15 & 7.7926 & 8.0806 & 8.6854 & 8.2081 & 8.5579 & 8.1239 & 10.1320 & 10.9140 \\
\hline PKG16 & 29 & 9.1078 & 10.4 & 9.4950 & 570 & 302 & 11.8000 & 12.9920 \\
\hline PKG17 & 8.0645 & 8.4915 & 9.2292 & 8.4558 & 9.0413 & 281 & 10.2900 & 11.3430 \\
\hline PKG18 & 20 & & 9.2231 & & 04 & 206 & 10.1930 & 11.1430 \\
\hline PKG19 & 7.5147 & 42 & 8.7277 & & 75 & 28 & 9.9814 & 10.7750 \\
\hline PKG20 & 7.6718 & 8.2921 & 9.0237 & 8.2806 & 398 & 326 & 10.0780 & 10.9920 \\
\hline PKG21 & 7.6114 & 8.1108 & 8.7216 & 960 & 36 & 8.0574 & 10.0060 & 10.7810 \\
\hline PKG22 & 7.9074 & 8.2559 & 8.8062 & 8.2624 & 8.7452 & & 10.6460 & 10.8050 \\
\hline PKG23 & 7.1461 & 7.7665 & 8.4981 & 8.0389 & 8.1048 & 647 & 9.8726 & 10.6660 \\
\hline PKG24 & & & & & & & 9.3228 & 2310 \\
\hline PKG25 & & & & & & & 10.4710 & 3190 \\
\hline PKG26 & 45 & 73 & & & & & 10.4770 & 2160 \\
\hline KG27 & 32 & 565 & 50 & & & & 900 & 0230 \\
\hline PKG28 & 05 & 35 & 66 & 62 & 21 & 26 & 300 & 3590 \\
\hline PKG29 & & 51 & 81 & 99 & 30 & 16 & 760 & 210 \\
\hline KG30 & 7.8 & 13 & 39 & 30 & 09 & 01 & 814 & 000 \\
\hline KG31 & 5.5994 & 7.6577 & 35 & 797 & 14 & 312 & 9.2321 & 680 \\
\hline PKG32 & 7.7322 & 7.9417 & 449 & 7.7972 & 36 & 993 & 9.7638 & 10.2790 \\
\hline PKG33 & 7.5932 & 8.1108 & 9.0962 & 8.4739 & 540 & 178 & 10.3020 & 11.3910 \\
\hline PKG34 & 7.3334 & 7.8027 & 8.7700 & 8.1114 & 8.3706 & 064 & 10.2470 & 10.9200 \\
\hline PKG35 & 7.8289 & 8.4492 & 9.1144 & 201 & 8.8540 & 568 & 9.9451 & 10.7140 \\
\hline KG36 & 814 & 8.7453 & 31 & & 549 & 154 & 10.6040 & 11.3010 \\
\hline PKG37 & 7.6053 & 52 & & & 19 & 55 & 10.2770 & 11.3430 \\
\hline KG38 & 46 & 19 & 62 & 31 & & 66 & 560 & 980 \\
\hline 339 & 05 & & 19 & 14 & & 79 & 110 & 830 \\
\hline PKG40 & 7.7 & 79 & 8.7820 & 83 & 392 & 843 & 920 & 10.9800 \\
\hline PKG41 & 7.9558 & 8.4552 & 9.5977 & 8.7518 & 9.1440 & 8.4743 & 10.8210 & 11.6090 \\
\hline PKG42 & 7.6839 & 8.3042 & 9.4406 & 8.6250 & 8.5700 & 8.1058 & 10.3200 & 11.2640 \\
\hline PKG43 & 7.8289 & 8.2256 & 9.1144 & 8.6008 & 8.5579 & 8.0876 & 10.3140 & 11.0710 \\
\hline PKG44 & 7.5811 & 8.2921 & 8.6914 & 8.1053 & 8.5700 & 8.1058 & 9.8243 & 10.5390 \\
\hline PKG45 & 8.0222 & 8.4190 & 8.8062 & 8.3772 & 8.8480 & 8.4381 & 10.3620 & 10.8720 \\
\hline PKG46 & 8.1189 & 8.6244 & 9.3560 & 8.6370 & \begin{tabular}{|c|}
9.4763 \\
\end{tabular} & 8.7764 & 10.7910 & 11.6330 \\
\hline KG47 & 7.3153 & 7.8208 & 9.0479 & 8.0630 & 8.2437 & 7.7795 & 9.9209 & 10.7020 \\
\hline KG48 & & & & & & & 10.1440 & 10.9800 \\
\hline KG49 & 7.6234 & 90 & 8.5404 & 7.7489 & 8.5942 & 212 & 9.6430 & 10.4000 \\
\hline PKG50 & 8.1551 & 8.8057 & 9.5433 & 8.6612 & 9.0775 & 8.5227 & 10.6580 & 11.8260 \\
\hline Mean & & & & & & & 10.2879 & 11.0760 \\
\hline SD & 0.5690 & 0.3519 & 0.4555 & 0.3588 & 0.4338 & 0.3811 & 0.4826 & 0.5728 \\
\hline Max & 8.9829 & 9.1078 & 10.4980 & 9.4950 & 9.8570 & 9.0302 & 11.8000 & 12.9920 \\
\hline Min & 5.5994 & 7.5852 & 8.1235 & 7.5797 & 7.9114 & 7.3686 & 9.2321 & 10.0680 \\
\hline Diff & 3.3835 & 1.5226 & 2.3745 & 1.9153 & 1.9456 & 1.6616 & 2.5679 & 2.9240 \\
\hline
\end{tabular}


Table C-1-17: TCB 2012 ${ }^{\text {th }}$ cycle; Daisy01 - Daisy08.

\begin{tabular}{|c|c|c|c|c|c|c|c|c|}
\hline & DAISY01 & DAISY02 & DAISY03 & DAISY04 & DAISY05 & DAISY06 & DAISY07 & DAISY08 \\
\hline PKG01 & 8.0645 & 6.0092 & 7.5308 & 6.1774 & 7.7639 & 5.4100 & 9.4169 & 7.7201 \\
\hline PKG02 & 6.5238 & 6.4926 & 7.7363 & 6.7333 & 7.8667 & 5.4644 & 9.9728 & 8.2578 \\
\hline PKG03 & 7.2609 & 6.7041 & 719 & 6.8843 & 8.3138 & 5.7363 & 9.9667 & .4995 \\
\hline PKG04 & 6.5359 & 570 & 7.5067 & .7784 & & & 9.7069 & .6416 \\
\hline PKG05 & 6.3969 & 6.4684 & 7.6215 & 6.3828 & 7.7519 & & 9.5377 & .0041 \\
\hline PKG06 & 5.8713 & 8763 & 7.2046 & .7484 & 7.1658 & 4.9931 & 9.1510 & .0253 \\
\hline PKG07 & 6.4694 & 6.2992 & 7.3315 & 6.0022 & 7.7760 & 5.3919 & 9.0423 & 6355 \\
\hline PKG08 & 6.8682 & 6.6376 & 8.2378 & 7.1139 & 8.4950 & 5.8692 & 10.4080 & .3635 \\
\hline PKG09 & 6.4392 & 6.0817 & 7.4946 & 6.2499 & 7.6431 & 5.3859 & 9.4773 & 8.2699 \\
\hline PKG10 & 7.0072 & 6.5107 & 7.8994 & 6.6305 & 8.2594 & 5.6215 & 10.1300 & 8.4089 \\
\hline PKG11 & 6.6507 & 6.1965 & 7.5067 & 6.3828 & 7.8123 & 5.2892 & 9.2840 & 7.5388 \\
\hline PKG12 & 446 & 316 & 7.8571 & 6.9206 & 8.6400 & 6.0445 & 10.1360 & 8.9406 \\
\hline PKG13 & 6.3184 & 32 & 7. & & & & 9.2477 & 733 \\
\hline PKG14 & 7.3636 & 512 & 834 & 193 & 884 & 934 & 10.1720 & 548 \\
\hline PKG15 & & 703 & 7.3919 & 136 & 354 & 530 & 9.2356 & 766 \\
\hline PKG16 & 607 & 7.2720 & 190 & 510 & 22 & 312 & 10.7700 & 052 \\
\hline PKG17 & 501 & 355 & 7.7000 & 157 & 540 & 578 & 6827 & 1431 \\
\hline PKG18 & 6.3244 & 6.0697 & 7.6034 & 6.3526 & 7.7942 & 886 & 9.5438 & 041 \\
\hline PKG19 & 6.2640 & 5.9549 & 7.4281 & 6.0928 & 7.4135 & 5.1140 & 9.1148 & .8289 \\
\hline PKG2O & 6.4875 & 5.9851 & 7.4704 & 6.2922 & 7.5525 & 5.3678 & 9.4954 & .9799 \\
\hline PKG21 & 6.2942 & 6.0999 & 7.5308 & 6.3043 & 7.7639 & 5.2711 & 9.3081 & 7.4905 \\
\hline PKG22 & 6.4452 & 6.1663 & 7.6698 & 6.4614 & 7.7398 & 2892 & 9.4471 & 980 \\
\hline PKG23 & 383 & 225 & 7.4160 & 20 & & & 9.1027 & 2307 \\
\hline PKG24 & & & & & & & & 120 \\
\hline PKG25 & & & & & & & & 347 \\
\hline PKG26 & & & 67 & 55 & 08 & 463 & 9.6646 & 893 \\
\hline PKG27 & 05 & 151 & 517 & 499 & 981 & 282 & 9.2779 & 382 \\
\hline PKG28 & 6.0706 & 6.1180 & 7.5671 & 6.2741 & 7.3168 & 5.2227 & 9.2719 & 509 \\
\hline PKG29 & 6.5117 & 6.3718 & 7.8813 & 6.9387 & 7.7942 & 5.4644 & 9.6827 & 2216 \\
\hline PKG30 & 6.4452 & 5.9186 & 7.5550 & 6.1895 & 7.4256 & 3798 & 9.1208 & 5268 \\
\hline PKG31 & 5.9438 & 5.5561 & 7.0535 & 5.6819 & 7.0752 & 5.2711 & 8.7946 & .9165 \\
\hline PKG32 & 6.2459 & 5.9609 & 7.2771 & 5.8209 & 7.3954 & 5.4342 & 9.0181 & 032 \\
\hline PKG33 & 6.6084 & 6.2449 & 7.6638 & 6.5520 & 7.8244 & 276 & 9.6163 & 210 \\
\hline PKG34 & 6.2519 & 8703 & 7. & & & & 565 & 397 \\
\hline PKG35 & & & & & & & & \\
\hline PKG36 & & & & & & & & \\
\hline PKG37 & 13 & 24 & 7. & 28 & 27 & 69 & 06 & 464 \\
\hline PKG38 & 776 & 449 & 7.7363 & 6.3768 & 83 & 342 & 886 & 7745 \\
\hline PKG39 & 6.5419 & 965 & 188 & 5887 & 7.7942 & 798 & 9.5136 & 1853 \\
\hline PKG40 & 6.3969 & 5.9367 & 7.6275 & 6.3405 & 7.5102 & 5.1925 & 9.3383 & 7.8772 \\
\hline PKG41 & 6.7776 & 6.5711 & 7.9055 & 6.7393 & 8.1506 & 505 & 9.6344 & 8.5358 \\
\hline PKG42 & 6.2640 & 6.0213 & 7.7363 & 6.4070 & 7.6552 & 5.3436 & 9.4773 & 2578 \\
\hline PKG43 & 6.3305 & 6.1845 & 7.5550 & 6.1532 & 7.6189 & 5.5671 & 9.3263 & .0766 \\
\hline PKG44 & 640 & 7 & 7.2 & 32 & 7.5 & & 8.9879 & 5268 \\
\hline PKG45 & & & & & & & & 305 \\
\hline PKG46 & & & & & & & & 8.4149 \\
\hline PKG47 & 6.3002 & & 7.3435 & & 68 & 248 & 9.2840 & 7.8712 \\
\hline PKG48 & & & & & & & 9.2538 & 7.4784 \\
\hline PKG49 & & & & & & & 8.7764 & 7.0434 \\
\hline PKG50 & 6.6628 & 6.4684 & 7.8511 & 6.6124 & 8.2171 & 699 & 9.9969 & 8.3545 \\
\hline Mean & 6.4965 & 6.2219 & 7.6250 & 6.4551 & 7.7614 & 5.4725 & 9.4875 & 7.9738 \\
\hline SD & 0.4010 & 0.3534 & 0.2866 & 0.6409 & 0.4624 & 0.2863 & 0.4048 & .5599 \\
\hline Max & 8.0645 & 7.2720 & 8.4190 & 9.7784 & 9.5222 & 6.4312 & 10.7700 & 9.6052 \\
\hline Min & 5.7383 & 5.5561 & 7.0535 & 5.6819 & 6.9 & 4.9086 & 8.7764 & 9165 \\
\hline Diff & 2.3262 & 1.7159 & 1.3655 & 4.0965 & 2.5618 & 1.5226 & 1.9936 & 2.6887 \\
\hline
\end{tabular}


Table C-1-18: TCB 2012 ${ }^{\text {th }}$ cycle; Daisy09 - Daisy 16.

\begin{tabular}{|c|c|c|c|c|c|c|c|c|}
\hline & DAISY09 & DAISY10 & DAISY11 & DAISY12 & DAISY13 & DAISY14 & DAISY15 & DAISY16 \\
\hline PKG01 & 7.7443 & 8.1954 & 8.9029 & 8.4437 & 8.7090 & 8.1722 & 10.1690 & 11.0170 \\
\hline PKG02 & 7.9437 & 8.3707 & 9.2110 & 8.5283 & 8.5579 & 8.0635 & 10.4160 & 11.0830 \\
\hline PKG03 & 8.6143 & 8.9144 & 9.3137 & 8.5645 & 9.4280 & 8.9154 & 10.5980 & 11.3910 \\
\hline PKG04 & 7.7987 & 8.3827 & 8.9089 & 8.1778 & 8.8419 & 8.3595 & 10.0600 & 10.1590 \\
\hline PKG05 & 7.4784 & 8.2317 & 9.0600 & 8.3833 & 8.5459 & 7.9185 & 10.3080 & 10.5210 \\
\hline PKG06 & 7.5086 & 7.6939 & 8.6068 & 7.7247 & 8.0564 & 7.5620 & 9.3953 & 10.1100 \\
\hline PKG07 & 7.5570 & 8.1169 & 8.8425 & 8.0328 & 8.6002 & 7.8943 & 9.9451 & 10.6840 \\
\hline PKG08 & 8.5781 & 9.1924 & 10.2680 & 9.1748 & 9.4763 & 8.8187 & 11.5890 & 12.4120 \\
\hline PKG09 & 7.7685 & 8.6788 & 9.1567 & 8.1295 & 8.3827 & 7.4109 & 10.2960 & 10.8170 \\
\hline PKG10 & 8.1310 & 8.6969 & 9.2231 & 8.7095 & 9.0715 & 8.3837 & 10.5980 & 11.7170 \\
\hline PKG11 & 8.0706 & 8.6848 & 8.6250 & 7.9724 & 8.9205 & 8.4441 & 10.0840 & 10.7990 \\
\hline PKG12 & 8.4331 & 9.3736 & 9.6219 & 8.5947 & 9.3494 & 8.9154 & 10.6760 & 11.7420 \\
\hline PKG13 & 7.2911 & 8.1652 & 8.7760 & 8.0993 & 8.2498 & 7.7251 & 10.0060 & 10.6960 \\
\hline PKG14 & 8.4210 & 8.7634 & 9.7306 & 9.0298 & 9.4522 & 8.5529 & 11.4310 & 9.9411 \\
\hline PKG15 & 7.4059 & 8.2559 & 8.5887 & 8.1899 & 8.5096 & 7.9607 & 10.1990 & 10.9260 \\
\hline PKG16 & 8.8077 & 9.1561 & 10.4740 & 9.4829 & 9.7059 & 8.8127 & 11.8850 & 12.9140 \\
\hline PKG17 & 8.0464 & 8.5398 & 9.2231 & 8.2926 & 8.8902 & 8.4320 & 10.4470 & 11.2040 \\
\hline PKG18 & 7.7805 & 8.3344 & 9.2412 & 8.3712 & 8.5640 & 8.1964 & 10.2470 & 11.0530 \\
\hline PKG19 & 7.5630 & 8.2619 & 9.0660 & 8.1114 & 8.3767 & 7.8037 & 10.0600 & 10.7690 \\
\hline PKG20 & 7.8530 & 8.5640 & 023 & 053 & 5519 & 118 & 10.2110 & 11.2940 \\
\hline PKG21 & 7.8470 & 646 & 14 & 510 & 552 & 695 & 693 & 10.7450 \\
\hline PKG22 & 7.9014 & 46 & 185 & 899 & 486 & 414 & 130 & 10.8530 \\
\hline PKG23 & 7.0555 & 7.6517 & 8.4618 & 7.9362 & 1960 & 5197 & 880 & 10.9140 \\
\hline PKG24 & 7.3878 & 8.0565 & 8.2685 & 7.7912 & 860 & 7.8762 & 9.6611 & 10.1530 \\
\hline PKG25 & 7.9739 & 8.4069 & 9.1748 & 8.3954 & 8.9567 & 8.5045 & 10.5190 & 11.3130 \\
\hline PKG26 & 8.0645 & 8.5942 & 9.0600 & 8.4377 & 8.9688 & 8.4199 & 10.6760 & 10.9620 \\
\hline PKG27 & 7.6234 & 8.0444 & 8.9271 & 8.1778 & 8.5640 & 8.1964 & 10.1990 & 10.9560 \\
\hline PKG28 & 7.5509 & 8.5459 & 8.6189 & 7.9060 & 8.2558 & 8.1360 & 9.9451 & 10.7140 \\
\hline PKG29 & 7.9497 & 8.2619 & 9.3802 & 8.3712 & 8.9084 & 8.4079 & 10.5370 & 11.5600 \\
\hline PKG30 & 7.9678 & 8.3888 & 8.5222 & 7.9301 & 8.6546 & 8.5529 & 9.9693 & 10.5030 \\
\hline PKG31 & 5.6054 & 7.7181 & 624 & 7.5434 & 994 & 339 & 053 & 10.0860 \\
\hline PKG32 & 7.5147 & 8.1773 & 8.4377 & 7.7247 & 217 & 7.8762 & $\overline{3451}$ & 10.1830 \\
\hline PKG33 & 7.7805 & 8.4794 & 083 & 8.4437 & 4915 & 1178 & 10.7250 & 11.2100 \\
\hline PKG34 & 7.4603 & 8.4250 & 8.6068 & 208 & 8.2981 & 7.8218 & 10.3140 & 10.8290 \\
\hline PKG35 & 7.7987 & 8.5942 & 8.8183 & 993 & 8.6788 & 8.0695 & 10.0480 & 10.6540 \\
\hline PKG36 & 8.4149 & 8.6728 & 9.2231 & 8.5404 & 9.3132 & 8.8248 & 10.6640 & 11.4030 \\
\hline PKG37 & 7.6718 & 8.2377 & 9.1567 & 8.3047 & 8.6848 & 7.9910 & 10.3980 & 11.3430 \\
\hline PKG38 & 8.5841 & 8.9930 & 9.1144 & 8.3531 & 9.3736 & 8.8489 & 10.3440 & 10.8410 \\
\hline PKG39 & 7.8289 & 8.6788 & 9.2231 & 8.3591 & 8.6909 & 8.1722 & 10.1260 & 11.0410 \\
\hline PKG40 & 7.7201 & 8.2075 & 8.9271 & 8.2141 & 8.6304 & 8.1843 & 10.1570 & 10.8590 \\
\hline PKG41 & 8.0887 & 8.3223 & 9.8092 & 8.7095 & 8.8480 & 8.2145 & 10.6100 & 11.5660 \\
\hline PKG42 & 7.8530 & 592 & 9.2775 & 8.3893 & 8.6486 & 8.1118 & 10.1690 & 11.1800 \\
\hline PKG43 & 7.8530 & 8.3223 & 8.9814 & 8.2866 & 8.4431 & 7.9366 & 10.2230 & 11.0410 \\
\hline PKG44 & 7.7866 & 8.0323 & 8.7337 & 8.0630 & 8.4492 & 7.9547 & 9.7336 & 10.7750 \\
\hline PKG45 & 8.0766 & 8.3525 & 8.8062 & 8.1960 & 8.8419 & 8.4260 & 10.4890 & 11.0530 \\
\hline PKG46 & 8.1914 & 8.8721 & 9.3681 & 8.6431 & 9.4219 & 8.7281 & 10.6580 & 11.7290 \\
\hline PKG47 & 7.2609 & 7.8269 & 8.8364 & 8.2564 & 8.2619 & 7.6164 & 9.8061 & 10.6540 \\
\hline PKG48 & 7.2307 & 7.8087 & 8.6129 & 8.1960 & 8.2860 & 7.8399 & 10.4040 & 10.7750 \\
\hline PKG49 & 7.4422 & 7.9356 & 8.3772 & 7.7730 & 8.5036 & 7.9426 & 9.6793 & 10.4000 \\
\hline PKG50 & 8.0585 & 8.8721 & 9.2050 & 8.6491 & 9.1319 & 8.3897 & 10.5860 & 11.8500 \\
\hline Mean & 7.8068 & 8.3988 & 9.0156 & 8.2814 & 8.7071 & 8.1876 & 10.2916 & 10.9879 \\
\hline SD & 0.4989 & 0.3819 & 0.4489 & 0.3631 & 0.4153 & 0.3769 & 0.4880 & 0.5705 \\
\hline Max & 8.8077 & 9.3736 & 10.4740 & 9.4829 & 9.7059 & 8.9154 & 11.8850 & 12.9140 \\
\hline Min & 5.6054 & 7.6517 & 8.2624 & 7.5434 & 7.8994 & 7.4109 & 9.1053 & 9.9411 \\
\hline Diff & 3.2023 & 1.7219 & 2.2116 & 1.9395 & 1.8065 & 1.5045 & 2.7797 & 2.9729 \\
\hline
\end{tabular}


Table C-1-19: TCC 100 ${ }^{\text {th }}$ cycle; Daisy01 - Daisy08.

\begin{tabular}{|c|c|c|c|c|c|c|c|c|}
\hline & DAISY01 & DAISY02 & DAISY03 & DAISY04 & DAISY05 & DAISY06 & DAISY07 & DAISY08 \\
\hline PKG01 & 6.1734 & 6.1240 & 7.5550 & 6.3768 & 8.0117 & 5.4040 & 9.2779 & 7.6597 \\
\hline PKG02 & 6.1734 & 6.2026 & 7.7846 & 6.4976 & 7.9815 & 5.8028 & 9.6888 & 8.1551 \\
\hline PKG03 & 6.6084 & 6.7766 & 7.9417 & 6.9508 & 8.5857 & 5.9297 & 9.8338 & 8.3243 \\
\hline PKG04 & 5.9619 & 6.1784 & 7.5308 & 6.7635 & 7.3833 & 5.4403 & 9.2235 & 7.6839 \\
\hline PKG05 & 6.1854 & 6.3234 & 7.7061 & 6.4251 & 7.8002 & 5.4886 & 9.4652 & 8.0947 \\
\hline PKG06 & 5.8592 & 5.7373 & 7.1985 & 5.7726 & 7.0510 & 4.9992 & 8.7221 & 7.1038 \\
\hline PKG07 & 6.1975 & 6.2630 & 7.3194 & 6.0747 & 7.6794 & 5.4221 & 8.9456 & 7.4240 \\
\hline PKG08 & 6.7292 & 6.5228 & 8.1955 & 7.2710 & 8.3802 & 5.7544 & 10.3530 & 9.5146 \\
\hline PKG09 & 6.1431 & 6.0697 & 7.4583 & 6.2982 & 7.5948 & 5.4644 & 9.4954 & 7.9316 \\
\hline PKG10 & 6.6386 & 6.5168 & 7.8148 & 6.5762 & 8.1748 & 5.5913 & 9.7069 & 8.2458 \\
\hline PKG11 & 6.3969 & 6.2026 & 7.5369 & 6.2136 & 7.8244 & 5.7001 & 9.4108 & 7.4422 \\
\hline PKG12 & 6.6930 & 6.6074 & 7.8450 & 6.6728 & 8.3923 & 5.8572 & 9.8217 & 8.4633 \\
\hline PKG13 & 6.0948 & 5.7615 & 7.3556 & 5.8934 & 7.3652 & 5.1805 & 9.1813 & 7.7322 \\
\hline PKG14 & 7.1038 & 7.0787 & 8.1653 & 7.3556 & 8.7669 & 5.9901 & 10.2390 & 8.8983 \\
\hline PKG15 & 6.2096 & 5.8521 & 7.3496 & 5.9961 & 7.6310 & 5.1442 & 9.0846 & 7.4543 \\
\hline PKG16 & 7.2186 & 7.3083 & 8.4009 & 7.5368 & 9.3228 & 6.4916 & 10.6860 & 9.6233 \\
\hline PKG17 & 6.6265 & 6.3657 & 7.6154 & 6.4735 & 8.2473 & 5.9659 & 9.6284 & 8.1793 \\
\hline PKG18 & 9 & 71 & 36 & 6.2 & 00 & 5.5611 & 290 & 283 \\
\hline PKG19 & 57 & 5.8763 & 254 & 5.9478 & 591 & 5.2167 & 313 & 932 \\
\hline PKG20 & & 6.0274 & 644 & 80 & 77 & 778 & 31 & 980 \\
\hline PKG21 & 86 & 6.2630 & 7.4886 & 68 & & 13 & 994 & 751 \\
\hline PKG22 & 6.3305 & 6.1784 & 7.7484 & 6.4312 & 7.5343 & 5.3798 & 306 & 107 \\
\hline PKG23 & 6.0404 & 5.6528 & 7.3435 & 6.0505 & 7.0026 & 5.0173 & 8.9335 & 1884 \\
\hline PKG24 & 6.0767 & 5.8582 & 7.0233 & 5.5369 & 7.3833 & 5.1865 & 8.6314 & 7.0434 \\
\hline PKG25 & 6.3667 & 6.3718 & 7.8934 & 6.7876 & 7.8485 & 5.4100 & 9.6102 & 8.1310 \\
\hline PKG26 & 6.3486 & 6.4866 & 7.8148 & 6.6245 & 7.5162 & 6.0505 & 9.4954 & 7.8953 \\
\hline PKG27 & 6.3848 & 36 & 7.6396 & 6.2 & 7.5041 & 5.2288 & 9.2417 & 7.6114 \\
\hline PKG28 & & & 006 & & 31 & 359 & 40 & 5268 \\
\hline PKG29 & & & & 87 & 21 & & & 947 \\
\hline PKG30 & 19 & 11 & 86 & 6.4070 & 37 & 59 & 46 & $\overline{878}$ \\
\hline PKG31 & 83 & 15 & 94 & 97 & 01 & 90 & 108 & 011 \\
\hline PKG32 & 996 & 92 & 7.2227 & 11 & 77 & 02 & 339 & 549 \\
\hline PKG33 & 6.4452 & 570 & 7.6879 & 6.3828 & 17 & 5.7121 & 9.5438 & 518 \\
\hline PKG34 & 6.1009 & 5.8401 & 7.5550 & 6.2620 & 7.2987 & 5.0536 & 054 & 7.6234 \\
\hline PKG35 & 6.3607 & 6.0757 & 7.4825 & 6.1351 & 7.9089 & 5.4221 & 356 & 8.0101 \\
\hline PKG36 & 6.6023 & 6.6376 & 8.0807 & 6.9749 & 7.9210 & 5.6940 & 157 & 8.2156 \\
\hline PKG37 & 6.3969 & 6.1240 & 7.5973 & 6.2801 & 7.7942 & 5.4584 & 9.4350 & 8.1733 \\
\hline PKG38 & 6.6265 & 6.4020 & 7.7000 & 6.8722 & 8.0660 & 5.5248 & 9.3806 & 7.7080 \\
\hline PKG39 & 6.3184 & 6.0576 & 7.5852 & 6.3587 & 7.8304 & 5.3798 & 9.4773 & 8.0041 \\
\hline PKG40 & & & & & 83 & 63 & & 3289 \\
\hline PKG41 & 6.5178 & 6.6 & & & 8.2413 & 51 & 552 & 8.5237 \\
\hline PKG42 & 6.2338 & 6.1 & & 6.3 & & 55 & 34 & 8.1068 \\
\hline PKG43 & 6.2338 & 34 & 88 & 51 & 31 & 100 & 88 & 832 \\
\hline PKG44 & 6.1734 & 5.8944 & 7.2408 & 6.0686 & 7.5404 & 5.4705 & 9.2175 & 7.9135 \\
\hline PKG45 & 6.3848 & 6.2328 & 7.7786 & 6.6003 & 7.6733 & 5.3678 & 9.6646 & 7.7080 \\
\hline PKG46 & 6.6386 & 6.5349 & 8.0686 & 6.9085 & 8.0721 & 6.1593 & 9.7492 & 8.4512 \\
\hline PKG47 & 6.1129 & 5.9428 & 7.5731 & 6.2318 & 7.3954 & 5.5430 & 9.3383 & 7.8651 \\
\hline PKG48 & 5.9498 & 5.6588 & 7.6336 & 6.0807 & 6.9543 & 4.9811 & 9.2719 & 7.5691 \\
\hline PKG49 & 6.1734 & 6.1059 & 7.2227 & 5.7061 & 7.5102 & 5.2288 & 8.8187 & 7.0374 \\
\hline PKG50 & 6.6628 & 6.2751 & 7.9175 & 6.5278 & 8.2111 & 5.5248 & 9.9123 & 8.4935 \\
\hline Mean & 6.3340 & 6.1895 & 7.6228 & 6.3986 & 7.7511 & 5.4786 & 9.4516 & 7.9087 \\
\hline SD & 0.2797 & 0.3494 & 0.2928 & 0.4284 & 0.4665 & 0.3270 & 0.3983 & 0.5433 \\
\hline Max & 7.2186 & 7.3083 & 8.4009 & 7.5368 & 9.3228 & 6.4916 & 10.6860 & 9.6233 \\
\hline Min & 5.7383 & 5.4715 & 7.0233 & 5.5369 & 6.9301 & 4.9690 & 8.6314 & 7.0011 \\
\hline Diff & 1.4803 & 1.8368 & 1.3776 & 1.9999 & 2.3927 & 1.5226 & 2.0546 & 2.6222 \\
\hline
\end{tabular}


Table C-1-20: TCC 100 ${ }^{\text {th }}$ cycle; Daisy09 - Daisy16.

\begin{tabular}{|c|c|c|c|c|c|c|c|c|}
\hline & DAISY09 & DAISY10 & DAISY11 & DAISY12 & DAISY13 & DAISY14 & DAISY15 & DAISY16 \\
\hline PKG01 & 7.5691 & 8.2921 & 8.8606 & 8.4195 & 8.5821 & 8.0695 & 10.0300 & 10.9200 \\
\hline PKG02 & 7.9739 & 8.6305 & 9.1506 & 8.6431 & 8.4371 & 8.1662 & 10.2590 & 11.1370 \\
\hline PKG03 & 8.7654 & 8.9628 & 9.3440 & 8.4195 & 9.6455 & 9.0906 & 10.6520 & 11.3970 \\
\hline PKG04 & 8.2518 & 8.1954 & 8.6370 & 8.0328 & 8.7815 & 8.3837 & 10.1690 & 10.6780 \\
\hline PKG05 & 7.4603 & 8.0383 & 8.9935 & 8.3833 & 8.6244 & 8.1058 & 10.2470 & 11.2880 \\
\hline PKG06 & 6.9165 & 7.5973 & 8.2866 & 7.6703 & 8.0021 & 7.8459 & 9.3651 & 10.0260 \\
\hline PKG07 & 7.5509 & 8.0625 & 8.9754 & 8.0449 & 8.5459 & 8.0272 & 9.8424 & 10.7390 \\
\hline PKG08 & 8.5841 & 8.9990 & 10.0750 & 9.2050 & 9.6395 & 8.8550 & 11.6310 & 12.5030 \\
\hline PKG09 & 7.5691 & 7.9779 & 9.0116 & 8.1053 & 8.2558 & 7.3686 & 9.9934 & 10.8230 \\
\hline PKG10 & 8.1068 & 8.5821 & 9.3681 & 8.6068 & 9.1017 & 8.3172 & 10.6760 & 11.5970 \\
\hline PKG11 & 8.2699 & 8.6607 & 8.9512 & 8.0872 & 9.0594 & 8.7281 & 10.1020 & 10.6060 \\
\hline PKG12 & 8.6385 & 8.7453 & 9.9240 & 8.6854 & 9.1923 & 8.7462 & 10.7610 & 11.7360 \\
\hline PKG13 & 7.3818 & 8.0565 & 9.2231 & 8.0328 & 8.1712 & 7.7795 & 9.8907 & 10.7390 \\
\hline PKG14 & 8.6627 & 8.7090 & 10.1480 & 8.9271 & 9.5911 & 8.7462 & 11.3050 & 12.6780 \\
\hline PKG15 & 7.4059 & 7.8450 & 8.8787 & 8.1597 & 8.4069 & 8.0030 & 10.0300 & 10.8720 \\
\hline PKG16 & 8.8500 & 8.9990 & 10.7940 & 9.4406 & 9.7724 & 9.0423 & 11.6250 & 12.9560 \\
\hline PKG17 & 8.1370 & 8.5096 & 9.2292 & 8.3833 & 8.8963 & 8.4864 & 10.5550 & 11.2040 \\
\hline PKG18 & 7.6234 & 8.2438 & 9.2835 & 8.3229 & 8.5881 & 8.2810 & 10.2110 & 11.0290 \\
\hline PKG19 & 7.3938 & 7.9779 & 8.9633 & 8.4195 & 8.3827 & 8.0393 & 9.9391 & 10.7930 \\
\hline PKG20 & 7.6295 & 8.2861 & 9.1506 & 8.1295 & 8.5459 & 8.1903 & 10.1630 & 10.9560 \\
\hline PKG21 & 7.5268 & 8.3888 & 8.8968 & 8.0087 & 8.5338 & 8.1239 & 9.9330 & 10.7200 \\
\hline PKG22 & 7.7503 & 8.5942 & 8.8425 & 8.2806 & 8.7150 & 8.4864 & 10.6520 & 10.9020 \\
\hline PKG23 & 7.1038 & 7.5308 & 8.7458 & 7.9724 & 8.0685 & 7.6889 & 9.8726 & 10.5330 \\
\hline PKG24 & 7.2488 & 8.1108 & 8.5222 & 7.7307 & 8.3163 & 7.8580 & 9.4013 & 10.1590 \\
\hline PKG25 & 7.8833 & 8.5277 & 9.3137 & 8.4074 & 8.9507 & 8.4804 & 10.4830 & 11.2040 \\
\hline PKG26 & 7.9678 & 8.6184 & 8.9210 & 8.4195 & 8.9688 & 8.5529 & 10.5370 & 11.0830 \\
\hline PKG27 & 7.5328 & 7.9658 & 8.7639 & 8.2141 & 8.6727 & 8.0695 & 10.2290 & 11.0040 \\
\hline PKG28 & 7.2428 & 7.7483 & 8.6491 & 8.0147 & 8.2015 & 7.7855 & 9.9934 & 10.7450 \\
\hline PKG29 & 7.9558 & 8.3223 & 9.0479 & 8.4558 & 8.9688 & 8.4502 & 10.8450 & 11.3610 \\
\hline PKG30 & 7.8047 & 8.1834 & 8.4981 & 7.9362 & 8.6002 & 8.2447 & 9.9209 & 10.5690 \\
\hline PKG31 & 5.3396 & 7.5248 & 8.1537 & 7.5616 & 7.7846 & 7.4713 & 9.1717 & 9.9229 \\
\hline PKG32 & 7.8833 & 8.2740 & 8.3470 & 7.7368 & 8.4069 & 8.0212 & 9.5886 & 10.2010 \\
\hline PKG33 & 7.5993 & 8.0867 & 9.1446 & 8.3772 & 8.6002 & 8.0755 & 10.2710 & 11.2460 \\
\hline PKG34 & 7.3334 & 7.7725 & 8.4679 & 7.9966 & 8.3344 & 7.8157 & 10.1440 & 11.0040 \\
\hline PKG35 & 7.7262 & 8.3223 & 8.6733 & 8.0933 & 8.8057 & 8.0876 & 9.8243 & 10.6420 \\
\hline PKG36 & 8.3606 & 338 & 9.1325 & 8.4195 & 9.3857 & 8.5891 & 10.4770 & 11.1980 \\
\hline PKG37 & 7.5086 & 8.0444 & 8.9633 & 8.2806 & 8.5761 & 8.0695 & 10.2830 & 11.2580 \\
\hline PKG38 & 8.4331 & 8.8057 & 8.7700 & 8.2383 & 9.2951 & 8.8066 & 10.3440 & 10.9560 \\
\hline PKG39 & 7.8168 & 8.4915 & 9.0539 & 8.3047 & 8.6002 & 8.0997 & 10.2290 & 11.0710 \\
\hline PKG40 & 7.9497 & 8.6425 & 8.7095 & 8.1899 & 8.5821 & 8.1601 & 10.1930 & 10.9200 \\
\hline PKG41 & 8.0947 & 8.3344 & 9.4406 & 8.6672 & 8.9265 & 8.2508 & 10.9900 & 11.5840 \\
\hline PKG42 & 7.6778 & 531 & 9.1627 & 8.4437 & 8.5036 & 8.1360 & 10.3140 & 11.1860 \\
\hline PKG43 & 7.6234 & 8.1 & 8.8546 & 8.2443 & 8.4794 & 7.9124 & 10.1380 & 11.0350 \\
\hline PKG44 & 7.5268 & 8.0625 & 8.5827 & 7.9966 & 8.3888 & 7.9366 & 9.7518 & 10.6780 \\
\hline PKG45 & 8.2397 & 8.3525 & 8.7398 & 8.3229 & 8.8600 & 8.3414 & 10.3560 & 10.9080 \\
\hline PKG46 & 8.1189 & 8.4673 & 9.3681 & 8.6189 & 9.2830 & 8.8127 & 10.7610 & 11.5360 \\
\hline PKG47 & 7.2186 & 7.7725 & 8.8425 & 8.0087 & 8.2377 & 7.7312 & 10.1200 & 10.6300 \\
\hline PKG48 & 7.3093 & 7.9840 & 8.5827 & 8.0570 & 8.3465 & 7.7553 & 10.1320 & 10.7450 \\
\hline PKG49 & 7.3818 & 8.1229 & 8.3229 & 7.6522 & 8.4190 & 7.9305 & 9.7095 & 10.4120 \\
\hline PKG50 & 8.0706 & 8.6788 & 9.2171 & 8.6310 & 9.1078 & 8.6012 & 10.9180 & 11.7660 \\
\hline Mean & 7.7594 & 8.2789 & 8.9996 & 8.2680 & 8.7028 & 8.2123 & 10.2606 & 11.0371 \\
\hline SD & 0.5729 & 0.3690 & 0.4867 & 0.3632 & 0.4464 & 0.3903 & 0.5047 & 0.5879 \\
\hline Max & 8.8500 & 8.9990 & 10.7940 & 9.4406 & 9.7724 & 9.0906 & 11.6310 & 12.9560 \\
\hline Min & 5.3396 & 7.5248 & 8.1537 & 7.5616 & 7.7846 & 7.3686 & 9.1717 & 9.9229 \\
\hline Diff & 3.5104 & 1.4742 & 2.6403 & 1.8790 & 1.9878 & 1.7220 & 2.4593 & 3.0331 \\
\hline
\end{tabular}


Table C-1-21: TCC 200 ${ }^{\text {th }}$ cycle; Daisy01 - Daisy08.

\begin{tabular}{|c|c|c|c|c|c|c|c|c|}
\hline & DAISY01 & DAISY02 & DAISY03 & DAISY04 & DAISY05 & DAISY06 & DAISY07 & DAISY08 \\
\hline PKG01 & 6.3184 & 6.0394 & 7.4281 & 6.1714 & 7.6673 & 5.5732 & 9.1752 & 7.7503 \\
\hline PKG02 & 6.4090 & 6.2811 & 7.6577 & 6.5762 & 7.6612 & 5.7061 & 9.6586 & 8.3001 \\
\hline PKG03 & 6.8380 & 6.8007 & 7.9477 & 6.9206 & 8.2413 & 6.1290 & 9.9425 & 8.8681 \\
\hline PKG04 & 6.3727 & 6.0697 & 7.6577 & 6.9689 & 7.2866 & 5.5430 & 9.4048 & 7.7322 \\
\hline PKG05 & 6.4634 & 6.2267 & 7.6275 & 6.4191 & 7.6310 & 5.8149 & 9.6767 & 8.1793 \\
\hline PKG06 & 5.9196 & 5.8401 & 7.0354 & 5.6940 & 7.0026 & 5.2107 & 8.8187 & 7.1642 \\
\hline PKG07 & 6.2640 & 6.2570 & 7.3315 & 6.1472 & 7.6431 & 5.7121 & 8.9577 & 7.4845 \\
\hline PKG08 & 6.7474 & 6.6195 & 8.2438 & 7.1502 & 8.3138 & 5.9780 & 10.3530 & 9.1158 \\
\hline PKG09 & 6.1734 & 6.1784 & 7.4825 & 6.2136 & 7.5706 & 5.8934 & 9.3565 & 8.0766 \\
\hline PKG10 & 6.7776 & 6.5651 & 7.8329 & 6.6849 & 8.2594 & 5.9236 & 9.7613 & 8.4452 \\
\hline PKG11 & 6.4271 & 6.2992 & 7.5188 & 6.3103 & 7.7760 & 5.5732 & 9.1933 & 7.4180 \\
\hline PKG12 & 6.7776 & 6.6618 & 7.8632 & 6.7635 & 8.5373 & 6.1230 & 9.7855 & 8.5660 \\
\hline PKG13 & 6.1854 & 5.7736 & 7.4523 & 6.1351 & 7.3350 & 5.2832 & 9.1631 & 7.7382 \\
\hline PKG14 & 7.1522 & 7.0787 & 8.3042 & 7.3375 & 8.7246 & 5.9297 & 10.2270 & 8.9768 \\
\hline PKG15 & 6.2096 & 5.8461 & 7.5671 & 6.3284 & 7.4921 & 5.3013 & 9.0967 & 7.4845 \\
\hline PKG16 & 7.2186 & 7.2841 & 8.6909 & 7.9537 & 9.3772 & 6.5399 & 10.6740 & 9.7019 \\
\hline PKG17 & 6.6084 & 6.3597 & 7.6879 & 6.7333 & 7.9754 & 5.7605 & 9.6465 & 8.2518 \\
\hline PKG18 & 6.4452 & 6.0274 & 7.6336 & 6.3405 & 7.8485 & 5.9599 & 9.3988 & 8.0585 \\
\hline PKG19 & 6.1975 & 5.8582 & 7.3435 & 6.2318 & 7.4377 & 5.3496 & 9.3021 & 7.5811 \\
\hline PKG20 & 6.3727 & 67 & 71 & 6.3 & 679 & 103 & 590 & 8.0222 \\
\hline PKG21 & \begin{tabular}{l|l|}
6.3727 \\
\end{tabular} & 65 & 52 & & 81 & 67 & 388 & 7.5207 \\
\hline PKG22 & 6.3909 & 6.0636 & 7.7302 & 6.6064 & 7.5948 & 13 & 56 & 7.7382 \\
\hline PKG23 & 5.8410 & 5.6165 & 7.4402 & 6.0082 & 7.0147 & 348 & 208 & 7.3999 \\
\hline PKG24 & 5.9679 & 5.8582 & 7.1985 & 5.6094 & 7.3893 & 5.3919 & 366 & 7.0676 \\
\hline PKG25 & 6.2821 & 6.3053 & 7.9296 & 6.7937 & 7.6552 & 5.7242 & 388 & 8.1008 \\
\hline PKG26 & 6.3546 & 6.4684 & 7.8209 & 6.5278 & 7.6612 & 5.9115 & 9.7190 & 7.9437 \\
\hline PKG27 & 2700 & 213 & 7.7 & 6.3889 & 881 & 5.8 & 356 & 7.6355 \\
\hline PKG28 & 3646 & 01 & 7.5671 & 6.2620 & 7.2141 & 5.5128 & 329 & 7.6476 \\
\hline PKG29 & 6809 & 866 & 8.0444 & 6.7876 & 35 & 263 & 948 & 8.1793 \\
\hline PKG30 & 6.3969 & 11 & 63 & 18 & 12 & 546 & 354 & 7.4784 \\
\hline PKG31 & 54 & 38 & 6.9 & 45 & 60 & 115 & 94 & 6.9346 \\
\hline PKG32 & 6.1975 & 99 & 7.2469 & 5.8270 & 54 & 38 & 275 & 7.3878 \\
\hline PKG33 & 6.3425 & 6.2570 & 7.6698 & 6.2982 & 310 & 130 & 13 & 8.2941 \\
\hline PKG34 & 6.0767 & 549 & 7.5792 & 6.0686 & 7.0208 & 5.0173 & 9.3625 & 7.3213 \\
\hline PKG35 & 6.4211 & 905 & 7.4523 & 357 & 766 & 5.5188 & 9.2960 & 7.6416 \\
\hline PKG36 & 6.6205 & 6.6678 & 8.0323 & 6.8904 & 7.8667 & 5.6880 & 10.1240 & 8.4693 \\
\hline PKG37 & 6.3184 & 6.2630 & 7.5127 & 6.1834 & 7.7821 & 5.4886 & 9.7492 & 8.0464 \\
\hline PKG38 & 6.8078 & 6.4503 & 7.6456 & 6.5037 & 7.9996 & 5.6578 & 9.4954 & 7.8409 \\
\hline PKG39 & 6.3607 & 6.0153 & 7.5429 & 6.4312 & 7.6552 & 5.2952 & 10.0390 & 8.1128 \\
\hline PKG40 & 75 & 53 & 7.6275 & 70 & & 109 & 383 & 7.9195 \\
\hline PKG41 & 361 & 16 & 90 & 6.7453 & 302 & 47 & 67 & 8.5841 \\
\hline PKG42 & 6.2519 & 74 & & & & & 52 & 8.3183 \\
\hline PKG43 & 6.0948 & 246 & 7.5188 & 199 & 881 & 11 & 235 & 8.0766 \\
\hline PKG44 & 6.1915 & & 7.2046 & 5.9478 & & 5.5732 & 8.9758 & 7.5388 \\
\hline PKG45 & 6.4694 & 6.3234 & 7.5973 & 6.5037 & 7.7639 & 5.6759 & 9.4108 & 7.9135 \\
\hline PKG46 & 6.5419 & 6.6497 & 7.9598 & 6.6487 & 8.0902 & 6.1593 & 9.6586 & 8.2760 \\
\hline PKG47 & 5.4967 & 6.0576 & 7.3738 & 6.0566 & 7.4377 & 5.5430 & 9.2960 & 7.8168 \\
\hline PKG48 & 5.3335 & 5.6648 & 7.4583 & 6.1472 & 6.9906 & 5.1684 & 9.1692 & 7.4966 \\
\hline PKG49 & 6.1190 & 5.9126 & 7.1502 & 5.6699 & 7.3229 & 5.3557 & 8.7281 & 7.1099 \\
\hline PKG50 & 6.7171 & 6.3174 & 7.8511 & 6.4795 & 8.2352 & 5.5309 & 9.9546 & 8.3847 \\
\hline Mean & 6.3504 & 6.2027 & 7.6250 & 6.3991 & 7.6775 & 5.5990 & 9.4866 & 7.9422 \\
\hline SD & 0.3479 & 0.3535 & 0.3160 & 0.4360 & 0.4665 & 0.3129 & 0.4314 & 0.5509 \\
\hline Max & 7.2186 & 7.2841 & 8.6909 & 7.9537 & 9.3772 & 6.5399 & 10.6740 & 9.7019 \\
\hline Min & 5.3335 & 5.5138 & 6.9750 & 5.6094 & 6.9060 & 5.0173 & 8.7281 & 6.9346 \\
\hline Diff & 1.8851 & 1.7703 & 1.7159 & 2.3443 & 2.4712 & 1.5226 & 1.9459 & 2.7673 \\
\hline
\end{tabular}


Table C-1-22: TCC 200 ${ }^{\text {th }}$ cycle; Daisy09 - Daisy16.

\begin{tabular}{|c|c|c|c|c|c|c|c|c|}
\hline & DAISY09 & DAISY10 & DAISY11 & DAISY12 & DAISY13 & DAISY14 & DAISY15 & DAISY16 \\
\hline PKG01 & 7.6295 & 8.1350 & 8.8243 & 8.4860 & 8.6848 & 8.1541 & 10.0060 & 10.8110 \\
\hline PKG02 & 7.7322 & 8.1350 & 9.2050 & 8.5283 & 8.5398 & 8.0333 & 10.6100 & 11.1070 \\
\hline PKG03 & 8.7533 & 8.8117 & 9.2533 & 8.6310 & 9.4763 & 8.7402 & 10.9180 & 11.3550 \\
\hline PKG04 & 7.9437 & 8.2256 & 8.7639 & 8.0751 & 8.6365 & 8.2568 & 9.9693 & 10.7510 \\
\hline PKG05 & 7.7745 & 8.0323 & 9.0962 & 8.4316 & 8.5519 & 7.8641 & 10.3380 & 11.2880 \\
\hline PKG06 & 7.0555 & 7.5308 & 8.2926 & 7.7912 & 8.0202 & 7.5076 & 10.3560 & 10.0500 \\
\hline PKG07 & 7.8470 & 7.8873 & 8.6491 & 8.1174 & 8.4733 & 8.0030 & 10.3560 & 10.6960 \\
\hline PKG08 & 8.5056 & 8.9990 & 10.0870 & 9.1567 & 9.3978 & 8.8006 & 11.6970 & 12.3400 \\
\hline PKG09 & 7.5328 & 8.0142 & 8.9029 & 8.2322 & 8.4673 & 7.3928 & 10.4590 & 10.7510 \\
\hline PKG10 & 8.1189 & 8.7634 & 9.3379 & 8.7095 & 9.1501 & 8.3716 & 10.8760 & 11.5360 \\
\hline PKG11 & 8.1491 & 8.4190 & 8.6431 & 8.0147 & 8.9688 & 8.5710 & 10.0780 & 10.6660 \\
\hline PKG12 & 8.5358 & 9.6757 & 9.6098 & 8.6854 & 9.1923 & 8.6737 & 10.7430 & 11.5240 \\
\hline PKG13 & 7.1884 & 7.9417 & 8.7337 & 8.1839 & 8.2860 & 7.8762 & 9.9089 & 10.7270 \\
\hline PKG14 & 8.4089 & 8.6788 & 9.8394 & 9.1023 & 9.4703 & 8.6797 & 11.2560 & 12.6780 \\
\hline PKG15 & 7.3334 & 8.0686 & 8.8666 & 8.1899 & 8.3767 & 7.9547 & 10.0960 & 10.7870 \\
\hline PKG16 & 8.8802 & 9.4461 & 10.6250 & 9.5010 & 9.6636 & 8.9637 & 11.9090 & $12.890 \mathrm{C}$ \\
\hline PKG17 & 8.0343 & 8.6969 & 9.3137 & 8.4074 & 8.9386 & 8.3958 & 10.3920 & 11.1740 \\
\hline PKG18 & 7.6355 & 8.2861 & 9.1808 & 8.3772 & 8.5821 & 8.2689 & 10.4100 & 11.0350 \\
\hline PKG19 & 7.4180 & 8.0021 & 8.7820 & 8.1839 & 8.4250 & 8.0030 & 10.5010 & 10.8230 \\
\hline PKG20 & 7.8893 & 8.4794 & 9.0660 & 8.1899 & 8.5398 & 8.0453 & 1980 & 3780 \\
\hline PKG21 & 7.5207 & 8.1652 & 8.8606 & 8.1174 & 8.4915 & 8.0755 & 810 & 3780 \\
\hline PKG22 & 7.7685 & 8.5157 & 8.8787 & 8.1416 & 8.6365 & 8.3776 & 10.4280 & 10.9140 \\
\hline PKG23 & 7.0917 & 7.5006 & 8.4739 & 7.9422 & 8.0021 & 7.7734 & 10.4040 & 10.5940 \\
\hline PKG24 & 7.2972 & 7.7785 & 8.3108 & 7.7368 & 8.2015 & 7.7191 & 9.8424 & 10.1530 \\
\hline PKG25 & 7.9255 & 8.3042 & 9.0539 & 8.2987 & 8.8359 & 8.4683 & 10.7060 & 11.1980 \\
\hline PKG26 & 7.9497 & 8.4311 & 8.9331 & 8.2503 & 8.9990 & 8.2991 & 10.6100 & 11.1920 \\
\hline PKG27 & 7.4905 & 7.9719 & 8.6129 & 8.1356 & 8.6244 & 8.4622 & 10.2290 & 10.9140 \\
\hline PKG28 & 7.1159 & 7.6698 & 8.6370 & 7.9482 & 8.2679 & 7.7009 & 10.0600 & 10.7270 \\
\hline PKG29 & 8.1 & 8.1592 & 9.6823 & 8.4618 & 8.9386 & 8.4139 & 10.6100 & 11.2160 \\
\hline PKG30 & 7.7020 & 8.2075 & 8.5706 & 8.0087 & 8.5579 & 8.0151 & 10.2170 & 10.5690 \\
\hline PKG31 & 5.2187 & 7.5248 & 8.0630 & 7.5193 & 7.7121 & 7.4834 & 657 & 9.8202 \\
\hline PKG32 & 7.4905 & 7.9719 & 8.2987 & 7.7912 & 8.4854 & 7.9426 & 9.6551 & 10.1830 \\
\hline PKG33 & 7.5872 & 8.0565 & 9.0781 & 8.5041 & 8.5036 & 7.9728 & 10.6160 & 11.2700 \\
\hline PKG34 & 7.2851 & 7.8571 & 8.5404 & 8.0570 & 8.4129 & 7.8580 & 10.5070 & 10.8050 \\
\hline PKG35 & 7.8651 & 8.3525 & 8.7156 & 8.1295 & 8.6184 & 7.9366 & 9.8666 & 10.6540 \\
\hline PKG36 & 8.2699 & 8.7090 & 9.1506 & 8.4558 & 9.2105 & 8.5770 & 10.6640 & 11.1860 \\
\hline PKG37 & 7.6355 & 8.2317 & 8.9573 & 8.3531 & 8.6244 & 7.9849 & 10.2770 & 11.1980 \\
\hline PKG38 & 8.3122 & 8.8842 & 8.7639 & 8.3893 & 9.2769 & 8.7160 & 10.2350 & 10.7930 \\
\hline PKG39 & 7.7624 & 8.8298 & 8.9573 & 8.2987 & 8.5700 & 8.2326 & 10.3140 & 10.9560 \\
\hline PKG40 & 7.9316 & 8.6909 & 8.7579 & 8.2806 & 8.4733 & 8.1360 & 10.2230 & 10.8290 \\
\hline PKG41 & 7.9014 & 8.3284 & 9.3923 & 8.7398 & 8.8721 & 8.2568 & 10.5310 & 11.5060 \\
\hline PKG42 & 7.8772 & 8.1108 & 9.1627 & 8.3 & 8.4311 & 8.0272 & 10.4350 & 11.2520 \\
\hline PKG43 & 7.7987 & 8.0806 & 8.8546 & 8.5041 & 8.4431 & 7.8701 & 10.5490 & 10.9560 \\
\hline PKG44 & 7.6355 & 8.0383 & 8.5464 & 7.9845 & 8.3344 & 7.8580 & 9.7699 & 10.5270 \\
\hline PKG45 & 8.0706 & 8.6546 & 8.7095 & 8.1839 & 8.7936 & 8.3233 & 11.1900 & 10.8290 \\
\hline PKG46 & 8.2881 & 8.3344 & 9.3500 & 8.7035 & 9.1742 & 8.6314 & 10.7910 & 11.5970 \\
\hline PKG47 & 7.4724 & 7.7846 & 8.8183 & 8.2564 & 8.0625 & 7.6889 & 9.9028 & 10.8230 \\
\hline PKG48 & 7.3757 & 7.7846 & 8.4981 & 8.0751 & 8.2075 & 7.8943 & 10.0420 & 10.6900 \\
\hline PKG49 & 7.3818 & 7.8027 & 8.2624 & 7.7187 & 8.4190 & 7.8762 & 9.7095 & 10.3760 \\
\hline PKG50 & 8.0645 & 8.6244 & 9.4708 & 8.7277 & 8.9930 & 8.5468 & 10.5980 & 11.6630 \\
\hline Mean & 7.7511 & 8.2717 & 8.9487 & 8.3009 & 8.6603 & 8.1535 & 10.3921 & 11.0027 \\
\hline SD & 0.5556 & 0.4591 & 0.4805 & 0.3707 & 0.4151 & 0.3668 & 0.4854 & 0.5723 \\
\hline Max & 8.8802 & 9.6757 & 10.6250 & 9.5010 & 9.6636 & 8.9637 & 11.9090 & 12.8900 \\
\hline Min & 5.2187 & 7.5006 & 8.0630 & 7.5193 & 7.7121 & 7.3928 & 9.1657 & 9.8202 \\
\hline Diff & 3.6615 & 2.1751 & 2.5620 & 1.9817 & 1.9515 & 1.5709 & 2.7433 & 3.0698 \\
\hline
\end{tabular}


Table C-1-23: TCC $300^{\text {th }}$ cycle; Daisy01 - Daisy08.

\begin{tabular}{|c|c|c|c|c|c|c|c|c|}
\hline & $\overline{A I S Y 01}$ & DAISY02 & DAISY03 & $\overline{D A I S Y 04}$ & DAISY05 & DAISY06 & DAISY07 & DAISY08 \\
\hline PKG01 & 7.3999 & 6.1603 & 7.8088 & 6.3768 & 7.7277 & 5.5188 & 9.6163 & 7.8107 \\
\hline PKG02 & 6.9226 & 6.2751 & 7.7544 & 6.7937 & 8.0781 & 5.5913 & 10.1060 & 8.6808 \\
\hline PKG03 & 7.2609 & .9216 & 8.0505 & 7.0837 & 8.4527 & 5.9297 & 10.1960 & 8.7352 \\
\hline PKG04 & 6.3788 & 1784 & 7.6577 & no ball & 7.5646 & 5.6517 & 9.7129 & 7.9014 \\
\hline PKG05 & 7776 & .4020 & 7.8813 & 6.4855 & 7.8304 & 5.7726 & 9.6707 & 11.3760 \\
\hline PKG06 & 6.3425 & 5.8582 & 7.1683 & 5.7605 & 7.1054 & 5.0838 & 8.9879 & 8.7473 \\
\hline PKG07 & 6.5903 & 6.3234 & 7.4583 & 6.2378 & 7.6371 & 5.5611 & 9.2477 & 7.7805 \\
\hline PKG08 & 7.1220 & 6.6618 & 8.4432 & 7.1502 & 8.2654 & 5.8330 & 10.4380 & 9.6898 \\
\hline PKG09 & 6.7776 & 6.1965 & 7.6396 & 6.5762 & 7.6612 & 5.5913 & 9.6344 & 8.0826 \\
\hline PKG10 & 6.9588 & 6.6557 & 7.9175 & 6.7453 & 8.3138 & 5.8874 & 10.0390 & 8.5116 \\
\hline PKG11 & 6.5661 & 6.2811 & 7.7302 & 6.3768 & 8.1385 & 5.6034 & 9.5619 & 7.6839 \\
\hline PKG12 & 7.0797 & 6.6316 & 7.8934 & 6.7816 & 8.7367 & 6.1713 & 10.1300 & 9.0735 \\
\hline PKG13 & 5359 & 038 & 7.4342 & 955 & 7.5585 & 5.5309 & 9.5075 & 8.7533 \\
\hline PKG14 & 664 & 7.0968 & 8.3284 & 7.3979 & 8.8878 & 5.9840 & 10.4800 & 9.6052 \\
\hline PKG15 & 6.5117 & 6.0032 & 7.5067 & 6.0807 & 7.6068 & 5.4040 & 9.2477 & 7.7322 \\
\hline PKG16 & 7.6295 & 7.5077 & 8.5942 & 7.7242 & 9.4074 & 6.5339 & 10.9520 & 9.8892 \\
\hline PKG17 & 6.9528 & 6.4443 & 7.8088 & 6.6426 & 8.1990 & 6.0263 & 10.0570 & 8.3847 \\
\hline PKG18 & 6.6446 & 6.0334 & 7.6698 & 6.4493 & 7.8485 & 5.5671 & 9.5982 & 8.3666 \\
\hline PKG19 & 4875 & 6.0213 & 7.6034 & 6.1170 & 7.5827 & 5.3255 & 9.3988 & 8.5116 \\
\hline PKG20 & 6.2640 & 6.0092 & 7.5429 & 6.2559 & 7.5404 & 5.5430 & 9.5377 & 8.1853 \\
\hline PKG21 & 199 & 872 & 550 & 037 & 7.7700 & 5.5128 & 9.3263 & 7.9255 \\
\hline PKG22 & 180 & 724 & 692 & 78 & 371 & .5551 & .6223 & 8.0947 \\
\hline PKG23 & 50 & 09 & 792 & & 147 & .2469 & .1390 & 7.5570 \\
\hline PKG24 & 211 & 274 & 744 & & 229 & .3013 & 9.2477 & 7.5449 \\
\hline PKG25 & 446 & 6.3718 & 8.0142 & 341 & 7.7579 & 5.5128 & 9.8519 & 8.2639 \\
\hline PKG26 & 359 & 6.5711 & 7.8269 & 383 & 7.7216 & 5.8934 & 9.8338 & 8.0343 \\
\hline PKG27 & 1144 & 999 & 7.7967 & 345 & 7.6431 & 5.3859 & 9.5317 & 7.7080 \\
\hline PKG28 & 030 & 2267 & 7.6034 & 6.4070 & 7.4316 & 5.4221 & 9.7371 & 7.7503 \\
\hline PKG29 & 742 & 4080 & 7.9719 & 601 & 337 & 5.7544 & 10.0390 & 8.1733 \\
\hline PKG30 & 6.5238 & 6.0636 & 7.7061 & 6.1955 & 7.4498 & 5.3496 & \begin{tabular}{|c|}
9.7673 \\
\end{tabular} & 7.4301 \\
\hline PKG31 & 371 & 346 & 321 & 088 & 9966 & 5.0717 & 9.4531 & 7.4422 \\
\hline PKG32 & 94 & 94 & 496 & 05 & 014 & 5.3134 & 148 & 7.4543 \\
\hline PKG33 & & 95 & 209 & 89 & 298 & 5.7182 & 9.8821 & 8.4089 \\
\hline PKG34 & 75 & 69 & 275 & 97 & 68 & 563 & 9.4652 & 7.5388 \\
\hline PKG35 & & 65 & 67 & 26 & 123 & 5.7484 & 9.4048 & 7.8107 \\
\hline PKG36 & & 947 & & & 654 & 5.7605 & .9365 & 8.3847 \\
\hline PKG37 & 011 & 6.2811 & 7.7363 & 389 & 8.0479 & 5.6215 & .6284 & 8.0766 \\
\hline PKG38 & 6.9769 & 6.4866 & 7.8088 & & 8.2171 & 5.6457 & .5619 & 7.8289 \\
\hline PKG39 & 655 & 6.0576 & 7.6275 & 6.3828 & 7.6552 & 5.6155 & 9.6707 & 8.1128 \\
\hline PKG40 & & 603 & 7.6698 & 949 & 7.5041 & 5.5067 & 9.5256 & 7.7624 \\
\hline PKG41 & 132 & 6.6678 & 7.9780 & 6.8843 & 8.2594 & 6.1532 & 8.8640 & 8.5358 \\
\hline PKG42 & & & 692 & 14 & ball & 5.6094 & 9.9425 & 8.1733 \\
\hline PKG43 & 936 & 397 & 7.6275 & 6.3345 & 7.7337 & 5.5611 & 9.4290 & 8.0162 \\
\hline PKG44 & & & 375 & & 95 & 5.7303 & 9.1390 & 7.5147 \\
\hline PKG45 & & & 25 & & $\overline{19}$ & 5.5913 & 9.6042 & 7.8289 \\
\hline PKG46 & 621 & 41 & 8.0505 & 360 & 265 & 6.4130 & 9.9667 & 8.4149 \\
\hline PKG47 & 6.3184 & 6.0455 & 7.4704 & 6.2076 & 7.5343 & 5.8692 & 9.6404 & 8.0585 \\
\hline PKG48 & 767 & 944 & 7.5671 & 6.4009 & 664 & 5.3255 & 3263 & 7.5388 \\
\hline PKG49 & 600 & 0153 & 7.2046 & & 7.3410 & 5.3496 & 8.9939 & 7.4240 \\
\hline PKG50 & 917 & 6.3959 & 8.0263 & 6.5883 & 8.2594 & 5.8995 & 10.2690 & 8.5237 \\
\hline Mean & 7049 & 6.2719 & 7.7254 & 6.4788 & 7.8013 & 5.6341 & 9.6807 & 8.2167 \\
\hline SD & 0.3449 & 0.3536 & 0.3028 & 0.4045 & 0.4826 & 0.3045 & 0.3969 & 0.7325 \\
\hline Max & 7.6295 & 7.5077 & 8.5942 & 7.7242 & 9.4074 & 6.5339 & 10.9520 & 11.3760 \\
\hline Min & 6.0767 & 5.6346 & 7.1321 & 5.6759 & 6.9664 & 5.0717 & 8.9879 & 7.4240 \\
\hline Diff & 1.5528 & 1.8731 & 1.4621 & 2.0483 & 2.4410 & 1.4622 & 1.9641 & 3.9520 \\
\hline
\end{tabular}


Table C-1-24: TCC $300^{\text {th }}$ cycle; Daisy09 - Daisy16.

\begin{tabular}{|c|c|c|c|c|c|c|c|c|}
\hline & DAISY09 & DAISY10 & DAISY11 & DAISY12 & DAISY13 & \begin{tabular}{|l|} 
DAISY14 \\
\end{tabular} & DAISY15 & DAISY16 \\
\hline PKG01 & 7.7443 & 8.5217 & 9.0539 & 8.3712 & 8.8298 & 8.6072 & 10.6040 & 11.0100 \\
\hline PKG02 & 7.7805 & 8.5580 & 9.4285 & 8.5645 & 8.4733 & 8.1903 & 10.5130 & 1.2940 \\
\hline PKG03 & 8.7412 & 9.0957 & 9.4165 & 8.6189 & 9.4461 & 9.1027 & 11.2860 & 11.5000 \\
\hline PKG04 & 7.9739 & 8.4855 & 9.2594 & 8.2081 & 8.7694 & 8.6556 & 10.2170 & 10.6960 \\
\hline PKG05 & 7.6657 & 2619 & 9.2775 & 8.6431 & 8.6365 & 8.1360 & 10.3980 & 11.6570 \\
\hline PKG06 & 7.0978 & 8.2075 & 8.4074 & 7.7187 & 7.9960 & 7.7312 & 9.4617 & 10.0920 \\
\hline PKG07 & 7.8228 & 8.4009 & 9.0841 & 8.0993 & 8.6184 & 8.0695 & 9.9814 & 10.9200 \\
\hline PKG08 & 8.7533 & 9.2165 & 10.2500 & 5192 & 9.4340 & 0725 & 11.6070 & 12.4790 \\
\hline PKG09 & 7.5751 & 8.6184 & 9.0116 & 1416 & 8.3465 & 7.5982 & 10.2170 & 10.9380 \\
\hline PKG10 & 8.2518 & 8.8178 & 8.8062 & .7156 & 9.2105 & 5227 & 10.7250 & 3560 \\
\hline PKG11 & 8.2820 & 9.0413 & 8.7458 & 8.2685 & 8.9990 & 8.7764 & 10.0900 & 9380 \\
\hline PKG12 & 8.6083 & 9.0534 & 9.6763 & 035 & 9.3011 & 8.9577 & 10.6880 & 3450 \\
\hline PKG13 & 7.4603 & 8.1290 & no ball & 8.0449 & 8.2921 & 8.2326 & 9.9330 & 9200 \\
\hline PKG14 & 8.7110 & 8.8057 & 9.8817 & 8.9633 & 9.5488 & 610 & 11.4920 & 12.6240 \\
\hline PKG15 & 7.6597 & 8.8117 & 8.8062 & 8.1658 & 8.6063 & 8.0212 & 10.1260 & 11.0410 \\
\hline PKG16 & 9.3273 & 495 & 10.6190 & \begin{tabular}{l|l|}
9.4648 \\
\end{tabular} & 9.8086 & 9.1571 & 12.2110 & 3190 \\
\hline PKG17 & 00 & & & 8.3651 & 8.9748 & 8.6133 & 3560 & 3730 \\
\hline PKG18 & & & & & & & & \\
\hline PKG19 & 170 & & & 76 & 8.6063 & 601 & 814 & 320 \\
\hline KG2O & & 50 & & 01 & 8.6304 & 772 & 480 & 190 \\
\hline PKG21 & 366 & 82 & 35 & 33 & 8.6727 & 320 & 390 & 200 \\
\hline PKG22 & 7.9920 & 036 & 243 & 470 & 8.7694 & 8.4924 & 430 & 230 \\
\hline PKG23 & 7.4784 & 7752 & 068 & 7.9664 & 8.0867 & 393 & 630 & 5940 \\
\hline PKG24 & 7.5993 & 7.9356 & 914 & 7.7912 & 02 & 695 & 3551 & 3280 \\
\hline KG25 & 156 & 552 & 446 & 229 & 8.9446 & 154 & 10.6580 & 2160 \\
\hline PKG26 & 128 & 59 & 298 & 564 & 13 & 677 & 4830 & 2040 \\
\hline PKG27 & & & & & & & & \\
\hline PKG28 & 188 & & & & & & & \\
\hline PKG29 & 197 & 86 & & & & & & 340 \\
\hline PKG30 & 07 & 82 & 12 & 22 & 80 & 22 & 130 & 750 \\
\hline KG31 & 100 & 19 & & 13 & 08 & 64 & 28 & 200 \\
\hline PKG32 & 376 & 06 & 197 & 912 & 8.6304 & 558 & 120 & 670 \\
\hline PKG33 & 739 & 740 & 679 & 437 & 8.7754 & 8.4804 & 150 & 4270 \\
\hline PKG34 & 7.7685 & 510 & 116 & 570 & 8.3767 & 266 & 220 & 10.9680 \\
\hline PKG35 & 7.8893 & 8.3707 & 727 & 389 & 8.8480 & 56 & 860 & 7630 \\
\hline PKG36 & 506 & 453 & 3440 & 893 & 9.4219 & 550 & 840 & 3610 \\
\hline KG37 & 101 & 256 & 231 & 229 & 8.8600 & 293 & 5250 & 4090 \\
\hline PKG38 & 302 & 3540 & 4195 & 383 & 9.5126 & 504 & 7120 & 10.9860 \\
\hline PKG39 & & & & & 8.6969 & 35 & 590 & 310 \\
\hline PKG40 & 03 & 40 & & & 8.7754 & 54 & 110 & 440 \\
\hline PKG41 & 10 & 27 & 917 & 337 & 9.1078 & 60 & 310 & 30 \\
\hline PKG42 & 14 & 138 & 017 & 772 & 8.6244 & 8.2206 & 2710 & 2520 \\
\hline PKG43 & 7.7382 & 256 & 083 & 108 & 8.5156 & 8.0876 & 2590 & 11.0770 \\
\hline PKG44 & 7.6839 & 256 & 8.7700 & 7.9905 & 8.5096 & 997 & 9.9089 & 10.6660 \\
\hline PKG45 & 8.2639 & 5821 & 8.9150 & 8.1778 & 8.8661 & 8.5468 & 10.5980 & 8900 \\
\hline PKG46 & 8.2881 & 7150 & 4829 & 6068 & 9.4703 & 9.0362 & 11.0390 & 11.7360 \\
\hline PKG47 & 7.6839 & 7.8994 & 9.2171 & .0449 & 8.2135 & 7.9185 & 9.9209 & 10.6840 \\
\hline PKG48 & 938 & 658 & 458 & 1476 & 8.3163 & 7.9547 & 10.2110 & 8170 \\
\hline PKG49 & 624 & 048 & 1679 & 428 & 8.4311 & 8.2991 & 9.8001 & 10.4610 \\
\hline PKG50 & 8.4270 & 7453 & 8.8123 & 6129 & 9.1561 & 8.6012 & 10.7430 & 11.6990 \\
\hline Mean & & 345 & 34 & 958 & 8.7887 & 8.4255 & 10.4689 & 11.1443 \\
\hline$\overline{S D}$ & 887 & 95 & 0.6049 & 786 & 0.4311 & 0.3983 & 0.5225 & 0.5949 \\
\hline Ma: & & & & & 9.8086 & 9.3504 & 12.2110 & 13.3190 \\
\hline Min & & 7.6819 & & 313 & 7.8208 & 7.5982 & 9.4617 & 10.0200 \\
\hline Diff & 3.9273 & 1.6676 & 3.6674 & 1.9879 & \begin{tabular}{|c|}
1.9878 \\
\end{tabular} & $\begin{array}{l}1.7522 \\
\end{array}$ & 2.7493 & 3.2990 \\
\hline
\end{tabular}


Table C-1-25: TCC $400^{\text {th }}$ cycle; Daisy01 - Daisy08.

\begin{tabular}{|c|c|c|c|c|c|c|c|c|}
\hline & AISY01 & DAISY02 & DAISY03 & DAISYO4 & DAISY05 & DAISY06 & DAISY07 & DAISY08 \\
\hline PKG01 & 6.1646 & 5.9884 & 7.4306 & 7.1946 & 8.0933 & 5.7939 & 9.6812 & 8.4324 \\
\hline PKG02 & 6.2552 & 6.2845 & 7.7389 & 7.4363 & 7.8213 & 1927 & 10.1650 & 9.2301 \\
\hline PKG03 & 7508 & 6.8223 & 7.9383 & 7.9500 & 8.4801 & 6.5372 & 9.7778 & 9.2362 \\
\hline PKG04 & 6.0256 & 6.1213 & 7.5636 & no ball & 7.3681 & 5.9631 & 9.2944 & 8.4445 \\
\hline PKG05 & 4003 & 6.4477 & 7.5757 & 7.3940 & 7.7488 & 6.2652 & 9.6026 & 8.8676 \\
\hline PKG06 & 5.6932 & 5.9158 & 7.1647 & 6.6144 & 7.2412 & 5.6186 & 8.7324 & 7.7918 \\
\hline PKG07 & 6.1283 & 6.3691 & 7.3642 & 7.0616 & 7.8093 & 5.8845 & 9.0829 & 8.2451 \\
\hline PKG08 & 6.6601 & 6.7680 & 8.2344 & 8.2280 & 8.2806 & 6.4647 & 10.5820 & 10.2030 \\
\hline PKG09 & 465 & 6.2966 & 7.5696 & 7.7566 & 7.5977 & 6.1685 & 9.3246 & 8.6983 \\
\hline PKG10 & 6.7266 & 6.6350 & 7.8355 & 7.6418 & 8.2021 & 6.1988 & 9.6691 & 9.3268 \\
\hline PKG11 & 382 & 6.3147 & 7.5817 & 7.3940 & 7.8032 & 202 & 9.5301 & 8.1726 \\
\hline PKG12 & 6.6481 & 6.6713 & 8.0048 & 7.7626 & 317 & 196 & 9.9471 & 9.1939 \\
\hline KG13 & 81 & 5.8796 & 48 & 7.2248 & $\overline{83}$ & 939 & 9.5784 & 8.4626 \\
\hline PKG14 & 11 & 7.1849 & 17 & 49 & 157 & 949 & 10.2430 & 9.7317 \\
\hline PKG15 & 88 & 5.9038 & 581 & 162 & 7.4467 & 362 & 9.2219 & 8.4445 \\
\hline PKG16 & 7.6754 & 7.5536 & 8.5487 & 9.5937 & 932 & 330 & 10.8410 & 10.3780 \\
\hline PKG17 & 6.5151 & 6.6290 & 7.6059 & 7.9500 & 68 & 614 & 9.9591 & 9.0609 \\
\hline PKG18 & 6.3459 & 6.2482 & 7.7389 & 7.4000 & 7.6823 & 5.9993 & 9.3790 & 8.8192 \\
\hline PKG19 & 921 & 6.0428 & 7.4367 & 6.9830 & 7.3620 & 5.8180 & 9.2944 & 8.3418 \\
\hline PKG20 & 948 & 6.0246 & 7.4971 & 7.2610 & 7.4648 & 5.9329 & 9.4757 & 8.7467 \\
\hline PKG21 & 22 & 6.1878 & 59 & & 665 & 95 & 9.0889 & 8.2149 \\
\hline PKG22 & 01 & 6.2482 & & & & & 9.4032 & 8.4808 \\
\hline PKG23 & & 5.7648 & & & & & 3.3911 & 8.1665 \\
\hline PKG24 & 300 & 6.0428 & 68 & & & & 8.6961 & 7.7677 \\
\hline PKG25 & 6.5151 & 6.3570 & 366 & 80 & & 70 & 9.6993 & 8.6319 \\
\hline PKG26 & 6.4547 & 6.7075 & 7.7389 & 7.4061 & 38 & 997 & 9.5240 & 8.5956 \\
\hline PKG27 & 6.5151 & 6.2180 & 7.6119 & 7.2731 & 7.5192 & 229 & 9.2642 & 8.2451 \\
\hline PKG28 & 948 & 6.4295 & 96 & 42 & 7.2291 & 33 & 9.4817 & 8.2753 \\
\hline PKG29 & 607 & 6.4597 & & & 446 & & 9.8987 & 9.1697 \\
\hline PKG30 & 668 & 6.0428 & 153 & 36 & 983 & 664 & 9.5663 & 8.4566 \\
\hline PKG31 & 36 & 5.7466 & 04 & 59 & 102 & 911 & 8.7142 & 7.6105 \\
\hline PKG32 & 239 & 6.0730 & 33 & & 62 & 603 & 9.0043 & 7.8704 \\
\hline PKG33 & & 6.4477 & & & & & 9.5724 & 8.9461 \\
\hline PKG34 & 92 & 6.1 & & & & & 9.3669 & 8.1303 \\
\hline PKG35 & & 6.2 & & & & & 9.2944 & 8.3660 \\
\hline PKG36 & 39 & 84 & & 06 & & & 10.1280 & 8.8857 \\
\hline PKG37 & 497 & 6.3087 & & & & 586 & 9.4938 & 8.7286 \\
\hline PKG38 & 717 & 323 & 7.7207 & 088 & & 713 & 9.5240 & 8.4022 \\
\hline PKG39 & 6.6058 & 6.0730 & 7.5938 & 7.3456 & 7.6642 & 933 & 9.5542 & 8.7286 \\
\hline PKG40 & & 334 & 7.5696 & 7.4544 & 7.7669 & 301 & 9.2702 & 8.4203 \\
\hline PKG41 & 7.5002 & 6.8405 & 7.9202 & 7.8774 & 8.1054 & 6.6460 & 9.6872 & 9.1516 \\
\hline PKG42 & 29 & 99 & 422 & & & 391 & 9.7597 & 8.8434 \\
\hline PKG43 & 305 & 94 & & & 21 & & 9.3548 & 8.6319 \\
\hline PKG44 & & & & & & & 8.9378 & 8.1424 \\
\hline PKG45 & & & & & & & 9.5542 & 8.4868 \\
\hline PKG46 & & 6.6833 & & 7.7868 & 900 & 542 & 9.6570 & 9.0065 \\
\hline PKG47 & 399 & 6.0488 & 7.4911 & 7.7324 & 7.6280 & 6.7124 & 9.4576 & 8.5654 \\
\hline PKG48 & & & & & & & 9.2219 & 8.1242 \\
\hline PKG49 & & 784 & 7.2252 & & & 389 & 8.8170 & 7.7375 \\
\hline PKG50 & 294 & 6.5504 & 7.9806 & 7.5692 & 8.4982 & 6.2592 & 10.1890 & 8.9763 \\
\hline Mean & & & & 701 & 401 & 357 & 9.5191 & 8.6317 \\
\hline SD & 693 & 0.3536 & 090 & & 597 & 0.3247 & 0.4391 & 0.5662 \\
\hline Max & 7.6754 & 7.5536 & 187 & 37 & 332 & 7.0630 & 10.8410 & 10.3780 \\
\hline Min & 5.6932 & 5.7466 & 104 & 5.1459 & 6.8302 & 5.6186 & 8.6961 & 7.6105 \\
\hline Diff & 1.9822 & 1.8070 & 1.4383 & 4.4478 & 2.3630 & 1.4444 & 2.1449 & 2.7675 \\
\hline
\end{tabular}


Table C-1-26: TCC 400 ${ }^{\text {th }}$ cycle; Daisy09 - Daisy16.

\begin{tabular}{|c|c|c|c|c|c|c|c|c|}
\hline & DAISY09 & DAISY10 & DAISY11 & DAISY12 & DAISY13 & DAISY 14 & DAISY15 & DAISY16 \\
\hline PKG01 & 7.6447 & 8.2118 & 8.9919 & 8.3267 & 8.8466 & 7.6778 & 10.7060 & 11.3060 \\
\hline PKG02 & 7.5843 & 8.2904 & 9.3485 & 8.6046 & 8.4598 & 7.6658 & 10.7600 & 11.3250 \\
\hline PKG03 & 8.6781 & 8.9491 & 9.4995 & 8.5200 & 9.4570 & 8.3849 & 0.7540 & 11.6750 \\
\hline PKG04 & 3139 & 3145 & 8.9315 & 8.2420 & 8.7499 & .9558 & .5240 & 10.7380 \\
\hline PKG05 & 370 & 453 & & 080 & 6290 & & .5970 & 1.4820 \\
\hline PKG06 & 6.9799 & 7.6679 & 8.4238 & 7.7707 & 0307 & & .5513 & 0.2910 \\
\hline PKG07 & 7.3909 & .0728 & 8.8287 & 8.1272 & 169 & 7.4603 & .0530 & 8890 \\
\hline PKG08 & 8.4606 & .0518 & 10.2970 & 9.3298 & 9.4630 & 8.3245 & .4490 & 5450 \\
\hline PKG09 & 5722 & .9882 & .0826 & 8.2481 & 8.2604 & 6.7593 & .3730 & 9140 \\
\hline PKG10 & 8.0557 & 8.5019 & 9.4572 & 8.7739 & 9.0702 & 7.9558 & 1710 & 6210 \\
\hline PKG11 & 7.9710 & 8.5502 & 8.8046 & 8.1574 & 8.9674 & 8.0586 & 1.1350 & .6240 \\
\hline PKG12 & 8.2913 & 8.8464 & 9.8017 & 8.9008 & 9.1910 & 8.2399 & 10.9530 & 1.8810 \\
\hline PKG13 & 7.2217 & 1574 & no ball & 8.3206 & 8.2664 & 7.5086 & 5000 & 0.9500 \\
\hline PKG14 & & & & & & & & 660 \\
\hline PKG15 & 92 & & & & & & 100 & 500 \\
\hline PKG16 & 329 & 31 & & & & & 750 & 160 \\
\hline PKG17 & 227 & & & 323 & & & 340 & 630 \\
\hline PKG18 & & 662 & 380 & .052 & 263 & 778 & 520 & 3610 \\
\hline PKG19 & 667 & 607 & 436 & 267 & 538 & & 190 & 9740 \\
\hline PKG20 & 7.6628 & 233 & 370 & 387 & & & 2700 & 2700 \\
\hline PKG21 & 7.4755 & 453 & 8.9073 & 997 & & 86 & 1620 & 8470 \\
\hline PKG22 & 7.7958 & 206 & 161 & 8.3146 & 076 & 504 & 5240 & 9680 \\
\hline PKG23 & 7.0162 & 6619 & 683 & 8.0728 & 8.0610 & 7.1400 & 7060 & .6240 \\
\hline PKG24 & 7.2821 & 184 & 315 & 7.8432 & 785 & 7.5570 & 5453 & 6360 \\
\hline PKG25 & 331 & & 518 & 596 & & 338 & 2210 & 3190 \\
\hline PKG26 & & & & & & & 540 & 120 \\
\hline PKG27 & & & & & & & 310 & 450 \\
\hline PKG28 & & 86 & jall & 395 & 66 & & 130 & 740 \\
\hline PKG29 & & 44 & 300 & 261 & & & 690 & 540 \\
\hline PKG30 & & 206 & & 882 & 80 & 93 & 710 & 900 \\
\hline PKG31 & & & 770 & 223 & & & 459 & 1130 \\
\hline PKG32 & & 942 & 27 & $\overline{064}$ & & & 480 & 3520 \\
\hline PKG33 & 782 & 755 & 726 & 8.6651 & 922 & 7.7020 & .5730 & 4450 \\
\hline PKG34 & 459 & 794 & 529 & 816 & 290 & 7.4603 & 4880 & .0040 \\
\hline PKG35 & & & & & & & 2040 & 380 \\
\hline PKG36 & & & & & & & 560 & 760 \\
\hline PKG37 & & & & & & & & \\
\hline PKG38 & & & & & & & & \\
\hline PKG39 & & & & 50 & & & 790 & 490 \\
\hline PKG40 & 03 & 45 & 82 & 302 & & 35 & 360 & 280 \\
\hline PKG41 & 46 & 771 & 171 & 436 & 575 & 887 & 660 & 7110 \\
\hline PKG42 & 931 & 415 & 633 & 4838 & 8.8466 & 449 & 5480 & .5600 \\
\hline PKG43 & 7.5661 & 502 & 9.1249 & 8.4415 & 8.6290 & 7.5086 & 0.7840 & 1.1130 \\
\hline PKG44 & 7.4392 & 8.1635 & 8.8650 & 8.1151 & 8.8043 & 7.4240 & .0710 & 0.6480 \\
\hline PKG45 & 8.0375 & 255 & 2880 & 8.3508 & 8.8889 & 7.9558 & 5730 & 9800 \\
\hline PKG46 & & 156 & & & & & 2250 & 390 \\
\hline PKG47 & & & & & & & & 930 \\
\hline PKG48 & & & & & & & & 170 \\
\hline PKG49 & & & & & & & & 600 \\
\hline PKG50 & & & & & & & 140 & 590 \\
\hline Mean & & & & & & & & 009 \\
\hline SD & 0.4406 & 0.3627 & .5062 & 0.3656 & 0.4170 & 0.3883 & .5006 & 0.5948 \\
\hline Max & 7929 & 9.2331 & 10.7810 & 7650 & 9.8437 & 8.5239 & 11.9750 & 13.2160 \\
\hline Min & 6.8228 & 7.6619 & & 7.7223 & 8.0307 & 6.7593 & 9.3459 & 10.0130 \\
\hline Diff & 1.9701 & 1.5712 & 2.3995 & 2.0427 & 1.8130 & 1.7646 & 2.6291 & 3.2030 \\
\hline
\end{tabular}


Table C-1-27: TCC 500 ${ }^{\text {th }}$ cycle; Daisy01 - Daisy08.

\begin{tabular}{|c|c|c|c|c|c|c|c|c|}
\hline & AISY01 & DAISY02 & DAISYO3 & DAISY04 & DAISY05 & DAISY06 & DAISY07 & DAISY08 \\
\hline PKG01 & 6.9684 & 6.4054 & 7.6905 & 7.2912 & 7.9845 & 5.9389 & 9.0829 & 8.7346 \\
\hline PKG02 & 6.5272 & 6.6290 & 7.7872 & 7.5572 & 7.6823 & 6.0235 & 9.7295 & 9.2664 \\
\hline PKG03 & 6.9140 & 6.8163 & 7.9564 & 7.8835 & 8.2504 & 6.3982 & 9.7295 & 1758 \\
\hline PKG04 & 1162 & 6.2059 & 7.4609 & no ball & 7.2956 & 6.0960 & 9.2158 & 8.6439 \\
\hline PKG05 & 0046 & 6.2905 & 7.6422 & 7.6720 & 7.6461 & 6.5553 & 9.4999 & 8.8555 \\
\hline PKG06 & 6.0196 & 5.8252 & 7.1164 & 6.8017 & 7.2835 & 5.6851 & 8.8230 & 8.0638 \\
\hline PKG07 & 6.5030 & 6.3328 & 7.3823 & 7.1160 & 7.5977 & 6.0839 & 8.9197 & 8.2451 \\
\hline PKG08 & 7.0288 & 6.7559 & 8.2646 & 8.2703 & 8.2927 & 6.5009 & 10.3820 & 9.8647 \\
\hline PKG09 & 6.2129 & 6.1274 & 7.4548 & 7.4423 & 7.5313 & 6.2169 & 9.4576 & 8.7346 \\
\hline PKG10 & 6.7629 & 6.6592 & 7.7872 & 8.3186 & 6.8000 & 6.4284 & 9.7355 & 8.8796 \\
\hline PKG11 & 7.0892 & 6.3147 & 7.5334 & 7.3879 & 7.7609 & 6.1746 & 9.1433 & 8.1544 \\
\hline PKG12 & 6.8777 & 6.5867 & 7.7630 & 7.7385 & 8.4015 & 6.4586 & 9.8020 & 9.2845 \\
\hline PKG13 & 6.3640 & 5.9521 & 7.2675 & 7.0133 & 7.3137 & 5.9268 & 9.1675 & 8.5775 \\
\hline PKG14 & 7.1678 & 7.1124 & 8.1317 & 8.3065 & 8.6432 & 6.6037 & 10.0920 & 9.6713 \\
\hline PKG15 & 6.1465 & 6.0125 & 7.4850 & 18 & 7.4104 & 5.8422 & 9.7295 & 8.3841 \\
\hline PKG16 & 7.1134 & 7.4267 & 8.3855 & 8.8262 & 9.1569 & 7.1778 & 10.9320 & 10.4150 \\
\hline PKG17 & 5091 & 6.5746 & 7.6482 & 7.6418 & 7.9966 & 6.4768 & 9.5361 & 9.0488 \\
\hline PKG18 & 2855 & 1032 & 7.5757 & & 7.6280 & 202 & 18 & 950 \\
\hline PKG19 & 1223 & 5.9158 & 7.2554 & 242 & 7.4648 & 5.9752 & 375 & 478 \\
\hline PKG20 & 6.1888 & 6.1092 & 7.3581 & 7.2671 & 7.3862 & 6.0839 & 9.4817 & 8.7286 \\
\hline PKG21 & 6.3036 & 6.2422 & 7.5696 & 7.2187 & 7.7005 & 5.9389 & 9.3186 & 8.3357 \\
\hline PKG22 & 2492 & 6.1938 & 7.6301 & 7.4967 & 7.4467 & 6.2592 & 999 & 8.4022 \\
\hline PKG23 & 8080 & 5.7527 & 7.3279 & 7.3517 & 330 & 5.6972 & & 8.1242 \\
\hline PKG24 & 9410 & 5.9702 & 7.0439 & 50 & 302 & 5.8543 & & 7.7918 \\
\hline PKG25 & 3580 & 4900 & 7.8476 & 8835 & 7.6703 & 6.1746 & 10. & 676 \\
\hline PKG26 & 2855 & 7800 & 7.6724 & & 6461 & 955 & & 896 \\
\hline PKG27 & 2734 & 6.2059 & 119 & & 7.4346 & 5.8059 & 10.4490 & 967 \\
\hline PKG28 & 35 & 312 & 032 & & 112 & 631 & 273 & 209 \\
\hline PKG29 & 80 & 6.5141 & 7.8597 & 68 & 84 & 6.2894 & 00 & 676 \\
\hline PKG30 & 1586 & 6.2059 & 7.5153 & 7.2308 & 7.6461 & 329 & & 638 \\
\hline PKG31 & 7295 & 5.6862 & 6.9411 & 6.7474 & 7.0055 & 5.6549 & 359 & 7.7314 \\
\hline PKG32 & 6.1042 & 6.1515 & 7.2554 & 6.8440 & 7.7669 & 5.9389 & 320 & 8.1424 \\
\hline PKG33 & 2915 & 6.3026 & 7.5999 & 7.5330 & 8.1054 & 6.0356 & 50 & 8.9642 \\
\hline PKG34 & 9410 & 6.2059 & 7.4609 & 7.2489 & 5.8996 & 5.5884 & 9.3488 & 8.0759 \\
\hline PKG35 & 2915 & 3570 & 7.4004 & & 8.0026 & 6.2713 & & 9.6532 \\
\hline PKG36 & 5272 & 6.7800 & 8.0652 & 675 & 8.1295 & 6.9481 & 10.3520 & 8.8555 \\
\hline PKG37 & 91 & 2845 & 7.6059 & 08 & 08 & 880 & & 231 \\
\hline PKG38 & 40 & 69 & 889 & & 21 & 38 & & 360 \\
\hline PKG39 & 058 & 5504 & 213 & 203 & 461 & 262 & 324 & 071 \\
\hline PKG40 & 1948 & 6.2120 & 7.6180 & 7.5028 & 7.4648 & 993 & 869 & 8.6258 \\
\hline PKG41 & 5997 & 6.6894 & 7.7932 & 7.8170 & 8.1416 & $\overline{372}$ & 81 & 9.2362 \\
\hline PKG42 & 6.2432 & 6.3026 & 7.6422 & 7.6478 & no ball & 5.9752 & 9.6086 & 8.9219 \\
\hline PKG43 & 6.4124 & 6.1153 & 7.5213 & 7.4061 & 5010 & 861 & 9.6268 & 8.9461 \\
\hline PKG44 & 6.1888 & 6.2482 & 7.2373 & 6.9830 & 7.3379 & 6.1383 & 9.0285 & 8.1665 \\
\hline PKG45 & 4970 & 2603 & 7.6724 & 7.7143 & 7.6400 & 6.0114 & 9.4273 & 8.4264 \\
\hline PKG46 & 6.6783 & 6.6592 & 108 & & & 12 & 51 & 280 \\
\hline PKG47 & 1646 & .0911 & 7.3400 & 7.4544 & & & & \\
\hline PKG48 & 8443 & 5.7889 & 7.4729 & & & & & \\
\hline & & .0911 & 7.0741 & & 442 & 752 & 882 & 254 \\
\hline PKG50 & 6.9019 & 6.5141 & 7.8295 & 7.7747 & 8.6009 & 6.4949 & 9.7960 & 9.1395 \\
\hline Mean & 4123 & 360 & 7.5866 & 7.4877 & 7.6788 & 6.1746 & 9.4693 & 728 \\
\hline SD & 0.3663 & 0.3417 & 0.2980 & 0.4382 & 0.5346 & 0.3310 & 0.5032 & 0.5454 \\
\hline Max & 7.1678 & 7.4267 & 8.3855 & 8.8262 & 9.1569 & 7.1778 & 10.9320 & 10.4150 \\
\hline Min & 5.7295 & 5.6862 & 6.9411 & 6.7050 & 5.8996 & 5.5884 & 8.6659 & 7.7254 \\
\hline Diff & 1.4383 & 1.7405 & 1.4444 & 2.1212 & 3.2573 & 1.5894 & 2.2661 & 2.6896 \\
\hline
\end{tabular}


Table C-1-28: TCC 500 ${ }^{\text {th }}$ cycle; Daisy09-Daisy16.

\begin{tabular}{|c|c|c|c|c|c|c|c|c|}
\hline & DAISY09 & DAISY10 & DAISY11 & DAISY12 & DAISY13 & DAISY14 & DAISY15 & DAISY16 \\
\hline PKG01 & 7.6387 & 8.2178 & 9.0644 & 8.3810 & 8.7620 & 7.6899 & 10.6270 & 11.3310 \\
\hline PKG02 & 7.5118 & 8.1755 & 9.2941 & 8.5261 & 8.5686 & 7.5630 & 10.8260 & 11.2340 \\
\hline PKG03 & 8.5572 & 9.0881 & 9.6808 & 8.6349 & 9.4630 & 8.4272 & 11.2010 & 11.6150 \\
\hline PKG04 & 7.7172 & 8.3750 & 9.0282 & 8.3448 & 8.7378 & 7.9196 & 10.9290 & 10.8290 \\
\hline PKG05 & 7.6447 & 8.5804 & 9.4572 & 8.4717 & 8.6169 & 7.6899 & 10.5730 & 11.5600 \\
\hline PKG06 & 6.8833 & 7.7223 & 8.4843 & 8.0970 & 8.1093 & 7.1521 & 10.2770 & 10.1400 \\
\hline PKG07 & 7.3728 & 7.9701 & 9.3122 & 8.2239 & 8.5505 & 7.6053 & 7840 & .9980 \\
\hline PKG08 & 8.4303 & 9.2089 & 10.5030 & 9.2996 & 9.4751 & 8.3487 & 11.9990 & 12.7450 \\
\hline PKG09 & 7.4876 & 8.1816 & 9.1853 & 8.3750 & 8.2906 & 9164 & 10.5240 & 0950 \\
\hline PKG10 & 7.9831 & & 9.4693 & 8.6893 & 9.0702 & 009 & 3870 & 3990 \\
\hline PKG11 & 7.9771 & 348 & 8.8771 & 816 & 9.0097 & 613 & 3670 & 9800 \\
\hline PKG12 & 8.3034 & 8.8826 & 9.6385 & 8.7316 & 9.1487 & 520 & 3690 & 7840 \\
\hline PKG13 & 7.0525 & 8.1091 & no ball & 8.3327 & 8.3087 & 7.4240 & 2830 & 7500 \\
\hline PKG14 & no ball & 8.8222 & 9.8803 & 9.1304 & 9.5355 & 8.2761 & 11.8480 & 10.5570 \\
\hline PKG15 & 7.3909 & 8.2178 & 9.1551 & 8.5684 & 8.5444 & 7.4905 & 10.4400 & 11.0350 \\
\hline PKG16 & 8.6781 & 9.1002 & 10.6840 & 9.5051 & 9.7893 & 8.5360 & 11.9810 & 1920 \\
\hline PKG17 & 7.8985 & & & & & 674 & 660 & 940 \\
\hline PKG18 & 7.4 & & 362 & & & 325 & 700 & 890 \\
\hline PKG19 & 7.3546 & & & & 00 & 724 & 070 & 078 \\
\hline PKG20 & 7.4936 & & & & & 987 & 890 & 2760 \\
\hline PKG21 & 7.3425 & 393 & 46 & 239 & 021 & 235 & 2460 & 3530 \\
\hline PKG22 & 7.6145 & 8.7074 & 919 & 8.4596 & 8.6532 & 7.8652 & 4280 & 9980 \\
\hline PKG23 & 6.9497 & 7.6196 & 8.6595 & 8.0003 & 8.0610 & 7.0735 & 1620 & 5930 \\
\hline PKG24 & 7.0766 & 7.9399 & 8.4238 & 7.9701 & 8.2302 & 7.5691 & 9.5272 & 4000 \\
\hline PKG25 & 7.7414 & 420 & 089 & 8.5200 & 493 & 366 & 3870 & 4270 \\
\hline PKG26 & 397 & & & & & & 690 & \\
\hline PKG27 & 7.3 & & 58 & 569 & & 309 & 640 & 190 \\
\hline PKG28 & 6.9 & & & 79 & & 81 & 500 & 140 \\
\hline PKG29 & 7.7112 & & 06 & & & 51 & 570 & 1700 \\
\hline PKG30 & 7.5238 & & & & 43 & 866 & 500 & 600 \\
\hline PKG31 & 88 & & & 344 & & 735 & 7024 & 100 \\
\hline PKG32 & 7.3667 & & 964 & 245 & & 312 & 3293 & 2550 \\
\hline PKG33 & 7.4695 & 8.0365 & 9.2941 & 8.6288 & 164 & 086 & 10.4760 & 3850 \\
\hline PKG34 & 7.3123 & 7.8915 & 502 & 8.2360 & 169 & 7.5570 & 4280 & 5590 \\
\hline PKG35 & 7.5299 & 8.4354 & 9.0221 & 8.1272 & 0883 & 7.7866 & 1560 & 9500 \\
\hline PKG36 & 8.4666 & 8.5381 & 9.2820 & 8.5503 & 4872 & 184 & 120 & 4330 \\
\hline 37 & & & & & & & 030 & \\
\hline PKG38 & & & & & & & 10 & \\
\hline PKG39 & 7.6 & & & & 82 & 37 & 60 & 550 \\
\hline PKG40 & 7.7233 & & & 04 & & 35 & 640 & 470 \\
\hline PKG41 & 8.0 & 9 & & 95 & & 10 & 960 & 3680 \\
\hline PKG42 & 7.5420 & 53 & 18 & 8.4777 & 290 & 7.6476 & 10.4760 & 3490 \\
\hline PKG43 & 7.5843 & 8.2481 & 9.0100 & 8.3629 & 8.5565 & 7.4784 & 10.7480 & 11.0950 \\
\hline PKG44 & 7.6749 & 8.0728 & 8.6837 & 8.1997 & 8.4779 & 7.4059 & 9.9441 & 10.6540 \\
\hline PKG45 & 8.0315 & 8.4777 & 8.9375 & 8.7134 & 8.9795 & 7.9377 & 10.5360 & 11.0160 \\
\hline PKG46 & 738 & 8.4535 & & & & 036 & 10.9650 & 11.7480 \\
\hline & & & & & & & 62 & 440 \\
\hline & & & & & & & 70 & \\
\hline & & & & & & & 114 & 690 \\
\hline PKG50 & & & & & & & 690 & $\overline{170}$ \\
\hline Mean & \begin{tabular}{|l|}
7.5962 \\
\end{tabular} & & & & & & 10.5481 & 1081 \\
\hline SD & 0.5581 & 0.3904 & 0.4736 & & 0.4148 & 0.4010 & 0.4951 & 0.6613 \\
\hline Max & 8.6781 & 9.2089 & 10.6840 & 051 & 9.7893 & 8.5481 & 11.9990 & 13.1920 \\
\hline Min & 5.1488 & 7.6196 & 8.2667 & 7.7344 & 7.9824 & 6.9164 & 9.5272 & 8.7078 \\
\hline Diff & \begin{tabular}{|l|}
3.5293 \\
\end{tabular} & 1.5893 & 2.4173 & 1.7707 & 1.8069 & 1.6317 & 2.4718 & 4.4842 \\
\hline
\end{tabular}


APPENDIX C-2

Derived Resistance Changes at the Measured Temperature Cycles

Table C-2-1: TCB238 ${ }^{\text {th }}$ cycle; Daisy01 - Daisy08.

\begin{tabular}{|c|c|c|c|c|c|c|c|c|}
\hline & DAISY01 & DAISY02 & DAISY03 & DAISY04 & DAISY05 & DAISY06 & DAISY07 & DAISY08 \\
\hline PKG01 & $0.07 \%$ & $5.63 \%$ & $2.31 \%$ & $-1.18 \%$ & $4.66 \%$ & $4.90 \%$ & $1.81 \%$ & $5.23 \%$ \\
\hline PKG02 & $1.25 \%$ & $2.71 \%$ & $7.65 \%$ & $6.35 \%$ & $3.11 \%$ & $11.68 \%$ & $5.12 \%$ & $7.52 \%$ \\
\hline PKG03 & $-0.56 \%$ & $4.53 \%$ & $2.30 \%$ & $1.22 \%$ & $4.21 \%$ & $4.50 \%$ & $4.10 \%$ & $9.44 \%$ \\
\hline PKG04 & $1.88 \%$ & $5.78 \%$ & $2.63 \%$ & $6.87 \%$ & $2.59 \%$ & $17.45 \%$ & $1.02 \%$ & $1.18 \%$ \\
\hline PKG05 & $1.85 \%$ & $3.71 \%$ & $2.37 \%$ & $6.40 \%$ & $2.41 \%$ & $12.64 \%$ & $2.43 \%$ & $0.15 \%$ \\
\hline PKG06 & $2.73 \%$ & $4.27 \%$ & $1.47 \%$ & $1.51 \%$ & $0.08 \%$ & $18.60 \%$ & $4.01 \%$ & $5.84 \%$ \\
\hline PKG07 & $-0.22 \%$ & $2.76 \%$ & $1.84 \%$ & $1.21 \%$ & $0.24 \%$ & $11.17 \%$ & $3.26 \%$ & $4.20 \%$ \\
\hline PKG08 & $-1.11 \%$ & $2.98 \%$ & $0.67 \%$ & $1.80 \%$ & $-1.01 \%$ & $1.45 \%$ & $0.94 \%$ & $3.71 \%$ \\
\hline PKG09 & $0.07 \%$ & $1.59 \%$ & $2.79 \%$ & $1.91 \%$ & $-1.26 \%$ & $10.22 \%$ & $4.36 \%$ & $1.31 \%$ \\
\hline PKG10 & $2.36 \%$ & $4.06 \%$ & $0.46 \%$ & $2.09 \%$ & $-0.14 \%$ & $10.29 \%$ & $2.20 \%$ & $4.04 \%$ \\
\hline PKG11 & $0.46 \%$ & $0.34 \%$ & $0.97 \%$ & $10.84 \%$ & $-0.61 \%$ & $8.92 \%$ & $2.45 \%$ & $3.86 \%$ \\
\hline PKG12 & $-1.84 \%$ & $2.40 \%$ & $-0.31 \%$ & $7.63 \%$ & $-0.64 \%$ & $2.66 \%$ & $1.43 \%$ & $-0.14 \%$ \\
\hline PKG13 & $-0.43 \%$ & $-0.70 \%$ & $1.57 \%$ & $1.63 \%$ & $-1.29 \%$ & $4.70 \%$ & $2.46 \%$ & $1.70 \%$ \\
\hline PKG14 & $-2.00 \%$ & $3.99 \%$ & $0.74 \%$ & $0.92 \%$ & $-1.30 \%$ & $-0.84 \%$ & $0.84 \%$ & $4.58 \%$ \\
\hline PKG15 & $0.17 \%$ & $4.27 \%$ & $0.16 \%$ & $0.10 \%$ & $-2.66 \%$ & $3.17 \%$ & $3.15 \%$ & $6.22 \%$ \\
\hline PKG16 & $2.39 \%$ & $2.06 \%$ & $0.94 \%$ & $0.56 \%$ & $-0.78 \%$ & $1.76 \%$ & $1.48 \%$ & $4.08 \%$ \\
\hline PKG17 & $-2.62 \%$ & $0.71 \%$ & $0.63 \%$ & $1.69 \%$ & $-1.92 \%$ & $-0.87 \%$ & $0.00 \%$ & $-3.16 \%$ \\
\hline PKG18 & $0.07 \%$ & $4.35 \%$ & $-0.08 \%$ & $3.89 \%$ & $0.54 \%$ & $4.17 \%$ & $0.32 \%$ & $1.25 \%$ \\
\hline PKG19 & $0.18 \%$ & $2.25 \%$ & $0.33 \%$ & $3.62 \%$ & $0.08 \%$ & $1.73 \%$ & $0.53 \%$ & $2.68 \%$ \\
\hline PKG20 & $-0.81 \%$ & $1.89 \%$ & $1.30 \%$ & $4.74 \%$ & $0.81 \%$ & $-3.36 \%$ & $0.91 \%$ & $3.33 \%$ \\
\hline PKG21 & $-0.02 \%$ & $2.76 \%$ & $-0.64 \%$ & $1.36 \%$ & $-1.32 \%$ & $2.74 \%$ & $0.46 \%$ & $-4.51 \%$ \\
\hline PKG22 & $-2.49 \%$ & $-1.83 \%$ & $2.12 \%$ & $-0.37 \%$ & $0.00 \%$ & $0.48 \%$ & $0.78 \%$ & $5.81 \%$ \\
\hline PKG23 & $1.88 \%$ & $2.81 \%$ & $1.47 \%$ & $-2.84 \%$ & $-0.60 \%$ & $0.51 \%$ & $0.95 \%$ & $8.17 \%$ \\
\hline PKG24 & $1.30 \%$ & $1.42 \%$ & $1.54 \%$ & $-3.68 \%$ & $-0.66 \%$ & $1.24 \%$ & $-1.04 \%$ & $1.98 \%$ \\
\hline PKG25 & $0.36 \%$ & $1.31 \%$ & $5.11 \%$ & $-0.89 \%$ & $-0.47 \%$ & $2.09 \%$ & $-0.56 \%$ & $-2.59 \%$ \\
\hline PKG26 & $1.62 \%$ & $2.38 \%$ & $-1.17 \%$ & $-0.37 \%$ & $-1.09 \%$ & $0.12 \%$ & $-1.75 \%$ & $2.28 \%$ \\
\hline PKG27 & $-1.27 \%$ & $0.76 \%$ & $-0.08 \%$ & $0.87 \%$ & $-0.96 \%$ & $2.11 \%$ & $-2.52 \%$ & $1.42 \%$ \\
\hline PKG28 & $-1.44 \%$ & $1.17 \%$ & $-0.88 \%$ & $-0.87 \%$ & $-0.33 \%$ & $2.57 \%$ & $-0.73 \%$ & $-0.91 \%$ \\
\hline PKG29 & $1.22 \%$ & $-0.83 \%$ & $-1.22 \%$ & $0.09 \%$ & $-0.16 \%$ & $2.09 \%$ & $-0.63 \%$ & $0.73 \%$ \\
\hline PKG30 & $-1.61 \%$ & $-3.25 \%$ & $0.32 \%$ & $0.40 \%$ & $-0.33 \%$ & $6.22 \%$ & $-1.38 \%$ & $2.39 \%$ \\
\hline PKG31 & $-3.05 \%$ & $1.16 \%$ & $-1.36 \%$ & $-4.27 \%$ & $0.79 \%$ & $-3.35 \%$ & $-0.28 \%$ & $0.42 \%$ \\
\hline PKG32 & $-1.60 \%$ & $0.04 \%$ & -1.8 & $-7.53 \%$ & $1.32 \%$ & $0.25 \%$ & $-0.41 \%$ & $-0.59 \%$ \\
\hline PKG33 & $-2.16 \%$ & $0.14 \%$ & $-0.39 \%$ & $-3.06 \%$ & $0.16 \%$ & $-3.76 \%$ & $-0.32 \%$ & $3.64 \%$ \\
\hline PKG35 & $-0.88 \%$ & $0.44 \%$ & $-1.12 \%$ & $-1.40 \%$ & $-0.78 \%$ & $-3.63 \%$ & $-0.72 \%$ & $3.16 \%$ \\
\hline PKG36 & $-1.23 \%$ & $2.07 \%$ & $1.04 \%$ & $-3.96 \%$ & $-1.05 \%$ & $-0.76 \%$ & $-0.12 \%$ & $4.55 \%$ \\
\hline PKG37 & $-0.97 \%$ & $0.34 \%$ & $0.55 \%$ & $-0.58 \%$ & $-1.15 \%$ & $0.92 \%$ & $-2.43 \%$ & $0.58 \%$ \\
\hline PKG38 & $-2.84 \%$ & $1.38 \%$ & $0.08 \%$ & $-4.40 \%$ & $-0.67 \%$ & $-5.94 \%$ & $-1.09 \%$ & $3.14 \%$ \\
\hline PKG39 & $-0.41 \%$ & $-0.06 \%$ & $-0.96 \%$ & -5.6 & $3 \%$ & $-7.11 \%$ & $-0.70 \%$ & $1.38 \%$ \\
\hline PKG40 & $-0.61 \%$ & $0.24 \%$ & $-0.77 \%$ & $-0.58 \%$ & $-1.68 \%$ & $-7.17 \%$ & $-0.59 \%$ & $-0.70 \%$ \\
\hline PKG41 & $-2.23 \%$ & $60 \%$ & $0.84 \%$ & $-0.54 \%$ & $-2.42 \%$ & $-4.60 \%$ & $-0.44 \%$ & $0.00 \%$ \\
\hline PKG42 & $-2.22 \%$ & $1.99 \%$ & $0.16 \%$ & $-2.98 \%$ & $-1.94 \%$ & $-0.11 \%$ & $-0.71 \%$ & $2.81 \%$ \\
\hline PKG43 & $-0.22 \%$ & $0.55 \%$ & $-1.12 \%$ & $-2.50 \%$ & $-1.88 \%$ & $2.66 \%$ & $-0.46 \%$ & $-1.11 \%$ \\
\hline PKG44 & $-1.98 \%$ & $2.37 \%$ & $-0.74 \%$ & $-6.73 \%$ & $-1.29 \%$ & $-2.02 \%$ & $0.41 \%$ & $2.49 \%$ \\
\hline PKG45 & $-1.26 \%$ & $1.32 \%$ & $0.71 \%$ & $-2.06 \%$ & $-1.94 \%$ & $1.56 \%$ & $0.39 \%$ & $2.93 \%$ \\
\hline PKG46 & $-2.01 \%$ & $-0.98 \%$ & $0.00 \%$ & $-3.03 \%$ & $-1.86 \%$ & $-1.32 \%$ & $-0.57 \%$ & $0.00 \%$ \\
\hline PKG47 & $-1.44 \%$ & $-0.36 \%$ & & & & $-1.15 \%$ & $0.00 \%$ & $0.23 \%$ \\
\hline PKG48 & $-2.06 \%$ & $3.45 \%$ & $-1.58 \%$ & $-2.71 \%$ & $-1.29 \%$ & $-1.52 \%$ & $-0.59 \%$ & $0.88 \%$ \\
\hline PKG49 & $-2.08 \%$ & $1.92 \%$ & $-1.41 \%$ & $-3.27 \%$ & $-0.57 \%$ & $1.36 \%$ & $0.63 \%$ & $2.74 \%$ \\
\hline PKG50 & $-1.02 \%$ & $1.12 \%$ & $0.77 \%$ & $-0.37 \%$ & $-1.17 \%$ & $1.40 \%$ & $-0.80 \%$ & $0.00 \%$ \\
\hline Mean & $-0.55 \%$ & $1.71 \%$ & $0.57 \%$ & $0.01 \%$ & $-0.39 \%$ & $2.20 \%$ & $0.56 \%$ & $2.21 \%$ \\
\hline SD & $1.52 \%$ & $1.87 \%$ & $1.76 \%$ & $3.69 \%$ & $1.56 \%$ & $5.63 \%$ & $1.73 \%$ & $2.80 \%$ \\
\hline Max & $2.73 \%$ & $5.78 \%$ & $7.65 \%$ & $10.84 \%$ & $4.66 \%$ & $18.60 \%$ & $5.12 \%$ & $9.44 \%$ \\
\hline Min & $-3.05 \%$ & $-3.25 \%$ & $-2.34 \%$ & $-7.53 \%$ & $-2.66 \%$ & $-7.17 \%$ & $-2.52 \%$ & $-4.51 \%$ \\
\hline Diff & $5.78 \%$ & $9.03 \%$ & $9.98 \%$ & $18.38 \%$ & $7.32 \%$ & $25.77 \%$ & $7.63 \%$ & $13.95 \%$ \\
\hline
\end{tabular}


Table C-2-2: TCB $238^{\text {th }}$ cycle; Daisy09 - Daisy16.

\begin{tabular}{|c|c|c|c|c|c|c|c|c|}
\hline & AISY09 & DAISY10 & DAISY11 & DAISY12 & $\overline{\text { DAISY13 }}$ & DAISY14 & DAISY15 & DAISY16 \\
\hline PKG01 & $4.02 \%$ & $1.71 \%$ & $1.23 \%$ & $0.29 \%$ & $-4.73 \%$ & $-0.45 \%$ & $3.21 \%$ & $0.56 \%$ \\
\hline PKG02 & $3.85 \%$ & $7.06 \%$ & $3.52 \%$ & $-1.34 \%$ & $0.50 \%$ & $3.99 \%$ & $5.35 \%$ & $4.98 \%$ \\
\hline PKG03 & $4.20 \%$ & $4.76 \%$ & $6.00 \%$ & $-3.12 \%$ & $1.16 \%$ & $-3.35 \%$ & $1.39 \%$ & $1.74 \%$ \\
\hline PKG04 & $2.09 \%$ & $7.41 \%$ & $6.21 \%$ & $-0.07 \%$ & $0.14 \%$ & $2.50 \%$ & $-0.65 \%$ & $-0.89 \%$ \\
\hline PKG05 & $1.79 \%$ & $7.52 \%$ & $2.62 \%$ & $1.22 \%$ & $0.07 \%$ & $-1.30 \%$ & $5.78 \%$ & $1.18 \%$ \\
\hline PKG06 & $0.87 \%$ & $7.01 \%$ & $2.00 \%$ & $-0.31 \%$ & $1.06 \%$ & $-1.67 \%$ & $0.13 \%$ & $0.47 \%$ \\
\hline PKG07 & $0.56 \%$ & $.18 \%$ & $0.76 \%$ & $-0.82 \%$ & $2.00 \%$ & $-4.34 \%$ & $7.74 \%$ & $0.56 \%$ \\
\hline PKG08 & $2.36 \%$ & $4.33 \%$ & $0.66 \%$ & $-2.00 \%$ & $0.38 \%$ & $-0.35 \%$ & $1.28 \%$ & $2.25 \%$ \\
\hline PKG09 & $0.56 \%$ & $1.29 \%$ & $1.71 \%$ & $1.01 \%$ & $-0.65 \%$ & $-3.26 \%$ & $3.03 \%$ & $0.62 \%$ \\
\hline PKG10 & $0.45 \%$ & $3.27 \%$ & $0.98 \%$ & $0.55 \%$ & $0.40 \%$ & $0.57 \%$ & $3.38 \%$ & $-0.58 \%$ \\
\hline PKG11 & $0.75 \%$ & $-0.83 \%$ & $0.92 \%$ & $1.65 \%$ & $0.60 \%$ & $1.05 \%$ & $4.31 \%$ & $1.21 \%$ \\
\hline PKG12 & $-0.36 \%$ & $-0.54 \%$ & $0.76 \%$ & $-1.36 \%$ & $-0.64 \%$ & $0.42 \%$ & $0.35 \%$ & $0.05 \%$ \\
\hline PKG13 & $67 \%$ & $0.30 \%$ & $1.19 \%$ & $-2.11 \%$ & $-1.57 \%$ & $-0.69 \%$ & $3.33 \%$ & $-0.06 \%$ \\
\hline PKG14 & $0 \%$ & $-1.69 \%$ & $-0.44 \%$ & $-1.19 \%$ & $0.25 \%$ & $1.68 \%$ & $-1.07 \%$ & $0.83 \%$ \\
\hline PKG15 & $0.24 \%$ & $-1.50 \%$ & $2.38 \%$ & $-1.99 \%$ & $-2.04 \%$ & $-1.68 \%$ & $-1.72 \%$ & $1.22 \%$ \\
\hline PKG16 & $1.30 \%$ & $1.12 \%$ & $3.56 \%$ & $-0.95 \%$ & $0.80 \%$ & $-1.72 \%$ & $3.56 \%$ & $0.84 \%$ \\
\hline PKG17 & $2.90 \%$ & $-0.14 \%$ & $2.67 \%$ & $-0.29 \%$ & $0.47 \%$ & $2.10 \%$ & $3.37 \%$ & $-0.05 \%$ \\
\hline PKG18 & $0.40 \%$ & $2.28 \%$ & $2.52 \%$ & $-2.92 \%$ & $1.48 \%$ & $1.04 \%$ & $3.61 \%$ & $0.88 \%$ \\
\hline PKG19 & $0 \%$ & $\%$ & & $-1.25 \%$ & $-2.65 \%$ & $-1.38 \%$ & $0.91 \%$ & $0.73 \%$ \\
\hline PKG20 & $3 \%$ & $\%$ & & $-1.66 \%$ & $-1.11 \%$ & $0.15 \%$ & $0.54 \%$ & $-0.38 \%$ \\
\hline PKG21 & $2 \%$ & $3.17 \%$ & $0.70 \%$ & $-2.82 \%$ & $-0.84 \%$ & $-1.59 \%$ & $2.19 \%$ & $-1.06 \%$ \\
\hline PKG22 & $2.50 \%$ & $3.16 \%$ & $1.72 \%$ & $-2.26 \%$ & $0.07 \%$ & $-0.15 \%$ & $2.13 \%$ & $-0.28 \%$ \\
\hline PKG23 & $1.73 \%$ & $6.62 \%$ & $0.78 \%$ & $-2.76 \%$ & $-0.67 \%$ & $-0.24 \%$ & $1.72 \%$ & $-1.02 \%$ \\
\hline PKG24 & $5.65 \%$ & $-0.38 \%$ & $3.17 \%$ & $-3.51 \%$ & $-0.72 \%$ & $0.23 \%$ & $1.54 \%$ & $-1.01 \%$ \\
\hline PKG25 & $90 \%$ & & & $0.28 \%$ & $-1.55 \%$ & $0.43 \%$ & $1.28 \%$ & $-1.03 \%$ \\
\hline PKG26 & -2 . & $\%$ & & $-1.00 \%$ & $-0.93 \%$ & $-1.69 \%$ & $0.86 \%$ & $-1.52 \%$ \\
\hline PKG27 & $\%$ & $\%$ & & $0.44 \%$ & $-1.79 \%$ & $-0.59 \%$ & $-0.12 \%$ & $-1.26 \%$ \\
\hline PKG28 & $-1.42 \%$ & $2.35 \%$ & $4 \%$ & $0.30 \%$ & $-0.73 \%$ & $4.21 \%$ & $0.00 \%$ & $-0.66 \%$ \\
\hline PKG29 & $-0.23 \%$ & $-1.93 \%$ & $1 \%$ & $-4.14 \%$ & $-0.34 \%$ & $1.75 \%$ & $-3.11 \%$ & $0.65 \%$ \\
\hline PKG30 & $92 \%$ & $4.62 \%$ & $4 \%$ & $-1.03 \%$ & $0.91 \%$ & $2.57 \%$ & $2.30 \%$ & $-0.11 \%$ \\
\hline PKG31 & $-0.70 \%$ & & & $-2.33 \%$ & $-1.92 \%$ & $-2.24 \%$ & $0.66 \%$ & $-0.61 \%$ \\
\hline PKG32 & $2 \%$ & $\%$ & & $-1.15 \%$ & $0.43 \%$ & $0.69 \%$ & $1.15 \%$ & $-0.19 \%$ \\
\hline PKG33 & $2 \%$ & & $\%$ & -0. & $-0.42 \%$ & $1.16 \%$ & $0.29 \%$ & $-0.43 \%$ \\
\hline PKG35 & $\%$ & $\%$ & $1 \%$ & $-6.40 \%$ & $-0.83 \%$ & $4.51 \%$ & $0.85 \%$ & $-0.84 \%$ \\
\hline PKG36 & $1 \%$ & & & $-0.99 \%$ & $-1.61 \%$ & $-0.70 \%$ & $0.45 \%$ & $-1.23 \%$ \\
\hline PKG37 & $4 \%$ & $5 \%$ & $7 \%$ & $-0.87 \%$ & $3.27 \%$ & $-0.83 \%$ & $-1.56 \%$ & $-2.53 \%$ \\
\hline PKG38 & $07 \%$ & $-1.73 \%$ & $\overline{8 \%}$ & $-1.22 \%$ & $1.35 \%$ & $-1.63 \%$ & $-1.15 \%$ & $-1.26 \%$ \\
\hline PKG39 & $5 \%$ & $1.72 \%$ & $0 \%$ & $-5.78 \%$ & $2.36 \%$ & $-0.37 \%$ & $1.68 \%$ & $-0.82 \%$ \\
\hline PKG40 & $8 \%$ & $\%$ & $-0.27 \%$ & $-4.97 \%$ & $1.67 \%$ & $-1.12 \%$ & $0.71 \%$ & $-1.16 \%$ \\
\hline PKG41 & $\%$ & $\%$ & & $-2.24 \%$ & $0.20 \%$ & $-3.81 \%$ & $2.20 \%$ & $-1.78 \%$ \\
\hline PKG42 & $\%$ & $\%$ & & $4 \%$ & $-0.76 \%$ & $-2.91 \%$ & $-2.90 \%$ & $-2.90 \%$ \\
\hline PKG43 & $8 \%$ & & $7 \%$ & $-0.07 \%$ & $-1.40 \%$ & $-4.69 \%$ & $-0.82 \%$ & $-2.43 \%$ \\
\hline PKG44 & $0.32 \%$ & $06 \%$ & $-0.97 \%$ & $0.91 \%$ & $0.21 \%$ & $-4.62 \%$ & $-0.67 \%$ & $-0.84 \%$ \\
\hline PKG45 & $5 \%$ & $36 \%$ & $1 \%$ & $0.07 \%$ & $-0.81 \%$ & $-1.41 \%$ & $-1.83 \%$ & $-1.92 \%$ \\
\hline PKG46 & & & $4 \%$ & $-2.58 \%$ & $-0.90 \%$ & $-0.97 \%$ & $-1.67 \%$ & $-1.39 \%$ \\
\hline PKG47 & $0.92 \%$ & $\%$ & & $1.41 \%$ & $0.00 \%$ & $1.27 \%$ & $-6.08 \%$ & $-0.68 \%$ \\
\hline PKG48 & & & & & $-0.86 \%$ & $1.54 \%$ & $0.00 \%$ & $-0.17 \%$ \\
\hline PKG49 & $7 \%$ & & & & $-0.50 \%$ & $-1.46 \%$ & $-3.71 \%$ & $-0.74 \%$ \\
\hline PKG50 & $0.07 \%$ & & & $-1.38 \%$ & $-0.20 \%$ & $1.05 \%$ & $-4.02 \%$ & $-3.14 \%$ \\
\hline Mean & $0.63 \%$ & $2.11 \%$ & $53 \%$ & $-1.30 \%$ & $-0.23 \%$ & $-0.44 \%$ & $0.82 \%$ & $-0.33 \%$ \\
\hline SD & $2.09 \%$ & $2.81 \%$ & $1.81 \%$ & $1.74 \%$ & $1.36 \%$ & $2.13 \%$ & $2.60 \%$ & $1.40 \%$ \\
\hline Max & $5.65 \%$ & $7.52 \%$ & $6.96 \%$ & $1.65 \%$ & $3.27 \%$ & $4.51 \%$ & $7.74 \%$ & $4.98 \%$ \\
\hline Min & $-5.07 \%$ & $-2.69 \%$ & $-0.97 \%$ & $-6.40 \%$ & $-4.73 \%$ & $-4.69 \%$ & $-6.08 \%$ & $-3.14 \%$ \\
\hline Diff & $10.72 \%$ & $10.21 \%$ & $7.93 \%$ & $8.05 \%$ & $8.00 \%$ & $9.20 \%$ & $13.82 \%$ & $8.12 \%$ \\
\hline
\end{tabular}


Table C-2-3: TCB $457^{\text {th }}$ cycle; Daisy01 - Daisy08.

\begin{tabular}{|c|c|c|c|c|c|c|c|c|}
\hline & DAISY01 & DAISY02 & DAISY03 & DAISY04 & DAISY05 & DAISY06 & DAISY07 & DAISY08 \\
\hline PKG01 & $1.66 \%$ & $3.04 \%$ & $2.39 \%$ & $-0.30 \%$ & $1.18 \%$ & $3.50 \%$ & $2.75 \%$ & $1.66 \%$ \\
\hline PKG02 & $2.62 \%$ & $8.75 \%$ & $4.14 \%$ & outliner & $2.49 \%$ & $5.78 \%$ & $2.40 \%$ & $4.99 \%$ \\
\hline PKG03 & $0.16 \%$ & $7.38 \%$ & $3.14 \%$ & $6.65 \%$ & $1.38 \%$ & $5.05 \%$ & $2.49 \%$ & $4.87 \%$ \\
\hline PKG04 & $1.38 \%$ & $6.30 \%$ & $2.55 \%$ & $8.32 \%$ & $1.54 \%$ & $5.73 \%$ & $-0.32 \%$ & $3.54 \%$ \\
\hline PKG05 & $3.42 \%$ & $6.38 \%$ & $1.42 \%$ & $9.70 \%$ & $1.40 \%$ & $3.79 \%$ & $1.02 \%$ & $7.38 \%$ \\
\hline PKG06 & $2.41 \%$ & $5.60 \%$ & $3.20 \%$ & $9.19 \%$ & $0.67 \%$ & $11.40 \%$ & $2.98 \%$ & $6.70 \%$ \\
\hline PKG07 & $-0.02 \%$ & $7.39 \%$ & $2.85 \%$ & $7.36 \%$ & $1.19 \%$ & $5.59 \%$ & $2.99 \%$ & $2.26 \%$ \\
\hline PKG08 & $-0.84 \%$ & $2.50 \%$ & $2.08 \%$ & $3.86 \%$ & $-0.79 \%$ & $7.03 \%$ & $1.41 \%$ & $0.33 \%$ \\
\hline PKG09 & $1.59 \%$ & $6.94 \%$ & $2.71 \%$ & $4.30 \%$ & $-0.39 \%$ & $12.06 \%$ & $2.54 \%$ & $3.99 \%$ \\
\hline PKG10 & $2.17 \%$ & $2.57 \%$ & $1.63 \%$ & $3.00 \%$ & $0.94 \%$ & $4.92 \%$ & $2.51 \%$ & $-0.94 \%$ \\
\hline PKG11 & $1.23 \%$ & $2.42 \%$ & $1.21 \%$ & $2.30 \%$ & $-1.30 \%$ & $4.34 \%$ & $2.32 \%$ & $-1.21 \%$ \\
\hline PKG12 & $-0.02 \%$ & $5.99 \%$ & $0.77 \%$ & $2.78 \%$ & $0.14 \%$ & $4.25 \%$ & $1.61 \%$ & $2.20 \%$ \\
\hline PKG13 & $0.58 \%$ & $4.70 \%$ & $0.00 \%$ & $4.80 \%$ & $-1.78 \%$ & $6.44 \%$ & $1.73 \%$ & $-0.85 \%$ \\
\hline PKG14 & $-0.11 \%$ & $5.31 \%$ & $2.68 \%$ & $2.50 \%$ & $-0.41 \%$ & $3.26 \%$ & $0.96 \%$ & $-0.40 \%$ \\
\hline PKG15 & $1.77 \%$ & $2.79 \%$ & $2.14 \%$ & $3.12 \%$ & $0.63 \%$ & $2.93 \%$ & $3.02 \%$ & $-0.39 \%$ \\
\hline PKG16 & $3.68 \%$ & $2.74 \%$ & $1.52 \%$ & $4.45 \%$ & $-0.72 \%$ & $1.76 \%$ & $2.11 \%$ & $2.51 \%$ \\
\hline PKG17 & $-0.12 \%$ & $3.88 \%$ & $-0.55 \%$ & $3.10 \%$ & $0.15 \%$ & $1.30 \%$ & $1.58 \%$ & $-3.09 \%$ \\
\hline PKG18 & $0.56 \%$ & $3.53 \%$ & $3.19 \%$ & $3.11 \%$ & $2.41 \%$ & $3.29 \%$ & $1.03 \%$ & $-1.91 \%$ \\
\hline PKG19 & $0.28 \%$ & $3.10 \%$ & $2.70 \%$ & $0.91 \%$ & $-0.40 \%$ & $3.58 \%$ & $2.20 \%$ & $1.57 \%$ \\
\hline PKG20 & $-0.81 \%$ & $1.38 \%$ & $1.54 \%$ & $0.10 \%$ & $2.03 \%$ & $-1.50 \%$ & $1.49 \%$ & $2.35 \%$ \\
\hline PKG21 & $-0.12 \%$ & $2.35 \%$ & $0.16 \%$ & $1.56 \%$ & $-0.54 \%$ & $3.57 \%$ & $0.79 \%$ & $-4.81 \%$ \\
\hline PKG22 & $-2.02 \%$ & $-1.63 \%$ & $0.47 \%$ & $0.83 \%$ & $0.72 \%$ & $1.31 \%$ & $1.68 \%$ & $0.70 \%$ \\
\hline PKG23 & $0.08 \%$ & $2.92 \%$ & $0.73 \%$ & $1.27 \%$ & $-0.60 \%$ & $2.95 \%$ & $3.13 \%$ & $1.67 \%$ \\
\hline PKG24 & $-0.23 \%$ & $2.48 \%$ & $0.60 \%$ & $-1.05 \%$ & $-0.25 \%$ & $2.59 \%$ & $-0.35 \%$ & $-3.30 \%$ \\
\hline PKG25 & $-0.22 \%$ & $1.31 \%$ & $1.86 \%$ & $4.10 \%$ & $0.71 \%$ & $1.16 \%$ & $1.32 \%$ & $-5.95 \%$ \\
\hline PKG26 & $0.85 \%$ & $2.96 \%$ & $-0.23 \%$ & $3.92 \%$ & $-1.09 \%$ & $1.53 \%$ & $-0.44 \%$ & $-1.22 \%$ \\
\hline PKG27 & $0.55 \%$ & $1.88 \%$ & $0.32 \%$ & $1.44 \%$ & $-0.96 \%$ & $2.11 \%$ & $-0.32 \%$ & $4.19 \%$ \\
\hline PKG28 & $-0.03 \%$ & $1.58 \%$ & $-0.16 \%$ & $0.38 \%$ & $-0.82 \%$ & $5.14 \%$ & $0.53 \%$ & $-3.11 \%$ \\
\hline PKG29 & $1.79 \%$ & $-0.15 \%$ & $0.23 \%$ & $1.17 \%$ & $-0.08 \%$ & $2.09 \%$ & $1.44 \%$ & $0.95 \%$ \\
\hline PKG30 & $0.57 \%$ & $-1.45 \%$ & $0.49 \%$ & $0.70 \%$ & $0.57 \%$ & $1.31 \%$ & $-0.13 \%$ & $1.98 \%$ \\
\hline PKG31 & $-1.38 \%$ & $0.72 \%$ & $-1.96 \%$ & $-4.48 \%$ & $0.18 \%$ & $0.25 \%$ & $2.75 \%$ & $-0.25 \%$ \\
\hline PKG32 & $-0.91 \%$ & $-0.26 \%$ & $0.00 \%$ & $-7.92 \%$ & $0.58 \%$ & $2.63 \%$ & $0.95 \%$ & $1.34 \%$ \\
\hline PKG33 & $-1.97 \%$ & $2.88 \%$ & $0.00 \%$ & $0.09 \%$ & $-0.62 \%$ & $-1.33 \%$ & $0.90 \%$ & $0.36 \%$ \\
\hline PKG35 & $-0.21 \%$ & $1.14 \%$ & $-2.16 \%$ & $-0.60 \%$ & $0.47 \%$ & $-1.93 \%$ & $1.57 \%$ & $1.19 \%$ \\
\hline PKG36 & $0.53 \%$ & $3.18 \%$ & $0.67 \%$ & $-2.53 \%$ & $-1.12 \%$ & $-0.33 \%$ & $1.12 \%$ & $2.39 \%$ \\
\hline PKG37 & $0.73 \%$ & $1.63 \%$ & $-0.55 \%$ & $0.00 \%$ & $-0.77 \%$ & $2.31 \%$ & $-0.19 \%$ & $-4.29 \%$ \\
\hline PKG38 & $-0.84 \%$ & $1.29 \%$ & $-1.55 \%$ & $-3.41 \%$ & $-0.30 \%$ & $-5.72 \%$ & $0.64 \%$ & $-2.99 \%$ \\
\hline PKG39 & $0.95 \%$ & $0.95 \%$ & $0.72 \%$ & $-3.03 \%$ & $-0.16 \%$ & $-6.34 \%$ & $0.64 \%$ & $-3.57 \%$ \\
\hline PKG40 & $-0.22 \%$ & $1.56 \%$ & $-1.32 \%$ & $3 \%$ & $-0.40 \%$ & $-6.49 \%$ & $1.70 \%$ & $0.23 \%$ \\
\hline PKG41 & $-1.31 \%$ & $3.51 \%$ & $-0.23 \%$ & $4.31 \%$ & $-1.47 \%$ & $-5.32 \%$ & $4.66 \%$ & $-2.57 \%$ \\
\hline PKG42 & $-1.07 \%$ & $4.15 \%$ & $-0.16 \%$ & $-0.56 \%$ & $-0.08 \%$ & $0.81 \%$ & $4.75 \%$ & $-1.62 \%$ \\
\hline PKG43 & $0.47 \%$ & $0.65 \%$ & $1.12 \%$ & $0.29 \%$ & $-1.57 \%$ & $3.26 \%$ & $6.34 \%$ & $-3.24 \%$ \\
\hline PKG44 & $-2.18 \%$ & $4.59 \%$ & $0.00 \%$ & $-3.60 \%$ & $-0.48 \%$ & $0.83 \%$ & $1.02 \%$ & $-1.20 \%$ \\
\hline PKG45 & $0.17 \%$ & $2.40 \%$ & $1.02 \%$ & $-2.15 \%$ & $-1.32 \%$ & $3.72 \%$ & $2.26 \%$ & $-1.77 \%$ \\
\hline PKG46 & $-1.56 \%$ & $1.24 \%$ & $1.36 \%$ & $-1.99 \%$ & $-0.82 \%$ & $0.11 \%$ & $0.31 \%$ & $0.00 \%$ \\
\hline PKG47 & $1.18 \%$ & $1.06 \%$ & $-0.97 \%$ & $0.88 \%$ & $-1.29 \%$ & $1.38 \%$ & $0.66 \%$ & $-1.37 \%$ \\
\hline PKG48 & $-0.74 \%$ & $4.11 \%$ & $-0.63 \%$ & $-0.39 \%$ & $-0.77 \%$ & $1.39 \%$ & $0.73 \%$ & $-1.51 \%$ \\
\hline PKG49 & $-1.40 \%$ & $2.76 \%$ & $-1.16 \%$ & $-4.36 \%$ & $0.82 \%$ & $1.48 \%$ & $1.61 \%$ & $-1.37 \%$ \\
\hline PKG50 & $-0.75 \%$ & $2.01 \%$ & $-0.08 \%$ & $1.30 \%$ & $0.88 \%$ & $1.52 \%$ & $0.55 \%$ & $-3.02 \%$ \\
\hline Mean & $0.25 \%$ & $2.95 \%$ & $0.81 \%$ & $1.40 \%$ & $0.00 \%$ & $2.25 \%$ & $1.62 \%$ & $0.07 \%$ \\
\hline SD & $1.34 \%$ & $2.26 \%$ & $1.47 \%$ & $3.59 \%$ & $1.04 \%$ & $3.66 \%$ & $1.37 \%$ & $2.94 \%$ \\
\hline Max & $3.68 \%$ & $8.75 \%$ & $4.14 \%$ & $9.70 \%$ & $2.49 \%$ & $12.06 \%$ & $6.34 \%$ & $7.38 \%$ \\
\hline Min & $-2.18 \%$ & $-1.63 \%$ & $-2.16 \%$ & $-7.92 \%$ & $-1.78 \%$ & $-6.49 \%$ & $-0.44 \%$ & $-5.95 \%$ \\
\hline Diff & $5.86 \%$ & $10.38 \%$ & $6.30 \%$ & $17.61 \%$ & $4.27 \%$ & $18.55 \%$ & $6.78 \%$ & $13.34 \%$ \\
\hline
\end{tabular}


Table C-2-4: TCB $457^{\text {th }}$ cycle; Daisy09 - Daisy16.

\begin{tabular}{|c|c|c|c|c|c|c|c|c|}
\hline & DAISY09 & DAISY10 & DAISY11 & DAISY12 & DAISY13 & DAISY14 & DAISY15 & DAISY16 \\
\hline PKG01 & $1.77 \%$ & $2.01 \%$ & $1.29 \%$ & $1.54 \%$ & $-3.04 \%$ & $-0.52 \%$ & $5.99 \%$ & $1.34 \%$ \\
\hline PKG02 & $3.77 \%$ & $10.36 \%$ & $-0.26 \%$ & $-0.35 \%$ & $3.67 \%$ & $2.46 \%$ & $5.10 \%$ & $2.29 \%$ \\
\hline PKG03 & $2.24 \%$ & $6.07 \%$ & $3.30 \%$ & $-2.15 \%$ & $2.32 \%$ & $-1.21 \%$ & $3.99 \%$ & $1.63 \%$ \\
\hline PKG04 & $3.95 \%$ & $10.15 \%$ & $2.09 \%$ & $2.08 \%$ & $2.35 \%$ & $1.32 \%$ & $0.59 \%$ & $-0.72 \%$ \\
\hline PKG05 & $4.55 \%$ & $10.79 \%$ & $2.09 \%$ & $1.65 \%$ & $0.98 \%$ & $1.07 \%$ & $2.83 \%$ & $2.20 \%$ \\
\hline PKG06 & $4.37 \%$ & $9.35 \%$ & $2.14 \%$ & $-0.31 \%$ & $1.67 \%$ & $-0.24 \%$ & $0.64 \%$ & $1.18 \%$ \\
\hline PKG07 & $2.48 \%$ & $1.83 \%$ & $-0.63 \%$ & $0.52 \%$ & $3.00 \%$ & $-3.46 \%$ & $1.05 \%$ & $0.00 \%$ \\
\hline PKG08 & $4.29 \%$ & $1.42 \%$ & $0.24 \%$ & $-1.36 \%$ & $0.26 \%$ & $1.66 \%$ & $0.48 \%$ & $0.68 \%$ \\
\hline PKG09 & $1.69 \%$ & $2.04 \%$ & $1.50 \%$ & $-0.50 \%$ & $0.29 \%$ & $-2.12 \%$ & $2.66 \%$ & $0.28 \%$ \\
\hline PKG10 & $4.24 \%$ & $5.19 \%$ & $1.37 \%$ & $-0.55 \%$ & $1.52 \%$ & $-0.71 \%$ & $1.84 \%$ & $0.77 \%$ \\
\hline PKG11 & $3.38 \%$ & $-0.21 \%$ & $2.82 \%$ & $1.27 \%$ & $0.33 \%$ & $-0.91 \%$ & $3.89 \%$ & $1.72 \%$ \\
\hline PKG12 & $0.93 \%$ & $2.42 \%$ & $4.58 \%$ & $-0.61 \%$ & $-0.84 \%$ & $0.56 \%$ & $1.38 \%$ & $1.73 \%$ \\
\hline PKG13 & $4.38 \%$ & $5.34 \%$ & $4.60 \%$ & $1.53 \%$ & $-2.35 \%$ & $-0.61 \%$ & $4.32 \%$ & $0.73 \%$ \\
\hline PKG14 & $0.29 \%$ & $3.25 \%$ & $3.74 \%$ & $-0.79 \%$ & $-0.19 \%$ & $1.33 \%$ & $0.69 \%$ & $2.43 \%$ \\
\hline PKG15 & $-0.32 \%$ & $4.27 \%$ & $0.07 \%$ & $-3.20 \%$ & $-0.63 \%$ & $-0.76 \%$ & $0.71 \%$ & $1.10 \%$ \\
\hline PKG16 & $-0.21 \%$ & $3.41 \%$ & $0.58 \%$ & $0.70 \%$ & $1.49 \%$ & $-2.32 \%$ & $-0.41 \%$ & $1.03 \%$ \\
\hline PKG17 & $3.51 \%$ & $-0.07 \%$ & $5.54 \%$ & $-0.07 \%$ & $0.07 \%$ & $1.60 \%$ & $2.90 \%$ & $1.47 \%$ \\
\hline PKG18 & $1.27 \%$ & $3.53 \%$ & $2.45 \%$ & $-2.92 \%$ & $1.41 \%$ & $0.89 \%$ & $4.70 \%$ & $2.25 \%$ \\
\hline PKG19 & $-0.40 \%$ & $2.76 \%$ & $1.95 \%$ & $1.25 \%$ & $-2.09 \%$ & $1.30 \%$ & $2.19 \%$ & $3.04 \%$ \\
\hline PKG20 & $1.17 \%$ & $9.69 \%$ & $2.11 \%$ & $-1.73 \%$ & $-1.46 \%$ & $1.95 \%$ & $2.10 \%$ & $-0.05 \%$ \\
\hline PKG21 & $1.61 \%$ & $4.28 \%$ & $0.84 \%$ & $-3.26 \%$ & $-1.74 \%$ & $-0.23 \%$ & $1.83 \%$ & $0.73 \%$ \\
\hline PKG22 & $1.88 \%$ & $4.78 \%$ & $-0.14 \%$ & $-3.53 \%$ & $-1.78 \%$ & $2.80 \%$ & $6.91 \%$ & $1.06 \%$ \\
\hline PKG23 & $4.07 \%$ & $7.43 \%$ & $0.07 \%$ & $-4.44 \%$ & $0.22 \%$ & $0.71 \%$ & $2.02 \%$ & $0.23 \%$ \\
\hline PKG24 & $1.16 \%$ & $5.74 \%$ & $2.14 \%$ & $-3.73 \%$ & $-0.87 \%$ & $1.23 \%$ & $3.08 \%$ & $0.18 \%$ \\
\hline PKG25 & $1.83 \%$ & $2.78 \%$ & $0.88 \%$ & $-2.69 \%$ & $0.07 \%$ & $0.51 \%$ & $3.26 \%$ & $0.75 \%$ \\
\hline PKG26 & $-1.62 \%$ & $3.81 \%$ & $1.58 \%$ & $-1.36 \%$ & $-0.93 \%$ & $-1.97 \%$ & $2.83 \%$ & $-0.65 \%$ \\
\hline PKG27 & $1.45 \%$ & $7.08 \%$ & $1.76 \%$ & $-1.38 \%$ & $-0.82 \%$ & $0.44 \%$ & $0.71 \%$ & $0.49 \%$ \\
\hline PKG28 & $1.08 \%$ & $6.03 \%$ & $0.91 \%$ & $-1.56 \%$ & $-1.17 \%$ & $3.32 \%$ & $1.45 \%$ & $0.23 \%$ \\
\hline PKG29 & $1.14 \%$ & $4.87 \%$ & $1.87 \%$ & $-3.94 \%$ & $0.13 \%$ & $1.24 \%$ & $0.17 \%$ & $3.11 \%$ \\
\hline PKG30 & $-1.08 \%$ & $2.93 \%$ & $1.56 \%$ & $-3.37 \%$ & $0.35 \%$ & $2.49 \%$ & $2.78 \%$ & $1.65 \%$ \\
\hline PKG31 & $1.57 \%$ & $1.01 \%$ & $0.67 \%$ & $-3.49 \%$ & $-1.31 \%$ & $-1.52 \%$ & $4.31 \%$ & $2.82 \%$ \\
\hline PKG32 & $5.37 \%$ & $0.96 \%$ & $0.07 \%$ & $-1.38 \%$ & $0.29 \%$ & $1.69 \%$ & $2.49 \%$ & $2.86 \%$ \\
\hline PKG33 & $1.92 \%$ & $3.39 \%$ & $1.32 \%$ & $-0.78 \%$ & $-1.47 \%$ & $3.56 \%$ & $2.49 \%$ & $2.59 \%$ \\
\hline PKG35 & $-0.92 \%$ & $7.47 \%$ & $3.58 \%$ & $-5.41 \%$ & $-1.10 \%$ & $0.90 \%$ & $1.28 \%$ & $0.29 \%$ \\
\hline PKG36 & $1.60 \%$ & $8.09 \%$ & $2.10 \%$ & $-0.99 \%$ & $-0.90 \%$ & $1.05 \%$ & $0.86 \%$ & $1.29 \%$ \\
\hline PKG37 & $1.26 \%$ & $4.24 \%$ & $1.14 \%$ & $-0.80 \%$ & $-0.14 \%$ & $0.60 \%$ & $0.99 \%$ & $0.68 \%$ \\
\hline PKG38 & $-3.15 \%$ & $-1.26 \%$ & $3.20 \%$ & $-1.08 \%$ & $-0.13 \%$ & $0.27 \%$ & $1.27 \%$ & $1.69 \%$ \\
\hline PKG39 & $2.92 \%$ & $4.88 \%$ & $0.94 \%$ & $-5.37 \%$ & $-0.21 \%$ & $0.15 \%$ & $3.23 \%$ & $2.51 \%$ \\
\hline PKG40 & $1.35 \%$ & $5.89 \%$ & $5.00 \%$ & $-5.32 \%$ & $-0.14 \%$ & $1.19 \%$ & $1.41 \%$ & $1.71 \%$ \\
\hline PKG41 & $0.91 \%$ & $4.63 \%$ & $2.76 \%$ & $-2.92 \%$ & $0.07 \%$ & $-3.24 \%$ & $0.18 \%$ & $2.29 \%$ \\
\hline PKG42 & $-0.61 \%$ & $0.07 \%$ & $3.61 \%$ & $-0.50 \%$ & $-0.76 \%$ & $-1.96 \%$ & $-2.00 \%$ & $-1.48 \%$ \\
\hline PKG43 & $0.32 \%$ & $2.85 \%$ & $5.60 \%$ & $-0.65 \%$ & $-1.61 \%$ & $-3.08 \%$ & $1.83 \%$ & $-0.48 \%$ \\
\hline PKG44 & $1.04 \%$ & $2.44 \%$ & $-0.14 \%$ & $1.14 \%$ & $0.28 \%$ & $-3.96 \%$ & $0.98 \%$ & $-0.39 \%$ \\
\hline PKG45 & $0.83 \%$ & $4.87 \%$ & $0.14 \%$ & $-1.17 \%$ & $-0.94 \%$ & $-1.55 \%$ & $-1.14 \%$ & $-1.53 \%$ \\
\hline PKG46 & $-0.15 \%$ & $6.74 \%$ & $0.32 \%$ & $-3.33 \%$ & $-1.22 \%$ & $-1.39 \%$ & $0.00 \%$ & $-0.97 \%$ \\
\hline PKG47 & $5.34 \%$ & $6.70 \%$ & $0.95 \%$ & $-0.52 \%$ & $-0.88 \%$ & $0.55 \%$ & $-3.82 \%$ & $-0.46 \%$ \\
\hline PKG48 & $5.67 \%$ & $2.69 \%$ & $0.63 \%$ & $0.00 \%$ & $-0.86 \%$ & $-1.00 \%$ & $0.86 \%$ & $-0.77 \%$ \\
\hline PKG49 & $6.41 \%$ & $-0.66 \%$ & $0.66 \%$ & $-1.16 \%$ & $-0.71 \%$ & $-0.69 \%$ & $-1.86 \%$ & $-1.94 \%$ \\
\hline PKG50 & $1.47 \%$ & $2.51 \%$ & $0.26 \%$ & $-1.80 \%$ & $-0.46 \%$ & $-1.62 \%$ & $-3.63 \%$ & $-2.43 \%$ \\
\hline Mean & $1.88 \%$ & $4.30 \%$ & $1.75 \%$ & $-1.40 \%$ & $-0.20 \%$ & $0.04 \%$ & $1.68 \%$ & $0.84 \%$ \\
\hline SD & $2.04 \%$ & $2.96 \%$ & $1.57 \%$ & $1.92 \%$ & $1.36 \%$ & $1.78 \%$ & $2.14 \%$ & $1.36 \%$ \\
\hline Max & $6.41 \%$ & $10.79 \%$ & $5.60 \%$ & $2.08 \%$ & $3.67 \%$ & $3.56 \%$ & $6.91 \%$ & $3.11 \%$ \\
\hline Min & $-3.15 \%$ & $-1.26 \%$ & $-0.63 \%$ & $-5.41 \%$ & $-3.04 \%$ & $-3.96 \%$ & $-3.82 \%$ & $-2.43 \%$ \\
\hline Diff & $9.56 \%$ & $12.05 \%$ & $6.23 \%$ & $7.49 \%$ & $6.71 \%$ & $7.52 \%$ & $10.73 \%$ & $5.54 \%$ \\
\hline
\end{tabular}


Table C-2-5: TCB $643^{\text {rd }}$ cycle; Daisy01 - Daisy08.

\begin{tabular}{|c|c|c|c|c|c|c|c|c|}
\hline & DAISY01 & DAISY02 & DAISY03 & DAISY04 & DAISY05 & DAISY06 & DAISY07 & DAISY08 \\
\hline PKG01 & $-1.31 \%$ & $1.18 \%$ & $0.99 \%$ & $1.28 \%$ & $0.08 \%$ & $0.58 \%$ & $0.87 \%$ & $-0.63 \%$ \\
\hline PKG02 & $1.34 \%$ & $5.37 \%$ & $0.16 \%$ & $4.45 \%$ & $-0.86 \%$ & $2.60 \%$ & $0.82 \%$ & $0.45 \%$ \\
\hline PKG03 & $1.78 \%$ & $4.17 \%$ & $-0.46 \%$ & $1.66 \%$ & $-0.80 \%$ & $2.85 \%$ & $1.80 \%$ & $0.36 \%$ \\
\hline PKG04 & $0.28 \%$ & $4.74 \%$ & $1.32 \%$ & $2.22 \%$ & $-1.62 \%$ & $1.59 \%$ & $-2.48 \%$ & $-1.89 \%$ \\
\hline PKG05 & $0.57 \%$ & $2.42 \%$ & $-0.08 \%$ & $3.49 \%$ & $-0.85 \%$ & $2.30 \%$ & $-0.32 \%$ & $-1.94 \%$ \\
\hline PKG06 & $0.82 \%$ & $2.71 \%$ & $0.17 \%$ & $2.16 \%$ & $-1.18 \%$ & $4.85 \%$ & $0.07 \%$ & $0.17 \%$ \\
\hline PKG07 & $2.73 \%$ & $3.77 \%$ & $1.01 \%$ & $1.41 \%$ & $2.13 \%$ & $3.45 \%$ & $0.88 \%$ & $-0.81 \%$ \\
\hline PKG08 & $2.15 \%$ & $1.75 \%$ & $0.30 \%$ & $0.26 \%$ & $-1.94 \%$ & $1.79 \%$ & $-0.17 \%$ & $-0.99 \%$ \\
\hline PKG09 & $1.78 \%$ & $3.13 \%$ & $1.07 \%$ & $-0.29 \%$ & $0.79 \%$ & $5.17 \%$ & $0.33 \%$ & $0.23 \%$ \\
\hline PKG10 & $1.63 \%$ & $0.98 \%$ & $0.00 \%$ & $-0.27 \%$ & $0.94 \%$ & $3.69 \%$ & $-0.13 \%$ & $-2.09 \%$ \\
\hline PKG11 & $2.67 \%$ & $2.52 \%$ & $0.73 \%$ & $-0.19 \%$ & $-1.30 \%$ & $1.93 \%$ & $-0.53 \%$ & $-1.53 \%$ \\
\hline PKG12 & $0.43 \%$ & $2.97 \%$ & $-0.70 \%$ & $0.72 \%$ & $-0.78 \%$ & $-1.17 \%$ & $-1.05 \%$ & $-0.85 \%$ \\
\hline PKG13 & $2.60 \%$ & $1.74 \%$ & $-0.66 \%$ & $0.41 \%$ & $-0.97 \%$ & $3.96 \%$ & $0.53 \%$ & $-2.24 \%$ \\
\hline PKG14 & $-0.62 \%$ & $1.88 \%$ & $1.34 \%$ & $0.50 \%$ & $1.30 \%$ & $1.68 \%$ & $-0.47 \%$ & $-0.40 \%$ \\
\hline PKG15 & $1.77 \%$ & $2.47 \%$ & $0.33 \%$ & $-0.91 \%$ & $0.23 \%$ & $1.22 \%$ & $0.87 \%$ & $-2.28 \%$ \\
\hline PKG16 & $3.34 \%$ & $0.80 \%$ & $1.08 \%$ & $-0.24 \%$ & $-0.91 \%$ & $2.34 \%$ & $0.57 \%$ & $-0.69 \%$ \\
\hline PKG17 & $1.00 \%$ & $1.29 \%$ & $-1.10 \%$ & $1.69 \%$ & $2.29 \%$ & $-0.87 \%$ & $0.44 \%$ & $-5.12 \%$ \\
\hline PKG18 & $0.46 \%$ & $2.09 \%$ & $-0.40 \%$ & $1.94 \%$ & $1.55 \%$ & $2.70 \%$ & $-0.07 \%$ & $-2.27 \%$ \\
\hline PKG19 & $-0.43 \%$ & $4.36 \%$ & $0.08 \%$ & $0.30 \%$ & $2.02 \%$ & $3.46 \%$ & $1.00 \%$ & $-1.50 \%$ \\
\hline PKG20 & $0.66 \%$ & $2.40 \%$ & $0.08 \%$ & $1.64 \%$ & $2.68 \%$ & $0.70 \%$ & $0.39 \%$ & $-1.06 \%$ \\
\hline PKG21 & $0.65 \%$ & $0.65 \%$ & $-1.99 \%$ & $-0.68 \%$ & $0.93 \%$ & $2.26 \%$ & $0.92 \%$ & $-7.21 \%$ \\
\hline PKG22 & $-0.88 \%$ & $-2.90 \%$ & $-0.32 \%$ & $-1.21 \%$ & $1.76 \%$ & $1.07 \%$ & $0.78 \%$ & $-1.08 \%$ \\
\hline PKG23 & $2.51 \%$ & $0.82 \%$ & $-0.98 \%$ & $-2.06 \%$ & $1.72 \%$ & $2.69 \%$ & $2.25 \%$ & $1.33 \%$ \\
\hline PKG24 & $1.71 \%$ & $0.15 \%$ & $-1.20 \%$ & $-1.89 \%$ & $0.41 \%$ & $1.61 \%$ & $-0.42 \%$ & $-3.80 \%$ \\
\hline PKG25 & $1.22 \%$ & $1.80 \%$ & $0.54 \%$ & $0.00 \%$ & $0.24 \%$ & $1.51 \%$ & $0.50 \%$ & $-6.65 \%$ \\
\hline PKG26 & $2.59 \%$ & $0.92 \%$ & $-0.70 \%$ & $0.65 \%$ & $-1.88 \%$ & $1.06 \%$ & $-0.88 \%$ & $-0.91 \%$ \\
\hline PKG27 & $0.17 \%$ & $1.17 \%$ & $-0.48 \%$ & $2.21 \%$ & $-0.64 \%$ & $1.24 \%$ & $-1.61 \%$ & $0.08 \%$ \\
\hline PKG28 & $1.38 \%$ & $1.58 \%$ & $-1.28 \%$ & $-0.29 \%$ & $-1.48 \%$ & $0.12 \%$ & $-0.07 \%$ & $-4.02 \%$ \\
\hline PKG29 & $2.27 \%$ & $0.62 \%$ & $-0.76 \%$ & $1.17 \%$ & $0.47 \%$ & $-0.23 \%$ & $1.25 \%$ & $-2.12 \%$ \\
\hline PKG30 & $3.83 \%$ & $-0.86 \%$ & $-0.97 \%$ & $1.09 \%$ & $0.49 \%$ & $-0.60 \%$ & $-0.98 \%$ & $0.25 \%$ \\
\hline PKG31 & $0.49 \%$ & $1.28 \%$ & $-1.45 \%$ & $-4.06 \%$ & $0.70 \%$ & $0.50 \%$ & $1.62 \%$ & $-3.68 \%$ \\
\hline PKG32 & $0.86 \%$ & $-0.56 \%$ & $-2.22 \%$ & $-6.68 \%$ & $0.41 \%$ & $3.38 \%$ & $0.20 \%$ & $-0.08 \%$ \\
\hline PKG33 & $-2.35 \%$ & $4.74 \%$ & $-0.94 \%$ & $-2.22 \%$ & $-0.15 \%$ & $1.11 \%$ & $0.58 \%$ & $-0.15 \%$ \\
\hline PKG35 & $1.50 \%$ & $0.64 \%$ & $-2.08 \%$ & $-1.50 \%$ & $-0.63 \%$ & $1.25 \%$ & $0.46 \%$ & $0.00 \%$ \\
\hline PKG36 & $2.76 \%$ & $3.09 \%$ & $-0.97 \%$ & $-2.87 \%$ & $0.30 \%$ & $-1.53 \%$ & $0.75 \%$ & $0.75 \%$ \\
\hline PKG37 & $0.55 \%$ & $-0.65 \%$ & $-1.65 \%$ & $-1.06 \%$ & $-1.00 \%$ & $1.85 \%$ & $-1.09 \%$ & $-5.46 \%$ \\
\hline PKG38 & $-1.11 \%$ & $-0.53 \%$ & $-1.55 \%$ & $-4.85 \%$ & $2.53 \%$ & $-6.91 \%$ & $0.26 \%$ & $-2.84 \%$ \\
\hline PKG39 & $5.22 \%$ & $-0.76 \%$ & $-0.56 \%$ & $-3.58 \%$ & $0.47 \%$ & $-4.37 \%$ & $-0.06 \%$ & $-2.11 \%$ \\
\hline PKG40 & $-0.22 \%$ & $-0.36 \%$ & $-2.09 \%$ & $2.89 \%$ & $0.96 \%$ & $-3.53 \%$ & $1.11 \%$ & $-1.33 \%$ \\
\hline PKG41 & $0.25 \%$ & $1.35 \%$ & $-0.15 \%$ & $1.17 \%$ & $1.61 \%$ & $1.33 \%$ & $1.70 \%$ & $-3.12 \%$ \\
\hline PKG42 & $-1.84 \%$ & $1.48 \%$ & $-0.94 \%$ & $-1.77 \%$ & $-0.47 \%$ & $-0.81 \%$ & $0.90 \%$ & $-1.11 \%$ \\
\hline PKG43 & $3.32 \%$ & $-0.97 \%$ & $0.00 \%$ & $-1.06 \%$ & $-2.12 \%$ & $3.38 \%$ & $1.11 \%$ & $-5.01 \%$ \\
\hline PKG44 & $-0.51 \%$ & $1.73 \%$ & $-1.40 \%$ & $-8.72 \%$ & $-0.08 \%$ & $1.07 \%$ & $1.09 \%$ & $-1.93 \%$ \\
\hline PKG45 & $0.36 \%$ & $0.63 \%$ & $-0.32 \%$ & $-3.85 \%$ & $1.79 \%$ & $1.80 \%$ & $1.74 \%$ & $-1.62 \%$ \\
\hline PKG46 & $2.24 \%$ & $-0.24 \%$ & $0.08 \%$ & $-2.51 \%$ & $0.89 \%$ & $-0.88 \%$ & $1.07 \%$ & $-0.15 \%$ \\
\hline PKG47 & $2.19 \%$ & $0.45 \%$ & $-2.42 \%$ & $-2.34 \%$ & $-0.49 \%$ & $-1.72 \%$ & $0.99 \%$ & $-2.06 \%$ \\
\hline PKG48 & $-0.53 \%$ & $5.43 \%$ & $-1.11 \%$ & $-2.23 \%$ & $0.34 \%$ & $1.14 \%$ & $0.53 \%$ & $-1.67 \%$ \\
\hline PKG49 & $0.17 \%$ & $3.07 \%$ & $-1.99 \%$ & $-5.45 \%$ & $2.71 \%$ & $1.36 \%$ & $3.78 \%$ & $-1.63 \%$ \\
\hline PKG50 & $-0.48 \%$ & $2.60 \%$ & $-0.23 \%$ & $-0.65 \%$ & $0.81 \%$ & $2.81 \%$ & $0.06 \%$ & $-2.18 \%$ \\
\hline Mean & $1.06 \%$ & $1.61 \%$ & $-0.51 \%$ & $-0.61 \%$ & $0.27 \%$ & $1.16 \%$ & $0.45 \%$ & $-1.73 \%$ \\
\hline SD & $1.53 \%$ & $1.78 \%$ & $0.98 \%$ & $2.60 \%$ & $1.29 \%$ & $2.24 \%$ & $1.03 \%$ & $1.87 \%$ \\
\hline Max & $5.22 \%$ & $5.43 \%$ & $1.34 \%$ & $4.45 \%$ & $2.71 \%$ & $5.17 \%$ & $3.78 \%$ & $1.33 \%$ \\
\hline Min & $-2.35 \%$ & $-2.90 \%$ & $-2.42 \%$ & $-8.72 \%$ & $-2.12 \%$ & $-6.91 \%$ & $-2.48 \%$ & $-7.21 \%$ \\
\hline Diff & $7.56 \%$ & $8.33 \%$ & $3.75 \%$ & $13.17 \%$ & $4.82 \%$ & $12.08 \%$ & $6.26 \%$ & $8.54 \%$ \\
\hline
\end{tabular}


Table C-2-6: TCB $643^{\text {rd }}$ cycle; Daisy09 - Daisyl6.

\begin{tabular}{|c|c|c|c|c|c|c|c|c|}
\hline & AISY09 & AISY10 & DAISY11 & DAISY12 & DAISY13 & DAISY14 & DAISY15 & DAISY16 \\
\hline PKG01 & $0.00 \%$ & $0.15 \%$ & $-0.20 \%$ & $3.44 \%$ & $-5.27 \%$ & $-1.72 \%$ & $4.23 \%$ & $2.68 \%$ \\
\hline PKG02 & $1.04 \%$ & $2.10 \%$ & $-3.71 \%$ & $-0.28 \%$ & $-0.86 \%$ & $0.15 \%$ & $4.98 \%$ & $0.76 \%$ \\
\hline PKG03 & $3.22 \%$ & $0.48 \%$ & $0.66 \%$ & $-1.39 \%$ & $0.06 \%$ & $-2.14 \%$ & $0.75 \%$ & $0.05 \%$ \\
\hline KG04 & $04 \%$ & $1.11 \%$ & $-0.35 \%$ & $-1.48 \%$ & $0.07 \%$ & $-0.81 \%$ & $0.41 \%$ & $-2.00 \%$ \\
\hline KG05 & $39 \%$ & $1.67 \%$ & $88 \%$ & $-0.86 \%$ & $0.28 \%$ & $-1.30 \%$ & $0.60 \%$ & $0.75 \%$ \\
\hline PKG06 & $33 \%$ & $3.22 \%$ & $0.30 \%$ & $1.24 \%$ & $-0.15 \%$ & $-2.94 \%$ & $-0.45 \%$ & $0.59 \%$ \\
\hline PKG07 & $05 \%$ & $1.68 \%$ & $-0.63 \%$ & $-1.19 \%$ & $1.14 \%$ & $-3.61 \%$ & $0.93 \%$ & $-0.85 \%$ \\
\hline PKG08 & $15 \%$ & $2.77 \%$ & $0.48 \%$ & $-2.78 \%$ & $1.34 \%$ & $0.14 \%$ & $-0.11 \%$ & $0.34 \%$ \\
\hline PKG09 & $41 \%$ & $0.00 \%$ & $0.89 \%$ & $-4.10 \%$ & $-0.51 \%$ & $-2.96 \%$ & $0.00 \%$ & $-0.61 \%$ \\
\hline PKG10 & $0.07 \%$ & $-0.28 \%$ & $1.11 \%$ & $-1.78 \%$ & $0.40 \%$ & $-1.78 \%$ & $0.58 \%$ & $-1.25 \%$ \\
\hline PKG11 & $1.13 \%$ & $-2.28 \%$ & $0.28 \%$ & $1.20 \%$ & $0.20 \%$ & $-0.98 \%$ & $2.67 \%$ & $-0.63 \%$ \\
\hline PKG12 & $4 \%$ & $-1.15 \%$ & $51 \%$ & $-2.65 \%$ & $-1.42 \%$ & $-0.70 \%$ & $3.10 \%$ & $-0.16 \%$ \\
\hline PKG13 & $25 \%$ & $-0.60 \%$ & $-5.51 \%$ & $-2.70 \%$ & $-2.56 \%$ & $-1.07 \%$ & $1.85 \%$ & $-0.95 \%$ \\
\hline PKG14 & $-0.50 \%$ & $-2.17 \%$ & $-6.91 \%$ & $0.46 \%$ & $-0.19 \%$ & $0.21 \%$ & $-0.32 \%$ & $0.39 \%$ \\
\hline PKG15 & $.00 \%$ & $-1.42 \%$ & $0.56 \%$ & $-4.26 \%$ & $-1.05 \%$ & $-0.46 \%$ & $-0.06 \%$ & $-0.17 \%$ \\
\hline PKG16 & $0.27 \%$ & $-2.82 \%$ & $0.28 \%$ & $-0.89 \%$ & $0.00 \%$ & $-3.11 \%$ & $0.42 \%$ & $0.00 \%$ \\
\hline PKG17 & $2.06 \%$ & $-3.22 \%$ & $4.07 \%$ & $-2.22 \%$ & $0.47 \%$ & $-0.94 \%$ & $0.18 \%$ & $0.33 \%$ \\
\hline KG18 & $0.71 \%$ & $0.15 \%$ & $3.25 \%$ & $-4.58 \%$ & $1.13 \%$ & $-1.70 \%$ & $1.39 \%$ & $0.55 \%$ \\
\hline PKG19 & $-0.08 \%$ & $-0.30 \%$ & $4.60 \%$ & $-1.54 \%$ & $-3.27 \%$ & $-0.15 \%$ & $-0.06 \%$ & $0.56 \%$ \\
\hline PKG20 & $09 \%$ & -0.5 & $\%$ & -3. & $-1.81 \%$ & $0.82 \%$ & $3.43 \%$ & $-0.82 \%$ \\
\hline PKG21 & $-0.48 \%$ & $-0.59 \%$ & $0.28 \%$ & -3.8 & $-1.88 \%$ & $0.60 \%$ & $0.73 \%$ & $-0.95 \%$ \\
\hline PKG22 & $0.47 \%$ & $-0.66 \%$ & $-0.55 \%$ & $-4.66 \%$ & $-1.78 \%$ & $0.15 \%$ & $2.66 \%$ & $0.29 \%$ \\
\hline PKG23 & $1.39 \%$ & $2.58 \%$ & $-0.99 \%$ & $-4.29 \%$ & $-1.26 \%$ & $-0.08 \%$ & $0.12 \%$ & $-0.11 \%$ \\
\hline PKG24 & $-0.17 \%$ & $-0.08 \%$ & $1.03 \%$ & $-4.92 \%$ & $-0.72 \%$ & $1.38 \%$ & $0.38 \%$ & $0.00 \%$ \\
\hline PKG25 & $69 \%$ & $2.12 \%$ & $7 \%$ & $-2.62 \%$ & $-0.47 \%$ & $-0.51 \%$ & $0.06 \%$ & $1.13 \%$ \\
\hline PKG26 & $-2.72 \%$ & $1.17 \%$ & $5 \%$ & $-2.57 \%$ & $-0.20 \%$ & $-3.17 \%$ & $1.21 \%$ & $-0.55 \%$ \\
\hline PKG27 & $10 \%$ & $\%$ & $\%$ & -1.7 & $-0.21 \%$ & $-0.22 \%$ & $-0.41 \%$ & $0.71 \%$ \\
\hline PKG28 & $-2.83 \%$ & $1.64 \%$ & $\%$ & $-2.24 \%$ & $-0.95 \%$ & $1.29 \%$ & $0.37 \%$ & $-0.55 \%$ \\
\hline PKG29 & $82 \%$ & $-2.93 \%$ & $9 \%$ & -5 & $0.13 \%$ & $0.44 \%$ & $-3.22 \%$ & $0.59 \%$ \\
\hline PKG30 & $-1.38 \%$ & $-0.15 \%$ & $8 \%$ & $-3.45 \%$ & $0.49 \%$ & $1.74 \%$ & $1.45 \%$ & $-0.41 \%$ \\
\hline PKG31 & $17 \%$ & $-1.95 \%$ & $0 \%$ & $-3.80 \%$ & $-1.07 \%$ & $-2.08 \%$ & $0.93 \%$ & $0.43 \%$ \\
\hline PKG32 & $29 \%$ & $-3.08 \%$ & $-1.78 \%$ & $-2.60 \%$ & $-0.64 \%$ & $0.61 \%$ & $1.66 \%$ & $0.30 \%$ \\
\hline PKG33 & $\%$ & $\%$ & $\%$ & -1 & $-1.82 \%$ & $\overline{1 \%}$ & $1.95 \%$ & $0.97 \%$ \\
\hline PKG35 & $2 \%$ & $\%$ & $8 \%$ & -5 & $-1.17 \%$ & $5 \%$ & $-0.24 \%$ & $-0.45 \%$ \\
\hline PKG36 & $9 \%$ & $\%$ & outliner & $8 \%$ & $-1.29 \%$ & $0.84 \%$ & $-0.97 \%$ & $0.11 \%$ \\
\hline PKG37 & $42 \%$ & $-1.02 \%$ & $77 \%$ & $-0.65 \%$ & $-0.35 \%$ & $-0.83 \%$ & $-1.04 \%$ & $-1.95 \%$ \\
\hline PKG38 & $36 \%$ & $-2.66 \%$ & $48 \%$ & $-2.16 \%$ & $0.19 \%$ & $-0.41 \%$ & $-1.15 \%$ & $-1.20 \%$ \\
\hline PKG39 & $3 \%$ & $0.65 \%$ & $-0.07 \%$ & $-6.05 \%$ & $-1.11 \%$ & $.96 \%$ & $1.50 \%$ & $-0.43 \%$ \\
\hline PKG40 & $4 \%$ & $\%$ & eer & -4 & $-1.11 \%$ & $0 \%$ & $-0.82 \%$ & $-0.44 \%$ \\
\hline PKG41 & & $\%$ & $\%$ & -1 & $-0.14 \%$ & $1 \%$ & $0.11 \%$ & $0.36 \%$ \\
\hline PKG42 & $9 \%$ & & $\%$ & $9 \%$ & $-1.67 \%$ & $4 \%$ & $-3.99 \%$ & $-2.80 \%$ \\
\hline PKG43 & $47 \%$ & & & $-0.07 \%$ & $-2.94 \%$ & $3 \%$ & $0.35 \%$ & $-1.02 \%$ \\
\hline PKG44 & $0 \%$ & $2.51 \%$ & $-0.48 \%$ & $0.99 \%$ & $-1.56 \%$ & $-4.40 \%$ & $-1.90 \%$ & $-0.84 \%$ \\
\hline PKG45 & $0.45 \%$ & $4.87 \%$ & $0.41 \%$ & $-0.95 \%$ & $-1.48 \%$ & $-2.61 \%$ & $-3.14 \%$ & $-1.92 \%$ \\
\hline PKG46 & $5 \%$ & $2.22 \%$ & $4 \%$ & $-3.26 \%$ & $-1.92 \%$ & $-1.32 \%$ & $-1.78 \%$ & $-1.24 \%$ \\
\hline PKG47 & & $3.65 \%$ & & $-2.00 \%$ & $-1.39 \%$ & $-0.47 \%$ & $-6.95 \%$ & $-0.51 \%$ \\
\hline PKG48 & $2 \%$ & $-0.45 \%$ & & & $-1.51 \%$ & $-1.23 \%$ & $-2.43 \%$ & $0.45 \%$ \\
\hline PKG49 & $3 \%$ & $36 \%$ & & $-1.78 \%$ & $-1.07 \%$ & $-0.92 \%$ & $-4.85 \%$ & $-2.06 \%$ \\
\hline PKG50 & $-2.13 \%$ & $-0.68 \%$ & $0.00 \%$ & $-1.86 \%$ & $-0.26 \%$ & $-2.25 \%$ & $-4.72 \%$ & $-2.48 \%$ \\
\hline Mean & $0.55 \%$ & $0.31 \%$ & $-0.12 \%$ & $-2.19 \%$ & $-0.84 \%$ & $-1.01 \%$ & $0.01 \%$ & $-0.31 \%$ \\
\hline SD & $2.41 \%$ & $2.00 \%$ & $2.43 \%$ & $1.95 \%$ & $1.20 \%$ & $1.52 \%$ & $2.27 \%$ & $1.03 \%$ \\
\hline Max & $5 \%$ & $87 \%$ & $5.71 \%$ & $3.44 \%$ & $1.34 \%$ & $1.74 \%$ & $4.98 \%$ & $2.68 \%$ \\
\hline Min & $9 \%$ & $-3.36 \%$ & $-6.91 \%$ & $-6.05 \%$ & $-5.27 \%$ & $-4.40 \%$ & $-6.95 \%$ & $-2.80 \%$ \\
\hline Diff & $12.24 \%$ & $8.23 \%$ & $12.63 \%$ & $9.49 \%$ & $6.61 \%$ & $6.14 \%$ & $11.93 \%$ & $5.48 \%$ \\
\hline
\end{tabular}


Table C-2-7: TCB $875^{\text {th }}$ cycle; Daisy01 - Daisy08.

\begin{tabular}{|c|c|c|c|c|c|c|c|c|}
\hline & DAISY01 & DAISY02 & DAISY03 & DAISY04 & DAISY05 & DAISY06 & DAISY07 & DAISY08 \\
\hline PKG01 & $0.07 \%$ & $4.39 \%$ & $1.98 \%$ & $-1.18 \%$ & $3.71 \%$ & $2.57 \%$ & $2.08 \%$ & $1.66 \%$ \\
\hline PKG02 & $1.93 \%$ & $4.65 \%$ & $1.51 \%$ & $2.84 \%$ & $2.18 \%$ & $10.50 \%$ & $1.96 \%$ & $4.61 \%$ \\
\hline PKG03 & outliner & $4.53 \%$ & $0.61 \%$ & $0.79 \%$ & $1.02 \%$ & $6.25 \%$ & $2.92 \%$ & $3.78 \%$ \\
\hline PKG04 & $0.38 \%$ & $7.97 \%$ & $1.64 \%$ & $1.35 \%$ & $4.13 \%$ & $9.64 \%$ & $-0.51 \%$ & $3.15 \%$ \\
\hline PKG05 & $1.75 \%$ & $1.33 \%$ & $-0.08 \%$ & $2.52 \%$ & $1.94 \%$ & $5.74 \%$ & $1.28 \%$ & $0.82 \%$ \\
\hline PKG06 & $2.94 \%$ & $5.82 \%$ & $1.47 \%$ & $1.41 \%$ & $1.51 \%$ & $10.74 \%$ & $1.45 \%$ & $1.72 \%$ \\
\hline PKG07 & $-0.02 \%$ & $2.86 \%$ & $4.28 \%$ & $1.01 \%$ & $1.50 \%$ & $9.15 \%$ & $1.90 \%$ & $1.86 \%$ \\
\hline PKG08 & $-0.66 \%$ & $2.69 \%$ & $0.74 \%$ & $3.60 \%$ & $0.07 \%$ & $5.13 \%$ & $1.11 \%$ & $0.79 \%$ \\
\hline PKG09 & $1.38 \%$ & $3.03 \%$ & $2.13 \%$ & $0.86 \%$ & $1.10 \%$ & $3.45 \%$ & $1.56 \%$ & $3.23 \%$ \\
\hline PKG10 & $-0.02 \%$ & $2.75 \%$ & $0.93 \%$ & $-1.36 \%$ & $0.07 \%$ & $2.57 \%$ & $1.26 \%$ & $0.36 \%$ \\
\hline PKG11 & $2.77 \%$ & $0.93 \%$ & $0.48 \%$ & $2.01 \%$ & $0.08 \%$ & $3.13 \%$ & $1.86 \%$ & $0.72 \%$ \\
\hline PKG12 & $-0.57 \%$ & $2.59 \%$ & $0.08 \%$ & $1.08 \%$ & $0.71 \%$ & $6.38 \%$ & $1.30 \%$ & $-0.07 \%$ \\
\hline PKG13 & $2.70 \%$ & $1.10 \%$ & $0.41 \%$ & $1.23 \%$ & $1.22 \%$ & $11.15 \%$ & $0.66 \%$ & $-1.24 \%$ \\
\hline PKG14 & $-0.54 \%$ & $2.41 \%$ & $1.04 \%$ & $1.25 \%$ & $-0.75 \%$ & $2.63 \%$ & $0.77 \%$ & $2.15 \%$ \\
\hline PKG15 & $1.07 \%$ & $4.16 \%$ & $1.31 \%$ & $0.30 \%$ & $-3.29 \%$ & $2.56 \%$ & $1.54 \%$ & $1.97 \%$ \\
\hline PKG16 & $2.13 \%$ & $2.32 \%$ & $1.59 \%$ & $1.59 \%$ & $1.50 \%$ & $3.22 \%$ & $1.25 \%$ & $2.58 \%$ \\
\hline PKG17 & $-0.58 \%$ & $1.19 \%$ & $-0.63 \%$ & $1.98 \%$ & $-0.44 \%$ & $4.88 \%$ & $0.76 \%$ & $-3.44 \%$ \\
\hline PKG18 & $0.75 \%$ & $2.91 \%$ & $0.64 \%$ & $2.53 \%$ & $-0.70 \%$ & $5.17 \%$ & $0.39 \%$ & $-0.95 \%$ \\
\hline PKG19 & $0.48 \%$ & $2.57 \%$ & $-0.16 \%$ & $1.51 \%$ & $-0.08 \%$ & $3.58 \%$ & $0.20 \%$ & $-1.65 \%$ \\
\hline PKG20 & $-0.91 \%$ & $2.71 \%$ & $0.41 \%$ & $1.35 \%$ & $0.98 \%$ & $1.50 \%$ & $1.04 \%$ & $0.91 \%$ \\
\hline PKG21 & $1.24 \%$ & $2.96 \%$ & $-0.56 \%$ & $-0.78 \%$ & $-0.31 \%$ & $4.52 \%$ & $0.99 \%$ & $-6.61 \%$ \\
\hline PKG22 & $-1.45 \%$ & $-0.84 \%$ & $0.31 \%$ & $-0.65 \%$ & $0.64 \%$ & $10.16 \%$ & $0.52 \%$ & $-1.47 \%$ \\
\hline PKG23 & $2.51 \%$ & $3.47 \%$ & $0.16 \%$ & $-3.04 \%$ & $-0.52 \%$ & $9.88 \%$ & $1.57 \%$ & $0.42 \%$ \\
\hline PKG24 & $2.02 \%$ & $2.05 \%$ & $-0.09 \%$ & $-1.37 \%$ & $1.31 \%$ & $9.64 \%$ & $-0.14 \%$ & $-3.55 \%$ \\
\hline PKG25 & $0.36 \%$ & $1.80 \%$ & $1.08 \%$ & $4.99 \%$ & $-0.39 \%$ & $5.69 \%$ & $-0.06 \%$ & $-6.86 \%$ \\
\hline PKG26 & $2.49 \%$ & $3.64 \%$ & $0.08 \%$ & $0.56 \%$ & $-0.63 \%$ & $2.82 \%$ & $-0.13 \%$ & $-0.76 \%$ \\
\hline PKG27 & $1.80 \%$ & $2.69 \%$ & $0.55 \%$ & $-0.58 \%$ & $-0.16 \%$ & $5.70 \%$ & $-1.42 \%$ & $-0.39 \%$ \\
\hline PKG28 & $0.38 \%$ & $1.37 \%$ & $-0.40 \%$ & $0.10 \%$ & $0.33 \%$ & $4.16 \%$ & $-0.20 \%$ & $-2.65 \%$ \\
\hline PKG29 & $1.98 \%$ & $1.20 \%$ & $-0.76 \%$ & $-0.27 \%$ & $-0.93 \%$ & $6.02 \%$ & $-0.12 \%$ & $-2.26 \%$ \\
\hline PKG30 & $3.34 \%$ & $1.04 \%$ & $0.08 \%$ & $1.49 \%$ & $0.08 \%$ & $5.02 \%$ & $-1.38 \%$ & $0.66 \%$ \\
\hline PKG31 & $0.29 \%$ & $1.39 \%$ & $-1.11 \%$ & $-3.33 \%$ & $-0.09 \%$ & $1.74 \%$ & $0.85 \%$ & $-3.18 \%$ \\
\hline PKG32 & $1.95 \%$ & $-0.16 \%$ & $-1.15 \%$ & $-7.06 \%$ & $1.15 \%$ & $3.75 \%$ & $0.81 \%$ & $0.75 \%$ \\
\hline PKG33 & $-0.58 \%$ & $0.82 \%$ & $-1.41 \%$ & $-1.76 \%$ & $0.86 \%$ & $0.77 \%$ & $0.38 \%$ & $-0.51 \%$ \\
\hline PKG35 & $2.84 \%$ & $1.85 \%$ & $-1.60 \%$ & $1.10 \%$ & $1.96 \%$ & $6.58 \%$ & $0.13 \%$ & $2.61 \%$ \\
\hline PKG36 & $2.30 \%$ & $5.12 \%$ & $-1.04 \%$ & $-3.88 \%$ & $-0.45 \%$ & $0.22 \%$ & $1.31 \%$ & $-0.08 \%$ \\
\hline PKG37 & $2.44 \%$ & $0.04 \%$ & $-0.55 \%$ & $0.48 \%$ & $0.61 \%$ & $2.20 \%$ & $-1.60 \%$ & $-4.87 \%$ \\
\hline PKG38 & $1.07 \%$ & $0.90 \%$ & $-1.24 \%$ & $-3.77 \%$ & $0.82 \%$ & $-4.86 \%$ & $-0.32 \%$ & $-2.07 \%$ \\
\hline PKG39 & $3.37 \%$ & $1.96 \%$ & $-0.32 \%$ & $-3.22 \%$ & $-0.08 \%$ & $1.20 \%$ & $-0.19 \%$ & $-3.79 \%$ \\
\hline PKG40 & $2.23 \%$ & $0.14 \%$ & $-2.56 \%$ & $0.77 \%$ & $-0.56 \%$ & $-4.44 \%$ & $3.07 \%$ & $0.47 \%$ \\
\hline PKG41 & $0.53 \%$ & $4.26 \%$ & $-0.38 \%$ & $-0.27 \%$ & $0.37 \%$ & $-3.99 \%$ & $0.76 \%$ & $-2.36 \%$ \\
\hline PKG42 & $3.31 \%$ & $2.92 \%$ & $-0.39 \%$ & $-2.15 \%$ & $0.08 \%$ & $4.86 \%$ & $0.51 \%$ & $-0.66 \%$ \\
\hline PKG43 & $0.17 \%$ & $1.36 \%$ & $0.00 \%$ & $-2.12 \%$ & $-1.73 \%$ & $9.30 \%$ & $0.98 \%$ & $-2.73 \%$ \\
\hline PKG44 & $-0.71 \%$ & $4.27 \%$ & $-0.58 \%$ & $-8.15 \%$ & $-0.24 \%$ & $6.77 \%$ & $0.68 \%$ & $-2.17 \%$ \\
\hline PKG45 & $2.16 \%$ & $2.69 \%$ & $1.42 \%$ & $-3.23 \%$ & $-0.78 \%$ & $7.79 \%$ & $2.26 \%$ & $-1.16 \%$ \\
\hline PKG46 & $0.70 \%$ & $-0.05 \%$ & $0.00 \%$ & $-4.07 \%$ & $0.00 \%$ & $3.42 \%$ & $1.45 \%$ & $1.98 \%$ \\
\hline PKG47 & $3.70 \%$ & $1.37 \%$ & $-1.61 \%$ & $-1.56 \%$ & $-0.65 \%$ & $4.14 \%$ & $1.52 \%$ & $-0.15 \%$ \\
\hline PKG48 & $-1.75 \%$ & $3.89 \%$ & $-1.97 \%$ & $-1.16 \%$ & $-0.69 \%$ & $2.92 \%$ & $0.33 \%$ & $-1.51 \%$ \\
\hline PKG49 & $1.84 \%$ & $2.13 \%$ & $-2.24 \%$ & $-5.16 \%$ & $0.98 \%$ & $7.28 \%$ & $1.61 \%$ & $3.42 \%$ \\
\hline PKG50 & $0.61 \%$ & $2.70 \%$ & $0.77 \%$ & $2.23 \%$ & $1.25 \%$ & $7.26 \%$ & $0.86 \%$ & $-2.53 \%$ \\
\hline Mean & $1.17 \%$ & $2.45 \%$ & $0.10 \%$ & $-0.39 \%$ & $0.38 \%$ & $4.70 \%$ & $0.81 \%$ & $-0.39 \%$ \\
\hline SD & $1.40 \%$ & $1.67 \%$ & $1.26 \%$ & $2.65 \%$ & $1.25 \%$ & $3.70 \%$ & $0.99 \%$ & $2.56 \%$ \\
\hline Max & $3.70 \%$ & $7.97 \%$ & $4.28 \%$ & $4.99 \%$ & $4.13 \%$ & $11.15 \%$ & $3.07 \%$ & $4.61 \%$ \\
\hline Min & $-1.75 \%$ & $-0.84 \%$ & $-2.56 \%$ & $-8.15 \%$ & $-3.29 \%$ & $-4.86 \%$ & $-1.60 \%$ & $-6.86 \%$ \\
\hline Diff & $5.45 \%$ & $8.81 \%$ & $6.83 \%$ & $13.14 \%$ & $7.42 \%$ & $16.00 \%$ & $4.67 \%$ & $11.48 \%$ \\
\hline
\end{tabular}


Table C-2-8: TCB 875 ${ }^{\text {th }}$ cycle; Daisy09 - Daisy16.

\begin{tabular}{|c|c|c|c|c|c|c|c|c|}
\hline & DAISY09 & DAISY10 & DAISY11 & DAISY12 & DAISY13 & DAISY14 & DAISY15 & DAISY16 \\
\hline PKG01 & $1.85 \%$ & $2.16 \%$ & $3.27 \%$ & $2.05 \%$ & $-2.63 \%$ & $-1.27 \%$ & $1.45 \%$ & $1.56 \%$ \\
\hline PKG02 & $2.81 \%$ & $3.76 \%$ & $-1.15 \%$ & $-1.13 \%$ & $1.30 \%$ & $2.38 \%$ & $0.90 \%$ & $1.53 \%$ \\
\hline PKG03 & $1.12 \%$ & $2.55 \%$ & $2.77 \%$ & $-2.84 \%$ & $1.42 \%$ & $-0.54 \%$ & $1.39 \%$ & $1.15 \%$ \\
\hline PKG04 & $1.24 \%$ & $3.56 \%$ & $2.44 \%$ & $-0.96 \%$ & $3.25 \%$ & $2.35 \%$ & $-1.36 \%$ & $0.11 \%$ \\
\hline PKG05 & $3.82 \%$ & $2.35 \%$ & $3.90 \%$ & $-0.14 \%$ & $0.98 \%$ & $1.98 \%$ & $0.60 \%$ & $0.97 \%$ \\
\hline PKG06 & $2.01 \%$ & $3.47 \%$ & $2.00 \%$ & $1.24 \%$ & $2.13 \%$ & $1.91 \%$ & $0.00 \%$ & $1.06 \%$ \\
\hline PKG07 & $1.20 \%$ & $1.90 \%$ & $0.56 \%$ & $-0.22 \%$ & $3.78 \%$ & $0.88 \%$ & $1.05 \%$ & $-0.22 \%$ \\
\hline PKG08 & $1.86 \%$ & $0.07 \%$ & $1.08 \%$ & $-1.68 \%$ & $0.83 \%$ & $1.38 \%$ & $0.48 \%$ & $0.98 \%$ \\
\hline PKG09 & $1.21 \%$ & $-0.45 \%$ & $0.82 \%$ & $-2.44 \%$ & $0.58 \%$ & $-1.21 \%$ & $1.54 \%$ & $0.22 \%$ \\
\hline PKG10 & $0.59 \%$ & $1.42 \%$ & $0.20 \%$ & $-1.44 \%$ & $1.06 \%$ & $0.35 \%$ & $0.98 \%$ & $0.21 \%$ \\
\hline PKG11 & $1.58 \%$ & $-1.04 \%$ & $0.92 \%$ & $-0.52 \%$ & $0.73 \%$ & $0.84 \%$ & $4.13 \%$ & $1.43 \%$ \\
\hline PKG12 & $1.00 \%$ & $0.87 \%$ & $1.02 \%$ & $-2.58 \%$ & $-0.90 \%$ & $-0.35 \%$ & $0.86 \%$ & $1.78 \%$ \\
\hline PKG13 & $1.68 \%$ & $0.23 \%$ & $1.74 \%$ & $-2.84 \%$ & $-1.99 \%$ & $-1.92 \%$ & $1.85 \%$ & $0.44 \%$ \\
\hline PKG14 & $-0.57 \%$ & $-0.61 \%$ & $1.31 \%$ & $-1.71 \%$ & $-0.25 \%$ & $0.42 \%$ & $2.82 \%$ & $2.29 \%$ \\
\hline PKG15 & $-0.08 \%$ & $-0.15 \%$ & $0.56 \%$ & $-3.48 \%$ & $-0.42 \%$ & $0.31 \%$ & $-0.54 \%$ & $0.88 \%$ \\
\hline PKG16 & $-0.48 \%$ & $-0.98 \%$ & $0.81 \%$ & $-0.06 \%$ & $0.43 \%$ & $-1.06 \%$ & $-0.56 \%$ & $0.84 \%$ \\
\hline PKG17 & $5.72 \%$ & $-1.92 \%$ & $2.40 \%$ & $-0.93 \%$ & $0.27 \%$ & $1.45 \%$ & $1.48 \%$ & $2.23 \%$ \\
\hline PKG18 & $1.43 \%$ & $0.96 \%$ & $0.60 \%$ & $-3.68 \%$ & $1.20 \%$ & $0.82 \%$ & $1.75 \%$ & $1.05 \%$ \\
\hline PKG19 & $0.24 \%$ & $-1.27 \%$ & $-0.28 \%$ & $-0.22 \%$ & $-2.65 \%$ & $-0.69 \%$ & $0.85 \%$ & $1.69 \%$ \\
\hline PKG20 & $-0.47 \%$ & $0.58 \%$ & $1.56 \%$ & $-1.94 \%$ & $-1.39 \%$ & $0.97 \%$ & $1.63 \%$ & $0.99 \%$ \\
\hline PKG21 & $0.80 \%$ & $-0.30 \%$ & $0.14 \%$ & $-3.11 \%$ & $-0.91 \%$ & $-0.30 \%$ & $0.73 \%$ & $0.62 \%$ \\
\hline PKG22 & $1.17 \%$ & $1.25 \%$ & $0.48 \%$ & $-3.67 \%$ & $-0.48 \%$ & $1.55 \%$ & $4.55 \%$ & $2.45 \%$ \\
\hline PKG23 & $1.30 \%$ & $2.58 \%$ & $-0.07 \%$ & $-3.05 \%$ & $1.04 \%$ & $-0.47 \%$ & $0.49 \%$ & $1.60 \%$ \\
\hline PKG24 & $0.25 \%$ & $0.23 \%$ & $3.10 \%$ & $-2.01 \%$ & $-0.36 \%$ & $-0.61 \%$ & $-0.26 \%$ & $1.01 \%$ \\
\hline PKG25 & $0.92 \%$ & $0.00 \%$ & $1.68 \%$ & $-2.05 \%$ & $-0.47 \%$ & $0.72 \%$ & $0.29 \%$ & $1.30 \%$ \\
\hline PKG26 & $-3.02 \%$ & $0.37 \%$ & $0.00 \%$ & $-2.00 \%$ & $0.53 \%$ & $-1.06 \%$ & $0.57 \%$ & $0.11 \%$ \\
\hline PKG27 & $-0.40 \%$ & $1.22 \%$ & $1.34 \%$ & $-1.46 \%$ & $-1.17 \%$ & $0.00 \%$ & $0.06 \%$ & $0.44 \%$ \\
\hline PKG28 & $-1.67 \%$ & $2.82 \%$ & $0.63 \%$ & $-1.49 \%$ & $0.81 \%$ & $2.02 \%$ & $-0.30 \%$ & $0.00 \%$ \\
\hline PKG29 & $-1.14 \%$ & $3.58 \%$ & $0.87 \%$ & $-4.69 \%$ & $1.35 \%$ & $1.68 \%$ & $-2.77 \%$ & $1.88 \%$ \\
\hline PKG30 & $-1.61 \%$ & $-0.95 \%$ & $0.64 \%$ & $-2.20 \%$ & $0.35 \%$ & $1.13 \%$ & $0.13 \%$ & $0.68 \%$ \\
\hline PKG31 & $0.09 \%$ & $-2.03 \%$ & $0.52 \%$ & $-2.48 \%$ & $-1.54 \%$ & $-1.04 \%$ & $1.72 \%$ & $1.96 \%$ \\
\hline PKG32 & $0.00 \%$ & $-2.94 \%$ & $0.71 \%$ & $0.31 \%$ & $0.36 \%$ & $1.23 \%$ & $1.15 \%$ & $0.47 \%$ \\
\hline PKG33 & $-3.99 \%$ & $-1.55 \%$ & $0.46 \%$ & $-1.06 \%$ & $-1.26 \%$ & $3.48 \%$ & $1.13 \%$ & $1.29 \%$ \\
\hline PKG35 & $-1.61 \%$ & $3.26 \%$ & $1.10 \%$ & $-5.27 \%$ & $-1.10 \%$ & $0.68 \%$ & $0.18 \%$ & $0.63 \%$ \\
\hline PKG36 & $1.60 \%$ & $1.21 \%$ & $1.25 \%$ & $-2.13 \%$ & $-1.16 \%$ & $0.84 \%$ & $0.06 \%$ & $0.59 \%$ \\
\hline PKG37 & $-0.16 \%$ & $0.80 \%$ & $0.94 \%$ & $-0.51 \%$ & $-0.56 \%$ & $0.60 \%$ & $0.30 \%$ & $-0.58 \%$ \\
\hline PKG38 & $-3.70 \%$ & $-1.40 \%$ & $0.95 \%$ & $-1.66 \%$ & $0.26 \%$ & $-1.16 \%$ & $-0.75 \%$ & $0.22 \%$ \\
\hline PKG39 & $2.37 \%$ & $1.15 \%$ & $-0.07 \%$ & $-6.60 \%$ & $-0.63 \%$ & $0.15 \%$ & $1.92 \%$ & $0.88 \%$ \\
\hline PKG40 & $-0.24 \%$ & $0.90 \%$ & $0.75 \%$ & $-5.11 \%$ & $-0.49 \%$ & $-0.30 \%$ & $-0.41 \%$ & $0.45 \%$ \\
\hline PKG41 & $-0.08 \%$ & $0.00 \%$ & $1.28 \%$ & $-2.51 \%$ & $-0.74 \%$ & $-3.24 \%$ & $0.63 \%$ & $1.04 \%$ \\
\hline PKG42 & $-3.93 \%$ & $-1.02 \%$ & $0.46 \%$ & $0.65 \%$ & $-1.18 \%$ & $-2.54 \%$ & $-3.42 \%$ & $-1.90 \%$ \\
\hline PKG43 & $-0.08 \%$ & $0.59 \%$ & $1.28 \%$ & $0.87 \%$ & $-1.40 \%$ & $-3.52 \%$ & $-1.06 \%$ & $-0.81 \%$ \\
\hline PKG44 & $0.48 \%$ & $-0.59 \%$ & $-0.42 \%$ & $0.91 \%$ & $-0.78 \%$ & $-3.16 \%$ & $3.12 \%$ & $-0.06 \%$ \\
\hline PKG45 & $-0.08 \%$ & $2.37 \%$ & $-0.41 \%$ & $-1.90 \%$ & $-1.41 \%$ & $-1.34 \%$ & $1.48 \%$ & $-0.61 \%$ \\
\hline PKG46 & $1.79 \%$ & $0.65 \%$ & $0.19 \%$ & $-2.78 \%$ & $-0.64 \%$ & $-0.56 \%$ & $-1.84 \%$ & $-1.54 \%$ \\
\hline PKG47 & $7.26 \%$ & $-0.99 \%$ & $0.88 \%$ & $-1.04 \%$ & $-0.73 \%$ & $0.32 \%$ & $-5.62 \%$ & $-1.18 \%$ \\
\hline PKG48 & $4.92 \%$ & $-2.46 \%$ & $0.77 \%$ & $1.78 \%$ & $-1.44 \%$ & $-0.54 \%$ & $-1.50 \%$ & $-0.66 \%$ \\
\hline PKG49 & $2.30 \%$ & $-3.79 \%$ & $2.63 \%$ & $-0.77 \%$ & $-1.14 \%$ & $-0.84 \%$ & $-0.54 \%$ & $-1.43 \%$ \\
\hline PKG50 & $3.61 \%$ & $-2.52 \%$ & $1.69 \%$ & $-1.73 \%$ & $-0.26 \%$ & $-1.40 \%$ & $-4.45 \%$ & $-2.28 \%$ \\
\hline Mean & $0.71 \%$ & $0.41 \%$ & $1.03 \%$ & $-1.68 \%$ & $-0.15 \%$ & $0.03 \%$ & $0.34 \%$ & $0.57 \%$ \\
\hline SD & $2.20 \%$ & $1.84 \%$ & $1.01 \%$ & $1.78 \%$ & $1.32 \%$ & $1.51 \%$ & $1.86 \%$ & $1.08 \%$ \\
\hline Max & $7.26 \%$ & $3.76 \%$ & $3.90 \%$ & $2.05 \%$ & $3.78 \%$ & $3.48 \%$ & $4.55 \%$ & $2.45 \%$ \\
\hline Min & $-3.99 \%$ & $-3.79 \%$ & $-1.15 \%$ & $-6.60 \%$ & $-2.65 \%$ & $-3.52 \%$ & $-5.62 \%$ & $-2.28 \%$ \\
\hline Diff & $11.25 \%$ & $7.55 \%$ & $5.05 \%$ & $8.65 \%$ & $6.43 \%$ & $7.00 \%$ & $10.16 \%$ & $4.73 \%$ \\
\hline
\end{tabular}


Table C-2-9: TCB $1016^{\text {th }}$ cycle; Daisy01 - Daisy08.

\begin{tabular}{|c|c|c|c|c|c|c|c|c|}
\hline & DAISY01 & DAISY02 & DAISY03 & DAISY04 & DAISY05 & DAISY06 & DAISY07 & DAISY08 \\
\hline PKG01 & outliner & $3.15 \%$ & $1.98 \%$ & $0.99 \%$ & $0.87 \%$ & $4.90 \%$ & $3.69 \%$ & $4.91 \%$ \\
\hline PKG02 & outliner & $5.47 \%$ & $1.99 \%$ & $4.83 \%$ & $-0.39 \%$ & $4.01 \%$ & $2.53 \%$ & $6.47 \%$ \\
\hline PKG03 & $13.83 \%$ & $4.35 \%$ & $1.68 \%$ & $1.31 \%$ & $-0.44 \%$ & $3.29 \%$ & $5.59 \%$ & $2.03 \%$ \\
\hline PKG04 & $11.41 \%$ & $4.84 \%$ & $3.29 \%$ & $1.84 \%$ & $-0.32 \%$ & $3.42 \%$ & $1.21 \%$ & $1.26 \%$ \\
\hline PKG05 & $11.10 \%$ & $2.12 \%$ & $2.14 \%$ & $3.59 \%$ & $-1.86 \%$ & $2.64 \%$ & $1.34 \%$ & $2.54 \%$ \\
\hline PKG06 & $13.64 \%$ & $2.71 \%$ & $2.94 \%$ & $1.41 \%$ & $-1.35 \%$ & $5.50 \%$ & $1.11 \%$ & $1.63 \%$ \\
\hline PKG07 & $9.43 \%$ & $4.37 \%$ & $1.84 \%$ & $2.62 \%$ & $-0.16 \%$ & $4.16 \%$ & $1.36 \%$ & $0.81 \%$ \\
\hline PKG08 & $8.95 \%$ & $1.75 \%$ & $1.26 \%$ & $0.43 \%$ & $-1.37 \%$ & $3.35 \%$ & $0.23 \%$ & $0.40 \%$ \\
\hline PKG09 & $9.83 \%$ & $4.37 \%$ & $2.13 \%$ & $-0.48 \%$ & $-1.34 \%$ & $1.84 \%$ & $2.02 \%$ & $2.23 \%$ \\
\hline PKG10 & $6.30 \%$ & $0.60 \%$ & $0.70 \%$ & $0.27 \%$ & $-1.08 \%$ & $1.68 \%$ & outliner & $-0.58 \%$ \\
\hline PKG11 & $8.55 \%$ & $0.74 \%$ & $2.10 \%$ & $-0.10 \%$ & $-2.06 \%$ & $1.93 \%$ & $2.19 \%$ & $0.40 \%$ \\
\hline PKG12 & $4.06 \%$ & $2.50 \%$ & $0.77 \%$ & $-0.63 \%$ & $0.00 \%$ & $1.06 \%$ & $1.36 \%$ & $-0.28 \%$ \\
\hline PKG13 & $6.24 \%$ & $2.37 \%$ & $1.07 \%$ & $1.23 \%$ & $-1.62 \%$ & $5.45 \%$ & $0.66 \%$ & $-2.08 \%$ \\
\hline PKG14 & $5.40 \%$ & $3.64 \%$ & $1.41 \%$ & $-0.17 \%$ & $0.27 \%$ & $1.26 \%$ & $1.25 \%$ & $-0.60 \%$ \\
\hline PKG15 & $8.24 \%$ & $3.53 \%$ & $1.15 \%$ & $0.60 \%$ & $-0.94 \%$ & $3.66 \%$ & $2.01 \%$ & $-1.42 \%$ \\
\hline PKG16 & $10.40 \%$ & $3.84 \%$ & $1.45 \%$ & $0.87 \%$ & $-0.39 \%$ & $3.32 \%$ & $1.20 \%$ & $0.57 \%$ \\
\hline PKG17 & $2.76 \%$ & $2.25 \%$ & $0.47 \%$ & $2.45 \%$ & $-2.07 \%$ & $2.71 \%$ & $-0.32 \%$ & $-3.16 \%$ \\
\hline PKG18 & $10.04 \%$ & $3.84 \%$ & $1.04 \%$ & $3.01 \%$ & $-1.09 \%$ & $2.94 \%$ & $0.26 \%$ & $-1.76 \%$ \\
\hline PKG19 & $10.03 \%$ & $2.04 \%$ & $1.72 \%$ & $-1.21 \%$ & $-1.21 \%$ & $3.08 \%$ & $0.27 \%$ & $-0.79 \%$ \\
\hline PKG20 & $8.78 \%$ & $2.40 \%$ & $0.49 \%$ & $-0.19 \%$ & $1.71 \%$ & $0.81 \%$ & $1.23 \%$ & $2.05 \%$ \\
\hline PKG21 & $6.85 \%$ & $3.86 \%$ & $0.08 \%$ & $1.95 \%$ & $-1.55 \%$ & $6.43 \%$ & $0.92 \%$ & $-4.96 \%$ \\
\hline PKG22 & $2.07 \%$ & $-0.74 \%$ & $0.55 \%$ & $-0.93 \%$ & $1.12 \%$ & $4.06 \%$ & $2.13 \%$ & $6.43 \%$ \\
\hline PKG23 & $6.32 \%$ & $3.14 \%$ & $0.00 \%$ & $-1.37 \%$ & $-1.12 \%$ & $2.57 \%$ & $2.25 \%$ & $8.34 \%$ \\
\hline PKG24 & $8.97 \%$ & $3.85 \%$ & $-0.51 \%$ & $-1.37 \%$ & $-1.07 \%$ & $2.96 \%$ & $-0.35 \%$ & $-2.31 \%$ \\
\hline PKG25 & $1.99 \%$ & $2.39 \%$ & $1.78 \%$ & $-0.18 \%$ & $0.31 \%$ & $2.90 \%$ & $1.32 \%$ & $-5.95 \%$ \\
\hline PKG26 & $3.56 \%$ & $2.77 \%$ & $0.08 \%$ & $1.87 \%$ & $-1.72 \%$ & $0.23 \%$ & $0.25 \%$ & $0.08 \%$ \\
\hline PKG27 & $2.18 \%$ & $4.43 \%$ & $0.40 \%$ & $1.64 \%$ & $-0.64 \%$ & $5.58 \%$ & $-0.39 \%$ & $0.95 \%$ \\
\hline PKG28 & $0.98 \%$ & $1.68 \%$ & $0.08 \%$ & $1.06 \%$ & $-1.56 \%$ & $1.96 \%$ & $1.85 \%$ & $-3.49 \%$ \\
\hline PKG29 & $5.52 \%$ & $1.59 \%$ & $0.30 \%$ & $0.99 \%$ & $-0.93 \%$ & $1.50 \%$ & $0.00 \%$ & $-1.39 \%$ \\
\hline PKG30 & $3.83 \%$ & $1.74 \%$ & $0.57 \%$ & $0.99 \%$ & $-0.57 \%$ & $6.45 \%$ & $1.31 \%$ & $1.57 \%$ \\
\hline PKG31 & $4.14 \%$ & $5.30 \%$ & $-1.02 \%$ & $-2.81 \%$ & $0.09 \%$ & $-2.36 \%$ & $1.06 \%$ & $-3.76 \%$ \\
\hline PKG32 & $3.82 \%$ & $3.26 \%$ & $-0.66 \%$ & $-7.35 \%$ & $1.48 \%$ & $8.76 \%$ & $0.27 \%$ & $0.33 \%$ \\
\hline PKG33 & $1.83 \%$ & $2.39 \%$ & $-0.47 \%$ & $-0.74 \%$ & $0.78 \%$ & $0.88 \%$ & $1.02 \%$ & $-0.44 \%$ \\
\hline PKG35 & $6.37 \%$ & $1.94 \%$ & $0.00 \%$ & $-1.40 \%$ & $1.88 \%$ & $1.25 \%$ & $0.72 \%$ & $0.32 \%$ \\
\hline PKG36 & $2.58 \%$ & $3.09 \%$ & $0.00 \%$ & $-2.53 \%$ & $-0.30 \%$ & $-1.20 \%$ & $1.19 \%$ & $1.42 \%$ \\
\hline PKG37 & $3.87 \%$ & $1.92 \%$ & $-0.55 \%$ & $-0.29 \%$ & $-0.08 \%$ & $3.00 \%$ & $-0.96 \%$ & $-3.64 \%$ \\
\hline PKG38 & $2.52 \%$ & $2.24 \%$ & $-1.55 \%$ & $-2.96 \%$ & $-0.74 \%$ & $-3.89 \%$ & $0.77 \%$ & $-1.23 \%$ \\
\hline PKG39 & $8.52 \%$ & $2.16 \%$ & $-0.32 \%$ & $-4.41 \%$ & $0.94 \%$ & $-4.70 \%$ & $-0.38 \%$ & $-1.75 \%$ \\
\hline PKG40 & $3.50 \%$ & $2.98 \%$ & $-2.33 \%$ & $1.25 \%$ & $-0.56 \%$ & $-1.71 \%$ & $1.37 \%$ & $1.17 \%$ \\
\hline PKG41 & $3.47 \%$ & $5.30 \%$ & $-1.00 \%$ & $0.09 \%$ & $-1.39 \%$ & $-4.30 \%$ & $4.28 \%$ & $-1.53 \%$ \\
\hline PKG42 & $4.75 \%$ & $5.38 \%$ & $-0.86 \%$ & $-1.21 \%$ & $0.08 \%$ & $4.86 \%$ & $2.57 \%$ & $-0.37 \%$ \\
\hline PKG43 & $3.61 \%$ & $2.47 \%$ & $0.00 \%$ & $-0.19 \%$ & $0.39 \%$ & $7.48 \%$ & $0.72 \%$ & $-3.39 \%$ \\
\hline PKG44 & $2.72 \%$ & $5.32 \%$ & $-1.40 \%$ & $-7.20 \%$ & $-0.56 \%$ & $4.87 \%$ & $3.94 \%$ & $-0.24 \%$ \\
\hline PKG45 & $1.30 \%$ & $4.36 \%$ & $-0.08 \%$ & $-2.78 \%$ & $-0.93 \%$ & $6.35 \%$ & $2.39 \%$ & $-0.23 \%$ \\
\hline PKG46 & $3.69 \%$ & $0.50 \%$ & $-0.08 \%$ & $-2.34 \%$ & $0.59 \%$ & $10.48 \%$ & $1.01 \%$ & $-0.07 \%$ \\
\hline PKG47 & $7.23 \%$ & $2.99 \%$ & $-1.85 \%$ & $0.68 \%$ & $-1.05 \%$ & $11.14 \%$ & $1.38 \%$ & $-1.22 \%$ \\
\hline PKG48 & $3.63 \%$ & $7.96 \%$ & $0.95 \%$ & $-2.23 \%$ & $-0.09 \%$ & $2.28 \%$ & $1.19 \%$ & $-0.64 \%$ \\
\hline PKG49 & $2.62 \%$ & $4.21 \%$ & $-0.08 \%$ & $-2.08 \%$ & $0.00 \%$ & $5.31 \%$ & $0.35 \%$ & $-0.08 \%$ \\
\hline PKG50 & $1.79 \%$ & $5.75 \%$ & $0.84 \%$ & $1.95 \%$ & $0.00 \%$ & $3.75 \%$ & $1.23 \%$ & $-2.67 \%$ \\
\hline Mean & $5.81 \%$ & $3.17 \%$ & $0.50 \%$ & $-0.19 \%$ & $-0.45 \%$ & $3.02 \%$ & $1.30 \%$ & $-0.08 \%$ \\
\hline SD & $3.43 \%$ & $1.60 \%$ & $1.22 \%$ & $2.36 \%$ & $0.97 \%$ & $3.27 \%$ & $1.25 \%$ & $2.75 \%$ \\
\hline Max & $13.83 \%$ & $7.96 \%$ & $3.29 \%$ & $4.83 \%$ & $1.88 \%$ & $11.14 \%$ & $5.59 \%$ & $8.34 \%$ \\
\hline Min & $0.98 \%$ & $-0.74 \%$ & $-2.33 \%$ & $-7.35 \%$ & $-2.07 \%$ & $-4.70 \%$ & $-0.96 \%$ & $-5.95 \%$ \\
\hline Diff & $12.84 \%$ & $8.70 \%$ & $5.61 \%$ & $12.18 \%$ & $3.95 \%$ & $15.85 \%$ & $6.55 \%$ & $14.29 \%$ \\
\hline
\end{tabular}


Table C-2-10: TCB $1016^{\text {th }}$ cycle; Daisy09 - Daisyl6.

\begin{tabular}{|c|c|c|c|c|c|c|c|c|}
\hline & AISY09 & DAISY10 & DAISY11 & DAISY12 & DAISY13 & DAISY14 & DAISY15 & DAISY16 \\
\hline PKG01 & $4.02 \%$ & $2.01 \%$ & $3.48 \%$ & $-0.37 \%$ & $-2.30 \%$ & $2.24 \%$ & $4.36 \%$ & $0.90 \%$ \\
\hline PKG02 & $3.21 \%$ & $4.96 \%$ & $0.77 \%$ & $-1.27 \%$ & $0.94 \%$ & $3.15 \%$ & $4.92 \%$ & $0.65 \%$ \\
\hline PKG03 & $0.91 \%$ & $2.21 \%$ & $3.30 \%$ & $-3.46 \%$ & $1.22 \%$ & $0.60 \%$ & $6.76 \%$ & $0.37 \%$ \\
\hline$\overline{K G 04}$ & $0.62 \%$ & $0.96 \%$ & $4.53 \%$ & $-1.48 \%$ & $-0.69 \%$ & $1.18 \%$ & $4.55 \%$ & $-2.27 \%$ \\
\hline KG05 & $36 \%$ & $1.44 \%$ & $3.97 \%$ & $-0.43 \%$ & $-0.28 \%$ & $1.37 \%$ & $2.71 \%$ & $0.59 \%$ \\
\hline KG06 & $36 \%$ & $.06 \%$ & $1.92 \%$ & $-0.31 \%$ & $0.38 \%$ & $-0.48 \%$ & $2.43 \%$ & $-1.01 \%$ \\
\hline PKG07 & $0.56 \%$ & $1.75 \%$ & $1.94 \%$ & $-0.22 \%$ & $1.00 \%$ & $-0.74 \%$ & $4.71 \%$ & $-0.33 \%$ \\
\hline PKG08 & $1.64 \%$ & $3.45 \%$ & $3.49 \%$ & $-2.07 \%$ & $-0.19 \%$ & $3.25 \%$ & $.69 \%$ & $0.34 \%$ \\
\hline PKG09 & $0.00 \%$ & $0.08 \%$ & $7.04 \%$ & $-2.52 \%$ & $-0.94 \%$ & $-2.05 \%$ & $5.87 \%$ & $-0.11 \%$ \\
\hline PKG10 & $1.64 \%$ & $1.35 \%$ & $3.99 \%$ & $-2.74 \%$ & $-0.99 \%$ & $2.27 \%$ & $1.60 \%$ & $-0.37 \%$ \\
\hline PKG11 & $3.16 \%$ & $-0.21 \%$ & $3.03 \%$ & $-0.97 \%$ & $0.60 \%$ & $0.77 \%$ & $5.59 \%$ & $0.34 \%$ \\
\hline PKG12 & $-0.57 \%$ & $-1.89 \%$ & $3.94 \%$ & $1.56 \%$ & $-1.48 \%$ & $2.65 \%$ & $1.15 \%$ & $1.63 \%$ \\
\hline PKG13 & $3.20 \%$ & $1.28 \%$ & $4.53 \%$ & $-1.38 \%$ & $-2.78 \%$ & $-1.00 \%$ & $4.75 \%$ & $0.11 \%$ \\
\hline PKG14 & $0.07 \%$ & $-1.97 \%$ & $0.44 \%$ & $-2.11 \%$ & $-0.44 \%$ & $0.98 \%$ & $2.87 \%$ & $1.61 \%$ \\
\hline PKG15 & $3.17 \%$ & $1.27 \%$ & $1.05 \%$ & $-2.34 \%$ & $-1.34 \%$ & $0.53 \%$ & $3.32 \%$ & $2.27 \%$ \\
\hline PKG16 & $-0.89 \%$ & $-0.13 \%$ & $-0.17 \%$ & $-0.44 \%$ & $1.67 \%$ & $-2.45 \%$ & $3.20 \%$ & $0.84 \%$ \\
\hline PKG17 & $1.75 \%$ & $-1.37 \%$ & $1.00 \%$ & $-1.07 \%$ & $1.28 \%$ & $1.31 \%$ & $4.62 \%$ & $1.03 \%$ \\
\hline PKG18 & $4.68 \%$ & $0.74 \%$ & $0.53 \%$ & $-2.36 \%$ & $0.35 \%$ & $2.23 \%$ & $3.97 \%$ & $0.77 \%$ \\
\hline PKG19 & $7.79 \%$ & $0.08 \%$ & $0.07 \%$ & $-1.76 \%$ & $-2.37 \%$ & $0.46 \%$ & $1.89 \%$ & $0.78 \%$ \\
\hline PKG20 & & $68 \%$ & $2.38 \%$ & $-2.73 \%$ & $-1.25 \%$ & $1.57 \%$ & $2.34 \%$ & $-0.11 \%$ \\
\hline PKG21 & $4 \%$ & $1.25 \%$ & $3.72 \%$ & $-3.40 \%$ & $-0.63 \%$ & $0.91 \%$ & $1.59 \%$ & $0.22 \%$ \\
\hline PKG22 & $5.40 \%$ & $1.91 \%$ & $1.44 \%$ & $-5.30 \%$ & $0.48 \%$ & $4.94 \%$ & $3.25 \%$ & $1.39 \%$ \\
\hline PKG23 & $2.08 \%$ & $4.20 \%$ & $1.84 \%$ & $-3.93 \%$ & $-0.37 \%$ & $0.31 \%$ & $4.78 \%$ & $0.69 \%$ \\
\hline PKG24 & $-0.33 \%$ & $1.68 \%$ & $2.14 \%$ & $-4.77 \%$ & $-1.38 \%$ & $-0.23 \%$ & $3.46 \%$ & $-0.24 \%$ \\
\hline PKG25 & $37 \%$ & $51 \%$ & $1.01 \%$ & $-2.26 \%$ & $0.54 \%$ & $1.45 \%$ & $0.76 \%$ & $2.48 \%$ \\
\hline PKG26 & $6 \%$ & $5.13 \%$ & $2.47 \%$ & $-1.71 \%$ & $-0.53 \%$ & $-1.62 \%$ & $5.25 \%$ & $-1.35 \%$ \\
\hline PKG27 & & $1.07 \%$ & $2.47 \%$ & $-1.09 \%$ & $-0.34 \%$ & $0.82 \%$ & $1.95 \%$ & $0.05 \%$ \\
\hline PKG28 & $1 \%$ & $6.03 \%$ & $1.40 \%$ & 0.1 & $0.15 \%$ & $3.48 \%$ & $0.73 \%$ & $-0.50 \%$ \\
\hline PKG29 & $7 \%$ & $2.15 \%$ & $3.55 \%$ & $-4.62 \%$ & $-0.27 \%$ & $2.99 \%$ & $0.88 \%$ & $0.65 \%$ \\
\hline PKG30 & $-1.54 \%$ & $0.59 \%$ & $1.84 \%$ & $-1.39 \%$ & $0.14 \%$ & $2.49 \%$ & $2.97 \%$ & $-0.35 \%$ \\
\hline PKG31 & $9 \%$ & $-2.49 \%$ & $1.11 \%$ & $-3.88 \%$ & $-0.84 \%$ & $-0.48 \%$ & $4.91 \%$ & $0.74 \%$ \\
\hline PKG32 & & $-0.37 \%$ & $-1.28 \%$ & $-1.45 \%$ & $1.36 \%$ & $1.30 \%$ & $1.15 \%$ & $3.80 \%$ \\
\hline PKG33 & $\%$ & $12 \%$ & $0.53 \%$ & -1 & $0.70 \%$ & $2.32 \%$ & $1.48 \%$ & $3.34 \%$ \\
\hline PKG35 & $\%$ & $0.87 \%$ & $\%$ & -5 & $0.21 \%$ & $0.07 \%$ & $0.79 \%$ & $2.37 \%$ \\
\hline PKG36 & & $42 \%$ & $1 \%$ & $9 \%$ & $-0.71 \%$ & $2.25 \%$ & $2.04 \%$ & $2.52 \%$ \\
\hline PKG37 & $6 \%$ & $-1.61 \%$ & $1.34 \%$ & $-0.43 \%$ & $1.11 \%$ & $5.33 \%$ & $0.64 \%$ & $0.84 \%$ \\
\hline PKG38 & $06 \%$ & $-2.13 \%$ & $2.39 \%$ & $-1.51 \%$ & $-0.19 \%$ & $0.13 \%$ & $1.55 \%$ & $1.80 \%$ \\
\hline PKG39 & & $51 \%$ & $0.47 \%$ & $-5.71 \%$ & $-0.69 \%$ & $0.67 \%$ & $1.68 \%$ & $1.31 \%$ \\
\hline PKG40 & & $86 \%$ & $1.23 \%$ & $-4.90 \%$ & $-1.39 \%$ & $1.04 \%$ & $2.18 \%$ & $1.66 \%$ \\
\hline PKG41 & $\%$ & $39 \%$ & $24 \%$ & -1. & $-0.34 \%$ & $-4.30 \%$ & $3.56 \%$ & $0.72 \%$ \\
\hline PKG42 & & $6 \%$ & $\%$ & & $-1.46 \%$ & $-2.18 \%$ & $0.40 \%$ & $-0.85 \%$ \\
\hline PKG43 & & $6 \%$ & $27 \%$ & $2 \%$ & $-1.75 \%$ & $-3.52 \%$ & $.35 \%$ & $0.06 \%$ \\
\hline PKG44 & & $6.72 \%$ & $-0.14 \%$ & $1.68 \%$ & $0.64 \%$ & $0.29 \%$ & $1.96 \%$ & $1.36 \%$ \\
\hline PKG45 & $0.75 \%$ & $1.65 \%$ & $2.07 \%$ & $-1.46 \%$ & $-1.01 \%$ & $-2.61 \%$ & $2.39 \%$ & $-0.71 \%$ \\
\hline PKG46 & $0.22 \%$ & $1.43 \%$ & $1.29 \%$ & $-3.33 \%$ & $-0.45 \%$ & $-1.67 \%$ & $-0.50 \%$ & $-0.77 \%$ \\
\hline PKG47 & $\%$ & $0.38 \%$ & $0.34 \%$ & $-1.33 \%$ & $-0.51 \%$ & $1.03 \%$ & $-1.92 \%$ & $1.18 \%$ \\
\hline PKG48 & & $.94 \%$ & $1.48 \%$ & & $-1.23 \%$ & $0.15 \%$ & $-1.39 \%$ & $2.23 \%$ \\
\hline PKG49 & & $.29 \%$ & $83 \%$ & & $1.07 \%$ & $0.23 \%$ & $-0.48 \%$ & $-0.28 \%$ \\
\hline PKG50 & $-1.77 \%$ & $1.63 \%$ & $-0.52 \%$ & $-1.80 \%$ & $-0.79 \%$ & $-0.35 \%$ & $-1.46 \%$ & $-1.62 \%$ \\
\hline Mean & $1.18 \%$ & $1.35 \%$ & $1.84 \%$ & $-1.87 \%$ & $-0.33 \%$ & $0.68 \%$ & $2.39 \%$ & $0.63 \%$ \\
\hline SD & $2.17 \%$ & $13 \%$ & $59 \%$ & $1.77 \%$ & $1.03 \%$ & $1.98 \%$ & $2.02 \%$ & $1.24 \%$ \\
\hline Max & $7.79 \%$ & $6.72 \%$ & $7.04 \%$ & $1.82 \%$ & $1.67 \%$ & $5.33 \%$ & $6.76 \%$ & $3.80 \%$ \\
\hline Min & $5 \%$ & $-2.49 \%$ & $-1.28 \%$ & $-5.83 \%$ & $-2.78 \%$ & $-4.30 \%$ & $-1.92 \%$ & $-2.27 \%$ \\
\hline Diff & $11.05 \%$ & $9.22 \%$ & $8.33 \%$ & $7.65 \%$ & $4.45 \%$ & $9.63 \%$ & $8.68 \%$ & $6.07 \%$ \\
\hline
\end{tabular}


Table C-2-11: TCB $1200^{\text {th }}$ cycle; Daisy01 - Daisy08.

\begin{tabular}{|c|c|c|c|c|c|c|c|c|}
\hline & DAISY01 & DAISY02 & DAISY03 & DAISY04 & DAISY05 & DAISY06 & DAISY07 & DAISY08 \\
\hline PKG01 & $4.13 \%$ & $3.56 \%$ & $2.06 \%$ & $0.20 \%$ & $1.11 \%$ & $0.58 \%$ & $2.95 \%$ & $3.33 \%$ \\
\hline PKG02 & $3.89 \%$ & $8.55 \%$ & $0.16 \%$ & $3.41 \%$ & $-0.86 \%$ & $6.02 \%$ & $2.21 \%$ & $8.33 \%$ \\
\hline PKG03 & $1.24 \%$ & $3.62 \%$ & $0.08 \%$ & $1.84 \%$ & $0.15 \%$ & $4.72 \%$ & $1.93 \%$ & $3.92 \%$ \\
\hline PKG04 & outliner & $9.74 \%$ & $1.89 \%$ & $0.29 \%$ & $-0.65 \%$ & $8.66 \%$ & $-1.34 \%$ & $4.25 \%$ \\
\hline PKG05 & $9.33 \%$ & $7.47 \%$ & $-0.16 \%$ & $2.71 \%$ & $-1.09 \%$ & $3.10 \%$ & $1.09 \%$ & $2.09 \%$ \\
\hline PKG06 & $5.38 \%$ & $4.38 \%$ & $1.82 \%$ & $-0.65 \%$ & $-2.86 \%$ & $7.20 \%$ & $3.12 \%$ & $3.69 \%$ \\
\hline PKG07 & $0.76 \%$ & $5.28 \%$ & $1.26 \%$ & $2.12 \%$ & $-0.55 \%$ & $4.63 \%$ & $2.24 \%$ & $2.10 \%$ \\
\hline PKG08 & $1.70 \%$ & $4.87 \%$ & $0.74 \%$ & $0.94 \%$ & $-1.51 \%$ & $3.79 \%$ & $2.75 \%$ & $1.66 \%$ \\
\hline PKG09 & $2.59 \%$ & $4.78 \%$ & $0.66 \%$ & $-1.62 \%$ & $-2.05 \%$ & $4.14 \%$ & $4.03 \%$ & $2.54 \%$ \\
\hline PKG10 & $4.65 \%$ & $2.01 \%$ & $0.00 \%$ & $0.09 \%$ & $-1.44 \%$ & $2.24 \%$ & $3.83 \%$ & $-0.50 \%$ \\
\hline PKG11 & $4.99 \%$ & $0.83 \%$ & $1.05 \%$ & $0.67 \%$ & $-1.83 \%$ & $11.33 \%$ & $2.32 \%$ & $0.72 \%$ \\
\hline PKG12 & $3.51 \%$ & $4.48 \%$ & $-0.31 \%$ & $1.35 \%$ & $-0.29 \%$ & $3.72 \%$ & $1.05 \%$ & $3.83 \%$ \\
\hline PKG13 & $4.83 \%$ & $1.84 \%$ & $-0.50 \%$ & $0.71 \%$ & $-1.05 \%$ & $9.29 \%$ & $1.00 \%$ & $0.31 \%$ \\
\hline PKG14 & $3.17 \%$ & $3.47 \%$ & $0.74 \%$ & $-0.33 \%$ & $-1.10 \%$ & $3.68 \%$ & $1.73 \%$ & $0.27 \%$ \\
\hline PKG15 & $6.95 \%$ & $4.59 \%$ & $0.08 \%$ & $-0.20 \%$ & $-2.74 \%$ & $3.54 \%$ & $0.80 \%$ & $0.87 \%$ \\
\hline PKG16 & $5.92 \%$ & $2.23 \%$ & $1.88 \%$ & $1.03 \%$ & $-1.69 \%$ & $2.83 \%$ & $1.71 \%$ & $0.88 \%$ \\
\hline PKG17 & $4.16 \%$ & $2.25 \%$ & $-1.10 \%$ & $3.29 \%$ & $-1.03 \%$ & $1.41 \%$ & $0.00 \%$ & $-3.02 \%$ \\
\hline PKG18 & $2.98 \%$ & $3.22 \%$ & $0.80 \%$ & $3.50 \%$ & outliner & $9.75 \%$ & $0.26 \%$ & $0.00 \%$ \\
\hline PKG19 & $1.99 \%$ & $3.31 \%$ & $0.74 \%$ & $1.11 \%$ & $-0.81 \%$ & $8.76 \%$ & $0.60 \%$ & $0.63 \%$ \\
\hline PKG20 & $1.34 \%$ & $3.73 \%$ & $0.41 \%$ & $0.00 \%$ & $0.81 \%$ & $3.71 \%$ & $0.32 \%$ & $0.68 \%$ \\
\hline PKG21 & $0.94 \%$ & $3.16 \%$ & $-0.24 \%$ & $-0.29 \%$ & $-0.23 \%$ & $9.52 \%$ & $0.85 \%$ & $-4.66 \%$ \\
\hline PKG22 & $-2.21 \%$ & $-1.24 \%$ & $-0.08 \%$ & $-2.59 \%$ & $-2.31 \%$ & $9.21 \%$ & $2.91 \%$ & $2.79 \%$ \\
\hline PKG23 & $1.88 \%$ & $2.70 \%$ & $0.24 \%$ & $-0.59 \%$ & $-0.52 \%$ & $3.46 \%$ & $0.82 \%$ & $6.50 \%$ \\
\hline PKG24 & $1.92 \%$ & $3.85 \%$ & $0.60 \%$ & $-2.00 \%$ & $0.16 \%$ & $9.76 \%$ & $-0.69 \%$ & $-1.07 \%$ \\
\hline PKG25 & $1.89 \%$ & $2.88 \%$ & $1.86 \%$ & $-0.54 \%$ & $-1.89 \%$ & $6.15 \%$ & $0.69 \%$ & $-5.88 \%$ \\
\hline PKG26 & $3.07 \%$ & $2.28 \%$ & $-0.31 \%$ & $1.77 \%$ & $-0.63 \%$ & $4.69 \%$ & $-1.06 \%$ & $1.45 \%$ \\
\hline PKG27 & $2.28 \%$ & $3.10 \%$ & $0.55 \%$ & $0.10 \%$ & $-0.96 \%$ & $6.45 \%$ & $3.68 \%$ & $-0.16 \%$ \\
\hline PKG28 & $1.49 \%$ & $1.88 \%$ & $-0.08 \%$ & $0.48 \%$ & $-0.33 \%$ & $5.38 \%$ & $2.64 \%$ & $-4.47 \%$ \\
\hline PKG29 & $2.84 \%$ & $2.66 \%$ & $-0.08 \%$ & $2.34 \%$ & $0.00 \%$ & $3.59 \%$ & $2.82 \%$ & $-1.60 \%$ \\
\hline PKG30 & $2.94 \%$ & $0.74 \%$ & $1.05 \%$ & $3.18 \%$ & $1.87 \%$ & $0.36 \%$ & $3.74 \%$ & $3.38 \%$ \\
\hline PKG31 & $-0.96 \%$ & $3.40 \%$ & $-1.11 \%$ & $-3.12 \%$ & $1.23 \%$ & $1.12 \%$ & $2.26 \%$ & $-3.43 \%$ \\
\hline PKG32 & $1.56 \%$ & $0.85 \%$ & $-0.41 \%$ & $-6.20 \%$ & $3.22 \%$ & $8.63 \%$ & $0.81 \%$ & $0.17 \%$ \\
\hline PKG33 & $-0.67 \%$ & $2.98 \%$ & $0.31 \%$ & $-1.21 \%$ & $1.09 \%$ & $0.00 \%$ & $1.79 \%$ & $0.22 \%$ \\
\hline PKG35 & $0.17 \%$ & $4.45 \%$ & $-1.04 \%$ & $-1.80 \%$ & $0.16 \%$ & $1.13 \%$ & $1.11 \%$ & $2.06 \%$ \\
\hline PKG36 & $1.56 \%$ & $2.81 \%$ & $-0.37 \%$ & $-3.12 \%$ & $-0.60 \%$ & $-0.65 \%$ & $0.81 \%$ & $0.97 \%$ \\
\hline PKG37 & $-0.78 \%$ & $0.83 \%$ & $-1.18 \%$ & $0.48 \%$ & $-0.61 \%$ & $3.00 \%$ & $-0.70 \%$ & $-3.56 \%$ \\
\hline PKG38 & $1.07 \%$ & $1.86 \%$ & $-1.39 \%$ & $-1.89 \%$ & $-0.45 \%$ & $-0.86 \%$ & $1.09 \%$ & $-0.54 \%$ \\
\hline PKG39 & $1.43 \%$ & $2.06 \%$ & $-0.08 \%$ & $-4.32 \%$ & $-0.39 \%$ & $-2.73 \%$ & $0.83 \%$ & $-3.42 \%$ \\
\hline PKG40 & $0.17 \%$ & $2.77 \%$ & $-2.01 \%$ & $2.12 \%$ & $-0.48 \%$ & $-4.10 \%$ & $1.63 \%$ & $1.02 \%$ \\
\hline PKG41 & $-0.02 \%$ & $2.01 \%$ & $-0.92 \%$ & $0.09 \%$ & $-1.10 \%$ & $-2.66 \%$ & $1.83 \%$ & $-0.83 \%$ \\
\hline PKG42 & $0.55 \%$ & $3.33 \%$ & $-0.39 \%$ & $2.05 \%$ & $1.16 \%$ & $8.91 \%$ & $0.38 \%$ & $-0.07 \%$ \\
\hline PKG43 & $3.71 \%$ & $-0.46 \%$ & $-0.40 \%$ & $-2.50 \%$ & $-1.96 \%$ & $11.83 \%$ & $2.42 \%$ & $-2.51 \%$ \\
\hline PKG44 & $0.07 \%$ & $4.69 \%$ & $-0.83 \%$ & $-7.96 \%$ & $-0.64 \%$ & $6.77 \%$ & $2.58 \%$ & $-0.72 \%$ \\
\hline PKG45 & $-0.40 \%$ & $2.89 \%$ & $0.16 \%$ & $-2.96 \%$ & $-1.09 \%$ & outliner & $3.23 \%$ & $0.39 \%$ \\
\hline PKG46 & $-0.11 \%$ & $0.41 \%$ & $0.38 \%$ & $-2.51 \%$ & $-0.30 \%$ & $5.30 \%$ & $1.76 \%$ & $-0.07 \%$ \\
\hline PKG47 & $3.20 \%$ & $0.35 \%$ & $-2.34 \%$ & $0.10 \%$ & $0.49 \%$ & $0.92 \%$ & $2.37 \%$ & $0.61 \%$ \\
\hline PKG48 & $-0.03 \%$ & $3.89 \%$ & $-2.05 \%$ & $-0.48 \%$ & $-0.17 \%$ & $9.00 \%$ & $1.12 \%$ & $1.20 \%$ \\
\hline PKG49 & $1.54 \%$ & $3.69 \%$ & $-1.41 \%$ & $-4.66 \%$ & $1.39 \%$ & $9.63 \%$ & $1.54 \%$ & $0.86 \%$ \\
\hline PKG50 & $-0.02 \%$ & $4.57 \%$ & $-0.62 \%$ & $0.56 \%$ & $-0.51 \%$ & $10.77 \%$ & $1.60 \%$ & $-2.32 \%$ \\
\hline Mean & $2.14 \%$ & $3.13 \%$ & $0.00 \%$ & $-0.31 \%$ & $-0.50 \%$ & $4.74 \%$ & $1.58 \%$ & $0.47 \%$ \\
\hline SD & $2.24 \%$ & $2.02 \%$ & $1.04 \%$ & $2.44 \%$ & $1.19 \%$ & $4.00 \%$ & $1.27 \%$ & $2.75 \%$ \\
\hline Max & $9.33 \%$ & $9.74 \%$ & $2.06 \%$ & $3.50 \%$ & $3.22 \%$ & $11.83 \%$ & $4.03 \%$ & $8.33 \%$ \\
\hline Min & $-2.21 \%$ & $-1.24 \%$ & $-2.34 \%$ & $-7.96 \%$ & $-2.86 \%$ & $-4.10 \%$ & $-1.34 \%$ & $-5.88 \%$ \\
\hline Diff & $11.53 \%$ & $10.98 \%$ & $4.40 \%$ & $11.46 \%$ & $6.08 \%$ & $15.93 \%$ & $5.37 \%$ & $14.22 \%$ \\
\hline
\end{tabular}


Table C-2-12: TCB $1200^{\text {th }}$ cycle; Daisy09 - Daisy16.

\begin{tabular}{|c|c|c|c|c|c|c|c|c|}
\hline & DAISYO9 & DAISY10 & DAISY11 & DAISY12 & DAISY13 & DAISY14 & DAISY15 & DAISY16 \\
\hline PKG01 & $2.58 \%$ & $2.38 \%$ & $-1.02 \%$ & $-0.07 \%$ & $-3.85 \%$ & $-1.19 \%$ & $5.14 \%$ & $1.45 \%$ \\
\hline PKG02 & $2.89 \%$ & $1.35 \%$ & $-3.20 \%$ & $-1.27 \%$ & $0.22 \%$ & $1.07 \%$ & $2.70 \%$ & $0.98 \%$ \\
\hline PKG03 & $1.12 \%$ & $1.10 \%$ & $2.04 \%$ & $-1.04 \%$ & $0.19 \%$ & $-2.68 \%$ & $0.34 \%$ & $2.47 \%$ \\
\hline PKG04 & $0.00 \%$ & $1.85 \%$ & $1.81 \%$ & $-1.33 \%$ & $0.48 \%$ & $0.66 \%$ & $0.29 \%$ & $-1.33 \%$ \\
\hline PKG05 & $2.85 \%$ & $1.82 \%$ & $1.55 \%$ & $1.00 \%$ & $0.14 \%$ & $1.83 \%$ & $1.47 \%$ & $-0.21 \%$ \\
\hline PKG06 & $2.45 \%$ & $2.01 \%$ & $1.03 \%$ & $-1.17 \%$ & $1.29 \%$ & $-1.19 \%$ & $3.52 \%$ & $0.30 \%$ \\
\hline PKG07 & $0.80 \%$ & $2.06 \%$ & $0.49 \%$ & $0.67 \%$ & $2.71 \%$ & $-1.91 \%$ & $2.29 \%$ & $0.06 \%$ \\
\hline PKG08 & $1.57 \%$ & $0.13 \%$ & $0.60 \%$ & $-1.42 \%$ & $0.26 \%$ & $0.48 \%$ & $-0.21 \%$ & $0.49 \%$ \\
\hline PKG09 & $0.72 \%$ & $-0.08 \%$ & $0.34 \%$ & $-2.09 \%$ & $0.22 \%$ & $-2.05 \%$ & $1.30 \%$ & $2.46 \%$ \\
\hline PKG10 & $0.22 \%$ & $0.92 \%$ & $0.85 \%$ & $-2.06 \%$ & $0.33 \%$ & $-0.21 \%$ & $0.46 \%$ & $-0.05 \%$ \\
\hline PKG11 & $0.98 \%$ & $-2.08 \%$ & $0.85 \%$ & $-0.30 \%$ & $0.00 \%$ & $-0.84 \%$ & $1.10 \%$ & $3.33 \%$ \\
\hline PKG12 & $0.07 \%$ & $-1.62 \%$ & $1.46 \%$ & $-1.76 \%$ & $-1.03 \%$ & $0.56 \%$ & $0.86 \%$ & $1.25 \%$ \\
\hline PKG13 & $3.29 \%$ & $1.20 \%$ & $0.98 \%$ & $-0.14 \%$ & $-2.56 \%$ & $-0.38 \%$ & $1.98 \%$ & $-0.39 \%$ \\
\hline PKG14 & $0.21 \%$ & $-1.76 \%$ & $0.81 \%$ & $0.00 \%$ & $0.44 \%$ & $1.19 \%$ & $-1.01 \%$ & $2.43 \%$ \\
\hline PKG15 & $-1.30 \%$ & $-0.75 \%$ & $0.35 \%$ & $-3.27 \%$ & $0.00 \%$ & $-0.08 \%$ & $-1.54 \%$ & $-0.11 \%$ \\
\hline PKG16 & $0.61 \%$ & $0.72 \%$ & $0.52 \%$ & $-0.38 \%$ & $0.50 \%$ & $-0.46 \%$ & $-0.51 \%$ & $-0.52 \%$ \\
\hline PKG17 & $2.67 \%$ & $-3.84 \%$ & $1.47 \%$ & $-0.71 \%$ & $-0.07 \%$ & $1.23 \%$ & $4.09 \%$ & $0.71 \%$ \\
\hline PKG18 & $2.54 \%$ & $0.22 \%$ & $0.93 \%$ & $-3.75 \%$ & $1.20 \%$ & $0.45 \%$ & $0.96 \%$ & $0.00 \%$ \\
\hline PKG19 & $0.80 \%$ & $5.00 \%$ & $1.74 \%$ & $0.73 \%$ & $-2.79 \%$ & $-0.31 \%$ & $0.12 \%$ & $1.06 \%$ \\
\hline PKG20 & $2.66 \%$ & $-0.51 \%$ & $1.90 \%$ & $-1.08 \%$ & $-0.49 \%$ & $0.52 \%$ & $1.02 \%$ & $-0.05 \%$ \\
\hline PKG21 & $1.37 \%$ & $0.00 \%$ & $1.68 \%$ & $-2.60 \%$ & $-0.91 \%$ & $-0.30 \%$ & $1.95 \%$ & $0.79 \%$ \\
\hline PKG22 & $2.66 \%$ & $1.84 \%$ & $0.41 \%$ & $-1.77 \%$ & $-1.09 \%$ & $2.80 \%$ & $2.48 \%$ & $0.11 \%$ \\
\hline PKG23 & outliner & $1.61 \%$ & $0.57 \%$ & $-2.84 \%$ & $0.00 \%$ & $0.39 \%$ & $3.37 \%$ & $0.46 \%$ \\
\hline PKG24 & $1.33 \%$ & $-0.23 \%$ & $2.14 \%$ & $-3.36 \%$ & $-0.36 \%$ & $0.77 \%$ & $0.26 \%$ & $0.35 \%$ \\
\hline PKG25 & $4.81 \%$ & $0.51 \%$ & $1.55 \%$ & $0.71 \%$ & $-0.54 \%$ & $0.94 \%$ & $1.22 \%$ & $0.97 \%$ \\
\hline PKG26 & $-0.66 \%$ & $1.32 \%$ & $1.10 \%$ & $-2.21 \%$ & $-1.06 \%$ & $-0.07 \%$ & $0.23 \%$ & $-0.65 \%$ \\
\hline PKG27 & $1.29 \%$ & $1.83 \%$ & $0.56 \%$ & $-0.95 \%$ & $-0.48 \%$ & $0.74 \%$ & $-0.18 \%$ & $-0.05 \%$ \\
\hline PKG28 & $-0.42 \%$ & $5.09 \%$ & $-0.14 \%$ & $-2.38 \%$ & $0.88 \%$ & $3.56 \%$ & $0.06 \%$ & $-0.39 \%$ \\
\hline PKG29 & $-0.15 \%$ & $-2.79 \%$ & $0.74 \%$ & $-4.41 \%$ & $0.27 \%$ & $1.97 \%$ & $-2.44 \%$ & $0.16 \%$ \\
\hline PKG30 & $2.85 \%$ & $1.68 \%$ & $-0.14 \%$ & $-2.86 \%$ & $0.49 \%$ & $1.74 \%$ & $1.58 \%$ & $-0.41 \%$ \\
\hline PKG31 & $0.17 \%$ & $-1.79 \%$ & $1.04 \%$ & $-2.48 \%$ & $-0.92 \%$ & $-1,20 \%$ & $4.11 \%$ & $0.43 \%$ \\
\hline PKG32 & $-0.16 \%$ & $-2.06 \%$ & $-1.78 \%$ & $-1.15 \%$ & $0.57 \%$ & $1.23 \%$ & $2.23 \%$ & $1.84 \%$ \\
\hline PKG33 & $-3.30 \%$ & $0.22 \%$ & $1.58 \%$ & $-1.06 \%$ & $-0.14 \%$ & $2.24 \%$ & $0.59 \%$ & $1.08 \%$ \\
\hline PKG35 & $-1.69 \%$ & $0.65 \%$ & $-1.24 \%$ & $-5.83 \%$ & $-0.14 \%$ & $0.38 \%$ & $-0.36 \%$ & $0.85 \%$ \\
\hline PKG36 & $4.72 \%$ & $0.50 \%$ & $0.33 \%$ & $0.00 \%$ & $0.26 \%$ & $-4.01 \%$ & $-0.34 \%$ & $0.65 \%$ \\
\hline PKG37 & $0.71 \%$ & $-1.98 \%$ & $-0.20 \%$ & $2.75 \%$ & $0.77 \%$ & $1.35 \%$ & $-1.62 \%$ & $-1.32 \%$ \\
\hline PKG38 & $-4.04 \%$ & $2.33 \%$ & $-0.48 \%$ & $-0.79 \%$ & $0.58 \%$ & $-4.41 \%$ & $-1.33 \%$ & $-1.04 \%$ \\
\hline PKG39 & $2.76 \%$ & $0.50 \%$ & $-1.14 \%$ & $-5.16 \%$ & $-0.69 \%$ & $-0.30 \%$ & $0.84 \%$ & $-0.27 \%$ \\
\hline PKG40 & $0.87 \%$ & $1.42 \%$ & $-0.48 \%$ & $-4.69 \%$ & $0.28 \%$ & $-0.82 \%$ & $-0.58 \%$ & $-0.55 \%$ \\
\hline PKG41 & $2.64 \%$ & $1.37 \%$ & $2.69 \%$ & $-0.95 \%$ & $0.61 \%$ & $-3.10 \%$ & $-0.50 \%$ & $-0.11 \%$ \\
\hline PKG42 & $0.15 \%$ & $-0.07 \%$ & $3.48 \%$ & $0.22 \%$ & $0.90 \%$ & $-1.09 \%$ & $0.62 \%$ & $1.16 \%$ \\
\hline PKG43 & $4.36 \%$ & $-0.44 \%$ & $2.30 \%$ & $0.51 \%$ & $-0.91 \%$ & $-2.42 \%$ & $3.72 \%$ & $-1.30 \%$ \\
\hline PKG44 & $6.09 \%$ & $0.89 \%$ & $-0.97 \%$ & $1.37 \%$ & $0.43 \%$ & $-3.30 \%$ & $-0.31 \%$ & $1.36 \%$ \\
\hline PKG45 & $1.65 \%$ & $1.36 \%$ & $1.17 \%$ & $-0.29 \%$ & $-0.27 \%$ & $-1.98 \%$ & $-2.51 \%$ & $-1.04 \%$ \\
\hline PKG46 & $2.53 \%$ & $1.36 \%$ & $0.32 \%$ & $-1.22 \%$ & $-0.45 \%$ & $0.83 \%$ & $-1.55 \%$ & $-1.13 \%$ \\
\hline PKG47 & $2.75 \%$ & $0.69 \%$ & $1.90 \%$ & $0.22 \%$ & $0.37 \%$ & $2.38 \%$ & $-3.53 \%$ & $1.52 \%$ \\
\hline PKG48 & $2.08 \%$ & $-1.57 \%$ & $0.49 \%$ & $0.44 \%$ & $-1.08 \%$ & $-0.31 \%$ & $-3.35 \%$ & $-0.72 \%$ \\
\hline PKG49 & $1.89 \%$ & $-2.33 \%$ & $0.58 \%$ & $-0.23 \%$ & $-0.14 \%$ & $-0.23 \%$ & $-3.77 \%$ & $-1.71 \%$ \\
\hline PKG50 & $3.53 \%$ & $-1.09 \%$ & $0.78 \%$ & $-0.42 \%$ & $0.59 \%$ & $0.21 \%$ & $-5.16 \%$ & $-1.88 \%$ \\
\hline Mean & $1.43 \%$ & $0.43 \%$ & $0.70 \%$ & $-1.24 \%$ & $-0.10 \%$ & $-0.11 \%$ & $0.41 \%$ & $0.28 \%$ \\
\hline SD & $1.94 \%$ & $1.78 \%$ & $1.19 \%$ & $1.74 \%$ & $1.05 \%$ & $1.72 \%$ & $2.15 \%$ & $1.14 \%$ \\
\hline $\operatorname{Max}$ & $6.09 \%$ & $5.09 \%$ & $3.48 \%$ & $2.75 \%$ & $2.71 \%$ & $3.56 \%$ & $5.14 \%$ & $3.33 \%$ \\
\hline Min & $-4.04 \%$ & $-3.84 \%$ & $-3.20 \%$ & $-5.83 \%$ & $-3.85 \%$ & $-4.41 \%$ & $-5.16 \%$ & $-1.88 \%$ \\
\hline Diff & $10.13 \%$ & $8.93 \%$ & $6.68 \%$ & $8.58 \%$ & $6.56 \%$ & $7.97 \%$ & $10.29 \%$ & $5.21 \%$ \\
\hline
\end{tabular}


Table C-2-13: TCB $1492^{\text {nd }}$ cycle; Daisy01 - Daisy08.

\begin{tabular}{|c|c|c|c|c|c|c|c|c|}
\hline & DAISY01 & DAISY02 & DAISY03 & DAISY04 & DAISY05 & DAISY06 & DAISY07 & DAISY08 \\
\hline PKG01 & $2.05 \%$ & $2.01 \%$ & $2.48 \%$ & $0.30 \%$ & $0.63 \%$ & $1.05 \%$ & $6.11 \%$ & $4.91 \%$ \\
\hline PKG02 & $1.05 \%$ & $4.76 \%$ & $1.51 \%$ & $3.60 \%$ & $-0.86 \%$ & $5.55 \%$ & $2.02 \%$ & $5.80 \%$ \\
\hline PKG03 & $-0.38 \%$ & $4.72 \%$ & $0.92 \%$ & $-0.79 \%$ & $-1.60 \%$ & $4.17 \%$ & $3.86 \%$ & $6.03 \%$ \\
\hline PKG04 & $0.07 \%$ & $5.26 \%$ & $1.97 \%$ & $-0.58 \%$ & $-1.54 \%$ & $5.12 \%$ & $-1.08 \%$ & $4.25 \%$ \\
\hline PKG05 & $0.17 \%$ & $2.32 \%$ & $0.00 \%$ & $1.16 \%$ & $-1.79 \%$ & $1.38 \%$ & $0.19 \%$ & $4.92 \%$ \\
\hline PKG06 & $3.15 \%$ & $5.05 \%$ & $1.04 \%$ & $0.86 \%$ & $-2.61 \%$ & $7.86 \%$ & $2.42 \%$ & $9.36 \%$ \\
\hline PKG07 & $2.83 \%$ & $2.66 \%$ & $4.86 \%$ & $2.62 \%$ & $-0.32 \%$ & $5.23 \%$ & $3.88 \%$ & $8.24 \%$ \\
\hline PKG08 & $0.79 \%$ & $1.75 \%$ & $0.00 \%$ & $0.09 \%$ & $-1.58 \%$ & $4.46 \%$ & $1.87 \%$ & $0.20 \%$ \\
\hline PKG09 & $3.70 \%$ & $3.44 \%$ & $1.15 \%$ & $-2.39 \%$ & $0.00 \%$ & $7.47 \%$ & $3.58 \%$ & $2.92 \%$ \\
\hline PKG10 & $1.99 \%$ & $1.07 \%$ & $0.08 \%$ & $-1.64 \%$ & $-2.38 \%$ & $3.91 \%$ & $1.19 \%$ & $-0.43 \%$ \\
\hline PKG11 & $0.46 \%$ & $1.33 \%$ & $0.32 \%$ & $0.10 \%$ & $-2.06 \%$ & $2.41 \%$ & $0.73 \%$ & $-0.16 \%$ \\
\hline PKG12 & $-0.11 \%$ & $2.69 \%$ & $0.08 \%$ & $-0.45 \%$ & $-0.93 \%$ & $5.42 \%$ & $0.68 \%$ & $6.17 \%$ \\
\hline PKG13 & $1.90 \%$ & $0.89 \%$ & $0.33 \%$ & $2.14 \%$ & $-0.89 \%$ & $4.95 \%$ & $1.59 \%$ & $0.46 \%$ \\
\hline PKG14 & $-0.54 \%$ & $3.47 \%$ & $0.52 \%$ & $0.92 \%$ & $-1.10 \%$ & $1.79 \%$ & $0.96 \%$ & $9.89 \%$ \\
\hline PKG15 & $-0.02 \%$ & $2.47 \%$ & $0.74 \%$ & $0.70 \%$ & $-3.21 \%$ & $11.84 \%$ & $1.88 \%$ & $-1.34 \%$ \\
\hline PKG16 & $1.96 \%$ & $2.83 \%$ & $0.87 \%$ & $1.27 \%$ & $-1.37 \%$ & $4.49 \%$ & $2.00 \%$ & $0.38 \%$ \\
\hline PKG17 & $-0.95 \%$ & $1.38 \%$ & $-1.57 \%$ & $1.79 \%$ & $-0.89 \%$ & $2.49 \%$ & $1.13 \%$ & $-3.65 \%$ \\
\hline PKG18 & $-0.22 \%$ & $2.50 \%$ & $0.48 \%$ & $3.50 \%$ & $-0.70 \%$ & $11.04 \%$ & $1.68 \%$ & $-0.81 \%$ \\
\hline PKG19 & $3.49 \%$ & $3.52 \%$ & $-0.16 \%$ & $2.41 \%$ & $0.32 \%$ & $11.35 \%$ & $1.67 \%$ & $0.08 \%$ \\
\hline PKG20 & $1.25 \%$ & $1.48 \%$ & $0.65 \%$ & $0.77 \%$ & $1.06 \%$ & $5.33 \%$ & $0.13 \%$ & $0.68 \%$ \\
\hline PKG21 & $-0.22 \%$ & $2.66 \%$ & $-0.24 \%$ & $-1.17 \%$ & $-1.01 \%$ & $6.31 \%$ & $2.57 \%$ & $-5.63 \%$ \\
\hline PKG22 & $-2.40 \%$ & $-1.14 \%$ & $-0.24 \%$ & $-0.37 \%$ & $-0.80 \%$ & $8.37 \%$ & $1.94 \%$ & $0.85 \%$ \\
\hline PKG23 & $1.45 \%$ & $2.14 \%$ & $0.00 \%$ & $1.47 \%$ & $0.26 \%$ & $7.83 \%$ & $1.57 \%$ & $3.17 \%$ \\
\hline PKG24 & $0.59 \%$ & $2.16 \%$ & $-0.94 \%$ & $-0.53 \%$ & $-0.25 \%$ & $5.19 \%$ & $0.35 \%$ & $-2.56 \%$ \\
\hline PKG25 & $-0.41 \%$ & $2.59 \%$ & $1.55 \%$ & $0.09 \%$ & $0.24 \%$ & $-7.78 \%$ & $2.70 \%$ & $-5.39 \%$ \\
\hline PKG26 & $1.91 \%$ & $3.06 \%$ & $-0.16 \%$ & $2.05 \%$ & $-0.63 \%$ & $7.27 \%$ & $-0.75 \%$ & $0.61 \%$ \\
\hline PKG27 & $2.57 \%$ & $1.57 \%$ & $-0.24 \%$ & $0.48 \%$ & $-0.56 \%$ & $6.45 \%$ & $-1.42 \%$ & $0.39 \%$ \\
\hline PKG28 & $2.59 \%$ & $1.88 \%$ & $-0.80 \%$ & $1.83 \%$ & $-0.82 \%$ & $7.83 \%$ & $1.25 \%$ & $-3.26 \%$ \\
\hline PKG29 & $1.70 \%$ & $1.01 \%$ & $-0.53 \%$ & $1.17 \%$ & $-1.63 \%$ & $3.48 \%$ & $0.88 \%$ & $-1.17 \%$ \\
\hline PKG30 & $0.37 \%$ & $-1.35 \%$ & $1.22 \%$ & $0.80 \%$ & $0.08 \%$ & $3.11 \%$ & $0.39 \%$ & $2.72 \%$ \\
\hline PKG31 & outliner & $1.95 \%$ & $-0.68 \%$ & $-2.92 \%$ & $0.61 \%$ & $2.60 \%$ & $1.84 \%$ & $-4.02 \%$ \\
\hline PKG32 & $-0.72 \%$ & $-0.86 \%$ & $-1.81 \%$ & $-7.63 \%$ & $0.00 \%$ & $7.76 \%$ & $0.74 \%$ & $0.50 \%$ \\
\hline PKG33 & $-2.90 \%$ & $0.92 \%$ & $-0.71 \%$ & $-0.65 \%$ & $0.16 \%$ & $8.85 \%$ & $0.45 \%$ & $-0.15 \%$ \\
\hline PKG35 & $-0.60 \%$ & $2.15 \%$ & $-0.72 \%$ & $-0.30 \%$ & $0.94 \%$ & $1.02 \%$ & $1.57 \%$ & $1.90 \%$ \\
\hline PKG36 & $1.28 \%$ & $1.43 \%$ & $-1.19 \%$ & $-2.78 \%$ & $-0.52 \%$ & $7.74 \%$ & $0.25 \%$ & $1.86 \%$ \\
\hline PKG37 & $-0.12 \%$ & $1.33 \%$ & $-1.97 \%$ & $-0.10 \%$ & $-0.61 \%$ & $9.36 \%$ & $0.90 \%$ & $-4.95 \%$ \\
\hline PKG38 & $-1.11 \%$ & $1.57 \%$ & $-1.39 \%$ & $-3.14 \%$ & $-0.89 \%$ & $1.51 \%$ & $4.37 \%$ & $-2.15 \%$ \\
\hline PKG39 & $0.27 \%$ & $1.45 \%$ & $-0.48 \%$ & $-0.64 \%$ & $-0.16 \%$ & $-4.26 \%$ & $0.90 \%$ & $-3.57 \%$ \\
\hline PKG40 & $-0.22 \%$ & $1.66 \%$ & $-3.26 \%$ & $4.14 \%$ & $-0.48 \%$ & $-1.94 \%$ & $2.81 \%$ & $-0.55 \%$ \\
\hline PKG41 & $-0.02 \%$ & $2.10 \%$ & $-1.07 \%$ & $0.72 \%$ & $-1.61 \%$ & $1.84 \%$ & $1.70 \%$ & $-2.22 \%$ \\
\hline PKG42 & $0.07 \%$ & $3.64 \%$ & $-1.57 \%$ & $0.37 \%$ & $-0.70 \%$ & $5.90 \%$ & $1.48 \%$ & $-0.96 \%$ \\
\hline PKG43 & $-0.03 \%$ & $1.66 \%$ & $-0.16 \%$ & $-2.22 \%$ & $-1.18 \%$ & $9.30 \%$ & $2.29 \%$ & $-4.27 \%$ \\
\hline PKG44 & $-2.47 \%$ & $2.79 \%$ & $-2.06 \%$ & $-8.15 \%$ & $0.32 \%$ & $6.30 \%$ & $1.22 \%$ & $-1.12 \%$ \\
\hline PKG45 & $-1.26 \%$ & $1.02 \%$ & $0.16 \%$ & $-4.57 \%$ & $-0.39 \%$ & $7.91 \%$ & $1.94 \%$ & $-1.31 \%$ \\
\hline PKG46 & $-0.84 \%$ & $0.22 \%$ & $-0.15 \%$ & $-4.15 \%$ & $-1.34 \%$ & $6.40 \%$ & $1.26 \%$ & $-0.37 \%$ \\
\hline PKG47 & $-0.33 \%$ & $-0.06 \%$ & $-2.58 \%$ & $-1.17 \%$ & $-1.21 \%$ & $2.07 \%$ & $1.71 \%$ & $-1.45 \%$ \\
\hline PKG48 & $-2.77 \%$ & $6.97 \%$ & $-2.45 \%$ & $-2.52 \%$ & $-0.43 \%$ & $4.18 \%$ & $0.46 \%$ & $-1.75 \%$ \\
\hline PKG49 & $-1.99 \%$ & $3.07 \%$ & $-1.33 \%$ & $-6.64 \%$ & $-0.33 \%$ & $10.73 \%$ & $2.38 \%$ & $0.43 \%$ \\
\hline PKG50 & $-1.29 \%$ & $4.27 \%$ & $-0.23 \%$ & $0.93 \%$ & $-1.61 \%$ & $6.91 \%$ & $2.71 \%$ & $-3.09 \%$ \\
\hline Mean & $0.33 \%$ & $2.19 \%$ & $-0.16 \%$ & $-0.39 \%$ & $-0.74 \%$ & $5.09 \%$ & $1.57 \%$ & $0.42 \%$ \\
\hline SD & $1.61 \%$ & $1.60 \%$ & $1.40 \%$ & $2.63 \%$ & $0.90 \%$ & $3.82 \%$ & $1.35 \%$ & $3.68 \%$ \\
\hline Max & $3.70 \%$ & $6.97 \%$ & $4.86 \%$ & $4.14 \%$ & $1.06 \%$ & $11.84 \%$ & $6.11 \%$ & $9.89 \%$ \\
\hline Min & $-2.90 \%$ & $-1.35 \%$ & $-3.26 \%$ & $-8.15 \%$ & $-3.21 \%$ & $-7.78 \%$ & $-1.42 \%$ & $-5.63 \%$ \\
\hline Diff & $6.60 \%$ & $8.32 \%$ & $8.12 \%$ & $12.29 \%$ & $4.27 \%$ & $19.61 \%$ & $7.53 \%$ & $15.53 \%$ \\
\hline
\end{tabular}


Table C-2-14: TCB $1492^{\text {nd }}$ cycle; Daisy09 - Daisy16.

\begin{tabular}{|c|c|c|c|c|c|c|c|c|}
\hline & DAISY09 & DAISY10 & DAISY11 & DAISY12 & DAISY13 & DAISY14 & DAISY15 & DAISY16 \\
\hline PKG01 & $1.61 \%$ & $4.47 \%$ & $0.34 \%$ & $-0.29 \%$ & $-3.04 \%$ & $0.00 \%$ & $1.15 \%$ & $-0.33 \%$ \\
\hline PKG02 & $0.56 \%$ & $3.45 \%$ & $-2.30 \%$ & $-1.42 \%$ & $2.30 \%$ & $-0.15 \%$ & $1.86 \%$ & $-0.23 \%$ \\
\hline PKG03 & $0.21 \%$ & $2.96 \%$ & $0.33 \%$ & $-2.42 \%$ & $3.22 \%$ & $-3.02 \%$ & $1.27 \%$ & $-0.90 \%$ \\
\hline PKG04 & $0.46 \%$ & $2.08 \%$ & $0.00 \%$ & $-0.82 \%$ & $-0.90 \%$ & $0.81 \%$ & $0.06 \%$ & $-2.38 \%$ \\
\hline PKG05 & $4.64 \%$ & $8.89 \%$ & $0.74 \%$ & $0.50 \%$ & $0.14 \%$ & $-0.69 \%$ & $0.18 \%$ & $-0.32 \%$ \\
\hline PKG06 & $2.36 \%$ & $3.47 \%$ & $0.15 \%$ & $0.78 \%$ & $2.73 \%$ & $0.32 \%$ & $2.94 \%$ & $-0.90 \%$ \\
\hline PKG07 & $0.16 \%$ & $5.94 \%$ & $-0.70 \%$ & $0.45 \%$ & $3.78 \%$ & $-2.06 \%$ & $3.28 \%$ & $0.22 \%$ \\
\hline PKG08 & $1.72 \%$ & $1.83 \%$ & $0.54 \%$ & $0.58 \%$ & $0.00 \%$ & $5.33 \%$ & $0.32 \%$ & $0.05 \%$ \\
\hline PKG09 & $1.29 \%$ & $2.12 \%$ & $-0.14 \%$ & $-2.88 \%$ & $-0.94 \%$ & $0.99 \%$ & $0.49 \%$ & $0.73 \%$ \\
\hline PKG10 & $0.89 \%$ & $2.21 \%$ & $0.65 \%$ & $0.34 \%$ & $-0.66 \%$ & $1.28 \%$ & $0.58 \%$ & $-0.63 \%$ \\
\hline PKG11 & $1.43 \%$ & $-1.87 \%$ & $0.07 \%$ & $0.00 \%$ & $-0.60 \%$ & $-0.49 \%$ & $4.80 \%$ & $1.21 \%$ \\
\hline PKG12 & $0.36 \%$ & $-2.02 \%$ & $1.08 \%$ & $-2.38 \%$ & $-1.10 \%$ & $-0.14 \%$ & $0.75 \%$ & $0.79 \%$ \\
\hline PKG13 & $4.30 \%$ & $0.53 \%$ & $0.77 \%$ & $-1.38 \%$ & $-3.13 \%$ & $0.54 \%$ & $2.41 \%$ & $-1.12 \%$ \\
\hline PKG14 & $0.00 \%$ & $-2.24 \%$ & $1.12 \%$ & $-1.52 \%$ & $-0.44 \%$ & $-0.49 \%$ & $2.98 \%$ & $0.88 \%$ \\
\hline PKG15 & $1.30 \%$ & $0.30 \%$ & $0.63 \%$ & $-3.84 \%$ & $-1.34 \%$ & $-0.46 \%$ & $-1.72 \%$ & $-0.17 \%$ \\
\hline PKG16 & $0.48 \%$ & $-0.52 \%$ & $-0.06 \%$ & $-0.95 \%$ & $1.05 \%$ & $-2.91 \%$ & $2.48 \%$ & $0.70 \%$ \\
\hline PKG17 & $3.81 \%$ & $-2.06 \%$ & $0.60 \%$ & $1.07 \%$ & $-0.47 \%$ & $1.45 \%$ & $1.30 \%$ & $2.39 \%$ \\
\hline PKG18 & $3.41 \%$ & $6.33 \%$ & $0.66 \%$ & $-4.37 \%$ & $0.42 \%$ & $1.11 \%$ & $0.96 \%$ & $2.31 \%$ \\
\hline PKG19 & $1.93 \%$ & $-0.60 \%$ & $4.95 \%$ & $0.00 \%$ & $-1.88 \%$ & $2.30 \%$ & $1.47 \%$ & $2.82 \%$ \\
\hline PKG20 & $-0.23 \%$ & $-0.07 \%$ & $1.16 \%$ & $-2.38 \%$ & $-1.05 \%$ & $0.37 \%$ & $0.18 \%$ & $0.39 \%$ \\
\hline PKG21 & $0.40 \%$ & $-0.59 \%$ & $0.56 \%$ & $-2.39 \%$ & $-1.12 \%$ & $2.04 \%$ & $0.24 \%$ & $0.11 \%$ \\
\hline PKG22 & $5.00 \%$ & $0.73 \%$ & $0.41 \%$ & $-3.04 \%$ & $-1.85 \%$ & $0.30 \%$ & $-0.35 \%$ & $0.34 \%$ \\
\hline PKG23 & $2.08 \%$ & $2.02 \%$ & $2.70 \%$ & $-3.85 \%$ & $-0.97 \%$ & $-1.26 \%$ & $-0.61 \%$ & $-0.06 \%$ \\
\hline PKG24 & $1.58 \%$ & $-1.07 \%$ & $1.47 \%$ & $-4.03 \%$ & $-0.87 \%$ & $-1.15 \%$ & $-0.19 \%$ & $0.29 \%$ \\
\hline PKG25 & $0.99 \%$ & $-0.66 \%$ & $0.27 \%$ & $-1.98 \%$ & $0.94 \%$ & $2.24 \%$ & $0.70 \%$ & $0.81 \%$ \\
\hline PKG26 & $-2.43 \%$ & $1.76 \%$ & $0.69 \%$ & $-2.78 \%$ & $-0.53 \%$ & $-2.96 \%$ & $0.00 \%$ & $-1.08 \%$ \\
\hline PKG27 & $0.16 \%$ & $1.90 \%$ & $0.85 \%$ & $-1.60 \%$ & $-2.20 \%$ & $-0.52 \%$ & $-0.29 \%$ & $-0.83 \%$ \\
\hline PKG28 & $-0.75 \%$ & $0.08 \%$ & $2.52 \%$ & $-0.97 \%$ & $0.81 \%$ & $2.51 \%$ & $0.61 \%$ & $-0.22 \%$ \\
\hline PKG29 & $-1.37 \%$ & $-0.36 \%$ & $1.61 \%$ & $-5.30 \%$ & $0.34 \%$ & $0.87 \%$ & $-3.00 \%$ & $0.86 \%$ \\
\hline PKG30 & $-1.31 \%$ & $-1.03 \%$ & $-0.57 \%$ & $-1.32 \%$ & $0.84 \%$ & $2.19 \%$ & $-0.48 \%$ & $-0.74 \%$ \\
\hline PKG31 & $0.35 \%$ & $-1.01 \%$ & $0.30 \%$ & $-3.03 \%$ & $-0.08 \%$ & $-2.48 \%$ & $0.66 \%$ & $1.41 \%$ \\
\hline PKG32 & $-0.72 \%$ & $0.07 \%$ & $-1.14 \%$ & $-2.37 \%$ & $-0.29 \%$ & $0.54 \%$ & $4.72 \%$ & $2.43 \%$ \\
\hline PKG33 & $-3.68 \%$ & $-0.44 \%$ & $-0.46 \%$ & $-1.41 \%$ & $-1.05 \%$ & $2.71 \%$ & $0.29 \%$ & $0.48 \%$ \\
\hline PKG35 & $-2.69 \%$ & $1.59 \%$ & $-0.62 \%$ & $-3.94 \%$ & $-1.79 \%$ & $0.45 \%$ & $0.91 \%$ & $0.17 \%$ \\
\hline PKG36 & $1.23 \%$ & $1.42 \%$ & $-0.39 \%$ & $-0.78 \%$ & $-0.19 \%$ & $0.92 \%$ & $-0.86 \%$ & $0.33 \%$ \\
\hline PKG37 & $-0.95 \%$ & $-1.25 \%$ & $-1.47 \%$ & $1.52 \%$ & $0.77 \%$ & $0.68 \%$ & $-1.09 \%$ & $-1.16 \%$ \\
\hline PKG38 & $-5.21 \%$ & $-4.32 \%$ & $-0.82 \%$ & $-1.87 \%$ & $-0.45 \%$ & $-1.70 \%$ & $-0.23 \%$ & $-0.77 \%$ \\
\hline PKG39 & $1.89 \%$ & $-0.93 \%$ & $-0.80 \%$ & $-5.23 \%$ & $-0.49 \%$ & $0.74 \%$ & $0.54 \%$ & $-0.66 \%$ \\
\hline PKG40 & $0.08 \%$ & $1.12 \%$ & $0.41 \%$ & $-4.34 \%$ & $0.00 \%$ & $-0.45 \%$ & $-1.05 \%$ & $-1.37 \%$ \\
\hline PKG41 & $2.12 \%$ & $-0.29 \%$ & $4.43 \%$ & $-3.19 \%$ & $0.07 \%$ & $-4.23 \%$ & $0.74 \%$ & $-0.06 \%$ \\
\hline PKG42 & $-1.59 \%$ & $-2.19 \%$ & $0.53 \%$ & $-0.72 \%$ & $-0.97 \%$ & $-1.74 \%$ & $-2.62 \%$ & $-2.32 \%$ \\
\hline PKG43 & $0.79 \%$ & $-0.29 \%$ & $1.01 \%$ & $0.00 \%$ & $-1.68 \%$ & $-3.15 \%$ & $0.23 \%$ & $0.00 \%$ \\
\hline PKG44 & $0.72 \%$ & $-2.44 \%$ & $-1.24 \%$ & $0.15 \%$ & $0.57 \%$ & $-3.67 \%$ & $-0.67 \%$ & $1.13 \%$ \\
\hline PKG45 & $3.08 \%$ & $0.43 \%$ & $2.41 \%$ & $-1.97 \%$ & $-1.34 \%$ & $-2.12 \%$ & $-2.06 \%$ & $-1.47 \%$ \\
\hline PKG46 & $0.45 \%$ & $0.65 \%$ & $0.45 \%$ & $-3.94 \%$ & $-1.28 \%$ & $0.07 \%$ & $-1.33 \%$ & $-1.59 \%$ \\
\hline PKG47 & $0.50 \%$ & $1.22 \%$ & $-0.88 \%$ & $-1.78 \%$ & $-0.88 \%$ & $0.95 \%$ & $-5.68 \%$ & $-1.69 \%$ \\
\hline PKG48 & $-0.25 \%$ & $-1.94 \%$ & $0.07 \%$ & $-0.37 \%$ & $0.58 \%$ & $-0.15 \%$ & $-3.47 \%$ & $-1.00 \%$ \\
\hline PKG49 & $2.22 \%$ & $-2.33 \%$ & $1.39 \%$ & $-1.16 \%$ & $-0.50 \%$ & $-0.31 \%$ & $-4.25 \%$ & $-2.00 \%$ \\
\hline PKG50 & $-1.40 \%$ & $-1.77 \%$ & $0.98 \%$ & $-1.17 \%$ & $-0.86 \%$ & $-1.05 \%$ & $-5.16 \%$ & $-2.99 \%$ \\
\hline Mean & $0.65 \%$ & $0.52 \%$ & $0.51 \%$ & $-1.71 \%$ & $-0.33 \%$ & $-0.12 \%$ & $0.08 \%$ & $-0.13 \%$ \\
\hline SD & $1.99 \%$ & $2.49 \%$ & $1.31 \%$ & $1.70 \%$ & $1.38 \%$ & $1.86 \%$ & $2.14 \%$ & $1.26 \%$ \\
\hline Max & $5.00 \%$ & $8.89 \%$ & $4.95 \%$ & $1.52 \%$ & $3.78 \%$ & $5.33 \%$ & $4.80 \%$ & $2.82 \%$ \\
\hline Min & $-5.21 \%$ & $-4.32 \%$ & $-2.30 \%$ & $-5.30 \%$ & $-3.13 \%$ & $-4.23 \%$ & $-5.68 \%$ & $-2.99 \%$ \\
\hline Diff & $10.21 \%$ & $13.21 \%$ & $7.25 \%$ & $6.81 \%$ & $6.92 \%$ & $9.56 \%$ & $10.47 \%$ & $5.81 \%$ \\
\hline
\end{tabular}


Table C-2-15: TCB $1724^{\text {th }}$ cycle; Daisy01 - Daisy08.

\begin{tabular}{|c|c|c|c|c|c|c|c|c|}
\hline & DAISY01 & DAISY02 & DAISY03 & DAISY04 & DAISY05 & DAISY06 & DAISY07 & DAISY08 \\
\hline PKG01 & $2.45 \%$ & $4.07 \%$ & $2.97 \%$ & $1.08 \%$ & $2.84 \%$ & $4.09 \%$ & $2.68 \%$ & $1.74 \%$ \\
\hline PKG02 & $1.64 \%$ & $2.91 \%$ & $2.39 \%$ & $3.98 \%$ & $-0.16 \%$ & $11.68 \%$ & $2.15 \%$ & $1.49 \%$ \\
\hline PKG03 & $2.23 \%$ & $5.08 \%$ & $2.07 \%$ & $0.52 \%$ & $-0.58 \%$ & $6.03 \%$ & $1.30 \%$ & $2.69 \%$ \\
\hline PKG04 & $2.48 \%$ & $5.36 \%$ & $3.12 \%$ & $6.77 \%$ & $-0.81 \%$ & $8.18 \%$ & $-0.95 \%$ & $1.65 \%$ \\
\hline PKG05 & $2.63 \%$ & $2.72 \%$ & $0.79 \%$ & $4.56 \%$ & $-0.31 \%$ & $4.48 \%$ & $1.85 \%$ & $2.09 \%$ \\
\hline PKG06 & $1.88 \%$ & $6.38 \%$ & $1.82 \%$ & $1.84 \%$ & $0.84 \%$ & $9.43 \%$ & $0.83 \%$ & $2.23 \%$ \\
\hline PKG07 & $1.65 \%$ & $4.57 \%$ & $2.52 \%$ & $7.87 \%$ & $2.21 \%$ & $9.98 \%$ & $2.45 \%$ & $1.37 \%$ \\
\hline PKG08 & $4.96 \%$ & $2.60 \%$ & $0.74 \%$ & $2.92 \%$ & $-0.36 \%$ & $7.25 \%$ & $2.00 \%$ & $1.52 \%$ \\
\hline PKG09 & $4.50 \%$ & $4.88 \%$ & $2.13 \%$ & $0.86 \%$ & $-0.79 \%$ & $3.10 \%$ & $3.12 \%$ & $3.38 \%$ \\
\hline PKG10 & $7.95 \%$ & $1.44 \%$ & $1.01 \%$ & $1.73 \%$ & $-0.22 \%$ & $6.82 \%$ & $4.08 \%$ & $-0.36 \%$ \\
\hline PKG11 & $8.45 \%$ & $2.12 \%$ & $1.21 \%$ & $1.25 \%$ & $-1.30 \%$ & $5.91 \%$ & $1.39 \%$ & $-0.56 \%$ \\
\hline PKG12 & $4.60 \%$ & $3.16 \%$ & $-0.15 \%$ & $0.00 \%$ & $2.07 \%$ & $3.51 \%$ & $2.17 \%$ & $-0.64 \%$ \\
\hline PKG13 & $6.95 \%$ & $1.00 \%$ & $1.07 \%$ & $0.31 \%$ & $-1.13 \%$ & $8.79 \%$ & $.11 \%$ & $-1.24 \%$ \\
\hline PKG14 & $4.54 \%$ & $4.61 \%$ & $1.34 \%$ & $0.00 \%$ & $0.75 \%$ & $3.05 \%$ & $.13 \%$ & $-0.07 \%$ \\
\hline PKG15 & $4.46 \%$ & $2.37 \%$ & $1.64 \%$ & $0.80 \%$ & $0.16 \%$ & $5.73 \%$ & $5.23 \%$ & $0.24 \%$ \\
\hline PKG16 & $11.18 \%$ & $3.59 \%$ & $2.53 \%$ & $0.79 \%$ & $1.82 \%$ & $5.46 \%$ & $1.71 \%$ & $0.31 \%$ \\
\hline PKG17 & $0.44 \%$ & $1.29 \%$ & $-0.55 \%$ & $1.69 \%$ & $-0.59 \%$ & $3.14 \%$ & $1.26 \%$ & $-5.33 \%$ \\
\hline PKG18 & $4.24 \%$ & $2.91 \%$ & $0.48 \%$ & $1.75 \%$ & $1.24 \%$ & $13.39 \%$ & $2.58 \%$ & $-1.76 \%$ \\
\hline PKG19 & $4.80 \%$ & $3.62 \%$ & $0.08 \%$ & $2.31 \%$ & $-0.97 \%$ & $7.03 \%$ & $53 \%$ & $-1.02 \%$ \\
\hline PKG20 & $1.44 \%$ & $1.27 \%$ & $0.24 \%$ & $0.00 \%$ & $4.15 \%$ & $2.90 \%$ & $65 \%$ & $0.00 \%$ \\
\hline PKG21 & $5.20 \%$ & $3.06 \%$ & $0.00 \%$ & $-0.78 \%$ & $0.31 \%$ & $6.78 \%$ & $3.75 \%$ & $-5.86 \%$ \\
\hline PKG22 & $3.30 \%$ & $-0.25 \%$ & $-0.55 \%$ & $-1.30 \%$ & $0.48 \%$ & $5.38 \%$ & $3.30 \%$ & $-0.31 \%$ \\
\hline PKG23 & $2.30 \%$ & $2.14 \%$ & $0.00 \%$ & $-3.23 \%$ & $1.12 \%$ & $5.39 \%$ & $1.29 \%$ & $0.08 \%$ \\
\hline PKG24 & $6.93 \%$ & $1.42 \%$ & $-0.34 \%$ & $-2.42 \%$ & $1.89 \%$ & $4.69 \%$ & $2.21 \%$ & $-2.97 \%$ \\
\hline PKG25 & $5.45 \%$ & $2.29 \%$ & $1.94 \%$ & $0.98 \%$ & $2.20 \%$ & outliner & $.08 \%$ & $-5.95 \%$ \\
\hline PKG26 & $7.14 \%$ & $3.84 \%$ & $1.01 \%$ & $2.71 \%$ & $-0.55 \%$ & $4.23 \%$ & $-0.13 \%$ & $3.05 \%$ \\
\hline PKG27 & $3.82 \%$ & $2.39 \%$ & $1.27 \%$ & $0.67 \%$ & $0.64 \%$ & $5.08 \%$ & $0.58 \%$ & $0.39 \%$ \\
\hline PKG28 & $4.00 \%$ & $4.54 \%$ & $1.12 \%$ & $0.96 \%$ & $0.16 \%$ & $6.97 \%$ & $4.68 \%$ & $-5.84 \%$ \\
\hline PKG29 & $5.04 \%$ & $4.31 \%$ & $2.06 \%$ & $1.44 \%$ & $1.63 \%$ & $3.24 \%$ & $1.38 \%$ & $1.31 \%$ \\
\hline PKG30 & $5.61 \%$ & $2.54 \%$ & $1.46 \%$ & $2.59 \%$ & $0.41 \%$ & $1.31 \%$ & $-0.52 \%$ & $-0.08 \%$ \\
\hline PKG31 & outliner & $5.63 \%$ & $-1.36 \%$ & $-1.04 \%$ & $5.52 \%$ & $5.46 \%$ & $1.77 \%$ & $-3.26 \%$ \\
\hline PKG32 & $0.86 \%$ & $1.45 \%$ & $-0.25 \%$ & $-6.10 \%$ & $0.99 \%$ & $6.76 \%$ & $.76 \%$ & $-1.00 \%$ \\
\hline PKG33 & $-1.97 \%$ & $3.18 \%$ & $0.86 \%$ & $-0.37 \%$ & $3.27 \%$ & $0.44 \%$ & $58 \%$ & $-1.17 \%$ \\
\hline PKG35 & $4.94 \%$ & $2.15 \%$ & $0.16 \%$ & $1.59 \%$ & $2.90 \%$ & $2.38 \%$ & $2.69 \%$ & $0.24 \%$ \\
\hline PKG36 & $5.83 \%$ & $4.01 \%$ & $0.67 \%$ & $-0.51 \%$ & $1.35 \%$ & $-0.33 \%$ & $2.75 \%$ & $0.15 \%$ \\
\hline PKG37 & $3.58 \%$ & $1.92 \%$ & $-0.79 \%$ & $1.64 \%$ & $2.84 \%$ & $6.93 \%$ & $1.47 \%$ & $-4.73 \%$ \\
\hline PKG38 & $3.24 \%$ & $3.68 \%$ & $-0.77 \%$ & $-1.35 \%$ & $1.71 \%$ & $-3.02 \%$ & $1.41 \%$ & $-2.07 \%$ \\
\hline PKG39 & $1.63 \%$ & $1.25 \%$ & $0.88 \%$ & $-2.48 \%$ & $0.78 \%$ & $-0.44 \%$ & $.01 \%$ & $-2.40 \%$ \\
\hline PKG40 & $0.27 \%$ & $1.26 \%$ & $-1.24 \%$ & $3.28 \%$ & $0.56 \%$ & $-1.48 \%$ & $3 \%$ & $1.72 \%$ \\
\hline PKG41 & $4.58 \%$ & $4.36 \%$ & $-0.15 \%$ & $1.44 \%$ & $-1.03 \%$ & $1.23 \%$ & $39 \%$ & $-0.07 \%$ \\
\hline PKG42 & $2.36 \%$ & $4.66 \%$ & $-0.39 \%$ & $-1.31 \%$ & $0.46 \%$ & $3.93 \%$ & $2.12 \%$ & $-0.15 \%$ \\
\hline PKG43 & $4.10 \%$ & $1.15 \%$ & $0.40 \%$ & $1.25 \%$ & $0.08 \%$ & $13.88 \%$ & $1.57 \%$ & $-3.17 \%$ \\
\hline PKG44 & $1.74 \%$ & $3.42 \%$ & $0.83 \%$ & $-6.92 \%$ & $-1.29 \%$ & $5.59 \%$ & $6.12 \%$ & $-0.48 \%$ \\
\hline PKG45 & $2.35 \%$ & $1.52 \%$ & $1.02 \%$ & $-0.63 \%$ & $0.23 \%$ & $11.50 \%$ & $2.45 \%$ & $0.62 \%$ \\
\hline PKG46 & $-0.39 \%$ & $-0.61 \%$ & $1.44 \%$ & $-2.08 \%$ & $-0.22 \%$ & $5.85 \%$ & $3.08 \%$ & $0.37 \%$ \\
\hline PKG47 & $1.79 \%$ & $-0.57 \%$ & $-1.13 \%$ & $0.98 \%$ & $0.41 \%$ & $2.30 \%$ & $2.11 \%$ & $-2.29 \%$ \\
\hline PKG48 & $-0.43 \%$ & $3.89 \%$ & $-1.58 \%$ & $-0.19 \%$ & $-0.43 \%$ & $6.47 \%$ & $2.57 \%$ & $-1.04 \%$ \\
\hline PKG49 & $5.47 \%$ & $2.44 \%$ & $-1.74 \%$ & $-5.65 \%$ & $2.05 \%$ & $5.55 \%$ & $2.38 \%$ & $-0.26 \%$ \\
\hline PKG50 & $4.88 \%$ & $3.78 \%$ & $0.61 \%$ & $2.14 \%$ & $1.25 \%$ & $11.12 \%$ & $1.79 \%$ & $-2.67 \%$ \\
\hline Mean & $3.69 \%$ & $2.87 \%$ & $0.67 \%$ & $0.54 \%$ & $0.79 \%$ & $5.36 \%$ & $2.41 \%$ & $-0.61 \%$ \\
\hline SD & $2.50 \%$ & $1.59 \%$ & $1.20 \%$ & $2.73 \%$ & $1.47 \%$ & $3.63 \%$ & $1.52 \%$ & $2.30 \%$ \\
\hline Max & $11.18 \%$ & $6.38 \%$ & $3.12 \%$ & $7.87 \%$ & $5.52 \%$ & $13.88 \%$ & $6.12 \%$ & $3.38 \%$ \\
\hline Min & $-1.97 \%$ & $-0.61 \%$ & $-1.74 \%$ & $-6.92 \%$ & $-1.30 \%$ & $-3.02 \%$ & $-0.95 \%$ & $-5.95 \%$ \\
\hline Diff & $13.15 \%$ & $6.99 \%$ & $4.87 \%$ & $14.79 \%$ & $6.81 \%$ & $16.91 \%$ & $7.07 \%$ & $9.33 \%$ \\
\hline
\end{tabular}


Table C-2-16: TCB $1724^{\text {th }}$ cycle; Daisy09 - Daisy 16.

\begin{tabular}{|c|c|c|c|c|c|c|c|c|}
\hline & AlSYO9 & DAISY10 & DAISY11 & DAISY12 & DAISY13 & $\overline{\text { DAISY14 }}$ & DAISY15 & DAISY16 \\
\hline PKG01 & $3.22 \%$ & $1.94 \%$ & $0.55 \%$ & $0.00 \%$ & $-3.99 \%$ & $0.67 \%$ & $0.07 \%$ & $0.67 \%$ \\
\hline PKG02 & $3.21 \%$ & $1.58 \%$ & $-1.34 \%$ & $0.42 \%$ & $1.08 \%$ & $2.92 \%$ & $1.80 \%$ & $1.37 \%$ \\
\hline KG03 & $1.89 \%$ & $1.17 \%$ & $1.78 \%$ & $-3.12 \%$ & $1.67 \%$ & $-1.61 \%$ & $0.52 \%$ & $2.69 \%$ \\
\hline SKG04 & $1.70 \%$ & $1.85 \%$ & $0.56 \%$ & $0.07 \%$ & $0.97 \%$ & $1.10 \%$ & $-0.12 \%$ & $-2.71 \%$ \\
\hline PKG05 & $2.36 \%$ & $1.37 \%$ & $1.14 \%$ & $0.07 \%$ & $-0.91 \%$ & $-0.76 \%$ & $0.77 \%$ & $-0.21 \%$ \\
\hline PKG06 & $1.66 \%$ & $1.21 \%$ & $1.55 \%$ & $0.00 \%$ & $2.51 \%$ & $-0.08 \%$ & $.20 \%$ & $-0.78 \%$ \\
\hline PKG07 & $0.88 \%$ & $1.52 \%$ & $0.00 \%$ & $1.12 \%$ & $2.50 \%$ & $-1.47 \%$ & $4.71 \%$ & $-0.51 \%$ \\
\hline PKG08 & $3.15 \%$ & $0.34 \%$ & $0.60 \%$ & $-1.29 \%$ & $0.00 \%$ & $2.15 \%$ & $1.12 \%$ & $0.34 \%$ \\
\hline PKG09 & $-0.16 \%$ & $0.38 \%$ & $0.55 \%$ & $-2.09 \%$ & $-0.72 \%$ & outliner & $1.67 \%$ & $0.44 \%$ \\
\hline PKG10 & $0.67 \%$ & $1.35 \%$ & $0.85 \%$ & $-1.85 \%$ & $-0.13 \%$ & $0.85 \%$ & $2.75 \%$ & $-0.99 \%$ \\
\hline PKG11 & $2.86 \%$ & $-1.87 \%$ & $0.28 \%$ & $0.08 \%$ & $-0.53 \%$ & $-0.91 \%$ & $2.31 \%$ & $0.00 \%$ \\
\hline PKG12 & $4.64 \%$ & $-1.28 \%$ & $0.95 \%$ & $-2.58 \%$ & $-1.48 \%$ & $0.91 \%$ & $1.90 \%$ & $1.20 \%$ \\
\hline PKG13 & $3.54 \%$ & $0.08 \%$ & $1.81 \%$ & $-2.77 \%$ & $-1.99 \%$ & $-1.00 \%$ & $2.60 \%$ & $0.00 \%$ \\
\hline PKG14 & $4.08 \%$ & $-0.68 \%$ & $0.44 \%$ & $-1.65 \%$ & $0.82 \%$ & $0.28 \%$ & $1.81 \%$ & $0.59 \%$ \\
\hline PKG15 & $4.79 \%$ & $0.30 \%$ & $0.49 \%$ & $-3.48 \%$ & $-0.42 \%$ & $2.44 \%$ & $-0.42 \%$ & $0.22 \%$ \\
\hline PKG16 & $1.36 \%$ & $-1.18 \%$ & $-0.28 \%$ & $-0.32 \%$ & $1.05 \%$ & $-1.12 \%$ & $0.78 \%$ & $0.70 \%$ \\
\hline PKG17 & $1.75 \%$ & $-3.63 \%$ & $1.87 \%$ & $0.00 \%$ & $1.08 \%$ & $4.86 \%$ & $0.83 \%$ & $1.79 \%$ \\
\hline PKG18 & $1.03 \%$ & $-0.29 \%$ & $1.26 \%$ & $-4.03 \%$ & $0.92 \%$ & $0.89 \%$ & $.75 \%$ & $1.26 \%$ \\
\hline G19 & $-0.08 \%$ & $-0.97 \%$ & $\%$ & -0. & $2 \%$ & $5 \%$ & $9 \%$ & $.45 \%$ \\
\hline PKG20 & $-0.86 \%$ & $0.00 \%$ & $56 \%$ & -1 & $\%$ & $2.02 \%$ & $1.54 \%$ & $0.16 \%$ \\
\hline PKG21 & $1.21 \%$ & $-0.89 \%$ & $1.26 \%$ & $-1.88 \%$ & $4 \%$ & $0.76 \%$ & $1.10 \%$ & $-0.33 \%$ \\
\hline PKG22 & $2.35 \%$ & $0.44 \%$ & $0.00 \%$ & $-3.39 \%$ & $-1.03 \%$ & $2.65 \%$ & $4.08 \%$ & $-0.33 \%$ \\
\hline PKG23 & $2.43 \%$ & $3.80 \%$ & $-0.21 \%$ & $-3.27 \%$ & $-0.37 \%$ & $-0.24 \%$ & $0.12 \%$ & $1.15 \%$ \\
\hline PKG24 & $2.33 \%$ & $-0.08 \%$ & $1.40 \%$ & $-4.10 \%$ & $9 \%$ & $-0.54 \%$ & $-1.03 \%$ & $0.24 \%$ \\
\hline PKG25 & $3.36 \%$ & $1.61 \%$ & $\%$ & -2 . & $4 \%$ & $8 \%$ & $2 \%$ & $1.41 \%$ \\
\hline PKG26 & $-1.84 \%$ & $2.71 \%$ & $37 \%$ & -2 . & & $5 \%$ & \%\% & $0.32 \%$ \\
\hline PKG27 & $1.45 \%$ & $1.52 \%$ & $0.56 \%$ & $-1.38 \%$ & $6 \%$ & $-0.30 \%$ & $0.24 \%$ & $-0.05 \%$ \\
\hline PKG28 & $-0.75 \%$ & $2.66 \%$ & $-0.70 \%$ & $-2.16 \%$ & $36 \%$ & $2.43 \%$ & $0.43 \%$ & $0.11 \%$ \\
\hline PKG29 & $99 \%$ & $-1.86 \%$ & $0.53 \%$ & $9 \%$ & $1 \%$ & $1.02 \%$ & $-2.06 \%$ & $1.29 \%$ \\
\hline PKG30 & $0.15 \%$ & $-0.88 \%$ & $2.84 \%$ & $-2.13 \%$ & $56 \%$ & $2.04 \%$ & $-0.12 \%$ & $-0.11 \%$ \\
\hline PKG31 & outliner & $-1.17 \%$ & $37 \%$ & $\%$ & $4 \%$ & $0 \%$ & $\%$ & $2.15 \%$ \\
\hline PKG32 & $65 \%$ & $-3.45 \%$ & $\%$ & $\%$ & $\% \%$ & $7 \%$ & & $1.24 \%$ \\
\hline PKG33 & $-3.61 \%$ & $-1.03 \%$ & $9 \%$ & $3 \%$ & $7 \%$ & $3.87 \%$ & $0.83 \%$ & $1.67 \%$ \\
\hline PKG35 & $-0.31 \%$ & $1.38 \%$ & $3.79 \%$ & $6 \%$ & $3 \%$ & $2.71 \%$ & $0.06 \%$ & $0.11 \%$ \\
\hline PKG36 & $1.89 \%$ & $2.77 \%$ & $3.48 \%$ & $1.77 \%$ & $7 \%$ & $3.80 \%$ & $-0.34 \%$ & $0.22 \%$ \\
\hline PKG37 & $-0.48 \%$ & $-1.10 \%$ & $-0.20 \%$ & $0.00 \%$ & $31 \%$ & $0.38 \%$ & $-1.45 \%$ & $-1.06 \%$ \\
\hline PKG38 & $1.30 \%$ & $-2.79 \%$ & $-0.68 \%$ & $3 \%$ & $9 \%$ & $-1.02 \%$ & $-1.21 \%$ & $-0.39 \%$ \\
\hline PKG39 & $1.58 \%$ & $-0.22 \%$ & $0.07 \%$ & $3 \%$ & $8 \%$ & $3.34 \%$ & $1.32 \%$ & $0.16 \%$ \\
\hline PKG40 & $\%$ & $2.09 \%$ & $\%$ & & $\% \%$ & $4 \%$ & $3 \%$ & $-0.11 \%$ \\
\hline PKG41 & $-0.53 \%$ & $1.16 \%$ & $\%$ & & $9 \%$ & $3 \%$ & $1.07 \%$ & $0.16 \%$ \\
\hline PKG42 & $-3.78 \%$ & $0.29 \%$ & $2.63 \%$ & $44 \%$ & $-1.46 \%$ & $54 \%$ & $-2.68 \%$ & $-1.74 \%$ \\
\hline PKG43 & $2.70 \%$ & $-0.37 \%$ & $1.82 \%$ & $3.49 \%$ & $-0.77 \%$ & $-1.91 \%$ & $0.71 \%$ & $-0.70 \%$ \\
\hline PKG44 & $56 \%$ & $1.40 \%$ & $-0.55 \%$ & $2.29 \%$ & $78 \%$ & $-1.54 \%$ & $-0.49 \%$ & $-1.25 \%$ \\
\hline PKG45 & $0 \%$ & $-0.14 \%$ & $41 \%$ & $9 \%$ & $1 \%$ & $-1.41 \%$ & $-2.28 \%$ & $-1.64 \%$ \\
\hline PKG46 & $0.00 \%$ & $2.29 \%$ & $-0.26 \%$ & $-2.92 \%$ & $2 \%$ & $0.97 \%$ & $-0.95 \%$ & $-0.82 \%$ \\
\hline PKG47 & $1.08 \%$ & $-1.45 \%$ & $1.84 \%$ & & $-0.22 \%$ & $1.98 \%$ & $-4.98 \%$ & $-0.46 \%$ \\
\hline PKG48 & & $-2.16 \%$ & & & & & $-3.07 \%$ & $1.23 \%$ \\
\hline PKG49 & $0 \%$ & $-1.90 \%$ & $29 \%$ & $35 \%$ & $3 \%$ & $1.84 \%$ & $-4.43 \%$ & $-1.49 \%$ \\
\hline PKG50 & $-0.66 \%$ & $-0.95 \%$ & $93 \%$ & $-0.97 \%$ & $-0.92 \%$ & $-0.91 \%$ & $-4.23 \%$ & $-0.91 \%$ \\
\hline Mean & $1.26 \%$ & $0.14 \%$ & $0.82 \%$ & $-1.33 \%$ & $0.08 \%$ & $0.74 \%$ & $0.33 \%$ & $0.14 \%$ \\
\hline SD & $1.86 \%$ & $1.68 \%$ & $1.24 \%$ & $1.93 \%$ & $1.36 \%$ & $1.80 \%$ & $2.02 \%$ & $1.06 \%$ \\
\hline Max & $79 \%$ & $3.80 \%$ & $79 \%$ & $3.49 \%$ & $2.51 \%$ & $4.86 \%$ & $4.71 \%$ & $2.69 \%$ \\
\hline $\mathrm{Mi}$ & $3 \%$ & $-3.63 \%$ & & $9 \%$ & $9 \%$ & $-2.75 \%$ & $-4.98 \%$ & $-2.71 \%$ \\
\hline Diff & $8.58 \%$ & $7.43 \%$ & $5.57 \%$ & $8.18 \%$ & $6.49 \%$ & $7.61 \%$ & $9.69 \%$ & $5.40 \%$ \\
\hline
\end{tabular}


Table C-2-17: TCB $2012^{\text {th }}$ cycle; Daisy01 - Daisy08.

\begin{tabular}{|c|c|c|c|c|c|c|c|c|}
\hline & DAISY01 & DAISYO2 & DAISY03 & DAISYO4 & DAISY05 & DAISY06 & DAISY07 & DAISY08 \\
\hline PKG01 & outliner & $2.83 \%$ & $2.89 \%$ & $0.79 \%$ & $1.42 \%$ & $4.55 \%$ & $4.56 \%$ & $1.27 \%$ \\
\hline PKG02 & $5.65 \%$ & $10.08 \%$ & $1.99 \%$ & $5.59 \%$ & $1.24 \%$ & $6.73 \%$ & $4.30 \%$ & $1.71 \%$ \\
\hline PKG03 & $8.07 \%$ & $1.78 \%$ & $0.99 \%$ & $-0.35 \%$ & $-0.22 \%$ & $4.17 \%$ & $2.49 \%$ & $2.18 \%$ \\
\hline PKG04 & $8.50 \%$ & $7.97 \%$ & $2.14 \%$ & outliner & $-1.86 \%$ & $9.64 \%$ & $2.23 \%$ & $-0.39 \%$ \\
\hline PKG05 & $4.21 \%$ & $6.09 \%$ & $-0.16 \%$ & $2.42 \%$ & $-0.31 \%$ & $10.57 \%$ & $0.96 \%$ & $-1.19 \%$ \\
\hline PKG06 & $2.94 \%$ & $8.04 \%$ & $3.20 \%$ & $2.92 \%$ & $-0.17 \%$ & $8.25 \%$ & $4.85 \%$ & $-0.17 \%$ \\
\hline PKG07 & $5.49 \%$ & $4.97 \%$ & $1.76 \%$ & $0.20 \%$ & $1.74 \%$ & $6.06 \%$ & $1.77 \%$ & $2.10 \%$ \\
\hline PKG08 & $2.97 \%$ & $4.11 \%$ & $1.19 \%$ & $1.03 \%$ & $1.08 \%$ & $8.37 \%$ & $0.88 \%$ & $2.65 \%$ \\
\hline PKG09 & $7.22 \%$ & $3.65 \%$ & $1.81 \%$ & $-1.15 \%$ & $-0.39 \%$ & $2.41 \%$ & $2.02 \%$ & $5.15 \%$ \\
\hline PKG10 & $6.21 \%$ & $0.88 \%$ & $1.32 \%$ & $-0.27 \%$ & $-1.23 \%$ & $4.02 \%$ & $5.28 \%$ & $0.43 \%$ \\
\hline PKG11 & $6.05 \%$ & $1.63 \%$ & $0.57 \%$ & $1.34 \%$ & $-1.45 \%$ & $5.55 \%$ & $1.92 \%$ & $0.40 \%$ \\
\hline PKG12 & $-0.30 \%$ & $3.73 \%$ & $0.46 \%$ & $2.87 \%$ & $1.92 \%$ & $6.38 \%$ & $3.97 \%$ & $4.96 \%$ \\
\hline PKG13 & $5.74 \%$ & $0.05 \%$ & $1.40 \%$ & $0.20 \%$ & $1.70 \%$ & $7.55 \%$ & $1.59 \%$ & $4.40 \%$ \\
\hline PKG14 & $4.97 \%$ & $4.08 \%$ & $0.74 \%$ & $0.83 \%$ & $-1.37 \%$ & $2.63 \%$ & $0.30 \%$ & $3.10 \%$ \\
\hline PKG15 & $1.97 \%$ & $2.58 \%$ & $0.49 \%$ & $3.52 \%$ & $-0.39 \%$ & $6.10 \%$ & $2.41 \%$ & $5.28 \%$ \\
\hline PKG16 & $3.08 \%$ & $1.73 \%$ & $0.72 \%$ & $3.26 \%$ & $2.54 \%$ & $3.80 \%$ & $1.48 \%$ & $-0.13 \%$ \\
\hline PKG17 & $5.27 \%$ & $0.62 \%$ & $-0.16 \%$ & $1.41 \%$ & $-1.48 \%$ & $1.52 \%$ & $1.01 \%$ & $-5.47 \%$ \\
\hline PKG18 & $1.33 \%$ & $3.02 \%$ & $0.48 \%$ & $2.14 \%$ & $0.31 \%$ & $6.69 \%$ & $1.87 \%$ & $-2.86 \%$ \\
\hline PKG19 & $4.20 \%$ & $3.73 \%$ & $0.57 \%$ & $1.41 \%$ & $-0.81 \%$ & $4.44 \%$ & $0.60 \%$ & $2.05 \%$ \\
\hline PKG20 & $5.06 \%$ & $1.58 \%$ & $0.49 \%$ & $0.77 \%$ & $1.63 \%$ & $2.90 \%$ & $1.68 \%$ & $0.00 \%$ \\
\hline PKG21 & $0.85 \%$ & $1.45 \%$ & $-0.56 \%$ & $1.46 \%$ & $-0.54 \%$ & $3.81 \%$ & $1.38 \%$ & $-6.91 \%$ \\
\hline PKG22 & $1.30 \%$ & $0.24 \%$ & $-0.08 \%$ & $-0.93 \%$ & $2.23 \%$ & $4.66 \%$ & $1.10 \%$ & $2.48 \%$ \\
\hline PKG23 & $0.40 \%$ & $2.81 \%$ & $0.08 \%$ & $-3.14 \%$ & $-0.94 \%$ & $4.23 \%$ & $2.52 \%$ & $-0.25 \%$ \\
\hline PKG24 & $1.41 \%$ & $2.69 \%$ & $0.00 \%$ & $0.21 \%$ & $2.79 \%$ & $5.93 \%$ & $1.11 \%$ & $1.24 \%$ \\
\hline PKG25 & $1.61 \%$ & $3.66 \%$ & $1.78 \%$ & $0.36 \%$ & $0.24 \%$ & $2.79 \%$ & $1.00 \%$ & $-6.16 \%$ \\
\hline PKG26 & $4.14 \%$ & $4.52 \%$ & $0.23 \%$ & $-0.28 \%$ & $2.11 \%$ & $5.75 \%$ & $0.00 \%$ & $-0.53 \%$ \\
\hline PKG27 & $0.65 \%$ & $1.06 \%$ & $0.24 \%$ & $-0.58 \%$ & $-1.19 \%$ & $11.41 \%$ & $-0.84 \%$ & $1.18 \%$ \\
\hline PKG28 & $1.18 \%$ & $3.52 \%$ & $0.48 \%$ & $0.19 \%$ & $-0.41 \%$ & $5.75 \%$ & $1.25 \%$ & $-5.23 \%$ \\
\hline PKG29 & $3.03 \%$ & $2.27 \%$ & $-0.53 \%$ & $3.33 \%$ & $0.23 \%$ & $4.75 \%$ & $0.44 \%$ & $-0.80 \%$ \\
\hline PKG30 & $5.51 \%$ & $-2.25 \%$ & $1.30 \%$ & $1.89 \%$ & $-0.16 \%$ & $6.45 \%$ & $-0.92 \%$ & $2.64 \%$ \\
\hline PKG31 & $2.47 \%$ & $2.73 \%$ & $-0.68 \%$ & $-2.08 \%$ & $2.54 \%$ & $8.19 \%$ & $2.83 \%$ & $-4.27 \%$ \\
\hline PKG32 & $2.05 \%$ & $-0.66 \%$ & $-0.90 \%$ & $-8.11 \%$ & $0.91 \%$ & $12.51 \%$ & $0.95 \%$ & $1.09 \%$ \\
\hline PKG33 & $1.56 \%$ & $1.22 \%$ & $-0.47 \%$ & $0.46 \%$ & $0.78 \%$ & $3.10 \%$ & $1.86 \%$ & $1.60 \%$ \\
\hline PKG35 & $4.56 \%$ & $4.25 \%$ & $-1.52 \%$ & $1.00 \%$ & $3.13 \%$ & $4.42 \%$ & $1.64 \%$ & $1.03 \%$ \\
\hline PKG36 & $4.62 \%$ & $3.36 \%$ & $-0.45 \%$ & $-2.78 \%$ & $-0.67 \%$ & $3.81 \%$ & $1.00 \%$ & $1.34 \%$ \\
\hline PKG37 & $1.30 \%$ & $1.13 \%$ & $-0.32 \%$ & $2.13 \%$ & $0.00 \%$ & $5.89 \%$ & $-0.58 \%$ & $-3.13 \%$ \\
\hline PKG38 & $1.79 \%$ & $3.58 \%$ & $-0.93 \%$ & $-5.21 \%$ & $-0.22 \%$ & $-2.92 \%$ & $-0.38 \%$ & $-1.30 \%$ \\
\hline PKG39 & $5.12 \%$ & $3.47 \%$ & $-0.80 \%$ & $-3.31 \%$ & $0.70 \%$ & $-2.62 \%$ & $0.70 \%$ & $-1.31 \%$ \\
\hline PKG40 & $3.70 \%$ & $-0.57 \%$ & $-2.17 \%$ & $1.16 \%$ & $-0.40 \%$ & $-2.16 \%$ & $1.05 \%$ & $2.03 \%$ \\
\hline PKG41 & $3.29 \%$ & $2.10 \%$ & $0.15 \%$ & $0.18 \%$ & $-1.03 \%$ & $2.46 \%$ & $0.38 \%$ & $-1.94 \%$ \\
\hline PKG42 & $-1.07 \%$ & $2.30 \%$ & $0.31 \%$ & $-1.12 \%$ & $-1.78 \%$ & $2.31 \%$ & $0.64 \%$ & $0.89 \%$ \\
\hline PKG43 & $3.02 \%$ & $3.58 \%$ & $0.32 \%$ & $-1.93 \%$ & $-1.18 \%$ & $11.23 \%$ & $0.85 \%$ & $-1.55 \%$ \\
\hline PKG44 & $1.54 \%$ & $3.63 \%$ & $-0.58 \%$ & $-8.05 \%$ & $0.32 \%$ & $5.82 \%$ & $1.16 \%$ & $0.08 \%$ \\
\hline PKG45 & $-0.69 \%$ & $3.68 \%$ & $1.65 \%$ & $-1.97 \%$ & $-1.63 \%$ & $10.19 \%$ & $1.23 \%$ & $-0.69 \%$ \\
\hline PKG46 & $-1.65 \%$ & $0.87 \%$ & $-0.61 \%$ & $-4.24 \%$ & $-0.89 \%$ & $7.83 \%$ & $1.01 \%$ & $2.35 \%$ \\
\hline PKG47 & $5.01 \%$ & $1.26 \%$ & $-2.09 \%$ & $-1.47 \%$ & $-1.94 \%$ & $5.05 \%$ & $1.32 \%$ & $-0.69 \%$ \\
\hline PKG48 & $2.82 \%$ & $5.43 \%$ & $-1.18 \%$ & $-2.23 \%$ & $-0.69 \%$ & $6.59 \%$ & $0.99 \%$ & $-1.35 \%$ \\
\hline PKG49 & $-1.00 \%$ & $4.42 \%$ & $-1.49 \%$ & $-5.36 \%$ & $0.33 \%$ & $8.51 \%$ & $1.54 \%$ & $-0.26 \%$ \\
\hline PKG50 & $0.16 \%$ & $5.36 \%$ & $-0.15 \%$ & $1.86 \%$ & $-0.29 \%$ & $9.83 \%$ & $1.91 \%$ & $-2.88 \%$ \\
\hline Mean & $3.07 \%$ & $2.94 \%$ & $0.28 \%$ & $-0.20 \%$ & $0.13 \%$ & $5.47 \%$ & $1.50 \%$ & $0.08 \%$ \\
\hline SD & $2.44 \%$ & $2.27 \%$ & $1.17 \%$ & $2.81 \%$ & $1.35 \%$ & $3.34 \%$ & $1.34 \%$ & $2.77 \%$ \\
\hline Max & $8.50 \%$ & $10.08 \%$ & $3.20 \%$ & $5.59 \%$ & $3.13 \%$ & $12.51 \%$ & $5.28 \%$ & $5.28 \%$ \\
\hline Min & $-1.65 \%$ & $-2.25 \%$ & $-2.17 \%$ & $-8.11 \%$ & $-1.94 \%$ & $-2.92 \%$ & $-0.92 \%$ & $-6.91 \%$ \\
\hline Diff & $10.15 \%$ & $12.34 \%$ & $5.37 \%$ & $13.70 \%$ & $5.08 \%$ & $15.42 \%$ & $6.20 \%$ & $12.19 \%$ \\
\hline
\end{tabular}


Table C-2-18: TCB 2012 ${ }^{\text {th }}$ cycle; Daisy09 - Daisy16.

\begin{tabular}{|c|c|c|c|c|c|c|c|c|}
\hline & DAISY09 & DAISY10 & DAISY11 & DAISY12 & DAISY13 & DAISY14 & DAISY15 & DAISY16 \\
\hline PKG01 & $3.14 \%$ & $1.04 \%$ & $0.41 \%$ & $2.27 \%$ & $-2.63 \%$ & $1.05 \%$ & $1.70 \%$ & $1.79 \%$ \\
\hline PKG02 & $5.54 \%$ & $4.06 \%$ & $-2.50 \%$ & $-0.14 \%$ & $1.94 \%$ & $2.46 \%$ & $3.54 \%$ & $0.49 \%$ \\
\hline PKG03 & $-0.28 \%$ & $1.72 \%$ & $1.65 \%$ & $-1.80 \%$ & $0.45 \%$ & $-1.14 \%$ & $1.39 \%$ & $-0.48 \%$ \\
\hline PKG04 & $0.00 \%$ & $2.82 \%$ & $2.79 \%$ & $0.30 \%$ & $1.04 \%$ & $1.77 \%$ & $-1.59 \%$ & $-6.97 \%$ \\
\hline PKG05 & $0.65 \%$ & $3.49 \%$ & $0.88 \%$ & $-0.72 \%$ & $-0.63 \%$ & $0.00 \%$ & $0.65 \%$ & $-6.75 \%$ \\
\hline PKG06 & $8.56 \%$ & $2.66 \%$ & $5.25 \%$ & $-0.70 \%$ & $1.29 \%$ & $-0.63 \%$ & $-0.45 \%$ & $-0.42 \%$ \\
\hline PKG07 & $0.24 \%$ & $2.28 \%$ & $1.67 \%$ & $-0.82 \%$ & $1.64 \%$ & $-3.83 \%$ & $1.92 \%$ & $-0.79 \%$ \\
\hline PKG08 & $1.57 \%$ & $2.91 \%$ & $2.46 \%$ & $-1.94 \%$ & $0.00 \%$ & $1.04 \%$ & $2.08 \%$ & $0.63 \%$ \\
\hline PKG09 & $3.46 \%$ & $8.62 \%$ & $3.62 \%$ & $-3.24 \%$ & $0.22 \%$ & $-6.98 \%$ & $5.25 \%$ & $0.06 \%$ \\
\hline PKG10 & $0.15 \%$ & $2.42 \%$ & $-0.13 \%$ & $-1.10 \%$ & $-0.86 \%$ & $-1.49 \%$ & $0.46 \%$ & $0.88 \%$ \\
\hline PKG11 & $0.45 \%$ & $-0.48 \%$ & $0.63 \%$ & $-1.12 \%$ & $-1.53 \%$ & $-2.31 \%$ & $1.40 \%$ & $2.47 \%$ \\
\hline PKG12 & $-0.36 \%$ & $4.44 \%$ & $1.21 \%$ & $-3.46 \%$ & $-0.26 \%$ & $2.72 \%$ & $1.26 \%$ & $1.57 \%$ \\
\hline PKG13 & $1.68 \%$ & $1.58 \%$ & $1.33 \%$ & $-2.33 \%$ & $-2.78 \%$ & $-1.84 \%$ & $2.23 \%$ & $-0.90 \%$ \\
\hline PKG14 & $-0.29 \%$ & $-1.69 \%$ & $0.31 \%$ & $-1.58 \%$ & $-1.45 \%$ & $-0.70 \%$ & $0.74 \%$ & outliner \\
\hline PKG15 & $-0.41 \%$ & $2.48 \%$ & $-0.63 \%$ & $-3.69 \%$ & $-0.98 \%$ & $0.38 \%$ & $0.24 \%$ & $0.33 \%$ \\
\hline PKG16 & $-0.61 \%$ & $-0.66 \%$ & $-0.51 \%$ & $-0.44 \%$ & $-0.50 \%$ & $-3.51 \%$ & $1.50 \%$ & $0.09 \%$ \\
\hline PKG17 & $1.53 \%$ & $-3.09 \%$ & $1.80 \%$ & $-1.93 \%$ & $-0.61 \%$ & $1.31 \%$ & $2.37 \%$ & $0.55 \%$ \\
\hline PKG18 & $2.06 \%$ & $1.47 \%$ & $1.46 \%$ & $-3.82 \%$ & $0.14 \%$ & $0.59 \%$ & $2.29 \%$ & $0.45 \%$ \\
\hline PKG19 & $0.56 \%$ & $2.09 \%$ & $4.60 \%$ & $-1.54 \%$ & $-3.41 \%$ & $-1.00 \%$ & $1.59 \%$ & $0.39 \%$ \\
\hline PKG20 & $1.48 \%$ & $3.28 \%$ & $2.45 \%$ & $-3.46 \%$ & $-1.46 \%$ & $0.52 \%$ & $1.87 \%$ & $2.92 \%$ \\
\hline PKG21 & $4.34 \%$ & $2.21 \%$ & $0.91 \%$ & $-3.62 \%$ & $-2.30 \%$ & $0.91 \%$ & $0.73 \%$ & $-0.67 \%$ \\
\hline PKG22 & $2.27 \%$ & $1.76 \%$ & $0.48 \%$ & $-4.24 \%$ & $-2.12 \%$ & $1.77 \%$ & $2.78 \%$ & $0.11 \%$ \\
\hline PKG23 & $1.13 \%$ & $2.26 \%$ & $-0.64 \%$ & $-4.51 \%$ & $-1.71 \%$ & $-2.12 \%$ & $-0.74 \%$ & $3.50 \%$ \\
\hline PKG24 & $1.66 \%$ & $1.99 \%$ & $0.88 \%$ & $-3.80 \%$ & $-0.72 \%$ & $0.00 \%$ & $2.56 \%$ & $-0.53 \%$ \\
\hline PKG25 & $0.84 \%$ & $1.68 \%$ & $2.15 \%$ & $-1.70 \%$ & $-0.20 \%$ & $1.73 \%$ & $1.28 \%$ & $1.35 \%$ \\
\hline PKG26 & $-1.84 \%$ & $4.25 \%$ & $2.81 \%$ & $-0.36 \%$ & $-1.26 \%$ & $-1.69 \%$ & $1.96 \%$ & $-1.95 \%$ \\
\hline PKG27 & $1.86 \%$ & $1.37 \%$ & $4.09 \%$ & $-1.46 \%$ & $-2.61 \%$ & $0.74 \%$ & $-0.64 \%$ & $-0.66 \%$ \\
\hline PKG28 & $4.08 \%$ & $10.73 \%$ & $-0.21 \%$ & $-2.53 \%$ & $0.22 \%$ & $8.90 \%$ & $-0.42 \%$ & $-1.23 \%$ \\
\hline PKG29 & $-0.08 \%$ & $-2.15 \%$ & $3.88 \%$ & $-5.91 \%$ & $-0.14 \%$ & $1.46 \%$ & $-3.33 \%$ & $2.52 \%$ \\
\hline PKG30 & $1.46 \%$ & $1.76 \%$ & $0.00 \%$ & $-3.74 \%$ & $0.14 \%$ & $6.95 \%$ & $-0.24 \%$ & $-1.03 \%$ \\
\hline PKG31 & outliner & $-0.39 \%$ & $1.33 \%$ & $-3.18 \%$ & $0.39 \%$ & $3.76 \%$ & $-0.07 \%$ & $2.33 \%$ \\
\hline PKG32 & $-0.24 \%$ & $-0.59 \%$ & $-0.57 \%$ & $-2.37 \%$ & $1.00 \%$ & $0.00 \%$ & $4.97 \%$ & $0.30 \%$ \\
\hline PKG33 & $-1.23 \%$ & $3.47 \%$ & $-0.46 \%$ & $-1.48 \%$ & $-1.82 \%$ & $3.87 \%$ & $4.97 \%$ & $0.05 \%$ \\
\hline PKG35 & $-0.69 \%$ & $3.12 \%$ & $0.41 \%$ & $-5.76 \%$ & $-1.17 \%$ & $0.38 \%$ & $0.97 \%$ & $-0.45 \%$ \\
\hline PKG36 & $1.09 \%$ & $1.92 \%$ & $0.33 \%$ & $0.21 \%$ & $-0.71 \%$ & $2.74 \%$ & $0.23 \%$ & $1.13 \%$ \\
\hline PKG37 & $0.40 \%$ & $-0.22 \%$ & $1.41 \%$ & $-0.65 \%$ & $0.00 \%$ & $-0.67 \%$ & $-0.29 \%$ & $-1.06 \%$ \\
\hline PKG38 & $-2.67 \%$ & $-1.13 \%$ & $2.79 \%$ & $-0.43 \%$ & $0.00 \%$ & $-0.54 \%$ & $-1.33 \%$ & $-1.81 \%$ \\
\hline PKG39 & $2.21 \%$ & $3.16 \%$ & $2.07 \%$ & $-4.82 \%$ & $-0.07 \%$ & $0.44 \%$ & $0.48 \%$ & $-0.22 \%$ \\
\hline PKG40 & $1.19 \%$ & $1.34 \%$ & $1.30 \%$ & $-4.90 \%$ & $-0.49 \%$ & $1.04 \%$ & $-1.11 \%$ & $-1.21 \%$ \\
\hline PKG41 & $1.13 \%$ & $-0.43 \%$ & $4.17 \%$ & $-2.04 \%$ & $-1.21 \%$ & $-4.16 \%$ & $-0.90 \%$ & $-0.22 \%$ \\
\hline PKG42 & $-1.67 \%$ & $-1.46 \%$ & $0.85 \%$ & $-0.36 \%$ & $-0.56 \%$ & $-2.47 \%$ & $-4.10 \%$ & $-2.48 \%$ \\
\hline PKG43 & $3.01 \%$ & $0.80 \%$ & $0.34 \%$ & $-0.29 \%$ & $-2.10 \%$ & $-3.74 \%$ & $-0.18 \%$ & $-0.97 \%$ \\
\hline PKG44 & $3.29 \%$ & $-1.77 \%$ & $-0.07 \%$ & $1.75 \%$ & $-0.64 \%$ & $-3.38 \%$ & $-1.41 \%$ & $0.97 \%$ \\
\hline PKG45 & $0.38 \%$ & $-0.93 \%$ & $0.41 \%$ & $-0.80 \%$ & $-1.68 \%$ & $-1.55 \%$ & $-1.08 \%$ & $0.00 \%$ \\
\hline PKG46 & $0.89 \%$ & $5.23 \%$ & $-0.13 \%$ & $-2.85 \%$ & $-0.26 \%$ & $0.42 \%$ & $-2.17 \%$ & $0.00 \%$ \\
\hline PKG47 & $0.33 \%$ & $-1.37 \%$ & $-0.54 \%$ & $1.26 \%$ & $0.00 \%$ & $-0.16 \%$ & $-6.08 \%$ & $-0.90 \%$ \\
\hline PKG48 & $-0.25 \%$ & $-3.51 \%$ & $0.21 \%$ & $0.67 \%$ & $-1.23 \%$ & $0.15 \%$ & $-0.58 \%$ & $-0.66 \%$ \\
\hline PKG49 & $1.23 \%$ & $-4.23 \%$ & $1.31 \%$ & $-0.54 \%$ & $0.36 \%$ & $0.84 \%$ & $-4.07 \%$ & $-1.49 \%$ \\
\hline PKG50 & $-1.84 \%$ & $-0.20 \%$ & $-0.72 \%$ & $-1.11 \%$ & $-0.33 \%$ & $-2.46 \%$ & $-4.88 \%$ & $-0.71 \%$ \\
\hline Mean & $1.07 \%$ & $1.43 \%$ & $1.17 \%$ & $-1.85 \%$ & $-0.64 \%$ & $0.03 \%$ & $0.36 \%$ & $-0.20 \%$ \\
\hline SD & $2.00 \%$ & $2.77 \%$ & $1.60 \%$ & $1.88 \%$ & $1.16 \%$ & $2.71 \%$ & $2.36 \%$ & $1.90 \%$ \\
\hline Max & $8.56 \%$ & $10.73 \%$ & $5.25 \%$ & $2.27 \%$ & $1.94 \%$ & $8.90 \%$ & $5.25 \%$ & $3.50 \%$ \\
\hline Min & $-2.67 \%$ & $-4.23 \%$ & $-2.50 \%$ & $-5.91 \%$ & $-3.41 \%$ & $-6.98 \%$ & $-6.08 \%$ & $-6.97 \%$ \\
\hline Diff & $11.23 \%$ & $14.96 \%$ & $7.74 \%$ & $8.18 \%$ & $5.36 \%$ & $15.87 \%$ & $11.34 \%$ & $10.47 \%$ \\
\hline
\end{tabular}


Table C-2-19: TCC $100^{\text {th }}$ cycle; Daisy01 - Daisy08.

\begin{tabular}{|c|c|c|c|c|c|c|c|c|}
\hline & AISY01 & DAISY02 & DAISY03 & DAISY04 & DAISY05 & DAISY06 & DAISY07 & DAISY08 \\
\hline PKG01 & $1.16 \%$ & $4.80 \%$ & $3.22 \%$ & $4.04 \%$ & $4.66 \%$ & $4.44 \%$ & $3.02 \%$ & $0.48 \%$ \\
\hline PKG02 & $-0.02 \%$ & $5.17 \%$ & $2.63 \%$ & $1.89 \%$ & $2.72 \%$ & $13.34 \%$ & $33 \%$ & $.45 \%$ \\
\hline PKG03 & $-1.64 \%$ & $2.88 \%$ & $61 \%$ & $0.61 \%$ & $3.05 \%$ & $7.68 \%$ & $2 \%$ & $07 \%$ \\
\hline PKG04 & $-1.03 \%$ & $.61 \%$ & $47 \%$ & $32 \%$ & $-1.05 \%$ & $.89 \%$ & $2.86 \%$ & $6 \%$ \\
\hline PKG05 & $76 \%$ & $3.71 \%$ & $95 \%$ & $10 \%$ & $.31 \%$ & $37 \%$ & $0.19 \%$ & $08 \%$ \\
\hline PKG06 & $2.73 \%$ & $5.49 \%$ & $3.12 \%$ & $3.35 \%$ & $-1.77 \%$ & $8.38 \%$ & $-0.07 \%$ & $0.94 \%$ \\
\hline PKG07 & $06 \%$ & $4.37 \%$ & $1.59 \%$ & $1.41 \%$ & $0.47 \%$ & $6.65 \%$ & $0.68 \%$ & $-0.73 \%$ \\
\hline PKG08 & $8 \%$ & $2.31 \%$ & $0.67 \%$ & $3.26 \%$ & $-0.29 \%$ & $6.25 \%$ & $35 \%$ & $31 \%$ \\
\hline PKG09 & $2.29 \%$ & $3.44 \%$ & $1.31 \%$ & $-0.38 \%$ & $-1.02 \%$ & $3.91 \%$ & $21 \%$ & $85 \%$ \\
\hline PKG10 & $2 \%$ & $0.98 \%$ & $23 \%$ & $-1.09 \%$ & $-2.24 \%$ & $3.47 \%$ & $8 \%$ & $1 \%$ \\
\hline PKG11 & $\%$ & $1.73 \%$ & $97 \%$ & $-1.34 \%$ & $-1.30 \%$ & $13.74 \%$ & $2 \%$ & \\
\hline PKG12 & $3 \%$ & $3.35 \%$ & $31 \%$ & $-0.81 \%$ & $-1.00 \%$ & $3.09 \%$ & $4 \%$ & \\
\hline PKG13 & $2.00 \%$ & $0.89 \%$ & $0.33 \%$ & $-0.41 \%$ & $-1.29 \%$ & $6.19 \%$ & $36 \%$ & $24 \%$ \\
\hline PKG14 & $1.27 \%$ & $3.03 \%$ & $0.52 \%$ & $1.33 \%$ & $-0.48 \%$ & $4.31 \%$ & $36 \%$ & $87 \%$ \\
\hline PKG15 & $37 \%$ & $2.26 \%$ & $-0.08 \%$ & $-0.10 \%$ & $-1.10 \%$ & $3.90 \%$ & $4 \%$ & $84 \%$ \\
\hline PKG16 & $2.91 \%$ & $2.23 \%$ & $0.51 \%$ & $-0.87 \%$ & $\%$ & $4.78 \%$ & $\% \%$ & $6 \%$ \\
\hline PKG17 & $\%$ & $1.10 \%$ & $25 \%$ & $0.75 \%$ & $\%$ & $7.05 \%$ & $\%$ & $5 \%$ \\
\hline PKG18 & & $1.79 \%$ & $38 \%$ & 1.1 & & & & $7 \%$ \\
\hline PKG19 & $2 \%$ & $2.36 \%$ & $-0.82 \%$ & -1.0 & $4 \%$ & $6.54 \%$ & & $2 \%$ \\
\hline PKG20 & $1.05 \%$ & $2.30 \%$ & $0.41 \%$ & $0.39 \%$ & $0.08 \%$ & $2.90 \%$ & $3 \%$ & $23 \%$ \\
\hline PKG21 & $1.72 \%$ & $4.16 \%$ & $-1.12 \%$ & $-2.04 \%$ & $-1.24 \%$ & $10.11 \%$ & $\%$ & $36 \%$ \\
\hline PKG22 & $0 \%$ & $0.43 \%$ & $0.94 \%$ & $-1.39 \%$ & $-0.48 \%$ & $6.45 \%$ & $\%$ & $8 \%$ \\
\hline PKG23 & $\%$ & $\%$ & $90 \%$ & -1. & $\%$ & $\%$ & & $3 \%$ \\
\hline PKG24 & & $\%$ & $1 \%$ & & & & & $\%$ \\
\hline PKG25 & $\%$ & $3.27 \%$ & $16 \%$ & $\%$ & $2 \%$ & $3.95 \%$ & $\% \%$ & $4 \%$ \\
\hline PKG26 & $2 \%$ & $4.52 \%$ & $0.47 \%$ & $2.33 \%$ & $-2.74 \%$ & $17.48 \%$ & $5 \%$ & $46 \%$ \\
\hline PKG27 & $1 \%$ & $.39 \%$ & $08 \%$ & $0.19 \%$ & $-1.11 \%$ & $7.32 \%$ & $\%$ & $17 \%$ \\
\hline PKG28 & & $1.88 \%$ & $40 \%$ & $3.67 \%$ & $3 \%$ & $9.05 \%$ & & $53 \%$ \\
\hline PKG29 & & $\%$ & $16 \%$ & $33 \%$ & & & & $3 \%$ \\
\hline PKG30 & & $\%$ & $1 \%$ & 5.4 & & & & $4 \%$ \\
\hline PKG31 & $\%$ & $\%$ & $2 \%$ & -2.8 & $\%$ & & & $9 \%$ \\
\hline PKG32 & $6 \%$ & $\%$ & $-1.64 \%$ & $\%$ & $3 \%$ & $3 \%$ & $3 \%$ & $2 \%$ \\
\hline PKG33 & & $41 \%$ & $-0.16 \%$ & & & & & $44 \%$ \\
\hline PKG35 & & $74 \%$ & $-0.96 \%$ & & & $\%$ & $\%$ & $4.82 \%$ \\
\hline PKG36 & & $52 \%$ & $-0.22 \%$ & $-2.70 \%$ & $0 \%$ & $2.72 \%$ & $7 \%$ & $42 \%$ \\
\hline PKG37 & $\%$ & $34 \%$ & $-0.95 \%$ & $0.48 \%$ & $\%$ & $\%$ & $\%$ & $30 \%$ \\
\hline PKG38 & & $8 \%$ & $9 \%$ & $\%$ & $4 \%$ & $\%$ & & $5 \%$ \\
\hline PKG39 & & & $\%$ & & $\%$ & $\%$ & & $0 \%$ \\
\hline PKG40 & & & $3 \%$ & & $\%$ & $\% \%$ & $\%$ & $1 \%$ \\
\hline PKG41 & $7 \%$ & $0 \%$ & $54 \%$ & & $0.07 \%$ & $-1.02 \%$ & $4 \%$ & $08 \%$ \\
\hline PKG42 & & $05 \%$ & $-0.39 \%$ & $-1.58 \%$ & ball & $1.97 \%$ & $1 \%$ & $-0.96 \%$ \\
\hline KG43 & & $\%$ & $6 \%$ & $-2.22 \%$ & $\%$ & $8.09 \%$ & $\%$ & $0 \%$ \\
\hline KG44 & $\%$ & $\%$ & $-0.99 \%$ & -4.8 & $0.56 \%$ & $7.61 \%$ & $\%$ & $22 \%$ \\
\hline KG45 & & $\%$ & $2 \%$ & -2.0 & $-1.17 \%$ & $6.47 \%$ & $\%$ & $-1.62 \%$ \\
\hline PKG46 & $\%$ & $24 \%$ & $1.21 \%$ & $-1.04 \%$ & $-0.67 \%$ & $12.47 \%$ & $5 \%$ & $2.79 \%$ \\
\hline PKG47 & $1.89 \%$ & $0.04 \%$ & $0.97 \%$ & & & $5.40 \%$ & $1 \%$ & $-0.76 \%$ \\
\hline PKG48 & & $0 \%$ & $24 \%$ & & $3 \%$ & $4.57 \%$ & $9 \%$ & $6 \%$ \\
\hline PKG49 & $0.17 \%$ & $36 \%$ & $-0.83 \%$ & $-6.35 \%$ & $1.97 \%$ & $6.79 \%$ & $3 \%$ & $-0.34 \%$ \\
\hline PKG50 & $0.16 \%$ & $21 \%$ & $9 \%$ & $0.56 \%$ & $37 \%$ & $7.02 \%$ & $5 \%$ & $-1.26 \%$ \\
\hline Mean & $7 \%$ & $40 \%$ & $0.24 \%$ & $-0.01 \%$ & $2 \%$ & $5.63 \%$ & $4 \%$ & $-0.81 \%$ \\
\hline SD & $2 \%$ & $55 \%$ & $1.18 \%$ & $2.90 \%$ & $1.51 \%$ & $3.95 \%$ & $67 \%$ & $2.38 \%$ \\
\hline Max & $3 \%$ & $6.61 \%$ & $3.22 \%$ & $8.32 \%$ & $4.66 \%$ & $17.48 \%$ & $7.72 \%$ & $22 \%$ \\
\hline Min & $-1.64 \%$ & $-1.06 \%$ & $-2.33 \%$ & $-7.63 \%$ & $-2.74 \%$ & $-2.85 \%$ & $-2.86 \%$ & $-5.86 \%$ \\
\hline Diff & $7.32 \%$ & $7.67 \%$ & $5.54 \%$ & $15.95 \%$ & $7.39 \%$ & $20.33 \%$ & $10.58 \%$ & $11.08 \%$ \\
\hline
\end{tabular}


Table C-2-20: TCC $100^{\text {th }}$ cycle; Daisy09 - Daisy16.

\begin{tabular}{|c|c|c|c|c|c|c|c|c|}
\hline & AISY09 & DAISY10 & DAISY11 & DAISY12 & DAISY13 & DAISY14 & DAISY15 & DAISY16 \\
\hline PKG01 & $0.81 \%$ & $2.24 \%$ & $-0.07 \%$ & $1.98 \%$ & $-4.05 \%$ & $-0.22 \%$ & $0.31 \%$ & $0.90 \%$ \\
\hline PKG02 & $4 \%$ & $7.29 \%$ & & $1.20 \%$ & & & & $98 \%$ \\
\hline PKG03 & $7 \%$ & $2.28 \%$ & $98 \%$ & $-3.46 \%$ & $2.77 \%$ & $80 \%$ & $1.90 \%$ & 0 \\
\hline PKG04 & $31 \%$ & $0.52 \%$ & $35 \%$ & $-1.48 \%$ & $0.35 \%$ & $06 \%$ & $-0.53 \%$ & \\
\hline PKG05 & $41 \%$ & $1.06 \%$ & $0.13 \%$ & $-0.72 \%$ & $0.28 \%$ & $2.37 \%$ & $0.06 \%$ & $0.05 \%$ \\
\hline PKG06 & $0.00 \%$ & $1.37 \%$ & $1.33 \%$ & $-1.40 \%$ & $0.61 \%$ & $3.10 \%$ & $-0.77 \%$ & $.25 \%$ \\
\hline PKG07 & $0.16 \%$ & $1.60 \%$ & $3.20 \%$ & $-0.67 \%$ & $1.00 \%$ & $-2.21 \%$ & $0.87 \%$ & $-0.28 \%$ \\
\hline PKG08 & $1.64 \%$ & $0.74 \%$ & & $1 \%$ & $\%$ & $1.45 \%$ & $5 \%$ & $37 \%$ \\
\hline PKG09 & $0.81 \%$ & $-0.15 \%$ & $8 \%$ & $-3.52 \%$ & $-1.30 \%$ & ttliner & $6 \%$ & $1 \%$ \\
\hline PKG10 & $15 \%$ & $1.07 \%$ & $4 \%$ & $-2.26 \%$ & $-0.53 \%$ & $-2.27 \%$ & $.20 \%$ & $15 \%$ \\
\hline PKG11 & $93 \%$ & $-0.76 \%$ & $4 \%$ & $30 \%$ & $0 \%$ & $0.98 \%$ & $.58 \%$ & $64 \%$ \\
\hline PKG12 & $2.07 \%$ & $-2.56 \%$ & $39 \%$ & $-2.44 \%$ & $-1.93 \%$ & $0.77 \%$ & $.07 \%$ & $52 \%$ \\
\hline PKG13 & $2.95 \%$ & $0.23 \%$ & & $-3.13 \%$ & $-3.70 \%$ & $15 \%$ & $1.05 \%$ & $50 \%$ \\
\hline PKG14 & & & & & & $\%$ & & \\
\hline PKG15 & & $\%$ & & & $3 \%$ & $\%$ & & $7 \%$ \\
\hline PKG16 & & & & & & & & $2 \%$ \\
\hline PKG17 & $7 \%$ & $\%$ & & & & & & $5 \%$ \\
\hline PKG18 & $0.00 \%$ & $0.37 \%$ & & $7 \%$ & $2 \%$ & $3 \%$ & $3 \%$ & $3 \%$ \\
\hline PKG19 & $-1.69 \%$ & $-1.42 \%$ & $42 \%$ & $2.20 \%$ & $-3.34 \%$ & $9 \%$ & $37 \%$ & $62 \%$ \\
\hline PKG20 & $40 \%$ & $-0.07 \%$ & $9 \%$ & $-3.17 \%$ & & $0 \%$ & $39 \%$ & $16 \%$ \\
\hline PKG21 & & & & & & & & \\
\hline PKG22 & & & & & & & & \\
\hline PKG23 & $\%$ & & & & & & & \\
\hline PKG24 & $-0.25 \%$ & $2.68 \%$ & & $\%$ & $\%$ & $3 \%$ & $\%$ & $7 \%$ \\
\hline PKG25 & $0 \%$ & $3.14 \%$ & & $6 \%$ & & $5 \%$ & & $38 \%$ \\
\hline PKG26 & $\%$ & $4 \%$ & $\%$ & $7 \%$ & $3 \%$ & & & $7 \%$ \\
\hline PKG27 & & & & & & & & \\
\hline PKG28 & & & & & & & & \\
\hline PKG29 & & $\%$ & & & & & & $5 \%$ \\
\hline PKG30 & $-0.62 \%$ & $\%$ & $\%$ & $7 \%$ & $\%$ & $\%$ & & $1 \%$ \\
\hline PKG31 & liner & & & & & & & $57 \%$ \\
\hline PKG32 & $4.65 \%$ & & $4 \%$ & $1 \%$ & & $4 \%$ & & $47 \%$ \\
\hline PKG33 & & & $77 \%$ & $6 \%$ & & & & $37 \%$ \\
\hline PKG35 & & & & & & & & \\
\hline PKG36 & & & & & & & & \\
\hline PKG37 & $\%$ & & $\%$ & $\%$ & & & & $0 \%$ \\
\hline PKG38 & $\%$ & $\%$ & & $\%$ & & $\%$ & & $7 \%$ \\
\hline PKG39 & & & $\% \%$ & $3 \%$ & & $5 \%$ & & $5 \%$ \\
\hline PKG40 & & $1 \%$ & $7 \%$ & & $4 \%$ & & $6 \%$ & $6 \%$ \\
\hline PKG41 & $1 \%$ & & $6 \%$ & $\%$ & $4 \%$ & $4 \%$ & $\%$ & $6 \%$ \\
\hline PKG42 & $-3.86 \%$ & & & $\%$ & & & & $2 \%$ \\
\hline PKG43 & & & & & $\%$ & & & $2 \%$ \\
\hline PKG44 & & & & & & & & $6 \%$ \\
\hline PKG45 & & & & & & $4 \%$ & $4 \%$ & $1 \%$ \\
\hline PKG46 & $0 \%$ & $0.43 \%$ & $3 \%$ & $-3.12 \%$ & $-1.73 \%$ & $1.39 \%$ & $2 \%$ & $.65 \%$ \\
\hline PKG47 & $5 \%$ & $06 \%$ & $8 \%$ & $8 \%$ & $\%$ & $\%$ & $7 \%$ & \\
\hline PKG48 & & & & & & & & \\
\hline PKG49 & & & & $\% \%$ & & & & \\
\hline PKG50 & & $\%$ & & & & & & \\
\hline Mean & & & & & & & & \\
\hline SD & & & & & & & $72 \%$ & \\
\hline Max & $5.94 \%$ & $29 \%$ & $49 \%$ & $2.20 \%$ & $2.77 \%$ & $4.21 \%$ & $14 \%$ & \\
\hline Min & $.38 \%$ & & & & & & $-3.77 \%$ & $2 \%$ \\
\hline Diff & $10.32 \%$ & $10.71 \%$ & $9.62 \%$ & $8.03 \%$ & $6.82 \%$ & $8.24 \%$ & $7.91 \%$ & $4.62 \%$ \\
\hline
\end{tabular}


Table C-2-21: TCC 200 ${ }^{\text {th }}$ cycle; Daisy01 - Daisy08.

\begin{tabular}{|c|c|c|c|c|c|c|c|c|}
\hline & DAISY01 & DAISY02 & DAISY03 & DAISY04 & DAISY05 & DAISY06 & DAISY07 & DAISY08 \\
\hline PKG01 & $3.54 \%$ & $3.35 \%$ & $1.49 \%$ & $0.69 \%$ & $0.16 \%$ & $7.71 \%$ & $1.88 \%$ & $1.66 \%$ \\
\hline PKG02 & $3.79 \%$ & $6.50 \%$ & $0.96 \%$ & $3.13 \%$ & $-1.40 \%$ & $11.45 \%$ & $1.01 \%$ & $2.23 \%$ \\
\hline PKG03 & $1.78 \%$ & $3.25 \%$ & $0.69 \%$ & $0.18 \%$ & $-1.09 \%$ & $11.30 \%$ & $2.24 \%$ & $6.61 \%$ \\
\hline PKG04 & $5.79 \%$ & $4.74 \%$ & $4.19 \%$ & $11.61 \%$ & $-2.35 \%$ & $11.96 \%$ & $-0.95 \%$ & $0.79 \%$ \\
\hline PKG05 & $5.29 \%$ & $2.12 \%$ & $-0.08 \%$ & $3.01 \%$ & $-1.86 \%$ & $10.57 \%$ & $2.43 \%$ & $0.97 \%$ \\
\hline PKG06 & $3.79 \%$ & $7.38 \%$ & $0.78 \%$ & $1.95 \%$ & $-2.44 \%$ & $12.97 \%$ & $1.04 \%$ & $1.80 \%$ \\
\hline PKG07 & $2.14 \%$ & $4.27 \%$ & $1.76 \%$ & $2.62 \%$ & $0.00 \%$ & $12.36 \%$ & $0.82 \%$ & $0.08 \%$ \\
\hline PKG08 & $1.16 \%$ & $3.83 \%$ & $1.26 \%$ & $1.55 \%$ & $-1.08 \%$ & $10.37 \%$ & $0.35 \%$ & $-0.07 \%$ \\
\hline PKG09 & $2.79 \%$ & $5.30 \%$ & $1.64 \%$ & $-1.72 \%$ & $-1.34 \%$ & $12.06 \%$ & $0.72 \%$ & $2.69 \%$ \\
\hline PKG10 & $2.73 \%$ & $1.72 \%$ & $0.46 \%$ & $0.54 \%$ & $-1.23 \%$ & $9.62 \%$ & $1.44 \%$ & $0.87 \%$ \\
\hline PKG11 & $2.48 \%$ & $3.31 \%$ & $0.73 \%$ & $0.19 \%$ & $-1.91 \%$ & $11.21 \%$ & $0.93 \%$ & $-1.21 \%$ \\
\hline PKG12 & $1.70 \%$ & $4.20 \%$ & $0.54 \%$ & $0.54 \%$ & $0.71 \%$ & $7.76 \%$ & $0.37 \%$ & $0.57 \%$ \\
\hline PKG13 & $3.51 \%$ & $1.10 \%$ & $1.65 \%$ & $3.68 \%$ & $-1.70 \%$ & $8.30 \%$ & $0.66 \%$ & $-1.16 \%$ \\
\hline PKG14 & $1.96 \%$ & $3.03 \%$ & $2.23 \%$ & $1.08 \%$ & $-0.96 \%$ & $3.26 \%$ & $0.84 \%$ & $0.00 \%$ \\
\hline PKG15 & $2.37 \%$ & $2.16 \%$ & $2.88 \%$ & $5.43 \%$ & $-2.90 \%$ & $7.08 \%$ & $0.87 \%$ & $-2.44 \%$ \\
\hline PKG16 & $2.91 \%$ & $1.90 \%$ & $3.98 \%$ & 4.6 & $0.98 \%$ & $5.56 \%$ & $0.57 \%$ & $0.88 \%$ \\
\hline PKG17 & $1.56 \%$ & $1.00 \%$ & $-0.31 \%$ & $4.80 \%$ & $-2.44 \%$ & $3.36 \%$ & $0.63 \%$ & $-4.21 \%$ \\
\hline PKG18 & $3.27 \%$ & $2.30 \%$ & $0.88 \%$ & $1.94 \%$ & $1.01 \%$ & $15.86 \%$ & $0.32 \%$ & $-2.20 \%$ \\
\hline PKG19 & $3.09 \%$ & $2.04 \%$ & $-0.57 \%$ & $3.72 \%$ & $-0.48 \%$ & $9.25 \%$ & $2.67 \%$ & $-1.18 \%$ \\
\hline PKG20 & $3.20 \%$ & $0.76 \%$ & $1.79 \%$ & $1.06 \%$ & $0.49 \%$ & $4.29 \%$ & outliner & $0.53 \%$ \\
\hline PKG21 & $2.11 \%$ & $3.06 \%$ & $0.16 \%$ & $0.58 \%$ & $-0.23 \%$ & $8.45 \%$ & $5.53 \%$ & $-6.53 \%$ \\
\hline PKG22 & $0.45 \%$ & $-1.43 \%$ & $0.71 \%$ & $1.30 \%$ & $0.32 \%$ & $10.64 \%$ & $1.94 \%$ & $-0.85 \%$ \\
\hline PKG23 & $2.19 \%$ & $2.70 \%$ & $0.41 \%$ & $-2.55 \%$ & $-0.17 \%$ & $11.16 \%$ & $2.72 \%$ & $2.08 \%$ \\
\hline PKG24 & $1.00 \%$ & $2.48 \%$ & $1.97 \%$ & $-2.42 \%$ & $0.33 \%$ & $10.25 \%$ & $0.90 \%$ & $-3.47 \%$ \\
\hline PKG25 & $-0.22 \%$ & $2.20 \%$ & $1.63 \%$ & $0.27 \%$ & $-0.39 \%$ & $9.98 \%$ & $0.63 \%$ & $-6.09 \%$ \\
\hline PKG26 & $1.82 \%$ & $4.23 \%$ & $0.54 \%$ & $0.84 \%$ & $-0.86 \%$ & $14.78 \%$ & $0.56 \%$ & $0.15 \%$ \\
\hline PKG27 & $-0.31 \%$ & $1.68 \%$ & $1.27 \%$ & $1.64 \%$ & $-1.19 \%$ & $11.53 \%$ & $-1.29 \%$ & $-0.16 \%$ \\
\hline PKG28 & $1.08 \%$ & $3.72 \%$ & $0.48 \%$ & $0.00 \%$ & $-1.81 \%$ & $11.62 \%$ & $-0.26 \%$ & $-4.02 \%$ \\
\hline PKG29 & $5.71 \%$ & $4.11 \%$ & $1.52 \%$ & $1.08 \%$ & $-0.93 \%$ & $15.52 \%$ & $0.56 \%$ & $-1.31 \%$ \\
\hline PKG30 & $4.72 \%$ & $-1.06 \%$ & $-0.16 \%$ & $2.59 \%$ & $-0.89 \%$ & $2.99 \%$ & $0.00 \%$ & $1.98 \%$ \\
\hline PKG31 & 1.6 & $1.95 \%$ & $-1.79 \%$ & $-0.83 \%$ & $0.09 \%$ & $3.47 \%$ & $4.17 \%$ & $-4.02 \%$ \\
\hline PKG32 & $1.26 \%$ & $1.65 \%$ & $-1.32 \%$ & $-8.01 \%$ & $0.91 \%$ & $11.26 \%$ & $-0.07 \%$ & $2.26 \%$ \\
\hline PKG33 & $-2.53 \%$ & $1.41 \%$ & $-0.39 \%$ & $-3.43 \%$ & $-1.71 \%$ & $1.55 \%$ & $3.39 \%$ & $0.07 \%$ \\
\hline PKG35 & $1.41 \%$ & $2.65 \%$ & $-1.36 \%$ & $-2.00 \%$ & $-1.80 \%$ & $3.63 \%$ & $0.85 \%$ & $0.00 \%$ \\
\hline PKG36 & $1.74 \%$ & $1.98 \%$ & $-0.82 \%$ & $-3.88 \%$ & $-2.47 \%$ & $2.62 \%$ & $4.56 \%$ & $4.55 \%$ \\
\hline PKG37 & $-0.78 \%$ & $2.61 \%$ & $-2.05 \%$ & $-1.06 \%$ & $-1.15 \%$ & $4.97 \%$ & $3.33 \%$ & $-3.13 \%$ \\
\hline PKG38 & $2.25 \%$ & $2.24 \%$ & $-2.09 \%$ & $-3.32 \%$ & $-1.56 \%$ & $1.08 \%$ & $0.96 \%$ & $-0.46 \%$ \\
\hline PKG39 & $2.21 \%$ & $0.45 \%$ & $-0.48 \%$ & $-2.20 \%$ & $-1.09 \%$ & $-4.16 \%$ & $6.27 \%$ & $-2.19 \%$ \\
\hline PKG40 & $0.47 \%$ & $0.75 \%$ & $-2.17 \%$ & $2.22 \%$ & $-1.84 \%$ & $-1.25 \%$ & $1.05 \%$ & $2.58 \%$ \\
\hline PKG41 & $0.07 \%$ & $3.04 \%$ & $-0.69 \%$ & $0.27 \%$ & $-1.76 \%$ & $-2.05 \%$ & $0.82 \%$ & $-1.39 \%$ \\
\hline PKG42 & $-1.27 \%$ & $2.40 \%$ & $-0.86 \%$ & $-1.96 \%$ & no ball & $4.40 \%$ & $0.51 \%$ & $1.62 \%$ \\
\hline PKG43 & $-0.81 \%$ & $-0.77 \%$ & $-0.16 \%$ & $-0.39 \%$ & $-2.74 \%$ & $11.11 \%$ & $-0.26 \%$ & $-1.55 \%$ \\
\hline PKG44 & $0.37 \%$ & $5.85 \%$ & $-1.49 \%$ & $-6.73 \%$ & $-1.37 \%$ & $9.63 \%$ & $1.02 \%$ & $0.24 \%$ \\
\hline PKG45 & $1.68 \%$ & $2.79 \%$ & $-0.95 \%$ & $-3.50 \%$ & $0.00 \%$ & $12.58 \%$ & $0.52 \%$ & $1.00 \%$ \\
\hline PKG46 & $-1.92 \%$ & $1.51 \%$ & $-0.15 \%$ & $-4.76 \%$ & $-0.45 \%$ & $12.47 \%$ & $0.50 \%$ & $0.66 \%$ \\
\hline PKG47 & outliner & $1.98 \%$ & $-1.69 \%$ & $-2.15 \%$ & $-0.32 \%$ & $5.40 \%$ & $1.45 \%$ & $-1.37 \%$ \\
\hline PKG48 & outliner & $3.01 \%$ & $-2.53 \%$ & $-1.45 \%$ & $-0.52 \%$ & $8.50 \%$ & $0.07 \%$ & $-1.11 \%$ \\
\hline PKG49 & $-0.71 \%$ & $2.03 \%$ & $-1.82 \%$ & $-6.94 \%$ & $-0.57 \%$ & $9.38 \%$ & $0.98 \%$ & $0.69 \%$ \\
\hline PKG50 & $0.98 \%$ & $2.90 \%$ & $-0.15 \%$ & $-0.19 \%$ & $-0.07 \%$ & $7.14 \%$ & $1.48 \%$ & $-2.53 \%$ \\
\hline Mean & $1.77 \%$ & $2.58 \%$ & $0.26 \%$ & $0.07 \%$ & $-0.92 \%$ & $8.06 \%$ & $1.29 \%$ & $-0.31 \%$ \\
\hline SD & $1.85 \%$ & $1.72 \%$ & $1.53 \%$ & $3.42 \%$ & $1.02 \%$ & $4.61 \%$ & $1.52 \%$ & $2.48 \%$ \\
\hline Max & $5.79 \%$ & $7.38 \%$ & $4.19 \%$ & $11.61 \%$ & $1.01 \%$ & $15.86 \%$ & $6.27 \%$ & $6.61 \%$ \\
\hline Min & $-2.53 \%$ & $-1.43 \%$ & $-2.53 \%$ & $-8.01 \%$ & $-2.90 \%$ & $-4.16 \%$ & $-1.29 \%$ & $-6.53 \%$ \\
\hline Diff & $8.32 \%$ & $8.81 \%$ & $6.72 \%$ & $19.62 \%$ & $3.91 \%$ & $20.01 \%$ & $7.56 \%$ & $13.14 \%$ \\
\hline
\end{tabular}


Table C-2-22: TCC 200 ${ }^{\text {th }}$ cycle; Daisy09 - Daisy16.

\begin{tabular}{|c|c|c|c|c|c|c|c|c|}
\hline & DAISY09 & DAISY10 & DAISY11 & DAISY12 & DAISY13 & DAISY14 & DAISY15 & DAISY16 \\
\hline PKG01 & $1.61 \%$ & $0.30 \%$ & $-0.48 \%$ & $2.78 \%$ & $-2.90 \%$ & $0.82 \%$ & $0.07 \%$ & $-0.11 \%$ \\
\hline PKG02 & $2.73 \%$ & $1.13 \%$ & $-2.56 \%$ & $-0.14 \%$ & $1.73 \%$ & $2.07 \%$ & $5.47 \%$ & $0.71 \%$ \\
\hline PKG03 & $1.33 \%$ & $0.55 \%$ & $0.99 \%$ & $-1.04 \%$ & $0.97 \%$ & $-3.08 \%$ & $4.45 \%$ & $-0.80 \%$ \\
\hline PKG04 & $1.86 \%$ & $0.89 \%$ & $1.12 \%$ & $-0.96 \%$ & $-1.31 \%$ & $0.51 \%$ & $-2.48 \%$ & $-1.55 \%$ \\
\hline PKG05 & $4.64 \%$ & $0.99 \%$ & $1.28 \%$ & $-0.14 \%$ & $-0.56 \%$ & $-0.69 \%$ & $0.95 \%$ & $0.05 \%$ \\
\hline PKG06 & $2.01 \%$ & $0.48 \%$ & $1.40 \%$ & $0.16 \%$ & $0.84 \%$ & $-1.35 \%$ & $9.73 \%$ & $-1.01 \%$ \\
\hline PKG07 & $4.09 \%$ & $-0.61 \%$ & $-0.56 \%$ & $0.22 \%$ & $0.14 \%$ & $-2.50 \%$ & $6.13 \%$ & $-0.68 \%$ \\
\hline PKG08 & $0.72 \%$ & $0.74 \%$ & $0.66 \%$ & $-2.13 \%$ & $-0.83 \%$ & $0.83 \%$ & $3.03 \%$ & $0.05 \%$ \\
\hline PKG09 & $0.32 \%$ & $0.30 \%$ & $0.75 \%$ & $-2.01 \%$ & $1.23 \%$ & outliner & $6.92 \%$ & $-0.55 \%$ \\
\hline PKG10 & $0.00 \%$ & $3.20 \%$ & $1.11 \%$ & $-1.10 \%$ & $0.00 \%$ & $-1.63 \%$ & $3.10 \%$ & $-0.68 \%$ \\
\hline PKG11 & $1.43 \%$ & $-3.53 \%$ & $0.85 \%$ & $-0.60 \%$ & $-1.00 \%$ & $-0.84 \%$ & $1.34 \%$ & $1.21 \%$ \\
\hline PKG12 & $0.86 \%$ & $7.81 \%$ & $1.08 \%$ & $-2.44 \%$ & $-1.93 \%$ & $-0.07 \%$ & $1.90 \%$ & $-0.31 \%$ \\
\hline PKG13 & $0.25 \%$ & $-1.20 \%$ & $0.84 \%$ & $-1.31 \%$ & $-2.35 \%$ & $0.08 \%$ & $1.24 \%$ & $-0.61 \%$ \\
\hline PKG14 & $-0.43 \%$ & $-2.64 \%$ & $1.43 \%$ & $-0.79 \%$ & $-1.26 \%$ & $0.77 \%$ & $-0.80 \%$ & $2.19 \%$ \\
\hline PKG15 & $-1.38 \%$ & $0.15 \%$ & $2.59 \%$ & $-3.69 \%$ & $-2.53 \%$ & $0.31 \%$ & $-0.78 \%$ & $-0.95 \%$ \\
\hline$\overline{\text { PKG16 }}$ & $0.20 \%$ & $2.49 \%$ & $0.92 \%$ & $-0.25 \%$ & $-0.93 \%$ & $-1.85 \%$ & $1.71 \%$ & $-0.09 \%$ \\
\hline PKG17 & $1.37 \%$ & $-1.30 \%$ & $2.80 \%$ & $-0.57 \%$ & $-0.07 \%$ & $0.87 \%$ & $1.83 \%$ & $0.28 \%$ \\
\hline PKG18 & $0.16 \%$ & $0.88 \%$ & $0.80 \%$ & $-3.75 \%$ & $0.35 \%$ & $1.48 \%$ & $3.91 \%$ & $0.28 \%$ \\
\hline PKG19 & $-1.37 \%$ & $-1.12 \%$ & $1.32 \%$ & $-0.66 \%$ & $-2.86 \%$ & $1.53 \%$ & $6.04 \%$ & $0.89 \%$ \\
\hline PKG20 & $1.95 \%$ & $2.26 \%$ & $2.04 \%$ & $-2.45 \%$ & $-1.60 \%$ & $-0.30 \%$ & $3.73 \%$ & $-0.87 \%$ \\
\hline PKG21 & $0.00 \%$ & $-0.22 \%$ & $2.88 \%$ & $-2.82 \%$ & $-1.88 \%$ & $0.98 \%$ & $2.87 \%$ & $0.56 \%$ \\
\hline PKG22 & $0.55 \%$ & $3.60 \%$ & $0.82 \%$ & $-4.80 \%$ & $-2.26 \%$ & $2.21 \%$ & $1.95 \%$ & $0.67 \%$ \\
\hline PKG23 & $1.65 \%$ & $0.24 \%$ & $-0.50 \%$ & $-4.44 \%$ & $-1.63 \%$ & $1.18 \%$ & $5.51 \%$ & $0.46 \%$ \\
\hline PKG24 & $0.42 \%$ & $-1.53 \%$ & $1.40 \%$ & $-4.48 \%$ & $-1.74 \%$ & $-1.99 \%$ & $4.49 \%$ & $-0.53 \%$ \\
\hline PKG25 & $0.23 \%$ & $0.44 \%$ & $0.81 \%$ & $-2.83 \%$ & $-1.55 \%$ & $1.30 \%$ & $3.08 \%$ & $32 \%$ \\
\hline PKG26 & $-3.24 \%$ & $2.27 \%$ & $1.37 \%$ & $-2.57 \%$ & $-0.93 \%$ & $-3.10 \%$ & $1.33 \%$ & $0.11 \%$ \\
\hline PKG27 & $0.08 \%$ & $0.46 \%$ & $0.42 \%$ & $-1.97 \%$ & $-1.92 \%$ & $4.01 \%$ & $-0.35 \%$ & $-1.04 \%$ \\
\hline PKG28 & $-1.92 \%$ & $-0.63 \%$ & $0.00 \%$ & $-2.01 \%$ & $0.37 \%$ & $3.07 \%$ & $0.73 \%$ & $-1.11 \%$ \\
\hline PKG29 & $1.82 \%$ & $-3.36 \%$ & outliner & $-4.89 \%$ & $0.20 \%$ & $1.53 \%$ & $-2.66 \%$ & $-0.53 \%$ \\
\hline PKG30 & $-1.92 \%$ & $-0.44 \%$ & $0.57 \%$ & $-2.79 \%$ & $-0.98 \%$ & $0.23 \%$ & $2.24 \%$ & $-0.41 \%$ \\
\hline PKG31 & outliner & $-2.88 \%$ & $-1.11 \%$ & $-3.49 \%$ & $-2.00 \%$ & $-0.88 \%$ & $0.60 \%$ & $-0.37 \%$ \\
\hline PKG32 & $-0.56 \%$ & $-3.08 \%$ & $-2.21 \%$ & $-1.53 \%$ & $0.57 \%$ & $0.84 \%$ & $1.91 \%$ & $0.30 \%$ \\
\hline PKG33 & $-3.68 \%$ & $-1.69 \%$ & $-0.79 \%$ & $-0.78 \%$ & $-1.68 \%$ & $2.01 \%$ & $3.91 \%$ & $0.59 \%$ \\
\hline PKG35 & $0.15 \%$ & $0.22 \%$ & $-0.76 \%$ & $-5.41 \%$ & $-1.86 \%$ & $-1.28 \%$ & $-0.85 \%$ & $-0.45 \%$ \\
\hline PKG36 & $-0.65 \%$ & $2.34 \%$ & $-0.46 \%$ & $-0.78 \%$ & $-1.80 \%$ & $-0.14 \%$ & $0.23 \%$ & $-0.80 \%$ \\
\hline PKG37 & $-0.08 \%$ & $-0.29 \%$ & $-0.80 \%$ & $-0.07 \%$ & $-0.70 \%$ & $-0.75 \%$ & $-1.45 \%$ & $-2.32 \%$ \\
\hline PKG38 & $-5.76 \%$ & $-2.33 \%$ & $-1.16 \%$ & $0.00 \%$ & $-1.03 \%$ & $-2.04 \%$ & $-2.37 \%$ & $-2.25 \%$ \\
\hline PKG39 & $1.34 \%$ & $4.96 \%$ & $-0.87 \%$ & $-5.50 \%$ & $-1.46 \%$ & $1.19 \%$ & $2.34 \%$ & $-0.99 \%$ \\
\hline PKG40 & $3.96 \%$ & $7.31 \%$ & $-0.62 \%$ & $-4.13 \%$ & $-2.30 \%$ & $0.45 \%$ & $-0.47 \%$ & $-1.48 \%$ \\
\hline PKG41 & $-1.21 \%$ & $-0.36 \%$ & $-0.26 \%$ & $-1.70 \%$ & $-0.94 \%$ & $-3.67 \%$ & $-1.63 \%$ & $-0.73 \%$ \\
\hline PKG42 & $-1.36 \%$ & $-2.04 \%$ & $-0.39 \%$ & $-1.00 \%$ & $-3.06 \%$ & $-3.49 \%$ & $-1.59 \%$ & $-1.85 \%$ \\
\hline PKG43 & $2.30 \%$ & $-2.12 \%$ & $-1.08 \%$ & $2.33 \%$ & $-2.10 \%$ & $-4.54 \%$ & $3.01 \%$ & $-1.73 \%$ \\
\hline PKG44 & $1.28 \%$ & $-1.70 \%$ & $-2.21 \%$ & $0.76 \%$ & $-1.99 \%$ & $-4.55 \%$ & $-1.04 \%$ & $-1.36 \%$ \\
\hline PKG45 & $0.30 \%$ & $2.65 \%$ & $-0.69 \%$ & $-0.95 \%$ & $-2.22 \%$ & $-2.75 \%$ & $5.53 \%$ & $-2.03 \%$ \\
\hline PKG46 & $2.08 \%$ & $-1.15 \%$ & $-0.32 \%$ & $-2.17 \%$ & $-2.88 \%$ & $-0.69 \%$ & $-0.95 \%$ & $-1.13 \%$ \\
\hline PKG47 & $3.26 \%$ & $-1.90 \%$ & $-0.75 \%$ & $1.26 \%$ & $-2.41 \%$ & $0.79 \%$ & $-5.15 \%$ & $0.67 \%$ \\
\hline PKG48 & $1.75 \%$ & $-3.81 \%$ & $-1.12 \%$ & $-0.82 \%$ & $-2.16 \%$ & $0.85 \%$ & $-4.04 \%$ & $-1.45 \%$ \\
\hline PKG49 & $0.41 \%$ & $-5.83 \%$ & $-0.07 \%$ & $-1.24 \%$ & $-0.64 \%$ & $0.00 \%$ & $-3.77 \%$ & $-1.71 \%$ \\
\hline PKG50 & $-1.77 \%$ & $-2.99 \%$ & $2.15 \%$ & $-0.21 \%$ & $-1.85 \%$ & $-0.63 \%$ & $-4.77 \%$ & $-2.28 \%$ \\
\hline Mean & $0.45 \%$ & $-0.04 \%$ & $0.26 \%$ & $-1.63 \%$ & $-1.22 \%$ & $-0.27 \%$ & $1.35 \%$ & $-0.52 \%$ \\
\hline SD & $1.97 \%$ & $2.64 \%$ & $1.28 \%$ & $1.88 \%$ & $1.17 \%$ & $1.92 \%$ & $3.21 \%$ & $0.98 \%$ \\
\hline Max & $4.64 \%$ & $7.81 \%$ & $2.88 \%$ & $2.78 \%$ & $1.73 \%$ & $4.01 \%$ & $9.73 \%$ & $2.19 \%$ \\
\hline Min & $-5.76 \%$ & $-5.83 \%$ & $-2.56 \%$ & $-5.50 \%$ & $-3.06 \%$ & $-4.55 \%$ & $-5.15 \%$ & $-2.32 \%$ \\
\hline Diff & $10.39 \%$ & $13.64 \%$ & $5.43 \%$ & $8.28 \%$ & $4.78 \%$ & $8.56 \%$ & $14.89 \%$ & $4.51 \%$ \\
\hline
\end{tabular}


Table C-2-23: TCC 300 ${ }^{\text {th }}$ cycle; Daisy01 - Daisy08.

\begin{tabular}{|c|c|c|c|c|c|c|c|c|}
\hline & DAISY01 & DAISY02 & DAISY03 & DAISY04 & DAISY05 & DAISY06 & DAISY07 & DAISY08 \\
\hline PKG01 & outliner & $5.42 \%$ & $6.69 \%$ & $4.04 \%$ & $0.95 \%$ & $6.66 \%$ & $6.78 \%$ & $2.46 \%$ \\
\hline PKG02 & $12.11 \%$ & $6.40 \%$ & $2.23 \%$ & $6.54 \%$ & $3.97 \%$ & $9.21 \%$ & $5.69 \%$ & $6.92 \%$ \\
\hline PKG03 & $8.07 \%$ & $5.08 \%$ & $1.99 \%$ & $2.54 \%$ & $1.45 \%$ & $7.68 \%$ & $4.84 \%$ & $5.01 \%$ \\
\hline PKG04 & $5.89 \%$ & $6.61 \%$ & $4.19 \%$ & no ball & $1.38 \%$ & $14.16 \%$ & $2.29 \%$ & $2.99 \%$ \\
\hline PKG05 & $10.41 \%$ & $5.00 \%$ & $3.24 \%$ & $4.07 \%$ & $0.70 \%$ & $9.77 \%$ & $2.37 \%$ & outliner \\
\hline PKG06 & $11.20 \%$ & $7.71 \%$ & $2.68 \%$ & $3.14 \%$ & $-1.01 \%$ & $10.22 \%$ & $2.98 \%$ & outliner \\
\hline PKG07 & $7.46 \%$ & $5.38 \%$ & $3.52 \%$ & $4.14 \%$ & $-0.08 \%$ & $9.39 \%$ & $4.08 \%$ & $4.04 \%$ \\
\hline PKG08 & $6.77 \%$ & $4.49 \%$ & $3.71 \%$ & $1.55 \%$ & $-1.65 \%$ & $7.70 \%$ & $1.17 \%$ & $6.23 \%$ \\
\hline PKG09 & $12.85 \%$ & $5.60 \%$ & $3.77 \%$ & $4.01 \%$ & $-0.16 \%$ & $6.32 \%$ & $3.71 \%$ & $2.77 \%$ \\
\hline PKG10 & $5.47 \%$ & $3.13 \%$ & $1.55 \%$ & $1.45 \%$ & $-0.58 \%$ & $8.95 \%$ & $4.33 \%$ & $1.66 \%$ \\
\hline PKG11 & $4.70 \%$ & $3.01 \%$ & $3.56 \%$ & $1.25 \%$ & $2.67 \%$ & $11.82 \%$ & $4.98 \%$ & $2.33 \%$ \\
\hline PKG12 & $6.23 \%$ & $3.73 \%$ & $0.93 \%$ & $0.81 \%$ & $3.06 \%$ & $8.61 \%$ & $3.91 \%$ & $6.53 \%$ \\
\hline PKG13 & $9.38 \%$ & $1.63 \%$ & $1.40 \%$ & $4.70 \%$ & $1.30 \%$ & $13.38 \%$ & $4.45 \%$ & $11.81 \%$ \\
\hline PKG14 & $6.44 \%$ & $3.29 \%$ & $2.53 \%$ & $1.91 \%$ & $0.89 \%$ & $4.21 \%$ & $3.33 \%$ & $7.00 \%$ \\
\hline PKG15 & $7.35 \%$ & $4.90 \%$ & $2.05 \%$ & $1.31 \%$ & $-1.41 \%$ & $9.15 \%$ & $2.55 \%$ & $0.79 \%$ \\
\hline PKG16 & $8.76 \%$ & $5.02 \%$ & $2.82 \%$ & $1.59 \%$ & $1.30 \%$ & $5.46 \%$ & $3.19 \%$ & $2.83 \%$ \\
\hline PKG17 & $6.85 \%$ & $2.34 \%$ & $1.25 \%$ & $3.39 \%$ & $0.30 \%$ & $8.13 \%$ & $4.91 \%$ & $-2.67 \%$ \\
\hline PKG18 & $6.46 \%$ & $2.40 \%$ & $1.36 \%$ & $3.69 \%$ & $1.01 \%$ & $8.22 \%$ & $2.45 \%$ & $1.54 \%$ \\
\hline PKG19 & $7.91 \%$ & $4.88 \%$ & $2.95 \%$ & $1.81 \%$ & $1.46 \%$ & $8.76 \%$ & $3.73 \%$ & $10.95 \%$ \\
\hline PKG20 & $1.44 \%$ & $1.99 \%$ & $1.46 \%$ & $0.19 \%$ & $1.46 \%$ & $6.25 \%$ & $2.14 \%$ & $2.57 \%$ \\
\hline PKG21 & $9.27 \%$ & $4.57 \%$ & $-0.24 \%$ & $4.67 \%$ & $-0.46 \%$ & $8.57 \%$ & $1.58 \%$ & $-1.50 \%$ \\
\hline PKG22 & $2.92 \%$ & $0.34 \%$ & $2.52 \%$ & $0.09 \%$ & $0.88 \%$ & $9.92 \%$ & $2.97 \%$ & $3.72 \%$ \\
\hline PKG23 & $7.16 \%$ & $3.69 \%$ & $2.28 \%$ & $3.63 \%$ & $-0.17 \%$ & $11.42 \%$ & $2.93 \%$ & $4.25 \%$ \\
\hline PKG24 & $8.67 \%$ & $5.43 \%$ & $1.63 \%$ & $-1.26 \%$ & $-0.57 \%$ & $8.40 \%$ & $5.95 \%$ & $3.05 \%$ \\
\hline PKG25 & $5.54 \%$ & $3.27 \%$ & $2.71 \%$ & $1.16 \%$ & $0.94 \%$ & $5.92 \%$ & $2.32 \%$ & $-4.20 \%$ \\
\hline PKG26 & $4.72 \%$ & $5.88 \%$ & $0.62 \%$ & $1.77 \%$ & $-0.08 \%$ & $14.43 \%$ & $1.75 \%$ & $1.29 \%$ \\
\hline PKG27 & $5.16 \%$ & $3.00 \%$ & $2.14 \%$ & $0.77 \%$ & $0.72 \%$ & $10.54 \%$ & $1.87 \%$ & $0.79 \%$ \\
\hline PKG28 & $6.72 \%$ & $5.36 \%$ & $0.96 \%$ & $2.32 \%$ & $1.15 \%$ & $9.79 \%$ & $6.33 \%$ & $-2.73 \%$ \\
\hline PKG29 & $8.77 \%$ & $2.85 \%$ & $0.61 \%$ & $2.16 \%$ & $-0.54 \%$ & $10.31 \%$ & $4.13 \%$ & $-1.39 \%$ \\
\hline PKG30 & $6.80 \%$ & $0.14 \%$ & $3.32 \%$ & $1.99 \%$ & $0.16 \%$ & $5.86 \%$ & $6.10 \%$ & $1.32 \%$ \\
\hline PKG31 & $\%$ & $4.18 \%$ & $0.43 \%$ & $0.10 \%$ & $1.40 \%$ & $4.09 \%$ & $10.53 \%$ & $3.01 \%$ \\
\hline PKG32 & $5.70 \%$ & $0.64 \%$ & $0.08 \%$ & $-4.48 \%$ & $0.99 \%$ & $10.01 \%$ & $2.03 \%$ & $3.18 \%$ \\
\hline PKG33 & $4.81 \%$ & $2.59 \%$ & $1.57 \%$ & $2.41 \%$ & $3.42 \%$ & $4.76 \%$ & $4.67 \%$ & $1.46 \%$ \\
\hline PKG35 & $7.71 \%$ & $2.75 \%$ & $-0.64 \%$ & $0.10 \%$ & $1.25 \%$ & $7.94 \%$ & $2.03 \%$ & $2.21 \%$ \\
\hline PKG36 & $9.17 \%$ & $3.92 \%$ & $0.00 \%$ & $-1.60 \%$ & $2.47 \%$ & $3.92 \%$ & $2.62 \%$ & $3.50 \%$ \\
\hline PKG37 & $9.94 \%$ & $2.91 \%$ & $0.87 \%$ & $2.22 \%$ & $2.23 \%$ & $7.51 \%$ & $2.05 \%$ & $-2.76 \%$ \\
\hline PKG38 & $4.79 \%$ & $2.82 \%$ & $0.00 \%$ & $-2.42 \%$ & $1.11 \%$ & $0.86 \%$ & $1.67 \%$ & $-0.61 \%$ \\
\hline PKG39 & $8.71 \%$ & $1.15 \%$ & $0.64 \%$ & $-2.94 \%$ & $-1.09 \%$ & $1.64 \%$ & $2.37 \%$ & $-2.19 \%$ \\
\hline PKG40 & $2.43 \%$ & $3.18 \%$ & $-1.63 \%$ & $2.02 \%$ & $-0.48 \%$ & $3.76 \%$ & $3.07 \%$ & $0.55 \%$ \\
\hline PKG41 & $6.88 \%$ & $3.61 \%$ & $1.07 \%$ & $2.34 \%$ & $0.29 \%$ & $4.19 \%$ & $2.77 \%$ & $-1.94 \%$ \\
\hline PKG42 & $4.75 \%$ & $3.84 \%$ & $2.04 \%$ & $-0.28 \%$ & no ball & $7.40 \%$ & $5.58 \%$ & $-0.15 \%$ \\
\hline PKG43 & $5.68 \%$ & $1.66 \%$ & $1.28 \%$ & $0.96 \%$ & $0.31 \%$ & $11.11 \%$ & $1.96 \%$ & $-2.28 \%$ \\
\hline PKG44 & $4.58 \%$ & $4.69 \%$ & $0.33 \%$ & $-6.06 \%$ & $-1.05 \%$ & $12.72 \%$ & $2.86 \%$ & $-0.08 \%$ \\
\hline PKG45 & $4.82 \%$ & $3.87 \%$ & $1.34 \%$ & $-1.08 \%$ & $-0.15 \%$ & $10.91 \%$ & $2.58 \%$ & $-0.08 \%$ \\
\hline PKG46 & $2.88 \%$ & $2.34 \%$ & $0.99 \%$ & $-2.08 \%$ & $0.00 \%$ & $17.10 \%$ & $3.71 \%$ & $2.35 \%$ \\
\hline PKG47 & $5.31 \%$ & $1.77 \%$ & $-0.40 \%$ & $0.29 \%$ & $0.97 \%$ & $11.60 \%$ & $5.21 \%$ & $1.68 \%$ \\
\hline PKG48 & $2.11 \%$ & $7.19 \%$ & $-1.11 \%$ & $2.61 \%$ & $-0.86 \%$ & $11.80 \%$ & $1.78 \%$ & $-0.56 \%$ \\
\hline PKG49 & $6.45 \%$ & $3.80 \%$ & $-1.08 \%$ & $-2.88 \%$ & $-0.33 \%$ & $9.25 \%$ & $4.05 \%$ & $5.13 \%$ \\
\hline PKG50 & $6.61 \%$ & $4.17 \%$ & $2.07 \%$ & $1.49 \%$ & $0.22 \%$ & $14.28 \%$ & $4.68 \%$ & $-0.91 \%$ \\
\hline Mean & $6.68 \%$ & $3.75 \%$ & $1.60 \%$ & $1.25 \%$ & $0.62 \%$ & $8.65 \%$ & $3.59 \%$ & $1.95 \%$ \\
\hline$S D$ & $2.47 \%$ & $1.72 \%$ & $1.56 \%$ & $2.48 \%$ & $1.24 \%$ & $3.38 \%$ & $1.75 \%$ & $3.38 \%$ \\
\hline Max & $12.85 \%$ & $7.71 \%$ & $6.69 \%$ & $6.54 \%$ & $3.97 \%$ & $17.10 \%$ & $10.53 \%$ & $11.81 \%$ \\
\hline Min & $1.44 \%$ & $0.14 \%$ & $-1.63 \%$ & $-6.06 \%$ & $-1.65 \%$ & $0.86 \%$ & $1.17 \%$ & $-4.20 \%$ \\
\hline Diff & $11.41 \%$ & $7.57 \%$ & $8.31 \%$ & $12.60 \%$ & $5.62 \%$ & $16.24 \%$ & $9.35 \%$ & $16.01 \%$ \\
\hline
\end{tabular}


Table C-2-24: TCC 300 ${ }^{\text {th }}$ cycle; Daisy09 - Daisyl6.

\begin{tabular}{|c|c|c|c|c|c|c|c|c|}
\hline & AISY09 & DAISY10 & DAISY11 & DAISY12 & DAISY13 & DAISY14 & DAISY15 & DAISY16 \\
\hline PKG01 & $3.14 \%$ & $5.07 \%$ & $2.11 \%$ & $1.39 \%$ & $-1.28 \%$ & $6.42 \%$ & $6.05 \%$ & $1.73 \%$ \\
\hline PKG02 & $3.37 \%$ & $6.38 \%$ & $-0.19 \%$ & $0.28 \%$ & $0.94 \%$ & $4.07 \%$ & $4.50 \%$ & $2.40 \%$ \\
\hline PKG03 & $1.19 \%$ & $3.79 \%$ & $2.77 \%$ & $-1.18 \%$ & $0.64 \%$ & $0.94 \%$ & $7.97 \%$ & $0.47 \%$ \\
\hline KG04 & $2.25 \%$ & $.08 \%$ & $6.83 \%$ & $0.67 \%$ & $0.21 \%$ & $5.37 \%$ & $-0.06 \%$ & $-2.05 \%$ \\
\hline PKG05 & $3.17 \%$ & $37 \%$ & $0 \%$ & $2.36 \%$ & $0.42 \%$ & $2.75 \%$ & $1.53 \%$ & $3.32 \%$ \\
\hline PKG06 & $2.62 \%$ & $51 \%$ & $2.81 \%$ & $-0.78 \%$ & $0.53 \%$ & $1.59 \%$ & $0.26 \%$ & $-0.60 \%$ \\
\hline PKG07 & $3.77 \%$ & $86 \%$ & $4.44 \%$ & $0.00 \%$ & $1.86 \%$ & $-1.69 \%$ & $2.29 \%$ & $1.40 \%$ \\
\hline PKG08 & $3.65 \%$ & $18 \%$ & $2.29 \%$ & $1.74 \%$ & $-0.45 \%$ & $3.95 \%$ & $2.24 \%$ & $1.18 \%$ \\
\hline PKG09 & $0.89 \%$ & $7.86 \%$ & $1.98 \%$ & $-3.09 \%$ & $-0.22 \%$ & $-4.63 \%$ & $4.45 \%$ & $1.17 \%$ \\
\hline PKG10 & $1.64 \%$ & $3.84 \%$ & $-4.65 \%$ & $-1.03 \%$ & $0.66 \%$ & $0.14 \%$ & $1.67 \%$ & $2.07 \%$ \\
\hline PKG11 & $3.08 \%$ & $3.60 \%$ & $2.04 \%$ & $2.55 \%$ & $-0.67 \%$ & $1.54 \%$ & $1.46 \%$ & $3.79 \%$ \\
\hline KG12 & $1.71 \%$ & $0.87 \%$ & $1.78 \%$ & $-2.24 \%$ & $-0.77 \%$ & $3.20 \%$ & $1.38 \%$ & $0.74 \%$ \\
\hline PKG13 & $4.04 \%$ & $1.13 \%$ & no ball & $-2.99 \%$ & $-2.28 \%$ & $4.61 \%$ & $1.48 \%$ & $1.18 \%$ \\
\hline PKG14 & $3.15 \%$ & $-1.22 \%$ & $1.87 \%$ & $-2.31 \%$ & $-0.44 \%$ & $2.88 \%$ & $1.28 \%$ & $1.76 \%$ \\
\hline PKG15 & $3.01 \%$ & $37 \%$ & $1.89 \%$ & $-3.98 \%$ & $0.14 \%$ & $1.14 \%$ & $-0.48 \%$ & $1.39 \%$ \\
\hline PKG16 & $5.25 \%$ & $1.44 \%$ & $0.86 \%$ & $-0.63 \%$ & $0.56 \%$ & $0.26 \%$ & $4.29 \%$ & $3.23 \%$ \\
\hline PKG17 & $8.01 \%$ & $3.22 \%$ & $2.40 \%$ & $-1.07 \%$ & $0.34 \%$ & $3.48 \%$ & $1.48 \%$ & $2.06 \%$ \\
\hline PKG18 & $2.46 \%$ & $2.57 \%$ & $4.78 \%$ & $-4.16 \%$ & $3.46 \%$ & $3.93 \%$ & $9.64 \%$ & $2.31 \%$ \\
\hline PKG19 & $4.34 \%$ & $1.72 \%$ & $2.16 \%$ & $-1.10 \%$ & $-0.77 \%$ & $3.53 \%$ & $0.79 \%$ & $1.91 \%$ \\
\hline PKG20 & $\%$ & $30 \%$ & $\%$ & $-2.09 \%$ & $-0.56 \%$ & $6.66 \%$ & $9.22 \%$ & $1.32 \%$ \\
\hline PKG21 & $3.54 \%$ & $40 \%$ & & $-3.11 \%$ & $1 \%$ & $5.44 \%$ & $5.98 \%$ & $0.95 \%$ \\
\hline PKG22 & $3.44 \%$ & $3.46 \%$ & $1 \%$ & $-2.40 \%$ & $-0.75 \%$ & $3.61 \%$ & $3.07 \%$ & $1.68 \%$ \\
\hline PKG23 & $7.19 \%$ & $5.25 \%$ & $1.06 \%$ & $-4.14 \%$ & $-0.59 \%$ & $4.64 \%$ & $3.07 \%$ & $0.46 \%$ \\
\hline PKG24 & $4.57 \%$ & $46 \%$ & $\%$ & $-3.80 \%$ & $-0.43 \%$ & $2.45 \%$ & $2.50 \%$ & $1.19 \%$ \\
\hline PKG25 & $3.90 \%$ & $2.27 \%$ & $1.82 \%$ & $-2.55 \%$ & $-0.34 \%$ & $6.65 \%$ & $2.62 \%$ & $0.48 \%$ \\
\hline PKG26 & $-1.25 \%$ & $\%$ & $2.47 \%$ & $-2.50 \%$ & $\%$ & $1.20 \%$ & $0.11 \%$ & $0.21 \%$ \\
\hline PKG27 & $0.73 \%$ & $28 \%$ & her & $-1.60 \%$ & $-0.28 \%$ & $4.60 \%$ & $-0.47 \%$ & $0.82 \%$ \\
\hline PKG28 & $-0.08 \%$ & $3.84 \%$ & $-4.62 \%$ & $-1.34 \%$ & $2.49 \%$ & $7.60 \%$ & $0.61 \%$ & $-0.44 \%$ \\
\hline PKG29 & $-0.08 \%$ & $-2.58 \%$ & outliner & $-5.03 \%$ & $3.66 \%$ & $3.86 \%$ & $-2.77 \%$ & $1.67 \%$ \\
\hline PKG30 & $-0.54 \%$ & $0.66 \%$ & $3 \%$ & $-3.59 \%$ & $2.38 \%$ & $5.82 \%$ & $5.20 \%$ & $1.54 \%$ \\
\hline PKG31 & iner & $86 \%$ & $2 \%$ & $-3.34 \%$ & -0. & $0.88 \%$ & $5.50 \%$ & $1.66 \%$ \\
\hline PKG32 & $\%$ & $\%$ & & $-1.53 \%$ & $9 \%$ & $2.92 \%$ & $5.68 \%$ & $1.12 \%$ \\
\hline PKG33 & $\%$ & $\%$ & -7. & $\%$ & $7 \%$ & $8.50 \%$ & $5.85 \%$ & $1.99 \%$ \\
\hline PKG35 & $3 \%$ & $44 \%$ & & $7 \%$ & $\%$ & $4.06 \%$ & $4.37 \%$ & $0.57 \%$ \\
\hline PKG36 & $2 \%$ & $77 \%$ & $4 \%$ & $-1.56 \%$ & $15 \%$ & $3.10 \%$ & $3.23 \%$ & $0.75 \%$ \\
\hline PKG37 & $4.82 \%$ & $-0.37 \%$ & $4 \%$ & $-0.43 \%$ & $2.02 \%$ & $3.53 \%$ & $0.93 \%$ & $-0.48 \%$ \\
\hline PKG38 & $-2.60 \%$ & $-2.66 \%$ & $4 \%$ & $-1.80 \%$ & $1.48 \%$ & $5.09 \%$ & $2.18 \%$ & $-0.50 \%$ \\
\hline PKG39 & $7 \%$ & $50 \%$ & $7 \%$ & $-5.43 \%$ & $0.00 \%$ & $2.67 \%$ & $1.80 \%$ & $0.60 \%$ \\
\hline PKG40 & $8 \%$ & $6 \%$ & & $-3.85 \%$ & $1.18 \%$ & $2.91 \%$ & $2.24 \%$ & $-0.44 \%$ \\
\hline PKG41 & $\%$ & $9 \%$ & & $-1.77 \%$ & $\%$ & $.69 \%$ & $3.50 \%$ & $0.10 \%$ \\
\hline PKG42 & $6 \%$ & $44 \%$ & $\%$ & $-0.50 \%$ & $3 \%$ & $-1.16 \%$ & $-3.14 \%$ & $-1.85 \%$ \\
\hline PKG43 & $1.51 \%$ & $-0.37 \%$ & $6 \%$ & $0.00 \%$ & $-1.26 \%$ & $-1.91 \%$ & $0.18 \%$ & $-0.65 \%$ \\
\hline PKG44 & $2 \%$ & $0.59 \%$ & $5 \%$ & $0.84 \%$ & $0.07 \%$ & $-1.61 \%$ & $0.37 \%$ & $-0.06 \%$ \\
\hline PKG45 & $2.70 \%$ & $9 \%$ & $5 \%$ & $-1.02 \%$ & $-1.41 \%$ & $-0.14 \%$ & $-0.06 \%$ & $-1.47 \%$ \\
\hline PKG46 & $2.08 \%$ & $3.37 \%$ & $9 \%$ & $-3.26 \%$ & $0.26 \%$ & $3.96 \%$ & $1.33 \%$ & $0.06 \%$ \\
\hline PKG47 & $6.18 \%$ & $-0.46 \%$ & $\%$ & $-1.33 \%$ & $-0.59 \%$ & $3.80 \%$ & $-4.98 \%$ & $-0.62 \%$ \\
\hline PKG48 & $0 \%$ & $57 \%$ & & $0.07 \%$ & $6 \%$ & $1.62 \%$ & $-2.43 \%$ & $-0.28 \%$ \\
\hline PKG49 & $9 \%$ & $.19 \%$ & & $-0.93 \%$ & $-0.50 \%$ & $37 \%$ & $-2.87 \%$ & $-0.91 \%$ \\
\hline PKG50 & $2.65 \%$ & $-1.63 \%$ & & $-1.52 \%$ & $-0.07 \%$ & $0.00 \%$ & $-3.47 \%$ & $-1.98 \%$ \\
\hline Mean & $2.71 \%$ & $2.02 \%$ & $3 \%$ & $-1.69 \%$ & $0.28 \%$ & $2.88 \%$ & $2.07 \%$ & $0.75 \%$ \\
\hline SD & $2.17 \%$ & $2.85 \%$ & $2.75 \%$ & $1.94 \%$ & $1.25 \%$ & $2.64 \%$ & $3.13 \%$ & $1.33 \%$ \\
\hline Max & $8.01 \%$ & $9.51 \%$ & $6.83 \%$ & $2.55 \%$ & $3.66 \%$ & $8.50 \%$ & $9.64 \%$ & $3.79 \%$ \\
\hline $\operatorname{Min}$ & $-2.60 \%$ & $-2.66 \%$ & $-7.46 \%$ & $-6.47 \%$ & $-2.28 \%$ & $-4.63 \%$ & $-4.98 \%$ & $-2.05 \%$ \\
\hline Diff & $10.61 \%$ & $12.17 \%$ & $14.29 \%$ & $9.02 \%$ & $5.93 \%$ & $13.13 \%$ & $14.62 \%$ & $5.84 \%$ \\
\hline
\end{tabular}


Table C-2-25: TCC $400^{\text {th }}$ cycle; Daisy01 - Daisy08.

\begin{tabular}{|c|c|c|c|c|c|c|c|c|}
\hline & DAISY01 & DAISY02 & DAISY03 & DAISY04 & DAISY05 & DAISY06 & DAISY07 & DAISY08 \\
\hline PKG01 & $1.02 \%$ & $2.48 \%$ & $1.52 \%$ & $17.38 \%$ & $5.72 \%$ & $11.97 \%$ & $7.50 \%$ & $10.61 \%$ \\
\hline PKG02 & $1.30 \%$ & $6.55 \%$ & $2.03 \%$ & $16.61 \%$ & $0.66 \%$ & $20.95 \%$ & $6.31 \%$ & $13.69 \%$ \\
\hline PKG03 & $0.48 \%$ & $3.58 \%$ & $0.57 \%$ & $15.08 \%$ & $1.78 \%$ & $18.71 \%$ & $0.54 \%$ & $11.03 \%$ \\
\hline PKG04 & $0.03 \%$ & $5.63 \%$ & $2.91 \%$ & no ball & $-1.26 \%$ & $20.44 \%$ & $-2.12 \%$ & $10.07 \%$ \\
\hline PKG05 & $4.26 \%$ & $5.75 \%$ & $-0.76 \%$ & $18.65 \%$ & $-0.35 \%$ & $19.13 \%$ & $1.65 \%$ & $9.47 \%$ \\
\hline PKG06 & $-0.18 \%$ & $8.77 \%$ & $2.63 \%$ & $18.43 \%$ & $0.88 \%$ & $21.81 \%$ & $0.05 \%$ & $10.72 \%$ \\
\hline PKG07 & $-0.07 \%$ & $6.14 \%$ & $2.22 \%$ & $17.89 \%$ & $2.17 \%$ & $15.75 \%$ & $2.23 \%$ & $10.25 \%$ \\
\hline PKG08 & $-0.15 \%$ & $6.16 \%$ & $1.15 \%$ & $16.85 \%$ & $-1.47 \%$ & $19.36 \%$ & $2.57 \%$ & $11.85 \%$ \\
\hline PKG09 & $2.34 \%$ & $7.31 \%$ & $2.82 \%$ & $22.68 \%$ & $-0.99 \%$ & $17.29 \%$ & $0.37 \%$ & $10.59 \%$ \\
\hline PKG10 & $1.95 \%$ & $2.81 \%$ & $0.50 \%$ & $14.94 \%$ & $-1.91 \%$ & $14.71 \%$ & $0.49 \%$ & $11.40 \%$ \\
\hline PKG11 & $1.86 \%$ & $3.57 \%$ & $1.57 \%$ & $17.40 \%$ & $-1.56 \%$ & $22.13 \%$ & $4.63 \%$ & $8.84 \%$ \\
\hline PKG12 & $-0.24 \%$ & $4.35 \%$ & $2.35 \%$ & $15.39 \%$ & $-0.53 \%$ & $11.22 \%$ & $2.03 \%$ & $7.94 \%$ \\
\hline PKG13 & $2.05 \%$ & $2.96 \%$ & $1.68 \%$ & $22.09 \%$ & $-0.85 \%$ & $18.77 \%$ & $5.23 \%$ & $8.09 \%$ \\
\hline PKG14 & $0.80 \%$ & $4.57 \%$ & $3.68 \%$ & $15.10 \%$ & $-1.06 \%$ & $13.10 \%$ & $1.00 \%$ & $8.41 \%$ \\
\hline PKG15 & $2.02 \%$ & $3.16 \%$ & $0.03 \%$ & $19.06 \%$ & $-3.49 \%$ & $17.88 \%$ & $2.26 \%$ & $10.07 \%$ \\
\hline PKG16 & $9.42 \%$ & $5.67 \%$ & $2.27 \%$ & $26.18 \%$ & $-1.00 \%$ & $14.00 \%$ & $2.15 \%$ & $7.91 \%$ \\
\hline PKG17 & $0.12 \%$ & $5.28 \%$ & $-1.38 \%$ & $23.73 \%$ & $-1.81 \%$ & $17.73 \%$ & $3.89 \%$ & $5.18 \%$ \\
\hline PKG18 & $1.68 \%$ & $6.05 \%$ & $2.27 \%$ & $18.98 \%$ & $-1.13 \%$ & $16.62 \%$ & $0.11 \%$ & $7.03 \%$ \\
\hline PKG19 & $1.34 \%$ & $5.26 \%$ & $0.69 \%$ & $16.22 \%$ & $-1.50 \%$ & $18.82 \%$ & $2.58 \%$ & $.73 \%$ \\
\hline PKG20 & $0.32 \%$ & $2.25 \%$ & $0.85 \%$ & $16.29 \%$ & $0.45 \%$ & $73 \%$ & $1.47 \%$ & $9.61 \%$ \\
\hline PKG21 & $2.26 \%$ & $2.91 \%$ & $0.43 \%$ & $18.02 \%$ & $-1.28 \%$ & $18.74 \%$ & $-1.01 \%$ & $2.09 \%$ \\
\hline PKG22 & $0.12 \%$ & $1.57 \%$ & $2.87 \%$ & $14.30 \%$ & $-0.52 \%$ & $27.80 \%$ & $0.63 \%$ & $8.66 \%$ \\
\hline PKG23 & $4.15 \%$ & $5.41 \%$ & $1.91 \%$ & $15.22 \%$ & $-0.30 \%$ & $33.56 \%$ & $5.77 \%$ & $12.66 \%$ \\
\hline PKG24 & $2.89 \%$ & $5.70 \%$ & $1.66 \%$ & $14.64 \%$ & $-0.45 \%$ & $26.75 \%$ & $-0.37 \%$ & $6.10 \%$ \\
\hline PKG25 & $3.48 \%$ & $3.03 \%$ & $2.36 \%$ & $13.32 \%$ & $0.20 \%$ & $25.02 \%$ & $0.74 \%$ & $0.06 \%$ \\
\hline PKG26 & $3.42 \%$ & $8.08 \%$ & $-0.51 \%$ & $14.41 \%$ & $-1.60 \%$ & $28.34 \%$ & $-1.45 \%$ & $8.37 \%$ \\
\hline PKG27 & $3.58 \%$ & $5.00 \%$ & $-0.28 \%$ & $15.70 \%$ & $-0.92 \%$ & $27.72 \%$ & $-0.99 \%$ & $7.81 \%$ \\
\hline PKG28 & $3.25 \%$ & $8.79 \%$ & $0.52 \%$ & $18.56 \%$ & $-1.60 \%$ & $21.35 \%$ & $3.54 \%$ & $3.86 \%$ \\
\hline PKG29 & $2.23 \%$ & $3.68 \%$ & $-0.65 \%$ & $21.99 \%$ & $-0.66 \%$ & $25.08 \%$ & $2.68 \%$ & $10.64 \%$ \\
\hline PKG30 & $5.87 \%$ & $-0.20 \%$ & $0.76 \%$ & $20.72 \%$ & $-0.53 \%$ & $16.08 \%$ & $3.92 \%$ & $15.32 \%$ \\
\hline PKG31 & $8.68 \%$ & $6.25 \%$ & $0.12 \%$ & outliner & $-1.01 \%$ & $16.81 \%$ & $1.89 \%$ & $5.34 \%$ \\
\hline PKG32 & $8.22 \%$ & $1.20 \%$ & $-1.36 \%$ & outliner & $0.78 \%$ & $3 \%$ & $0.79 \%$ & $8.94 \%$ \\
\hline PKG33 & $2.26 \%$ & $4.50 \%$ & $-0.28 \%$ & outliner & $-0.97 \%$ & $15.00 \%$ & $1.39 \%$ & $7.94 \%$ \\
\hline PKG35 & $2.13 \%$ & $3.60 \%$ & $-1.17 \%$ & $16.99 \%$ & $-1.14 \%$ & $16.51 \%$ & $0.83 \%$ & $9.48 \%$ \\
\hline PKG36 & $1.79 \%$ & $4.44 \%$ & $1.23 \%$ & $12.17 \%$ & $-1.83 \%$ & $14.77 \%$ & $4.60 \%$ & $9.69 \%$ \\
\hline PKG37 & $12.27 \%$ & $3.36 \%$ & $-0.99 \%$ & $19.85 \%$ & $3.26 \%$ & $23.52 \%$ & $0.62 \%$ & $5.09 \%$ \\
\hline PKG38 & $3.21 \%$ & $3.54 \%$ & $-1.13 \%$ & $11.62 \%$ & $1.75 \%$ & $12.04 \%$ & $1.27 \%$ & $6.66 \%$ \\
\hline PKG39 & $6.15 \%$ & $1.41 \%$ & $0.19 \%$ & $11.70 \%$ & $-0.98 \%$ & $8.48 \%$ & $1.13 \%$ & $5.24 \%$ \\
\hline PKG40 & $11.10 \%$ & $2.73 \%$ & $-2.91 \%$ & $18.93 \%$ & $3.00 \%$ & $9.85 \%$ & $0.31 \%$ & $9.07 \%$ \\
\hline PKG41 & $14.30 \%$ & $6.29 \%$ & $0.34 \%$ & $17.10 \%$ & $-1.58 \%$ & $12.54 \%$ & $0.93 \%$ & $5.13 \%$ \\
\hline PKG42 & $6.81 \%$ & $5.33 \%$ & $-0.91 \%$ & $15.61 \%$ & no ball & $14.29 \%$ & $3.64 \%$ & $8.04 \%$ \\
\hline PKG43 & $4.65 \%$ & $2.83 \%$ & $0.68 \%$ & $14.09 \%$ & $-0.75 \%$ & $22.40 \%$ & $1.16 \%$ & $5.22 \%$ \\
\hline PKG44 & $1.21 \%$ & $10.34 \%$ & $-0.38 \%$ & $9.13 \%$ & $-0.69 \%$ & $23.60 \%$ & $0.59 \%$ & $8.27 \%$ \\
\hline PKG45 & $5.44 \%$ & $6.68 \%$ & $0.90 \%$ & $12.05 \%$ & $-0.82 \%$ & $27.63 \%$ & $2.05 \%$ & $8.32 \%$ \\
\hline PKG46 & $2.11 \%$ & $2.03 \%$ & $2.31 \%$ & $11.54 \%$ & $0.78 \%$ & $26.98 \%$ & $0.49 \%$ & $9.55 \%$ \\
\hline PKG47 & $5.67 \%$ & $1.83 \%$ & $-0.13 \%$ & $24.93 \%$ & $2.23 \%$ & $27.64 \%$ & $3.21 \%$ & $8.07 \%$ \\
\hline PKG48 & $5.21 \%$ & $10.10 \%$ & $-0.68 \%$ & $16.99 \%$ & $-0.82 \%$ & $28.10 \%$ & $0.64 \%$ & $7.16 \%$ \\
\hline PKG49 & $3.17 \%$ & $8.34 \%$ & $-0.79 \%$ & $11.34 \%$ & $3.40 \%$ & $21.29 \%$ & $2.01 \%$ & $9.57 \%$ \\
\hline PKG50 & $2.66 \%$ & $6.69 \%$ & $1.49 \%$ & $16.60 \%$ & $3.12 \%$ & $21.25 \%$ & $3.87 \%$ & $4.35 \%$ \\
\hline Mean & $3.44 \%$ & $4.77 \%$ & $0.72 \%$ & $16.81 \%$ & $-0.15 \%$ & $19.56 \%$ & $1.83 \%$ & $8.33 \%$ \\
\hline SD & $3.34 \%$ & $2.36 \%$ & $1.43 \%$ & $3.72 \%$ & $1.76 \%$ & $5.70 \%$ & $2.01 \%$ & $2.82 \%$ \\
\hline Max & $14.30 \%$ & $10.34 \%$ & $3.68 \%$ & $26.18 \%$ & $5.72 \%$ & $33.56 \%$ & $7.50 \%$ & $15.32 \%$ \\
\hline Min & $-0.24 \%$ & $-0.20 \%$ & $-2.91 \%$ & $9.13 \%$ & $-3.49 \%$ & $8.48 \%$ & $-2.12 \%$ & $0.06 \%$ \\
\hline Diff & $14.55 \%$ & $10.55 \%$ & $6.59 \%$ & $17.05 \%$ & $9.21 \%$ & $25.08 \%$ & $9.61 \%$ & $15.25 \%$ \\
\hline
\end{tabular}


Table C-2-26: TCC $400^{\text {th }}$ cycle; Daisy09 - Daisy16.

\begin{tabular}{|c|c|c|c|c|c|c|c|c|}
\hline & DAISY09 & DAISY10 & DAISY11 & DAISY12 & DAISY13 & DAISY14 & DAISY15 & DAISY16 \\
\hline PKG01 & $1.81 \%$ & $1.25 \%$ & $1.41 \%$ & $0.85 \%$ & $-1.10 \%$ & $-5.07 \%$ & $7.07 \%$ & $4.46 \%$ \\
\hline PKG02 & $76 \%$ & $3.06 \%$ & $-1.04 \%$ & $0.75 \%$ & $0.77 \%$ & $-2.60 \%$ & $6.96 \%$ & $2.68 \%$ \\
\hline PKG03 & $46 \%$ & $12 \%$ & $68 \%$ & $-2.31 \%$ & $0.76 \%$ & $-7.02 \%$ & $2.88 \%$ & $2.00 \%$ \\
\hline PKG04 & $19 \%$ & $1.98 \%$ & $3.05 \%$ & $1.08 \%$ & $-0.02 \%$ & $-3.15 \%$ & $2.94 \%$ & $-1.67 \%$ \\
\hline PKG05 & $3.46 \%$ & $2.41 \%$ & $4.09 \%$ & $0.76 \%$ & $0.33 \%$ & $-4.87 \%$ & $3.48 \%$ & $77 \%$ \\
\hline PKG06 & $0.92 \%$ & $2.31 \%$ & $3.01 \%$ & $-0.11 \%$ & $0.97 \%$ & $-6.42 \%$ & $1.20 \%$ & $36 \%$ \\
\hline PKG07 & $-1.96 \%$ & $1.73 \%$ & $1.51 \%$ & $0.34 \%$ & $1.84 \%$ & $-9.11 \%$ & $3.03 \%$ & $1.11 \%$ \\
\hline PKG08 & $18 \%$ & $1.33 \%$ & $2.75 \%$ & $-0.28 \%$ & $-0.14 \%$ & $-4.62 \%$ & $0.85 \%$ & $1.71 \%$ \\
\hline PKG09 & $35 \%$ & $-0.02 \%$ & $2.79 \%$ & $-1.82 \%$ & $-1.25 \%$ & outliner & $6.04 \%$ & $0.95 \%$ \\
\hline PKG10 & $-0.78 \%$ & $0.12 \%$ & $2.40 \%$ & $-0.37 \%$ & $-0.87 \%$ & $-6.52 \%$ & $5.90 \%$ & $0.05 \%$ \\
\hline PKG11 & $9 \%$ & $-2.03 \%$ & $2.73 \%$ & $1.17 \%$ & $-1.02 \%$ & $-6.77 \%$ & $11.96 \%$ & $81 \%$ \\
\hline PKG12 & $3 \%$ & $-1.43 \%$ & $3.10 \%$ & $-0.02 \%$ & $-1.95 \%$ & $-5.07 \%$ & $.89 \%$ & $8 \%$ \\
\hline PKG13 & $72 \%$ & $1.48 \%$ & no ball & $0.34 \%$ & $-2.58 \%$ & $-4.59 \%$ & $7.27 \%$ & $45 \%$ \\
\hline PKG14 & ball & $-0.09 \%$ & $3.67 \%$ & $-0.15 \%$ & $-0.33 \%$ & $-4.76 \%$ & $2.60 \%$ & $10 \%$ \\
\hline PKG15 & $24 \%$ & $1.10 \%$ & $3.27 \%$ & $-1.09 \%$ & $-1.56 \%$ & $-6.23 \%$ & $0.34 \%$ & $.55 \%$ \\
\hline PKG16 & $-0.78 \%$ & $0.18 \%$ & $2.40 \%$ & $2.52 \%$ & $0.92 \%$ & $-6.67 \%$ & $2.27 \%$ & $43 \%$ \\
\hline PKG17 & $4 \%$ & $-1.66 \%$ & $4.32 \%$ & $1.26 \%$ & $0.12 \%$ & $-2.02 \%$ & $2.24 \%$ & $67 \%$ \\
\hline PKG18 & & $0.64 \%$ & $7 \%$ & $-3.43 \%$ & $-0.30 \%$ & $-5.77 \%$ & $.34 \%$ & $4 \%$ \\
\hline PKG19 & $5 \%$ & $-0.40 \%$ & $19 \%$ & $1.07 \%$ & $-2.52 \%$ & $-3.44 \%$ & $2.18 \%$ & $30 \%$ \\
\hline PKG20 & $-0.97 \%$ & $1.58 \%$ & $2.84 \%$ & $-0.68 \%$ & $-1.27 \%$ & $-5.83 \%$ & $2.45 \%$ & $.70 \%$ \\
\hline PKG21 & & $-0.47 \%$ & $3.42 \%$ & $-1.84 \%$ & $-0.99 \%$ & $-6.11 \%$ & $2.68 \%$ & $.28 \%$ \\
\hline PKG22 & $\%$ & $1.23 \%$ & $2.38 \%$ & $-2.78 \%$ & $-1.45 \%$ & $-5.44 \%$ & $2.88 \%$ & $17 \%$ \\
\hline PKG23 & & $2.40 \%$ & $3 \%$ & $-2.86 \%$ & $1 \%$ & $-7.07 \%$ & $.57 \%$ & $5 \%$ \\
\hline PKG24 & & $1 \%$ & $\%$ & $-3.16 \%$ & $1 \%$ & -4 . & $4 \%$ & $0 \%$ \\
\hline PKG25 & & $-1.34 \%$ & $1 \%$ & $-0.95 \%$ & $9 \%$ & $0 \%$ & $6 \%$ & $1 \%$ \\
\hline PKG26 & $4 \%$ & $2.98 \%$ & $41 \%$ & $-0.67 \%$ & $-1.21 \%$ & $-7.82 \%$ & $2.70 \%$ & $18 \%$ \\
\hline PKG27 & $7 \%$ & $3.63 \%$ & $19 \%$ & $1.21 \%$ & $-1.39 \%$ & $-5.33 \%$ & $0.94 \%$ & $3.77 \%$ \\
\hline PKG28 & $16 \%$ & $0.52 \%$ & no ball & $0.72 \%$ & $0.72 \%$ & $-1.52 \%$ & $1.26 \%$ & $.17 \%$ \\
\hline PKG29 & $0 \%$ & $1.55 \%$ & outliner & $-4.17 \%$ & $19 \%$ & $-2.39 \%$ & $-2.12 \%$ & $.47 \%$ \\
\hline PKG30 & $2 \%$ & $0.93 \%$ & $3.88 \%$ & $-3.04 \%$ & $1.45 \%$ & $-4.97 \%$ & $0.78 \%$ & $74 \%$ \\
\hline PKG31 & & $\%$ & $\%$ & $-0.88 \%$ & $5 \%$ & -7. & $2.57 \%$ & $9 \%$ \\
\hline PKG32 & $\%$ & $-2.81 \%$ & $7 \%$ & $1.19 \%$ & $1.70 \%$ & $-3.90 \%$ & $1.84 \%$ & $6 \%$ \\
\hline PKG33 & & $-0.24 \%$ & $2.43 \%$ & $1.10 \%$ & $6 \%$ & $-1.45 \%$ & $3.48 \%$ & $15 \%$ \\
\hline PKG35 & $6 \%$ & $1.86 \%$ & $34 \%$ & $-3.68 \%$ & $8 \%$ & $-3.89 \%$ & $2.54 \%$ & $34 \%$ \\
\hline PKG36 & $6 \%$ & $1.40 \%$ & $5.18 \%$ & $0.61 \%$ & $1.86 \%$ & $-1.74 \%$ & $3.91 \%$ & $1.77 \%$ \\
\hline PKG37 & $5 \%$ & $-0.39 \%$ & $2.66 \%$ & $2.07 \%$ & $1.10 \%$ & $-4.12 \%$ & $0.75 \%$ & $-0.27 \%$ \\
\hline PKG38 & $\%$ & $\%$ & $\%$ & $2.06 \%$ & $4 \%$ & $1 \%$ & $6 \%$ & $3 \%$ \\
\hline PKG39 & & $\%$ & $\%$ & $-4.63 \%$ & $\%$ & $\%$ & $2.99 \%$ & $6 \%$ \\
\hline PKG40 & $1 \%$ & $2.66 \%$ & $45 \%$ & $-4.36 \%$ & $4 \%$ & $-5.88 \%$ & $.29 \%$ & $33 \%$ \\
\hline PKG41 & $-1.17 \%$ & $3.81 \%$ & $19 \%$ & $-1.66 \%$ & $3.36 \%$ & $-9.01 \%$ & $0.56 \%$ & $1.04 \%$ \\
\hline PKG42 & $37 \%$ & $1.95 \%$ & $2.87 \%$ & $0.76 \%$ & $1.72 \%$ & $-9.29 \%$ & $-0.53 \%$ & $0.84 \%$ \\
\hline PKG43 & & $3.56 \%$ & $1.94 \%$ & $1.57 \%$ & $0.05 \%$ & $-8.93 \%$ & $5.30 \%$ & $-0.32 \%$ \\
\hline PKG44 & & $7 \%$ & $3 \%$ & $2.41 \%$ & $4 \%$ & $-9.82 \%$ & $2.01 \%$ & $-0.22 \%$ \\
\hline PKG45 & & $3.49 \%$ & $5.91 \%$ & $1.07 \%$ & $6 \%$ & $-7.05 \%$ & $-0.29 \%$ & $6 \%$ \\
\hline PKG46 & & & $4.17 \%$ & $-1.86 \%$ & $0.69 \%$ & $-7.08 \%$ & $3.04 \%$ & $-0.77 \%$ \\
\hline PKG47 & $3 \%$ & $1.42 \%$ & $1.48 \%$ & $0.42 \%$ & $1.08 \%$ & $-5.45 \%$ & $-2.67 \%$ & $39 \%$ \\
\hline PKG48 & $37 \%$ & $0.73 \%$ & $1.60 \%$ & $1.90 \%$ & $5 \%$ & $-6.32 \%$ & $-0.88 \%$ & $-0.28 \%$ \\
\hline PKG49 & $2 \%$ & $-1.19 \%$ & $2.39 \%$ & $3.29 \%$ & $1.34 \%$ & $-5.82 \%$ & $0.95 \%$ & $-0.92 \%$ \\
\hline PKG50 & $31 \%$ & $-1.58 \%$ & $1.29 \%$ & $0.25 \%$ & $0.71 \%$ & $-6.24 \%$ & $-2.83 \%$ & $0.20 \%$ \\
\hline Mean & & $1.03 \%$ & $2.86 \%$ & $-0.33 \%$ & $0.32 \%$ & $-5.45 \%$ & $2.55 \%$ & $1.27 \%$ \\
\hline SD & & $1.85 \%$ & $1.25 \%$ & $1.98 \%$ & $1.60 \%$ & $2.13 \%$ & $2.76 \%$ & $1.41 \%$ \\
\hline Max & $83 \%$ & $6.93 \%$ & $5.91 \%$ & $3.29 \%$ & $5.05 \%$ & $-1.45 \%$ & $11.96 \%$ & $4.67 \%$ \\
\hline Min & $-3.94 \%$ & $-2.81 \%$ & $-1.04 \%$ & $-4.63 \%$ & $-2.58 \%$ & $-9.82 \%$ & $-2.83 \%$ & $-1.67 \%$ \\
\hline Diff & $7.76 \%$ & $9.75 \%$ & $6.95 \%$ & $7.93 \%$ & $7.63 \%$ & $8.37 \%$ & $14.80 \%$ & $6.33 \%$ \\
\hline
\end{tabular}


Table C-2-27: TCC 500 ${ }^{\text {th }}$ cycle; Daisy01 - Daisy08.

\begin{tabular}{|c|c|c|c|c|c|c|c|c|}
\hline & DAISY01 & DAISY02 & DAISY03 & DAISY04 & DAISY05 & DAISY06 & DAISY07 & DAISY08 \\
\hline PKG01 & $14.19 \%$ & $9.61 \%$ & $5.07 \%$ & $18.96 \%$ & $4.30 \%$ & $14.77 \%$ & $0.85 \%$ & $14.58 \%$ \\
\hline PKG02 & $5.71 \%$ & $12.40 \%$ & $2.66 \%$ & $18.51 \%$ & $-1.13 \%$ & $17.65 \%$ & $1.75 \%$ & $14.13 \%$ \\
\hline PKG03 & $2.91 \%$ & $3.49 \%$ & $0.80 \%$ & $14.11 \%$ & $-0.98 \%$ & $16.19 \%$ & $0.05 \%$ & $10.31 \%$ \\
\hline PKG04 & $1.53 \%$ & $7.09 \%$ & $1.51 \%$ & no ball & $-2.23 \%$ & $23.13 \%$ & $-2.94 \%$ & $12.67 \%$ \\
\hline PKG05 & $14.11 \%$ & $3.17 \%$ & $0.11 \%$ & $23.11 \%$ & $-1.67 \%$ & $24.65 \%$ & $0.56 \%$ & $9.32 \%$ \\
\hline PKG06 & $5.54 \%$ & $7.10 \%$ & $1.94 \%$ & $21.78 \%$ & $1.47 \%$ & $23.25 \%$ & $1.09 \%$ & $14.58 \%$ \\
\hline PKG07 & $6.04 \%$ & $5.53 \%$ & $2.47 \%$ & $18.80 \%$ & $-0.59 \%$ & $19.67 \%$ & $0.39 \%$ & $10.25 \%$ \\
\hline PKG08 & $5.37 \%$ & $5.97 \%$ & $1.52 \%$ & $17.45 \%$ & $-1.33 \%$ & $20.03 \%$ & $0.63 \%$ & $8.14 \%$ \\
\hline PKG09 & $3.45 \%$ & $4.43 \%$ & $1.26 \%$ & $17.71 \%$ & $-1.85 \%$ & $18.21 \%$ & $1.80 \%$ & $11.06 \%$ \\
\hline PKG10 & $2.50 \%$ & $3.18 \%$ & $-0.12 \%$ & $25.12 \%$ & outliner & $18.96 \%$ & $1.18 \%$ & $6.06 \%$ \\
\hline PKG11 & $13.04 \%$ & $3.57 \%$ & $0.92 \%$ & $17.30 \%$ & $-2.10 \%$ & $23.21 \%$ & $0.38 \%$ & $8.60 \%$ \\
\hline PKG12 & $3.20 \%$ & $3.02 \%$ & $-0.74 \%$ & $15.03 \%$ & $-0.89 \%$ & $13.67 \%$ & $0.54 \%$ & $9.00 \%$ \\
\hline PKG13 & $6.50 \%$ & $4.23 \%$ & $-0.87 \%$ & $18.52 \%$ & $-1.98 \%$ & $21.49 \%$ & $0.71 \%$ & $9.56 \%$ \\
\hline PKG14 & $2.18 \%$ & $3.52 \%$ & $0.11 \%$ & $14.43 \%$ & $-1.88 \%$ & $15.00 \%$ & $-0.49 \%$ & $7.74 \%$ \\
\hline PKG15 & $1.33 \%$ & $5.06 \%$ & $1.76 \%$ & $18.15 \%$ & $-3.96 \%$ & $18.00 \%$ & $7.89 \%$ & $9.28 \%$ \\
\hline PKG16 & $1.41 \%$ & $3.89 \%$ & $0.32 \%$ & $16.08 \%$ & $-1.40 \%$ & $15.86 \%$ & $3.01 \%$ & $8.29 \%$ \\
\hline PKG17 & $0.03 \%$ & $4.41 \%$ & $-0.83 \%$ & $18.94 \%$ & $-2.18 \%$ & $16.21 \%$ & $-0.52 \%$ & $5.04 \%$ \\
\hline PKG18 & $0.71 \%$ & $3.59 \%$ & $0.11 \%$ & $18.59 \%$ & $-1.83 \%$ & $18.97 \%$ & $4.30 \%$ & $6.74 \%$ \\
\hline PKG19 & $1.84 \%$ & $3.05 \%$ & $-1.77 \%$ & $23.57 \%$ & $-0.12 \%$ & $22.03 \%$ & $1.18 \%$ & $8.81 \%$ \\
\hline PKG20 & $0.23 \%$ & $3.69 \%$ & $-1.02 \%$ & $16.39 \%$ & $-0.61 \%$ & $16.62 \%$ & $1.54 \%$ & $9.38 \%$ \\
\hline PKG21 & $1.00 \%$ & $3.82 \%$ & $-0.05 \%$ & $16.18 \%$ & $-1.35 \%$ & $16.96 \%$ & $1.50 \%$ & $3.60 \%$ \\
\hline PKG22 & $-1.78 \%$ & $0.68 \%$ & $-0.60 \%$ & $14.95 \%$ & $-1.64 \%$ & $23.86 \%$ & $1.66 \%$ & $7.66 \%$ \\
\hline PKG23 & $1.61 \%$ & $5.19 \%$ & $-1.11 \%$ & $19.24 \%$ & $-1.33 \%$ & $20.98 \%$ & $4.61 \%$ & $12.08 \%$ \\
\hline PKG24 & $0.54 \%$ & $4.43 \%$ & $-0.22 \%$ & $16.64 \%$ & $0.20 \%$ & $19.71 \%$ & $-0.02 \%$ & $6.43 \%$ \\
\hline PKG25 & $0.99 \%$ & $5.19 \%$ & $0.58 \%$ & $16.35 \%$ & $-0.20 \%$ & $18.64 \%$ & $4.81 \%$ & $2.80 \%$ \\
\hline PKG26 & $0.71 \%$ & $9.25 \%$ & $-1.37 \%$ & $14.78 \%$ & $-1.06 \%$ & $22.24 \%$ & $1.55 \%$ & $8.30 \%$ \\
\hline PKG27 & $-0.26 \%$ & $4.79 \%$ & $-0.28 \%$ & $16.85 \%$ & $-2.03 \%$ & $19.16 \%$ & $11.68 \%$ & $7.18 \%$ \\
\hline PKG28 & $0.23 \%$ & $7.97 \%$ & $-0.37 \%$ & $17.30 \%$ & $-1.44 \%$ & $20.74 \%$ & $2.95 \%$ & $3.18 \%$ \\
\hline PKG29 & $0.60 \%$ & $4.56 \%$ & $-0.81 \%$ & $15.96 \%$ & $-1.13 \%$ & $20.56 \%$ & $4.25 \%$ & $6.99 \%$ \\
\hline PKG30 & $0.82 \%$ & $2.49 \%$ & $0.76 \%$ & $19.03 \%$ & $2.80 \%$ & $17.40 \%$ & $0.05 \%$ & $9.96 \%$ \\
\hline PKG31 & $-1.22 \%$ & $5.13 \%$ & $-2.26 \%$ & $16.28 \%$ & $1.53 \%$ & $16.06 \%$ & $1.32 \%$ & $7.01 \%$ \\
\hline PKG32 & $-0.27 \%$ & $2.51 \%$ & $-1.20 \%$ & $8.04 \%$ & $5.98 \%$ & $22.96 \%$ & $0.32 \%$ & $12.70 \%$ \\
\hline PKG33 & $-3.31 \%$ & $2.15 \%$ & $-1.30 \%$ & $15.50 \%$ & $4.40 \%$ & $10.57 \%$ & $5.23 \%$ & $8.16 \%$ \\
\hline PKG35 & $-0.64 \%$ & $5.41 \%$ & $-2.05 \%$ & $16.49 \%$ & $3.72 \%$ & $17.76 \%$ & $1.16 \%$ & outliner \\
\hline PKG36 & $0.31 \%$ & $3.70 \%$ & $-0.41 \%$ & $13.94 \%$ & $0.79 \%$ & $25.35 \%$ & $6.91 \%$ & $9.32 \%$ \\
\hline PKG37 & $2.21 \%$ & $2.97 \%$ & $-0.83 \%$ & $15.69 \%$ & $1.88 \%$ & $21.79 \%$ & outliner & $2.61 \%$ \\
\hline PKG38 & $3.84 \%$ & $4.88 \%$ & $-0.90 \%$ & $13.86 \%$ & $4.50 \%$ & $13.33 \%$ & outliner & $6.21 \%$ \\
\hline PKG39 & $6.15 \%$ & $9.38 \%$ & $-0.76 \%$ & $17.40 \%$ & $-1.21 \%$ & $10.89 \%$ & outliner & $6.19 \%$ \\
\hline PKG40 & $0.42 \%$ & $4.04 \%$ & $-2.29 \%$ & $19.70 \%$ & $-1.00 \%$ & $13.04 \%$ & $1.35 \%$ & $11.73 \%$ \\
\hline PKG41 & $0.58 \%$ & $3.94 \%$ & $-1.27 \%$ & $16.20 \%$ & $-1.14 \%$ & $10.70 \%$ & $2.19 \%$ & $6.10 \%$ \\
\hline PKG42 & $-1.40 \%$ & $7.08 \%$ & $-0.91 \%$ & $18.03 \%$ & no ball & $14.41 \%$ & $2.04 \%$ & $9.00 \%$ \\
\hline PKG43 & $4.36 \%$ & $2.43 \%$ & $-0.13 \%$ & $18.04 \%$ & $-2.71 \%$ & $27.59 \%$ & $4.10 \%$ & $9.05 \%$ \\
\hline PKG44 & $0.32 \%$ & $9.18 \%$ & $-1.04 \%$ & $9.51 \%$ & $-2.14 \%$ & $20.74 \%$ & $1.61 \%$ & $8.59 \%$ \\
\hline PKG45 & $2.12 \%$ & $1.77 \%$ & $0.03 \%$ & $14.47 \%$ & $-1.60 \%$ & $19.24 \%$ & $0.69 \%$ & $7.55 \%$ \\
\hline PKG46 & $0.12 \%$ & $1.66 \%$ & $0.49 \%$ & $13.88 \%$ & $-1.45 \%$ & $24.55 \%$ & $0.68 \%$ & $8.59 \%$ \\
\hline PKG47 & $2.75 \%$ & $2.54 \%$ & $-2.14 \%$ & $20.44 \%$ & $1.09 \%$ & $21.43 \%$ & $-0.41 \%$ & $7.39 \%$ \\
\hline PKG48 & $-1.80 \%$ & $5.27 \%$ & $-2.34 \%$ & $18.44 \%$ & $-0.73 \%$ & $20.74 \%$ & $1.10 \%$ & $12.98 \%$ \\
\hline PKG49 & $2.28 \%$ & $5.11 \%$ & $-2.87 \%$ & $12.13 \%$ & $4.06 \%$ & $22.03 \%$ & $0.75 \%$ & $9.40 \%$ \\
\hline PKG50 & $3.75 \%$ & $6.10 \%$ & $-0.43 \%$ & $19.77 \%$ & $4.36 \%$ & $25.81 \%$ & $-0.14 \%$ & $6.25 \%$ \\
\hline Mean & $2.38 \%$ & $4.77 \%$ & $-0.22 \%$ & $17.03 \%$ & $-0.17 \%$ & $19.12 \%$ & $1.87 \%$ & $8.55 \%$ \\
\hline SD & $3.68 \%$ & $2.34 \%$ & $1.48 \%$ & $3.13 \%$ & $2.33 \%$ & $4.06 \%$ & $2.50 \%$ & $2.85 \%$ \\
\hline Max & $14.19 \%$ & $12.40 \%$ & $5.07 \%$ & $25.12 \%$ & $5.98 \%$ & $27.59 \%$ & $11.68 \%$ & $14.58 \%$ \\
\hline Min & $-3.31 \%$ & $0.68 \%$ & $-2.87 \%$ & $8.04 \%$ & $-3.96 \%$ & $10.57 \%$ & $-2.94 \%$ & $2.61 \%$ \\
\hline Diff & $17.51 \%$ & $11.71 \%$ & $7.94 \%$ & $17.07 \%$ & $9.93 \%$ & $17.01 \%$ & $14.62 \%$ & $11.97 \%$ \\
\hline
\end{tabular}


Table C-2-28: TCC 500 ${ }^{\text {th }}$ cycle; Daisy09 - Daisy16.

\begin{tabular}{|c|c|c|c|c|c|c|c|c|}
\hline & DAISY09 & DAISY10 & DAISY11 & DAISY12 & DAISY13 & DAISY14 & DAISY15 & DAISY16 \\
\hline PKG01 & $1.73 \%$ & $1.32 \%$ & $2.23 \%$ & $1.51 \%$ & $-2.04 \%$ & $-4.92 \%$ & $6.28 \%$ & $4.69 \%$ \\
\hline PKG02 & $-0.20 \%$ & $1.63 \%$ & $-1.62 \%$ & $-0.17 \%$ & $2.07 \%$ & $-3.90 \%$ & $7.61 \%$ & $1.86 \%$ \\
\hline PKG03 & $-0.94 \%$ & $3.71 \%$ & $5.65 \%$ & $-0.99 \%$ & $0.82 \%$ & $-6.55 \%$ & $7.16 \%$ & $1.48 \%$ \\
\hline PKG04 & $-1.05 \%$ & $2.72 \%$ & $4.17 \%$ & $2.34 \%$ & $-0.15 \%$ & $-3.59 \%$ & $6.91 \%$ & $-0.83 \%$ \\
\hline PKG05 & $2.89 \%$ & $7.88 \%$ & $5.30 \%$ & $0.33 \%$ & $0.19 \%$ & $-2.89 \%$ & $3.24 \%$ & $2.46 \%$ \\
\hline PKG06 & $-0.48 \%$ & $3.04 \%$ & $3.75 \%$ & $4.09 \%$ & $1.96 \%$ & $-6.02 \%$ & $8.89 \%$ & $-0.13 \%$ \\
\hline PKG07 & $-2.20 \%$ & $0.43 \%$ & $7.07 \%$ & $1.54 \%$ & $1.05 \%$ & $-7.35 \%$ & $10.52 \%$ & $2.13 \%$ \\
\hline PKG08 & $-0.18 \%$ & $3.09 \%$ & $4.81 \%$ & $-0.60 \%$ & $-0.01 \%$ & $-4.35 \%$ & $5.69 \%$ & $3.33 \%$ \\
\hline PKG09 & $-0.28 \%$ & $2.40 \%$ & $3.95 \%$ & $-0.31 \%$ & $-0.88 \%$ & outliner & $7.59 \%$ & $2.63 \%$ \\
\hline PKG10 & $-1.67 \%$ & $1.05 \%$ & $2.53 \%$ & $-1.33 \%$ & $-0.87 \%$ & $-4.81 \%$ & $3.20 \%$ & $2.45 \%$ \\
\hline PKG11 & $-0.71 \%$ & $-1.06 \%$ & $3.58 \%$ & $1.47 \%$ & $-0.55 \%$ & $-5.58 \%$ & $4.24 \%$ & $4.18 \%$ \\
\hline PKG12 & $-1.89 \%$ & $-1.03 \%$ & $1.38 \%$ & $-1.92 \%$ & $-2.40 \%$ & $-4.93 \%$ & $3.09 \%$ & $1.94 \%$ \\
\hline PKG13 & $-1.64 \%$ & $0.88 \%$ & no ball & $0.48 \%$ & $-2.08 \%$ & $-5.67 \%$ & $5.06 \%$ & $-0.40 \%$ \\
\hline PKG14 & no ball & $-1.03 \%$ & $1.85 \%$ & $-0.48 \%$ & $-0.58 \%$ & $-3.91 \%$ & $4.42 \%$ & outliner \\
\hline PKG15 & $-0.61 \%$ & $2.00 \%$ & $5.92 \%$ & $0.76 \%$ & $-0.58 \%$ & $-5.55 \%$ & $2.60 \%$ & $1.33 \%$ \\
\hline PKG16 & $-2.08 \%$ & $-1.26 \%$ & $1.48 \%$ & $-0.21 \%$ & $0.36 \%$ & $-6.54 \%$ & $2.32 \%$ & $2.25 \%$ \\
\hline PKG17 & $-0.34 \%$ & $4.03 \%$ & $3.65 \%$ & $3.12 \%$ & $-0.15 \%$ & $-1.87 \%$ & $5.50 \%$ & $1.36 \%$ \\
\hline PKG18 & $-2.02 \%$ & $7.26 \%$ & $2.17 \%$ & $-2.46 \%$ & $0.90 \%$ & $-4.73 \%$ & $4.51 \%$ & $0.77 \%$ \\
\hline PKG19 & $-2.21 \%$ & $0.95 \%$ & $3.47 \%$ & $1.88 \%$ & $-2.11 \%$ & $-5.20 \%$ & $4.08 \%$ & outliner \\
\hline PKG20 & $-3.16 \%$ & $0.49 \%$ & $5.29 \%$ & $0.05 \%$ & $-0.71 \%$ & $-3.36 \%$ & $2.64 \%$ & $2.75 \%$ \\
\hline PKG21 & $-2.37 \%$ & $-0.54 \%$ & $2.23 \%$ & $-1.55 \%$ & $-1.76 \%$ & $-4.67 \%$ & $3.53 \%$ & $0.33 \%$ \\
\hline PKG22 & $-1.45 \%$ & $5.93 \%$ & $2.11 \%$ & $-1.09 \%$ & $-2.07 \%$ & $-4.04 \%$ & $1.95 \%$ & $1.45 \%$ \\
\hline PKG23 & $-0.39 \%$ & $1.83 \%$ & $1.68 \%$ & $-3.74 \%$ & $-0.91 \%$ & $-7.93 \%$ & $3.06 \%$ & $0.46 \%$ \\
\hline PKG24 & $-2.62 \%$ & $0.51 \%$ & $2.78 \%$ & $-1.60 \%$ & $-1.39 \%$ & $-3.90 \%$ & $1.14 \%$ & $1.89 \%$ \\
\hline PKG25 & $-2.10 \%$ & $-0.31 \%$ & $4.76 \%$ & $-0.24 \%$ & $-0.28 \%$ & $-0.27 \%$ & $2.90 \%$ & $2.37 \%$ \\
\hline PKG26 & $-5.18 \%$ & $0.86 \%$ & $3.48 \%$ & $0.47 \%$ & $-0.88 \%$ & $-7.61 \%$ & $1.89 \%$ & $1.24 \%$ \\
\hline PKG27 & $-1.90 \%$ & $5.31 \%$ & $1.39 \%$ & $0.70 \%$ & $-0.91 \%$ & $-7.19 \%$ & $1.94 \%$ & $0.82 \%$ \\
\hline PKG28 & $-3.79 \%$ & $2.87 \%$ & no ball & $1.31 \%$ & $0.13 \%$ & $-4.19 \%$ & $1.63 \%$ & $0.62 \%$ \\
\hline PKG29 & $-3.07 \%$ & $-3.03 \%$ & $3.66 \%$ & $-4.03 \%$ & $0.73 \%$ & $-1.95 \%$ & $-0.39 \%$ & $1.72 \%$ \\
\hline PKG30 & $-4.19 \%$ & $1.88 \%$ & $1.26 \%$ & $-1.50 \%$ & $1.87 \%$ & $-2.63 \%$ & $1.57 \%$ & $0.45 \%$ \\
\hline PKG31 & outliner & $-0.80 \%$ & $1.39 \%$ & $-0.73 \%$ & $1.44 \%$ & $-6.31 \%$ & $6.49 \%$ & $2.57 \%$ \\
\hline PKG32 & $-2.21 \%$ & $-2.89 \%$ & $0.12 \%$ & $1.42 \%$ & $1.77 \%$ & $-3.75 \%$ & $3.75 \%$ & $1.00 \%$ \\
\hline PKG33 & $-5.18 \%$ & $-1.94 \%$ & $1.57 \%$ & $0.68 \%$ & $1.94 \%$ & $-3.93 \%$ & $2.53 \%$ & $1.62 \%$ \\
\hline PKG35 & $-4.11 \%$ & $1.21 \%$ & $2.73 \%$ & $-5.44 \%$ & $3.49 \%$ & $-3.14 \%$ & $2.06 \%$ & $2.32 \%$ \\
\hline PKG36 & $1.71 \%$ & $0.33 \%$ & $0.97 \%$ & $0.33 \%$ & $1.15 \%$ & $-3.15 \%$ & $0.68 \%$ & $1.39 \%$ \\
\hline PKG37 & $-1.62 \%$ & $-1.78 \%$ & $1.19 \%$ & $2.36 \%$ & $1.03 \%$ & $-5.39 \%$ & $1.68 \%$ & $-0.38 \%$ \\
\hline PKG38 & $-4.55 \%$ & $-3.61 \%$ & $2.30 \%$ & $3.07 \%$ & $1.15 \%$ & $-3.92 \%$ & $1.03 \%$ & $0.11 \%$ \\
\hline PKG39 & $-0.04 \%$ & $-0.74 \%$ & $0.72 \%$ & $-2.85 \%$ & $1.16 \%$ & $-5.93 \%$ & $3.35 \%$ & $0.81 \%$ \\
\hline PKG40 & $1.23 \%$ & $-0.54 \%$ & $1.08 \%$ & $-4.01 \%$ & $0.40 \%$ & $-5.88 \%$ & $1.88 \%$ & $0.50 \%$ \\
\hline PKG41 & $1.25 \%$ & $0.05 \%$ & $2.04 \%$ & $-1.93 \%$ & $-0.01 \%$ & $-8.52 \%$ & $0.84 \%$ & $2.39 \%$ \\
\hline PKG42 & $-5.56 \%$ & $-1.63 \%$ & $0.58 \%$ & $0.69 \%$ & $-0.78 \%$ & $-8.05 \%$ & $-1.21 \%$ & $-1.00 \%$ \\
\hline PKG43 & $-0.51 \%$ & $-0.09 \%$ & $0.66 \%$ & $0.63 \%$ & $-0.79 \%$ & $-9.29 \%$ & $4.95 \%$ & $-0.48 \%$ \\
\hline PKG44 & $1.80 \%$ & $-1.28 \%$ & $-0.64 \%$ & $3.48 \%$ & $-0.30 \%$ & $-10.04 \%$ & $0.72 \%$ & $-0.17 \%$ \\
\hline PKG45 & $-0.19 \%$ & $0.55 \%$ & $1.91 \%$ & $5.46 \%$ & $-0.15 \%$ & $-7.26 \%$ & $-0.64 \%$ & $-0.33 \%$ \\
\hline PKG46 & $-0.56 \%$ & $0.27 \%$ & $1.01 \%$ & $-2.20 \%$ & $-0.27 \%$ & $-5.62 \%$ & $0.65 \%$ & $0.16 \%$ \\
\hline PKG47 & $-0.13 \%$ & $-1.01 \%$ & $0.73 \%$ & $-0.03 \%$ & $0.49 \%$ & $-4.50 \%$ & $-4.64 \%$ & $-0.07 \%$ \\
\hline PKG48 & $-2.63 \%$ & $-3.98 \%$ & $1.74 \%$ & $0.64 \%$ & $-0.38 \%$ & $-6.39 \%$ & $-1.51 \%$ & $0.62 \%$ \\
\hline PKG49 & $-0.12 \%$ & $-4.76 \%$ & $1.88 \%$ & $1.67 \%$ & $0.05 \%$ & $-5.05 \%$ & $-2.46 \%$ & $0.11 \%$ \\
\hline PKG50 & $-1.87 \%$ & $-2.53 \%$ & $0.76 \%$ & $-0.99 \%$ & $-0.41 \%$ & $-5.82 \%$ & $-2.34 \%$ & $-1.83 \%$ \\
\hline Mean & $-1.43 \%$ & $0.58 \%$ & $2.40 \%$ & $0.00 \%$ & $-0.01 \%$ & $-5.17 \%$ & $2.91 \%$ & $1.17 \%$ \\
\hline SD & $1.92 \%$ & $2.69 \%$ & $1.79 \%$ & $2.16 \%$ & $1.27 \%$ & $1.96 \%$ & $3.02 \%$ & $1.35 \%$ \\
\hline $\operatorname{Max}$ & $2.89 \%$ & $7.88 \%$ & $7.07 \%$ & $5.46 \%$ & $3.49 \%$ & $-0.27 \%$ & $10.52 \%$ & $4.69 \%$ \\
\hline Min & $-5.56 \%$ & $-4.76 \%$ & $-1.62 \%$ & $-5.44 \%$ & $-2.40 \%$ & $-10.04 \%$ & $-4.64 \%$ & $-1.83 \%$ \\
\hline Diff & $8.45 \%$ & $12.64 \%$ & $8.68 \%$ & $10.90 \%$ & $5.89 \%$ & $9.77 \%$ & $15.16 \%$ & $6.52 \%$ \\
\hline
\end{tabular}




\section{APPENDIX D}

Average Resistance Changes for Each Measured Temperature Cycling Test

Figure D-1: Average resistance changes for each measured temperature cycling test.

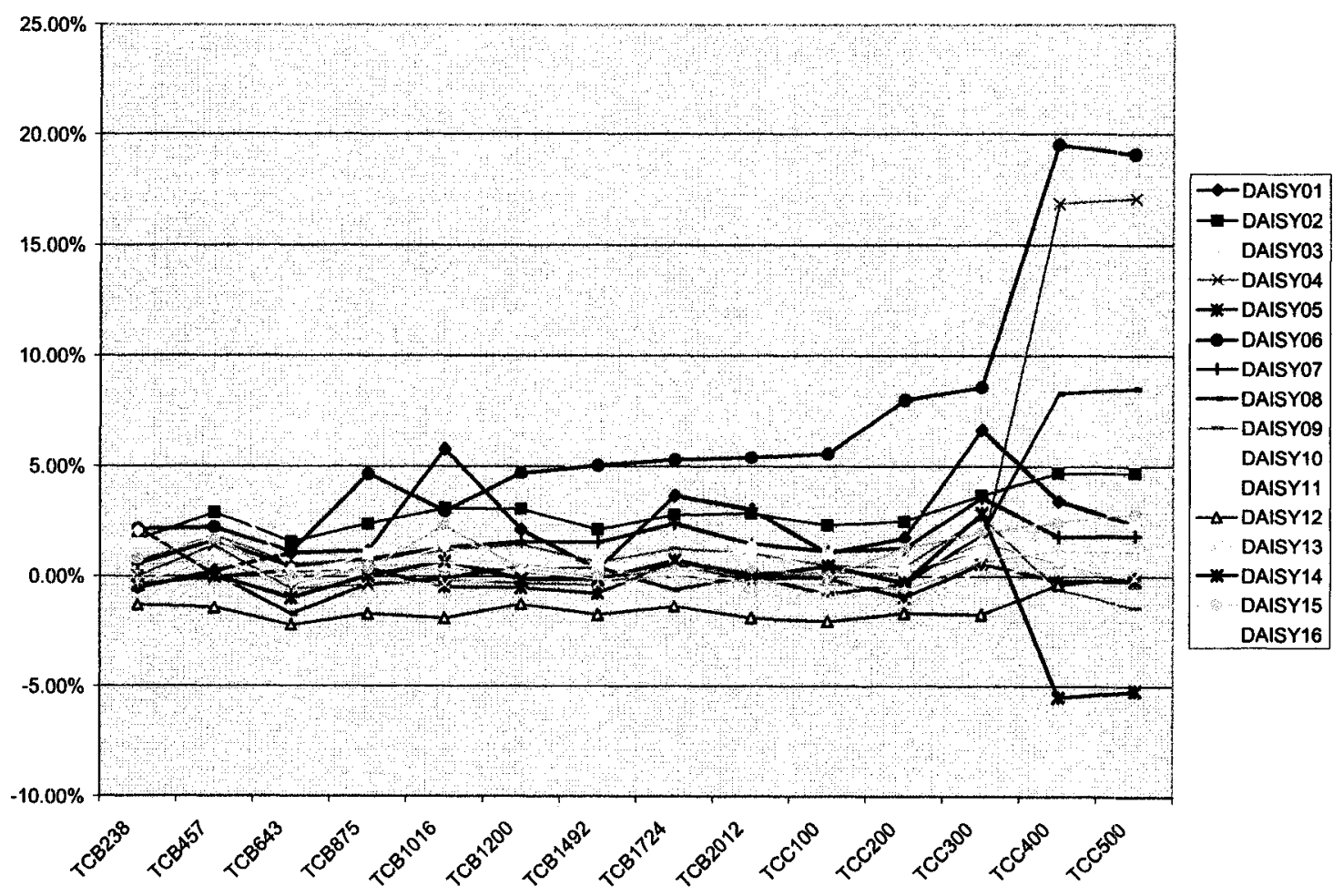




\section{APPENDIX E}

Average Resistance Changes for Each Daisy Chain

Figure E-1: Average resistance changes for each daisy chain.

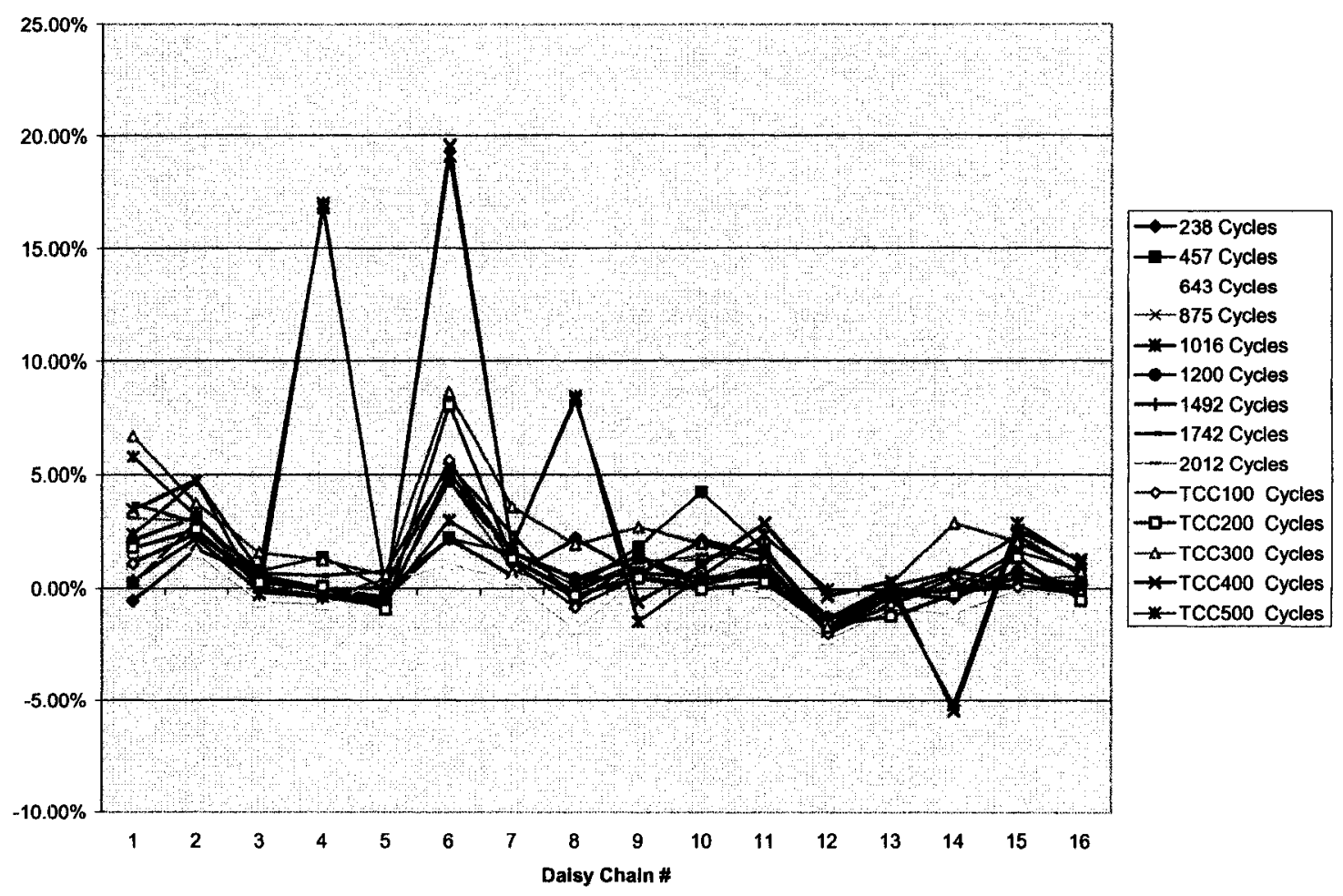


APPENDIX F-1

Calculated Effects at the Measured Temperature Cycles

Table F-1-1: TCB $238^{\text {th }}$ cycle.

\begin{tabular}{|c|c|c|c|c|c|c|c|c|c|}
\hline & & $\overline{1}$ & $\sqrt{2}$ & $\sqrt{3}$ & 4 & 12 & 13 & 14 & 23 \\
\hline DAISY06 & $2.20 \%$ & $-2.20 \%$ & $-2.20 \%$ & $-2.20 \%$ & $-2.20 \%$ & $2.20 \%$ & $2.20 \%$ & $2.20 \%$ & $2.20 \%$ \\
\hline DAISY14 & $-0.44 \%$ & $-0.44 \%$ & $0.44 \%$ & $0.44 \%$ & $0.44 \%$ & $0.44 \%$ & $0.44 \%$ & $0.44 \%$ & $-0.44 \%$ \\
\hline DAISY02 & $1.71 \%$ & $-1.71 \%$ & $1.71 \%$ & $-1.71 \%$ & $-1.71 \%$ & $-1.71 \%$ & $1.71 \%$ & $1.71 \%$ & $-1.71 \%$ \\
\hline DAISY10 & $2.11 \%$ & $2.11 \%$ & $2.11 \%$ & $-2.11 \%$ & $-2.11 \%$ & $2.11 \%$ & $-2.11 \%$ & $-2.11 \%$ & $-2.11 \%$ \\
\hline DAISY08 & $2.21 \%$ & $-2.21 \%$ & $-2.21 \%$ & $2.21 \%$ & $-2.21 \%$ & $2.21 \%$ & $-2.21 \%$ & $2.21 \%$ & $-2.21 \%$ \\
\hline DAISY16 & $-0.33 \%$ & $-0.33 \%$ & $0.33 \%$ & $-0.33 \%$ & $0.33 \%$ & $0.33 \%$ & $-0.33 \%$ & $0.33 \%$ & $0.33 \%$ \\
\hline DAISY04 & $0.01 \%$ & $-0.01 \%$ & $0.01 \%$ & $0.01 \%$ & $-0.01 \%$ & $-0.01 \%$ & $-0.01 \%$ & $0.01 \%$ & $0.01 \%$ \\
\hline DAISY12 & $-1.30 \%$ & $-1.30 \%$ & $-1.30 \%$ & $-1.30 \%$ & $1.30 \%$ & $-1.30 \%$ & $-1.30 \%$ & $1.30 \%$ & $-1.30 \%$ \\
\hline DAISY05 & $-0.39 \%$ & $0.39 \%$ & $0.39 \%$ & $0.39 \%$ & $-0.39 \%$ & $-0.39 \%$ & $-0.39 \%$ & $0.39 \%$ & $-0.39 \%$ \\
\hline DAISY13 & $-0.23 \%$ & $-0.23 \%$ & $0.23 \%$ & $0.23 \%$ & $-0.23 \%$ & $0.23 \%$ & $0.23 \%$ & $-0.23 \%$ & $-0.23 \%$ \\
\hline DAISY01 & $-0.55 \%$ & $0.55 \%$ & $-0.55 \%$ & $0.55 \%$ & $-0.55 \%$ & $0.55 \%$ & $-0.55 \%$ & $0.55 \%$ & $0.55 \%$ \\
\hline DAISY09 & $0.63 \%$ & $0.63 \%$ & $0.63 \%$ & $-0.63 \%$ & $0.63 \%$ & $0.63 \%$ & $-0.63 \%$ & $0.63 \%$ & $-0.63 \%$ \\
\hline DAISY07 & $0.56 \%$ & $-0.56 \%$ & $-0.56 \%$ & $0.56 \%$ & $0.56 \%$ & $0.56 \%$ & $-0.56 \%$ & $-0.56 \%$ & $-0.56 \%$ \\
\hline DAISY15 & $0.82 \%$ & $0.82 \%$ & $-0.82 \%$ & $0.82 \%$ & $0.82 \%$ & $-0.82 \%$ & $0.82 \%$ & $0.82 \%$ & $-0.82 \%$ \\
\hline DAISY03 & $0.57 \%$ & $-0.57 \%$ & $0.57 \%$ & $0.57 \%$ & $0.57 \%$ & $-0.57 \%$ & $-0.57 \%$ & $-0.57 \%$ & $0.57 \%$ \\
\hline DAISY11 & $1.53 \%$ & $1.53 \%$ & $1.53 \%$ & $1.53 \%$ & $1.53 \%$ & $1.53 \%$ & $1.53 \%$ & $1.53 \%$ & $1.53 \%$ \\
\hline & Contrast & $-3.54 \%$ & $0.31 \%$ & $-0.98 \%$ & $-3.25 \%$ & $5.98 \%$ & $-1.73 \%$ & $8.64 \%$ & $-5.22 \%$ \\
\hline & Effect & $-0.44 \%$ & $0.04 \%$ & $-0.12 \%$ & $-0.41 \%$ & $0.75 \%$ & $-0.22 \%$ & $1.08 \%$ & $-0.65 \%$ \\
\hline
\end{tabular}

\begin{tabular}{|l|r|r|r|r|r|r|r|r|}
\hline & & \multicolumn{1}{|l|}{} & \multicolumn{1}{l|}{34} & 123 & 124 & 134 & 234 & 1234 \\
\hline DAISY06 & $2.20 \%$ & $2.20 \%$ & $2.20 \%$ & $-2.20 \%$ & $-2.20 \%$ & $-2.20 \%$ & $-2.20 \%$ & $2.20 \%$ \\
\hline DAISY14 & $-0.44 \%$ & $-0.44 \%$ & $-0.44 \%$ & $-0.44 \%$ & $-0.44 \%$ & $-0.44 \%$ & $0.44 \%$ & $0.44 \%$ \\
\hline DAISY02 & $1.71 \%$ & $-1.71 \%$ & $1.71 \%$ & $1.71 \%$ & $1.71 \%$ & $-1.71 \%$ & $1.71 \%$ & $-1.71 \%$ \\
\hline DAISY10 & $2.11 \%$ & $-2.11 \%$ & $2.11 \%$ & $-2.11 \%$ & $-2.11 \%$ & $2.11 \%$ & $2.11 \%$ & $2.11 \%$ \\
\hline DAISY08 & $2.21 \%$ & $2.21 \%$ & $-2.21 \%$ & $2.21 \%$ & $-2.21 \%$ & $2.21 \%$ & $2.21 \%$ & $-2.21 \%$ \\
\hline DAISY16 & $-0.33 \%$ & $-0.33 \%$ & $0.33 \%$ & $0.33 \%$ & $-0.33 \%$ & $0.33 \%$ & $-0.33 \%$ & $-0.33 \%$ \\
\hline DAISY04 & $0.01 \%$ & $-0.01 \%$ & $-0.01 \%$ & $-0.01 \%$ & $0.01 \%$ & $0.01 \%$ & $-0.01 \%$ & $0.01 \%$ \\
\hline DAISY12 & $-1.30 \%$ & $1.30 \%$ & $1.30 \%$ & $-1.30 \%$ & $1.30 \%$ & $1.30 \%$ & $1.30 \%$ & $1.30 \%$ \\
\hline DAISY05 & $-0.39 \%$ & $0.39 \%$ & $0.39 \%$ & $0.39 \%$ & $-0.39 \%$ & $-0.39 \%$ & $-0.39 \%$ & $0.39 \%$ \\
\hline DAISY13 & $-0.23 \%$ & $0.23 \%$ & $0.23 \%$ & $-0.23 \%$ & $0.23 \%$ & $0.23 \%$ & $-0.23 \%$ & $-0.23 \%$ \\
\hline DAISY01 & $-0.55 \%$ & $-0.55 \%$ & $0.55 \%$ & $-0.55 \%$ & $0.55 \%$ & $-0.55 \%$ & $0.55 \%$ & $-0.55 \%$ \\
\hline DAISY09 & $0.63 \%$ & $0.63 \%$ & $-0.63 \%$ & $-0.63 \%$ & $0.63 \%$ & $-0.63 \%$ & $-0.63 \%$ & $-0.63 \%$ \\
\hline DAISY07 & $0.56 \%$ & $-0.56 \%$ & $0.56 \%$ & $0.56 \%$ & $0.56 \%$ & $-0.56 \%$ & $-0.56 \%$ & $0.56 \%$ \\
\hline DAISY15 & $0.82 \%$ & $-0.82 \%$ & $0.82 \%$ & $-0.82 \%$ & $-0.82 \%$ & $0.82 \%$ & $-0.82 \%$ & $-0.82 \%$ \\
\hline DAISY03 & $0.57 \%$ & $0.57 \%$ & $0.57 \%$ & $-0.57 \%$ & $-0.57 \%$ & $-0.57 \%$ & $0.57 \%$ & $-0.57 \%$ \\
\hline DAISY11 & $1.53 \%$ & $1.53 \%$ & $1.53 \%$ & $1.53 \%$ & $1.53 \%$ & $1.53 \%$ & $1.53 \%$ & $1.53 \%$ \\
\hline & Contrast & $2.51 \%$ & $9.01 \%$ & $-2.12 \%$ & $-2.55 \%$ & $1.49 \%$ & $5.24 \%$ & $1.48 \%$ \\
\hline & Effect & $0.31 \%$ & $1.13 \%$ & $-0.27 \%$ & $-0.32 \%$ & $0.19 \%$ & $0.65 \%$ & $0.19 \%$ \\
\hline
\end{tabular}


Table F-1-2: TCB $457^{\text {th }}$ cycle.

\begin{tabular}{|l|r|r|r|r|r|r|r|r|r|}
\hline & & 1 & 2 & 3 & 4 & 12 & 13 & 14 & 23 \\
\hline DAISY06 & $2.25 \%$ & $-2.25 \%$ & $-2.25 \%$ & $-2.25 \%$ & $-2.25 \%$ & $2.25 \%$ & $2.25 \%$ & $2.25 \%$ & $2.25 \%$ \\
\hline DAISY14 & $0.04 \%$ & $0.04 \%$ & $-0.04 \%$ & $-0.04 \%$ & $-0.04 \%$ & $-0.04 \%$ & $-0.04 \%$ & $-0.04 \%$ & $0.04 \%$ \\
\hline DAISY02 & $2.95 \%$ & $-2.95 \%$ & $2.95 \%$ & $-2.95 \%$ & $-2.95 \%$ & $-2.95 \%$ & $2.95 \%$ & $2.95 \%$ & $-2.95 \%$ \\
\hline DAISY10 & $4.30 \%$ & $4.30 \%$ & $4.30 \%$ & $-4.30 \%$ & $-4.30 \%$ & $4.30 \%$ & $-4.30 \%$ & $-4.30 \%$ & $-4.30 \%$ \\
\hline DAISY08 & $0.07 \%$ & $-0.07 \%$ & $-0.07 \%$ & $0.07 \%$ & $-0.07 \%$ & $0.07 \%$ & $-0.07 \%$ & $0.07 \%$ & $-0.07 \%$ \\
\hline DAISY16 & $0.84 \%$ & $0.84 \%$ & $-0.84 \%$ & $0.84 \%$ & $-0.84 \%$ & $-0.84 \%$ & $0.84 \%$ & $-0.84 \%$ & $-0.84 \%$ \\
\hline DAISY04 & $1.40 \%$ & $-1.40 \%$ & $1.40 \%$ & $1.40 \%$ & $-1.40 \%$ & $-1.40 \%$ & $-1.40 \%$ & $1.40 \%$ & $1.40 \%$ \\
\hline DAISY12 & $-1.40 \%$ & $-1.40 \%$ & $-1.40 \%$ & $-1.40 \%$ & $1.40 \%$ & $-1.40 \%$ & $-1.40 \%$ & $1.40 \%$ & $-1.40 \%$ \\
\hline DAISY05 & $0.00 \%$ & $0.00 \%$ & $0.00 \%$ & $0.00 \%$ & $0.00 \%$ & $0.00 \%$ & $0.00 \%$ & $0.00 \%$ & $0.00 \%$ \\
\hline DAISY13 & $-0.20 \%$ & $-0.20 \%$ & $0.20 \%$ & $0.20 \%$ & $-0.20 \%$ & $0.20 \%$ & $0.20 \%$ & $-0.20 \%$ & $-0.20 \%$ \\
\hline DAISY01 & $0.25 \%$ & $-0.25 \%$ & $0.25 \%$ & $-0.25 \%$ & $0.25 \%$ & $-0.25 \%$ & $0.25 \%$ & $-0.25 \%$ & $-0.25 \%$ \\
\hline DAISY09 & $1.88 \%$ & $1.88 \%$ & $1.88 \%$ & $-1.88 \%$ & $1.88 \%$ & $1.88 \%$ & $-1.88 \%$ & $1.88 \%$ & $-1.88 \%$ \\
\hline DAISY07 & $1.62 \%$ & $-1.62 \%$ & $-1.62 \%$ & $1.62 \%$ & $1.62 \%$ & $1.62 \%$ & $-1.62 \%$ & $-1.62 \%$ & $-1.62 \%$ \\
\hline DAISY15 & $1.68 \%$ & $1.68 \%$ & $-1.68 \%$ & $1.68 \%$ & $1.68 \%$ & $-1.68 \%$ & $1.68 \%$ & $1.68 \%$ & $-1.68 \%$ \\
\hline DAISY03 & $0.81 \%$ & $-0.81 \%$ & $0.81 \%$ & $0.81 \%$ & $0.81 \%$ & $-0.81 \%$ & $-0.81 \%$ & $-0.81 \%$ & $0.81 \%$ \\
\hline DAISY11 & $1.75 \%$ & $1.75 \%$ & $1.75 \%$ & $1.75 \%$ & $1.75 \%$ & $1.75 \%$ & $1.75 \%$ & $1.75 \%$ & $1.75 \%$ \\
\hline & Contrast & $-0.47 \%$ & $5.65 \%$ & $-4.69 \%$ & $-2.66 \%$ & $2.70 \%$ & $-1.60 \%$ & $5.32 \%$ & $-8.94 \%$ \\
\hline & Effect & $-0.06 \%$ & $0.71 \%$ & $-0.59 \%$ & $-0.33 \%$ & $0.34 \%$ & $-0.20 \%$ & $0.67 \%$ & $-1.12 \%$ \\
\hline
\end{tabular}

\begin{tabular}{|l|r|r|r|r|r|r|r|r|}
\hline & & \multicolumn{1}{|l|}{24} & \multicolumn{1}{l}{3} & \multicolumn{1}{l|}{123} & 124 & 134 & 234 & 1234 \\
\hline DAISY06 & $2.25 \%$ & $2.25 \%$ & $2.25 \%$ & $-2.25 \%$ & $-2.25 \%$ & $-2.25 \%$ & $-2.25 \%$ & $2.25 \%$ \\
\hline DAISY14 & $0.04 \%$ & $0.04 \%$ & $0.04 \%$ & $0.04 \%$ & $0.04 \%$ & $0.04 \%$ & $-0.04 \%$ & $-0.04 \%$ \\
\hline DAISY02 & $2.95 \%$ & $-2.95 \%$ & $2.95 \%$ & $2.95 \%$ & $2.95 \%$ & $-2.95 \%$ & $2.95 \%$ & $-2.95 \%$ \\
\hline DAISY10 & $4.30 \%$ & $-4.30 \%$ & $4.30 \%$ & $-4.30 \%$ & $-4.30 \%$ & $4.30 \%$ & $4.30 \%$ & $4.30 \%$ \\
\hline DAISY08 & $0.07 \%$ & $0.07 \%$ & $-0.07 \%$ & $0.07 \%$ & $-0.07 \%$ & $0.07 \%$ & $0.07 \%$ & $-0.07 \%$ \\
\hline DAISY16 & $0.84 \%$ & $0.84 \%$ & $-0.84 \%$ & $-0.84 \%$ & $0.84 \%$ & $-0.84 \%$ & $0.84 \%$ & $0.84 \%$ \\
\hline DAISY04 & $1.40 \%$ & $-1.40 \%$ & $-1.40 \%$ & $-1.40 \%$ & $1.40 \%$ & $1.40 \%$ & $-1.40 \%$ & $1.40 \%$ \\
\hline DAISY12 & $-1.40 \%$ & $1.40 \%$ & $1.40 \%$ & $-1.40 \%$ & $1.40 \%$ & $1.40 \%$ & $1.40 \%$ & $1.40 \%$ \\
\hline DAISY05 & $0.00 \%$ & $0.00 \%$ & $0.00 \%$ & $0.00 \%$ & $0.00 \%$ & $0.00 \%$ & $0.00 \%$ & $0.00 \%$ \\
\hline DAISY13 & $-0.20 \%$ & $0.20 \%$ & $0.20 \%$ & $-0.20 \%$ & $0.20 \%$ & $0.20 \%$ & $-0.20 \%$ & $-0.20 \%$ \\
\hline DAISY01 & $0.25 \%$ & $0.25 \%$ & $-0.25 \%$ & $0.25 \%$ & $-0.25 \%$ & $0.25 \%$ & $-0.25 \%$ & $0.25 \%$ \\
\hline DAISY09 & $1.88 \%$ & $1.88 \%$ & $-1.88 \%$ & $-1.88 \%$ & $1.88 \%$ & $-1.88 \%$ & $-1.88 \%$ & $-1.88 \%$ \\
\hline DAISY07 & $1.62 \%$ & $-1.62 \%$ & $1.62 \%$ & $1.62 \%$ & $1.62 \%$ & $-1.62 \%$ & $-1.62 \%$ & $1.62 \%$ \\
\hline DAISY15 & $1.68 \%$ & $-1.68 \%$ & $1.68 \%$ & $-1.68 \%$ & $-1.68 \%$ & $1.68 \%$ & $-1.68 \%$ & $-1.68 \%$ \\
\hline DAISY03 & $0.81 \%$ & $0.81 \%$ & $0.81 \%$ & $-0.81 \%$ & $-0.81 \%$ & $-0.81 \%$ & $0.81 \%$ & $-0.81 \%$ \\
\hline DAISY11 & $1.75 \%$ & $1.75 \%$ & $1.75 \%$ & $1.75 \%$ & $1.75 \%$ & $1.75 \%$ & $1.75 \%$ & $1.75 \%$ \\
\hline & Contrast & $-2.45 \%$ & $12.59 \%$ & $-8.10 \%$ & $2.71 \%$ & $0.74 \%$ & $2.80 \%$ & $6.20 \%$ \\
\hline & Effect & $-0.31 \%$ & $1.57 \%$ & $-1.01 \%$ & $0.34 \%$ & $0.09 \%$ & $0.35 \%$ & $0.77 \%$ \\
\hline
\end{tabular}


Table F-1-3: TCB $643^{\text {rd }}$ cycle.

\begin{tabular}{|l|r|r|r|r|r|r|r|r|r|}
\hline & & 1 & 2 & 3 & 4 & 12 & 13 & 14 & 23 \\
\hline DAISY06 & $1.16 \%$ & $-1.16 \%$ & $-1.16 \%$ & $-1.16 \%$ & $-1.16 \%$ & $1.16 \%$ & $1.16 \%$ & $1.16 \%$ & $1.16 \%$ \\
\hline DAISY14 & $-1.01 \%$ & $-1.01 \%$ & $1.01 \%$ & $1.01 \%$ & $1.01 \%$ & $1.01 \%$ & $1.01 \%$ & $1.01 \%$ & $-1.01 \%$ \\
\hline DAISY02 & $1.61 \%$ & $-1.61 \%$ & $1.61 \%$ & $-1.61 \%$ & $-1.61 \%$ & $-1.61 \%$ & $1.61 \%$ & $1.61 \%$ & $-1.61 \%$ \\
\hline DAISY10 & $0.31 \%$ & $0.31 \%$ & $0.31 \%$ & $-0.31 \%$ & $-0.31 \%$ & $0.31 \%$ & $-0.31 \%$ & $-0.31 \%$ & $-0.31 \%$ \\
\hline DAISY08 & $-1.73 \%$ & $1.73 \%$ & $1.73 \%$ & $-1.73 \%$ & $1.73 \%$ & $-1.73 \%$ & $1.73 \%$ & $-1.73 \%$ & $1.73 \%$ \\
\hline DAISY16 & $-0.31 \%$ & $-0.31 \%$ & $0.31 \%$ & $-0.31 \%$ & $0.31 \%$ & $0.31 \%$ & $-0.31 \%$ & $0.31 \%$ & $0.31 \%$ \\
\hline DAISY04 & $-0.61 \%$ & $0.61 \%$ & $-0.61 \%$ & $-0.61 \%$ & $0.61 \%$ & $0.61 \%$ & $0.61 \%$ & $-0.61 \%$ & $-0.61 \%$ \\
\hline DAISY12 & $-2.19 \%$ & $-2.19 \%$ & $-2.19 \%$ & $-2.19 \%$ & $2.19 \%$ & $-2.19 \%$ & $-2.19 \%$ & $2.19 \%$ & $-2.19 \%$ \\
\hline DAISY05 & $0.27 \%$ & $-0.27 \%$ & $-0.27 \%$ & $-0.27 \%$ & $0.27 \%$ & $0.27 \%$ & $0.27 \%$ & $-0.27 \%$ & $0.27 \%$ \\
\hline DAISY13 & $-0.84 \%$ & $-0.84 \%$ & $0.84 \%$ & $0.84 \%$ & $-0.84 \%$ & $0.84 \%$ & $0.84 \%$ & $-0.84 \%$ & $-0.84 \%$ \\
\hline DAISY01 & $1.06 \%$ & $-1.06 \%$ & $1.06 \%$ & $-1.06 \%$ & $1.06 \%$ & $-1.06 \%$ & $1.06 \%$ & $-1.06 \%$ & $-1.06 \%$ \\
\hline DAISY09 & $0.55 \%$ & $0.55 \%$ & $0.55 \%$ & $-0.55 \%$ & $0.55 \%$ & $0.55 \%$ & $-0.55 \%$ & $0.55 \%$ & $-0.55 \%$ \\
\hline DAISY07 & $0.45 \%$ & $-0.45 \%$ & $-0.45 \%$ & $0.45 \%$ & $0.45 \%$ & $0.45 \%$ & $-0.45 \%$ & $-0.45 \%$ & $-0.45 \%$ \\
\hline DAISY15 & $0.01 \%$ & $0.01 \%$ & $-0.01 \%$ & $0.01 \%$ & $0.01 \%$ & $-0.01 \%$ & $0.01 \%$ & $0.01 \%$ & $-0.01 \%$ \\
\hline DAISY03 & $-0.51 \%$ & $0.51 \%$ & $-0.51 \%$ & $-0.51 \%$ & $-0.51 \%$ & $0.51 \%$ & $0.51 \%$ & $0.51 \%$ & $-0.51 \%$ \\
\hline DAISY11 & $-0.12 \%$ & $-0.12 \%$ & $-0.12 \%$ & $-0.12 \%$ & $-0.12 \%$ & $-0.12 \%$ & $-0.12 \%$ & $-0.12 \%$ & $-0.12 \%$ \\
\hline & Contrast & $-5.31 \%$ & $2.09 \%$ & $-8.12 \%$ & $3.64 \%$ & $-0.71 \%$ & $4.90 \%$ & $1.95 \%$ & $-5.80 \%$ \\
\hline & Effect & $-0.66 \%$ & $0.26 \%$ & $-1.02 \%$ & $0.45 \%$ & $-0.09 \%$ & $0.61 \%$ & $0.24 \%$ & $-0.73 \%$ \\
\hline
\end{tabular}

\begin{tabular}{|l|r|r|r|r|r|r|r|r|}
\hline & & \multicolumn{1}{|l}{24} & \multicolumn{1}{l}{34} & 123 & 124 & 134 & 234 & 1234 \\
\hline DAISY06 & $1.16 \%$ & $1.16 \%$ & $1.16 \%$ & $-1.16 \%$ & $-1.16 \%$ & $-1.16 \%$ & $-1.16 \%$ & $1.16 \%$ \\
\hline DAISY14 & $-1.01 \%$ & $-1.01 \%$ & $-1.01 \%$ & $-1.01 \%$ & $-1.01 \%$ & $-1.01 \%$ & $1.01 \%$ & $1.01 \%$ \\
\hline DAISY02 & $1.61 \%$ & $-1.61 \%$ & $1.61 \%$ & $1.61 \%$ & $1.61 \%$ & $-1.61 \%$ & $1.61 \%$ & $-1.61 \%$ \\
\hline DAISY10 & $0.31 \%$ & $-0.31 \%$ & $0.31 \%$ & $-0.31 \%$ & $-0.31 \%$ & $0.31 \%$ & $0.31 \%$ & $0.31 \%$ \\
\hline DAISY08 & $-1.73 \%$ & $-1.73 \%$ & $1.73 \%$ & $-1.73 \%$ & $1.73 \%$ & $-1.73 \%$ & $-1.73 \%$ & $1.73 \%$ \\
\hline DAISY16 & $-0.31 \%$ & $-0.31 \%$ & $0.31 \%$ & $0.31 \%$ & $-0.31 \%$ & $0.31 \%$ & $-0.31 \%$ & $-0.31 \%$ \\
\hline DAISY04 & $-0.61 \%$ & $0.61 \%$ & $0.61 \%$ & $0.61 \%$ & $-0.61 \%$ & $-0.61 \%$ & $0.61 \%$ & $-0.61 \%$ \\
\hline DAISY12 & $-2.19 \%$ & $2.19 \%$ & $2.19 \%$ & $-2.19 \%$ & $2.19 \%$ & $2.19 \%$ & $2.19 \%$ & $2.19 \%$ \\
\hline DAISY05 & $0.27 \%$ & $-0.27 \%$ & $-0.27 \%$ & $-0.27 \%$ & $0.27 \%$ & $0.27 \%$ & $0.27 \%$ & $-0.27 \%$ \\
\hline DAISY13 & $-0.84 \%$ & $0.84 \%$ & $0.84 \%$ & $-0.84 \%$ & $0.84 \%$ & $0.84 \%$ & $-0.84 \%$ & $-0.84 \%$ \\
\hline DAISY01 & $1.06 \%$ & $1.06 \%$ & $-1.06 \%$ & $1.06 \%$ & $-1.06 \%$ & $1.06 \%$ & $-1.06 \%$ & $1.06 \%$ \\
\hline DAISY09 & $0.55 \%$ & $0.55 \%$ & $-0.55 \%$ & $-0.55 \%$ & $0.55 \%$ & $-0.55 \%$ & $-0.55 \%$ & $-0.55 \%$ \\
\hline DAISY07 & $0.45 \%$ & $-0.45 \%$ & $0.45 \%$ & $0.45 \%$ & $0.45 \%$ & $-0.45 \%$ & $-0.45 \%$ & $0.45 \%$ \\
\hline DAISY15 & $0.01 \%$ & $-0.01 \%$ & $0.01 \%$ & $-0.01 \%$ & $-0.01 \%$ & $0.01 \%$ & $-0.01 \%$ & $-0.01 \%$ \\
\hline DAISY03 & $-0.51 \%$ & $-0.51 \%$ & $-0.51 \%$ & $0.51 \%$ & $0.51 \%$ & $0.51 \%$ & $-0.51 \%$ & $0.51 \%$ \\
\hline DAISY11 & $-0.12 \%$ & $-0.12 \%$ & $-0.12 \%$ & $-0.12 \%$ & $-0.12 \%$ & $-0.12 \%$ & $-0.12 \%$ & $-0.12 \%$ \\
\hline & Contrast & $0.09 \%$ & $5.69 \%$ & $-3.63 \%$ & $3.56 \%$ & $-1.74 \%$ & $-0.71 \%$ & $4.08 \%$ \\
\hline & Effect & $0.01 \%$ & $0.71 \%$ & $-0.45 \%$ & $0.44 \%$ & $-0.22 \%$ & $-0.09 \%$ & $0.51 \%$ \\
\hline
\end{tabular}


Table F-1-4: TCB $875^{\text {th }}$ cycle.

\begin{tabular}{|l|r|r|r|r|r|r|r|r|r|}
\hline & & 1 & 2 & 4 & 12 & 13 & 14 & 23 \\
\hline DAISY06 & $4.70 \%$ & $-4.70 \%$ & $-4.70 \%$ & $-4.70 \%$ & $-4.70 \%$ & $4.70 \%$ & $4.70 \%$ & $4.70 \%$ & $4.70 \%$ \\
\hline DAISY14 & $0.03 \%$ & $0.03 \%$ & $-0.03 \%$ & $-0.03 \%$ & $-0.03 \%$ & $-0.03 \%$ & $-0.03 \%$ & $-0.03 \%$ & $0.03 \%$ \\
\hline DAISY02 & $2.45 \%$ & $-2.45 \%$ & $2.45 \%$ & $-2.45 \%$ & $-2.45 \%$ & $-2.45 \%$ & $2.45 \%$ & $2.45 \%$ & $-2.45 \%$ \\
\hline DAISY10 & $0.41 \%$ & $0.41 \%$ & $0.41 \%$ & $-0.41 \%$ & $-0.41 \%$ & $0.41 \%$ & $-0.41 \%$ & $-0.41 \%$ & $-0.41 \%$ \\
\hline DAISY08 & $-0.39 \%$ & $0.39 \%$ & $0.39 \%$ & $-0.39 \%$ & $0.39 \%$ & $-0.39 \%$ & $0.39 \%$ & $-0.39 \%$ & $0.39 \%$ \\
\hline DAISY16 & $0.57 \%$ & $0.57 \%$ & $-0.57 \%$ & $0.57 \%$ & $-0.57 \%$ & $-0.57 \%$ & $0.57 \%$ & $-0.57 \%$ & $-0.57 \%$ \\
\hline DAISY04 & $-0.39 \%$ & $0.39 \%$ & $-0.39 \%$ & $-0.39 \%$ & $0.39 \%$ & $0.39 \%$ & $0.39 \%$ & $-0.39 \%$ & $-0.39 \%$ \\
\hline DAISY12 & $-1.68 \%$ & $-1.68 \%$ & $-1.68 \%$ & $-1.68 \%$ & $1.68 \%$ & $-1.68 \%$ & $-1.68 \%$ & $1.68 \%$ & $-1.68 \%$ \\
\hline DAISY05 & $0.38 \%$ & $-0.38 \%$ & $-0.38 \%$ & $-0.38 \%$ & $0.38 \%$ & $0.38 \%$ & $0.38 \%$ & $-0.38 \%$ & $0.38 \%$ \\
\hline DAISY13 & $-0.15 \%$ & $-0.15 \%$ & $0.15 \%$ & $0.15 \%$ & $-0.15 \%$ & $0.15 \%$ & $0.15 \%$ & $-0.15 \%$ & $-0.15 \%$ \\
\hline DAISY01 & $1.17 \%$ & $-1.17 \%$ & $1.17 \%$ & $-1.17 \%$ & $1.17 \%$ & $-1.17 \%$ & $1.17 \%$ & $-1.17 \%$ & $-1.17 \%$ \\
\hline DAISY09 & $0.71 \%$ & $0.71 \%$ & $0.71 \%$ & $-0.71 \%$ & $0.71 \%$ & $0.71 \%$ & $-0.71 \%$ & $0.71 \%$ & $-0.71 \%$ \\
\hline DAISY07 & $0.81 \%$ & $-0.81 \%$ & $-0.81 \%$ & $0.81 \%$ & $0.81 \%$ & $0.81 \%$ & $-0.81 \%$ & $-0.81 \%$ & $-0.81 \%$ \\
\hline DAISY15 & $0.34 \%$ & $0.34 \%$ & $-0.34 \%$ & $0.34 \%$ & $0.34 \%$ & $-0.34 \%$ & $0.34 \%$ & $0.34 \%$ & $-0.34 \%$ \\
\hline DAISY03 & $0.10 \%$ & $-0.10 \%$ & $0.10 \%$ & $0.10 \%$ & $0.10 \%$ & $-0.10 \%$ & $-0.10 \%$ & $-0.10 \%$ & $0.10 \%$ \\
\hline DAISY11 & $1.03 \%$ & $1.03 \%$ & $1.03 \%$ & $1.03 \%$ & $1.03 \%$ & $1.03 \%$ & $1.03 \%$ & $1.03 \%$ & $1.03 \%$ \\
\hline & Contrast & $-7.58 \%$ & $-2.50 \%$ & $-9.31 \%$ & $-1.29 \%$ & $1.86 \%$ & $7.83 \%$ & $6.52 \%$ & $-2.06 \%$ \\
\hline & Effect & $-0.95 \%$ & $-0.31 \%$ & $-1.16 \%$ & $-0.16 \%$ & $0.23 \%$ & $0.98 \%$ & $0.81 \%$ & $-0.26 \%$ \\
\hline
\end{tabular}

\begin{tabular}{|l|r|r|r|r|r|r|r|r|}
\hline & & \multicolumn{1}{|l|}{24} & \multicolumn{1}{l}{123} & \multicolumn{1}{l|}{124} & 134 & 234 & 1234 \\
\hline DAISY06 & $4.70 \%$ & $4.70 \%$ & $4.70 \%$ & $-4.70 \%$ & $-4.70 \%$ & $-4.70 \%$ & $-4.70 \%$ & $4.70 \%$ \\
\hline DAISY14 & $0.03 \%$ & $0.03 \%$ & $0.03 \%$ & $0.03 \%$ & $0.03 \%$ & $0.03 \%$ & $-0.03 \%$ & $-0.03 \%$ \\
\hline DAISY02 & $2.45 \%$ & $-2.45 \%$ & $2.45 \%$ & $2.45 \%$ & $2.45 \%$ & $-2.45 \%$ & $2.45 \%$ & $-2.45 \%$ \\
\hline DAISY10 & $0.41 \%$ & $-0.41 \%$ & $0.41 \%$ & $-0.41 \%$ & $-0.41 \%$ & $0.41 \%$ & $0.41 \%$ & $0.41 \%$ \\
\hline DAISY08 & $-0.39 \%$ & $-0.39 \%$ & $0.39 \%$ & $-0.39 \%$ & $0.39 \%$ & $-0.39 \%$ & $-0.39 \%$ & $0.39 \%$ \\
\hline DAISY16 & $0.57 \%$ & $0.57 \%$ & $-0.57 \%$ & $-0.57 \%$ & $0.57 \%$ & $-0.57 \%$ & $0.57 \%$ & $0.57 \%$ \\
\hline DAISY04 & $-0.39 \%$ & $0.39 \%$ & $0.39 \%$ & $0.39 \%$ & $-0.39 \%$ & $-0.39 \%$ & $0.39 \%$ & $-0.39 \%$ \\
\hline DAISY12 & $-1.68 \%$ & $1.68 \%$ & $1.68 \%$ & $-1.68 \%$ & $1.68 \%$ & $1.68 \%$ & $1.68 \%$ & $1.68 \%$ \\
\hline DAISY05 & $0.38 \%$ & $-0.38 \%$ & $-0.38 \%$ & $-0.38 \%$ & $0.38 \%$ & $0.38 \%$ & $0.38 \%$ & $-0.38 \%$ \\
\hline DAISY13 & $-0.15 \%$ & $0.15 \%$ & $0.15 \%$ & $-0.15 \%$ & $0.15 \%$ & $0.15 \%$ & $-0.15 \%$ & $-0.15 \%$ \\
\hline DAISY01 & $1.17 \%$ & $1.17 \%$ & $-1.17 \%$ & $1.17 \%$ & $-1.17 \%$ & $1.17 \%$ & $-1.17 \%$ & $1.17 \%$ \\
\hline DAISY09 & $0.71 \%$ & $0.71 \%$ & $-0.71 \%$ & $-0.71 \%$ & $0.71 \%$ & $-0.71 \%$ & $-0.71 \%$ & $-0.71 \%$ \\
\hline DAISY07 & $0.81 \%$ & $-0.81 \%$ & $0.81 \%$ & $0.81 \%$ & $0.81 \%$ & $-0.81 \%$ & $-0.81 \%$ & $0.81 \%$ \\
\hline DAISY15 & $0.34 \%$ & $-0.34 \%$ & $0.34 \%$ & $-0.34 \%$ & $-0.34 \%$ & $0.34 \%$ & $-0.34 \%$ & $-0.34 \%$ \\
\hline DAISY03 & $0.10 \%$ & $0.10 \%$ & $0.10 \%$ & $-0.10 \%$ & $-0.10 \%$ & $-0.10 \%$ & $0.10 \%$ & $-0.10 \%$ \\
\hline DAISY11 & $1.03 \%$ & $1.03 \%$ & $1.03 \%$ & $1.03 \%$ & $1.03 \%$ & $1.03 \%$ & $1.03 \%$ & $1.03 \%$ \\
\hline & Contrast & $5.75 \%$ & $9.65 \%$ & $-3.56 \%$ & $1.08 \%$ & $-4.93 \%$ & $-1.31 \%$ & $6.20 \%$ \\
\hline & Effect & $0.72 \%$ & $1.21 \%$ & $-0.44 \%$ & $0.13 \%$ & $-0.62 \%$ & $-0.16 \%$ & $0.77 \%$ \\
\hline
\end{tabular}


Table F-1-5: TCB $1016^{\text {th }}$ cycle.

\begin{tabular}{|l|r|r|r|r|r|r|r|r|r|}
\hline & & 1 & 2 & 4 & 12 & 13 & 14 & 23 \\
\hline DAISY06 & $3.02 \%$ & $-3.02 \%$ & $-3.02 \%$ & $-3.02 \%$ & $-3.02 \%$ & $3.02 \%$ & $3.02 \%$ & $3.02 \%$ & $3.02 \%$ \\
\hline DAISY14 & $0.68 \%$ & $0.68 \%$ & $-0.68 \%$ & $-0.68 \%$ & $-0.68 \%$ & $-0.68 \%$ & $-0.68 \%$ & $-0.68 \%$ & $0.68 \%$ \\
\hline DAISY02 & $3.17 \%$ & $-3.17 \%$ & $3.17 \%$ & $-3.17 \%$ & $-3.17 \%$ & $-3.17 \%$ & $3.17 \%$ & $3.17 \%$ & $-3.17 \%$ \\
\hline DAISY10 & $1.35 \%$ & $1.35 \%$ & $1.35 \%$ & $-1.35 \%$ & $-1.35 \%$ & $1.35 \%$ & $-1.35 \%$ & $-1.35 \%$ & $-1.35 \%$ \\
\hline DAISY08 & $-0.08 \%$ & $0.08 \%$ & $0.08 \%$ & $-0.08 \%$ & $0.08 \%$ & $-0.08 \%$ & $0.08 \%$ & $-0.08 \%$ & $0.08 \%$ \\
\hline DAISY16 & $0.63 \%$ & $0.63 \%$ & $-0.63 \%$ & $0.63 \%$ & $-0.63 \%$ & $-0.63 \%$ & $0.63 \%$ & $-0.63 \%$ & $-0.63 \%$ \\
\hline DAISY04 & $-0.19 \%$ & $0.19 \%$ & $-0.19 \%$ & $-0.19 \%$ & $0.19 \%$ & $0.19 \%$ & $0.19 \%$ & $-0.19 \%$ & $-0.19 \%$ \\
\hline DAISY12 & $-1.87 \%$ & $-1.87 \%$ & $-1.87 \%$ & $-1.87 \%$ & $1.87 \%$ & $-1.87 \%$ & $-1.87 \%$ & $1.87 \%$ & $-1.87 \%$ \\
\hline DAISY05 & $-0.45 \%$ & $0.45 \%$ & $0.45 \%$ & $0.45 \%$ & $-0.45 \%$ & $-0.45 \%$ & $-0.45 \%$ & $0.45 \%$ & $-0.45 \%$ \\
\hline DAISY13 & $-0.33 \%$ & $-0.33 \%$ & $0.33 \%$ & $0.33 \%$ & $-0.33 \%$ & $0.33 \%$ & $0.33 \%$ & $-0.33 \%$ & $-0.33 \%$ \\
\hline DAISY01 & $5.81 \%$ & $-5.81 \%$ & $5.81 \%$ & $-5.81 \%$ & $5.81 \%$ & $-5.81 \%$ & $5.81 \%$ & $-5.81 \%$ & $-5.81 \%$ \\
\hline DAISY09 & $1.18 \%$ & $1.18 \%$ & $1.18 \%$ & $-1.18 \%$ & $1.18 \%$ & $1.18 \%$ & $-1.18 \%$ & $1.18 \%$ & $-1.18 \%$ \\
\hline DAISY07 & $1.30 \%$ & $-1.30 \%$ & $-1.30 \%$ & $1.30 \%$ & $1.30 \%$ & $1.30 \%$ & $-1.30 \%$ & $-1.30 \%$ & $-1.30 \%$ \\
\hline DAISY15 & $2.39 \%$ & $2.39 \%$ & $-2.39 \%$ & $2.39 \%$ & $2.39 \%$ & $-2.39 \%$ & $2.39 \%$ & $2.39 \%$ & $-2.39 \%$ \\
\hline DAISY03 & $0.50 \%$ & $-0.50 \%$ & $0.50 \%$ & $0.50 \%$ & $0.50 \%$ & $-0.50 \%$ & $-0.50 \%$ & $-0.50 \%$ & $0.50 \%$ \\
\hline DAISY11 & $1.84 \%$ & $1.84 \%$ & $1.84 \%$ & $1.84 \%$ & $1.84 \%$ & $1.84 \%$ & $1.84 \%$ & $1.84 \%$ & $1.84 \%$ \\
\hline & Contrast & $-7.21 \%$ & $4.63 \%$ & $-9.90 \%$ & $5.55 \%$ & $-6.37 \%$ & $10.14 \%$ & $3.04 \%$ & $-12.54 \%$ \\
\hline & Effect & $-0.90 \%$ & $0.58 \%$ & $-1.24 \%$ & $0.69 \%$ & $-0.80 \%$ & $1.27 \%$ & $0.38 \%$ & $-1.57 \%$ \\
\hline
\end{tabular}

\begin{tabular}{|l|r|r|r|r|r|r|r|r|}
\hline & & \multicolumn{1}{l|}{24} & \multicolumn{1}{l|}{34} & \multicolumn{1}{l|}{123} & 124 & 134 & 234 & 1234 \\
\hline DAISY06 & $3.02 \%$ & $3.02 \%$ & $3.02 \%$ & $-3.02 \%$ & $-3.02 \%$ & $-3.02 \%$ & $-3.02 \%$ & $3.02 \%$ \\
\hline DAISY14 & $0.68 \%$ & $0.68 \%$ & $0.68 \%$ & $0.68 \%$ & $0.68 \%$ & $0.68 \%$ & $-0.68 \%$ & $-0.68 \%$ \\
\hline DAISY02 & $3.17 \%$ & $-3.17 \%$ & $3.17 \%$ & $3.17 \%$ & $3.17 \%$ & $-3.17 \%$ & $3.17 \%$ & $-3.17 \%$ \\
\hline DAISY10 & $1.35 \%$ & $-1.35 \%$ & $1.35 \%$ & $-1.35 \%$ & $-1.35 \%$ & $1.35 \%$ & $1.35 \%$ & $1.35 \%$ \\
\hline DAISY08 & $-0.08 \%$ & $-0.08 \%$ & $0.08 \%$ & $-0.08 \%$ & $0.08 \%$ & $-0.08 \%$ & $-0.08 \%$ & $0.08 \%$ \\
\hline DAISY16 & $0.63 \%$ & $0.63 \%$ & $-0.63 \%$ & $-0.63 \%$ & $0.63 \%$ & $-0.63 \%$ & $0.63 \%$ & $0.63 \%$ \\
\hline DAISY04 & $-0.19 \%$ & $0.19 \%$ & $0.19 \%$ & $0.19 \%$ & $-0.19 \%$ & $-0.19 \%$ & $0.19 \%$ & $-0.19 \%$ \\
\hline DAISY12 & $-1.87 \%$ & $1.87 \%$ & $1.87 \%$ & $-1.87 \%$ & $1.87 \%$ & $1.87 \%$ & $1.87 \%$ & $1.87 \%$ \\
\hline DAISY05 & $-0.45 \%$ & $0.45 \%$ & $0.45 \%$ & $0.45 \%$ & $-0.45 \%$ & $-0.45 \%$ & $-0.45 \%$ & $0.45 \%$ \\
\hline DAISY13 & $-0.33 \%$ & $0.33 \%$ & $0.33 \%$ & $-0.33 \%$ & $0.33 \%$ & $0.33 \%$ & $-0.33 \%$ & $-0.33 \%$ \\
\hline DAISY01 & $5.81 \%$ & $5.81 \%$ & $-5.81 \%$ & $5.81 \%$ & $-5.81 \%$ & $5.81 \%$ & $-5.81 \%$ & $5.81 \%$ \\
\hline DAISY09 & $1.18 \%$ & $1.18 \%$ & $-1.18 \%$ & $-1.18 \%$ & $1.18 \%$ & $-1.18 \%$ & $-1.18 \%$ & $-1.18 \%$ \\
\hline DAISY07 & $1.30 \%$ & $-1.30 \%$ & $1.30 \%$ & $1.30 \%$ & $1.30 \%$ & $-1.30 \%$ & $-1.30 \%$ & $1.30 \%$ \\
\hline DAISY15 & $2.39 \%$ & $-2.39 \%$ & $2.39 \%$ & $-2.39 \%$ & $-2.39 \%$ & $2.39 \%$ & $-2.39 \%$ & $-2.39 \%$ \\
\hline DAISY03 & $0.50 \%$ & $0.50 \%$ & $0.50 \%$ & $-0.50 \%$ & $-0.50 \%$ & $-0.50 \%$ & $0.50 \%$ & $-0.50 \%$ \\
\hline DAISY11 & $1.84 \%$ & $1.84 \%$ & $1.84 \%$ & $1.84 \%$ & $1.84 \%$ & $1.84 \%$ & $1.84 \%$ & $1.84 \%$ \\
\hline & Contrast & $8.19 \%$ & $9.55 \%$ & $2.09 \%$ & $-2.64 \%$ & $3.76 \%$ & $-5.70 \%$ & $7.93 \%$ \\
\hline & Effect & $1.02 \%$ & $1.19 \%$ & $0.26 \%$ & $-0.33 \%$ & $0.47 \%$ & $-0.71 \%$ & $0.99 \%$ \\
\hline
\end{tabular}


Table F-1-6: TCB $1200^{\text {th }}$ cycle.

\begin{tabular}{|l|r|r|r|r|r|r|r|r|r|}
\hline & & 1 & 2 & 3 & 4 & 12 & 13 & 14 & 23 \\
\hline DAISY06 & $4.74 \%$ & $-4.74 \%$ & $-4.74 \%$ & $-4.74 \%$ & $-4.74 \%$ & $4.74 \%$ & $4.74 \%$ & $4.74 \%$ & $4.74 \%$ \\
\hline DAISY14 & $-0.11 \%$ & $-0.11 \%$ & $0.11 \%$ & $0.11 \%$ & $0.11 \%$ & $0.11 \%$ & $0.11 \%$ & $0.11 \%$ & $-0.11 \%$ \\
\hline DAISY02 & $3.13 \%$ & $-3.13 \%$ & $3.13 \%$ & $-3.13 \%$ & $-3.13 \%$ & $-3.13 \%$ & $3.13 \%$ & $3.13 \%$ & $-3.13 \%$ \\
\hline DAISY10 & $0.43 \%$ & $0.43 \%$ & $0.43 \%$ & $-0.43 \%$ & $-0.43 \%$ & $0.43 \%$ & $-0.43 \%$ & $-0.43 \%$ & $-0.43 \%$ \\
\hline DAISY08 & $0.47 \%$ & $-0.47 \%$ & $-0.47 \%$ & $0.47 \%$ & $-0.47 \%$ & $0.47 \%$ & $-0.47 \%$ & $0.47 \%$ & $-0.47 \%$ \\
\hline DAISY16 & $0.28 \%$ & $0.28 \%$ & $-0.28 \%$ & $0.28 \%$ & $-0.28 \%$ & $-0.28 \%$ & $0.28 \%$ & $-0.28 \%$ & $-0.28 \%$ \\
\hline DAISY04 & $-0.31 \%$ & $0.31 \%$ & $-0.31 \%$ & $-0.31 \%$ & $0.31 \%$ & $0.31 \%$ & $0.31 \%$ & $-0.31 \%$ & $-0.31 \%$ \\
\hline DAISY12 & $-1.24 \%$ & $-1.24 \%$ & $-1.24 \%$ & $-1.24 \%$ & $1.24 \%$ & $-1.24 \%$ & $-1.24 \%$ & $1.24 \%$ & $-1.24 \%$ \\
\hline DAISY05 & $-0.50 \%$ & $0.50 \%$ & $0.50 \%$ & $0.50 \%$ & $-0.50 \%$ & $-0.50 \%$ & $-0.50 \%$ & $0.50 \%$ & $-0.50 \%$ \\
\hline DAISY13 & $-0.10 \%$ & $-0.10 \%$ & $0.10 \%$ & $0.10 \%$ & $-0.10 \%$ & $0.10 \%$ & $0.10 \%$ & $-0.10 \%$ & $-0.10 \%$ \\
\hline DAISY01 & $2.14 \%$ & $-2.14 \%$ & $2.14 \%$ & $-2.14 \%$ & $2.14 \%$ & $-2.14 \%$ & $2.14 \%$ & $-2.14 \%$ & $-2.14 \%$ \\
\hline DAISY09 & $1.43 \%$ & $1.43 \%$ & $1.43 \%$ & $-1.43 \%$ & $1.43 \%$ & $1.43 \%$ & $-1.43 \%$ & $1.43 \%$ & $-1.43 \%$ \\
\hline DAISY07 & $1.58 \%$ & $-1.58 \%$ & $-1.58 \%$ & $1.58 \%$ & $1.58 \%$ & $1.58 \%$ & $-1.58 \%$ & $-1.58 \%$ & $-1.58 \%$ \\
\hline DAISY15 & $0.41 \%$ & $0.41 \%$ & $-0.41 \%$ & $0.41 \%$ & $0.41 \%$ & $-0.41 \%$ & $0.41 \%$ & $0.41 \%$ & $-0.41 \%$ \\
\hline DAISY03 & $0.00 \%$ & $0.00 \%$ & $0.00 \%$ & $0.00 \%$ & $0.00 \%$ & $0.00 \%$ & $0.00 \%$ & $0.00 \%$ & $0.00 \%$ \\
\hline DAISY11 & $0.70 \%$ & $0.70 \%$ & $0.70 \%$ & $0.70 \%$ & $0.70 \%$ & $0.70 \%$ & $0.70 \%$ & $0.70 \%$ & $0.70 \%$ \\
\hline & Contrast & $-9.47 \%$ & $-0.49 \%$ & $-9.27 \%$ & $-1.73 \%$ & $2.17 \%$ & $6.27 \%$ & $7.90 \%$ & $-6.67 \%$ \\
\hline & Effect & $-1.18 \%$ & $-0.06 \%$ & $-1.16 \%$ & $-0.22 \%$ & $0.27 \%$ & $0.78 \%$ & $0.99 \%$ & $-0.83 \%$ \\
\hline
\end{tabular}

\begin{tabular}{|c|c|c|c|c|c|c|c|c|}
\hline & & 24 & 34 & 123 & 124 & 134 & 234 & 1234 \\
\hline DAISY06 & $4.74 \%$ & $4.74 \%$ & $4.74 \%$ & $-4.74 \%$ & $-4.74 \%$ & $-4.74 \%$ & $-4.74 \%$ & $4.74 \%$ \\
\hline DAISY14 & $-0.11 \%$ & $-0.11 \%$ & $-0.11 \%$ & $-0.11 \%$ & $-0.11 \%$ & $-0.11 \%$ & $0.11 \%$ & $0.11 \%$ \\
\hline DAISY02 & $3.13 \%$ & $-3.13 \%$ & $3.13 \%$ & $3.13 \%$ & $3.13 \%$ & $-3.13 \%$ & $3.13 \%$ & $-3.13 \%$ \\
\hline DAISY10 & $0.43 \%$ & $-0.43 \%$ & $0.43 \%$ & $-0.43 \%$ & $-0.43 \%$ & $0.43 \%$ & $0.43 \%$ & $0.43 \%$ \\
\hline DAISY08 & $0.47 \%$ & $0.47 \%$ & $-0.47 \%$ & $0.47 \%$ & $-0.47 \%$ & $0.47 \%$ & $0.47 \%$ & $-0.47 \%$ \\
\hline DAISY16 & $0.28 \%$ & $0.28 \%$ & $-0.28 \%$ & $-0.28 \%$ & $0.28 \%$ & $-0.28 \%$ & $0.28 \%$ & $0.28 \%$ \\
\hline DAISY04 & $-0.31 \%$ & $0.31 \%$ & $0.31 \%$ & $0.31 \%$ & $-0.31 \%$ & $-0.31 \%$ & $0.31 \%$ & $-0.31 \%$ \\
\hline DAISY12 & $-1.24 \%$ & $1.24 \%$ & $1.24 \%$ & $-1.24 \%$ & $1.24 \%$ & $1.24 \%$ & $1.24 \%$ & $1.24 \%$ \\
\hline DAISY05 & $-0.50 \%$ & $0.50 \%$ & $0.50 \%$ & $0.50 \%$ & $-0.50 \%$ & $-0.50 \%$ & $-0.50 \%$ & $0.50 \%$ \\
\hline DAISY13 & $-0.10 \%$ & $0.10 \%$ & $0.10 \%$ & $-0.10 \%$ & $0.10 \%$ & $0.10 \%$ & $-0.10 \%$ & $-0.10 \%$ \\
\hline DAISY01 & $2.14 \%$ & $2.14 \%$ & $-2.14 \%$ & $2.14 \%$ & $-2.14 \%$ & $2.14 \%$ & $-2.14 \%$ & $2.14 \%$ \\
\hline DAISY09 & $1.43 \%$ & $1.43 \%$ & $-1.43 \%$ & $-1.43 \%$ & $1.43 \%$ & $-1.43 \%$ & $-1.43 \%$ & $-1.43 \%$ \\
\hline DAISY07 & $1.58 \%$ & $-1.58 \%$ & $1.58 \%$ & $1.58 \%$ & $1.58 \%$ & $-1.58 \%$ & $-1.58 \%$ & $1.58 \%$ \\
\hline DAISY15 & $0.41 \%$ & $-0.41 \%$ & $0.41 \%$ & $-0.41 \%$ & $-0.41 \%$ & $0.41 \%$ & $-0.41 \%$ & $-0.41 \%$ \\
\hline DAISY03 & $0.00 \%$ & $0.00 \%$ & $0.00 \%$ & $0.00 \%$ & $0.00 \%$ & $0.00 \%$ & $0.00 \%$ & $0.00 \%$ \\
\hline DAISY11 & $0.70 \%$ & $0.70 \%$ & $0.70 \%$ & $0.70 \%$ & $0.70 \%$ & $0.70 \%$ & $0.70 \%$ & $0.70 \%$ \\
\hline & Contrast & $6.24 \%$ & $8.74 \%$ & $0.08 \%$ & $-0.63 \%$ & $-6.59 \%$ & $-4.23 \%$ & $5.86 \%$ \\
\hline & Effect & $0.78 \%$ & $1.09 \%$ & $0.01 \%$ & $-0.08 \%$ & $-0.82 \%$ & $-0.53 \%$ & $0.73 \%$ \\
\hline
\end{tabular}


Table F-1-7: TCB $1492^{\text {nd }}$ cycle.

\begin{tabular}{|l|r|r|r|r|r|r|r|r|r|}
\hline & & 1 & 2 & 3 & 4 & 12 & 13 & 14 & 23 \\
\hline DAISY06 & $5.09 \%$ & $-5.09 \%$ & $-5.09 \%$ & $-5.09 \%$ & $-5.09 \%$ & $5.09 \%$ & $5.09 \%$ & $5.09 \%$ & $5.09 \%$ \\
\hline DAISY14 & $-0.12 \%$ & $-0.12 \%$ & $0.12 \%$ & $0.12 \%$ & $0.12 \%$ & $0.12 \%$ & $0.12 \%$ & $0.12 \%$ & $-0.12 \%$ \\
\hline DAISY02 & $2.19 \%$ & $-2.19 \%$ & $2.19 \%$ & $-2.19 \%$ & $-2.19 \%$ & $-2.19 \%$ & $2.19 \%$ & $2.19 \%$ & $-2.19 \%$ \\
\hline DAISY10 & $0.52 \%$ & $0.52 \%$ & $0.52 \%$ & $-0.52 \%$ & $-0.52 \%$ & $0.52 \%$ & $-0.52 \%$ & $-0.52 \%$ & $-0.52 \%$ \\
\hline DAISY08 & $0.42 \%$ & $-0.42 \%$ & $-0.42 \%$ & $0.42 \%$ & $-0.42 \%$ & $0.42 \%$ & $-0.42 \%$ & $0.42 \%$ & $-0.42 \%$ \\
\hline DAISY16 & $-0.13 \%$ & $-0.13 \%$ & $0.13 \%$ & $-0.13 \%$ & $0.13 \%$ & $0.13 \%$ & $-0.13 \%$ & $0.13 \%$ & $0.13 \%$ \\
\hline DAISY04 & $-0.39 \%$ & $0.39 \%$ & $-0.39 \%$ & $-0.39 \%$ & $0.39 \%$ & $0.39 \%$ & $0.39 \%$ & $-0.39 \%$ & $-0.39 \%$ \\
\hline DAISY12 & $-1.71 \%$ & $-1.71 \%$ & $-1.71 \%$ & $-1.71 \%$ & $1.71 \%$ & $-1.71 \%$ & $-1.71 \%$ & $1.71 \%$ & $-1.71 \%$ \\
\hline DAISY05 & $-0.74 \%$ & $0.74 \%$ & $0.74 \%$ & $0.74 \%$ & $-0.74 \%$ & $-0.74 \%$ & $-0.74 \%$ & $0.74 \%$ & $-0.74 \%$ \\
\hline DAISY13 & $-0.33 \%$ & $-0.33 \%$ & $0.33 \%$ & $0.33 \%$ & $-0.33 \%$ & $0.33 \%$ & $0.33 \%$ & $-0.33 \%$ & $-0.33 \%$ \\
\hline DAISY01 & $0.33 \%$ & $-0.33 \%$ & $0.33 \%$ & $-0.33 \%$ & $0.33 \%$ & $-0.33 \%$ & $0.33 \%$ & $-0.33 \%$ & $-0.33 \%$ \\
\hline DAISY09 & $0.65 \%$ & $0.65 \%$ & $0.65 \%$ & $-0.65 \%$ & $0.65 \%$ & $0.65 \%$ & $-0.65 \%$ & $0.65 \%$ & $-0.65 \%$ \\
\hline DAISY07 & $1.57 \%$ & $-1.57 \%$ & $-1.57 \%$ & $1.57 \%$ & $1.57 \%$ & $1.57 \%$ & $-1.57 \%$ & $-1.57 \%$ & $-1.57 \%$ \\
\hline DAISY15 & $0.08 \%$ & $0.08 \%$ & $-0.08 \%$ & $0.08 \%$ & $0.08 \%$ & $-0.08 \%$ & $0.08 \%$ & $0.08 \%$ & $-0.08 \%$ \\
\hline DAISY03 & $-0.16 \%$ & $0.16 \%$ & $-0.16 \%$ & $-0.16 \%$ & $-0.16 \%$ & $0.16 \%$ & $0.16 \%$ & $0.16 \%$ & $-0.16 \%$ \\
\hline DAISY11 & $0.51 \%$ & $0.51 \%$ & $0.51 \%$ & $0.51 \%$ & $0.51 \%$ & $0.51 \%$ & $0.51 \%$ & $0.51 \%$ & $0.51 \%$ \\
\hline & Contrast & $-8.83 \%$ & $-3.90 \%$ & $-7.39 \%$ & $-3.96 \%$ & $4.83 \%$ & $3.48 \%$ & $8.66 \%$ & $-3.47 \%$ \\
\hline & Effect & $-1.10 \%$ & $-0.49 \%$ & $-0.92 \%$ & $-0.50 \%$ & $0.60 \%$ & $0.43 \%$ & $1.08 \%$ & $-0.43 \%$ \\
\hline
\end{tabular}

\begin{tabular}{|l|r|r|r|r|r|r|r|r|}
\hline & \multicolumn{2}{|l|}{24} & \multicolumn{1}{l|}{34} & \multicolumn{1}{l|}{123} & 124 & 134 & 234 & 1234 \\
\hline DAISY06 & $5.09 \%$ & $5.09 \%$ & $5.09 \%$ & $-5.09 \%$ & $-5.09 \%$ & $-5.09 \%$ & $-5.09 \%$ & $5.09 \%$ \\
\hline DAISY14 & $-0.12 \%$ & $-0.12 \%$ & $-0.12 \%$ & $-0.12 \%$ & $-0.12 \%$ & $-0.12 \%$ & $0.12 \%$ & $0.12 \%$ \\
\hline DAISY02 & $2.19 \%$ & $-2.19 \%$ & $2.19 \%$ & $2.19 \%$ & $2.19 \%$ & $-2.19 \%$ & $2.19 \%$ & $-2.19 \%$ \\
\hline DAISY10 & $0.52 \%$ & $-0.52 \%$ & $0.52 \%$ & $-0.52 \%$ & $-0.52 \%$ & $0.52 \%$ & $0.52 \%$ & $0.52 \%$ \\
\hline DAISY08 & $0.42 \%$ & $0.42 \%$ & $-0.42 \%$ & $0.42 \%$ & $-0.42 \%$ & $0.42 \%$ & $0.42 \%$ & $-0.42 \%$ \\
\hline DAISY16 & $-0.13 \%$ & $-0.13 \%$ & $0.13 \%$ & $0.13 \%$ & $-0.13 \%$ & $0.13 \%$ & $-0.13 \%$ & $-0.13 \%$ \\
\hline DAISY04 & $-0.39 \%$ & $0.39 \%$ & $0.39 \%$ & $0.39 \%$ & $-0.39 \%$ & $-0.39 \%$ & $0.39 \%$ & $-0.39 \%$ \\
\hline DAISY12 & $-1.71 \%$ & $1.71 \%$ & $1.71 \%$ & $-1.71 \%$ & $1.71 \%$ & $1.71 \%$ & $1.71 \%$ & $1.71 \%$ \\
\hline DAISY05 & $-0.74 \%$ & $0.74 \%$ & $0.74 \%$ & $0.74 \%$ & $-0.74 \%$ & $-0.74 \%$ & $-0.74 \%$ & $0.74 \%$ \\
\hline DAISY13 & $-0.33 \%$ & $0.33 \%$ & $0.33 \%$ & $-0.33 \%$ & $0.33 \%$ & $0.33 \%$ & $-0.33 \%$ & $-0.33 \%$ \\
\hline DAISY01 & $0.33 \%$ & $0.33 \%$ & $-0.33 \%$ & $0.33 \%$ & $-0.33 \%$ & $0.33 \%$ & $-0.33 \%$ & $0.33 \%$ \\
\hline DAISY09 & $0.65 \%$ & $0.65 \%$ & $-0.65 \%$ & $-0.65 \%$ & $0.65 \%$ & $-0.65 \%$ & $-0.65 \%$ & $-0.65 \%$ \\
\hline DAISY07 & $1.57 \%$ & $-1.57 \%$ & $1.57 \%$ & $1.57 \%$ & $1.57 \%$ & $-1.57 \%$ & $-1.57 \%$ & $1.57 \%$ \\
\hline DAISY15 & $0.08 \%$ & $-0.08 \%$ & $0.08 \%$ & $-0.08 \%$ & $-0.08 \%$ & $0.08 \%$ & $-0.08 \%$ & $-0.08 \%$ \\
\hline DAISY03 & $-0.16 \%$ & $-0.16 \%$ & $-0.16 \%$ & $0.16 \%$ & $0.16 \%$ & $0.16 \%$ & $-0.16 \%$ & $0.16 \%$ \\
\hline DAISY11 & $0.51 \%$ & $0.51 \%$ & $0.51 \%$ & $0.51 \%$ & $0.51 \%$ & $0.51 \%$ & $0.51 \%$ & $0.51 \%$ \\
\hline & Contrast & $5.42 \%$ & $11.60 \%$ & $-2.06 \%$ & $-0.68 \%$ & $-6.57 \%$ & $-3.23 \%$ & $6.55 \%$ \\
\hline & Effect & $0.68 \%$ & $1.45 \%$ & $-0.26 \%$ & $-0.08 \%$ & $-0.82 \%$ & $-0.40 \%$ & $0.82 \%$ \\
\hline
\end{tabular}


Table F-1-8: TCB $1724^{\text {th }}$ cycle.

\begin{tabular}{|l|r|r|r|r|r|r|r|r|r|}
\hline & & 1 & 2 & 3 & 12 & 13 & 14 & 23 \\
\hline DAISY06 & $5.36 \%$ & $-5.36 \%$ & $-5.36 \%$ & $-5.36 \%$ & $-5.36 \%$ & $5.36 \%$ & $5.36 \%$ & $5.36 \%$ & $5.36 \%$ \\
\hline DAISY14 & $0.74 \%$ & $0.74 \%$ & $-0.74 \%$ & $-0.74 \%$ & $-0.74 \%$ & $-0.74 \%$ & $-0.74 \%$ & $-0.74 \%$ & $0.74 \%$ \\
\hline DAISY02 & $2.87 \%$ & $-2.87 \%$ & $2.87 \%$ & $-2.87 \%$ & $-2.87 \%$ & $-2.87 \%$ & $2.87 \%$ & $2.87 \%$ & $-2.87 \%$ \\
\hline DAISY10 & $0.14 \%$ & $0.14 \%$ & $0.14 \%$ & $-0.14 \%$ & $-0.14 \%$ & $0.14 \%$ & $-0.14 \%$ & $-0.14 \%$ & $-0.14 \%$ \\
\hline DAISY08 & $-0.61 \%$ & $0.61 \%$ & $0.61 \%$ & $-0.61 \%$ & $0.61 \%$ & $-0.61 \%$ & $0.61 \%$ & $-0.61 \%$ & $0.61 \%$ \\
\hline DAISY16 & $0.14 \%$ & $0.14 \%$ & $-0.14 \%$ & $0.14 \%$ & $-0.14 \%$ & $-0.14 \%$ & $0.14 \%$ & $-0.14 \%$ & $-0.14 \%$ \\
\hline DAISY04 & $0.54 \%$ & $-0.54 \%$ & $0.54 \%$ & $0.54 \%$ & $-0.54 \%$ & $-0.54 \%$ & $-0.54 \%$ & $0.54 \%$ & $0.54 \%$ \\
\hline DAISY12 & $-1.33 \%$ & $-1.33 \%$ & $-1.33 \%$ & $-1.33 \%$ & $1.33 \%$ & $-1.33 \%$ & $-1.33 \%$ & $1.33 \%$ & $-1.33 \%$ \\
\hline DAISY05 & $0.79 \%$ & $-0.79 \%$ & $-0.79 \%$ & $-0.79 \%$ & $0.79 \%$ & $0.79 \%$ & $0.79 \%$ & $-0.79 \%$ & $0.79 \%$ \\
\hline DAISY13 & $0.08 \%$ & $0.08 \%$ & $-0.08 \%$ & $-0.08 \%$ & $0.08 \%$ & $-0.08 \%$ & $-0.08 \%$ & $0.08 \%$ & $0.08 \%$ \\
\hline DAISY01 & $3.69 \%$ & $-3.69 \%$ & $3.69 \%$ & $-3.69 \%$ & $3.69 \%$ & $-3.69 \%$ & $3.69 \%$ & $-3.69 \%$ & $-3.69 \%$ \\
\hline DAISY09 & $1.26 \%$ & $1.26 \%$ & $1.26 \%$ & $-1.26 \%$ & $1.26 \%$ & $1.26 \%$ & $-1.26 \%$ & $1.26 \%$ & $-1.26 \%$ \\
\hline DAISY07 & $2.41 \%$ & $-2.41 \%$ & $-2.41 \%$ & $2.41 \%$ & $2.41 \%$ & $2.41 \%$ & $-2.41 \%$ & $-2.41 \%$ & $-2.41 \%$ \\
\hline DAISY15 & $0.33 \%$ & $0.33 \%$ & $-0.33 \%$ & $0.33 \%$ & $0.33 \%$ & $-0.33 \%$ & $0.33 \%$ & $0.33 \%$ & $-0.33 \%$ \\
\hline DAISY03 & $0.67 \%$ & $-0.67 \%$ & $0.67 \%$ & $0.67 \%$ & $0.67 \%$ & $-0.67 \%$ & $-0.67 \%$ & $-0.67 \%$ & $0.67 \%$ \\
\hline DAISY11 & $0.82 \%$ & $0.82 \%$ & $0.82 \%$ & $0.82 \%$ & $0.82 \%$ & $0.82 \%$ & $0.82 \%$ & $0.82 \%$ & $0.82 \%$ \\
\hline & Contrast & $-13.53 \%$ & $-0.57 \%$ & $-11.98 \%$ & $2.21 \%$ & $-0.24 \%$ & $7.44 \%$ & $3.41 \%$ & $-2.57 \%$ \\
\hline & Effect & $-1.69 \%$ & $-0.07 \%$ & $-1.50 \%$ & $0.28 \%$ & $-0.03 \%$ & $0.93 \%$ & $0.43 \%$ & $-0.32 \%$ \\
\hline
\end{tabular}

\begin{tabular}{|l|r|r|r|r|r|r|r|r|}
\hline & & 24 & \multicolumn{1}{l|}{34} & \multicolumn{1}{l|}{123} & 124 & 134 & 234 & 1234 \\
\hline DAISY06 & $5.36 \%$ & $5.36 \%$ & $5.36 \%$ & $-5.36 \%$ & $-5.36 \%$ & $-5.36 \%$ & $-5.36 \%$ & $5.36 \%$ \\
\hline DAISY14 & $0.74 \%$ & $0.74 \%$ & $0.74 \%$ & $0.74 \%$ & $0.74 \%$ & $0.74 \%$ & $-0.74 \%$ & $-0.74 \%$ \\
\hline DAISY02 & $2.87 \%$ & $-2.87 \%$ & $2.87 \%$ & $2.87 \%$ & $2.87 \%$ & $-2.87 \%$ & $2.87 \%$ & $-2.87 \%$ \\
\hline DAISY10 & $0.14 \%$ & $-0.14 \%$ & $0.14 \%$ & $-0.14 \%$ & $-0.14 \%$ & $0.14 \%$ & $0.14 \%$ & $0.14 \%$ \\
\hline DAISY08 & $-0.61 \%$ & $-0.61 \%$ & $0.61 \%$ & $-0.61 \%$ & $0.61 \%$ & $-0.61 \%$ & $-0.61 \%$ & $0.61 \%$ \\
\hline DAISY16 & $0.14 \%$ & $0.14 \%$ & $-0.14 \%$ & $-0.14 \%$ & $0.14 \%$ & $-0.14 \%$ & $0.14 \%$ & $0.14 \%$ \\
\hline DAISY04 & $0.54 \%$ & $-0.54 \%$ & $-0.54 \%$ & $-0.54 \%$ & $0.54 \%$ & $0.54 \%$ & $-0.54 \%$ & $0.54 \%$ \\
\hline DAISY12 & $-1.33 \%$ & $1.33 \%$ & $1.33 \%$ & $-1.33 \%$ & $1.33 \%$ & $1.33 \%$ & $1.33 \%$ & $1.33 \%$ \\
\hline DAISY05 & $0.79 \%$ & $-0.79 \%$ & $-0.79 \%$ & $-0.79 \%$ & $0.79 \%$ & $0.79 \%$ & $0.79 \%$ & $-0.79 \%$ \\
\hline DAISY13 & $0.08 \%$ & $-0.08 \%$ & $-0.08 \%$ & $0.08 \%$ & $-0.08 \%$ & $-0.08 \%$ & $0.08 \%$ & $0.08 \%$ \\
\hline DAISY01 & $3.69 \%$ & $3.69 \%$ & $-3.69 \%$ & $3.69 \%$ & $-3.69 \%$ & $3.69 \%$ & $-3.69 \%$ & $3.69 \%$ \\
\hline DAISY09 & $1.26 \%$ & $1.26 \%$ & $-1.26 \%$ & $-1.26 \%$ & $1.26 \%$ & $-1.26 \%$ & $-1.26 \%$ & $-1.26 \%$ \\
\hline DAISY07 & $2.41 \%$ & $-2.41 \%$ & $2.41 \%$ & $2.41 \%$ & $2.41 \%$ & $-2.41 \%$ & $-2.41 \%$ & $2.41 \%$ \\
\hline DAISY15 & $0.33 \%$ & $-0.33 \%$ & $0.33 \%$ & $-0.33 \%$ & $-0.33 \%$ & $0.33 \%$ & $-0.33 \%$ & $-0.33 \%$ \\
\hline DAISY03 & $0.67 \%$ & $0.67 \%$ & $0.67 \%$ & $-0.67 \%$ & $-0.67 \%$ & $-0.67 \%$ & $0.67 \%$ & $-0.67 \%$ \\
\hline DAISY11 & $0.82 \%$ & $0.82 \%$ & $0.82 \%$ & $0.82 \%$ & $0.82 \%$ & $0.82 \%$ & $0.82 \%$ & $0.82 \%$ \\
\hline & Contrast & $6.24 \%$ & $8.79 \%$ & $-0.57 \%$ & $1.24 \%$ & $-5.03 \%$ & $-8.10 \%$ & $8.45 \%$ \\
\hline & Effect & $0.78 \%$ & $1.10 \%$ & $-0.07 \%$ & $0.15 \%$ & $-0.63 \%$ & $-1.01 \%$ & $1.06 \%$ \\
\hline
\end{tabular}


Table F-1-9: TCB 2012 $2^{\text {th }}$ cycle.

\begin{tabular}{|l|r|r|r|r|r|r|r|r|r|}
\hline & & 1 & 2 & 3 & 12 & 13 & 14 & 23 \\
\hline DAISY06 & $5.47 \%$ & $-5.47 \%$ & $-5.47 \%$ & $-5.47 \%$ & $-5.47 \%$ & $5.47 \%$ & $5.47 \%$ & $5.47 \%$ & $5.47 \%$ \\
\hline DAISY14 & $0.03 \%$ & $0.03 \%$ & $-0.03 \%$ & $-0.03 \%$ & $-0.03 \%$ & $-0.03 \%$ & $-0.03 \%$ & $-0.03 \%$ & $0.03 \%$ \\
\hline DAISY02 & $2.94 \%$ & $-2.94 \%$ & $2.94 \%$ & $-2.94 \%$ & $-2.94 \%$ & $-2.94 \%$ & $2.94 \%$ & $2.94 \%$ & $-2.94 \%$ \\
\hline DAISY10 & $1.43 \%$ & $1.43 \%$ & $1.43 \%$ & $-1.43 \%$ & $-1.43 \%$ & $1.43 \%$ & $-1.43 \%$ & $-1.43 \%$ & $-1.43 \%$ \\
\hline DAISY08 & $0.08 \%$ & $-0.08 \%$ & $-0.08 \%$ & $0.08 \%$ & $-0.08 \%$ & $0.08 \%$ & $-0.08 \%$ & $0.08 \%$ & $-0.08 \%$ \\
\hline DAISY16 & $-0.20 \%$ & $-0.20 \%$ & $0.20 \%$ & $-0.20 \%$ & $0.20 \%$ & $0.20 \%$ & $-0.20 \%$ & $0.20 \%$ & $0.20 \%$ \\
\hline DAISY04 & $-0.20 \%$ & $0.20 \%$ & $-0.20 \%$ & $-0.20 \%$ & $0.20 \%$ & $0.20 \%$ & $0.20 \%$ & $-0.20 \%$ & $-0.20 \%$ \\
\hline DAISY12 & $-1.85 \%$ & $-1.85 \%$ & $-1.85 \%$ & $-1.85 \%$ & $1.85 \%$ & $-1.85 \%$ & $-1.85 \%$ & $1.85 \%$ & $-1.85 \%$ \\
\hline DAISY05 & $0.13 \%$ & $-0.13 \%$ & $-0.13 \%$ & $-0.13 \%$ & $0.13 \%$ & $0.13 \%$ & $0.13 \%$ & $-0.13 \%$ & $0.13 \%$ \\
\hline DAISY13 & $-0.64 \%$ & $-0.64 \%$ & $0.64 \%$ & $0.64 \%$ & $-0.64 \%$ & $0.64 \%$ & $0.64 \%$ & $-0.64 \%$ & $-0.64 \%$ \\
\hline DAISY01 & $3.07 \%$ & $-3.07 \%$ & $3.07 \%$ & $-3.07 \%$ & $3.07 \%$ & $-3.07 \%$ & $3.07 \%$ & $-3.07 \%$ & $-3.07 \%$ \\
\hline DAISY09 & $1.07 \%$ & $1.07 \%$ & $1.07 \%$ & $-1.07 \%$ & $1.07 \%$ & $1.07 \%$ & $-1.07 \%$ & $1.07 \%$ & $-1.07 \%$ \\
\hline DAISY07 & $1.50 \%$ & $-1.50 \%$ & $-1.50 \%$ & $1.50 \%$ & $1.50 \%$ & $1.50 \%$ & $-1.50 \%$ & $-1.50 \%$ & $-1.50 \%$ \\
\hline DAISY15 & $0.36 \%$ & $0.36 \%$ & $-0.36 \%$ & $0.36 \%$ & $0.36 \%$ & $-0.36 \%$ & $0.36 \%$ & $0.36 \%$ & $-0.36 \%$ \\
\hline DAISY03 & $0.28 \%$ & $-0.28 \%$ & $0.28 \%$ & $0.28 \%$ & $0.28 \%$ & $-0.28 \%$ & $-0.28 \%$ & $-0.28 \%$ & $0.28 \%$ \\
\hline DAISY11 & $1.17 \%$ & $1.17 \%$ & $1.17 \%$ & $1.17 \%$ & $1.17 \%$ & $1.17 \%$ & $1.17 \%$ & $1.17 \%$ & $1.17 \%$ \\
\hline & Contrast & $-11.90 \%$ & $1.20 \%$ & $-12.35 \%$ & $-0.77 \%$ & $3.35 \%$ & $7.54 \%$ & $5.88 \%$ & $-5.87 \%$ \\
\hline & Effect & $-1.49 \%$ & $0.15 \%$ & $-1.54 \%$ & $-0.10 \%$ & $0.42 \%$ & $0.94 \%$ & $0.73 \%$ & $-0.73 \%$ \\
\hline
\end{tabular}

\begin{tabular}{|l|r|r|r|r|r|r|r|r|}
\hline & & \multicolumn{1}{|l|}{24} & \multicolumn{1}{l|}{34} & 123 & 124 & 134 & 234 & 1234 \\
\hline DAISY06 & $5.47 \%$ & $5.47 \%$ & $5.47 \%$ & $-5.47 \%$ & $-5.47 \%$ & $-5.47 \%$ & $-5.47 \%$ & $5.47 \%$ \\
\hline DAISY14 & $0.03 \%$ & $0.03 \%$ & $0.03 \%$ & $0.03 \%$ & $0.03 \%$ & $0.03 \%$ & $-0.03 \%$ & $-0.03 \%$ \\
\hline DAISY02 & $2.94 \%$ & $-2.94 \%$ & $2.94 \%$ & $2.94 \%$ & $2.94 \%$ & $-2.94 \%$ & $2.94 \%$ & $-2.94 \%$ \\
\hline DAISY10 & $1.43 \%$ & $-1.43 \%$ & $1.43 \%$ & $-1.43 \%$ & $-1.43 \%$ & $1.43 \%$ & $1.43 \%$ & $1.43 \%$ \\
\hline DAISY08 & $0.08 \%$ & $0.08 \%$ & $-0.08 \%$ & $0.08 \%$ & $-0.08 \%$ & $0.08 \%$ & $0.08 \%$ & $-0.08 \%$ \\
\hline DAISY16 & $-0.20 \%$ & $-0.20 \%$ & $0.20 \%$ & $0.20 \%$ & $-0.20 \%$ & $0.20 \%$ & $-0.20 \%$ & $-0.20 \%$ \\
\hline DAISY04 & $-0.20 \%$ & $0.20 \%$ & $0.20 \%$ & $0.20 \%$ & $-0.20 \%$ & $-0.20 \%$ & $0.20 \%$ & $-0.20 \%$ \\
\hline DAISY12 & $-1.85 \%$ & $1.85 \%$ & $1.85 \%$ & $-1.85 \%$ & $1.85 \%$ & $1.85 \%$ & $1.85 \%$ & $1.85 \%$ \\
\hline DAISY05 & $0.13 \%$ & $-0.13 \%$ & $-0.13 \%$ & $-0.13 \%$ & $0.13 \%$ & $0.13 \%$ & $0.13 \%$ & $-0.13 \%$ \\
\hline DAISY13 & $-0.64 \%$ & $0.64 \%$ & $0.64 \%$ & $-0.64 \%$ & $0.64 \%$ & $0.64 \%$ & $-0.64 \%$ & $-0.64 \%$ \\
\hline DAISY01 & $3.07 \%$ & $3.07 \%$ & $-3.07 \%$ & $3.07 \%$ & $-3.07 \%$ & $3.07 \%$ & $-3.07 \%$ & $3.07 \%$ \\
\hline DAISY09 & $1.07 \%$ & $1.07 \%$ & $-1.07 \%$ & $-1.07 \%$ & $1.07 \%$ & $-1.07 \%$ & $-1.07 \%$ & $-1.07 \%$ \\
\hline DAISY07 & $1.50 \%$ & $-1.50 \%$ & $1.50 \%$ & $1.50 \%$ & $1.50 \%$ & $-1.50 \%$ & $-1.50 \%$ & $1.50 \%$ \\
\hline DAISY15 & $0.36 \%$ & $-0.36 \%$ & $0.36 \%$ & $-0.36 \%$ & $-0.36 \%$ & $0.36 \%$ & $-0.36 \%$ & $-0.36 \%$ \\
\hline DAISY03 & $0.28 \%$ & $0.28 \%$ & $0.28 \%$ & $-0.28 \%$ & $-0.28 \%$ & $-0.28 \%$ & $0.28 \%$ & $-0.28 \%$ \\
\hline DAISY11 & $1.17 \%$ & $1.17 \%$ & $1.17 \%$ & $1.17 \%$ & $1.17 \%$ & $1.17 \%$ & $1.17 \%$ & $1.17 \%$ \\
\hline & Contrast & $7.32 \%$ & $11.74 \%$ & $-2.04 \%$ & $-1.76 \%$ & $-2.48 \%$ & $-4.24 \%$ & $8.54 \%$ \\
\hline & Effect & $0.92 \%$ & $1.47 \%$ & $-0.26 \%$ & $-0.22 \%$ & $-0.31 \%$ & $-0.53 \%$ & $1.07 \%$ \\
\hline
\end{tabular}


Table F-1-10: TCC $100^{\text {th }}$ cycle.

\begin{tabular}{|l|r|r|r|r|r|r|r|r|r|r|}
\hline & & 1 & 2 & 3 & 4 & 12 & 13 & 14 & 23 & 24 \\
\hline DAISY06 & $5.63 \%$ & $-5.63 \%$ & $-5.63 \%$ & $-5.63 \%$ & $-5.63 \%$ & $5.63 \%$ & $5.63 \%$ & $5.63 \%$ & $5.63 \%$ & $5.63 \%$ \\
\hline DAISY14 & $0.49 \%$ & $0.49 \%$ & $-0.49 \%$ & $-0.49 \%$ & $-0.49 \%$ & $-0.49 \%$ & $-0.49 \%$ & $-0.49 \%$ & $0.49 \%$ & $0.49 \%$ \\
\hline DAISY02 & $2.40 \%$ & $-2.40 \%$ & $2.40 \%$ & $-2.40 \%$ & $-2.40 \%$ & $-2.40 \%$ & $2.40 \%$ & $2.40 \%$ & $-2.40 \%$ & $-2.40 \%$ \\
\hline DAISY10 & $0.11 \%$ & $0.11 \%$ & $0.11 \%$ & $-0.11 \%$ & $-0.11 \%$ & $0.11 \%$ & $-0.11 \%$ & $-0.11 \%$ & $-0.11 \%$ & $-0.11 \%$ \\
\hline DAISY08 & $-0.81 \%$ & $0.81 \%$ & $0.81 \%$ & $-0.81 \%$ & $0.81 \%$ & $-0.81 \%$ & $0.81 \%$ & $-0.81 \%$ & $0.81 \%$ & $-0.81 \%$ \\
\hline DAISY16 & $-0.24 \%$ & $-0.24 \%$ & $0.24 \%$ & $-0.24 \%$ & $0.24 \%$ & $0.24 \%$ & $-0.24 \%$ & $0.24 \%$ & $0.24 \%$ & $-0.24 \%$ \\
\hline DAISY04 & $-0.01 \%$ & $0.01 \%$ & $-0.01 \%$ & $-0.01 \%$ & $0.01 \%$ & $0.01 \%$ & $0.01 \%$ & $-0.01 \%$ & $-0.01 \%$ & $0.01 \%$ \\
\hline DAISY12 & $-2.01 \%$ & $-2.01 \%$ & $-2.01 \%$ & $-2.01 \%$ & $2.01 \%$ & $-2.01 \%$ & $-2.01 \%$ & $2.01 \%$ & $-2.01 \%$ & $2.01 \%$ \\
\hline DAISY05 & $-0.02 \%$ & $0.02 \%$ & $0.02 \%$ & $0.02 \%$ & $-0.02 \%$ & $-0.02 \%$ & $-0.02 \%$ & $0.02 \%$ & $-0.02 \%$ & $0.02 \%$ \\
\hline DAISY13 & $-0.72 \%$ & $-0.72 \%$ & $0.72 \%$ & $0.72 \%$ & $-0.72 \%$ & $0.72 \%$ & $0.72 \%$ & $-0.72 \%$ & $-0.72 \%$ & $0.72 \%$ \\
\hline DAISY01 & $1.07 \%$ & $-1.07 \%$ & $1.07 \%$ & $-1.07 \%$ & $1.07 \%$ & $-1.07 \%$ & $1.07 \%$ & $-1.07 \%$ & $-1.07 \%$ & $1.07 \%$ \\
\hline DAISY09 & $0.50 \%$ & $0.50 \%$ & $0.50 \%$ & $-0.50 \%$ & $0.50 \%$ & $0.50 \%$ & $-0.50 \%$ & $0.50 \%$ & $-0.50 \%$ & $0.50 \%$ \\
\hline DAISY07 & $1.14 \%$ & $-1.14 \%$ & $-1.14 \%$ & $1.14 \%$ & $1.14 \%$ & $1.14 \%$ & $-1.14 \%$ & $-1.14 \%$ & $-1.14 \%$ & $-1.14 \%$ \\
\hline DAISY15 & $0.07 \%$ & $0.07 \%$ & $-0.07 \%$ & $0.07 \%$ & $0.07 \%$ & $-0.07 \%$ & $0.07 \%$ & $0.07 \%$ & $-0.07 \%$ & $-0.07 \%$ \\
\hline DAISY03 & $0.24 \%$ & $-0.24 \%$ & $0.24 \%$ & $0.24 \%$ & $0.24 \%$ & $-0.24 \%$ & $-0.24 \%$ & $-0.24 \%$ & $0.24 \%$ & $0.24 \%$ \\
\hline DAISY11 & $1.01 \%$ & $1.01 \%$ & $1.01 \%$ & $1.01 \%$ & $1.01 \%$ & $1.01 \%$ & $1.01 \%$ & $1.01 \%$ & $1.01 \%$ & $1.01 \%$ \\
\hline & Contrast & $-10.43 \%$ & $-2.21 \%$ & $-10.07 \%$ & $-2.26 \%$ & $2.26 \%$ & $6.96 \%$ & $7.28 \%$ & $0.37 \%$ & $6.92 \%$ \\
\hline & Effect & $-1.30 \%$ & $-0.28 \%$ & $-1.26 \%$ & $-0.28 \%$ & $0.28 \%$ & $0.87 \%$ & $0.91 \%$ & $0.05 \%$ & $0.86 \%$ \\
\hline
\end{tabular}

\begin{tabular}{|l|r|r|r|r|r|r|r|r|}
\hline & & \multicolumn{1}{|l|}{24} & 34 & 123 & 124 & 134 & 234 & 1234 \\
\hline DAISY06 & $5.63 \%$ & $5.63 \%$ & $5.63 \%$ & $-5.63 \%$ & $-5.63 \%$ & $-5.63 \%$ & $-5.63 \%$ & $5.63 \%$ \\
\hline DAISY14 & $0.49 \%$ & $0.49 \%$ & $0.49 \%$ & $0.49 \%$ & $0.49 \%$ & $0.49 \%$ & $-0.49 \%$ & $-0.49 \%$ \\
\hline DAISY02 & $2.40 \%$ & $-2.40 \%$ & $2.40 \%$ & $2.40 \%$ & $2.40 \%$ & $-2.40 \%$ & $2.40 \%$ & $-2.40 \%$ \\
\hline DAISY10 & $0.11 \%$ & $-0.11 \%$ & $0.11 \%$ & $-0.11 \%$ & $-0.11 \%$ & $0.11 \%$ & $0.11 \%$ & $0.11 \%$ \\
\hline DAISY08 & $-0.81 \%$ & $-0.81 \%$ & $0.81 \%$ & $-0.81 \%$ & $0.81 \%$ & $-0.81 \%$ & $-0.81 \%$ & $0.81 \%$ \\
\hline DAISY16 & $-0.24 \%$ & $-0.24 \%$ & $0.24 \%$ & $0.24 \%$ & $-0.24 \%$ & $0.24 \%$ & $-0.24 \%$ & $-0.24 \%$ \\
\hline DAISY04 & $-0.01 \%$ & $0.01 \%$ & $0.01 \%$ & $0.01 \%$ & $-0.01 \%$ & $-0.01 \%$ & $0.01 \%$ & $-0.01 \%$ \\
\hline DAISY12 & $-2.01 \%$ & $2.01 \%$ & $2.01 \%$ & $-2.01 \%$ & $2.01 \%$ & $2.01 \%$ & $2.01 \%$ & $2.01 \%$ \\
\hline DAISY05 & $-0.02 \%$ & $0.02 \%$ & $0.02 \%$ & $0.02 \%$ & $-0.02 \%$ & $-0.02 \%$ & $-0.02 \%$ & $0.02 \%$ \\
\hline DAISY13 & $-0.72 \%$ & $0.72 \%$ & $0.72 \%$ & $-0.72 \%$ & $0.72 \%$ & $0.72 \%$ & $-0.72 \%$ & $-0.72 \%$ \\
\hline DAISY01 & $1.07 \%$ & $1.07 \%$ & $-1.07 \%$ & $1.07 \%$ & $-1.07 \%$ & $1.07 \%$ & $-1.07 \%$ & $1.07 \%$ \\
\hline DAISY09 & $0.50 \%$ & $0.50 \%$ & $-0.50 \%$ & $-0.50 \%$ & $0.50 \%$ & $-0.50 \%$ & $-0.50 \%$ & $-0.50 \%$ \\
\hline DAISY07 & $1.14 \%$ & $-1.14 \%$ & $1.14 \%$ & $1.14 \%$ & $1.14 \%$ & $-1.14 \%$ & $-1.14 \%$ & $1.14 \%$ \\
\hline DAISY15 & $0.07 \%$ & $-0.07 \%$ & $0.07 \%$ & $-0.07 \%$ & $-0.07 \%$ & $0.07 \%$ & $-0.07 \%$ & $-0.07 \%$ \\
\hline DAISY03 & $0.24 \%$ & $0.24 \%$ & $0.24 \%$ & $-0.24 \%$ & $-0.24 \%$ & $-0.24 \%$ & $0.24 \%$ & $-0.24 \%$ \\
\hline DAISY11 & $1.01 \%$ & $1.01 \%$ & $1.01 \%$ & $1.01 \%$ & $1.01 \%$ & $1.01 \%$ & $1.01 \%$ & $1.01 \%$ \\
\hline & Contrast & $6.92 \%$ & $13.34 \%$ & $-3.70 \%$ & $1.69 \%$ & $-5.03 \%$ & $-4.91 \%$ & $7.15 \%$ \\
\hline & Effect & $0.86 \%$ & $1.67 \%$ & $-0.46 \%$ & $0.21 \%$ & $-0.63 \%$ & $-0.61 \%$ & $0.89 \%$ \\
\hline
\end{tabular}


Table F-1-11: TCC $200^{\text {th }}$ cycle.

\begin{tabular}{|l|r|r|r|r|r|r|r|r|r|}
\hline & & 1 & 2 & 3 & 4 & 12 & 13 & 14 & \multicolumn{1}{|c|}{23} \\
\hline DAISY06 & $8.06 \%$ & $-8.06 \%$ & $-8.06 \%$ & $-8.06 \%$ & $-8.06 \%$ & $8.06 \%$ & $8.06 \%$ & $8.06 \%$ & $8.06 \%$ \\
\hline DAISY14 & $-0.27 \%$ & $-0.27 \%$ & $0.27 \%$ & $0.27 \%$ & $0.27 \%$ & $0.27 \%$ & $0.27 \%$ & $0.27 \%$ & $-0.27 \%$ \\
\hline DAISY02 & $2.58 \%$ & $-2.58 \%$ & $2.58 \%$ & $-2.58 \%$ & $-2.58 \%$ & $-2.58 \%$ & $2.58 \%$ & $2.58 \%$ & $-2.58 \%$ \\
\hline DAISY10 & $-0.04 \%$ & $-0.04 \%$ & $-0.04 \%$ & $0.04 \%$ & $0.04 \%$ & $-0.04 \%$ & $0.04 \%$ & $0.04 \%$ & $0.04 \%$ \\
\hline DAISY08 & $-0.31 \%$ & $0.31 \%$ & $0.31 \%$ & $-0.31 \%$ & $0.31 \%$ & $-0.31 \%$ & $0.31 \%$ & $-0.31 \%$ & $0.31 \%$ \\
\hline DAISY16 & $-0.52 \%$ & $-0.52 \%$ & $0.52 \%$ & $-0.52 \%$ & $0.52 \%$ & $0.52 \%$ & $-0.52 \%$ & $0.52 \%$ & $0.52 \%$ \\
\hline DAISY04 & $0.07 \%$ & $-0.07 \%$ & $0.07 \%$ & $0.07 \%$ & $-0.07 \%$ & $-0.07 \%$ & $-0.07 \%$ & $0.07 \%$ & $0.07 \%$ \\
\hline DAISY12 & $-1.63 \%$ & $-1.63 \%$ & $-1.63 \%$ & $-1.63 \%$ & $1.63 \%$ & $-1.63 \%$ & $-1.63 \%$ & $1.63 \%$ & $-1.63 \%$ \\
\hline DAISY05 & $-0.92 \%$ & $0.92 \%$ & $0.92 \%$ & $0.92 \%$ & $-0.92 \%$ & $-0.92 \%$ & $-0.92 \%$ & $0.92 \%$ & $-0.92 \%$ \\
\hline DAISY13 & $-1.22 \%$ & $-1.22 \%$ & $1.22 \%$ & $1.22 \%$ & $-1.22 \%$ & $1.22 \%$ & $1.22 \%$ & $-1.22 \%$ & $-1.22 \%$ \\
\hline DAISY01 & $1.77 \%$ & $-1.77 \%$ & $1.77 \%$ & $-1.77 \%$ & $1.77 \%$ & $-1.77 \%$ & $1.77 \%$ & $-1.77 \%$ & $-1.77 \%$ \\
\hline DAISY09 & $0.45 \%$ & $0.45 \%$ & $0.45 \%$ & $-0.45 \%$ & $0.45 \%$ & $0.45 \%$ & $-0.45 \%$ & $0.45 \%$ & $-0.45 \%$ \\
\hline DAISY07 & $1.29 \%$ & $-1.29 \%$ & $-1.29 \%$ & $1.29 \%$ & $1.29 \%$ & $1.29 \%$ & $-1.29 \%$ & $-1.29 \%$ & $-1.29 \%$ \\
\hline DAISY15 & $1.35 \%$ & $1.35 \%$ & $-1.35 \%$ & $1.35 \%$ & $1.35 \%$ & $-1.35 \%$ & $1.35 \%$ & $1.35 \%$ & $-1.35 \%$ \\
\hline DAISY03 & $0.26 \%$ & $-0.26 \%$ & $0.26 \%$ & $0.26 \%$ & $0.26 \%$ & $-0.26 \%$ & $-0.26 \%$ & $-0.26 \%$ & $0.26 \%$ \\
\hline DAISY11 & $0.26 \%$ & $0.26 \%$ & $0.26 \%$ & $0.26 \%$ & $0.26 \%$ & $0.26 \%$ & $0.26 \%$ & $0.26 \%$ & $0.26 \%$ \\
\hline & Contrast & $-14.42 \%$ & $-3.74 \%$ & $-9.65 \%$ & $-4.70 \%$ & $3.14 \%$ & $10.73 \%$ & $11.32 \%$ & $-1.96 \%$ \\
\hline & Effect & $-1.80 \%$ & $-0.47 \%$ & $-1.21 \%$ & $-0.59 \%$ & $0.39 \%$ & $1.34 \%$ & $1.41 \%$ & $-0.24 \%$ \\
\hline
\end{tabular}

\begin{tabular}{|l|r|r|r|r|r|r|r|r|}
\hline & \multicolumn{2}{|l|}{24} & \multicolumn{1}{l|}{34} & \multicolumn{1}{l|}{123} & 124 & 134 & 234 & 1234 \\
\hline DAISY06 & $8.06 \%$ & $8.06 \%$ & $8.06 \%$ & $-8.06 \%$ & $-8.06 \%$ & $-8.06 \%$ & $-8.06 \%$ & $8.06 \%$ \\
\hline DAISY14 & $-0.27 \%$ & $-0.27 \%$ & $-0.27 \%$ & $-0.27 \%$ & $-0.27 \%$ & $-0.27 \%$ & $0.27 \%$ & $0.27 \%$ \\
\hline DAISY02 & $2.58 \%$ & $-2.58 \%$ & $2.58 \%$ & $2.58 \%$ & $2.58 \%$ & $-2.58 \%$ & $2.58 \%$ & $-2.58 \%$ \\
\hline DAISY10 & $-0.04 \%$ & $0.04 \%$ & $-0.04 \%$ & $0.04 \%$ & $0.04 \%$ & $-0.04 \%$ & $-0.04 \%$ & $-0.04 \%$ \\
\hline DAISY08 & $-0.31 \%$ & $-0.31 \%$ & $0.31 \%$ & $-0.31 \%$ & $0.31 \%$ & $-0.31 \%$ & $-0.31 \%$ & $0.31 \%$ \\
\hline DAISY16 & $-0.52 \%$ & $-0.52 \%$ & $0.52 \%$ & $0.52 \%$ & $-0.52 \%$ & $0.52 \%$ & $-0.52 \%$ & $-0.52 \%$ \\
\hline DAISY04 & $0.07 \%$ & $-0.07 \%$ & $-0.07 \%$ & $-0.07 \%$ & $0.07 \%$ & $0.07 \%$ & $-0.07 \%$ & $0.07 \%$ \\
\hline DAISY12 & $-1.63 \%$ & $1.63 \%$ & $1.63 \%$ & $-1.63 \%$ & $1.63 \%$ & $1.63 \%$ & $1.63 \%$ & $1.63 \%$ \\
\hline DAISY05 & $-0.92 \%$ & $0.92 \%$ & $0.92 \%$ & $0.92 \%$ & $-0.92 \%$ & $-0.92 \%$ & $-0.92 \%$ & $0.92 \%$ \\
\hline DAISY13 & $-1.22 \%$ & $1.22 \%$ & $1.22 \%$ & $-1.22 \%$ & $1.22 \%$ & $1.22 \%$ & $-1.22 \%$ & $-1.22 \%$ \\
\hline DAISY01 & $1.77 \%$ & $1.77 \%$ & $-1.77 \%$ & $1.77 \%$ & $-1.77 \%$ & $1.77 \%$ & $-1.77 \%$ & $1.77 \%$ \\
\hline DAISY09 & $0.45 \%$ & $0.45 \%$ & $-0.45 \%$ & $-0.45 \%$ & $0.45 \%$ & $-0.45 \%$ & $-0.45 \%$ & $-0.45 \%$ \\
\hline DAISY07 & $1.29 \%$ & $-1.29 \%$ & $1.29 \%$ & $1.29 \%$ & $1.29 \%$ & $-1.29 \%$ & $-1.29 \%$ & $1.29 \%$ \\
\hline DAISY15 & $1.35 \%$ & $-1.35 \%$ & $1.35 \%$ & $-1.35 \%$ & $-1.35 \%$ & $1.35 \%$ & $-1.35 \%$ & $-1.35 \%$ \\
\hline DAISY03 & $0.26 \%$ & $0.26 \%$ & $0.26 \%$ & $-0.26 \%$ & $-0.26 \%$ & $-0.26 \%$ & $0.26 \%$ & $-0.26 \%$ \\
\hline DAISY11 & $0.26 \%$ & $0.26 \%$ & $0.26 \%$ & $0.26 \%$ & $0.26 \%$ & $0.26 \%$ & $0.26 \%$ & $0.26 \%$ \\
\hline & Contrast & $8.24 \%$ & $15.77 \%$ & $-6.23 \%$ & $-5.29 \%$ & $-7.34 \%$ & $-11.01 \%$ & $8.17 \%$ \\
\hline & Effect & $1.03 \%$ & $1.97 \%$ & $-0.78 \%$ & $-0.66 \%$ & $-0.92 \%$ & $-1.38 \%$ & $1.02 \%$ \\
\hline
\end{tabular}


Table F-1-12: TCC $300^{\text {th }}$ cycle.

\begin{tabular}{|l|r|r|r|r|r|r|r|r|r|}
\hline & & 1 & 2 & 3 & 4 & 12 & 13 & 14 & 23 \\
\hline DAISY06 & $8.65 \%$ & $-8.65 \%$ & $-8.65 \%$ & $-8.65 \%$ & $-8.65 \%$ & $8.65 \%$ & $8.65 \%$ & $8.65 \%$ & $8.65 \%$ \\
\hline DAISY14 & $2.88 \%$ & $2.88 \%$ & $-2.88 \%$ & $-2.88 \%$ & $-2.88 \%$ & $-2.88 \%$ & $-2.88 \%$ & $-2.88 \%$ & $2.88 \%$ \\
\hline DAISY02 & $3.75 \%$ & $-3.75 \%$ & $3.75 \%$ & $-3.75 \%$ & $-3.75 \%$ & $-3.75 \%$ & $3.75 \%$ & $3.75 \%$ & $-3.75 \%$ \\
\hline DAISY10 & $2.02 \%$ & $2.02 \%$ & $2.02 \%$ & $-2.02 \%$ & $-2.02 \%$ & $2.02 \%$ & $-2.02 \%$ & $-2.02 \%$ & $-2.02 \%$ \\
\hline DAISY08 & $1.95 \%$ & $-1.95 \%$ & $-1.95 \%$ & $1.95 \%$ & $-1.95 \%$ & $1.95 \%$ & $-1.95 \%$ & $1.95 \%$ & $-1.95 \%$ \\
\hline DAISY16 & $0.75 \%$ & $0.75 \%$ & $-0.75 \%$ & $0.75 \%$ & $-0.75 \%$ & $-0.75 \%$ & $0.75 \%$ & $-0.75 \%$ & $-0.75 \%$ \\
\hline DAISY04 & $1.25 \%$ & $-1.25 \%$ & $1.25 \%$ & $1.25 \%$ & $-1.25 \%$ & $-1.25 \%$ & $-1.25 \%$ & $1.25 \%$ & $1.25 \%$ \\
\hline DAISY12 & $-1.69 \%$ & $-1.69 \%$ & $-1.69 \%$ & $-1.69 \%$ & $1.69 \%$ & $-1.69 \%$ & $-1.69 \%$ & $1.69 \%$ & $-1.69 \%$ \\
\hline DAISY05 & $0.62 \%$ & $-0.62 \%$ & $-0.62 \%$ & $-0.62 \%$ & $0.62 \%$ & $0.62 \%$ & $0.62 \%$ & $-0.62 \%$ & $0.62 \%$ \\
\hline DAISY13 & $0.28 \%$ & $0.28 \%$ & $-0.28 \%$ & $-0.28 \%$ & $0.28 \%$ & $-0.28 \%$ & $-0.28 \%$ & $0.28 \%$ & $0.28 \%$ \\
\hline DAISY01 & $6.68 \%$ & $-6.68 \%$ & $6.68 \%$ & $-6.68 \%$ & $6.68 \%$ & $-6.68 \%$ & $6.68 \%$ & $-6.68 \%$ & $-6.68 \%$ \\
\hline DAISY09 & $2.71 \%$ & $2.71 \%$ & $2.71 \%$ & $-2.71 \%$ & $2.71 \%$ & $2.71 \%$ & $-2.71 \%$ & $2.71 \%$ & $-2.71 \%$ \\
\hline DAISY07 & $3.59 \%$ & $-3.59 \%$ & $-3.59 \%$ & $3.59 \%$ & $3.59 \%$ & $3.59 \%$ & $-3.59 \%$ & $-3.59 \%$ & $-3.59 \%$ \\
\hline DAISY15 & $2.07 \%$ & $2.07 \%$ & $-2.07 \%$ & $2.07 \%$ & $2.07 \%$ & $-2.07 \%$ & $2.07 \%$ & $2.07 \%$ & $-2.07 \%$ \\
\hline DAISY03 & $1.60 \%$ & $-1.60 \%$ & $1.60 \%$ & $1.60 \%$ & $1.60 \%$ & $-1.60 \%$ & $-1.60 \%$ & $-1.60 \%$ & $1.60 \%$ \\
\hline DAISY11 & $1.23 \%$ & $1.23 \%$ & $1.23 \%$ & $1.23 \%$ & $1.23 \%$ & $1.23 \%$ & $1.23 \%$ & $1.23 \%$ & $1.23 \%$ \\
\hline & Contrast & $-17.84 \%$ & $-3.27 \%$ & $-16.83 \%$ & $-0.79 \%$ & $-0.18 \%$ & $5.77 \%$ & $5.45 \%$ & $-8.70 \%$ \\
\hline & Effect & $-2.23 \%$ & $-0.41 \%$ & $-2.10 \%$ & $-0.10 \%$ & $-0.02 \%$ & $0.72 \%$ & $0.68 \%$ & $-1.09 \%$ \\
\hline
\end{tabular}

\begin{tabular}{|l|r|r|r|r|r|r|r|r|}
\hline & & \multicolumn{1}{|l|}{24} & \multicolumn{1}{l|}{34} & \multicolumn{1}{l|}{123} & 124 & 134 & 234 & 1234 \\
\hline DAISY06 & $8.65 \%$ & $8.65 \%$ & $8.65 \%$ & $-8.65 \%$ & $-8.65 \%$ & $-8.65 \%$ & $-8.65 \%$ & $8.65 \%$ \\
\hline DAISY14 & $2.88 \%$ & $2.88 \%$ & $2.88 \%$ & $2.88 \%$ & $2.88 \%$ & $2.88 \%$ & $-2.88 \%$ & $-2.88 \%$ \\
\hline DAISY02 & $3.75 \%$ & $-3.75 \%$ & $3.75 \%$ & $3.75 \%$ & $3.75 \%$ & $-3.75 \%$ & $3.75 \%$ & $-3.75 \%$ \\
\hline DAISY10 & $2.02 \%$ & $-2.02 \%$ & $2.02 \%$ & $-2.02 \%$ & $-2.02 \%$ & $2.02 \%$ & $2.02 \%$ & $2.02 \%$ \\
\hline DAISY08 & $1.95 \%$ & $1.95 \%$ & $-1.95 \%$ & $1.95 \%$ & $-1.95 \%$ & $1.95 \%$ & $1.95 \%$ & $-1.95 \%$ \\
\hline DAISY16 & $0.75 \%$ & $0.75 \%$ & $-0.75 \%$ & $-0.75 \%$ & $0.75 \%$ & $-0.75 \%$ & $0.75 \%$ & $0.75 \%$ \\
\hline DAISY04 & $1.25 \%$ & $-1.25 \%$ & $-1.25 \%$ & $-1.25 \%$ & $1.25 \%$ & $1.25 \%$ & $-1.25 \%$ & $1.25 \%$ \\
\hline DAISY12 & $-1.69 \%$ & $1.69 \%$ & $1.69 \%$ & $-1.69 \%$ & $1.69 \%$ & $1.69 \%$ & $1.69 \%$ & $1.69 \%$ \\
\hline DAISY05 & $0.62 \%$ & $-0.62 \%$ & $-0.62 \%$ & $-0.62 \%$ & $0.62 \%$ & $0.62 \%$ & $0.62 \%$ & $-0.62 \%$ \\
\hline DAISY13 & $0.28 \%$ & $-0.28 \%$ & $-0.28 \%$ & $0.28 \%$ & $-0.28 \%$ & $-0.28 \%$ & $0.28 \%$ & $0.28 \%$ \\
\hline DAISY01 & $6.68 \%$ & $6.68 \%$ & $-6.68 \%$ & $6.68 \%$ & $-6.68 \%$ & $6.68 \%$ & $-6.68 \%$ & $6.68 \%$ \\
\hline DAISY09 & $2.71 \%$ & $2.71 \%$ & $-2.71 \%$ & $-2.71 \%$ & $2.71 \%$ & $-2.71 \%$ & $-2.71 \%$ & $-2.71 \%$ \\
\hline DAISY07 & $3.59 \%$ & $-3.59 \%$ & $3.59 \%$ & $3.59 \%$ & $3.59 \%$ & $-3.59 \%$ & $-3.59 \%$ & $3.59 \%$ \\
\hline DAISY15 & $2.07 \%$ & $-2.07 \%$ & $2.07 \%$ & $-2.07 \%$ & $-2.07 \%$ & $2.07 \%$ & $-2.07 \%$ & $-2.07 \%$ \\
\hline DAISY03 & $1.60 \%$ & $1.60 \%$ & $1.60 \%$ & $-1.60 \%$ & $-1.60 \%$ & $-1.60 \%$ & $1.60 \%$ & $-1.60 \%$ \\
\hline DAISY11 & $1.23 \%$ & $1.23 \%$ & $1.23 \%$ & $1.23 \%$ & $1.23 \%$ & $1.23 \%$ & $1.23 \%$ & $1.23 \%$ \\
\hline & Contrast & $14.57 \%$ & $13.25 \%$ & $-1.00 \%$ & $-4.77 \%$ & $-0.92 \%$ & $-13.94 \%$ & $10.58 \%$ \\
\hline & Effect & $1.82 \%$ & $1.66 \%$ & $-0.13 \%$ & $-0.60 \%$ & $-0.12 \%$ & $-1.74 \%$ & $1.32 \%$ \\
\hline
\end{tabular}


Table F-1-13: TCC $400^{\text {th }}$ cycle.

\begin{tabular}{|c|c|c|c|c|c|c|c|c|c|}
\hline & & 1 & 2 & $\sqrt{3}$ & 4 & 12 & 13 & 14 & 23 \\
\hline DAISY06 & $19.56 \%$ & $-19.56 \%$ & $-19.56 \%$ & $-19.56 \%$ & $-19.56 \%$ & $19.56 \%$ & $19.56 \%$ & $19.56 \%$ & $19.56 \%$ \\
\hline DAISY 14 & $-5.45 \%$ & $-5.45 \%$ & $5.45 \%$ & $5.45 \%$ & $5.45 \%$ & $5.45 \%$ & $5.45 \%$ & $5.45 \%$ & $-5.45 \%$ \\
\hline DAISY02 & $4.77 \%$ & $-4.77 \%$ & $4.77 \%$ & $-4.77 \%$ & $-4.77 \%$ & $-4.77 \%$ & $4.77 \%$ & $4.77 \%$ & $-4.77 \%$ \\
\hline DAISY10 & $1.03 \%$ & $1.03 \%$ & $1.03 \%$ & $-1.03 \%$ & $-1.03 \%$ & $1.03 \%$ & $-1.03 \%$ & $-1.03 \%$ & $-1.03 \%$ \\
\hline DAISY08 & $8.33 \%$ & $-8.33 \%$ & $-8.33 \%$ & $8.33 \%$ & $-8.33 \%$ & $8.33 \%$ & $-8.33 \%$ & $8.33 \%$ & $-8.33 \%$ \\
\hline DAISY16 & $1.27 \%$ & $1.27 \%$ & $-1.27 \%$ & $1.27 \%$ & $-1.27 \%$ & $-1.27 \%$ & $1.27 \%$ & $-1.27 \%$ & $-1.27 \%$ \\
\hline DAISY04 & $16.81 \%$ & $-16.81 \%$ & $16.81 \%$ & $16.81 \%$ & $-16.81 \%$ & $-16.81 \%$ & $-16.81 \%$ & $16.81 \%$ & $16.81 \%$ \\
\hline DAISY12 & $-0.33 \%$ & $-0.33 \%$ & $-0.33 \%$ & $-0.33 \%$ & $0.33 \%$ & $-0.33 \%$ & $-0.33 \%$ & $0.33 \%$ & $-0.33 \%$ \\
\hline DAISY05 & $-0.15 \%$ & $0.15 \%$ & $0.15 \%$ & $0.15 \%$ & $-0.15 \%$ & $-0.15 \%$ & $-0.15 \%$ & $0.15 \%$ & $-0.15 \%$ \\
\hline DAISY 13 & $0.32 \%$ & $0.32 \%$ & $-0.32 \%$ & $-0.32 \%$ & $0.32 \%$ & $-0.32 \%$ & $-0.32 \%$ & $0.32 \%$ & $0.32 \%$ \\
\hline DAISY01 & $3.44 \%$ & $-3.44 \%$ & $3.44 \%$ & $-3.44 \%$ & $3.44 \%$ & $-3.44 \%$ & $3.44 \%$ & $-3.44 \%$ & $-3.44 \%$ \\
\hline DAISY09 & $-0.61 \%$ & $-0.61 \%$ & $-0.61 \%$ & $0.61 \%$ & $-0.61 \%$ & $-0.61 \%$ & $0.61 \%$ & $-0.61 \%$ & $0.61 \%$ \\
\hline DAISY07 & $1.83 \%$ & $-1.83 \%$ & $-1.83 \%$ & $1.83 \%$ & $1.83 \%$ & $1.83 \%$ & $-1.83 \%$ & $-1.83 \%$ & $-1.83 \%$ \\
\hline DAISY15 & $2.55 \%$ & $2.55 \%$ & $-2.55 \%$ & $2.55 \%$ & $2.55 \%$ & $-2.55 \%$ & $2.55 \%$ & $2.55 \%$ & $-2.55 \%$ \\
\hline DAISY03 & $0.72 \%$ & $-0.72 \%$ & $0.72 \%$ & $0.72 \%$ & $0.72 \%$ & $-0.72 \%$ & $-0.72 \%$ & $-0.72 \%$ & $0.72 \%$ \\
\hline \multirow[t]{3}{*}{ DAISY11 } & $2.86 \%$ & $2.86 \%$ & $2.86 \%$ & $2.86 \%$ & $2.86 \%$ & $2.86 \%$ & $2.86 \%$ & $2.86 \%$ & $2.86 \%$ \\
\hline & trast & $-53.68 \%$ & $0.44 \%$ & $11.13 \%$ & $-35.04 \%$ & $8.11 \%$ & $11.00 \%$ & $52.23 \%$ & $1.72 \%$ \\
\hline & Effect & $-6.71 \%$ & $0.05 \%$ & $139 \%$ & $-4.38 \%$ & $101 \%$ & $137 \%$ & $6.53 \%$ & 146 \\
\hline
\end{tabular}

\begin{tabular}{|l|r|r|r|r|r|r|r|r|}
\hline & & \multicolumn{1}{|l|}{24} & \multicolumn{1}{l}{123} & \multicolumn{1}{l|}{124} & 134 & 234 & 1234 \\
\hline DAISY06 & $19.56 \%$ & $19.56 \%$ & $19.56 \%$ & $-19.56 \%$ & $-19.56 \%$ & $-19.56 \%$ & $-19.56 \%$ & $19.56 \%$ \\
\hline DAISY14 & $-5.45 \%$ & $-5.45 \%$ & $-5.45 \%$ & $-5.45 \%$ & $-5.45 \%$ & $-5.45 \%$ & $5.45 \%$ & $5.45 \%$ \\
\hline DAISY02 & $4.77 \%$ & $-4.77 \%$ & $4.77 \%$ & $4.77 \%$ & $4.77 \%$ & $-4.77 \%$ & $4.77 \%$ & $-4.77 \%$ \\
\hline DAISY10 & $1.03 \%$ & $-1.03 \%$ & $1.03 \%$ & $-1.03 \%$ & $-1.03 \%$ & $1.03 \%$ & $1.03 \%$ & $1.03 \%$ \\
\hline DAISY08 & $8.33 \%$ & $8.33 \%$ & $-8.33 \%$ & $8.33 \%$ & $-8.33 \%$ & $8.33 \%$ & $8.33 \%$ & $-8.33 \%$ \\
\hline DAISY16 & $1.27 \%$ & $1.27 \%$ & $-1.27 \%$ & $-1.27 \%$ & $1.27 \%$ & $-1.27 \%$ & $1.27 \%$ & $1.27 \%$ \\
\hline DAISY04 & $16.81 \%$ & $-16.81 \%$ & $-16.81 \%$ & $-16.81 \%$ & $16.81 \%$ & $16.81 \%$ & $-16.81 \%$ & $16.81 \%$ \\
\hline DAISY12 & $-0.33 \%$ & $0.33 \%$ & $0.33 \%$ & $-0.33 \%$ & $0.33 \%$ & $0.33 \%$ & $0.33 \%$ & $0.33 \%$ \\
\hline DAISY05 & $-0.15 \%$ & $0.15 \%$ & $0.15 \%$ & $0.15 \%$ & $-0.15 \%$ & $-0.15 \%$ & $-0.15 \%$ & $0.15 \%$ \\
\hline DAISY13 & $0.32 \%$ & $-0.32 \%$ & $-0.32 \%$ & $0.32 \%$ & $-0.32 \%$ & $-0.32 \%$ & $0.32 \%$ & $0.32 \%$ \\
\hline DAISY01 & $3.44 \%$ & $3.44 \%$ & $-3.44 \%$ & $3.44 \%$ & $-3.44 \%$ & $3.44 \%$ & $-3.44 \%$ & $3.44 \%$ \\
\hline DAISY09 & $-0.61 \%$ & $-0.61 \%$ & $0.61 \%$ & $0.61 \%$ & $-0.61 \%$ & $0.61 \%$ & $0.61 \%$ & $0.61 \%$ \\
\hline DAISY07 & $1.83 \%$ & $-1.83 \%$ & $1.83 \%$ & $1.83 \%$ & $1.83 \%$ & $-1.83 \%$ & $-1.83 \%$ & $1.83 \%$ \\
\hline DAISY15 & $2.55 \%$ & $-2.55 \%$ & $2.55 \%$ & $-2.55 \%$ & $-2.55 \%$ & $2.55 \%$ & $-2.55 \%$ & $-2.55 \%$ \\
\hline DAISY03 & $0.72 \%$ & $0.72 \%$ & $0.72 \%$ & $-0.72 \%$ & $-0.72 \%$ & $-0.72 \%$ & $0.72 \%$ & $-0.72 \%$ \\
\hline DAISY11 & $2.86 \%$ & $2.86 \%$ & $2.86 \%$ & $2.86 \%$ & $2.86 \%$ & $2.86 \%$ & $2.86 \%$ & $2.86 \%$ \\
\hline & Contrast & $3.29 \%$ & $-1.22 \%$ & $-25.42 \%$ & $-14.29 \%$ & $1.87 \%$ & $-18.66 \%$ & $37.30 \%$ \\
\hline & Effect & $0.41 \%$ & $-0.15 \%$ & $-3.18 \%$ & $-1.79 \%$ & $0.23 \%$ & $-2.33 \%$ & $4.66 \%$ \\
\hline
\end{tabular}


Table F-1-14: TCC $500^{\text {th }}$ cycle.

\begin{tabular}{|l|r|r|r|r|r|r|r|r|r|}
\hline & & 1 & 2 & 4 & 12 & 13 & 14 \\
\hline DAISY06 & $19.12 \%$ & $-19.12 \%$ & $-19.12 \%$ & $-19.12 \%$ & $-19.12 \%$ & $19.12 \%$ & $19.12 \%$ & $19.12 \%$ & $19.12 \%$ \\
\hline DAISY14 & $-5.17 \%$ & $-5.17 \%$ & $5.17 \%$ & $5.17 \%$ & $5.17 \%$ & $5.17 \%$ & $5.17 \%$ & $5.17 \%$ & $-5.17 \%$ \\
\hline DAISY02 & $4.77 \%$ & $-4.77 \%$ & $4.77 \%$ & $-4.77 \%$ & $-4.77 \%$ & $-4.77 \%$ & $4.77 \%$ & $4.77 \%$ & $-4.77 \%$ \\
\hline DAISY10 & $0.58 \%$ & $0.58 \%$ & $0.58 \%$ & $-0.58 \%$ & $-0.58 \%$ & $0.58 \%$ & $-0.58 \%$ & $-0.58 \%$ & $-0.58 \%$ \\
\hline DAISY08 & $8.55 \%$ & $-8.55 \%$ & $-8.55 \%$ & $8.55 \%$ & $-8.55 \%$ & $8.55 \%$ & $-8.55 \%$ & $8.55 \%$ & $-8.55 \%$ \\
\hline DAISY16 & $1.17 \%$ & $1.17 \%$ & $-1.17 \%$ & $1.17 \%$ & $-1.17 \%$ & $-1.17 \%$ & $1.17 \%$ & $-1.17 \%$ & $-1.17 \%$ \\
\hline DAISY04 & $17.03 \%$ & $-17.03 \%$ & $17.03 \%$ & $17.03 \%$ & $-17.03 \%$ & $-17.03 \%$ & $-17.03 \%$ & $17.03 \%$ & $17.03 \%$ \\
\hline DAISY12 & $0.00 \%$ & $0.00 \%$ & $0.00 \%$ & $0.00 \%$ & $0.00 \%$ & $0.00 \%$ & $0.00 \%$ & $0.00 \%$ & $0.00 \%$ \\
\hline DAISY05 & $-0.17 \%$ & $0.17 \%$ & $0.17 \%$ & $0.17 \%$ & $-0.17 \%$ & $-0.17 \%$ & $-0.17 \%$ & $0.17 \%$ & $-0.17 \%$ \\
\hline DAISY13 & $-0.01 \%$ & $-0.01 \%$ & $0.01 \%$ & $0.01 \%$ & $-0.01 \%$ & $0.01 \%$ & $0.01 \%$ & $-0.01 \%$ & $-0.01 \%$ \\
\hline DAISY01 & $2.38 \%$ & $-2.38 \%$ & $2.38 \%$ & $-2.38 \%$ & $2.38 \%$ & $-2.38 \%$ & $2.38 \%$ & $-2.38 \%$ & $-2.38 \%$ \\
\hline DAISY09 & $-1.43 \%$ & $-1.43 \%$ & $-1.43 \%$ & $1.43 \%$ & $-1.43 \%$ & $-1.43 \%$ & $1.43 \%$ & $-1.43 \%$ & $1.43 \%$ \\
\hline DAISY07 & $1.87 \%$ & $-1.87 \%$ & $-1.87 \%$ & $1.87 \%$ & $1.87 \%$ & $1.87 \%$ & $-1.87 \%$ & $-1.87 \%$ & $-1.87 \%$ \\
\hline DAISY15 & $2.91 \%$ & $2.91 \%$ & $-2.91 \%$ & $2.91 \%$ & $2.91 \%$ & $-2.91 \%$ & $2.91 \%$ & $2.91 \%$ & $-2.91 \%$ \\
\hline DAISY03 & $-0.22 \%$ & $0.22 \%$ & $-0.22 \%$ & $-0.22 \%$ & $-0.22 \%$ & $0.22 \%$ & $0.22 \%$ & $0.22 \%$ & $-0.22 \%$ \\
\hline DAISY11 & $2.40 \%$ & $2.40 \%$ & $2.40 \%$ & $2.40 \%$ & $2.40 \%$ & $2.40 \%$ & $2.40 \%$ & $2.40 \%$ & $2.40 \%$ \\
\hline & Contrast & $-52.88 \%$ & $-2.76 \%$ & $13.63 \%$ & $-38.33 \%$ & $8.05 \%$ & $11.37 \%$ & $52.89 \%$ & $12.19 \%$ \\
\hline & Effect & $-6.61 \%$ & $-0.35 \%$ & $1.70 \%$ & $-4.79 \%$ & $1.01 \%$ & $1.42 \%$ & $6.61 \%$ & $1.52 \%$ \\
\hline
\end{tabular}

\begin{tabular}{|l|r|r|r|r|r|r|r|r|}
\hline & \multicolumn{1}{|l|}{24} & \multicolumn{1}{l|}{\begin{tabular}{l}
12 \\
\hline
\end{tabular}} & \multicolumn{1}{l|}{123} & 124 & 134 & 234 & 1234 \\
\hline DAISY06 & $19.12 \%$ & $19.12 \%$ & $19.12 \%$ & $-19.12 \%$ & $-19.12 \%$ & $-19.12 \%$ & $-19.12 \%$ & $19.12 \%$ \\
\hline DAISY14 & $-5.17 \%$ & $-5.17 \%$ & $-5.17 \%$ & $-5.17 \%$ & $-5.17 \%$ & $-5.17 \%$ & $5.17 \%$ & $5.17 \%$ \\
\hline DAISY02 & $4.77 \%$ & $-4.77 \%$ & $4.77 \%$ & $4.77 \%$ & $4.77 \%$ & $-4.77 \%$ & $4.77 \%$ & $-4.77 \%$ \\
\hline DAISY10 & $0.58 \%$ & $-0.58 \%$ & $0.58 \%$ & $-0.58 \%$ & $-0.58 \%$ & $0.58 \%$ & $0.58 \%$ & $0.58 \%$ \\
\hline DAISY08 & $8.55 \%$ & $8.55 \%$ & $-8.55 \%$ & $8.55 \%$ & $-8.55 \%$ & $8.55 \%$ & $8.55 \%$ & $-8.55 \%$ \\
\hline DAISY16 & $1.17 \%$ & $1.17 \%$ & $-1.17 \%$ & $-1.17 \%$ & $1.17 \%$ & $-1.17 \%$ & $1.17 \%$ & $1.17 \%$ \\
\hline DAISY04 & $17.03 \%$ & $-17.03 \%$ & $-17.03 \%$ & $-17.03 \%$ & $17.03 \%$ & $17.03 \%$ & $-17.03 \%$ & $17.03 \%$ \\
\hline DAISY12 & $0.00 \%$ & $0.00 \%$ & $0.00 \%$ & $0.00 \%$ & $0.00 \%$ & $0.00 \%$ & $0.00 \%$ & $0.00 \%$ \\
\hline DAISY05 & $-0.17 \%$ & $0.17 \%$ & $0.17 \%$ & $0.17 \%$ & $-0.17 \%$ & $-0.17 \%$ & $-0.17 \%$ & $0.17 \%$ \\
\hline DAISY13 & $-0.01 \%$ & $0.01 \%$ & $0.01 \%$ & $-0.01 \%$ & $0.01 \%$ & $0.01 \%$ & $-0.01 \%$ & $-0.01 \%$ \\
\hline DAISY01 & $2.38 \%$ & $2.38 \%$ & $-2.38 \%$ & $2.38 \%$ & $-2.38 \%$ & $2.38 \%$ & $-2.38 \%$ & $2.38 \%$ \\
\hline DAISY09 & $-1.43 \%$ & $-1.43 \%$ & $1.43 \%$ & $1.43 \%$ & $-1.43 \%$ & $1.43 \%$ & $1.43 \%$ & $1.43 \%$ \\
\hline DAISY07 & $1.87 \%$ & $-1.87 \%$ & $1.87 \%$ & $1.87 \%$ & $1.87 \%$ & $-1.87 \%$ & $-1.87 \%$ & $1.87 \%$ \\
\hline DAISY15 & $2.91 \%$ & $-2.91 \%$ & $2.91 \%$ & $-2.91 \%$ & $-2.91 \%$ & $2.91 \%$ & $-2.91 \%$ & $-2.91 \%$ \\
\hline DAISY03 & $-0.22 \%$ & $-0.22 \%$ & $-0.22 \%$ & $0.22 \%$ & $0.22 \%$ & $0.22 \%$ & $-0.22 \%$ & $0.22 \%$ \\
\hline DAISY11 & $2.40 \%$ & $2.40 \%$ & $2.40 \%$ & $2.40 \%$ & $2.40 \%$ & $2.40 \%$ & $2.40 \%$ & $2.40 \%$ \\
\hline & Contrast & $-0.19 \%$ & $-1.28 \%$ & $-24.20 \%$ & $-12.86 \%$ & $3.27 \%$ & $-19.63 \%$ & $35.31 \%$ \\
\hline & Effect & $-0.02 \%$ & $-0.16 \%$ & $-3.02 \%$ & $-1.61 \%$ & $0.41 \%$ & $-2.45 \%$ & $4.41 \%$ \\
\hline
\end{tabular}




\section{APPENDIX F-2}

\section{Detailed Effect and Sum of Square (SS) at the Measured Temperature Cycles}

Table F-2-1: TCB $1200^{\text {th }}$ cycle.

\begin{tabular}{|l|r|r|r|r|r|r|r|r|r|}
\hline & & 1 & 2 & 3 & 4 & 12 & 13 & 14 & 23 \\
\hline DAISY06 & 2.32423 & -2.32423 & -2.32423 & -2.32423 & -2.32423 & 2.32423 & 2.32423 & 2.32423 & 2.32423 \\
\hline DAISY14 & -0.05316 & -0.05316 & 0.05316 & 0.05316 & 0.05316 & 0.05316 & 0.05316 & 0.05316 & -0.05316 \\
\hline DAISY02 & 1.53590 & -1.53590 & 1.53590 & -1.53590 & -1.53590 & -1.53590 & 1.53590 & 1.53590 & -1.53590 \\
\hline DAISY10 & 0.20983 & 0.20983 & 0.20983 & -0.20983 & -0.20983 & 0.20983 & -0.20983 & -0.20983 & -0.20983 \\
\hline DAISY08 & 0.22838 & -0.22838 & -0.22838 & 0.22838 & -0.22838 & 0.22838 & -0.22838 & 0.22838 & -0.22838 \\
\hline DAISY16 & 0.13486 & 0.13486 & -0.13486 & 0.13486 & -0.13486 & -0.13486 & 0.13486 & -0.13486 & -0.13486 \\
\hline DAISY04 & -0.15006 & 0.15006 & -0.15006 & -0.15006 & 0.15006 & 0.15006 & 0.15006 & -0.15006 & -0.15006 \\
\hline DAISY12 & -0.60876 & -0.60876 & -0.60876 & -0.60876 & 0.60876 & -0.60876 & -0.60876 & 0.60876 & -0.60876 \\
\hline DAISY05 & -0.24382 & 0.24382 & 0.24382 & 0.24382 & -0.24382 & -0.24382 & -0.24382 & 0.24382 & -0.24382 \\
\hline DAISY13 & -0.05009 & -0.05009 & 0.05009 & 0.05009 & -0.05009 & 0.05009 & 0.05009 & -0.05009 & -0.05009 \\
\hline DAISY01 & 1.04682 & -1.04682 & 1.04682 & -1.04682 & 1.04682 & -1.04682 & 1.04682 & -1.04682 & -1.04682 \\
\hline DAISY09 & 0.69956 & 0.69956 & 0.69956 & -0.69956 & 0.69956 & 0.69956 & -0.69956 & 0.69956 & -0.69956 \\
\hline DAISY07 & 0.77479 & -0.77479 & -0.77479 & 0.77479 & 0.77479 & 0.77479 & -0.77479 & -0.77479 & -0.77479 \\
\hline DAISY15 & 0.20098 & 0.20098 & -0.20098 & 0.20098 & 0.20098 & -0.20098 & 0.20098 & 0.20098 & -0.20098 \\
\hline DAISY03 & 0.00125 & -0.00125 & 0.00125 & 0.00125 & 0.00125 & -0.00125 & -0.00125 & -0.00125 & 0.00125 \\
\hline DAISY11 & 0.34365 & 0.34365 & 0.34365 & 0.34365 & 0.34365 & 0.34365 & 0.34365 & 0.34365 & 0.34365 \\
\hline & Contrast & -4.64063 & -0.23796 & -4.54419 & -0.84811 & 1.06137 & 3.07337 & 3.87075 & -3.26789 \\
\hline & Effect & -0.01184 & -0.00061 & -0.01159 & -0.00216 & 0.00271 & 0.00784 & 0.00987 & -0.00834 \\
\hline & SS & 0.02747 & 0.00007 & 0.02634 & 0.00092 & 0.00144 & 0.01205 & 0.01911 & 0.01362 \\
\hline
\end{tabular}

\begin{tabular}{|l|r|r|r|r|r|r|r|r|}
\hline & & \multicolumn{1}{|l|}{24} & \multicolumn{1}{|c|}{123} & 124 & 134 & 234 & 1234 \\
\hline DAISY06 & 2.32423 & 2.32423 & 2.32423 & -2.32423 & -2.32423 & -2.32423 & -2.32423 & 2.32423 \\
\hline DAISY14 & -0.05316 & -0.05316 & -0.05316 & -0.05316 & -0.05316 & -0.05316 & 0.05316 & 0.05316 \\
\hline DAISY02 & 1.53590 & -1.53590 & 1.53590 & 1.53590 & 1.53590 & -1.53590 & 1.53590 & -1.53590 \\
\hline DAISY10 & 0.20983 & -0.20983 & 0.20983 & -0.20983 & -0.20983 & 0.20983 & 0.20983 & 0.20983 \\
\hline DAISY08 & 0.22838 & 0.22838 & -0.22838 & 0.22838 & -0.22838 & 0.22838 & 0.22838 & -0.22838 \\
\hline DAISY16 & 0.13486 & 0.13486 & -0.13486 & -0.13486 & 0.13486 & -0.13486 & 0.13486 & 0.13486 \\
\hline DAISY04 & -0.15006 & 0.15006 & 0.15006 & 0.15006 & -0.15006 & -0.15006 & 0.15006 & -0.15006 \\
\hline DAISY12 & -0.60876 & 0.60876 & 0.60876 & -0.60876 & 0.60876 & 0.60876 & 0.60876 & 0.60876 \\
\hline DAISY05 & -0.24382 & 0.24382 & 0.24382 & 0.24382 & -0.24382 & -0.24382 & -0.24382 & 0.24382 \\
\hline DAISY13 & -0.05009 & 0.05009 & 0.05009 & -0.05009 & 0.05009 & 0.05009 & -0.05009 & -0.05009 \\
\hline DAISY01 & 1.04682 & 1.04682 & -1.04682 & 1.04682 & -1.04682 & 1.04682 & -1.04682 & 1.04682 \\
\hline DAISY09 & 0.69956 & 0.69956 & -0.69956 & -0.69956 & 0.69956 & -0.69956 & -0.69956 & -0.69956 \\
\hline DAISY07 & 0.77479 & -0.77479 & 0.77479 & 0.77479 & 0.77479 & -0.77479 & -0.77479 & 0.77479 \\
\hline DAISY15 & 0.20098 & -0.20098 & 0.20098 & -0.20098 & -0.20098 & 0.20098 & -0.20098 & -0.20098 \\
\hline DAISY03 & 0.00125 & 0.00125 & 0.00125 & -0.00125 & -0.00125 & -0.00125 & 0.00125 & -0.00125 \\
\hline DAISY11 & 0.34365 & 0.34365 & 0.34365 & 0.34365 & 0.34365 & 0.34365 & 0.34365 & 0.34365 \\
\hline & Contrast & 3.05682 & 4.28057 & 0.04070 & -0.31091 & -3.22912 & -2.07444 & 2.87370 \\
\hline & Effect & 0.00780 & 0.01092 & 0.00010 & -0.00079 & -0.00824 & -0.00529 & 0.00733 \\
\hline & SS & 0.01192 & 0.02337 & 0.00000 & 0.00012 & 0.01330 & 0.00549 & 0.01053 \\
\hline
\end{tabular}


Table F-2-2: TCB $2012^{\text {th }}$ cycle.

\begin{tabular}{|l|r|r|r|r|r|r|r|r|r|}
\hline & & 1 & \multicolumn{1}{|l|}{2} & \multicolumn{1}{|c|}{3} & \multicolumn{1}{l|}{4} & 12 & 13 & 14 & 23 \\
\hline DAISY06 & 2.67933 & -2.67933 & -2.67933 & -2.67933 & -2.67933 & 2.67933 & 2.67933 & 2.67933 & 2.67933 \\
\hline DAISY14 & 0.01570 & 0.01570 & -0.01570 & -0.01570 & -0.01570 & -0.01570 & -0.01570 & -0.01570 & 0.01570 \\
\hline DAISY02 & 1.44270 & -1.44270 & 1.44270 & -1.44270 & -1.44270 & -1.44270 & 1.44270 & 1.44270 & -1.44270 \\
\hline DAISY10 & 0.70109 & 0.70109 & 0.70109 & -0.70109 & -0.70109 & 0.70109 & -0.70109 & -0.70109 & -0.70109 \\
\hline DAISY08 & 0.04150 & -0.04150 & -0.04150 & 0.04150 & -0.04150 & 0.04150 & -0.04150 & 0.04150 & -0.04150 \\
\hline DAISY16 & -0.09873 & -0.09873 & 0.09873 & -0.09873 & 0.09873 & 0.09873 & -0.09873 & 0.09873 & 0.09873 \\
\hline DAISY04 & -0.09807 & 0.09807 & -0.09807 & -0.09807 & 0.09807 & 0.09807 & 0.09807 & -0.09807 & -0.09807 \\
\hline DAISY12 & -0.90808 & -0.90808 & -0.90808 & -0.90808 & 0.90808 & -0.90808 & -0.90808 & 0.90808 & -0.90808 \\
\hline DAISY05 & 0.06234 & -0.06234 & -0.06234 & -0.06234 & 0.06234 & 0.06234 & 0.06234 & -0.06234 & 0.06234 \\
\hline DAISY13 & -0.31602 & -0.31602 & 0.31602 & 0.31602 & -0.31602 & 0.31602 & 0.31602 & -0.31602 & -0.31602 \\
\hline DAISY01 & 1.50364 & -1.50364 & 1.50364 & -1.50364 & 1.50364 & -1.50364 & 1.50364 & -1.50364 & -1.50364 \\
\hline DAISY09 & 0.52486 & 0.52486 & 0.52486 & -0.52486 & 0.52486 & 0.52486 & -0.52486 & 0.52486 & -0.52486 \\
\hline DAISY07 & 0.73262 & -0.73262 & -0.73262 & 0.73262 & 0.73262 & 0.73262 & -0.73262 & -0.73262 & -0.73262 \\
\hline DAISY15 & 0.17750 & 0.17750 & -0.17750 & 0.17750 & 0.17750 & -0.17750 & 0.17750 & 0.17750 & -0.17750 \\
\hline DAISY03 & 0.13939 & -0.13939 & 0.13939 & 0.13939 & 0.13939 & -0.13939 & -0.13939 & -0.13939 & 0.13939 \\
\hline DAISY11 & 0.57562 & 0.57562 & 0.57562 & 0.57562 & 0.57562 & 0.57562 & 0.57562 & 0.57562 & 0.57562 \\
\hline & Contrast & -5.83151 & 0.58690 & -6.05188 & -0.37549 & 1.64318 & 3.69325 & 2.87946 & -2.87495 \\
\hline & Effect & -0.01488 & 0.00150 & -0.01544 & -0.00096 & 0.00419 & 0.00942 & 0.00735 & -0.00733 \\
\hline & $S S$ & 0.04338 & 0.00044 & 0.04672 & 0.00018 & 0.00344 & 0.01740 & 0.01058 & 0.01054 \\
\hline
\end{tabular}

\begin{tabular}{|c|c|c|c|c|c|c|c|c|}
\hline & & 24 & 34 & 123 & 124 & 134 & 234 & 1234 \\
\hline DAISY06 & 2.67933 & 2.67933 & 2.67933 & -2.67933 & -2.67933 & -2.67933 & -2.67933 & 2.67933 \\
\hline DAISY14 & 0.01570 & 0.01570 & 0.01570 & 0.01570 & 0.01570 & 0.01570 & -0.01570 & -0.01570 \\
\hline DAISY02 & 1.44270 & -1.44270 & 1.44270 & 1.44270 & 1.44270 & -1.44270 & 1.44270 & -1.44270 \\
\hline DAISY10 & 0.70109 & -0.70109 & 0.70109 & -0.70109 & -0.70109 & 0.70109 & 0.70109 & 0.70109 \\
\hline DAISY08 & 0.04150 & 0.04150 & -0.04150 & 0.04150 & -0.04150 & 0.04150 & 0.04150 & -0.04150 \\
\hline DAls & -0.09 & -0.09873 & 0. & 73 & 73 & & 73 & 73 \\
\hline DAISY04 & -0.09807 & 0.09807 & 0.0 & 07 & 807 & 07 & 007 & 307 \\
\hline$\overline{\text { DAISY12 }}$ & -0.90808 & 0.90808 & 0.90808 & -0.90808 & 0.90808 & 0.90808 & 0.90808 & 0.90808 \\
\hline DAISY05 & 0.06234 & -0.06234 & -0.06234 & -0.06234 & 0.06234 & 0.06234 & 0.06234 & -0.06234 \\
\hline DAIS & -0.31602 & 0.31602 & 0.31602 & -0.3 & & 602 & 02 & $\overline{602}$ \\
\hline DAls & 1.50 & 1.50 & -1.5 & & & & & \\
\hline DAIS & 0.52486 & 0.52486 & -0.52486 & -0.52486 & 0.52486 & -0.52486 & -0.52486 & -0.52486 \\
\hline DAISY07 & 0.73262 & -0.73262 & 0.73262 & 0.73262 & 0.73262 & -0.73262 & -0.73262 & 0.73262 \\
\hline DAISY15 & 0.17750 & -0.17750 & 0.17750 & -0.17750 & -0.17750 & 0.17750 & -0.17750 & -0.17750 \\
\hline DAISY03 & 0.13939 & 0.13939 & 0.13939 & -0.13939 & -0.13939 & -0.13939 & 0.13939 & -0.13939 \\
\hline$\overline{D A I S Y 11}$ & 0.57562 & 0.57562 & 0.57562 & 0.57562 & 0.57562 & 0.57562 & 0.57562 & 0.57562 \\
\hline & Oontrast & 3.58723 & 5.75251 & -1.00004 & -0.8 & -1.2 & & 356 \\
\hline & Effect & 0.00915 & 0.01467 & -0.0 & -0.0 & -0 . & & 0.01067 \\
\hline & SS & 0.01641 & 0.04221 & 0.00128 & 0.00095 & $\overline{0.0}$ & 0.00552 & 0.02232 \\
\hline
\end{tabular}


Table F-2-3: TCC $300^{\text {th }}$ cycle.

\begin{tabular}{|c|c|c|c|c|c|c|c|c|c|}
\hline & & 1 & 2 & 3 & 4 & 12 & 13 & 14 & 23 \\
\hline DAISY06 & 24038 & .24038 & 4038 & 4038 & 4038 & 4 & 38 & 4 & \\
\hline AISY14 & 4130 & 41309 & $\overline{9}$ & .41309 & 1309 & -1.41309 & 1309 & -1.41309 & 4130 \\
\hline$\overline{\mathrm{A} 1 \mathrm{SY} 02}$ & 83659 & 83659 & 3659 & 1.83659 & -1.83659 & & & 3659 & -1.83659 \\
\hline & & & & & & & & 47 & $\overline{04}$ \\
\hline & & & & & & & & & $=$ \\
\hline AISY16 & 965 & 965 & -0 . & 0.3 & 965 & -0 . & 965 & -0.3 & -0.3696 \\
\hline$\overline{44}$ & & & & & & & & & \\
\hline $\bar{A}$ & & & & & & & & & - \\
\hline DAISY05 & 52 & -0.3 & -0 . & -0.3 & 352 & & 352 & 352 & 0.3035 \\
\hline$\overline{A I}$ & & & & & & & & & 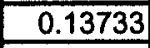 \\
\hline$\overline{\mathrm{DAl}}$ & 37 & -3.2 & & -3 & & & 87 & -3.2 & -3.27287 \\
\hline$\overline{D A I S}$ & 87 & & & -1 & & & & & -1.3268 \\
\hline $\mathrm{Al}$ & 1.7 & -1.7 & -1 & & & & -1 . & -1 . & -1.7604 \\
\hline DAl & 1.0 & 1.0 & & & & & & & -1.0156 \\
\hline$\overline{D A I S}$ & 0.78299 & -0.7 & & & & -0 . & & -0 . & 0.78 \\
\hline DA & 0.60413 & & & & & & & & 0.60413 \\
\hline & ontrast & & & -8.2 & & & & & \\
\hline & Effect & -0.0 & -0. & -0.0 & -0.0 & -0 . & 722 & 381 & -0.01088 \\
\hline & & 0.09747 & 0.00327 & 0.08675 & 0.00019 & 0.00001 & 0.01021 & 0.00909 & 0.0 \\
\hline
\end{tabular}

\begin{tabular}{|l|r|r|r|r|r|r|r|r|}
\hline & & \multicolumn{1}{|c|}{24} & 34 & 123 & 124 & 134 & \multicolumn{1}{l|}{234} & 1234 \\
\hline DAISY06 & 4.24038 & 4.24038 & 4.24038 & -4.24038 & -4.24038 & -4.24038 & -4.24038 & 4.24038 \\
\hline DAISY14 & 1.41309 & 1.41309 & 1.41309 & 1.41309 & 1.41309 & 1.41309 & -1.41309 & -1.41309 \\
\hline DAISY02 & 1.83659 & -1.83659 & 1.83659 & 1.83659 & 1.83659 & -1.83659 & 1.83659 & -1.83659 \\
\hline DAISY10 & 0.99047 & -0.99047 & 0.99047 & -0.99047 & -0.99047 & 0.99047 & 0.99047 & 0.99047 \\
\hline DAISY08 & 0.95776 & 0.95776 & -0.95776 & 0.95776 & -0.95776 & 0.95776 & 0.95776 & -0.95776 \\
\hline DAISY16 & 0.36965 & 0.36965 & -0.36965 & -0.36965 & 0.36965 & -0.36965 & 0.36965 & 0.36965 \\
\hline DAISY04 & 0.61393 & -0.61393 & -0.61393 & -0.61393 & 0.61393 & 0.61393 & -0.61393 & 0.61393 \\
\hline DAISY12 & -0.83026 & 0.83026 & 0.83026 & -0.83026 & 0.83026 & 0.83026 & 0.83026 & 0.83026 \\
\hline DAISY05 & 0.30352 & -0.30352 & -0.30352 & -0.30352 & 0.30352 & 0.30352 & 0.30352 & -0.30352 \\
\hline DAISY13 & 0.13733 & -0.13733 & -0.13733 & 0.13733 & -0.13733 & -0.13733 & 0.13733 & 0.13733 \\
\hline DAISY01 & 3.27287 & 3.27287 & -3.27287 & 3.27287 & -3.27287 & 3.27287 & -3.27287 & 3.27287 \\
\hline DAISY09 & 1.32687 & 1.32687 & -1.32687 & -1.32687 & 1.32687 & -1.32687 & -1.32687 & -1.32687 \\
\hline DAISY07 & 1.76043 & -1.76043 & 1.76043 & 1.76043 & 1.76043 & -1.76043 & -1.76043 & 1.76043 \\
\hline DAISY15 & 1.01568 & -1.01568 & 1.01568 & -1.01568 & -1.01568 & 1.01568 & -1.01568 & -1.01568 \\
\hline DAISY03 & 0.78299 & 0.78299 & 0.78299 & -0.78299 & -0.78299 & -0.78299 & 0.78299 & -0.78299 \\
\hline DAISY11 & 0.60413 & 0.60413 & 0.60413 & 0.60413 & 0.60413 & 0.60413 & 0.60413 & 0.60413 \\
\hline & Contrast & 7.14005 & 6.49209 & -0.49155 & -2.33901 & -0.45254 & -6.83056 & 5.18296 \\
\hline & Effect & 0.01821 & 0.01656 & -0.00125 & -0.00597 & -0.00115 & -0.01742 & 0.01322 \\
\hline & SS & 0.06503 & 0.05376 & 0.00031 & 0.00698 & 0.00026 & 0.05951 & 0.03426 \\
\hline
\end{tabular}


Table F-2-4: TCC 500 ${ }^{\text {th }}$ cycle.

\begin{tabular}{|c|c|c|c|c|c|c|c|c|c|}
\hline & & 1 & 2 & 3 & 4 & 12 & 13 & 14 & 23 \\
\hline$\overline{\text { AlSY06 }}$ & 9.36827 & 36827 & .36827 & -9.36827 & -9.36827 & 9.36827 & 9.36827 & 9.36827 & 9.36827 \\
\hline & 4 & $\overline{14}$ & & & & & & 53214 & \\
\hline 02 & 13 & -2.3 & & -2.33613 & 613 & -2.33613 & & 2.33613 & -2.33613 \\
\hline$\overline{0}$ & 28652 & 0.28652 & 0.28652 & & -0.28652 & 0.28652 & -0.28652 & -0.28652 & -0.28652 \\
\hline & & & & & & & & & \\
\hline & & & & & -0.57284 & & & -0.57284 & 284 \\
\hline & & & & & & & & & \\
\hline & & & & & & & & 0.00096 & 096 \\
\hline |DA| & 16 & 10 & & 8116 & -0.08116 & & -0.08116 & 0.08116 & -0.08116 \\
\hline$\overline{D A I S Y}$ & -0.00249 & -0.00249 & 0.00249 & 0.00249 & -0.00249 & & & -0.00249 & -0.00249 \\
\hline & & & & & & & & & 859 \\
\hline DAls & .70237 & -0.7 & .70237 & 0.7 & -0.70237 & -0.70237 & 0.70237 & -0.70237 & 0237 \\
\hline$\overline{D A I S}$ & 0.91420 & -0.91420 & -0.91420 & 0.91420 & 0.91420 & 0.91420 & -0.91420 & -0.91420 & -0.91420 \\
\hline & & & & & & & & & \\
\hline D/ & -0.1 & & & & & & & 841 & $\overline{841}$ \\
\hline \multirow[t]{4}{*}{ DAISY11 } & 1.17503 & 1. & & & & & & 1.17503 & \\
\hline & 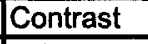 & & & & & & & & 446 \\
\hline & & & & & & & & & \\
\hline & & 0.856 & 0.00233 & 0.05686 & 0.44992 & 0.01985 & 0.03962 & 0.85673 & 0.0455 \\
\hline
\end{tabular}

\begin{tabular}{|c|c|c|c|c|c|c|c|c|}
\hline & & 24 & 34 & 123 & 124 & 134 & 234 & 1234 \\
\hline DAISY06 & 9.36827 & 9.368 & 9.36827 & -9.368 & -9.36827 & -9.36 & -9.36 & 9.36827 \\
\hline DAISY14 & -2.53214 & -2.53214 & -2.53214 & -2.53214 & -2.53214 & -2.53214 & 2.53214 & 2.53214 \\
\hline DAISY02 & 2.33613 & -2.33613 & 2.33613 & 2.33613 & 2.33613 & -2.33613 & 2.33613 & -2.33613 \\
\hline DAISY10 & 0.28652 & -0.28652 & 0.28652 & -0.28652 & -0.28652 & 0.28652 & 0.28652 & 0.28652 \\
\hline DAls & 4.19 & 4.11 & 36 & 4.1 & -4 . & $\overline{86}$ & $\overline{86}$ & -4.19086 \\
\hline 16 & 0.57 & 0.57284 & -0.57284 & -0.57284 & 0.57284 & -0.57284 & 0.57284 & 0.57284 \\
\hline DAISY04 & 8.34691 & -8.34 & -8.34691 & -8.34691 & 8.34691 & 91 & 91 & 8.34691 \\
\hline DAISY12 & 0.00096 & -0.00096 & -0.00096 & $\overline{096}$ & -0.00096 & $\overline{096}$ & -0.00096 & -0.00096 \\
\hline DAISY05 & -0.08116 & 0.08116 & 0.08116 & 0.08116 & -0.08116 & -0.08116 & -0.08116 & 0.08116 \\
\hline DAISY13 & -0.00249 & 0.00249 & 0.00249 & -0.00249 & 0.00249 & 0.00249 & -0.00249 & -0.00249 \\
\hline$\overline{\text { DAIS }}$ & 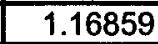 & 1.16 & -1.16 & & & & -1.16859 & 1.16859 \\
\hline & -0.70 & -0.7 & 0.7 & & -0.7 & & 237 & 0.70237 \\
\hline DA! & 0.91 & -0.9 & 0.9 & 0.9 & 0.9 & -0.5 & 420 & 0.91420 \\
\hline DAI: & 1.42574 & -1.42574 & 1.42574 & -1.42574 & -1.42574 & 1.42574 & -1.42574 & -1.42574 \\
\hline DAISY03 & -0.10841 & -0.10841 & -0.10841 & 0.10841 & 0.10841 & 0.10841 & -0.10841 & 0.10841 \\
\hline \multirow[t]{4}{*}{ DAISY11 } & 1.17503 & 1.17503 & 1.17503 & 1.17503 & 1.17503 & 1.17503 & 1.17503 & 1.17503 \\
\hline & Contrast & -0.0 & -0.6 & -11. & -6.3 & & -9.6 & 17.3 \\
\hline & Effect & -0.0 & -0.0 & -0.0 & -0.0 & & -0.02454 & 0.04413 \\
\hline & & 0.00001 & 0.00050 & 0.17933 & 0.05063 & 0.00327 & 0.11806 & 0.38176 \\
\hline
\end{tabular}




\section{APPENDIX G}

Cracked Via Cross-section Micrographs
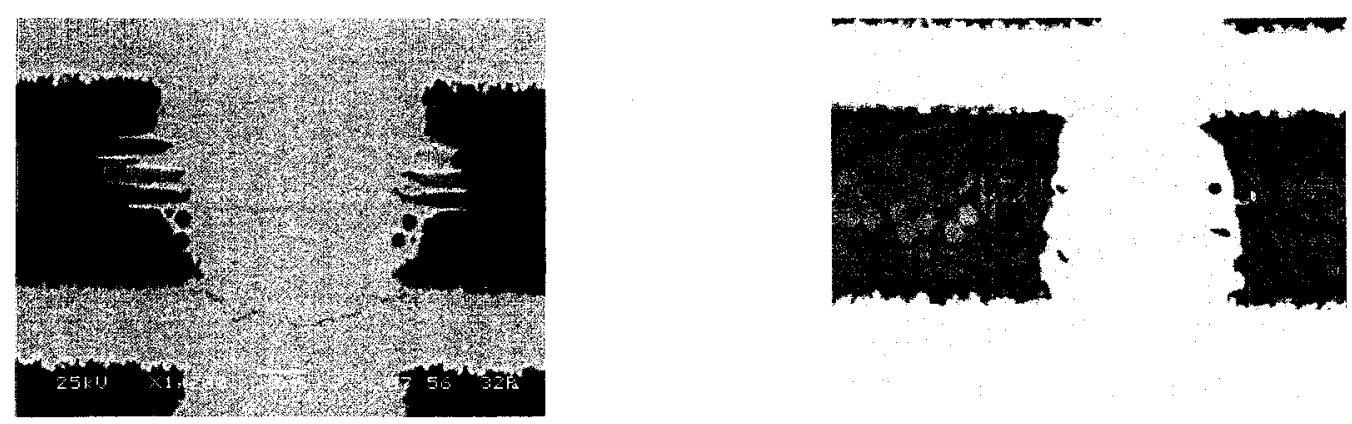

PKG\#36_DC\#06_Ball\#Y4_V2-3

PKG\#36_DC\#06_Ball\#Y4_V9-10
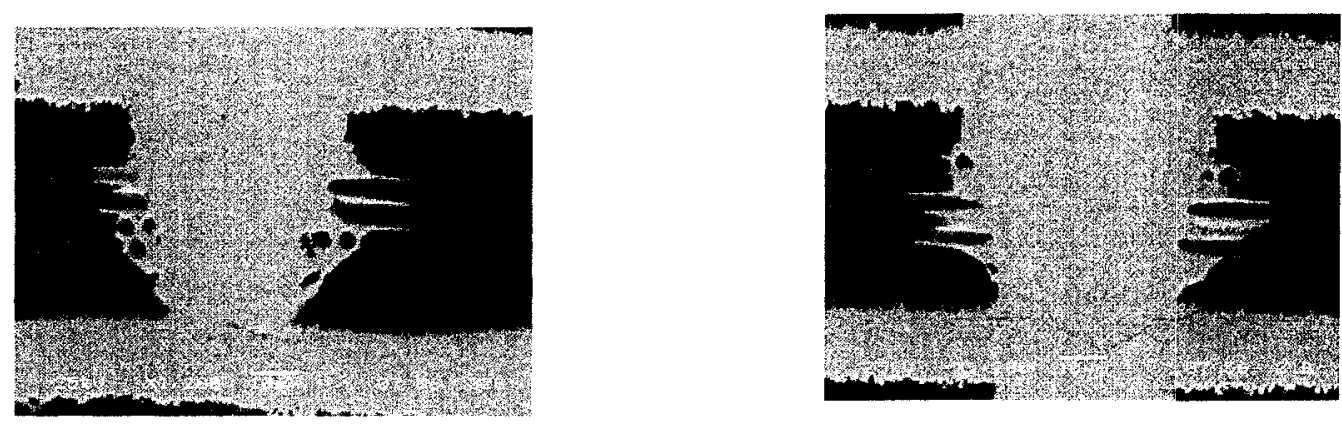

PKG\#36_DC\#06_Ball\#Y4_V4-5
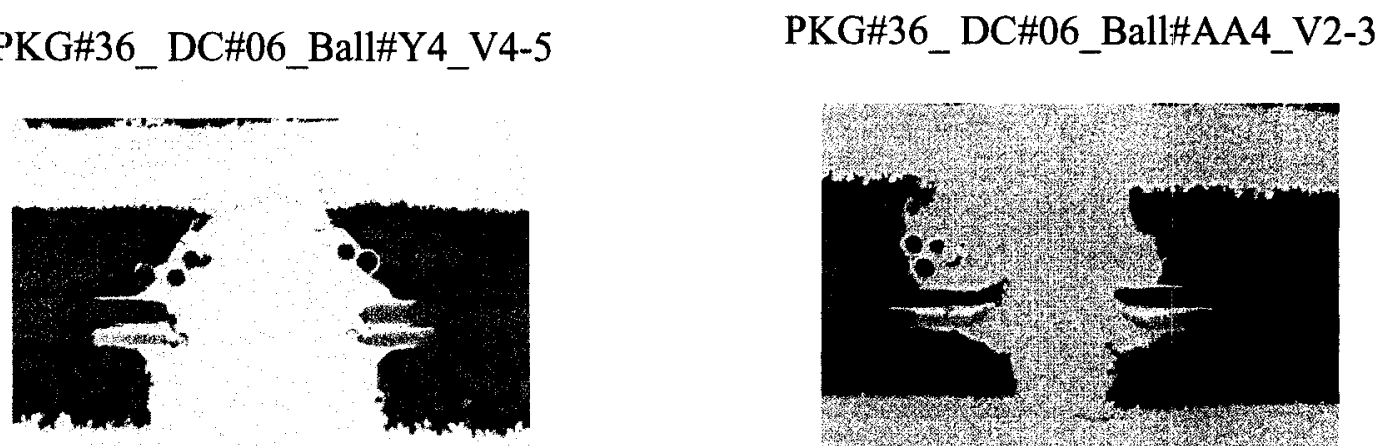

PKG\#36_DC\#06_Ball\#Y4_V6-7

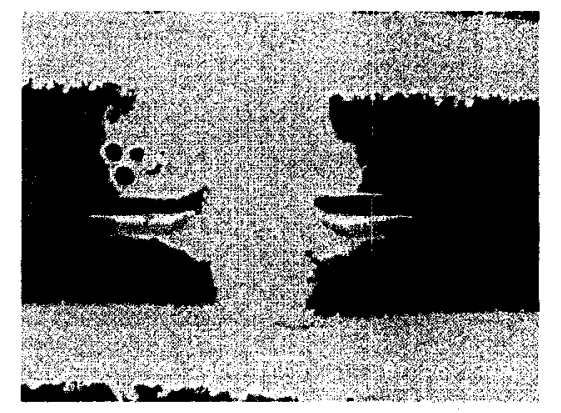

PKG\#36 DC\#06 Ball\#AA4 V4-5 

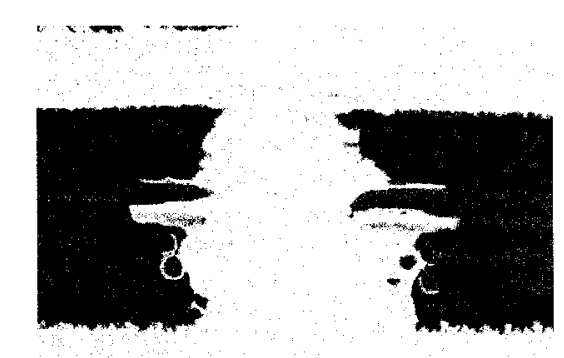

PKG\#36_DC\#06_Ball\#AA4_V6-7
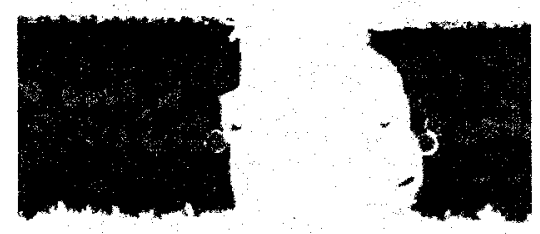

PKG\#36_DC\#06_Ball\#AA4_V9-10

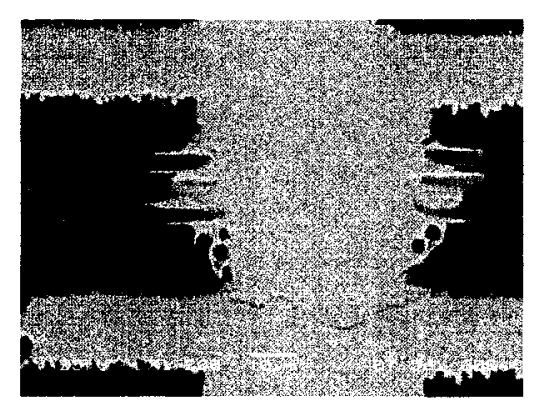

PKG\#36_DC\#06_Ball\#AB4_V2-3

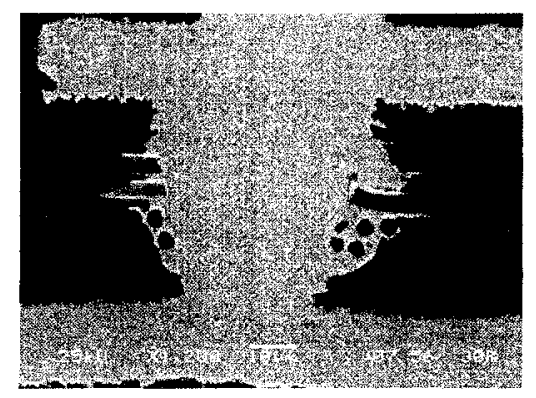

PKG\#36_DC\#06_Ball\#AB4_V4-5

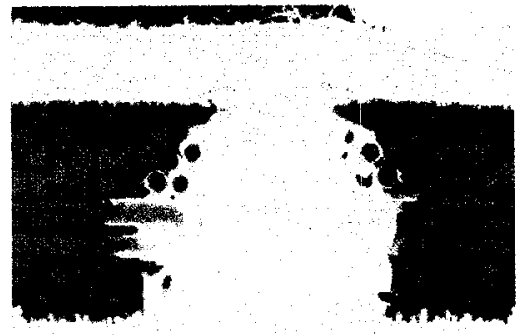

PKG\#36_DC\#06_Ball\#AB4_V6-7

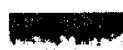

Hermentming
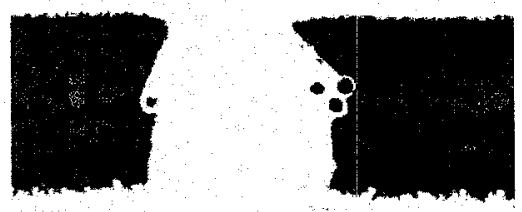

PKG\#36_DC\#06_Ball\#AB4_V7-8
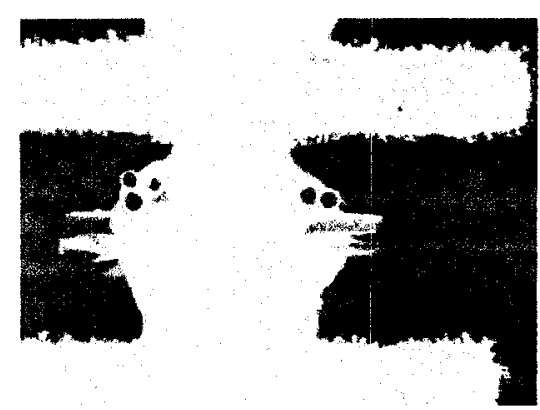

PKG\#36_DC\#06_Ball\#AB4_V8-9

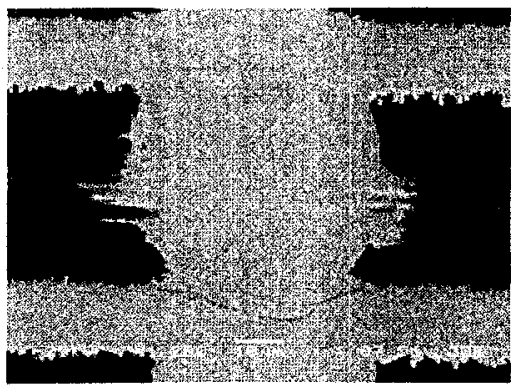

PKG\#36_DC\#06_Ball\#AC4_V2-3 


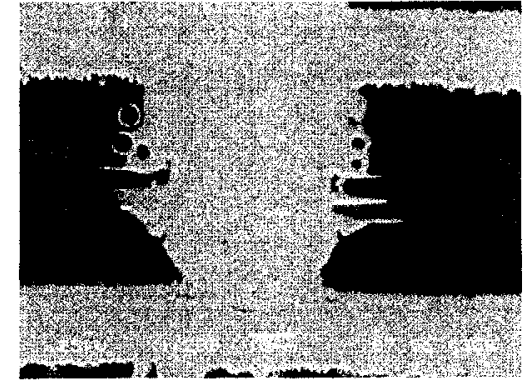

PKG\#36_DC\#06_Ball\#AC4_V4-5
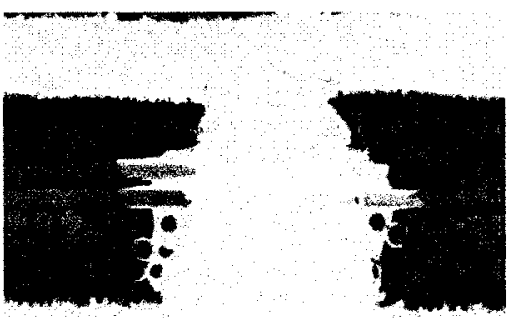

PKG\#36_DC\#06_Ball\#AC4_V6-7
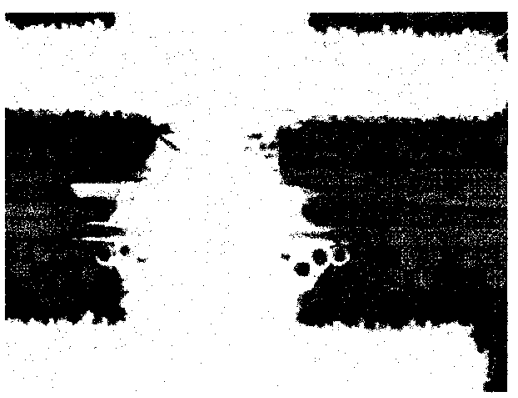

PKG\#36_DC\#06_Ball\#AC4_V8-9

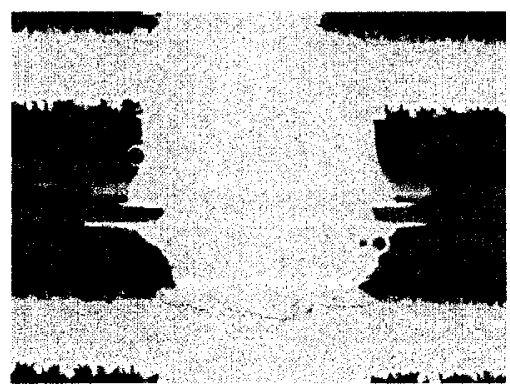

PKG\#36_DC\#06_Ball\#AD4_V2-3

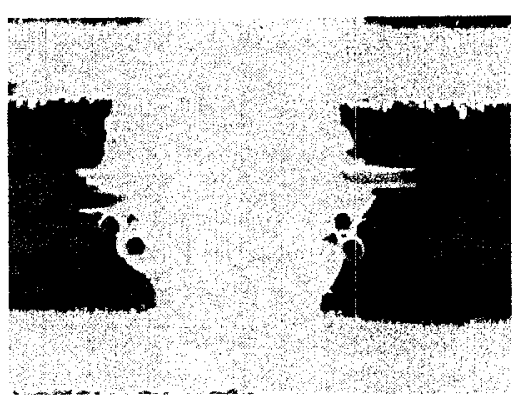

PKG\#36_DC\#06_Balli\#AD4_V4-5
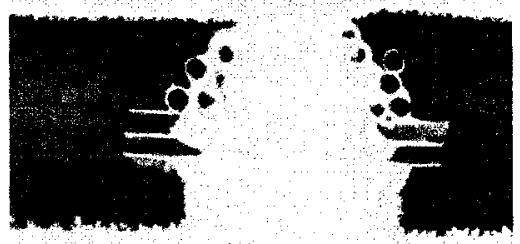

PKG\#36_DC\#06_Balli\#AD4_V6-7
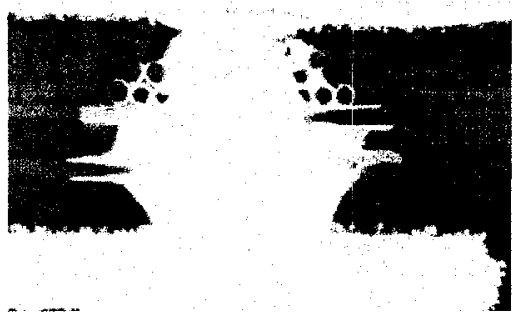

PKG\#36_DC\#06_Ball\#AD4_V8-9

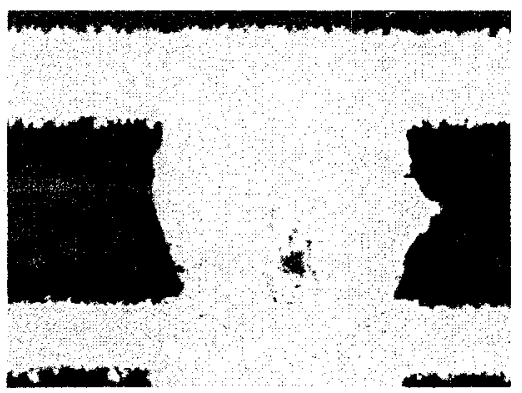

PKG\#43_DC\#06_BalliAAB9_V1-2 


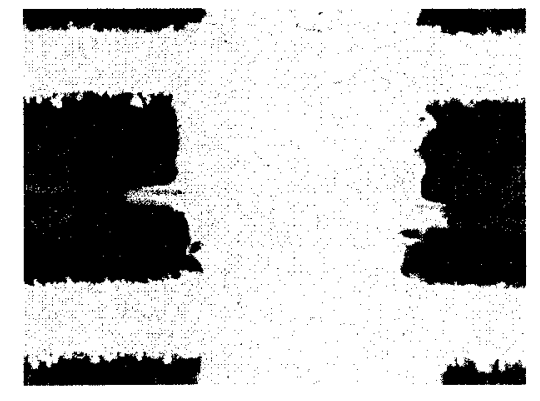

PKG\#43_DC\#06_Ball\#AB9_V2-3
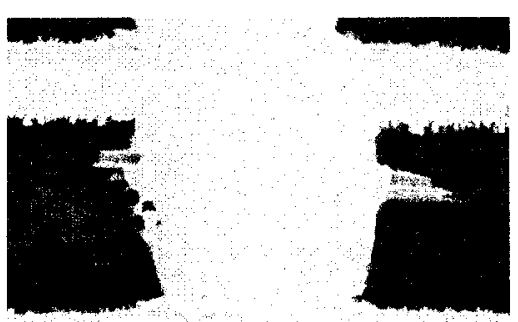

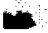

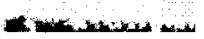

PKG\#43_DC\#06_Ball\#AB9_V3-4
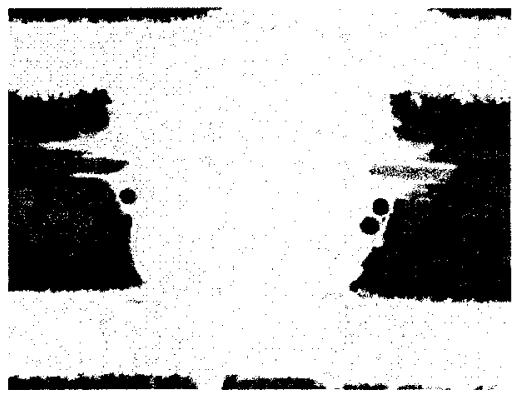

PKG\#43_DC\#06_Ball\#AB9_V4-5

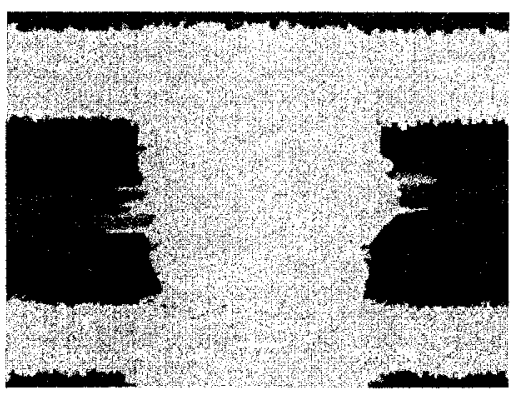

PKG\#43_DC\#06_Ball\#AB10_V1-2

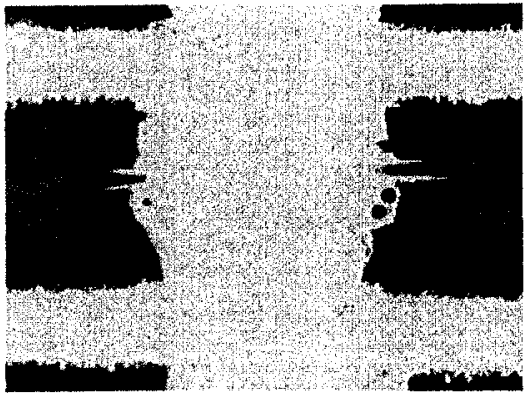

PKG\#43_DC\#06_Ball\#AB10_V2-3

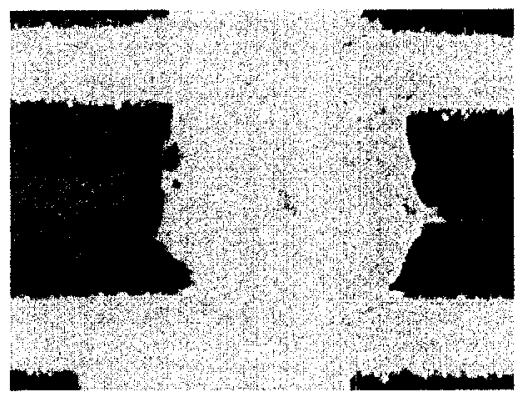

PKG\#43_DC\#06_Ball\#AB10_V3-4

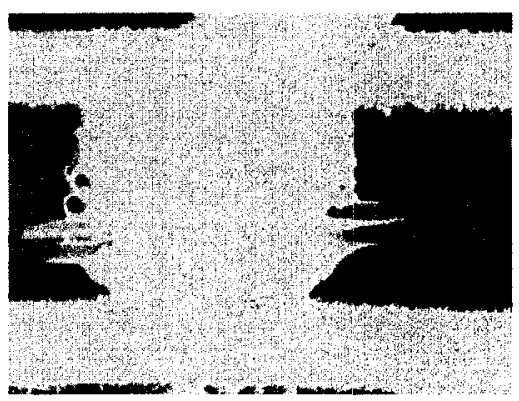

PKG\#43_DC\#06_Ball\#AB10_V4-5

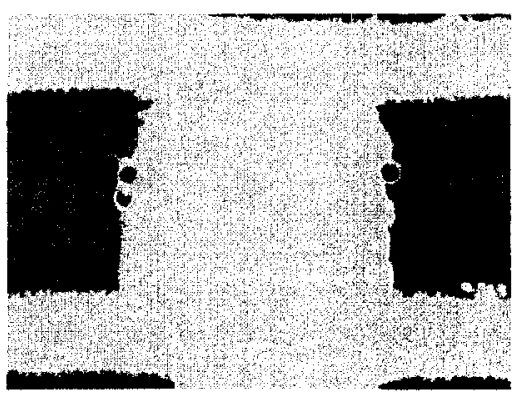

PKG\#43_DC\#06_Ball\#AB10_V6-7 


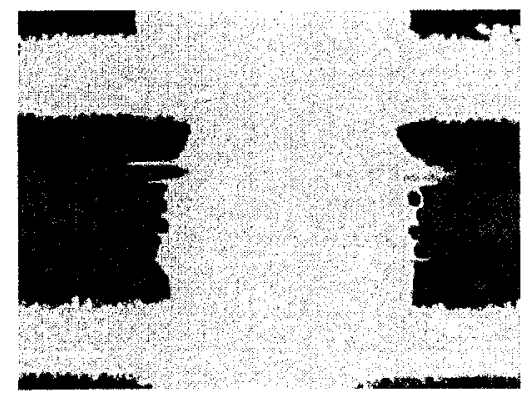

PKG\#43_DC\#06_Ball\#AB10_V7-8

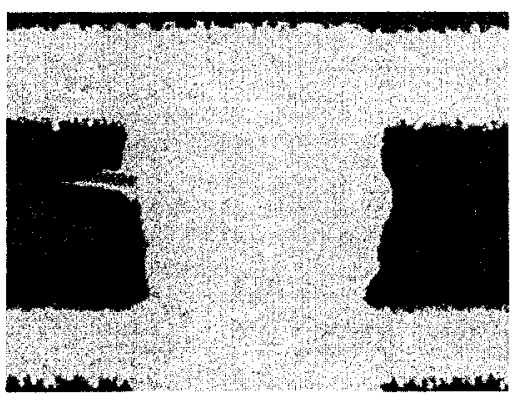

PKG\#43_DC\#06_Ball\#AB11_V1-2

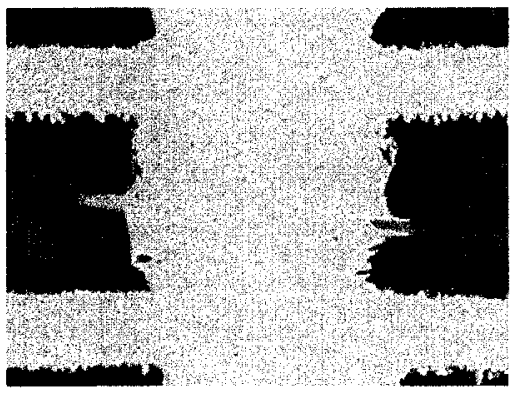

PKG\#43_DC\#06_Ball\#AB11_V2-3

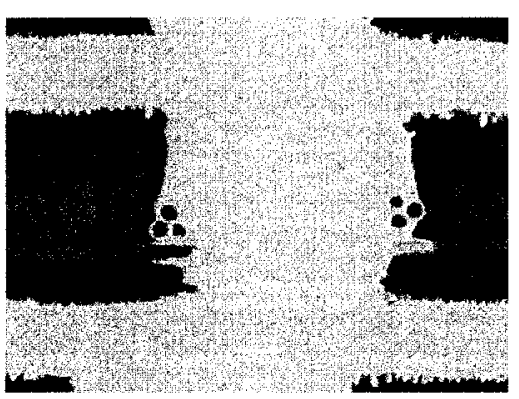

PKG\#43_DC\#06_Ball\#AB11_V3-4

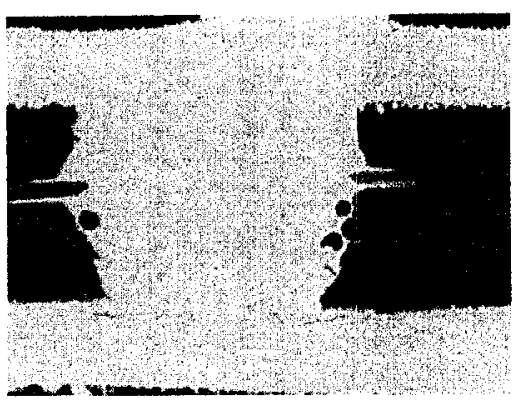

PKG\#43_DC\#06_Ball\#AB11_V4-5

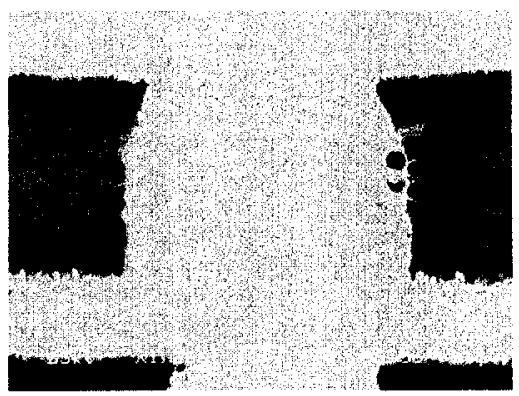

PKG\#43_DC\#06_Ball\#AB11_V6-7

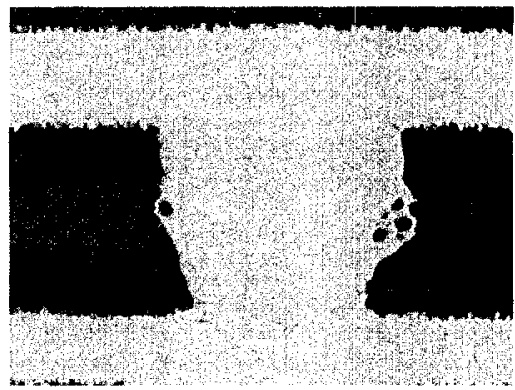

PKG\#43_DC\#06_Ball\#AB12_V1-2

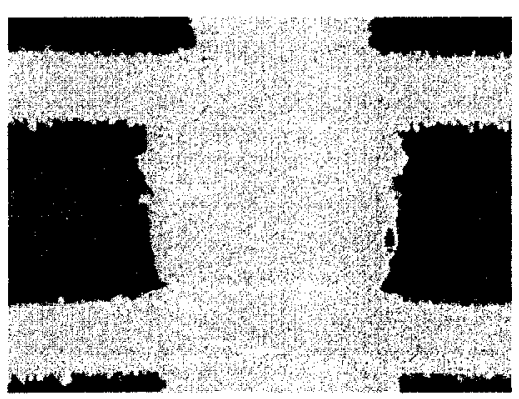

PKG\#43_DC\#06_Ball\#AB12_V2-3 


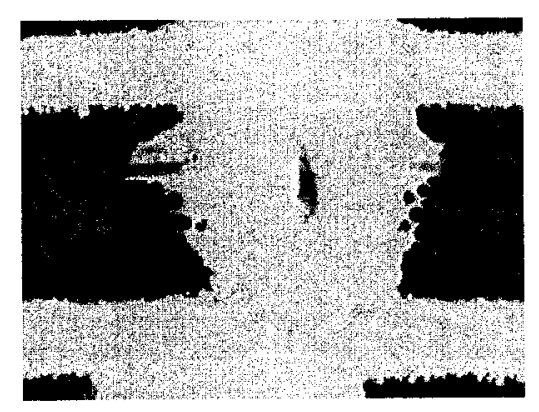

PKG\#43_DC\#06_Ball\#AB12_V3-4

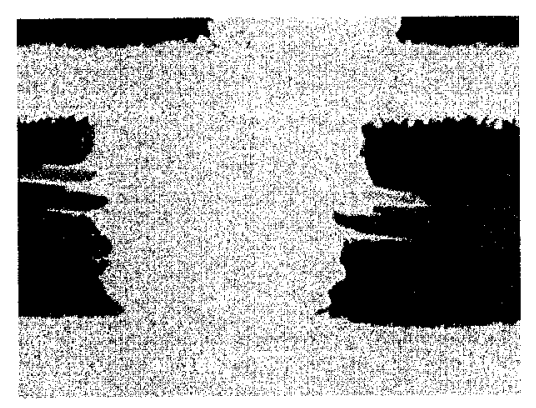

PKG\#43_DC\#06_Ball\#AB12_V4-5

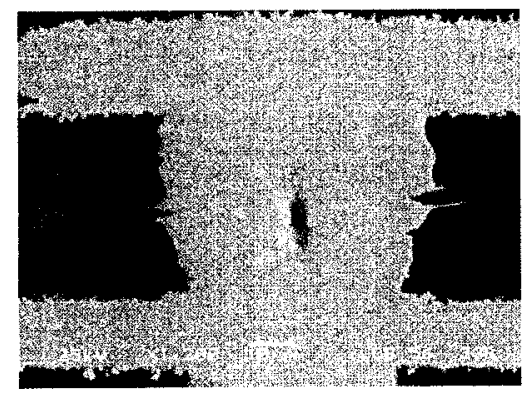

PKG\#43_DC\#06_Ball\#AB13_V1-2

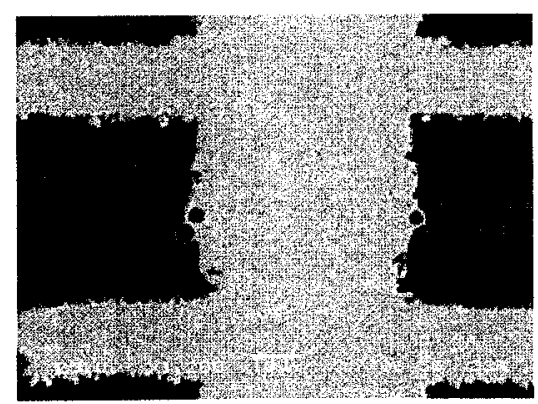

PKG\#43_DC\#06_Ball\#AB13_V2-3

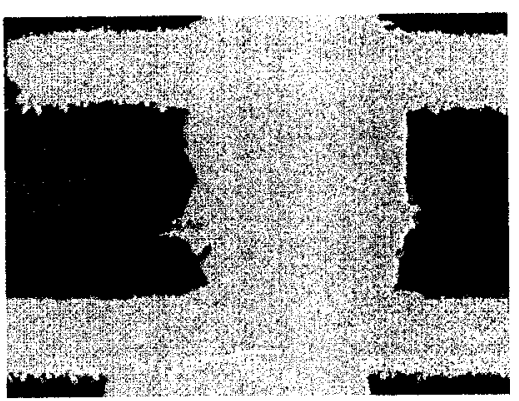

PKG\#43_DC\#06_Ball\#AB13_V3-4

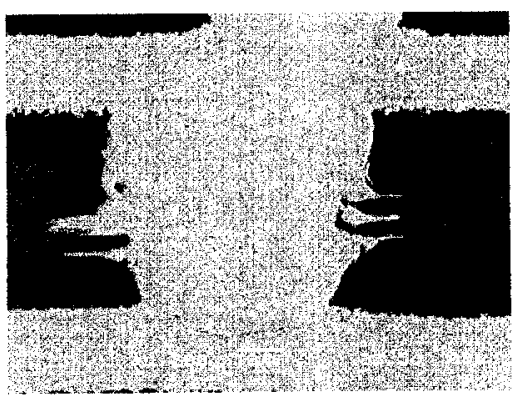

PKG\#43_DC\#06_Ball\#AB13_V4-5

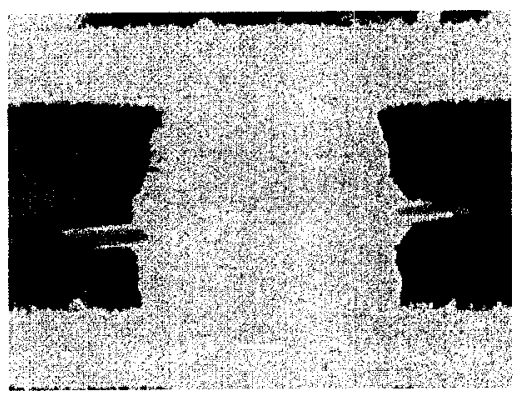

PKG\#43_DC\#06_Ball\#AB13_V6-7
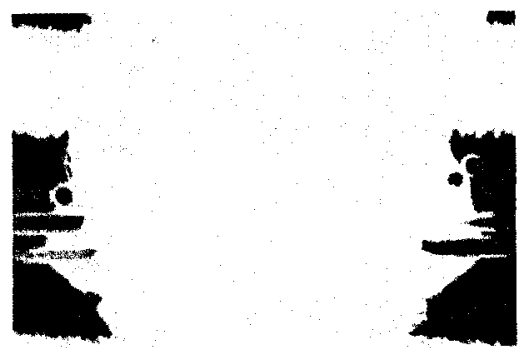

PKG\#06_DC\#04_Ball\#AT39_V4-5 


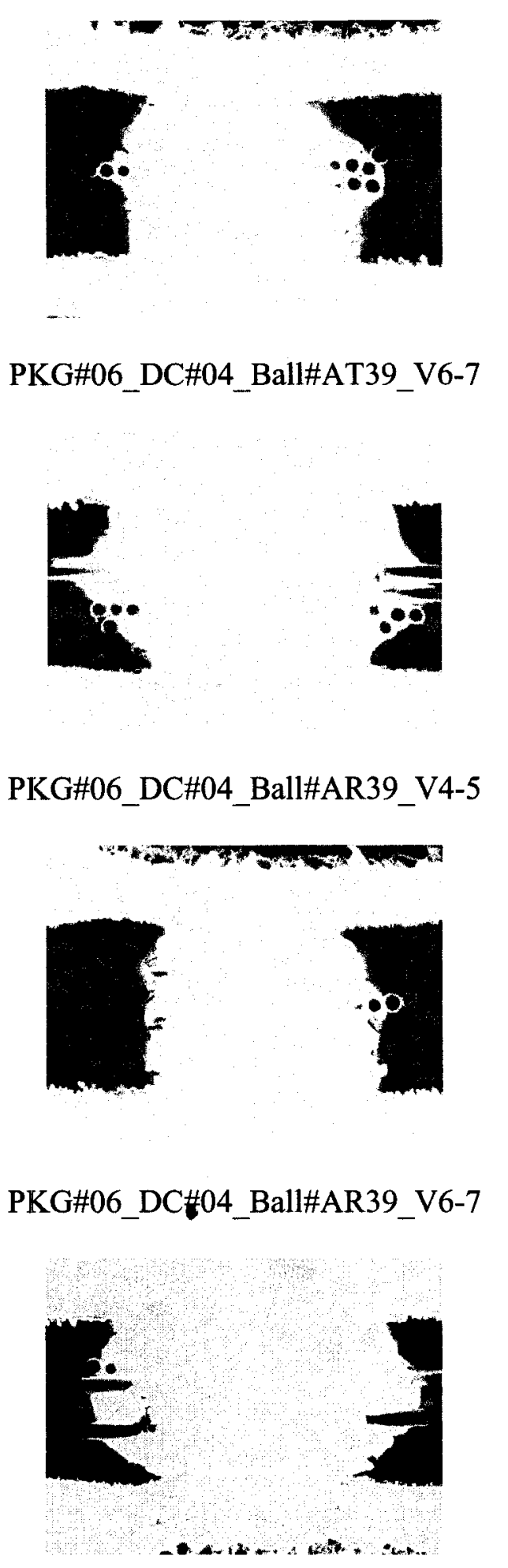

PKG\#06_DC\#04_Ball\#AP39_V4-5

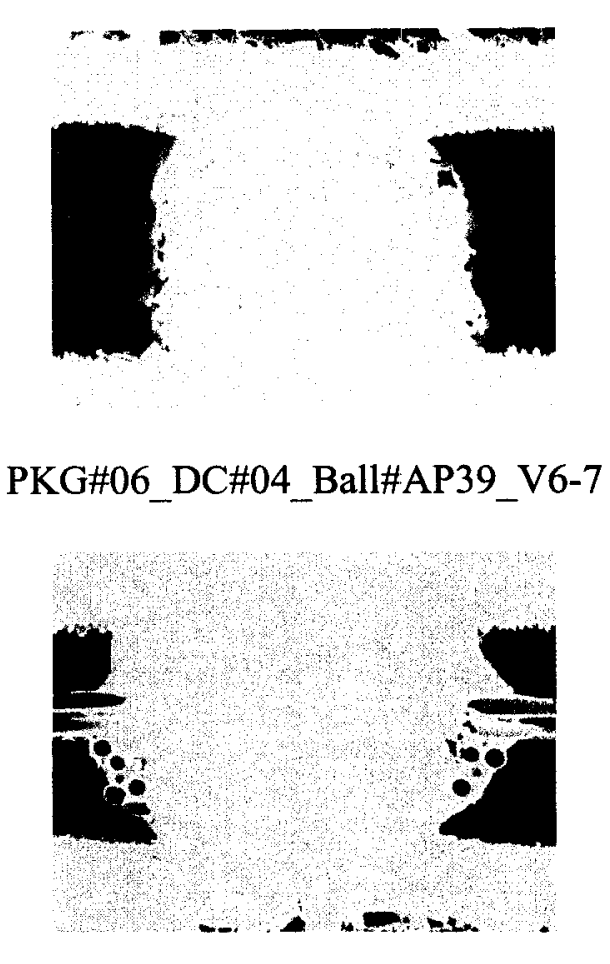

PKG\#06_DC\#04_Ball\#AN39_V4-5

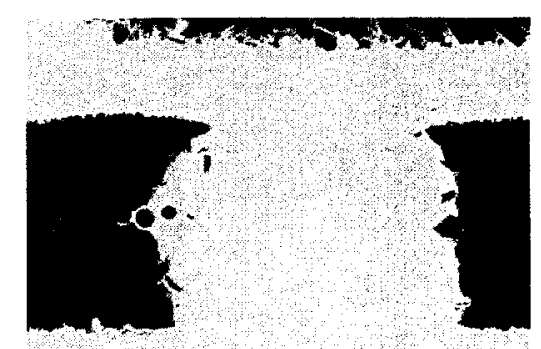

PKG\#06_DC\#04_Ball\#AN39_V6-7

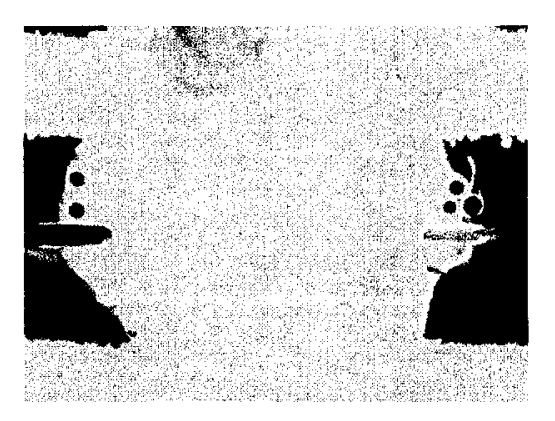

PKG\#06_DC\#04_Ball\#AM39_V4-5 


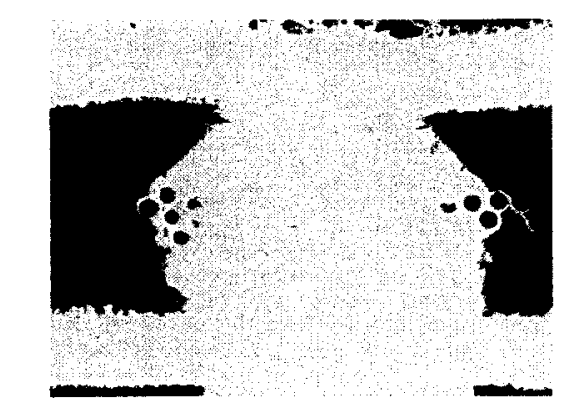

PKG\#06_DC\#04_Ball\#AM39_V6-7
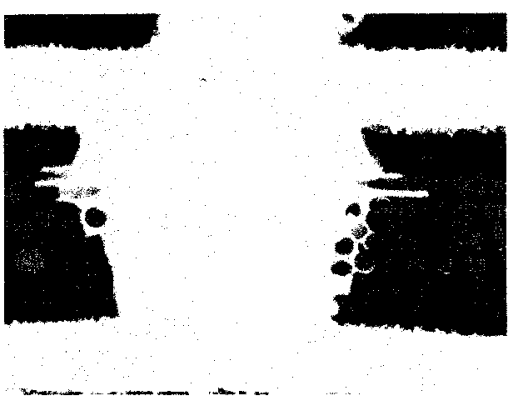

PKG\#48_DC\#08_Ball\#AJ12_V4-5

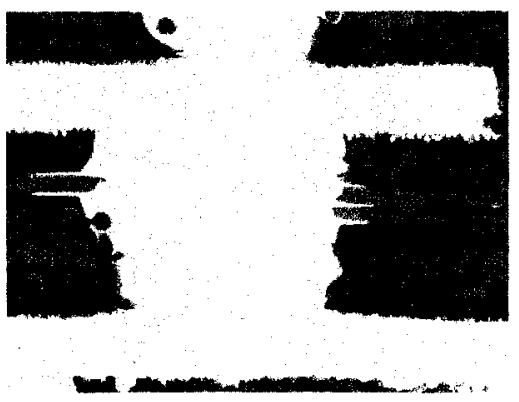

PKG\#48_DC\#08_Ball\#AJ15_V4-5

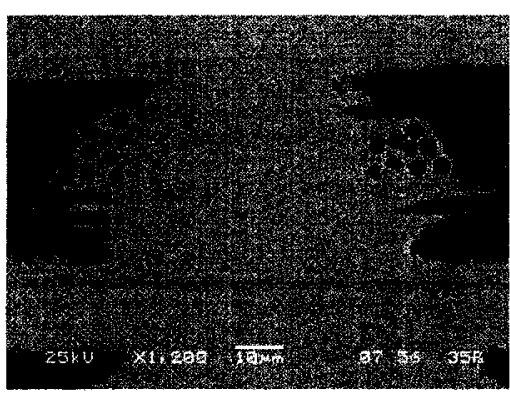

PKG\#02_DC\#02_Ball\#C36_V7-8

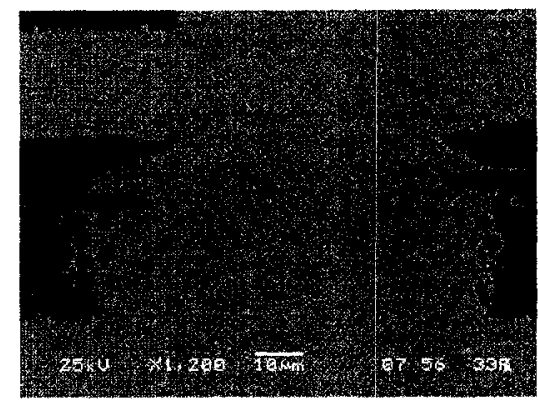

PKG\#02_DC\#02_BalliC35_V7-8

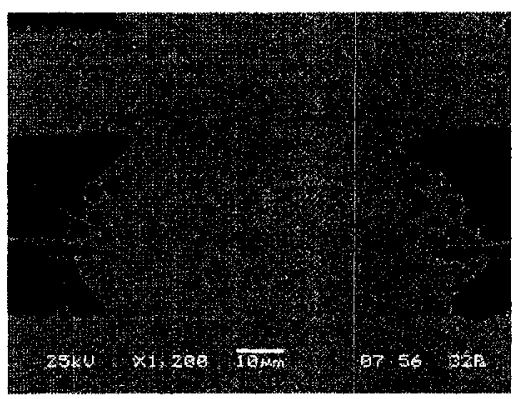

PKG\#02_DC\#02_BalliC34_V7-8

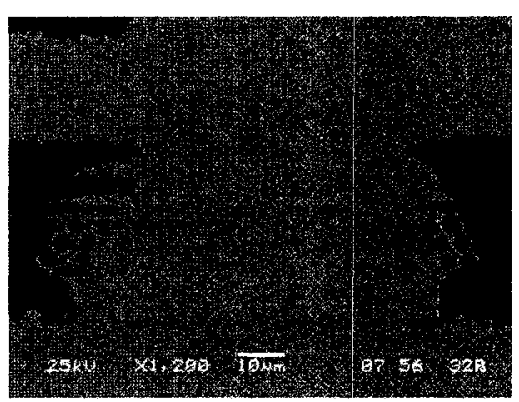

PKG\#02_DC\#02_Ball\#C33_V7-8

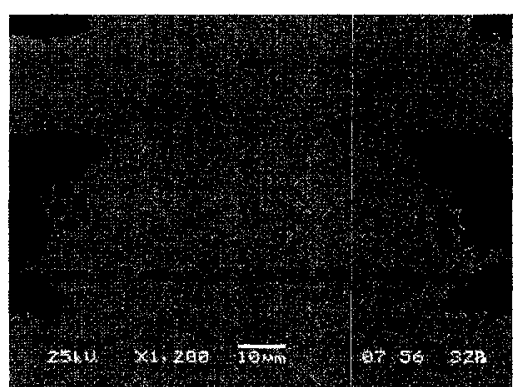

PKG\#02_DC\#02_Ball\#C32_V7-8 


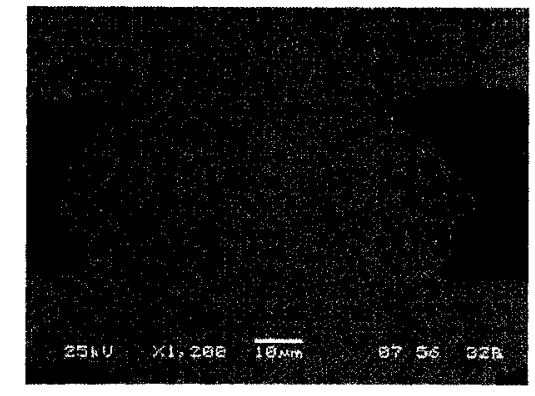

PKG\#02_DC\#02_Ball\#C31_V7-8

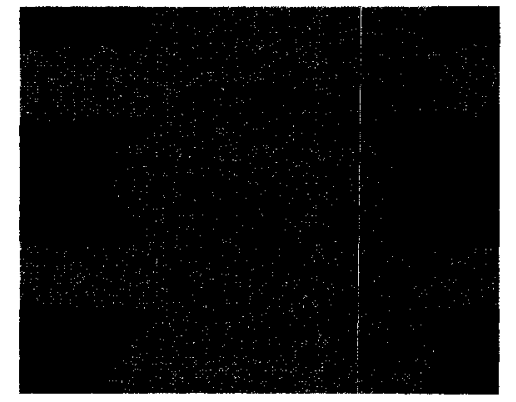

PKG\#02_DC\#02_Ball\#C30_V7-8 